\title{
DESARROLLO Y CARACTERIZACIÓN DE BIOCOMPOSITES ENFIBRADOS PROCEDENTES \\ DE RECURSOS RENOVABLES. \\ ESTUDIO DE SU DEGRADACIÓN EN TIERRA
}

TESIS DOCTORAL

PRESENTADA POR:

Rosana Moriana Torró

DIRIGIDA POR: Amparo Ribes Greus 



\section{SUMMARY}

The purpose of this $\mathrm{PhD}$ thesis is to study and predict the properties and biodegradability of new biocomposites based of biodegradable polymers obtained from renawable resources. Two different starch-based thermoplastics have been used as polymeric matrices (Mater-Bi KE03B1 ${ }^{\circledR}$ and Mater-Bi $\mathrm{NF} 01 \mathrm{U} \circledast$ ), and have been reinforced with different natural fibres (cotton, flax, kenaf, hemp, and jute) with the aim to prepare biodegradable materials with improved service life properties.

The polymeric matrices, the natural fibres and the reinforced biocomposites were characterised, with the objective of assessing the influence of each natural fibre in the polymeric matrix properties. The methodology used involves the combined application of Spectroscopic Analysis (FTIR-ATR), Mechanical Analysis (Tensile Tests), Mophological Analysis (SEM) and Thermal Analysis (DMTA, TGA, DSC). Moreover, the properties of the reinforced biocomposites has been correlated with the chemical composition of the natural fibres. The degradability of the matrices and biocomposites has been studied through the performance of degradation in soil and water absorption tests. The hydrolysis process is considered as a first stage of the biodegradation process. The degradation and absorption processes have been monotorised by means of changes in the thermal properties of the materials. In particular, the control parameters selected are the onset and the maximum rate of thermodegradation temperatures, and the activation energies of each thermal decomposition process. These parameters are used to control the thermal stability and designate the changes in the molecular environments that promote or hinder the thermodegradation process. These results are completed with morphological and spectroscopic studies.

In general, these studies reveal some relevant results. The addition of the natural fibres on the polymeric matrices increases the stiffness of the matrix and its thermal stability, and reduces the break deformation. Moreover, the presence of the fibres increases the absorption capacity and assures the degradation of the polymeric matrix components. Each reinforced biocomposite shows specific properties depending on the matrix and natural fibre used, as well as their combination. The reinforced biocomposites of jute are the stiffest and toughest. On the other hand, although the presence of the rest of natural fibres (kenaf, hemp, cotton and flax) enhances the stiffness of the biocomposites, cotton and flax seem to promote a decrease in the thoughness. The thermal stability of the biocomposites increases with higher hemicellulose and lignin contents in the fibres, with kenaf and jute biocomposites displaying the greatest thermal stabilities. The addition of natural fibres to the polymeric matrices results in slower degradation of the starch component wherease the behaviour of the synthetic component depends on the hydrofility of the polymeric matrix. In the reinforced Mater-Bi KE biocomposites, the degradation of the natural fibres facilitates the microorganisms attack to the synthetic component from the begining of the test. Contrarialy, the synthetic component in the reinforced Mater-Bi NF present the same behaviour as the polymeric matrix. The biocomposites of flax shows the lowest capacity of degradation, while the presence of kenaf seems to promote the degradation of the synthetic component of the resulting biocomposites.

This study confirms that the reinforcement of Mater-Bi NF and Mater-Bi KE with natural fibres broadens their applications, at the same time that the capacity of the degradation in soil is assured at the end of the service life. In the design of the reinforced biocomposites, the selection of one fibre will depend on the final required properties. 



\section{RESUMEN}

El propósito de la presente Tesis Doctoral es estudiar y predecir las características y la biodegradabilidad de diferentes biocomposites desarrollados a partir de materiales biodegradables procedentes de fuentes renovables. Para ello, se emplean dos termoplásticos de base almidón como matrices poliméricas (Mater-Bi KE03B1 ${ }^{\circledR}$ y Mater-Bi NF01Uß), que se refuerzan con distintas fibras naturales (algodón, cáñamo, kenaf, lino y yute) con el fin de mejorar sus propiedades mientras están en servicio, al tiempo que se mantiene su biodegradabilidad.

Las fibras naturales, las matrices poliméricas y los biocomposites reforzados se caracterizan con el objetivo de estudiar de la influencia de cada fibra natural en las propiedades de la matriz polimérica. Para ello se emplea una metodología basada en el Análisis Espectroscópico (FTIR-ATR), Mecánico (Ensayos de Tensión), Morfológico (SEM) y Térmico (DMTA, TGA, DSC). Así mismo se establecen correlaciones entre la composición química de las fibras naturales y las propiedades de los biocomposites reforzados. La degradabilidad de las matrices poliméricas y de los biocomposites se evalúa mediante enasayos de degradación en tierra y de absorción en agua. La hidrólisis de las matrices poliméricas y de los biocomposites se estudia como étapa previa a su biodegradación en tierra. Ambos procesos, la degradación en tierra y la absorción de agua se monitorizan mediante cambios en las propiedades térmicas. En particular, los parámetros térmicos de control escogidos son: las temperaturas de inicio y máxima velocidad de termodegradación como marcador de la estabilidad térmica; y las energías de activación de cada proceso de descomposición, puesto que este parámetro permite discernir los cambios en los entornos moleculares que facilitan o dificultan el proceso de termodegradación. Estos estudios de degradación, se complementan con análisis morfológicos y espectroscópicos. Finalmente, mediante la caracterización de los biocomposites reforzados degradados se determina la influencia de las fibras naturales sobre el proceso de degradación de las matrices poliméricas estudiadas.

En general, de estos estudios se concluye que, la adición de las fibras naturales a las matrices termoplásticas aumenta la rigidez del material, disminuye su deformación a rotura, mejora su estabilidad térmica, aumenta su capacidad de absorción de agua y garantiza la degradación de los componentes de la matriz polimérica. Sin embargo, cada biocomposite diseñado presenta unas propiedades específicas. Los biocomposites de yute son los más rígidos y resistentes, en cambio los biocomposites de algodón y lino aumentan la rigidez pero pierden parte de la resistencia a rotura mostrada por la matriz polimérica. La estabilidad térmica de los biocomposites aumenta en función del contenido de hemicelulosa y lignina de las fibras naturales, siendo los biocomposites más estables los que se preparan con kenaf ó yute. Cuando se añaden las fibras naturales a las matrices poliméricas, la degradación del almidón de ambas matrices se relentiza y el comportamiento del componente sintético en función del tiempo de degradación depende de la hidrofilidad de la matriz polimérica. En los biocomposites de Mater-Bi KE la degradación de las fibras naturales va a propiciar un aumento en el área superficial de ataque de los microorganismos al material sintético, facilitando su accesibilidad desde el inicio del proceso de degradación en tierra. En cambio, el material sintético de los biocomposites de Mater-Bi NF ofrece el mismo comportamiento que el de la matriz polimérica durante el proceso de degradación. Los biocomposites de lino presentan la menor capacidad de degradación, mientras que la presencia de kenaf parece aumentar el grado de degradación del componente sintético de los biocomposites resultantes.

Así, con este estudio se confirma que el Mater-Bi NF y el Mater-Bi KE aumentan sus aplicaciones cuando se refuerzan con fibras naturales al mismo tiempo que mantienen su capacidad para degradarse en el momento en el que finaliza su vida útil. En el diseño del biocomposite, la selección de una u otra fibra natural como material de refuerzo dependerá de las propiedades finales requeridas. 



\section{RESUM}

El propòsit de la present Tesi Doctoral és estudiar i predir les característiques i la biodegradabilitat de nous biocomposites conformats a partir de materials biodegradables procedents de fonts renovables. Per al disseny dels biocomposites s'empren dos termoplàstics de base almidó com a matrius polimèriques (Mater-Bi KE03B1® i Mater-Bi NF01Uß), que es reforcen amb diferents fibres naturals (cotó, cànem, kenaf, lli i jute), amb la finalitat de millorar les seves propietats mentre estan en servei, al mateix temps que es manté la seua biodegradabilitat.

Amb l'objectiu d'avaluar la influència de cada fibra natural en les propietats de la matriu polimérica, es caracteritzen les fibres naturals, les matrius polimèriques $\mathrm{i}$ els biocomposites reforçats. Per a això s'ha desenvolupat una metodologia basada en l'Anàlisi Espectroscòpica (FTIR-ATR), l'Anàlisi Mecànica (Assajos de Tensió), l'Anàlisi Morfològica (SEM) i l'Anàlisi Tèrmica (DMTA, TGA, DSC). Així mateix s'han establert correlacions entre la composició química de les fibres naturals i les propietats dels biocomposites reforçats. La degradabilitat de les matrius polimèriques i dels biocomposites s'avalua mitjançant assaigs de degradació en terra $\mathrm{i}$ d'absorció d'aigua; la hidròlisis de les matrius polimèriques i dels biocomposites s'estudia com etapa previa a la biodegradació en terra. Ambdos processos, la degradació en terra i l'absorció en aigua es monotoritzen mitjançant canvis en les propietats tèrmiques. Els paràmetres térmics de control per al estudi del proces de degradació són: les temperatures d'inici i màxima velocitat de termodegradació com a marcador de l'estabilitat tèrmica de la matriu polimérica i del biocomposite; i les energies d'activació de cada procés de descomposició, ja que aquest paràmetre permet destriar els canvis en els entorns moleculars que faciliten o dificulten el procés de termodegradació. Aquests anàlisis es complementen amb estudis morfològics i espectroscòpics.

En general, es conclou que l'adició de les fibres naturals a les matrius termoplàstiques augmenta la rigidesa del material, disminuïx la seva deformació a trencament, millora la seva estabilitat tèrmica, augmenta la seva capacitat d'absorció d'aigua i garanteix la degradació dels components de la matriu polimèrica. No obstant això, cada biocomposite dissenyat presenta unes propietats específiques. Els biocomposites de jute són els més rígids i resistents, en canvi els biocomposites de cotó i lli augmenten la seva rigidesa i perden part de la resistència ruptura mostrada per la matriu polimèrica. L'estabilitat tèrmica dels biocomposites augmenta en funció del contingut de hemicel.lulosa/pectina i lignina de les fibres naturals, sent els biocomposites més estables aquells que es preparen amb kenaf ó jute. Quan s'afegixen les fibres naturals a les matrius polimèriques, la degradació del almidó d'ambdues matrius es relentitza i el comportament del component sintètic en funció del temps de degradació depen de la hidrofilitat de la matriu polimérica. En els biocomposites de Mater-Bi KE la degradació de les fibres naturals propicia un augment en l'àrea superficial d'atac dels microorganismes al material sintètic, facilitant la seva accessibilitat des de l'inici del procés de degradació en terra. En canvi, el material sintètic dels biocomposites de Mater-Bi NF ofereix el mateix comportament que el de la matriu polimérica durant el procés de degradació. Els biocomposites de lli són els que presenten una menor capacitat de degradació, mentre que la presència de kenaf sembla augmentar el grau de degradació del component sintètic dels biocomposites resultants.

Així, amb aquest estudi es confirma que el Mater-Bi NF i el Mater-Bi KE augmenten les seves aplicacions quan es reforcen amb fibres naturals al mateix temps que mantenen la seva capacitat per a degradar-se en el moment en el que finalitza la seva vida útil. En el disseny del biocomposite, la selecció d'una o altra fibra natural com material de reforç dependrà de les propietats finals requerides. 



\section{AGRADECIMIENTOS}

No m'agradaria acabar aquest projecte sense deixar de donar tots els meus agraïments a totes aquelles persones que m'han ensenyat, ajudat i recolzat durant aquests últims anys.

Gràcies a la meua directora, Amparo Ribes Greus per haver-me donat l'oportunitat de dur a terme aquest treball de investigació i haver-me ensenyat a valorar el que és un grup de treball.

I wish to express my gratitude to Prof. Sigbritt Karlsson, for giving me the opportunity to perform my temporary stays in her group, for her encouragement and support. Thank you to my laboratory mates to make me feel at home. Especially Emma are thanked for their kidness, patient and helpfulness.

Igualment, m'agradaria donar les gràcies a Fran, per deixar-me formar part activa dels seus dos móns durant tots aquests anys, per ser la meua guia esperitual i el meu amic incondicional. Per que sense tu no seria qui soc!

També voldria donar les gràcies als meus companys de treball, sense la seua ajuda aquest treball no havera sigut possible. Gràcies Jose per les xarraetes interminables i els cafenets de germanor. Gràcies Alf per ajudar-me a trovar força i sentit al treball realitzat durant tot aquest temps. Laura, que dirt-te que no t'haja dit ja, has sigut sempre un dels meus pilars fonamentals, se que no podria haver trovat a millor persona en qui compartir tots els aspectes de la meva vida. Gràcies per estar ahí sempre!

Gràcies Cristina per el teu entusiasme, per estar sempre disposta a tirar una mà sense esperar res a canvi, tan sols un somriure ó una cervesseta. A més, gràcies per haver introduït a María José dins de la nostra família. I com no, gràcies a Roberto i Marta, "les noves adquisicions" que fan que el laboratori siga un lloc on sempre hi ha algú dispost a ajudar i a soltar unes rialles.

Gràcies als meus amics per la seua comprensió i recolzament, per estar ahi sempre. Gràcies Maria i Julio, per obrir-me les portes de la vostra casa i del vostre dia a dia; gràcies a vosaltres, estar a València aquest any, a adquirit un sentit espècial. Gràcies a Raquel, Revy, Isi, Jose $i$ als xiquets per traure' $m$ de casa i fer-me sentir que el dia a dia val la pena. I cannot forget my friends in Stockholm; I feel so thankful for sharing with you my temporary stays. Julieta, Jocke, Eugen, Agnes, Jennie, Matthew, Eric, Peffe are thanked for accepting me into the group, I do not feel far from you but I miss you! Special thanks to Steven (our tiburon), you know to make me feel so well that only with you I feel at home.

Esta tesis que resumeix tants anys d'esforços i treball va dedicada especialment a la meua família. Sense tots vosaltres no seria qui soc, em sent afortunada de poder formar part de les vostres vides; ser filla, germana, neboda, cosina, cunyada, nora, tia, novia del papa i parella, per a mi és un honor. Papà i Mamà, em sent afortunada de ser la vostra filla per que pense que mai podré fer-ho tan be com vosaltres ho haveu fet, per que sou tan autèntics com especials i així ho transmitiu a tot aquells que us envolten, perquè de vegades entre nosaltres no fa falta parlar per a dir tot el que es sent, però hui necessite dir-vos que sense el vostre esforç i suport incondicional açò no havera estat possible. Moltes gràcies als meus nanos: Alex gràcies per la teua vitalitat $i$ alegria, per estar ahí sempre per a mi, per fer-me sentir tan especial quan estic al teu costat. Sabri, has format part activa de la el.laboració de esta tesis, sense la teua ajuda no havera pogut seguir endavant, gràcies per els ànims constants i la teua comprensió, gràcies, perquè hui en dia eres una de les meues millor amigues. Sandra, gràcies per els teus ànims i per demostrar-me que casi tens tu més ganes que jo de que acabe per així poder disfrutar més tranquilament l'una de l'altra. I com no... gràcies Gon, per la teua paciència i ajuda, per ser una persona tan il.lusionada, per conseguir traure de mi la força i energia que ningú més sap, per compartir la teua vida en mi, per formar part del meu futur i haver fet possible el meu dia a dia durant aquest ultim any. 



\begin{tabular}{|c|c|}
\hline Mater-Bi KE03B1 & Mater-Bi KE \\
\hline Mater-Bi NF01U & Mater-Bi NF \\
\hline TGA & Análisis Termogravimétrico \\
\hline $\mathrm{DSC}$ & Calorimetría Diferencial de Barrido \\
\hline DMTA & Análisis Dinamo-Mecánico-Térmico \\
\hline FTIR & Espectroscopia Infraroja por Transformada de Fourier \\
\hline ATR & Refractancia Total Atenuada \\
\hline SEM & Microscopia Electrónica de Barrido \\
\hline $\mathrm{GC}$ & Cromatografía de Gases \\
\hline$\beta$ & Velocidad de Calentamiento \\
\hline Tpico/Tpeak & Temperatura Máxima de Descomposición Térmica \\
\hline $\mathrm{Ea}$ & Energía de Activación \\
\hline A & Factor Pre-exponenecial \\
\hline$f(\alpha)$ & Función Diferencial del Modelo Cinético de un Proceso \\
\hline$g(\alpha)$ & Función Integral del Modelo Cinético de un Proceso \\
\hline $\mathrm{Tf}, \mathrm{Tm}$ & Temperatura de Fusión \\
\hline $\mathrm{Tc}$ & Temperatura de Cristalizazión \\
\hline$\Delta \mathrm{Hf}, \Delta \mathrm{Hm}$ & Entalpía de Fusión \\
\hline$\Delta \mathrm{Hc}$ & Entalpía de Cristalización \\
\hline $\operatorname{Tg}$ & Temperatura de Transición Vítrea \\
\hline Tmax & Temperatura Máxima de las Relajaciones \\
\hline E' & Módulo de Almacenamiento \\
\hline E” & Módulo de Pérdidas \\
\hline Tang $\delta$ & Tangente de Pérdidas \\
\hline$\alpha_{\mathrm{f}}$ & Coeficiente de Dilatación Térmica \\
\hline$f_{\mathrm{g}}$ & Volumen Libre Relativo \\
\hline A & Absorbancia \\
\hline I & Intensidad \\
\hline $\mathrm{E}$ & Módulo de Young \\
\hline Mt & Capacidad de Absorción a un Tiempo Determinado \\
\hline Ms & Capacidad Máxima de Saturación \\
\hline Ts & Tiempo de Saturación \\
\hline $\mathrm{D}$ & Coeficiente de Difusión \\
\hline
\end{tabular}





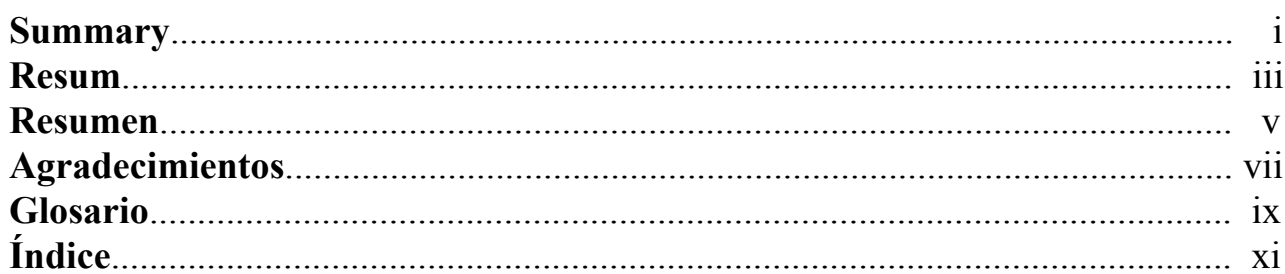

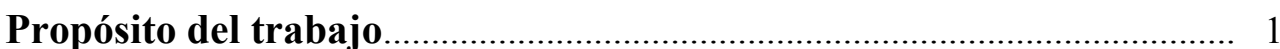

Capítulo 1. Antecedentes

1.1. Materiales biodegradables.................................................................. 13

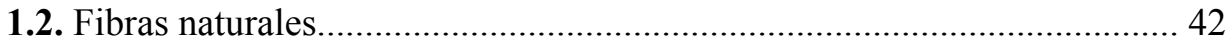

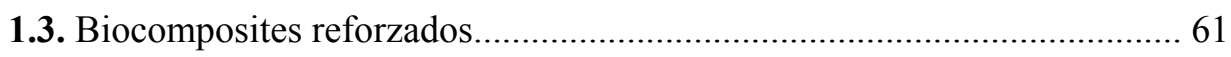

Capítulo 2. Procedimiento experimental

2.1. Materiales y preparación de muestras............................................................ 77

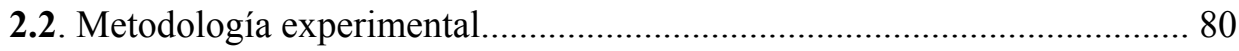

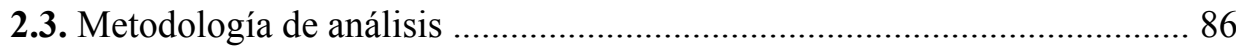

Capítulo 3. Caracterización de fibras naturales

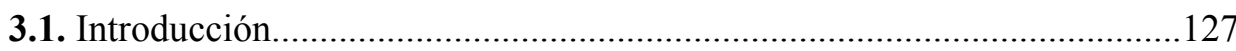

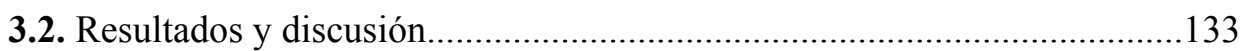

Capítulo 4. Caracterización de matrices poliméricas y biocomposites

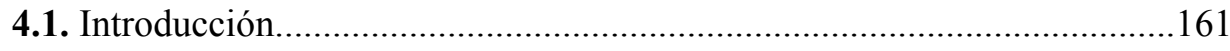

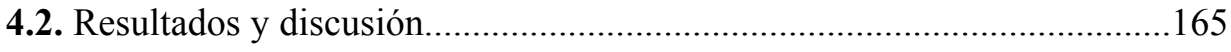

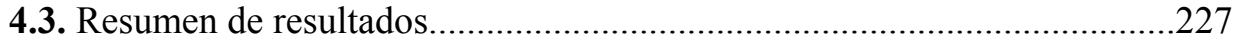

Capítulo 5. Estudio del proceso de absorción en agua

5.1. Introducción

5.2. Resultados y discusión.

Capítulo 6. Caracterización de la degradación en tierra de las matrices poliméricas y sus biocomposites

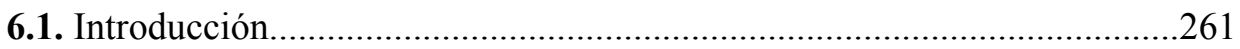

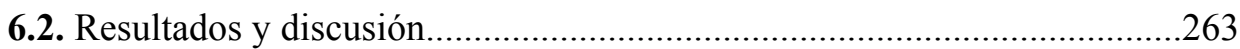

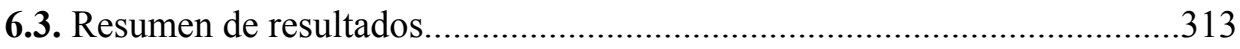

Capítulo 7. Conclusiones y trabajo futuro

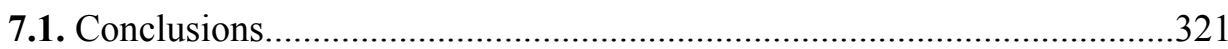

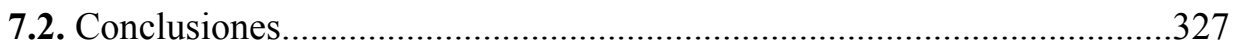

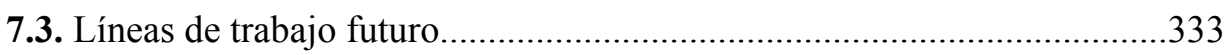





\section{Propósito del trabajo}



Los materiales poliméricos representan un gran avance para la sociedad, al permitir la producción de un sinfín de productos de bajo coste y enorme utilidad. Sin embargo, su naturaleza inerte y su resistencia a la biodegradación generan un grave problema medioambiental derivado de la gestión de sus residuos. En la actualidad, la deposición de los residuos poliméricos en vertederos controlados no garantiza un procedimiento adecuado desde el punto de vista de crecimiento sostenible. Además, otras actuaciones de gestión como el reciclaje mecánico y la incineración no siempre son soluciones adecuadas a estos problemas [1]. En estos casos, el desarrollo de materiales biodegradables representa una opción eficaz para gestionar adecuadamente dichos residuos plásticos [1,2]. Actualmente, la mayoría de los esfuerzos dentro de este campo se centran en el diseño de polímeros biodegradables procedentes de recursos renovables. Este tipo de materiales supone una alternativa real al uso de recursos fósiles y permite cerrar el ciclo de vida del material, al tiempo que fortalece al sector agrícola dentro de la industria no alimentaria [3-10].

Con el objetivo de mejorar las propiedades mecánicas de los materiales biodegradables y reducir los costes de producción, manteniendo al mismo tiempo su biodegradabilidad, se propone el diseño de materiales compuestos por una matriz biodegradable y fibras naturales, que cumplan las regulaciones medioambientales y den respuesta a la preocupación social creciente que considera necesario sustituir los composites poliméricos convencionales constituidos por matrices sintéticas (compuestos epóxis, fenólicos y poliestirénicos) reforzadas con fibras de carbón ó vidrio [11,12]. En este contexto, el reto es diseñar un composite con estabilidad funcional y estructural durante su almacenamiento y uso, a la vez biodegradable tras su vida en servicio, asegurando el ciclo del material sin ningún tipo de daño ambiental $[13,14]$. Para ello, la caracterización de la matriz polimérica y del biocomposite resultante es fundamental. Así como, el estudio de la influencia de los procesos de biodegradación sobre los materiales base y los biocomposites resultantes.

Diferentes termoplásticos biodegradables comerciales y no comerciales (poliésteres, Biopol $^{\mathrm{TM}}$, Bioceta ${ }^{\mathrm{TM}}$, Mater-Bi ${ }^{\circledR}$, Sconacell $^{\mathrm{TM}}$, compuestos de almidón plastificado, etc) se han analizado recientemente para comprobar su utilidad como matrices en los biocomposites reforzados [15-17]. Oksman y col. [18] propusierón el ácido poli(láctico) (PLA) como matriz polimérica para preparar biocomposites de lino. Este estudio comprobó la mejora de las propiedades mecánicas al reforzar el PLA. 
Wollerdorfer y col. [19] evaluaron las propiedades mecánicas de diferentes biocomposites, constituidos por una matriz biodegradable comercial y fibras naturales. En este estudio, fibras de lino, yute, coco y celulosa regenerada se usaron como sistema de refuerzo en distintos tipos de matrices poliméricas; compuestos de base almidón (Mater-Bi $\mathrm{ZI} 01 \mathrm{U}^{\mathrm{TM}}$ y $\mathrm{Tone}^{\mathrm{TM}}$ ), materiales de base celulósica (Bioplas $\mathrm{GS} 902^{\mathrm{TM}}$ ) y poliestirénos (Bionolle $3020^{\mathrm{TM}}$ y Biopol D300G ${ }^{\mathrm{TM}}$ ). Cuando estas matrices se enfribraron se observó un aumento en el módulo de Young [20], debido a la similitud química existente entre los polisacaridos empleados como matriz polimérica y los componentes de las fibras naturales. Curvelo y col. [21] diseñaron composites de almidón de maiz termoplastificado y fibra de eucaliptus. En este estudio, no sólo se comprobó un aumento de las propiedades mecánicas de la matriz polimérica reforzada sino, una buena adhesión entre la matriz y la fibra. Por otra parte, Puglia y col. [22] y Avérous y col. [23] mostraron un aumento en las propiedades mecánicas y en la estabilidad térmica al añadir fibras de celulosa a dos polímero biodegradables comerciales de base almidón (Mater-Bi ZF03Uß y Mater-Bi YI01Uß).

Los materiales biodegradables se caracterizan por ser sensibles a la temperatura, por tanto, el estudio de la degradación térmica de los biocomposites es un aspecto a tener en cuenta para fijar los parámetros de procesado, temperatura de extrusión e inyección, y diseñar las condiciones de uso del producto final [24]. Ruseckaite y col. [25] realizaron un exhaustivo estudio sobre la descomposición térmica del biocomposite de poli( $\varepsilon$-caprolactona)/fibra de sisal y de sus materiales base, asociando el aumento de la estabilidad térmica del biocomposite con las interacciones sólido-sólido ó sólido-gas producidas entre la fibra de sisal y la matriz sintética. Alvarez y col. [26] aplicaron distintos módelos cinéticos para determinar la ecuación cinética que describe el mecanismo de descomposición térmica del biomposite Mater-Bi Y/fibra de sisal. En los biocomposites constituidos por compuestos de almidón plastificado y microfibras de celulosa, Dufresne y col. [27] además de un aumento de las propiedades mecánicas y de la estabilidad térmica, observaron un aumento de la resistencia al agua debido a las interacciones entre la fibra y la matriz y/ó entre la misma fibra [28-30].

Las fibras naturales lignocelulósicas se degradan biológicamente porque los organismos reconocen los carbohidratos de la pared celular y tienen sistemas enzimáticos específicos capaces de hidrolizar sus compuestos en unidades asimilables por los organismos 
[31]. Sin embargo, Modelli y col. [32] comprobaron como las fibras naturales se mantenían estables durante el proceso de degradación en tierra de un termoplástico de almidón, pero favorecian el ataque microbiológico y la absorción del agua para iniciar la hidrólisis del almidón. Imman y col. [33] estudiaron la degradación en tierra de composites de poli(vinil alcohol), almidón y fibras de naranja. Este estudio indicó que el almidón era la parte más biodegradable de la matriz y de su biocomposite, y que la presencia de las fibras de naranja no afectaba significativamente a su proceso de degradación en tierra. Del mismo modo, Avella y col. [34] demostraron que la fibra de caña de trigo no influia significativamente en la biodegradabilidad del poli(3-hidroxibutirato-co-3-hidroxivalerato). En cambio, Di Franco y col. [35] observaron un aumento de la degradación en tierra del copolímero de almidón y poli( $\varepsilon$-caprolactona) en presencia de las fibras de sisal. Dash y col. [36] sometieron a un biocomosite de BAK $1095^{\mathrm{TM}}$ y fibra de jute a un proceso de degradación en tierra, comprobando una reducción de un $30 \%$ en peso en tan solo 21 días. Las fibras de yute se mezclaron también con otras dos matrices comerciales biodegradables, BAK $2195^{\mathrm{TM}} \mathrm{y}$ Biopol $^{\mathrm{TM}}$, y los biocomposites resultantes se sometieron a un proceso de degradación en tierra [37]. En este estudio la fibra de yute se trató previamente para mejorar su adhesión con la matriz polimérica y se demostró como la modificación de la fibra disminuia la velocidad de degradación del material. De entre todos estos estudios cabe destacar el interés que despiertan los compuestos de base almidón como matriz polimérica, por su bajo coste, abundancia en la naturaleza, buena compatibilidad con las fibras naturales y alta degradabilidad [38].

Para diseñar composites de calidad, además de una interfase adecuada entre la matriz y la fibra natural, capaz de transmitir esfuerzos de carga transversal y longitudinal se debe tener en cuenta la arquitectura del refuerzo (geometría, proporción volumétrica, orientación de las fibras,etc) y las propiedades intrínsicas que poseen los materiales base [39]. La morfología y la composición química de las fibras naturales (estructura de las fibras, contenido de celulosa, hemicelulosa y lignina, grado de cristalización, etc.) determinan sus propiedades fínales [16]. Tradicionalmente la fibra natural se modificaba con objeto de reducir su naturaleza hidrofílica y polar, y mejorar su compatibilidad con la matriz polimérica cuando ésta era hidrófoba. Los tratamientos más usados para este propósito son químicos, como por ejemplo, la alcalinación o la cianoetilación [40]. Sin embargo, estos tratamientos no son necesarios cuando la matriz polimérica esta compuesta por copolimeros de almidón y presentan un caràcter mayoritariamente hidrofílico. De este modo, se consigue disminuir 
costes de producción y no alterar la velocidad ni el mecanismo de degradación. Debido a la alta cristalinidad y al alto peso molecular que presenta la celulosa, componente mayoritario de las fibras naturales, éstas permanecen en estado sólido durante la temperatura de procesado de la mayoría de los termoplásticos. Sin embargo, pueden degradarse como consecuencia de la baja estabilidad térmica de la hemicelulosa. La ruptura del enlace glicosídico de los materiales celulósicos produce una pérdida de masa, cristalinidad, y una reducción del grado de polimerización. Sridhar y col. [38] demostró que las fibras de yute perdían el $60 \%$ del límite de fluencia cuando se sometieron a un proceso térmico a $300^{\circ} \mathrm{C}$ durante 24 horas en condiciones de vacío. Yao y col. [41]. estudiaron la descomposición térmica de diferentes fibras naturales con el objetivo de entender y predecir el comportamiento térmico de estos materiales lignocelúlosicos durante el procesado de los composites.

Teniendo en cuenta todos los resultados anteriores, el propósito de este proyecto de tesis es diseñar dos series de biocomposites enfibrados procedentes de recursos renovables, conformados a partir de dos matrices comerciales de base almidón (Mater-Bi KE03B1® y Mater-Bi NF01U®) y cinco fibras naturales diferentes (algodón, cañamo, kenaf, lino y yute). Estos biocomposites (Mater-Bi KE/algodón, Mater-Bi KE/cañamo, Mater-Bi KE/kenaf, Mater-Bi KE/lino, Mater-Bi KE/jute, Mater-Bi NF/algodón, Mater-Bi NF /cañamo, Mater-Bi NF/kenaf, Mater-Bi NF/lino, Mater-Bi NF/yute) además de ofrecer una estabilidad estructural y funcional durante su ciclo de vida deben ser biodegradables tras su uso.

Con el objetivo de evaluar la influencia de cada fibra natural en la matriz polimérica y poder determinar las aplicaciones industriales de los distintos biocomposites, se caracterizan las fibras naturales y los biocomposites reforzados. Además, se propone el anàlisis del proceso de abosorción de agua de los composites y de las matrices poliméricas como estudio complementario a la caracterización de los biocomposites y como estudio previo a la biodegradación en tierra. El análisis de la degradación en tierra de cada material se lleva a cabo mediante la monotorización de los cambios en sus propiedades en función del tiempo de degradación. La degradación en tierra de cada composite se compara con su matriz respectiva para determinar la influencia de cada una de las fibras naturales sobre el proceso de degradación. 
Para ello, se han considerado técnicas experimentales de Análisis Espectroscópico, Anàlisis Mecánico, Análisis Morfológico y Análisis Térmico. De todas las técnicas analíticas utilizadas en este estudio se les ha dado mayor importanca a aquellas que se basan en el análisis térmico, ya que previamente se ha demostrado la validez, eficacia y sensibilidad de las mismas para el estudio del comportamiento macroscópico de los polímeros sometidos a diferentes tipos de degradación [42-50]. Las técnicas de Análisis Térmico escogidas son: la Termogravimetría (TGA), la Calorimetría Diferencial de Barrido (DSC) y el Análisis TermoDinámo-Mecánico (DMTA). El Análisis Espectroscópico se basa en la Espectrometría Infrarroja con Transformada de Fourier (FTIR) y el Análisis Mecánico en Ensayos de Tensión (INSTRON). El Análisis Morfológico se realiza mediante la Microscopía Electrónica de Barrido (SEM).

Esquematicamente y resumiendo lo anterior, los objetivos específicos de este trabajo son:

i) Definir de una metodología precisa, sencilla y eficaz que permita caracterizar a los materiales base y a los composites diseñados, y además monotorizar el proceso de degradación en tierra de los mismos.

ii) Caracterizar térmica, mecánica, química y morfológicamente a las fibras naturales (algodón, cañamo, kenaf, lino y yute).

iii) Caracterizar termo-mecánica, estructural y morfológicamente a las matrices poliméricas (Mater-Bi NF, Mater-Bi KE).

iv) Caracterizar termo-mecánica, estructural y morfológicamente a los biocomposites reforzados con fibras naturales.

v) Determinar la influencia de cada una de las fibras naturales en las propiedades térmicas, mecánicas, estrurales y morfológicas.

vi) Estudiar el proceso de absorción de agua de ambas matrices poliméricas y de los biocomposites, así como la influencia del proceso de aborción en las propiedades térmicas de los materiales estudiados.

vii) Estudiar el proceso de degradación en tierra de las matrices poliméricas mediante la monotorización en función del tiempo de exposición de las propiedades térmicas, estructurales y morfológicas del material degradado.

viii) Determinar la influencia de cada una de las fibras naturales sobre el proceso de degradación de la matriz polimérica en tierra. 
Los resultados experimentales y la discusión de los mismos que han dado lugar a la consecución de los objetivos anteriormente definidos, se han estructurado en los siguientes siete capítulos que se exponen a continuación. En el primero de ellos, se exponen los antecedentes y el estado del arte en el desarrollo de los biocomposites procedentes de fuentes renovables. El segundo capítulo describe el procedimiento experimental aplicado para la obtención de los resultados experimentales discutidos en los capitulos 3, 4, 5 y 6 . En el tercer capítulo se describe la caracterización de las fibras naturales empleadas como sistema de refuerzo en los biocomposites diseñados. En el cuarto capítulo se caracterizan las matrices poliméricas y los biocomposites obtenidos a partir de estas matrices y de las fibras descritas en el capitulo anterior. Además, se discute la influencia de las fibras naturales en las propiedades de las matrices poliméricas y se correlacionan con su composición química. El capítulo quinto se estudia el proceso de absorción de agua y su influencia en las propiedades térmicas de los materiales puros y sus biocomposites. En este estudio se determina la influencia de la hidrólisis como etapa prevía a la biodegradación en tierra de los materiales. En el sexto capítulo se analiza la degradación en tierra de las matrices poliméricas y de los biocomposites diseñados, estableciéndose la influencia de las fibras naturales en el proceso de degradación de las matrices. En el séptimo y último capítulo se presentan las principales conclusiones obtenidas como resultado del presente trabajo de Tesis Doctoral.

\section{Referencias}

1. Bastioli C. Polym Degrad Stab 1998; 59: 263.

2. Mohanty AK, Misra M, Drzal TD editors. Natural Fibers, Biopolymers and Biocomposites. Boca Raton: Taylor \& Francis, 2005.

3. Griffin GJL, editor. Chemistry and Technology of Biodegradable Polymers. Glasgow: Blackie Academic Professional, 1994.

4. Erlandsson B, Karlsson S, Albertsson AC. Polym Degrad Stab 1997; 55: 237.

5. Albertsson AC, Erlandsson B, Hakkarainen M, Karlsson S. J Environ Polym Degrd 1998; 6: 187.

6. Scott G, editor. Degradable Polymers. Netherlands: Kluwer Academic Publishers, 2002.

7. Marcelo AV, Edwin LT, Amstrong RC. Polymer 1995; 36: 1869.

8. Chandra R, Rustgi R. Polym Degrad Stab 1997; 56: 185.

9.Clarinval A, Halleux J. In: Smith R editor. Biodegradable polymers for industrial applications. London; Woodhead Publishing, 2005.

10. Bastioli C editor. Handbook of Biodegradable Polymers. Shrewsbury: Rapra Technology, 2005.

11. Bastioli C, Facci C, Biodegradable Plastic Conference, Frankfurt, 1999. 
12. Mohanty AK, Misra M, Hinrichsen G. Macromol Mater Eng 2000; 276/277: 1.

13. Foelster Th, Textilverdlung 1995; 30: 2.

14. Wielage B, Lampke Th, Utschich H, Soergel F. J Mater Process Tech 2003; 139: 140.

15. Mohanty AK, Misra M, Drzal TD. J Polymer Environ 2002; 10: 1/2.

16. Bledzki AK, Gassan J. Prog Polym Sci 1999; 24: 221.

17. Alvarez VA, Ruseckaite RA, Vazquez A. Polym Degrad Stab 2006; 91: 3156.

18.Oskman K, Skrifvars M, Selin JF. Comp Sci Tec 2003; 63: 1317.

19. Wollerdorfer M, Cyras VP, Bader H. Ind Crop Prod 1998; 8: 105.

20. Cyras VP, Iannace S, Kenny JM, Vazquez A. Polym Composites 2001; 22: 1

21. Curvelo AAS, Carvalho AJF, Agnelli JAM. Carbohyd Polym 2001; 45: 183.

22. Puglia D, Tomassuci A, Kenny JM. Polym Adv Tech 2003; 14: 749.

23. Averous L, Fringant C, Moro L. Starch 2001; 53: 368.

24. Alvarez V, Iannoni S, Kenny JM, Vazquez A. J Composites Materials 2005; 10: 1.

25. Ruseckeait AR, Jiménez A. Polym Degrad Stab 2003; 81: 353.

26. Alvarez VA, Vázquez A. Polym Degrad Stab 2004; 84: 13.

27. Dufresne A, Mignon MR. Macromolecules 1998; 31: 2693.

28. Dufresne A, Dupeyre D, Vignon MR. J Appl Polym Sci 2000; 76: 2080.

29. Alvarez VA, Ruseckaite RA, Vázquez A. J Appl Polym Sci 2003; 90: 3157.

30. Alvarez VA, Ruseckaite RA, Vázquez A. J of Thermoplastic Composite Materials 2007; 20: 291.

31. Sabaa MW. Polym Degrad Stab 1991; 32: 209.

32. Modelli A, Roninelli G, Scandola M, Mergaert J, Cnockert M. Biomacromolecules 2004; 5: 596.

33. Imman SH, Cinelli P, Gordon SH, Chielline E. J Polym Environ 2005; 13: 47.

34. Avella M, La Rota G, Martuscelli E, Raimo M. J of Materials Science 2000; 35; 829.

35. Di Franco CR, Cyras VP, Busalmen JP, Ruseckaite RA, Vazquez A. Polym Degrad Stab 2004; 86: 95.

36. Dash BN, Sarkar M, Rana AK, Mishra M, Mohanty AK, Tripathy SS. J Rein Plast Comp 2002; 21:16.

37. Chander K, Mohanty AK, Joergensen RG. Biol Fertil Soils 2002; 36: 344.

38. Sridhar M, Basavarajjapa G, Kasturi S, Balasubramanian N. Textil Res J 1982;7: 87.

39. Fowler PA, Hughes JM, Elias RM. Sci Food Agric 2006; 86:1781.

40. Ismail H, Mega L, Abdul-Khalil HPS. Polymer Int 2001; 50: 606.

41. Yao F, Wu Q, Lei Y, Guo W, Xu Y. Polym Degrad Stab 2008; 93: 90.

42. Contat L, Ribes-Greus A, Díaz-Calleja R. J Appli Polymer Sci 2001; 82: 2174.

43 .Contat L, Ribes-Greus A, Imrie CT. J Appli Polymer Sci 2002; 86: 764.

44. Sáenz de Juano-Arbona V, Vallés-Lluch A, Contat L, Ribes-Greus A. J Appli Polymer Sci 2003; 88: 1242 . 
45. Flaqué C, Contat L, Ribes-Greus A. J Appli Polymer Sci 2000; 76: 326.

46. Contat L, Ribes-Greus A. J Appli Polymer Sci 2000; 78: 1707.

47. Contat L, Ribes-Greus A, Haider N, Karlsson S. J Appli Polymer Sci 2001; 79: 1101.

48. Contat L, Ribes-Greus A J Appli Polymer Sci 2002; 83 : 1683.

49. Moriana R, Contat L, Santonja-Blasco L, Ribes-Greus A. J Appli Polymer Sci 2008; 109: 1177.

50. Santonja-Blasco L, Contat L, Moriana R, Ribes-Greus A. J Appli Polymer Sci 2007; 106 : 2218. 


\section{Antecedentes}

1.1 Materiales biodegradables

1.2 Fibras naturales

1.3 Biocomposites 



\subsection{MATERIALES BIODEGRADABLES}

Debido a una precupación social creciente y a una normativa más restrictiva, el uso de los materiales biodegradables se ha extendido enormemente durante las últimas decadas. Dentro de este paradigma, surge la necesidad de diseñar composites degradables como alternativa a los composites sintéticos y como solución frente a la falta de estabilidad estructural y dimensional que presentan ciertos materiales biodegradables ante aplicaciones específicas. Actualmente, diferentes composites conformados a partir de fibras naturales como los composites de polipropileno/fibra de lino, están ganando importancia en diversos sectores industriales (automóvil, construcción, ocio, etc.) [1]. Estos composites son materiales compuestos por fibras naturales y por una matriz no biodegradable. Su biodegradabilidad presenta cierta controversia, y es cuestionada por la comunidad científica.

En esta tesis se pretende dar un paso más, y diseñar biocomposites a partir de fibras naturales y matrices biodegradables "composites verdes". Para ello en este capítulo se presenta una revisión del estado del arte de los materiales biodegradables. Se parte de las definiciones fundamentales de degradación y polímeros biodegradables para realizar una clasificación y analísis de los mismos independientemente de su orígen. Posteriormente, se resumirán los estudios más importantes realizados sobre las fibras naturales y sus correspondientes biocomposites.

\subsubsection{Definiciones: degradación, biodegradación y polímeros biodegradables}

El término degradación es un término muy amplio y controvertido que engloba todos aquellos cambios irreversibles que se producen a lo largo del tiempo sobre las propiedades de un material polimérico, tanto físicos como químicos.

Según W.Schnabel y col. [2], el término degradación se utiliza, para señalar "los cambios en las propiedades físicas causadas por las reacciones químicas que implican la ruptura de enlaces en la cadena principal o en los grupos laterales de las macromoléculas".

El proceso de degradación de un material polimérico implica una pérdida de funcionalidad y puede iniciarse de distintos modos, dependiendo de los factores externos 
responsables de la degradación (Tabla 1.1). Sin embargo, hay que tener en cuenta que estos procesos degradativos difícilmente se producen de forma aislada en el medio ambiente.

Tabla 1.1.Clasificación de los distintos modos de degradación

\begin{tabular}{cl}
\hline Modo de Degradación & Agente Iniciador de la Degradación \\
\hline Degradación Quimica & Agentes químicos \\
Degradación Térmica & Temperatura \\
Degradación Bilológica & Ataque enzimático \\
Degradación Mecánica & Fuerza de cizalla \\
Fotodegradación & Radiación UV o visible sobre grupo cromóforo \\
Degradación Ambiental & Luz solar y parámetros climáticos \\
Degradación por Radiación & Radiación electromagnética Rayos -X, Rayos - $\gamma$ o de partículas \\
\hline
\end{tabular}

El agente iniciador de un proceso de degradación se define como el componente responsable del inicio de la degradación (agente químico, temperature, ataque enzimático, radiación UV...), sin embargo existen otros componentes a tener en cuenta; el sustrato que se va a degradar (sustancia, materia orgánica) y el ambiente donde se va a producir la degradación (condiciones específicas de humedad, $\mathrm{pH}$...)

La biodegradación (degradación biológica) de un material polimérico requiere de una degradación previa donde las cadenas poliméricas se acortan y debilitan, produciendo oligómeros/monómeros asimilables por los microorganismos [3]. La biodegradación puede ser aerobia ó anaerobia. La biodegradación aeróbica consiste en una degradación acelerada heterogénea de la materia orgánica mediante una población de microorganismos en un ambiente húmedo, templado y aeróbico bajo condiciones controladas [4].

$$
\text { Materia orgánica }+\mathrm{S}+\mathrm{O}_{2} \rightarrow \mathrm{CO}_{2}+\mathrm{H}_{2} \mathrm{O}+\mathrm{NO}_{2}+\mathrm{SC}_{2}
$$

La biodegradación anaeróbica es la desintegración del material orgánico en ausencia de oxígeno como consecuencia de una serie de interacciones metabólicas de diferentes grupos de microorganismos para producir gas metano, dióxido de carbono, ácido sulfhídrico, amoníaco, hidrógeno, agua y productos compuestos (adecuados como fertilizantes para la tierra).

Materia orgánica $+\mathrm{H}_{2} \mathrm{O}+$ Nutrientes $\rightarrow$ Materia orgánica resitente $+\mathrm{CO}_{2}+\mathrm{CH}_{4}+\mathrm{NH}_{3}+\mathrm{H}_{2} \mathrm{~S}+\mathrm{Q}$ 
De modo general, la biodegradabilidad de un material se define como la capacidad final de integración total del material polimérico en el ciclo natural (mineralización y formación de biomasa), independientemente de los mecanismos degradativos involucrados [5]. Sin embargo, la ASTM standard D5988-03 [6], define la biodegradabilidad de los materiales plásticos como la capacidad de desintegración de los materiales en $\mathrm{CO}_{2}, \mathrm{CH}_{4}, \mathrm{H}_{2} \mathrm{O}$, componentes inorgánicos o biomasa debido a la acción predominantemente de las enzimas.

Según Albertsson y col. [7], la biodegradación se define como un proceso que tiene lugar a través de la acción enzimática y/ó las reacciones químicas asociadas con los organismos vivos ( bacterias, hongos, etc.) y sus productos intermedios. En esta definición, se incluye además la necesidad de considerar las reacciones abióticas (fotooxidación, oxidación e hidrólisis) como reacciones que pueden afectar al polímero antes, durante o en lugar de la biodegradacion causada por los factores ambientales. Esta definición, se puede entender como una definición de compromiso entre las dos anteriores.

A partir de las definiciones de degradación, degradabilidad y biodegradación diferentes autores y diversas normas estandarizadas proponen las siguientes definiciones para el término de polímeros biodegradables.

Según la normativa ISO 472: 1988 [8], se dice que un plástico es biodegradable cuando su estructura química puede sufrir cambios significativos cuando se somete a un ambiente específico, dando como resultado la pérdida de alguna de sus propiedades. Los microorganismos son los responsables de los cambios producidos en la estructura química. Esta pérdida, se puede medir a partir de un método de ensayo estandarizado adecuado y se aplica durante un periodo de tiempo para determinar su posterior clasificación.

Según la normativa "ASTM D20 on plastics Subcommittee D20.96 proposal", se dice que un material es biodegradable cuando los enlaces de su cadena polimérica principal, pueden sufrir escisiones debido a fuerzas químicas, biológicas y/o físicas del ambiente, en un ratio determinado que produzca la fragmentación o desintegración de los plásticos.

Según Halley y col. [9], los polímeros biodegradables son materiales que sucumben a la acción de enzimas biológicas para formar biomasa, $\mathrm{CO}_{2} \mathrm{y}$ agua, en un periodo de tiempo y 
en un ambiente determinado. Además, estos autores definen a los polímeros biodegradables como polímeros sostenibles; materiales obtenidos mediante procesos respetuoso con el medioambiente, a partir de recursos renovables ó mediante metodos que minimizan el impacto ambiental durante su procesado. En este contexto, nace la clasificación de los polímeros biodegradables en dos grandes grupos, dependiendo de su orígen. Los polímeros biodegradables procedentes de recursos renovables se denominan polímeros biodegradables naturales y los polímeros biodegradables procedentes de recursos fósiles/petrolíferos son lo llamados polímeros biodegradables sintéticos.

\subsubsection{Características de la biodegradabilidad de un material polimérico}

A continuación, se describen una serie de factores que pueden ser determinantes para definir la biodegradablidad de un material.

\section{a) Presencia de enlaces hidrolizables}

Las macromoléculas de origen natural (proteínas, celulosa o almidón) generalmente son degradadas en sistemas biológicos mediante dos etapas [10]. En la primera etapa se produce la escisión de las cadenas poliméricas por los grupos terminales, debido a un proceso de hidrólisis y/o de oxidación. Estos fragmentos de la cadena principal, se liberan dentro del medio de reacción y a partir de este momento, se inicia la escisión por diferentes puntos de la cadena, disminuyendo la velocidad de reducción del peso molecular del polímero residual.

La presencia de enlaces hidrolizables en las moléculas biodegradables determina la escisión inicial de las cadenas poliméricas y por tanto su posterior asimilación. Un método habitual para diseñar y sintetizar polímeros biodegradables consiste en la introducción de enlaces hidrolizables en la cadena polimérica (amida, enamina, éster, urea ó uretano).

Sin embargo, un polímero que contenga estructuras totalmente hidrofílicas suele ser más difícil de biodegradar que aquellos polímeros que contengan segmentos hidrofílicos e hidrofóbicos a la vez. Por tanto, el balance hidrofobicidad-hidrofibicidad afecta decisivamente a la degradación de los polímeros. 


\section{b) Flexibilidad de la cadena}

La cadena molecular de un polímero biodegradable debe poseer la suficiente flexibilidad como para adaptarse al punto activo de la enzima. Se ha comprobado que los poliésteres alifáticos de cadena flexible son fácilmente degradables por sistemas biológicos, pero si se introducen grupos aromáticos en estos polímeros, la cadena se hace más rígida y su degradación se complica.

\section{c) Morfología}

La morfología del polímero va ser un parámetro estructural determinante para definir la biodegradabilidad del polímero. Los polímeros que presenten unidades pequeñas de repetición y una estructura más regular, adoptan estructuras compactas en las que los grupos hidrolizables son poco accesibles para las enzimas. Por el contrario, unidades de repetición más largas y menos ordenadas, en general, dan lugar a estructuras menos regulares aumentando la posibilidad de la degradación.

Por todo esto, los polímeros amorfos, se degradan con mayor facilidad que los cristalinos [11]. En general, en los materiales semicristalinos se degrada primero la zona amorfa y la velocidad de degradación depende del número, forma y tamaño de los cristales. Sin embargo, aunque la cristalinidad disminuya, la velocidad de degradación puede no aumentar debido a la disminución de la accesibilidad de las enzimas a los grupos hidrolizables.

Dependiendo de la zona donde se localice la degradación existen dos tipos de degradación, la degradación superficial (erosion) y la degradación interna. La degradación superficial tiene lugar cuando las moleculas catalíticas, las enzimas ó los catalizadores alcalinos actúan exclusivamente sobre la superficie de los plásticos y las moléculas de agua no pueden difundirse dentro de las capas internas. Por tanto, la forma de la muestra, el espesor y la cristalinidad van a ser parámetros que condicionen la degradación del material polimérico. 


\section{d) Tamaño molecular}

El tamaño molecular depende directamente del peso molecular y, en algunos casos, este tamaño determina la asimilación de los materiales por los microorganismos. La ruptura de la estructura polimérica en partes más pequeñas se debe a la acción de las enzimas extracelulares de los microorganismos que atacan la parte final de las cadenas moleculares. Por tanto, a medida que el número de finales de cadena aumenta el peso molecular del polímero disminuye. Asimismo, la solubilidad, cristalinidad y otros parámetros físicos que influyen en la biodegradación del polímero dependen del peso molecular.

\subsubsection{Mecanismos de degradación de los polímeros biodegradables en el medio ambiente}

Del mismo modo que resulta interesante el estudio de los factores que determinan la degradación de un material polimérico, entender los mecanismos de degradación medioambiental es fundamental para diseñar materiales biodegradables

Los materiales poliméricos pueden verse sometidos a una degradación biológia, química y/ó física en el medio ambiente (Figura 1.1). Los mecanismo de degradación enzimáticos, consiguen transformar a los polímeros naturales en nueva materia prima (biomasa) [12].

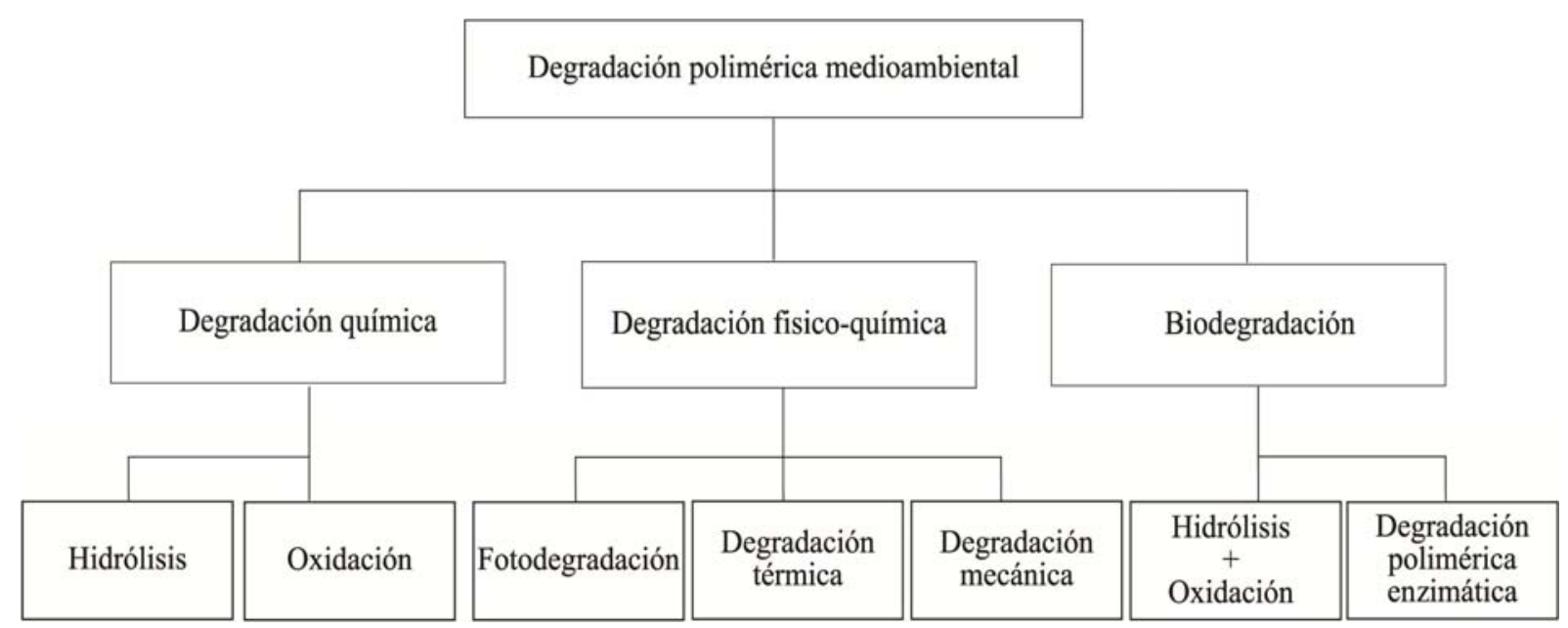

Figura 1.1. Modos de degradación medioambiental 
La biodegradación, envuelve, por lo general diversas reacciones químicas que se suceden, tal como la hidrólisis y oxidación/reducción, con o sin la intervención de microorganismos. Como ya se ha indicado con anterioridad, los polímeros biodegradables se degradan generalmente a través de dos etapas.

o En la primera etapa de degradación, se produce la ruptura de las cadenas, formándose fragmentos de bajo peso molecular que podrán ser asimilados por los microorganismos en una étapa posterior. La reducción del peso molecular, se produce principalmente al romperse las cadenas vía hidrólisis u oxidación. La hidrólisis tiene lugar en un ambiente húmedo, con o sin acción enzimática. Las hidrolasas son las enzimas responsables de la hidrólisis en un ambiente biótico. En cambio, en condiciones abioticas, la autocatálisis, el calor o los catalízadores metálicos son los responsables de la hidrólisis. La ruptura oxidativa, se produce en presencia de oxígeno, catalizadores metálicos, luz UV ó enzimas denominadas oxireductasas.

o En la segunda etapa, los fragmentos de bajo peso molecular son asimilados por los microorganismos para producir: $\mathrm{CO}_{2}, \mathrm{H}_{2} \mathrm{O}$ y productos metabólicos, en condiciones aeróbicas; y $\mathrm{CH}_{4}$ como producto mayoritario bajo condiciones anaérobicas.

\subsubsection{Importancia de los polímeros biodegradables frente a los polímeros sintéticos no biodegradables tradicionales}

El uso creciente e indiscriminado de plásticos sintéticos no biodegradables, ha propiciado la aparición de un problema medioambiental relativo a sus residuos. La deposición de estos materiales polímericos en un vertedero controlado no es una solución respetuosa con el medio ambiente. En 1970 la comunidad científica dio la voz de alarma ante el aumento creciente del volumen de plásticos en los residuos urbanos y la disminución alarmante de las zonas de vértido. Desde entonces, tanto en el sector privado como en el público, se han evaluado diversas opciones de gestión de residuos, como la incineración y el reciclaje [9].

Inicialmente, la generación de energía por incineración, se consideró como una solución viable y ecológica para la gestión de los residuos poliméricos. En este proceso, los hidrocarburos de los residuos reemplazan el uso del combustible fósil para generar energía térmica. Esta capacidad de autofinanciación convierte a este tratamiento de residuos en una de 
las opciones más atractivas para las autoridades locales [13]. Sin embargo, el desconocimiento de muchos de los polímeros vertidos como residuos, convierte los beneficios ecológicos en insuficientes frente a la energía consumida durante el transporte y la preparación para su inceneración. Por todos estos factores, esta opción despierta una gran desconfianza en la mayoría de la población, limitando su desarrollo.

Por otra parte, y tomando como referencia el reciclaje industrial (reciclaje de vidrios y metales), se empezaron a desarrollar procesos de recuperación para los residuos poliméricos. Sin embargo, los polímeros cada vez que se reprocesan pueden perder propiedades físicas y mecánicas, debido a una proceso de peroxidación. Además, el proceso de reciclaje de los residuos poliméricos domésticos se complica cuando estos están contaminados de residuos biológicos ó mezclados con otros tipos de plásticos. Por tanto, a pesar de que el reciclaje se podría considerar como una buena alternativa de gestión, la experiencia práctica demuestra que el reprocesado de los plásticos mezclados y contaminados producen mezclas poliméricas con bajas propiedades mecánicas y falta de durabilidad en comparación con los productos vírgenes [14-16].

Por todo esto, surge la idea de solucionar este problema desde su origen gana importancia. La alternativa puede ser diseñar polímeros biodegradables que permitan cerrar el ciclo del material sin ningún tipo de daño medioambiental, ya que los residuos poliméricos son devueltos al ciclo natural del carbón, mediante la biodegradación [17]. Además, si los materiales biodegradables diseñados provienen de recursos renovables los residuos se convierten en abono para la obtención de materias primas del nuevo material natural renovable, contribuyendo a la conservación de las fuentes petroquímicas. De este modo se contribuye a crear un proceso de reciclaje natural integral "reciclaje biológico" (Figura 1.2). 


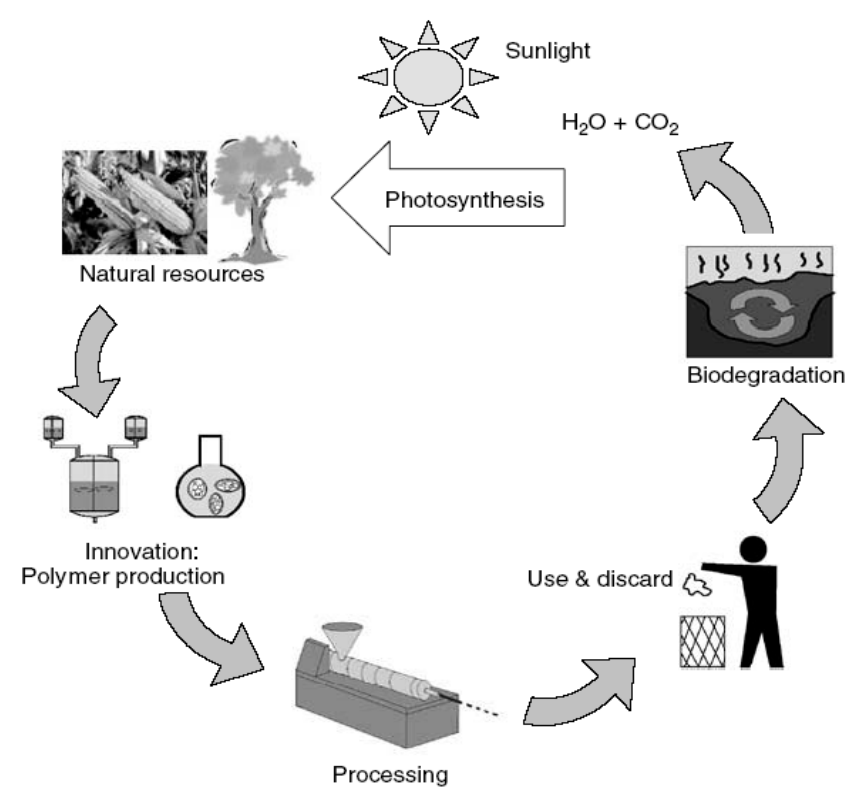

Figura 1.2. Ciclo de vida de los polímeros biodegradables propuesto por Mohanty y col.[1]

\subsubsection{Clasificación de los polímeros biodegradables}

Los materiales biodegradables de acuerdo con su procedencia u orígen se pueden clasificar en dos grandes grupos: polímeros renovables ó naturales, que son aquellos polímeros que provienen de recursos naturales; y polímeros sintéticos, que son aquellos polímeros diseñados a partir de fuentes fósiles /petrolíferas.

Los polímeros de origen natural desde un punto de vista químico, incluyen cuatro subgrupos:

i. Polisacáridos

Homopolisacáridos (almidón, celulosa, quitina...)

Heteropolisacáridos (gomas naturales,...)

ii. Proteínas

iii. Lípidos

iv. Poliésteres alifáticos

Poliésteres producidos por microorganismos o por plantas (PHA, PHB...)

Poliésteres sintetizados a partir de monómeros biológicos (PLA)

Los polímeros de origen sintético incluyen seis subgrupos:

i. Poliésteres alifáticos (PCL)

ii. Poliésteres aromáticos o mezclas de ambos 
iii. Poliamidas (nylon 6 policaprolactama; nylon 6,6 polihexametilendiamina adipato)

iv. Polieteres (PEG)

v. Polivinilalcoholes (PVOH, PEVOH)

vi. Poliolefinas modificadas. ( PE con almidón,...)

\subsubsection{Estructura y propiedades del almidón y del poliéster}

De entre los polímeros biodegradables naturales destacan los polisacáridos, y dentro de este grupo se va hacer especial hincapie en el almidón por ser el material base empleado junto a los poliesteres, como matriz polimérica para la conformación de los biocomposites de esta tesis.

\section{a) Almidón}

\section{Descripción}

Este polisacárido se obtiene exclusivamente de los vegetales que lo sintetizan a partir de dióxido de carbono y agua. En este proceso se absorbe energía del sol y se almacena en forma de glucosa y enlaces moléculares formando largas cadenas de almidón, que pueden llegar a contener de 2000 o 3000 unidades de glucosa. El almidón se puede encontrar en las raíces y los tallos, en los tubérculos, en los frutos, en el polen y en las semillas. Los principales cultivos de almidón incluyen las patatas, el trigo y el arroz.

\section{Estructura química}

El almidón es una poliglucosa unida a través de uniones $\alpha$-acetal y constituida por dos componentes mayoritarios; la amilosa y la amilopectina. La amilosa principalmente presenta uniones de tipo $\alpha-(1,4)$ entre las unidades de glucosa, y en la amilopectina las unidades de glucosa también pueden estar unidas mediante enlaces $\alpha-(1,6)[18]$.

En la amilosa las unidades de glucosa forman una estructura prácticamente lineal con escasas ramificaciones, con un peso molecular de 0,2-2 millones. La longitud de la cadena de amilosa puede variar entre 50 y 60.000 unidades monoméricas de glucosa. La diferencia en la estereoquímica de los carbonos anoméricos favorece la adopción de una conformación helicoidal, debido a que al formarse el enlace $\alpha-(1,4)$ los anillos de glucosa no se pueden 
situar en una misma zona planar, cada vuelta de hélice consta de seis móleculas de glucosa. El interior de la hélice contiene sólo átomos de hidrógeno y es, por tanto, lipofílico, mientras que los grupos hidroxilo están situados en el exterior de la hélice.

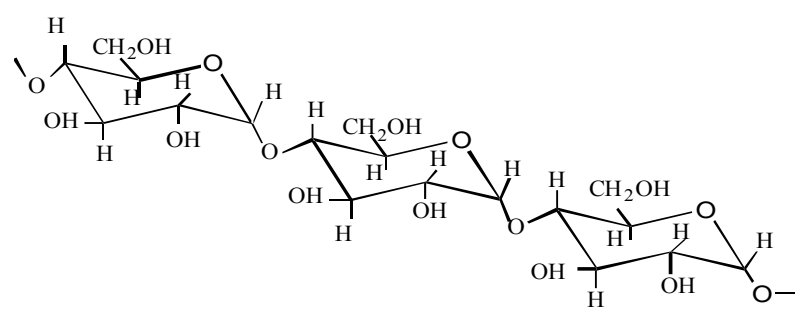

En la amilopectina alrededor del 5\% de los monómeros de glucosa están unidos mediante enlaces $\alpha-(1,6)$, creándose una estructura ramificada cada 10-60 unidades de glucosa. Su peso molecular es del orden de 100-400 millones, lo que la convierte en uno de los biopolímeros naturales más largos.

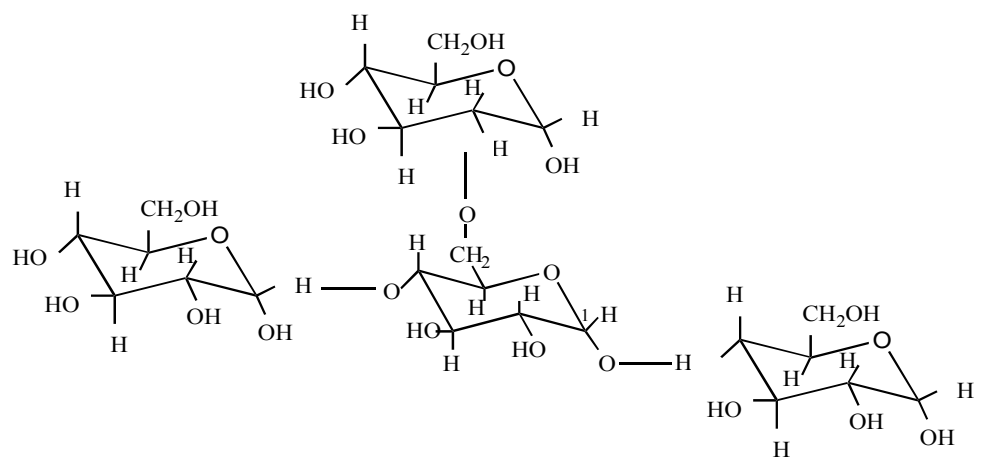

Además de la amilosa y la amilopectina, los gránulos de almidón contienen cantidades muy pequeñas de proteínas, grasas y fosfatos. La naturaleza química de la amilosa permite su asociación con pequeñas moléculas hidrófobas, por lo que es común que la fracción de amilosa se encuentre asociada con una proporción alta de lípidos [18]. La amilopectina puede contener grupos fosfatos unidos de manera covalente. El nivel de fosforilación del almidón varía con el origen botánico del almidón; el almidón que proviene de cereales presenta niveles de fosforilación imperceptibles, mientras que el almidón de patata esta altamente fosforilado.

\section{Cristalinidad}

El almidón es único entre los carbohidratos por organizarse en la naturaleza en forma de gránulos, esto es debido a que las cadenas laterales de amilopectina son capaces de formar 
estructuras helicoidales, las cuales cristalizan. Cuando los gránulos de almidón son examinados bajo un microscopio de polarización, se muestra una cierta birrefringencia lo que implica un alto grado de organización molecular dentro de los gránulos. La difracción de rayos-X demuestra que el almidón es parcialmente cristalino, con una proporción del 20 al $45 \%[19]$.

El análisis estructural [20] de los gránulos muestra que las cadenas laterales de amilopectina forman dobles hélices y están arregladas de tal manera que se forman paquetes que contienen entre 9 y 17 cadenas laterales en intervalos regulares de aproximadamente 9-10 nm de largo sobre el eje de la molécula y dan lugar a las lámelas cristalinas que se encuentran alternadas con lámelas amorfas formadas por las regiones donde se localizan los puntos de ramificación y por los espacios entre los agregados de dobles hélices (Figura 1.3).

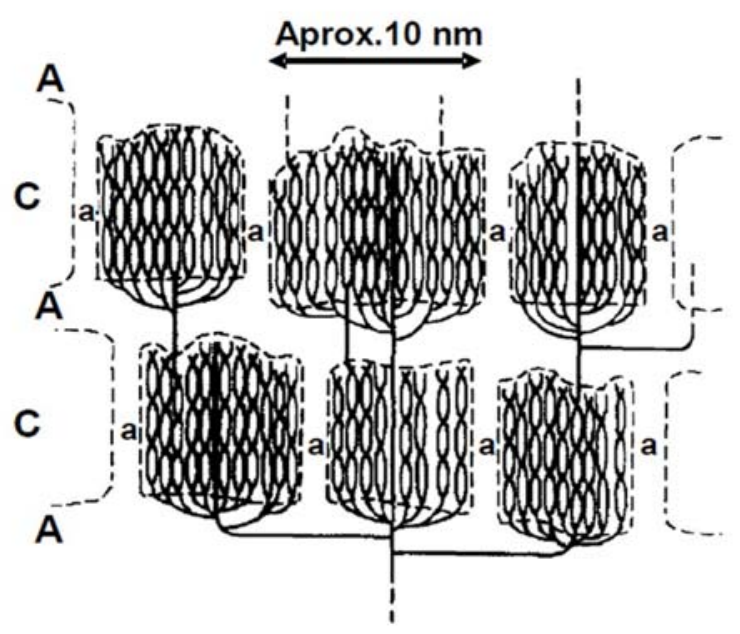

Figura 1.3. Esquema del empaquetamiento de las cadenas laterales de amilopectina en las lámelas. A) lámelas amorfas (zona de ramificación) de aproximadamente $4 \mathrm{~nm}$ de largo; C) lámelas cristalinas (paquetes de cadenas laterales de amilopectina) de $6 \mathrm{~nm}$ de largo en promedio; a) regiones amorfas entre los paquetes cristalinos. Figura tomada de Gallant y col., 1997 [21]

La Figura 1.4 proporciona una visión más general sobre la estructura del gránulo de almidón. Este modelo de empaquetamiento propone la existencia de difrerentes tipos de cadenas de amilopectina que varían en longitud y por tanto, en densidad de empaquetamiento, originando tres tipos diferentes de cristalinidad: tipo-A, tipo-B y tipo-C. 


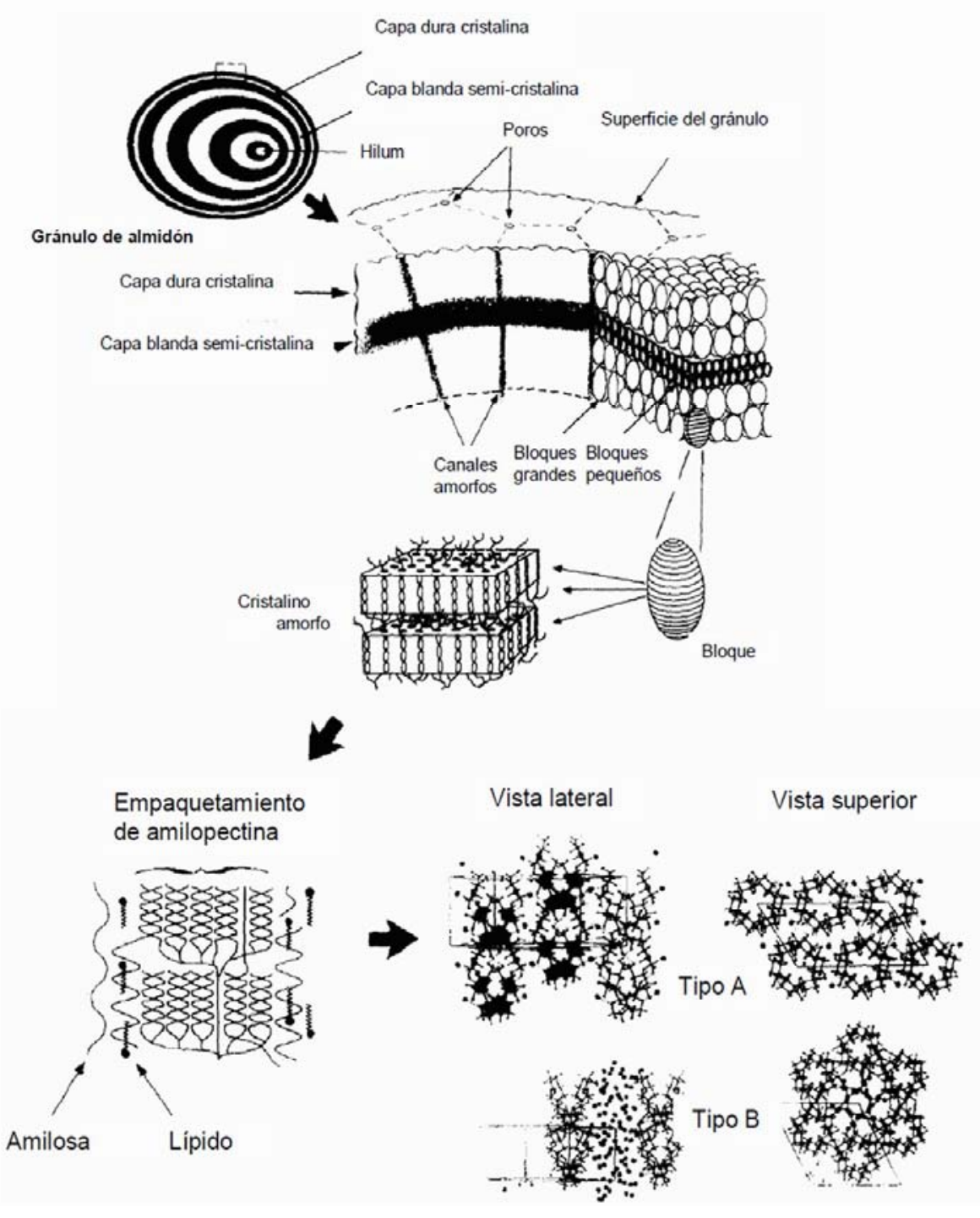

Figura 1.4. Estructura del gránulo de almidón tomada de Beral y col. [22]

La cristalinidad de tipo-A muestra el empaquetamiento más denso; las dobles hélices están arregladas de tal manera que permiten que las moléculas de agua queden incluidas en el empaquetamiento en menor cantidad que en las cadenas tipo-B. La cantidad de agua que puede incorporarse en las estructuras cristalinas se estima en $0,1 \mathrm{~g}$ por gramo de almidón seco para el tipo-A y en 0,25g por gramo en el tipo-B. En algunos almidones principalmente del tipo A, se ha observado la presencia de canales amorfos o poros que podrían estar relacionados con la mayor o menor susceptibilidad del almidón a la degradación enzimàtica. 
Los almidones cuyos gránulos presentan esta estructuras de tipo-A, tienden a ser más fácilmente degradados.

La cristalinidad de tipo-A se encuentra normalmente en los almidones procedentes de granos o semillas, mientras que la de tipo-B se encuentra en los tubérculos. La cristalinidad de tipo-C es menos conocida y se cree que es una forma intermedia entre el tipo-A y el tipo$\mathrm{B}$, que aparece en el almidón de algunas plantas, como por ejemplo en el guisante.

\section{Gelatinización}

El procesado de los gránulos de almidón normalmente implica la utilización de temperaturas elevadas en presencia de un medio acuoso; en estas condiciones se produce la gelatinización del almidón. A pesar de que los gránulos de almidón son insolubles en agua fría, cuando se calientan en un medio acuoso sufren un proceso denominado gelatinización, que es la disrupción de la ordenación de las moléculas de los gránulos y la fusión de la parte cristalina del almidón.

Durante la gelatinización se produce un proceso de hinchado, los gránulos van absorbiendo agua hasta que se desintegran formando un engrudo. La amilosa se dispersa en agua caliente dando lugar a largas micelas hidratadas [23]. La gelatinización total se produce normalmente dentro de un intervalo más o menos amplio de temperatura, donde los gránulos más grandes son los que gelatinizan primero. La temperatura de iniciación de la gelatinización es determinante para definir las condiciones iniciales de procesado.

\section{Retrogradación}

Por otra parte, cuando el almidón se enfría tiende a retrogradarse ó recristalizar produciéndose la liberación de agua u otras moléculas de solvente. La retrogradación se define como la insolubilización y la precipitación espontánea, principalmente de las moléculas de amilosa, debido a que sus cadenas lineales se orientan paralelamente y se ordenan entre sí por puentes de hidrógeno a través de sus múltiples grupos hidróxilos. El grado de retrogradación del almidón está directamente relacionado con la proporción de almidón/amilopectina, las fracciones de amilosa, las secciones lineales de amilopectina y la presencia de lípidos que posea el polisacárido en su composición. La mayor parte de la 
amilosa recristaliza irreversible y rápidamente, mientras que las cadenas laterales de amilopectina recristalizan reversiblemente y mucho más despacio [1].

\section{Biodegradación del almidón}

La biodegradación del almidón implica la asociación temporal de los gránulos con diferentes enzimas. En primer lugar, se necesita de una enzima capaz de actuar en la superficie semicristalina del gránulo, la $\alpha$-amilasa. Esta enzima actúa primero con actividad endo (en los enlaces interiores de las cadenas) y después con actividad exo (en los extremos de cadena), pero siempre sobre los enlaces glicosídicos $\alpha-(1,4)$. Tras el ataque aleatorio de esta enzima sobre las cadenas de amilosa los productos finales resultantes son: unidades de $\alpha$ glucosa y dímeros formando unidades de $\alpha$-maltosa. Una vez iniciada la degradación del almidón, las enzimas $\alpha$-amilasas actúan sobre el almidón con actividad exo, de forma que el producto final obtenido es la $\alpha$-maltosa.

Las enzimas que hidrolizan los enlaces $\alpha-(1,6)$, se conocen como enzimas desramificadoras y pueden dividirse en isoamilasas o dextrinasas límite. Otro grupo de enzimas que también participan en la degradación del almidón son las enzimas desproporcionadoras o enzimas D. Estas enzimas son incapaces de actuar sobre cadenas de menos de cuatro glucosas por lo que generan maltotriosas.

Una vez enumeradas las enzimas que intervienen en la degradación del almidón, cabe destacar la influencia que tiene sobre el proceso de biodegradación, parámetros como la proporción de amilosa/amilopectina y la longitud de las cadenas de amilopectina. Los almidones que presentan mayor resistencia a la degradación enzimática son aquellos con mayor contenido de amilosa, de momento no se conoce cual es la razón de esta relación [21].

\section{Tratamientos físicos y químicos para obtener productos comerciales de base de almidón}

A continuación, se va a describir la evolución en el mercado de los materiales compuestos de almidón. Esta evolución consta de dos grupos diferenciados, una primera generación de materiales que se caracterizan por contener en su formulación almidón granular y una segunda generación donde el almidón está plastificado. 


\section{1) Primera generación de polímeros de almidón}

Los primeros materiales que presentaron en su formulación polímeros de almidón fueron mezclas donde el almidón se utilizaba como un aditivo para conseguir potenciar la degradación de los polímeros sintéticos convencionales.

El almidón en su estado granular fue utilizado como material de relleno, como carga o aditivo en mezclas de poliolefinas desde los años 70. Griffin [24] fue el primero en presentar el almidón de maíz granular, como un aditivo capaz de acelerar el proceso de degradación en los polietilenos de baja densidad (LDPE). Con objeto de mejorar la resistencia de los copolímeros almidón y LDPE, el almidón fue tratado superficialmente con silanos, consiguiendo mejorar la compatibilidad entre ambos componentes, al hacer la superficie del almidón altamente hidrófoba.

También, se realizaron ensayos de degradación de estos nuevos copolímeros de almidón y LDPE, descubriendo que la matriz poliolefínica se degradaba en plantas de compostaje de residuos sólidos urbanos, pero no al ser simplemente enterrada en tierra de jardín. Se comprobó que la presencia de aceite insaturado de cocina era la responsable de la degradación oxidativa del polímero sintético. Bajo estas premisas, en 1987 se patentó un masterbatch compuesto de: almidón granular, caucho, catalizadores de metales de transición y polietileno de baja densidad, bajo el nombre comercial Polyclean. Este masterbatch, puede degradarse por medio de un proceso de fotooxidación, seguido de un proceso de biodegradación. Este último punto es discutible, y algunos autores defienden el hecho de que sólo se degrada el almidón, quedando la matriz polimérica fragmentada pero no degradada [25]. Las principales aplicaciones de estos compuestos son: la elaboración de bolsas, envases desechables y mantillos agrícolas.

\section{2) Segunda generación de polímeros de almidón}

Esta segunda generación de polímeros de almidón surge ante la necesidad de mejorar los problemas mecánicos y de procesado, derivados del uso del almidón en su estado natural. En esta generación se incluyen el almidón termoplastificado, modificado y mezclado [26]. 


\section{1) Almidón termoplástificado}

Los gránulos de almidón muestran propiedades hidrofílicas y fuertes interacciones intermoleculares por medio de puentes de hidrógeno debido a la presencia de grupos hidroxílicos. Estos fuertes enlaces de hidrógeno son responsables de las pobres propiedades térmicas que presenta este carbohidrato, alcanzándose la temperatura de descomposición térmica antes que la temperatura de fusión del polímero. Por tanto, todos los intentos de fundir el almidón por simple calentamiento conducen a su pirólisis y no a su fusión. Por este motivo el almidón no se puede procesar mediante los sistemas tradicionales de fusión [27]. Para hacer posible su procesado, al almidón se le añaden plastificantes, sustancias que se pueden unir a la molécula de almidón reduciendo los enlaces de hidrógeno existentes entre las cadenas.

El almidón termoplastificado se define como el almidón plastificado que ha sido procesado para destruir completamente la estructura cristalina, formando así, un almidón amorfo termoplástico. El procedimiento típico para conseguir un almidón termoplástico implica un aumento de temperatura en presencia de un medio acuoso, estas condiciones de procesado conllevan a su vez, a un proceso de gelatinización [9]. Por tanto, entender el mecanismo de gelatinización permite controlar los cambios en la estructura y optimizar las condiciones del procesado del almidón. La Figura 1.5 muestra el proceso de gelatinización de forma esquemàtica.

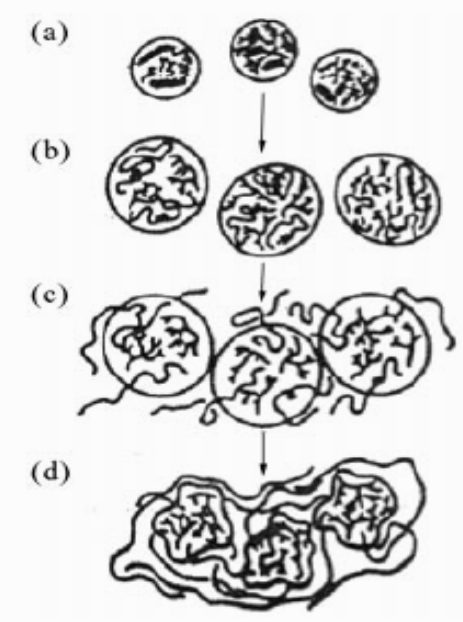

Figura 1.5. Proceso de gelatinización del almidón: (a) gránulos de almidón compuestos de amilosa (lineal) y amilopectina (ramificaciones); (b) la adición de agua rompe la cristalinidad y destruye las helices;

(c) la adición de calor y de agua provoca el hinchado, extrayendo a la amilosa del gránulo;

(d) los gránulos, formados mayoritariamente por la amilopectina, se colapsan y se mantienen en una matriz de amilosa (tomada de Lai y Kokini, 1991) [28]. 
Desde 1970 el uso del almidón termoplastificado ha despertado un gran interés en la comunidad científica. Uno de los primeros estudios sobre el procesado, la reología y las propiedades de almidón termoplastificado fue realizado por Lai y Kokini [28]. En estas investigaciones se estudiaron los efectos de los constituyentes del almidón, la humedad del almidón, las propiedades reológicas y la fragmentación del almidón termoplasficado durante el procesado. Willett y col. [29] a su vez estudiaron el efecto de la temperatura, de humedad y de los aditivos sobre las propiedades del mismo.

Estos estudios dieron como resultado una serie de productos comerciales de base almidón, como ejemplo se describen los siguientes:

Supol (Supol, Alemania)

Este termoplástico proviene del almidón de patata. Se comercializa en forma de pelets que pueden ser inyectados para producir, por ejemplo, platos de usar y tirar.

Evercon (Cornstarch, Japón)

Este material comercial se elabora a partir de almidón de maíz, que puede ser inyectado para producir las partes más pequeñas de la cubertería.

Végémat (Végémat, Francia)

A partir del almidón de la patata, del trigo, del maíz o la tapioca se conforma este material comercial que se caracteriza por sus diversas aplicaciones en el campo de la alimentación, en juguetes para mascotas y en accesorios veterinarios.

A pesar de la existencia de diversas marcas comerciales de almidón termoplastificado, actualmente existen pocas aplicaciones industriales, debido a las limitaciones de uso de este material. El almidón termoplastificado por lo general, se caracteriza por tener una gran solubilidad en agua [30] y exhibir una baja estabilidad estructural, con propiedades mecánicas variables con el tiempo [31]. Con la finalidad de mejorar estos problemas se han propuesto diversas modificaciones físicas y químicas como:

o La sustitución química de los grupos $\mathrm{OH}$ por acetilación ó esterificación

- La adición de agentes que potencien el entrecruzamiento de las cadenas

o La copolimerización por injerto y el mezclado físico con otros polímeros 
Todas estas modificaciones propuestas implican de forma general la sustitución de los grupos hidroxilos, de modo que a medida que aumenta la sustitución de los grupos hidroxilos disminuye la temperatura de gelatinización, se reduce la retrogradación y se mejora la flexibilidad de los productos finales.

\section{2) Almidón termoplastificado modificado y mezclas de almidón termoplastificado}

Narayan y col. [32] y Sagar y col. [33] comprobaron un aumento de la resistencia del agua y la termoplasticidad del material al esterificar un compuesto de almidón. Bae y col. [34] estudiaron la hidroxipropilación de la amilasa, demostrando una mayor facilidad de procesado durante la extrusión, una disminución de la absorción de humedad y un aumento en la flexibilidad y resistencia del producto final. Por otro lado, Rivard y col. [35] analizaron cómo influía el proceso de acetilación del almidón sobre su biodegradabilidad. Este estudio demostró como un alto nivel de acetilación reducia la biodegradación del almidón, indicando la necesidad de realizar un balance entre la mejora de las propiedades y la pérdida de biodegradación para conseguir el diseño de un material óptimo. Iman y col. [36] propusieron modificaciones químicas específicas del almidón (sustitución de grupos hidroxílos concretos por sustancias como el n-butilo y el palmitato) para obtener materiales biodegradables con una morfológica superficial variable, susceptibles a la adhesión de los microorganismos y capaces de controlar la biodegradación.

Por otra parte, se ha estudiado el entrecruzamiento de las cadenas de almidón. Imman y col. [37] usaron como agente precursor la hexametoximetilmelamina para entrecruzar químicamente el almidón con el alcohol polivinílico (PVOH). De este modo se obtuvo una compleja red intermolecular e intramolecular, entre la madera, el almidón y el PVOH, estableciéndose fuertes enlaces entre ellos.

Del mismo modo, se han desarrollado diferentes mezclas reactivas de termoplásticos de almidón. Mani y col. [38] propusieron diferentes técnicas para conseguir compatibilizar las mezclas de poliésteres y almidón. Estudiaron el desarrollo de los injertos de ácido maleico en las mezclas de almidón y poliéster, encontrando un aumento significativo en las propiedades de tensión de las mezclas compatibilizadas. Algunos de los más recientes estudios relacionados en el campo de la copolimerización por injerto, son la síntesis del almidón-gpolimetacrilato y el almidón-g-poliestireno. Este proceso genera radicales libres en el almidón 
y a su vez, estos radicales libres reaccionan con los monómeros vinílicos. Los copolímeros de base almidón obtenidos mediante este procedimiento pueden procesarse mediante inyección o extrusión. La película obtenida se caracteriza por ofrecer propiedades similares al polietileno de baja densidad. Sin embargo, estos copolímeros que presentan enlaces con los polímeros vinílicos ofrecen una biodegradabilidad limitada.

La inclusión de determinados injertos en las moléculas de almidón afectan negativamente a su biodegradabilidad. Por este motivo, en la actualidad, el mezclado físico es una de las vías más estudiadas para conseguir mejorar las propiedades del almidón termoplastificado [39-40]. Los materiales formados por moléculas de almidón y monómeros de sustancias sintéticas biodegradables ofrecen propiedades de mezcla mejores que las ofrecidas por el almidón por si sólo, sin alterar su biodegradabilidad y a un coste menor que mediante las demás modificaciones propuestas. Por todo esto, este estudio se centra en el diseño de copolimeros de almidón y polímeros sintéticos biodegradables, capaces de consiguir gelatinizar el granulo del almidón y obtener una mezcla de base almidón plastificado y biodegradable.

Algunos ejemplos de este tipo de copolímeros comerciales son:

\section{Bioplast (Biotec, Alemania)}

Este material es una mezcla de almidón y poli(ع-caprolactona) que se comercializa en diferentes grados dependiendo del tipo de procesado que se requiera para su elaboración: inyección, inyección por soplado ó extrusión. Para su conformación se usa glicerol como plastificante, reactivos de mezclado durante la operación de polimerización por extrusión. Sus principales aplicaciones se destinan a embalaje alimenticio.

\section{Mater-Bi (Novamont, Italia)}

Bajo esta denominación comercial, Novamont SpA (Novara, Italia) vende una gran gama de copolímeros de almidón termoplastificados (con plastificantes naturales) y materiales sintéticos biodegradables. Esta familia de materiales puede llegar a alcanzar contenidos mayores del 50\% en almidón. Los principales usos de estos materiales son: como bolsas de compra, embalaje de alimentación, productos de higiene, mantillos agrícolas, cubertería, etc. 
$\mathrm{Su}$ nomenclatura depende del tipo de polímeros sintéticos que se mezclan con el almidón, se pueden encontrar mezclas de derivados de celulosa, poli( $\varepsilon$-caprolactona), poli(etilen-vinil-alcohol), etilen-vinil alcohol, celulosa, poliestireno, etc. En 1997, Novamont SpA producía cuatro grados diferentes de materiales biodegradables comercializados bajo el nombre de Mater-Bi [41]:

o Grado Z. Este producto es compostable y biodegradable principalmente cuando se encuentra conformado como película o lámina. Su tiempo de biodegradación varía entre 20 - 45 días. Esta formado por almidón termoplastificado y policaprolactona, y fue introducido en el mercado en 1992. Dentro de esta clase de Mater-Bi se pueden encontrar diferentes nomenclaturas, como el ZI01U, ZF03U/A.

o Grado V. Estos productos son compostables, biodegradables y solubles. Su duración ante la biodegradación en un ambiente acuoso puede llegar a ser menor a 45 días. Estan formados por almidón termoplastificado con aditivos naturales en más de un $85 \%$.

o Grado Y. Este tipo de Mater-Bi, se define como biodegradable y compostable. Está compuesto por almidón termoplastificado y derivados de celulosa. $\mathrm{Su}$ biodegradación depende del medio en el que se realice. Puede tardar hasta 4 meses en degradarse bajo condiciones de compost y sólo 30 días en condiciones anaeróbicas. Sus propiedades mecánicas son muy similares al poliestireno.

o Grado A. Este material es biodegradable y no compostable. Su tiempo de biodegradación es de 2 años en un ambiente líquido. Contienen almidón ampliamente acomplejado con copolimeros de etilen-vinil alcohol.

La tecnología usada por Novamot SpA para procesar materiales de base almidón implica unas condiciones de procesado capaces de destruir prácticamente toda la cristalinidad que presentan las moléculas de amilosa y amilopectina en el gránulo del almidón [42]. Esta pérdida de la cristalinidad se produce en presencia de macromoléculas las cuales son capaces de formar complejos con la amilosa. El complejo formado entre el agente acomplejante y la amilosa se caracteriza por que la amilosa adquiere una configuración de hélice alrededor del agente acomplejante. 
La Figura 1.6 muestra los distintos modelos límite de conformación propuestos para el Mater-Bi [43]. La estructura "droplet-like" es una estructura compleja que se caracteriza por tener un interior formado por la amilopectina amorfa del almidón rodeada por las cadenas de los complejos de amilosa, lo cual convierte a la amilopectina en insoluble. A su vez, las estructuras "droplet" pueden interaccionar entre ellas por medio de enlaces por puentes de hidrógeno, produciendo un esqueleto de estructura tipo gel. Por otra parte, la estructura de capa consiste en una capa microscópica de moléculas de amilopectina intercaladas con capas de agente complejante, tales capas se encuentran unidas por medio de la amilosa complejada.

Estas dos estructuras junto a todas las que se pueden derivar de ellas explican el amplio grado de propiedades mecánicas, físico-químicas, y reológicas y los diferentes grados de biodegradación que pueden alcanzar los productos Mater-Bi.

Pese a estas diferencias en la estructura del Mater-Bi, Bastioli y col. [43] propusieron un mecanismo de biodegradación general para este tipo de compuestos que se produce por étapas:

o El componente natural, incluso si queda protegido por una estructura interpenetrable, es inicialmente hidrolizado por enzimas extracelulares.

o El componente sintético se biodegrada a través de la adsorción superficial de los microorganismos, favorecido por la creciente área superficial que aumenta a médida que el componente natural se hidroliza. Por tanto, la presencia del almidón aumenta la velocidad de degradación del polímero sintético.
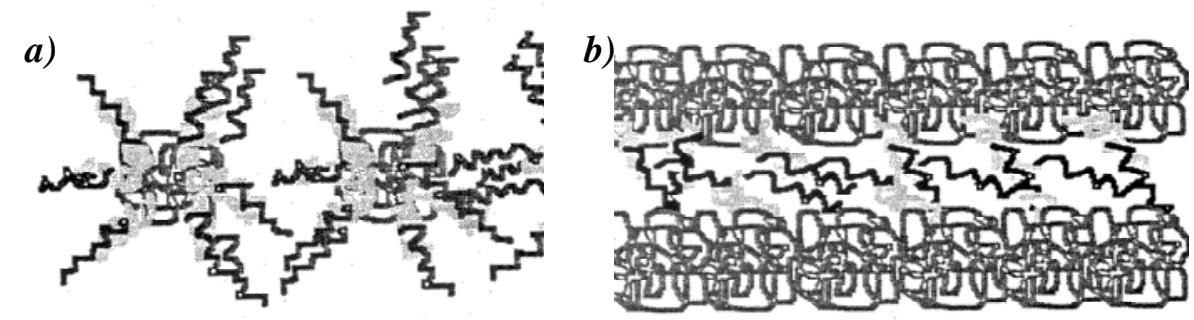

Figura 1.6. Estructuras límite del Mater-Bi: a) “droplet-like” y b) estructura de capa [43]. 


\section{b) Poliésteres}

\section{Poliésteres alifáticos}

Los poliésteres constituyen un grupo importante dentro de los polímeros biodegradables y se caracterizan por la presencia de enlaces ésteres (-CO-O-) en la cadena principal. No presentan interacciones intermoleculares fuertes y, por tanto, sus propiedades son sensibles a las variaciones estructurales. Además, son fácilmente hidrolizables y poseen una elevada impermeabilidad a los gases.

Dentro de la familia de los poliésteres alifáticos pueden encontrarse polímeros naturales (poli- $\beta$-hidroxialcanoatos, poli- $\beta$-hidroxibutirato, poli- $\beta$-hidroxivalerato, etc.), polímeros sintéticos (poli-e-caprolactona) ó polímeros con orígen doble, fósil o natural (poliácido láctico). Los poliesteres biodegradables naturales pueden ser producidos por microorganismos ó a partir de monómeros de orígen biológico.

\section{1) Poliésteres producidos directamente por microorganismos}

Existen poliésteres que son sintetizados por ciertas bacterias como material de reserva. En esta categoría, se encuentran los poli- $\beta$-hidroxialcanoatos (PHA), poli- $\beta$-hidroxibutirato (PHB) y poli- $\beta$-hidroxibutirato-co- $\beta$-hidroxivalerato (PHB/PHV). Estos poliésteres se caracterizan por tener un radical específico en su estructura química (Tabla 1.2). Generalmente, una disminución de la longitud de las cadenas alifáticas causa una disminución en el punto de fusión y en la temperatura de transición vítrea.

Tabla 1.2. Clasificación de los poliésteres

\begin{tabular}{cl}
\hline Polímero/grado(compañia) & \multicolumn{1}{c}{ Radical } \\
\hline$P H A$ & ---- \\
$P H B$ & $\mathrm{CH}_{3}$ \\
$P H V$ & $-\mathrm{CH}_{2}-\mathrm{CH}_{3}$ \\
PHBHx (Kaneda) & $-\mathrm{CH}_{2}-\mathrm{CH}_{2}-\mathrm{CH}_{3}$ \\
PHBO (Nodax) & $\mathrm{CH}_{3} \mathrm{o} / \mathrm{y}-\left(\mathrm{CH}_{2}\right)_{4}-\mathrm{CH}_{3}$ \\
PHBOd (Nodax) & $\mathrm{CH}_{3} \mathrm{o} / \mathrm{y}-\left(\mathrm{CH}_{2}\right)_{14}-\mathrm{CH}_{3}$ \\
\hline
\end{tabular}

Estos productos se caracterizan por ser termoplásticos, por lo que pueden ser fácilmente transformados mediante fundido en piezas ó fibras por inyección ó extrusión. Presentan propiedades mecánicas aceptables y una gran facilidad de formación de 
copolímeros que, con sus distintas características, cubren un amplio rango de aplicaciones, destacando como polímeros biocompatibles.

\section{1) Poli- $\beta$-hidroxialcanoatos (PHA)}

Estos poliésteres se identificaron por primera vez en 1925. Se encuentran almacenados como reserva energética en las células de muchas bacterias (como por ejemplo, en la Alcaligenes Eutrophus). El PHA puede formularse con diversos grados de cristalinidad, para diversificar sus usos, se puede mezclar con facilidad y se transforma y confecciona mediate equipamiento tradicional. Entre sus numerosas aplicaciones destaca su uso en la elaboración de recipientes para cosméticos, artículos deshechables, implantes médicos, etc.

\section{2) Poli- $\beta$-hidroxibutirato (PHB)}

Este homopolímero es el más conocido de la familia, y se caracteriza por ser altamente cristalino, frágil, térmicamente inestable, con un alto peso molecular, insoluble en agua y baja resistencia química. Además, si se mantiene por encima de su punto de fusión durante períodos de tiempo largo se degrada rápidamente.

\section{3) Poli- $\beta$-hidroxibutirato-co- $\beta$-hidroxivalerato (PHBV)}

Con la finalidad de mejorar las propiedades mecánicas del PHB se propone la copolimerización de este poliéster con otro poliéster de la misma serie, el poli- $\beta$ hidroxivalerato. El poli- $\beta$-hidroxibutirato-co- $\beta$-hidroxivalerato, es un compuesto de ácido $\beta$ hidroxibutírico (HB) y de ácido $\beta$-hidroxivalérico (HV), siendo el HB el componente mayoritario $(100-70 \%)$.

El PHBV se produce mediante la fermentación bacteriana del Alcaligenes Eutrophus. Para su obtención, se alimenta a los microorganismos con glucosa, ácido propiónico y otros ingredientes, se deja suficiente tiempo para que se multipliquen y a continuación se añade más glucosa, de manera que las bacterias no utilicen el exceso de glucosa para multiplicarse, generándose PHBV. Cuando el peso del PHBV alcanza el 80\% del peso seco de la bacteria, esta se separa del polímero.

La copolimerización del HB con HV conduce a la mejora de la procesabilidad de este nuevo material, puesto que disminuye la cristalinidad y el punto de fusión, aumentando la 
flexibilidad, disminuyendo la rigidez y la resistencia térmica. Las propiedades barrera del material se pueden ajustar variando el contenido de los comonómeros.

La utilización de este polímero presenta una serie de ventajas puesto que es biocompatible. Pero sus aplicaciones se ven limitadas por su elevado coste de producción.

Hoy en día se pueden encontrar en el mercado diferentes poliésteres y mezclas de poliésteres bajo el nombre comercial de:

Biomer (Biomer, Alemania)

Es un PHB producido a partir de la Alcaligenes Latus, cuyos pelets son comercializados para ser transformados por equipamiento convencional. Este producto se caracteriza por ser muy duro y por poder cubrir un amplio rango de temperatura (de -30 a $120^{\circ} \mathrm{C}$ ).

\section{Biopol (Metabolix, USA)}

Es un copolímero de PHB/PHV (90\%/10\%). Se procesa mediante inyección ó moldeado para la producción de fibras o películas. Destaca por sus aplicaciones de embalaje electrónico.

\section{2) Poliésteres obtenidos a partir de monomeros de origen biológico}

\section{1) Poliácido láctico (PLA)}

Este poliéster se clasifica dentro de la categoría de biopolímero de origen natural porque su monómero (ácido láctico) todavía se obtiene mayoritariamente por fermentación. Aunque también podría situarse en la categoría de los poliésteres sintéticos porque puede ser sintetizado a partir de fuentes petrolíferas.

El PLA es un polímero termoplástico rígido que puede ser semicristalino o amorfo en función de las propiedades de estereopureza de la cadena principal. Las formas más comunes y naturales del ácido las conforman el L-ácido láctico y el 2-hidroxiácido propanoico. Sin embargo, el D-ácido láctico también puede formarse a través de la acción de microorganismos. El PLA se puede preparar tanto por condensación/esterificación directa del ácido láctico, como por polimerización por apertura de anillo del dímero cíclico láctido, como se muestra en la Figura 1.7. 


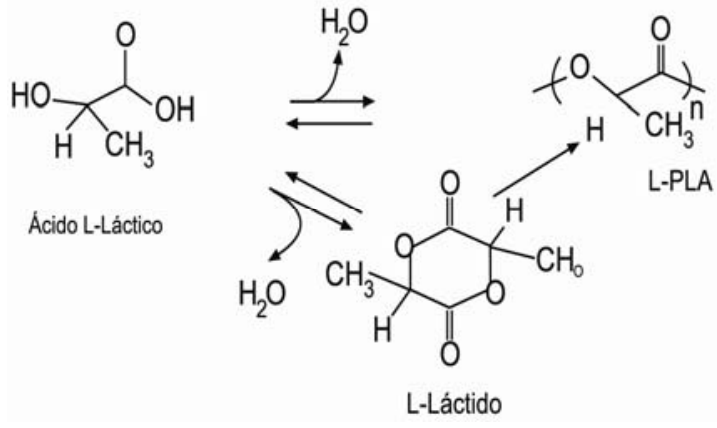

Figura 1.7. Obtención del ácido poliláctico

La condensación directa es una reacción en equilibrio, donde la presencia de trazas de agua en las etapas finales de polimerización del láctido limitan su peso molecular. Debido a esta dificultad, la forma mayorítaria de obtener PLA es mediante la reacción de polimerización por apertura de anillo. Este proceso que se muestra en la Figura 1.8 combina los beneficios económicos y medioambientales de sintetizar tanto el dímero láctido como el PLA en fase fundida.

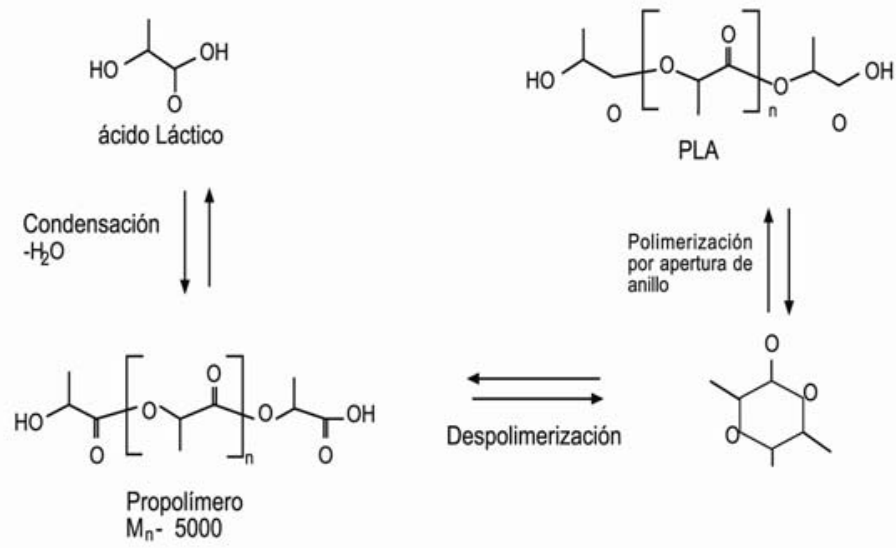

Figura 1.8. Obtención del ácido poliláctico por apertura de anillo

El proceso comienza con la fermentación de la dextrosa, seguido de una condensación continua de ácido láctico acuoso para obtener un prepolímero de PLA de bajo peso molecular. A continuación, los oligómeros de bajo peso molecular se convierten en una mezcla de estereoisómeros láctidos en presencia de un catalizador, que son purificados posteriormente por destilación a vacío. Finalmente, el PLA se produce empleando un catalizador estañoorgánico, mediante una polimerización de apertura de anillo de láctido en la fusión, eliminando así completamente el empleo de solventes caros y poco respetuosos con el medio 
ambiente. Una vez la polimerización se completa, el monómero restante se elimina a vacío y se recircula al principio del proceso, por lo que el aprovechamiento de materias primas es muy elevado.

El PLA posee unas propiedades organolépticas excelentes, por lo que es un material muy interesante en aplicaciones de envases de plástico en contacto con alimentos y bebidas.

\section{3) Poliésteres de orígen fósil/petrolifero}

\section{1) Poli(E-caprolactona)}

La poli(E-caprolactona) (PCL) es un termoplástico cristalino, con una temperatura de fusión de 59 a $64{ }^{\circ} \mathrm{C}$, que puede ser fabricado en un amplio rango de pesos moleculares. La PCL se obtiene por polimerización por apertura de anillo de la $\varepsilon$-caprolactona, que es un mónomero cíclico de lactona. Posee buenas propiedades mecánicas y una alta biodegradabilidad. Actualmente, se produce a escala industrial bajo las siguientes marcas registradas, Celgreen ${ }^{\mathrm{TM}}$, $\mathrm{TONE}^{\mathrm{TM}}$ y $\mathrm{CAPA}^{\mathrm{TM}}$ por las industrias Daicel, Union Carbide y Solvay, respectivamente.

La PCL se usa en el campo de biomedicina, destaca su aplicación para la elaboración de cápsulas de medicamentos de liberación controlada. Para usos agrícolas se mezcla con alcanodioles y poliésteres ácidos alcanodicarboxílicos en la fabricación de contenedores para plántulas. También puede emplearse en la fabricación de frascos y contenedores.

\section{Poliésteres aromáticos y mezclas de poliésteres aromáticos y alifáticos}

Los poliésteres aromáticos se obtienen mediante una reacción de policondensación de dioles alifáticos y ácidos dicarboxílicos $\mathrm{El}$ anillo aromático confiere al polímero una alta resistencia frente a la hidrólisis y a los agentes químicos. Esta resistencia hidrolítica se traduce en una dificil degradación. Por ejemplo, el PET (polietilen tereftalato) y el PBT (polibutilen teraftalato) son poliésteres obtenidos a partir de glicoles alifáticos y ácidos tereftalatos, que pueden modificarse mediante la adición de monomeros sensitivos a la hidrólisis (eter, amidas ó grupos alifáticos) dando como resultado una familia de poliésteres biodegradables. Actualmente, existen en el mercado diferentes marcas comerciales como, Biomax (DuPont), Ecoflex (Basf) y Eastar Bio (Eastman Chemical). 


\section{Biodegradación de los poliésteres}

En general, las enzimas llamadas esterasas son las principales responsables de la degradación de los poliésteres en monómeros, dímeros o trímeros. Los productos de degradación, que resultan de la hidrólisis de los enlaces éster en las posiciones finales de las cadenas, son solubles en agua y difunden a través del entorno acuoso hasta que entran en contacto con las células a las que servirán de nutrientes.

\subsubsection{Evolución en el mercado de los polímeros biodegradables}

La evolución del mercado de los polímeros biodegradables es un fenómeno relativamente reciente, si se compara con la historia de los plásticos convencionales. Desde 1970 se han desarrollando productos con un objetivo doble, ser usados satisfactoriamente durante su vida en servicio y degradados durante su eliminación. Los materiales biodegradables fueron sensitivamente mejorados durante la decada de los 90, tanto en términos técnicos como de biodegradabilidad, gracias al esfuerzo de diversas compañias líderes en el mercado.

Una de las compañias pioneras en el diseño de materiales biodegradables, fue la “Zeneca Bio Products (ICI)", en Reino Unido. Su experiencia en el desarrollo de proteínas, procesos de fermentación y en el procesado y la evaluación de los polímeros condujo sus esfuerzos hacia el diseño en 1981 de un polimero biodegradable denominado Biopol ${ }^{\mathrm{TM}}$. Posteriormente, en 1996 este producto fue adquirido por Mosanto, compañía que se encargó de su distribución hasta 1999. En el 2001 la licencia de esta tecnología paso a Metabolix.

Por otra parte, una gran compañía farmacéutica de Estados Unidos, Warner-Lamber, en 1990 introdujo uno de los primeros materiales comerciales derivados del almidón, Novon $^{\mathrm{TM}}$. En 1993 se suspendierón los estudios sobre este tipo de productos por su alto coste. Tras el cierre de la línea de investigación de esta compañía, la empresa italiana Novamont emergió como la compañía dominante de los productos derivados del almidón. Novamont, empezó su activadad investigadora en 1989 como parte del grupo italiano Montedison [44]. En 1990 se inició la comercialización de su producto estrella, el Mater-Bi®, con una producción inicial de más de 4000 toneladas al año. En 1997, Novamont se consolidó como máxima productora de productos de base almidón con la adquisición de la cartera de 
productos desarrollados por la Warner-Lambert [44]. En el año 2001 su producción alcazó las 16000 toneladas al [45].

La evolución más destacable en el mercado de los materiales biodegradables en 1990 viene de la mano de la creación de "Cargill Dow Polymers" por la compañía americana "Dow Chemical and Cargill”. En 1991, esta compañía empezó a comercializar con PLA produciendo, 4500 toneladas la planta en Savage, Minnesota, America. A finales de 1997, esta compañía ya comercializaba el PLA y en la planta de Blair, Nebraska, America se llegaron a producir 140000 toneladas de PLA al año. Con la entrada de esta compañía en el mercado de los materiales biodegradables, se facilitó el desarrollo de la tecnología aplicable, y se empezó a reducir los precios de coste hasta llegar a ser competitivos con los polímeros sintéticos convencionales.

A finales de 1990, un gran número de compañias químicas introdujeron en el mercado diversos polímeros biodegradables derivados de fuentes petroquímicas: Biomax $^{\mathrm{TM}}$, comercializado por DuPont; Eastar Bio copolyester, comercializado por Eastman; BAK

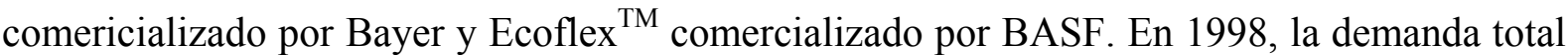
de materiales biodegradable en Estados Unidos, Europa y Japón alcanzaba 18000 toneladas valoradas en 70 milloness de dolares, según la "SRI's Chemical Economics Handbook" [46]. Siendo, los polímeros derivados del almidón los líderes en el mercado, seguidos de cerca por los compuestos de PLA.

Actualmente, distintos factores tanto económicos como medio ambientales dirigen al mercado hacía una utilización mayor de polímeros biodegradables, llegando a alcanzar un crecimiento mayor el plástico biodegradable que el tradicional [47]. En el 2002 la producción mundial de los polímeros biodegradables alcanzaba las 260000 toneladas, aumentando en un $60 \%$ durante los últimos años [48].

La sustitución de los materiales sintéticos convencionales por los materiales biodegradables empieza a ser una realidad. Los sectores donde se utilizan mayoritariamente este tipo de materiales en detrimento de los tradicionales son el sector del embalaje, bolsa de plástico, mantillo agrícola, etc. 


\subsection{FIBRAS NATURALES}

Las fibras naturales son materiales lignocelulósicos que se encuentran ampliamente distribuidos por la biosfera en forma de árboles, plantas y cultivos. En general, se puede decir que los materiales lignocelulósicos son los biomateriales renovables más abundantes en la tierra. Durante las últimas decadas, el uso de las fibras naturales está ganando importancia en aplicaciones industriales, tecnología de tejidos textiles, composites, pasta celulósica y papel, ingeniería civil y actividades de construcción [49]. En términos de unidades de masa, la producción neta de las fibras naturales por año se estima en $2.10^{11}$ toneladas, en comparación con las $1,5.10^{18}$ toneladas de producción de los polímeros sintéticos [50]. De entre todas las fibras naturales destacan las de orígen vegetal (lino, cañamo, linaza, yute, sisal y el kenaf) por sus excelentes propiedades mecánicas.

El uso de las fibras naturales, como alternativa frente al uso de las fibras sintéticas tiene una serie de ventajas e inconvenientes. El uso de las fibras naturales en el diseño de los composites permite reducir el peso molecular del material y mantener una dureza y rigidez adecuada en el biocomposite. La manipulación y el tratamiento de las biofibras son generalmente menos peligrosos que el de las fibras sintéticas. Además, las fibras naturales no son abrasivas, por lo que su procesado no va a implicar costes inesperados, su producción no necesita energía, y cuando se queman o se someten a compostaje la emisión de $\mathrm{CO}_{2}$ es inferior a la emitida por las fibras sintéticas [51]. Sin embargo, mientras las fibras convencionales se elaboran en un rango predeterminado de propiedades, las propiedades de las fibras naturales varían considerablemente [52]. Tanto la calidad de las biofibras, como la mayoría de sus propiedades dependen de factores como: lugar de origen, edad de la planta de la cual proceden, condiciones de cuidado y cultivo, proceso de extracción y composición química [51].

En este capítulo, se caracterizan y describen las fibras naturales más empleadas como sistema de refuerzo en el diseño de los biocomposites. Además se evalua su aspecto estructural, su composición química, su degradación, coste y disponibilidad. 


\subsubsection{Clasificación de las fibras naturales}

Teniendo en cuenta el origen de las fibras naturales, se propone la siguiente clasificación.

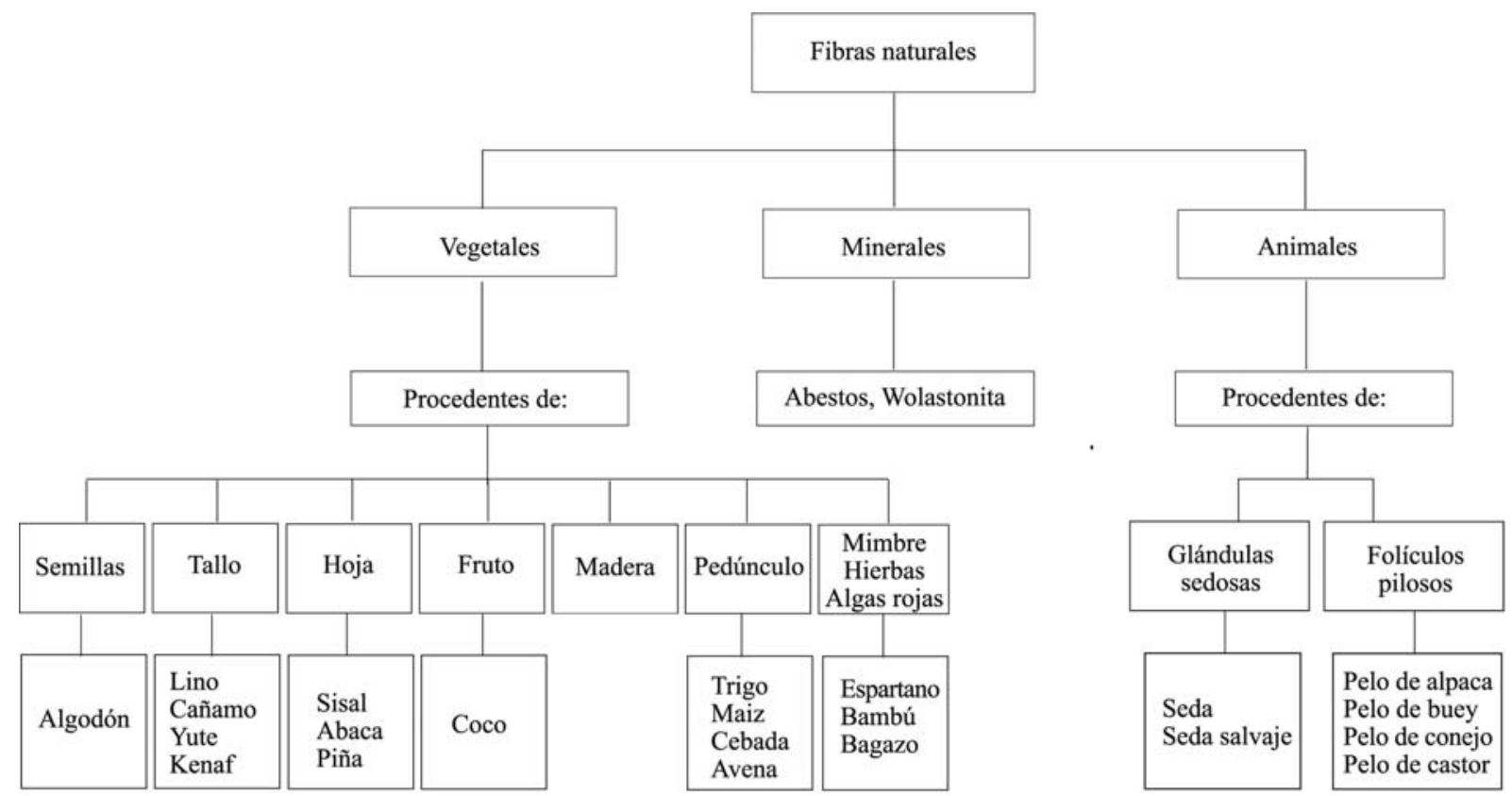

Figura 1.9. Clasificación de las fibras naturales

Este trabajo se centra en las fibras naturales de origen vegetal, que son las que ofrecen mejores características tanto a nivel técnico como medioambiental [1]. A continuación se describen con detalle algunas de las fibras naturales más utilizadas en la fabricación de los biocomposites.

\section{a) Fibras procedentes de la semilla}

Fibra de algodón (Gossypium spp., Malvacea)

Esta fibra de orígen vegetal es la fibra natural de mayor producción a nivel mundial. La planta de algodón es un arbusto nativo de las regiones tropicales y subtropicales que puede alcanzar una altura de 0,8 a 1,5 m. Su fruto es una cápsula que tiene en su interior entre $15 \mathrm{y}$ 20 semillas envueltas en una fibra que al crecer abre la cápsula y sale al exterior [1]. Los países con mayor producción de algodón en el mundo son: Estados Unidos, China, India, Uzbequistan, Pakistan. 
La fibra de algodón tiene una estructura compuesta por tres capas. Una primera capa externa de cera que protege a la pared primaria. Una capa secundaria formada principalmente de celulosa y una tercera capa que rodea el lumen [49]. Las fibras de algodón maduras poseen una sección lateral en forma de judía y su contorno superficial se caracteriza por ser plano y retorcido. Cuando el fruto de algodón madura, revienta, mostrando un paquete de fibras de longitud y diámetro variable entre 25 a $60 \mathrm{~mm}$ y 12 a $45 \mu \mathrm{m}$, respectivamente.

Esta fibra, que puede adquirir diferentes tonalidades, desde el blanco crema al gris sucio, se caracteriza por ser hidrofílica e hincharse en presencia de agua. Además, desprede una cantidad considerable de calor cuando absorbe humedad y su secado se produce de manera lenta y constante. Es estable en agua y su tenacidad es mayor cuando está mojada que cuando está seca. Por otra parte, esta fibra tiene una alta capacidad de absorción de tierra y aceite. Su dureza y su módulo inicial es más bajo que el de la fibra de cañamo, mientras que su flexibilidad, tensión de rotura y su recuperación elástica es mayor. Esta fibra es resistente a las sustancias alcalinas pero se degrada en presencia de ácidos. La resistencia microbiótica es baja pero presenta una alta resistencia frente al moho. El algodón quema eficaz y rápidamente, puede ser esterilizado y hervido, y no causan irritaciones ni alergias para la piel. Innumerables productos se confeccionana a partir de la fibra de algodón, principalmente textiles y articulos de hilos.

\section{b) Fibras procedentes del tallo (ó de su corteza)}

La mayoría de las fibras provientes del tallo de las plantas se obtienen a partir de hierbas cultivadas en la agricultura, como por ejemplo: el lino, el cáñamo, el kenaf, el yute y el ramio. La forma y el tamaño de los tallos de las plantas cultivadas para la extracción de fibras naturales de la corteza del tallo son diferentes pero todas ellas contienen fibras en el floema, como se puede ver en la Figura 1.10.

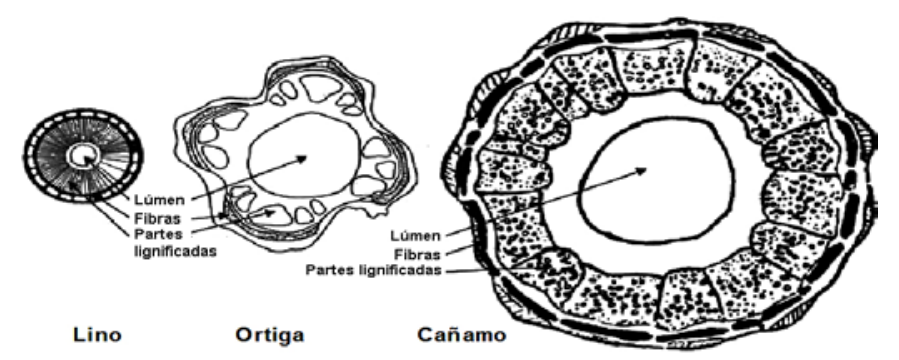

Figura 1.10. Comparación esquemática de una sección transversal del lino, la ortiga y el cañamo, tomada de Sheer-Tribel y col. [53] 
Las fibras extraídas de la corteza del tallo se caracterizan por ser largas, pero al tener una estructura heterogénea, son más cortas que las fibras de madera, que pueden llegar a alcanzar una longitud de $2,7 \mathrm{~mm}$. Pese a su heterogeneidad, todas las fibras procedentes de la corteza del tallo tienen una estructura similar. Estas fibras provienen de un tallo rígido herbáceo que contiene nodos a intervalos regulares formando estrías o canales en su superficie. La estructura interior del tallo se muestra en la Figura 1.11, donde se puede apreciar de dentro a fuera, distintas regiones; un interior hueco que conforma el lumen, seguido de una región médular compuesta de un espeso tejido de madera que es el responsable de dar sosten a la planta, el cámbium que se define como el área diferencial por donde se separan las fibras naturales del resto del tallo durante el cosechado, el floema que contiene células de clorofila y fibras naturales, el córtex que es una capa delgada que contiene clorofila en sus celdas, y finalmente la capa epidérmica protectora que posee una cutícula sedosa.

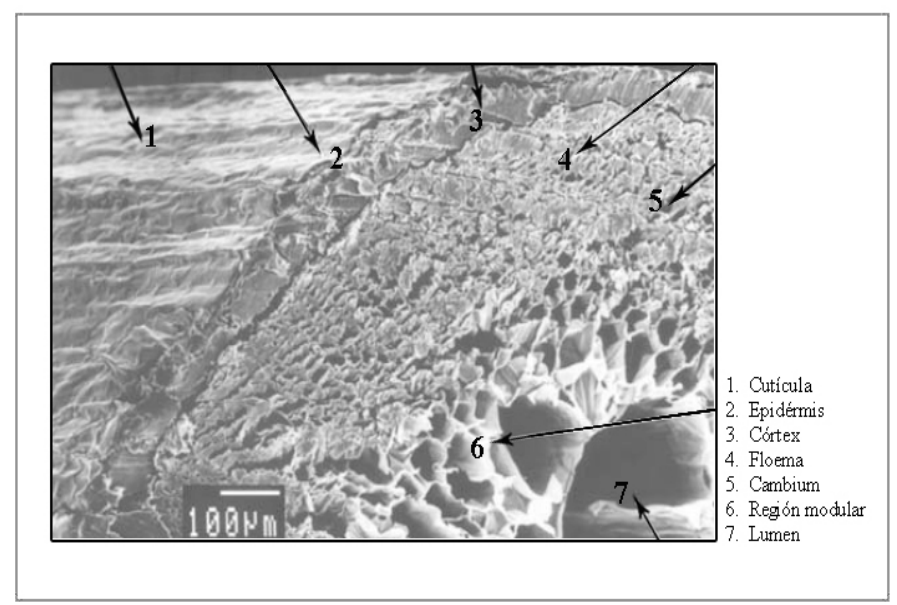

Figura 1.11. Micrografía lateral det tallo de lino tomada de Lampke y col. [54]

Las fibras procedentes del tallo tienen una resistencia a la tracción alta, por esto se utilizan para la elaboración de productos textiles, cuerdas, hilo, papel, materiales compuestos y arpillera. Fibras como el kenaf, el lino y el sisal se usan en biocomposites en combinación con polipropileno para aplicaciones en automóviles.

\section{Fibra de lino (Linum usitatissimum L., Linaceae)}

La planta del lino es nativa de la región que se extiende desde el Mediterráneo oriental a la India. Es una planta dicotiledónea de entre 80 y $150 \mathrm{~cm}$ de altura, con un tallo delgado delimitado por la raíz y las ramas que contienen las semillas. Las hojas son verdes de 20 a 40 
$\mathrm{mm}$ de largo y $3 \mathrm{~mm}$ de ancho. Las flores son de color azul claro y tienen un diámetro de 15 a $25 \mathrm{~mm}$. El fruto es una ronda que contiene varias semillas de color marrón brillante. La porción central de la planta se usa para producir fibras. Los paquetes de fibras de lino son de 60 a $140 \mathrm{~cm}$ de longitud y sus diámetros varían de 40 a $80 \mu \mathrm{m}$.

El color de la fibra de lino varía desde el amarillo hasta el gris y se caracteriza por ser, suave, brillante, flexible e inextensible. Estas fibras tienen una estructura molecular fina determinada por las condiciones de cultivo y recogida, que marcan las propiedades finales de la fibra. La temperatura de descomposición de la fibra de lino es de $200^{\circ} \mathrm{C}$ [55]. Estas fibras pierden fuerza gradualmente con la exposición a la luz solar. Además, el lino permanece en suspensión con ácidos débiles, posee buena resistencia a las disoluciones alcalinas pero es atacado por los ácidos calientes diluidos o ácidos fuertes.

Actualmente, la fibra de lino se usa principalmente como refuerzo de los materiales en los composites, en campos de aplicación donde los productos están sometidos a rangos de estrés medio, como por ejemplo en el interior de los automóviles [56].

\section{Fibra de cáñamo (Cannabis sativa L., Cannabaceae)}

La fibra de cáñamo se extrae comúnmente de la parte exterior del tallo del cáñamo, esta planta es nativa de Asia Central y su cultivo se remonta 15000 años atrás. El cáñamo salvaje y el canaboideo, son plantas típicamente dioicas. Aunque también se pueden encontrar especies de estas plantas monoicas, es decir, plantas que tienen tanto flores masculinas como femeninas. Se prefiere la variedad dioica para obtener fibras de cáñamo destinadas al textil, mientras que las variedades monoicas se usan fundamentalmente para obtener fibras destinadas a la fabricación del papel. Las plantas de cáñamo tienen una altura que varía de 1,2 a 5 m [1] y su contenido en líber en el tallo varia de un 28 a un 46\% [1]. Es una planta que no necesita prácticamente herbicidas minerales, pesticidas, fungicidas y fertilizantes. Esta planta, crece rápidamente, repone el suelo con nitrógeno y nutrientes, y produce una gran cantidad de oxígeno, con lo que se consigue preparar la tierra para la próxima plantación.

Las fibras extraídas de la planta de cáñamo tienen una longitud promedio que varía de 13 a $25 \mathrm{~mm}$, su estructura transversal es poligonal y presenta irregularidades en su superficie. Se caracteriza por su alta resistencia a la humedad, peso ligero, alta tenacidad (sobre un $20 \%$ mayor a la del lino) y una elongación pequeña hasta rotura [1]. 
Actualmente, la industria textil utiliza la fibra de cáñamo por su resistencia al agua y a los esfuerzos mecánicos, insensibilidad al lavado y a las polillas [1]. Además de su aplicación en la industria textil, este tipo de fibra cuenta con miles de usos en diferentes sectores: como el sector del papel, plástico, alimenticio y energético.

\section{Fibra de kenaf ( Hibiscus cannabinus L.Malvaceae)}

La planta de kenaf es nativa del sur de Ásia ó África, aunque su origen natural exacto es desconocido. Se trata de una planta herbácea de rápido crecimiento que puede alcanzar una altura de 2,4 a 6 metros en cinco meses. Las hojas no presentan una forma definida y cuentan con una longitud de 10 a $15 \mathrm{~cm}$. El fruto es una cápsula de $2 \mathrm{~cm}$ de diámetro, que contiene varias semillas. Los tallos son, generalmente redondos y tienen espinas de diferentes tamaños. El cultivo de la fibra de kenaf tiene una larga historia en la India, Bangladesh, Tailandia, África y en el sureste de Europa.

La planta de kenaf posee dos tipos de fibras; las fibras largas situadas en la capa cortical y las fibras cortas situadas en la zona de la lignina. Las fibras de kenaf individuales son cortas, con una longitud entre 1,5 a $6 \mathrm{~mm}$ y poseen una forma poligonal. Su superfice es estriada e irregular. El lumen varía de amplitud dependiendo de la zona de la célula, llegando incluso a desaparecer. El kenaf es una fibra que puede presentar una gran variedad de colores.

Tanto el tallo del kenaf como las fibras procedentes de la capa exterior del tallo se aplican para usos específicos, dentro de los sectores del papel, textil y composites. Historicamente, los principales usos de la fibra de kenaf son la fabricación de cuerda, hilo, tela tosca y papel. Nuevas aplicaciones de la fibra de kenaf se incluyen en la ingeniería de la madera, aislamiento y las prendas de vestir de tela de calidad.

Fibra de yute (Corchorus capsularis, Tiliaceae)

El yute es una planta originaria de la zona este del Mediterráneo, puede alcanzar una altura entre 2 y $3,5 \mathrm{~m}$ y un diámetro de 2 a $3 \mathrm{~cm}$. En la actualidad, esta fibra se define como la fibra más versátil, ecológica, natural y duradera disponible. Además, es una de las fibras naturales más baratas y su producción se sitúa en segundo lugar, por detrás del algodón. La fibra de yute se caracteriza por ser de color marron y tener una sección lateral poligonal, con un tamaño de espesor variable y una gran longitud. El yute es sensible al ataque químico y 
fotoquímico. La fibra de yute es fuerte pero quebradiza y tiene una baja tensión a rotura, debido al alto contenido de lignina en su formulación. Además, tiene una fuerza de tensión menor que el lino y el cañamo, fuerza que pierde en función a la exposición solar. Estas fibras, presentan poca resistencia ante la humedad y los ácidos. El yute es la planta que puede producir fibras con mayor grado higroscópico.

La textura sedosa de esta fibra, su biodegradabilidad, su resistencia al calor y al fuego, permiten su aplicación en diversos sectores: ocio, mobiliario, etc.

\subsubsection{Aspectos estructurales de las fibras naturales}

Las fibras naturales vegetales están compuestas mayoritariamente por tres polímeros estructurales (celulosa, hemicelulosa y lignina) y en menor medida por una serie de compuestos de bajo peso molecular solubles en agua, proteínas y sales minerales. El contenido de cada uno de ellos dependerá de la variedad y la edad de la planta o especie de la que provengan [57].

Las biofibras de origen vegetal son paquetes de células vegetales de paredes gruesas y alargadas. Jayaramam y col. [58] definieron estas fibras como agrupaciones de microfibrillas huecas adheridas a una matriz de hemicelulosa/lignina. Considerando una fibra vegetal como una célula individual, su longitud típica varia entre 1 y $50 \mathrm{~mm}$ y su diámetro entre 10 y 50 $\mu \mathrm{m}$. Las fibras vegetales comprenden diversas microestructuras organizadas jerárquicamente [59] que se disponen en tubos microscópicos concéntricos alrededor del lumen central (Figura 1.12).

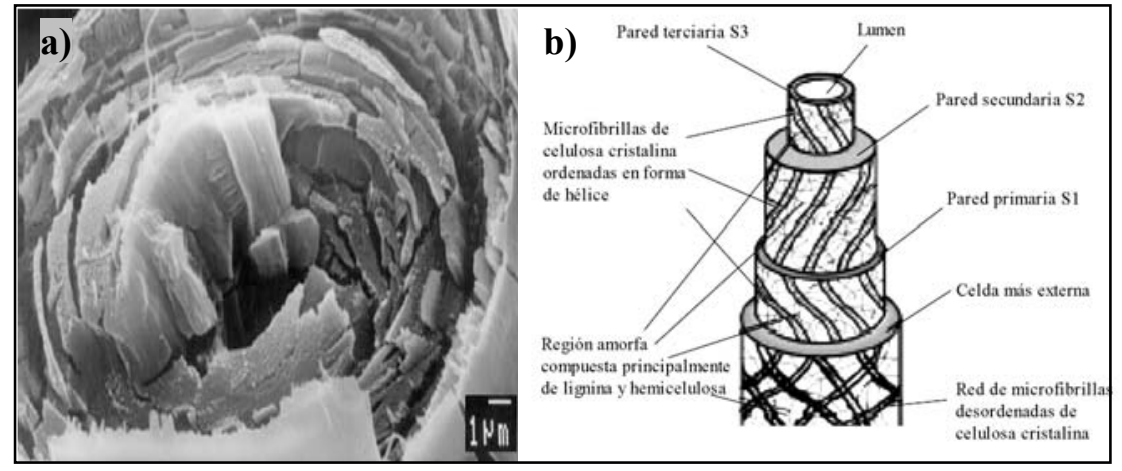

Figura 1.12. Estructura celular de una fibra natural. a) Micrografia transversal de la fibra de lino tomada por Bismarck y col.[60] y b) Representación esquemática tomada de Maya y col. [51] 
En primer lugar, la pared celular de la fibra no es una membrana homogénea sino que se encuentra constituida de una pared primaria y una pared secundaria. La pared primaria es la capa formada durante el crecimiento de la celula. Las paredes primarias de dos células adyacentes están unidas entre sí por lignina, denominándose esta capa, lámina media. La pared celular secundaria (S), consta a su vez de tres capas (S1, S2 y S3), estas capas están formadas por fibrillas de celulosa semicristalinas orientadas e introducidas en la matriz de hemicelulosa/ lignina de composición variable. En la capa exterior e interior (S1 y S3) las fibrillas están dispuestas formando un amplio ángulo con el eje de la célula, mientras que la disposición de las fibrillas en la capa intermedia gruesa (S2) es prácticamente paralela al eje.

En la Figura 1.13 se muestra una representación esquemática de las relaciones entre los principales constituyentes de la pared secundaria de una fibra natural.

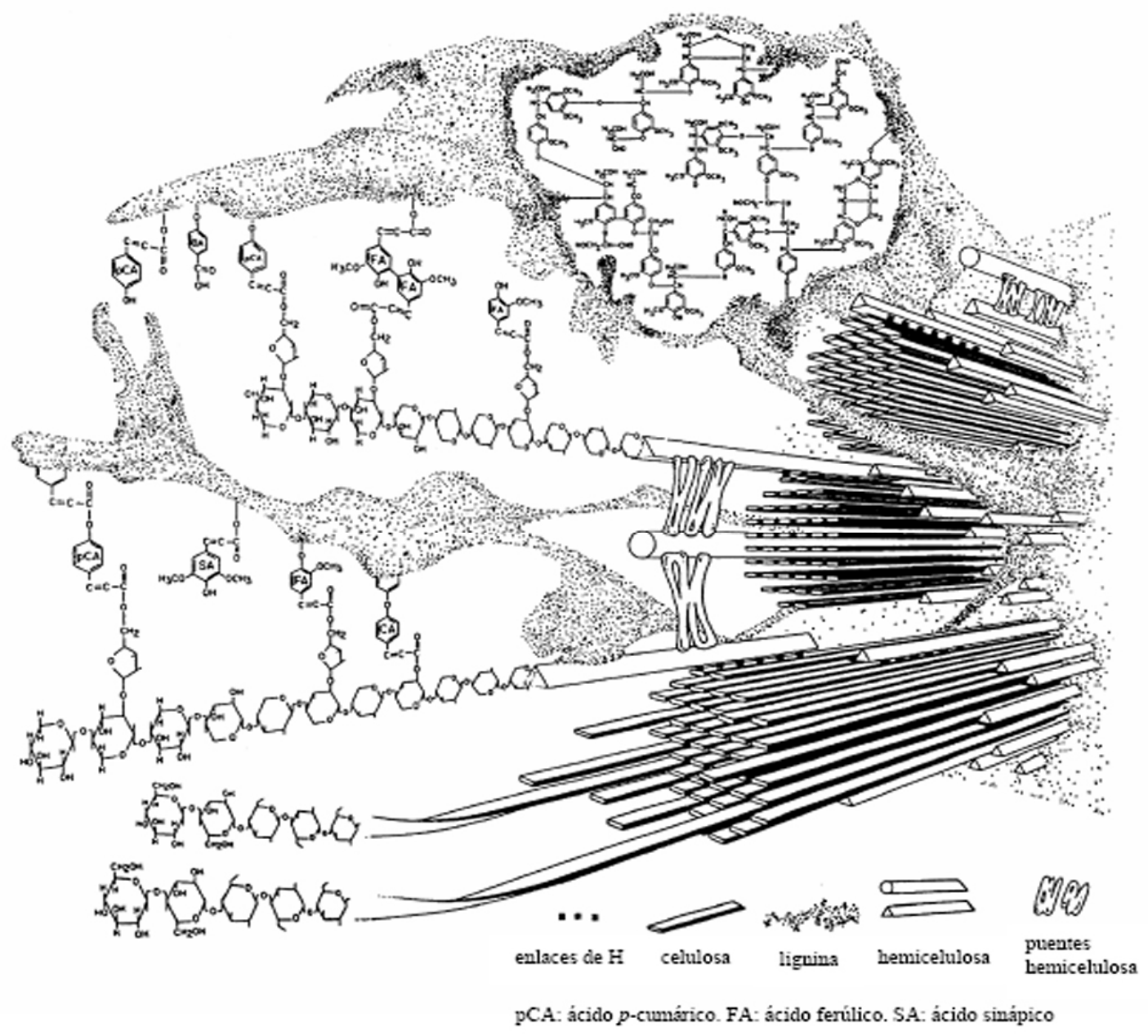

Figura 1.13. Representación esquemática de las relaciones entre los principales constituyentes de la pared secundaria (celulosa, lignina y hemicelulosa) de una angiosperma herbácea. Se muestran las microfibrillas de celulosa inmersas en una matriz de lignina en la que también se incluye la hemicelulosa. Las uniones entre estos polímeros se completan mediante puentes intermoleculares formados por los ácidos p-hidroxicinámicos. Tomada de Bidlack y col. [61] 
La formación de la pared celular tiene lugar a través de los siguientes procesos: depósito de microfibrillas de celulosa, constituyéndose el marco de la pared celular; adición de las cadenas principales de hemicelulosa alrededor de las microfibrillas y reforzamiento de la pared; adición de las ramificaciones de las hemicelulosas; y acumulación de la lignina incrustándose en todos los espacios del entramado

Las cadenas de celulosa que se agregan formando microfibrillas en la pared celular se caracterizan por tener un diámetro de 10 a $30 \mathrm{~nm}$ y por poseer de 30 a 100 moléculas de celulosa en su conformación. Por otra parte, la matriz hemicelulosa/lignina de la pared celular se presenta en fase amorfa y puede incluir pectina en su conformación. Las moléculas de hemicelulosa están unidas mediante enlaces de hidrógeno a la celulosa y actúan como una matriz de cemento, formado redes de celulosa y hemicelulosa, que se cree que constituyen el principal componente estructural de las fibras naturales.

La lignina se encuentra en mayor proporción en la lámina media. El resto de las capas de la pared vegetal, incluyendo la pared secundaria (S2) que es la capa más gruesa, presenta también lignina en su composición, pero esta capa, principalmente está constituida por celulosa y hemicelulosa. La Figura 1.13, muestra como la lignina forma una matriz amorfa en la pared vegetal, los enlaces inter-polímeros que pueden ser directos, enlaces éter entre $\mathrm{OH}$ alcohólicos (de los polisacáridos) y fenólicos (de la lingnina), o a través de puentes formados por los ácidos p-hidroxicinámicos. Estos últimos son precursores de la lignina pero en muchas plantas herbáceas se encuentran también en forma libre, incluidos en la fracción extraíble y formando puentes lignina-polisacárido [62]. Los enlaces hidrofóbicos de lignina afectan a las propiedades de otros enlaces de forma que actúan como agentes acomplejantes y aumentan la dureza del compuesto de celulosa y hemicelulosa [51]. La composición, el radio entre la celulosa y la lignina/hemicelulosa y la orientación de la celulosa microfílica son parámetros estructurales que varían en la pared celular de una fibra natural a otra. La celda más externa (S1) es porosa y contiene prácticamente todos los compuestos no celulósicos, excepto proteínas, sales inorgánicas, y materia colorante, que se encuentran en el lúmen de la fibra.

La estructura conformacional, el ángulo microfibrial, las dimensiones de las celdas y sus defectos, así como la composición química de las fibras son las variables más importantes para determinar las principales propiedades de las fibras [52]. En general, la tensión y el 
módulo de Young aumentan a medida que crece el contenido en celulosa de la fibra [51]. Algunas de las propiedades de las fibras más importantes se muestran en la siguiente tabla.

Tabla 1.3. Propiedades físicas y mecánicas de las fibras naturales [49,1]

\begin{tabular}{cccccc}
\hline Fibras & $\begin{array}{c}\text { Densidad } \\
\mathrm{g} / \mathrm{cm}^{3}\end{array}$ & $\begin{array}{c}\text { Diametro } \\
\mu \mathrm{m}\end{array}$ & $\begin{array}{c}\text { Fuerza de Tensión } \\
\mathrm{MPa}\end{array}$ & $\begin{array}{c}\text { Módulo de Young } \\
\mathrm{GPa}\end{array}$ & $\begin{array}{c}\text { Deformación a rotura } \\
\%\end{array}$ \\
\hline Algodón & $1,50-1,60$ & - & $287-800$ & $5,5-12,6$ & $7,0-8,0$ \\
Yute & $1,30-1,45$ & $25-200$ & $393-773$ & $13-26,5$ & $1,16-1,5$ \\
Lino & 1,50 & - & $345-1100$ & 27,6 & $2,7-3,2$ \\
Cáñamo & - & - & 690 & 70 & 1,6 \\
Sisal & 1,45 & $50-200$ & $468-640$ & $9,4-22,0$ & $3,0-7,0$ \\
Kenaf & - & - & 930 & 53 & 1,6 \\
\hline
\end{tabular}

\subsubsection{Constituyentes químicos}

Como ya se ha dicho, la mayor parte de las fibras procedentes de las plantas, con excepción del algodón, están compuestas por tres polímeros estructurales (celulosa, hemicelulosa y lígnina) y por una serie de compuestos de bajo peso molecular solubles en agua (fracción hidrosoluble) o solventes orgánicos (los denominados extraíbles). También presentan pequeños contenidos en proteína y sales minerales (estimadas como cenizas tras la combustión).

\section{a) Celulosa}

La celulosa ( $\alpha$-celulosa) es el componente mayoritario de las fibras naturales vegetales. Desde el punto de vista estructural, la celulosa es un polímero lineal formado por unidades de $\beta$-D-glucopiranosa unido mediante un enlace $\beta$-(1,4)- glicosídico dando lugar a unidades de celobiosa que se repite a lo largo de la cadena polimérica. Cada monómero posee tres grupos hidróxilicos que pueden formar enlaces de hidrógeno intra e intermoleculares.

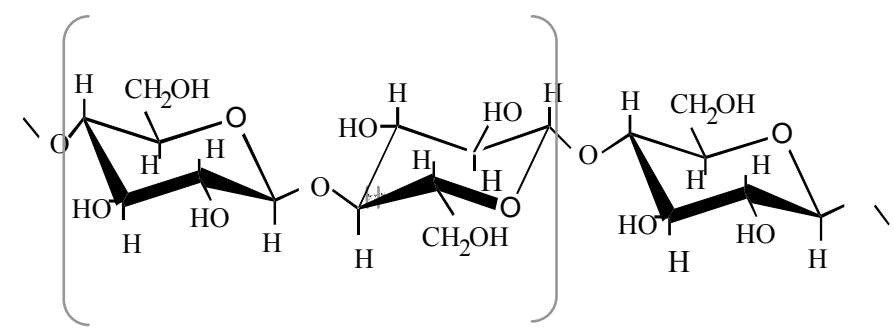

Estos enlaces juegan un papel importante en la cristalinidad y en las propiedades físicas de la celulosa. Los enlaces de hidrógeno intermoleculares permiten una estructura de 
alta cristalinidad [63]. Buschle-Diller y col. [64] definieron la cristalinidad de la celulosa como un factor clave a tener en cuenta durante su proceso de degradación.

\section{Cristalinidad de la celulosa}

La celulosa cristaliza de diferentes formas dependiendo de su procedencia y de los tratamientos a los que se somete. Se conocen cuatro configuraciones cristalinas distintas: celulosa I, II, III y IV.

La celulosa I se corresponde con la celulosa en su estado nativo. La celulosa II se obtiene tras someter a la celulosa I a una disolución o mercerización. Este alomorfo se conoce como celulosa "regenerada". La celulosa III aparece al someter a la celulosa I y a la celulosa II a tratamientos específicos con amoníaco o aminas. A partir de la celulosa I se obtiene el

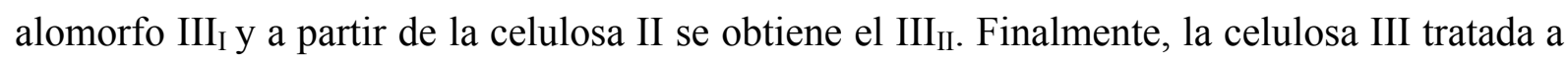
alta temperatura con glicerol da lugrar a la celulosa IV. A su vez, la celulosa IV puede ser de tipo $\mathrm{IV}_{\mathrm{I}}$ y $\mathrm{IV}_{\mathrm{II}}$ dependiendo de su orígen, $\mathrm{III}_{\mathrm{I}}$ ó III $\mathrm{II}_{\mathrm{II}}$ respectivamente. Generalmente, se acepta que la celulosa $I_{\mathrm{I}}$ es la forma desordenada de la celulosa I y por tanto su configuración podría encontrarse en alguna planta vegetal [65].

\section{Estructura cristalina de la celulosa en estado nativo}

Del estudio de la historia del arte de la cristalografía de la celulosa destacan tres citas bibliográficas. En 1973, Meyer y Misch [66] propusieron una estructura para la celulosa I basada en un modelo monoclínico de dos cadenas con un empaquetamiento paralelo dentro de la unidad celular. En 1974, Sarko y Muggli [67] junto a Gardner y Blackwell [68] propusieron un modelo que constaba de una unidad monoclínica con dos cadenas paralelas con la misma geometría. En 1984, Atalla y VanderHart [69,70] enunciaron la coexistencia de dos fases cristalinas en la celulosa $\mathrm{I}_{\mathrm{\alpha}} \mathrm{I}_{\alpha} \mathrm{y} \mathrm{I}_{\beta}$, cuyas proporciones varían dependiendo del orígen de la celulosa. La celulosa $\mathrm{I}_{\alpha}$ se encuentra mayoritariamente en bacterias y algas, mientras que la celulosa $\mathrm{I}_{\beta}$ es la fase principal de las plantas superiores.

El descubrimiento de este dimorfismo en la celulosa I ha dado lugar a un gran número de publicaciones sobre el estudio de las propiedades de cada fase y el procedimiento para su interconversión. Estos estudios se llevaron a cabo mediante las técnicas de Rayos-X, Difracción de Neutrones, Espectroscopía Raman y Espectroscopía Infraroja mediante 
Transformadas de Fourier [71-75]. A través de estos esudios se conoce que la celulosa $\mathrm{I}_{\alpha}$ tiene una celda unitaria triclínica constituida por una sola cadena molecular, mientras que la celulosa $\mathrm{I}_{\beta}$ tiene una celda unitaria monoclínica constituida por dos cadenas paralelas [75].

La estructura de la celulosa permite un gran número de enlaces por puentes de hidrógenos inter e intramoleculares (Figura 1.14) [76]. Los enlaces intramoleculares se forman: entre el oxígeno del carbono $6(\mathrm{O} 6)$ y el hidrógeno del oxígeno del carbono $2(2 \mathrm{OH})$; y entre el oxígeno del enlace glicosídico (O5) y el hidrógeno del oxígeno del carbono 3 $(3 \mathrm{OH})$. Las cadenas forman una capa en el plano ac que se unen entre ellas por medio de puentes de hidrógeno intermoleculares entre el oxígeno del carbon $3(\mathrm{O} 3)$ y el hidrógeno del oxígeno del carbono $6(6 \mathrm{OH})$.

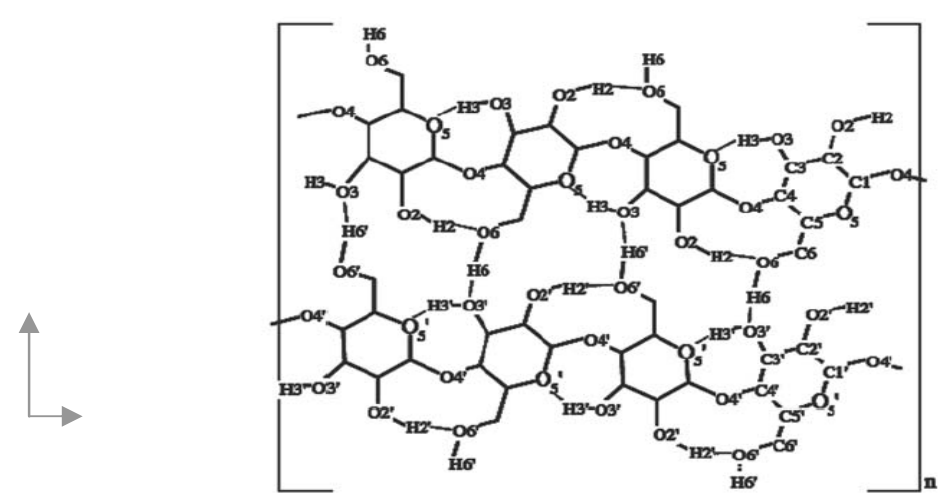

Figure 1.14. Estructura de la celulosa I.

Diversos estudios han constatado la aplicabilidad de la espectroscopía por infrarrojos (FTIR) para la caracterización de la estructura de la celulosa, para la obtención del modelo de puentes de hidrógeno (hydrogen -bonding patterns) y para la determinación del mayor alomorfo en su estructura y su indice de cristalinidad [77-84]. Scwanninger y col. [85] asignaron las bandas $3455-3410 \mathrm{~cm}^{-1}, 3375-3340 \mathrm{~cm}^{-1}$ y $3310-3230 \mathrm{~cm}^{-1}$ de los espectros de la celulosa I a los enlaces intramoleculares del tipo $2 \mathrm{OH} \ldots . . \mathrm{O} 6$ y $3 \mathrm{OH} . . .05$ y a los enlaces de tipo intermolecular $6 \mathrm{OH}$...O3 respectivamente. Sugiyama y col. [75] identificaron las bandas de la celulosa I y I ; las bandas a 3240 y $750 \mathrm{~cm}^{-1}$ se asignaron a la fase cristalina $\mathrm{I}_{\alpha} \mathrm{y}$ las bandas a 3270 y $710 \mathrm{~cm}^{-1}$ a la fase $\mathrm{I}_{\beta}$. O'connor y col. [86] definieron un índice de cristalinidad mediante el cociente de las intensidades de las bandas a 1481 y $893 \mathrm{~cm}^{-1}$. 


\section{b) Hemicelulosa}

La hemicelulosa es un polisacárido químicamente heterogéneo, constituido por diferentes unidades de monosacáridos incluyendo pentosas (xilosas y arabinosas) y hexosas (glucosa, manosa y galactosa) enlazadas entre sí por enlaces glicosídicos, formando estructuras ramificadas y en general amorfas. En menor cantidad también se encuentran ácidos urónicos en su composición. La Figura 1.15 muestra los monosácridos constituyentes de las hemicelulosas. La cadena polimérica de hemicelulosa esta ramificada y es mucho más corta que la de celulosa. Su grado de polimerización es de 10 a 100 veces menor que el de la celulosa, variando por tanto, dentro del rango entre 50-300 unidades. Como ya se ha dicho previamanete, al describir el aspecto estructural de las fibras naturales, la hemicelulosa actúa como mátriz soporte para las microfibrillas de celulosa en la pared celular, encontrando algunas hemicelulosas asociadas a la porción celulósica y otras asociadas a la lignina.

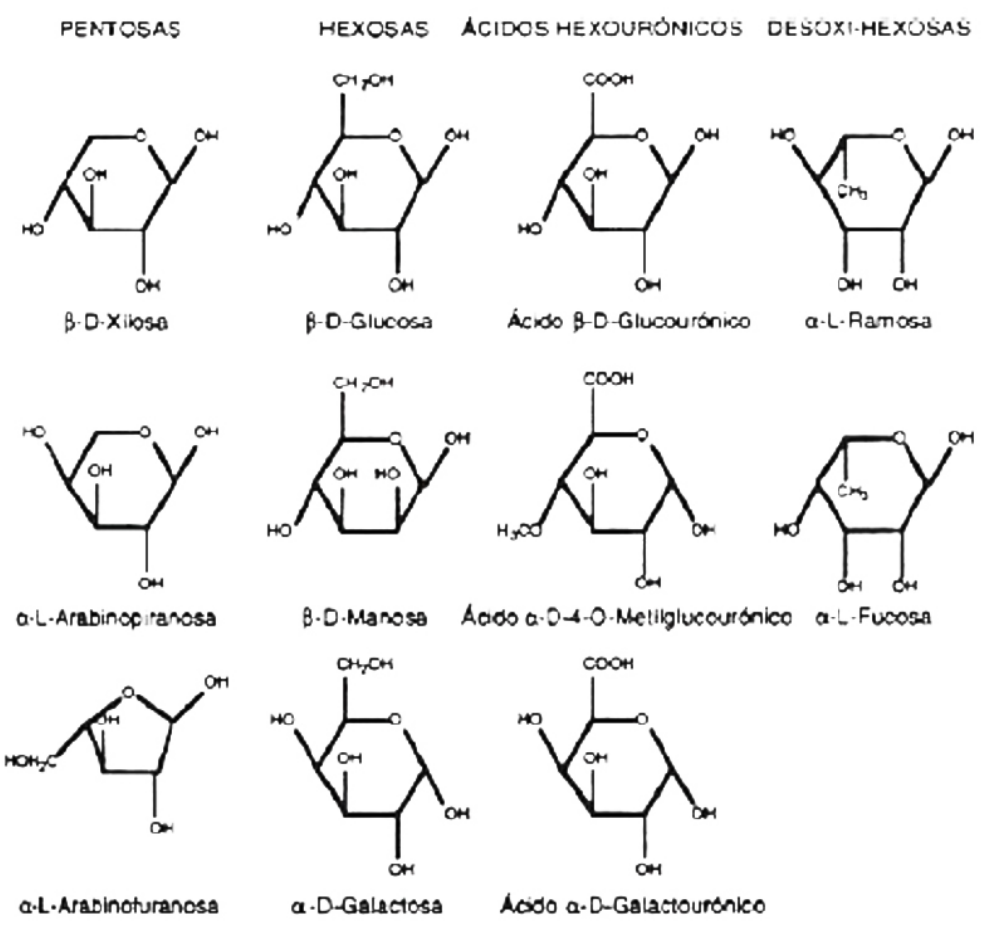

Figura 1.15.Monómeros de la hemicelulosa [87]

La reactividad química de la hemicelulosa se basa en la presencia de un grupo carbonilo terminal libre y los grupos hidroxilos de las unidades de polisacáridos presentes en la cadena así como en las ramificaciones, por lo que pueden experimentar reacciones de oxidación, reducción, nitración y acetilación. Son importantes las reacciones de hidrólisis 
rompiendo los enlaces glicosídicos y degradándose las cadenas de hemicelulosa. Estas reacciones ocurren con mayor facilidad que en las celulosas, debido a que son sustancias amorfas, presentan bajo grado de cristalinidad y una mayor accesibilidad por parte de los reactivos químicos.

Dependiendo del tipo de planta estudiado, las hemicelulosas pueden llegar a presentar grandes variaciones en su composición, en cambio la estructura de la celulosa siempre es la misma en las distintas especies [9].

\section{c) Lignina}

La lignina aporta rigidez a las plantas. Se trata de un compuesto complejo, un copolímero tridimensional formado por constituyentes alifáticos y aromáticos con alto peso molecular y generalmente resistente a la degradación microbiológica. Aunque su estructura química no ha sido definida con exactitud, la mayor parte de los grupos funcionales que forman la macromolécula están definidos. La lignina se caracteriza por su alto contenido en carbono y su bajo contenido en hidrógeno. También se han identificado grupos funcionales como el hidróxilo, metóxilo y carbonilo. Se cree que la estructura de la molécula de la lignina deriva del compuesto 4-hidroxi-3-metoxi fenolpropano. En la Figura 1.16 se muestra la estructura de la lignina propuesta por Antal y col. [91]. La lignina es un polímero amorfo, hidrofóbico y termoplástico, con una temperatura de transición vítrea alrededor de uno $90^{\circ} \mathrm{C} \mathrm{y}$ una temperatura inicial de fusión de $200^{\circ} \mathrm{C}$. No es hidrolizable por los ácidos, pero es soluble en alcalinos calientes y fácilmente condensable con fenol.

A pesar de que el tipo de enlace entre la lignina y la celulosa se desconoce, se cree que la lignina se une a los carbohidratos de la celulosa, dando lugar a dos tipos de uniones: una sensible y otro resistente a la alcalinidad. El enlace sensible a la alcanilidad forma una combinación tipo éster entre los grupos hidroxilos de la lignina con los carboxilos de la hemicelulosa. El enlace resistnte a la alcalinidad es de tipo éter y tiene lugar entre los hidroxilos de la lignina y los hidroxilos de la celulosa. Por todo esto, la lignina es polifuncional, por lo que existe combinada con más de una cadena molecular de celulosa y/o hemicelulosa, dando lugar a ramificaciones en su estructura. 


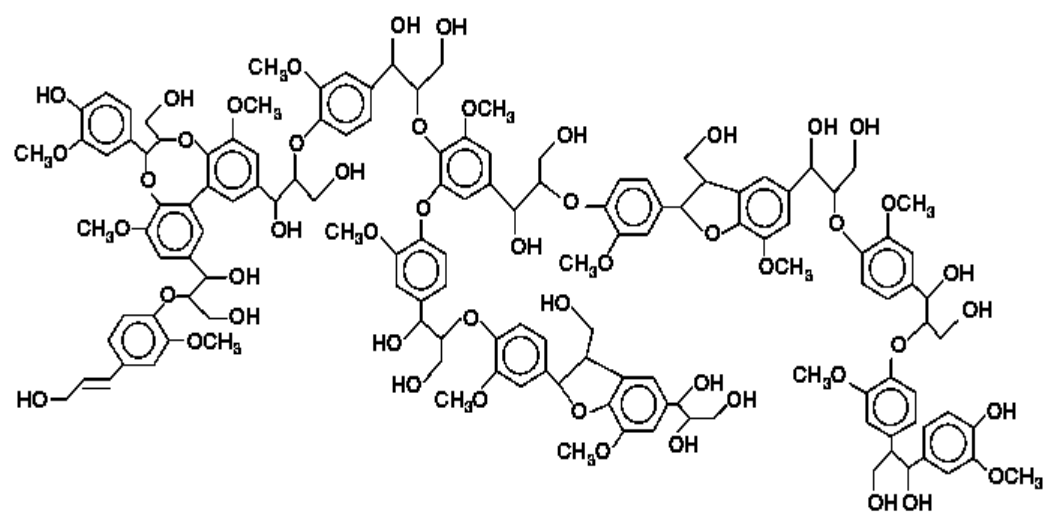

Figura 1.16. Estructura de la lignina [91]

\section{d) Pectinas}

En general, se conoce como pectinas a los heteropolisacáridos presentes en las fibras naturales. Las pectinas son una mezcla de polímeros ácidos y neutros muy ramificados, siendo el ácido galacturónico el mayoritario. Estos ácidos presentan enlaces $\alpha$-(1-ó-4) entre ellos que son interrumpidos por residuos de L-ramosa, D-galactosa y L-arabinosa unidos a su vez mediante enalces covalentes a los ácidos.

\section{e) Compuestos extraíbles}

La composición de materiales lignocelulósicos, incluye también una fracción de bajo peso molecular soluble en solventes orgánicos que engloba diferentes compuestos lipofílicos y polares [87]. Una de las principales funciones de los compuestos extraíbles es la protección de la planta contra patógenos.

Los extraíbles polares engloban diferentes compuestos fenólicos libres de bajo peso molecular, lignanos, taninos y flavonoiedes, entre otros. Los compuestos fenólicos libres incluyen precusores de la lignina, aldéhidos y cetonas aromáticos. Los taninos hidrolizables son ésteres del ácido gálico y sus dímeros con monosacáricos. Los flavonoides presentan diferentes estructuras derivadas del anillo de flavona.

A pesar de que muchas especies vegetales contienen cantidades muy significativas de extraíbles polares, la fracción lipofílica es la predominante (ácidos grasos libres, alcoholes grasoso libres, hidrocarburos, ceras, grasas, terpenos y esteroides). 
Finalmente la composición química de las fibras naturales más importantes se resume en la siguiente tabla.

Tabla 1.4. Composición química de las fibras naturales [49]

\begin{tabular}{ccccc}
\hline Fibras & $\begin{array}{c}\text { Celulosa } \\
\%\end{array}$ & $\begin{array}{c}\text { Hemicelulosa } \\
\%\end{array}$ & $\begin{array}{c}\text { Lignina } \\
\%\end{array}$ & $\begin{array}{c}\text { Pectina } \\
\%\end{array}$ \\
\hline Algodón & 82,7 & 5,2 & - & - \\
Yute & $61,0-71,5$ & $13,6-20,4$ & $12-13$ & 0,2 \\
Lino & 71 & $18,6-20,6$ & 2,2 & 2,3 \\
Cañamo & $70,2-74,4$ & $17,9-22,4$ & $3,7-5,7$ & 1,9 \\
Sisal & $67-78$ & $10,0-14,2$ & $8,0-11,0$ & 10,0 \\
Kenaf & $31-39$ & 21,5 & $15-19$ & - \\
\hline
\end{tabular}

\subsubsection{Degradación de las fibras naturales}

Para la elaboración de composites, además de la selección de una matriz adecuada, es muy importante conocer la respuesta de las fibras ante un proceso de degradación durante un periodo de tiempo determinado. En el apartado siguiente, se profundiza sobre los diferentes tipos de degradación a los que pueden verse sometidas las fibras naturales. Cuando una fibra natural se degrada, además de producirse una alteración en sus propiedades organolépticas, se producen también cambios en sus propiedades físico-químicas. La ruptura del enlace glicol de los materiales celulósicos produce una pérdida de masa y cristalinidad, y una reducción del grado de polimerización.

\section{a) Degradación térmica}

Controlar y predecir la degradación térmica de las fibras naturales es de vital importancia para: asegurar las condiciones óptimas del procesado de los composites reforzados; y estimar su influencia en las propiedades del composite resultante durante su ciclo de vida [89]. La celulosa, componente mayoritario de las fibras naturales se descompone entre $325-400^{\circ} \mathrm{C}$ y se caracteriza por una baja masa residual final [90]. La hemicelulosa descompone a temperatures menores $\left(225-325^{\circ} \mathrm{C}\right)$, debido a que es más facil de hidrolizar que la celulosa. Finalmente, la lignina es el componente que contribuye de forma mayoritaria a la formación del residuo, y presenta la descomposición térmica más amplia, entre $200-600^{\circ} \mathrm{C}$. Además, la fracción de la materia inorgánica soluble en agua tiene un papel importante en la descomposición térmica debido a su efecto catalítico [91]. 
Debido a la complejidad de las reacciones de descomposición térmica de las fibras naturales, la comunidad científica centro sus esfuerzos en determinar la cinética de descomposición de los componentes principales de las fibras naturales por individual, actualmente el módelo cinético global de las fibras naturales, aún no ha sido determinado [9497]. Sin embargo, diferentes autores proponen el uso de los módelos isoconversionales de cinética libre para determinar la energía de activación en función del grado de conversión sin necesidad de asumir ningún mecanismo de descomposición [89,96].

La celulosa es el componente mayoritario de las fibras naturales. De su degradación térmica se obtienen tres fracciones de productos diferentes: una fase gaseosa combustible, una fase líquida o condensable y una fase sólida carbonosa [97,98]. La fase gaseosa tiene como compuestos mayoritarios el $\mathrm{CO}, \mathrm{CO}_{2}, \mathrm{H}_{2}, \mathrm{CH}_{4}$ y otros hidrocarburos ligeros. La fracción condensable está constituida por dos fases: una fase orgánica y una fase acuosa. La producción de la masa residual se ve favorecida por una temperatura entre $400-500^{\circ} \mathrm{C}$, una presión moderada de $1 \mathrm{MPa}$ y un elevado tiempo de residencia para fomentar el contacto entre la fase vaporosa y la sólida que da lugar a la aparición de reacciones secudarias de formación de residuo [102]. La proporción de la producción de esta fracción depende de la composición inicial de las fibras naturales; la lignina y la materia extractiva potencian su producción [49], mientras que la materia inorgánica altera el mecanismo de descomposición térmica de los materiales lignocelulósicos y aumenta la producción de fracción sólida [103].

\section{b) Biodegradación}

Las fibras naturales lignicelulósicas son degradadas biológicamente por los organismos que reconocen la cadena carbohidratada del polímero, principalmente la de la hemicelulosa de la pared celular, y son capaces de hidrolizar estos polímeros en unidades digestibles. La cristalinidad de la celulosa es responsable de la dureza del material lignocelulósico, por tanto, su biodegradación debilita las paredes celulares de las fibras.

La celulosa se biodegrada por la acción de las enzimas celulasas, presentes en gran cantidad de hongos y bacterias. La biodegradación se produce tanto en ambientes aeróbicos como anaeróbicos. El proceso de biodegradación es relativamente lento, debido a las características estructurales de la celulosa (insolubilidad en agua y gran alcalinidad). 
Las celulasas tienen dos mecanismos distintos de actuación y reciben el nombre de endocelulasas cuando atacan a enlaces situados en posiciones aleatorias dentro de la cadena, produciendo monómeros de $\alpha$-glucosa y celobiosa ( un disacárido que contiene dos unidades de $\alpha$-glucosa). En cambio, cuando las enzimas atacan solamente los extremos de las cadenas generando celobiosas y en algunos casos también celtotriosos (trisacáridos), se denominan exocelulasas.

\section{c) Fotodegradación}

La radiación UV ataca en primer lugar a la lignina, la cual es responsable de que la coloración de la muestra cambie. En comparación con la lignina, la celulosa es menos susceptible a la fotodegradación UV. Por tanto, a medida que la lignina se degrada, la superficie de las fibras naturales aumenta su contenido en celulosa. Después de ser degradada la lignina, las fibras, ricas en hidratos de carbono emergen fácilmente a la superficie, con lo que se expone nueva lignina a degradación.

\section{d) Absorción de humedad}

Las biofibras cambian sus dimensiones con la variación de su contenido de humedad en su composición. Las paredes celulares de los polímeros contienen grupos hidroxilo y otros compuestos oxigenados que se enlazan con el agua mediante puentes de hidrógeno. El componente de hemicelulosa es el mayor responsable de la absorción de humedad, pero la accesibilidad y la proporción amorfa/cristalina de la celulosa y la cantidad de lignina tambien influyen sobre este parámetro.

\subsubsection{Coste, Disponibilidad y Desarrollo Sostenible de las Biofibras}

El suministro mundial de fibras sintéticas está disminuyendo, mientras que la demanda de materias primas renovables continua aumentando. El precio de las biofibras varía dependiendo de la disponibilidad que ofrece el país para su cultivo.

Las fibras de yute provienen de la India y Bangladesh, su producción es mayoritaria en los paises tropicales de la India. El kenaf crece en América, el lino se cultiva mayoritariamente en Europa Central, pero en la actualidad tambien crece en otras partes del mundo como Canada, Argentina, la India y Rusia y el cáñamo es original de Asia Central. 
En estos momentos, los precios de las fibras naturales han experimentado un fuerte descenso. Hasta hace unos años el precio de las fibras naturales podía llegar a ser un 30\% superior al de las fibras sintéticas, dependiendo de su lugar de origen. Estas razones económicas limitaban su extensión, sin embargo, las biofibras proporcionan grandes ventajas que día a día son valoradas y exigidas por los consumidores y las autoridades. 


\subsection{BIOCOMPOSITES}

Los composites poliméricos tradicionales han llegado a alcanzar una gran importancia en distintos sectores industriales (construcción, industria aeroespacial, defensa, marina, transporte...) donde la obtención de diferentes materiales que combinen una alta fuerza, dureza y durabilidad junto con un bajo peso es fundamental [1].

La selección del material polimérico que va a constituir la matriz polimérica del biocomposite enfibrado, varía de acuerdo al producto final proyectado. Algunos de los materiales más usados son los poliésteres insaturado, las resinas epóxicas, los poliuretanos y los termoplásticos. Como sistema de refuerzo en un composite, se han utilizado mayoritariamente fibras de vidrio, aramidas y carbón [96]. Estas fibras proceden de recursos no renovables, y su uso contribuye a aumentar el problema de acumulación de residuos. Además las fibras sintéticas presentan otros inconvenientes de carácter ambiental, energéticos y de procesado por lo que se buscan alternativas viables en las fibras naturales [97]. La Tabla 1.5 resume las características y propiedades que justifican tal elección.

Tabla 1.5. Comparación entre las fibras naturales y de vidrio [97]

\begin{tabular}{rcc}
\hline & Fibras de vidrio & Fibras naturales \\
\hline Densidad & Doble que las FN & Baja \\
Coste & Mayor que las FN & Baja \\
Renovable & No & Si \\
Reciclable & $N o$ & $S i$ \\
CO neutral & No & Si \\
Consumo Energía & Alto & Bajo \\
Abrasión & Si & no \\
Riesgo inhalación & Si & no \\
Finalidad & no biodegradable & biodegradable \\
\hline
\end{tabular}

Los primeros composites que fueron diseñados a partir de fibras naturales se denominaron "biocomposites", por estar formados parcial ó totalmente por materiales de origen natural [1]. Sin embargo, las matrices poliméricas de estos primeros biocomposites eran polímeros convencionales (polipropileno, polietileno, epoxis, etc) [55,98]. Estos biocomposites se usan fundamentalmente en el campo de la construcción y del automóvil y son ya una alternativa real frente al uso de los composites procedentes de fuentes no renovables $[98,99]$. 
El diseño de biocomposites formados a partir de una matriz biodegradable y fibras naturales (composites verdes) es una alternativa más ambiciosa y respetuosa con el medio ambiente que la anterior. El diseño de este tipo de biocomposite permite: la conservación de los recursos petrolíferos, la completa degradación biológica de sus componentes, la reducción del volumen de los residuos poliméricos, la reducción de la cantidad de dióxido de carbono emitido a la atmósfera y nuevas aplicaciones para los recursos agrícolas. Por tanto, el diseño de "composites verdes" presenta grandes ventajas, no sólo por cubrir una serie de aplicaciones específicas, sino por ser una alternativa de gestión de residuos [100,101].

Las primeras investigaciones sobre biocomposites provenientes de recursos renovables fueron desarrolladas en 1989 en el Institute of Structural Mechanics at DLR (Deutsches Zentrum für Luft- and Raumfahrt) en Braunschweig, Alemania, dirigidas por el grupo de investigación del doctor Hermann [92]. Actualmente, el estudio y el diseño de este tipo de composites se encuentra aún en una fase inicial, pero sin duda, los biocomposites constituidos por una matriz biodegradable y fibras naturales, tienen el potencial necesario para construir el nuevo material del siglo XXI [1].

\subsubsection{Clasificación de los biocomposites}

Como ya se ha dicho, los biocomposites son materiales compuestos de fibras naturales y polímeros no biodegradables sintéticos (PP, PE y epoxis) ó polímeros biodegradables (PLA, PHA). También se usa este término para definir a los composites conformados a partir de fibras sintéticas y polímeros biodegradables. De entre todos los tipos de biocomposites, los más respetuosos con el medio ambiente, se conocen como "composites verdes" y están formados por fibras naturales y polímeros biodegradables [1,49]. En la Figura 1.16 se esquematiza de forma sencilla la clasificación de los biocomposites de fibras naturales. 


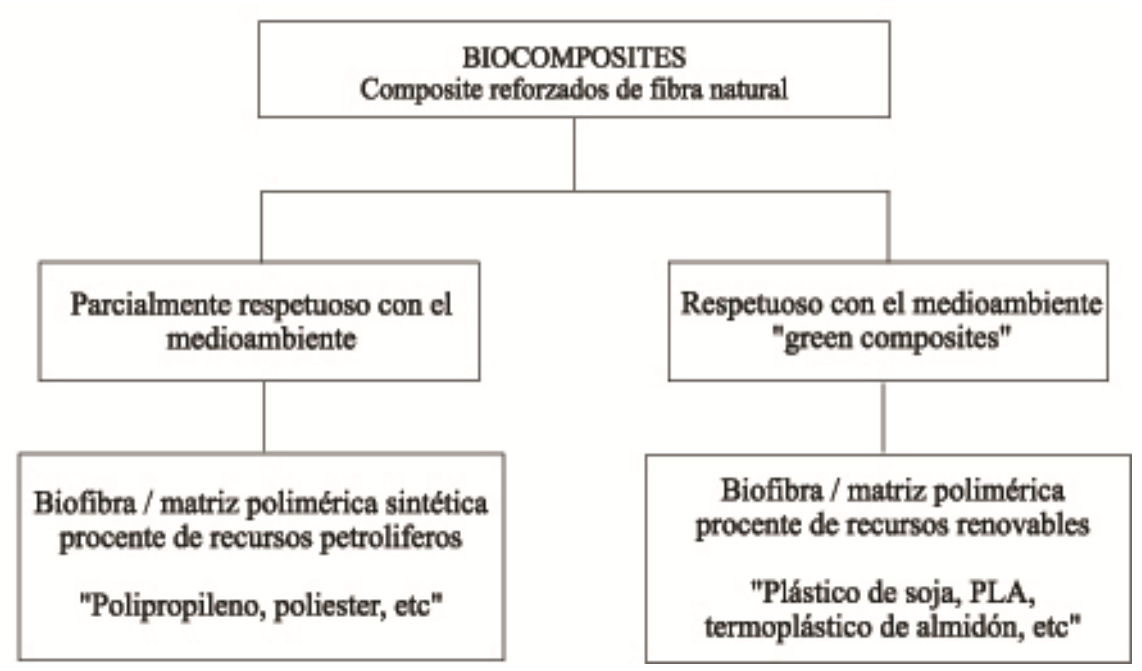

Figura 1.16. Clasificación de los biocomposites de fibras naturales [1]

\subsubsection{Descripción de los composites respetuosos con el medio ambiente}

\section{a) Composites verdes}

Actualmente un gran número de investigadores centran sus esfuerzos en el desarrollo de los composites verdes [102-106]. Las características más atractivas de estos biocomposites es que tanto la matriz polimérica como las fibras naturales son materiales biodegradables, que pueden ser depositados en la naturaleza sin que su eliminación suponga ningún tipo de riesgo medioambiental.

Existen un gran número de polímeros biodegradables que se pueden usar como matriz polimérica. De entre todos ellos, destacan los compuestos de almidón termoplastificado y sus mezclas, debido a que su uso además de no dañar el medio ambiente, y preservar los recursos petrolíferos, presenta una naturaleza polar que asegura la compatibilidad entre sus principales componentes y la fibra natural.

Patel y Bastioli [107] han estudiado en profundidad el diseño y la evaluación del ciclo de vida de los composites verdes. Estos biocomposites se usan mayoritariamente para la confección de productos de corta vida o de usar y tirar. Pero actualmente, su desarrollo se extiende a otras aplicaciones en las que se requiere, una vida útil de varios años [106]. 
Dependiendo de los materiales poliméricos escogidos como matriz polimérica, se puede realizar una subclasificación [108].

\section{Composites basados en termoplásticos biodegradables}

Dentro de esta categoría se encuentran aquellos composites cuyas matrices poliméricas están conformadas por:

o Polímeros biodegradables sintéticos tales como el ácido poli(glicol) (PGA), el poli(vinil alcohol) (PVA), etc.

o Polímeros biodegradables naturales tales como el ácido poli(láctico) (PLA), el almidón termoplastificado (TPS) y sus mezclas, la celulosa regenerada, etc.

Imam y col. [109] evaluaron la estabilidad térmica de los composites diseñados a partir de la mezcla de poli(vinil alcohol), almidón y fibras lignocelulósicas. En este estudio, el análisis termogravimétrico se utilizó para confirmar la formulación escogida, asegurándose la estabilidad del composite durante su procesado y vida útil. Además se estudió la degradación de los materiales base y del biocomposite. Se demostró que la celulosa y el almidón se degradaban más rapidamente que el PVA. Pero que al adicionar la fibra natural la velocidad de degradación del PVA aumentaba.

Por otra parte, Plackett y col. [110] usaron un PLA comercial para diseñar un biocomposite de yute. Se estudió la degradación de la matriz polimérica de este biocomposite durante su procesado y la mejora de sus propiedades mecánicas tras su enfibrado, comprobándose un aumento de las propiedades de tensión tras el enfibrado y pequeños cambios en su distribución de pesos moleculares tras el procesado.

Pan y col. [111] diseñaron un composite a partir del PLLA (poli (ácido (L-láctico)) y de la fibra de kenaf. Se ensayaron diversas formulaciones para escoger la composición óptima del composite $(0 \%, 10 \%, 20 \%$ y $30 \%$ de fibra). Masirek y col. [112] reforzaron el PLLA con fibra de cáñamo y no se observó una mejora en la estabilidad térmica de la matriz pero si en el módulo de elasticidad. 
En los últimos años se han realizado un gran número de estudios sobre composites verdes de base almidón [113-115], debido a que este polisacárido se considera como el material procedente de recursos renovables que muestra una mayor facilidad para convertirse en plástico, y cerrar completamente el ciclo del material [116].

\section{Composites de soja}

La composición típica de la planta de soja es de un 20\% de aceite y un $40 \%$ en proteínas. Las proteínas (polipéptidos) presentes en este compuesto, cubren un gran rango de tamaños moleculares y se componen mayoritariamente de aminoácidos no polares y no reactivos, y de amino ácidos polares y reactivos.

Thames y col. [117] sometieron a estos materiales a diferentes modificaciones para mejorar su resistencia al agua y su reactividad, y poder introducirlos así en el campo de los bioplásticos. Wang y col. [118] prepararon diferentes composiciones de plásticos de proteínas de soja y comprobaron sus propiedades mecánicas. Lodha y col. [119] estudiaron las propiedades térmicas y de tensión de un composite verde de soja con fibras de ramio, demostrando que estos composites verdes, tienen un enorme potencial para aplicaciones en recintos cubiertos.

\section{Composites basados en goma natural}

El refuerzo de las gomas naturales mediante fibras naturales, implica un crecimiento del módulo y de la fuerza, con buenos enlaces a altas concentraciones de fibras.

Seal y col. [120] comprobaron que la biodegradación de la goma natural vulcanizada era posible, pese a la dificultad que ofrecía la estabilidad de los enlaces de las cadenas poli(cis-1,4-isopropano). Varghese y col. [121] investigaron los efectos que producía la adición de las fibras de sisal sobre las propiedades termo-mecánicas de las gomas naturales. Ismail y col. [122] incorporaron fibras de aceite de palma a la matriz de goma. Se observó la tendencia general de reducción en la tensión con el crecimiento de la concentración de la fibra en su formulación.

Por otra parte, Mathew y col. [123] adicionaron fibras naturales modificadas sobre gomas naturales. Sometieron a las fibras naturales a diferentes tratamientos químicos 
(maceración, acetilzación, benzoilación y tratamiento con disocianato de tolueno y agentes acomplejantes de silano) y estudiaron sus efectos sobre la calidad de los biocomposites resultantes.

Recientemente se han conseguido diseñar composites de goma usando una combinación de fibras naturales de hojas y frutas [124]. Estos nuevos composites, como se verá a continuación se denominan composites híbridos y se usan en un gran número de aplicaciones.

\section{b) Composites híbridos}

El término híbrido se usa para describir el fenómeno de un aumento sinergético en las propiedades de las composites al mezclar dos o más tipos de fibras en su formulación. El comportamiento de los composites híbridos ideales es la suma del comportamiento de los componentes individuales, las propiedades de un tipo de fibra pueden complementar a las propiedades de las otras. El diseño de composites híbridos implica un balance entre el coste y el uso [125]. Las propiedades de un composite híbrido dependen mayoritariamente del contenido de fibra, de la longitud individual de la fibra, de la orientación, del tipo de enlaces entre la fibra y la matriz y el empaquetamiento de ambas fibras. Para conseguir diseñar un composite híbrido competitivo, cabe tener en cuenta tanto a la matriz polimérica como a la fibra natural y al sistema fibras/matriz polimérica que deben ser química, mecánica, física y térmicamente estables.

Las propiedades de un sistema híbrido compuesto por dos componentes puede predecirse mediante la ecuación general de las mezclas ideales.

$$
P_{H}=P_{1} V_{1}+P_{2} V_{2}
$$

donde $\mathrm{P}_{\mathrm{H}}$ es la propiedad que va a ser investigada, $P_{1}$ es la propiedad correspondiente al primer sistema, $\mathrm{P}_{2}$ responde a las propiedades del segundo sistema. $V_{1}$ y $V_{2}$ son las fracciones relativas volumétricas del primer y segundo sistema, donde $V_{1}+V_{2}=1$. 
Dependiendo del signo de desviación entre el valor experimental resultante y el valor esperado mediante las ecuaciones antes definidas, se considerará que la hibridación ha tenido un efecto positivo o negativo.

Los biocomposites híbridos pueden ser diseñados a partir de la combinación de más de dos fibras, donde una de ellas podría ser de origen sintético y la otra de origen natural ó bien, podrían ser las dos fibras de origen natural. La hibridación con fibras de vidrio proporciona un método para mejorar las propiedades mecánicas de los biocomposites de fibras naturales. La hibridación de las fibras de hojas de palma con fibra de vidrio aumenta la fuerza de tensión, el módulo de Young, y la elongación hasta rotura de los composites de fibras de hoja de palma. Además, se observa como la fuerza de impacto de los composites híbridos crece con la adición de fibras de vidrio. Sin embargo, también se observó un efecto negativo de la hibridación en la fuerza de tensión y el modulo de Young, mientras la hibridación resulta positiva para la elongación hasta rotura de los composites.

Burgueño y col. [126] diseñaron biocomposites de interior celular fabricados a partir de cáñamo y lino comerciales con poliésteres insaturados los cuales, fueron hibridados con yute, lana y algodón unidireccional. La caracterización de estos materiales demostró que se mejoraban propiedades como la dureza, fuerza y resistencia de absorción, al igual que el comportamiento estructural, evaluado a partir de diferentes ensayos a flexión realizados a escala de laboratorio. Estos composites híbridos ofrecen una alternativa económica y ambiental frente a los composites enteramente sintéticos.

Otra alternativa innovadora para el diseño de composites híbridos es la incorporación de dos fibras naturales en la matriz. Recientemente, Idicula y col. [127] estudiaron la influencia de la hibridación de fibras cortas de banana y sisal dispuestas aleatoriamente con una fracción volumétrica de 0,4 sobre una matríz de poliéster. Se observa un efecto positivo en la fuerza y el módulo de flexión de los composites. Posteriormente, en el 2006, Idicula y col. [128] investigaron las propiedades termofísicas de los composites de sisal y banana después de someterles a modificaciones químicas, observándose un aumento del $43 \%$ en la conductividad térmica. 


\subsubsection{Factores que determinan la calidad de un composite}

La calidad de un composite depende de la combinación de muchos factores; pero, fundamentalmente está determinada, por las propiedades intrínsecas de los constituyentes. Los factores más utilizados para determinar la calidad del biocomposite diseñado, son los mismos que se han usan para cualquier composite enfibrado, arquitectura del refuerzo e interfase fibra/matriz.

\section{a) Arquitectura del refuerzo}

Se define como arquitectura del refuerzo, al conjunto de una serie de factores estructurales de las fibras: geometría, orientación, disposición del empaquetamiento de las fibras y fracción volumétrica que ocupa la fibra.

La fracción volumétrica de la fibra $(V f)$ es un factor importante en el diseño de un biocomposite [100]. A medida que la fracción volumétrica de la fibra crece en el biocomposite, aumentan la mayoría de sus propiedades mecánicas, hasta alcanzar un límite, en donde por más fibra que se añada las propiedades no se modifican. El máximo $V f$ alcanzable, viene determinado por la orientación y la disposición de empaquetamiento de las fibras, y estas propiedades a su vez, dependen del proceso de elaboración escogido. Las fibras madereras provenientes de maderas blanda, se caracterizan por tener una longitud de 1,5 a 5 $\mathrm{mm}$ y unas dimensiones transversales de 15 a $80 \mu \mathrm{m}$. Por otra parte, la geometría de las fibras vegetales depende fundamentalmente de la morfología del tisú de la fibra y de la forma en la cual se cosecha y recoge.

Otro factor importante es la relación de forma, ésta se define como el cociente entre la longitud de la fibra y su diámetro; por tanto las fibras con un parámetro relación de forma alta, son largas y delgadas, mientras que las fibras con un parámetro bajo son más cortas y más anchas. La relación de forma de una fibra vegetal individual procedente del tallo o de la corteza de las plantas es más alta que las fibras madereras. Algunos autores, consideran ventajoso conseguir la máxima longitud posible de fibra, ya que a más alta relación de forma se puede alcanzar una mayor eficacia de refuerzo [101]. 
El uso de nanobiofras como sistema de refuerzo [129] y un control de la alineación de las fibras naturales añadidas [130], son otras de las vías propuestas para conseguir mejorar la arquitectura del refuerzo, y así aumentar la calidad del composite.

\section{b) Interfase entre la fibra y la matriz}

La interfase entre la fibra y la matriz es otro factor a considerar para determinar la calidad del biocomposite. La interfase sirve para transferir las cargas aplicadas desde el exterior a las fibras naturales. Para conseguir un sistema de refuerzo real, se requiere de enlaces capaces de transferir adecuadamente las tensiones aplicadas a las fibras naturales. La dureza ó la habilidad del material para resistir a la propagación de las grietas es una propiedad mecánica importante determinada por la interfase.

Debido a la incompatibilidad entre las fibras naturales, hidrofilicas, y las matrices poliméricas hidrófobas, se han propuesto diferentes métodos para mejorar su adhesión: la modificación química de las fibras ó/y adición de los agentes compatibilizantes. En un principio, la selección de una matriz biodegradable polar, evitaría la necesidad de estas modificaciones. De ahí, el interés por el diseño de composites verdes de base almidón.

\section{Referencias}

1. Mohanty AK, Misra M, Drzal TD editors. Natural Fibers, Biopolymers and Biocomposites. Boca Raton: Taylor \& Francis, 2005.

2. Schnabel W. Polymer Degradation, Principles and Practical Applications. München: Hanser, 1981.

3. Mohee R, Unmar GD, Mudhoo A, Khadoo P. Waste Management 2008; $28: 1624$.

4. Narayan R. Science and Engineering of Composting 1989; 339.

5. Chandra R, Rustgi R. Polym Degrad Stab 1997; 56: 185.

6. ASTM D5988. Standard test methods for determining aerobic biodegradation in soil of plastic materials or residual plastic materials after composting, 2003.

7. Albertsson AC, Erlandsson B, Hakkarainen M, Karlsson S. J Environ Polym Degrd 1998; 6: 187.

8. ISO 472: 1988-Plastics-Vocabulary.

9. Smith $\mathrm{R}$ editor. Biodegradable polymers for industrial applications. London; Woodhead Publishing, 2005

10. Göpferich A. Biomaterials 1996: 17; 103.

11. Scott G. Polym Degrad Stab 1999; 68:1. 
12. Tucker $\mathrm{N}$, Johnson $\mathrm{M}$ editors. Low Environmental Impact Polymers. Shrewsbury:Rapra Technology 2004.

13. Amass W, Amass A, Tighe B. Polymer International 1998; 47:89.

14. Sadrmohaghegh C, Scott G, Setudeh E. Polymer Plast Technology Engineering 1985; 24: 149.

15. Sadrmohaghegh C, Scott G. Polym Degrad Stab 1980-1981; 3: 333.

16. Sadrmohaghegh C, Scott G, Setudeh E. Polym Degrad Stab 1980-1081; 3: 469.

17. Scott G, Gilead D, editors. Degradable Polymers, Principles and Applications. Kluwer Academic Publisher/ Chapmant and Hall, 1995.

18. Morrison, W. Cer Foods World 1995,40, 437.

19. Jenkins PJ, Donald AM. Int J Biol Macrom 1995; 17: 315.

20. Gallant D, Bouchet B, Baldwin P. Eur J Clint Nutr 1992; 46. S3

21. Gallant D, Bouchet, B, Baldwin P. Carbohydrate Polymers 1997; 32: 177.

22. Bernal L, Martínez E. Rev del Centro de Inv (Méx) 2006; 7, 77.

23. Primo Yúfera E. Química orgánica básica y aplicada de la molécula a la industria. Barcelona: Editiorial Reverte S.A, 1995.

24. Griffin GJL. editor. Chemistry and Technology of Biodegradable Polymers. Glasgow: Blackie Academic Professional, 1994.

25. Clarinval AM, Halleux J. In: Smith R editor. Biodegradable polymers for industrial applications. London; Woodhead Publishing, 2005

26. Lourdin D, Della Valle G, Colonna P, Poussin D. Cautchoucs et Plastiques 1999 ; 780 : 39.

27. Avérous, L.; Fringant, Christophe.; Moro, Laurence. Starch/Stärke 2001; 53: 368.

28. Lai LS, Kokini JL. Biotechnology 1991; 7: 251.

29. Willett JL, Jasberg BK, Swanson CL. Poly Eng and Sci 1995; 35: 202.

30. Zobel HF. Starch/Stärke 1988; 40: 1.

31. Soest Van JJG. Starch plastics structure-property relationships. Utrecht University (Netherland). P \& L Press, Wageningen, 1996.

32. Narayan R. Microfibre reinforced biodegradable starch ester composites with enhanced shock absorbance and processability, U.D. Patent allowed, 1997.

33. Sagar AD, Merril EW. Polymer 1995b; 36: 1883.

34. Bae SO, Lim ST. Cereal Chem 1998; 75: 449.

35. Rivard D, Monens L, Brigham J, Kelley S. Enzyme and microbial technology 1995; 17: 848.

36. Imman SH, Harry-O’Kuru, RE. Appl Environ Microbial 1991; 57: 1128.

37. Imman SH. Polym Degrad Stab 2001; 73: 529.

38. Mani R, Bhattacharya M, Tang J. J Poly Sci 1999; 37: 1693.

39. Willet JL. J Appl Polym Sci 1994, 54, 1685.

40. Mao LJ, Imam S, Gordon S, Cinelli P, Chielline E. J Polym Environ 2000; 8: 205. 
41. Coi EJ, Kim CH, Park JK. Macromolecules 1999; 32: 22.

42. Bastioli C. Polym Degrad Stab 1998; 59: 263

43. Bastioli C editor. Handbook of Biodegradable Polymers. Shrewsbury: Rapra Technology, 2005.

44. Anon. Italian Technology Plast 2000; 1: 182.

45. Bastioli C. Macromolecular Symposia 1998; 135: 193.

46. Bohalmann Gm, Yoshida Y. Biodegradable Polymers, CEH Marketing Research Repor, SRI Chemical and Health Business Services, Menlo Park, CA, USA, 2000.

47. Guilbert $S$, Ensa M, Inra, France P

48. Ernst \& Young. The Current Market for Energy and Industrial Bioproducts and Foreseeable Future Developments for 2015/2030, January 2007.

49. Mohanty AK, Misra M, Hinrichsen G. Macromol Mater Eng 2000; 276/277: 1.

50. Hon DNS. Polym News 1992; 17(4): 102.

51. Jacob M, Sabu T. Carbohydr Polym 2008; 71: 343.

52. Satyanarayana KG, Ravikumar KK, Sukumaran K., Mukherjee PS, Pillai SGK, Kulkarni AK. J of Material Science 1986; 21: 1.

53. Scheer-Triebel M, Léon J. Pflanzenbauwissenschaften 2000; 4: 26.

54. Lampke T, Technische Universität Chemnitz, Lehrstuhl für Verbundwerkstoffe, 2001.

55. Wielage B, Lampke T, Marx G, Nestler K., Starke D. Thermochim Acta 1999; 337: 169.

56. Kessler RW, Kohler R. Chemtech 1996; 12: 34.

57. Mediavilla V, Bassetti P, Leupin M, Mosimann E. Agarforschung 1999; 6: 393.

58. Jayaraman K. Compos Sci Tech 2003; 63: 367.

59. Brett C, Waldron K. Physiology and Biochemistry of Plant Cell Walls, $2^{\text {nd }}$ ed., Chapman \& Hall, London, 1996.

60. Bismarck A, Askargota IA, Springer J, Lampke T, Wielage B, Stamboulies A. Polym Compos 2002; 23: 872 .

61. Bidlack JE, Malonge M, Benson R. Proc Okla Acad Sci 1992; 72: 51

62. Sun RC, Sun XF, Wang SQ, Zhu W, Wang XY. Ind Crops Prod 2002; 15: 179.

63. Scallan AM. Textile Res $J$ 1971; 41(8): 647.

64. Buschle-Diller G, Zeronian SH, Pan N, Yoon MY. Textile Res J 1994; 64(5): 270

65. Chanzy H, Imada K, Vuong R. Protoplasma 1978; 94: 299.

66. Meyer KH, Misch L. Chem Acta 1937; 20: 232.

67. Sarko A, Muggli R. Macromolecules 1974; 7: 486.

68. Gardner KH, Blackwell J, Biopolymers 1974; 13: 1975.

69. Atalla RH, VanderHart DL. Science 1984: 223; 283.

70. VanderHart DL, Atalla RH. Macromolecules 1984; 17: 1465.

71. Atalla RH, Whitmore RE, VanderHart DL. Biocomposite 1985; 24: 421. 
72. Marrinan HJ, Mann J. J Polymer Sci 1956; 21: 301.

73. Wiley JH, Atalla RH. Carbohydr Res 1987; 160: 113.

74. Imai J, Sugiyama T, Horii IF. J Struct Biol 1999; 127: 248.

75. Sugiyama J, Vuong R, Chanzy H. Macromolecules 1999; 24: 4168.

76. Gardner KH, Blackwell J. Bioquim Biophys Acta 1974; 343: 232.

77. Marrinan HJ, Mann J. J Appl Chem 1954; 4: 204.

78. Tsuboi M, J Polym Sci 1957; 25: 159.

79. Michell AJ, Carbohydr Res 1993; 241: 47.

80. Kondo T, Cellulose 1997; 4: 281.

81. Kondo T, in: S. Dimitriu Editors, Polysaccharides: Structural Diversity and Functional Versatility, Marcel Dekker, New York, 1998, Chap. 4.

82. Akerholm M, Hinterstoisser B, Salmen L. Carbohyd Res 2004; 339: 569.

83. Focher B, Naggi A, Torri G, Cosani A, Terbojevich M. Carbohyd Res 1992; 17 : 97.

84. Olsson AM, Salmén L. Carbohydr Res 2004; 339: 813.

85. Scwanninger M, Rodrigues JC, Pereira H, Hinters-toisser B. Vib Spectrosc 2004; 36: 23.

86. O'Connor RT, DuPré EF, Mitcham Donald. Textil Res J 1958; 38: 382.

87. Fengel D, Wegener G. Chemistry, ultrastructure, reactions. Berlin-New York; Walter de Gruyter, 1984.

88. Rouchi AM. Chem Eng News 2000; 13: 29.

89. Yao F, Wu Q, Lei Y, Guo W, Xu Y. Poym Degrad Stab 2008; 93: 90.

90. Di Blasi C, Branca C. Industrial and Engineering Chemistry Research 2001;40.

91. Antal MJ Jr, Varhegyi G. Ind Eng Chem Res 1995; 34: 703.

92. Capart R, Khezami L, Burnharm AK. Thermochim Acta 2004; 417:79.

93. Maciejewski M. Thermochim Acta 2000; 355:145.

94. Broido A, Nelson MA. Combust Flame 1975; 24: 263.

95. Broido A. In; Shafizadeh F, Sarkanen KV, Tillman DA, editors. Academic Press: New York, 1976.

96. Wambua P, Ivens J, Verpoest I. Comp Sci Tech 2003; 63:1259.

97. Wollerdorfer M, Bader H. Ind Crop Prod 1998; 8; 105.

98. Wielage B, Lampke Th, Utschick F, Soergel F. J Mater Process Tech 2003; 139:140.

99. Larbig H, Scherzer H, Dahlke B, Poltrock R. Journal of Cellular Plastics 1998; 34: 361.

100. Mohanty AK, Misra M, Drzal LT. J Polym Environ 2002; 10: 19.

101. Fowler PA, Hughes JM, Elias RM. Sci Food Agric 2006; 86:1781.

102. Hermann AS, Nickel J, Riedel U. Polym Degrad Stab 1998; 59: 251.

103. Chen BQ, Evans JRG. Carbohydr Polym 2005; 61:455.

104. Follain N, Joly C, Dole P, Bliard C. J Appl Polym Sci 2005; 97:1783. 
105. Gallstedt M, Mattozzi A, Johansson E, Hedenqvist MS. Biomacromolecules 2004; 5: 220.

106. Wang Q, Padua GW. J Agric Food Chem 2005; 53:3444.

107. Pate M, Bastioli C, Marini L, Würdinger E. Life-cycle assessment of bio-based polymers and natural fibres. Biopolymers. Wiley-VCH, 2003.

108. Vink ETH, Rabago KR, Glassner DA, Gruber PR. Polym Degrad Stab 2003; 80: 403.

109. Imam SH, Cinelli P, Gordon SH, Chiellini E. J Polym Environ 2005; 13: 47.

110. Plackett D, Andersen TL, Pedersen WB, Nielsen L. Compos Sci Tech 2003; 63: 1287.

111. Pan P, Zhu B, Kai W, Serizawa S, Iji M, Inoue Y. J Appl Polym Sci 2007; $105: 1511$.

112. Masirek R, Kulinski Z, Chionna D, Piorkowska E, Pracella M. J Appli Polym Sci 2007; 105: 255.

113. Cyras VP, Iannace S, Kenny JM, Vazquez A. Polym Composites 2001; 22: 1.

114. Curvelo AAS, Carvalho AJF, Agnelli JAM. Carbohyd Polym 2001; 45: 183.

115. Puglia D, Tomassuci A, Kenny JM. Polym Adv Tech 2003; 14: 749.

116. Hocking PJ. J Macromol Sci-Rev Macromol Chem Phys 1992; C32: 35.

117. Thames SF, Yu H. Surf Coat Tech 1999; 115: 208.

118. Wang S, Sue HJ, Jane J. J Macromol Sci Pure Appl Chem 1996; A33 (55): 557.

119. Lodha P, Netravali AN. Compos Sci Tech 2005; 65: 1211.

120. Seal KJ, Morton LHG. Biotechnology 1996; 8: 583.

121. Varghese S, Kuriakose B, Thomas S, Koshy AT. J Adhes Sci Tech 1994; 8: 235.

122. Ismail H, Rosnah N, Ishiaku US. Polym Int 1997; 43: 223.

123. Mathew L, Joseph KU, Joseph R. Progr Rubber Plast Tech 2004; 20: 337.

124. Jacob M, Francis B, Varughese KT, Thomas S. Polymer Compos 2006; 27: 671.

125. Thwe MM, Liao K. Compos Sci Tech 2003; 63: 375.

126. Burgueño R, Quagliata MJ, Mohanty AK, Mehta G, Drzal LT, Misra M. Compos Appl Sci Manuf 2005; 36: 581.

127. Idicula M, Neelakantan NR, Oommen Z, Joseph K, Thomas S. J Appl Polym Sci 2005; 96:1699.

128. Idicula M, Boudenne A, Umadevi L, Ibos L, Candau Y, Thomas S. Compos Sci Tech 2006; 66: 2719.

129. Nakagaito AN, Yano H. Appl Phys A: Mater Sci Process 2004; 78: 547.

130. Hughes M, Hill CAS, Sèbe G, Hague J, Spear M and Mott L. Compos Interface 2000; 7: 13. 



\section{Procedimiento experimental}

2.1 Materiales y preparación de las muestras

2.2 Metodología experimental

2.3 Metodología de análisis 



\subsection{MATERALES Y PREPARACIÓN DE LAS MUESTRAS}

En este estudio se han preparado dos series de biocomposites a partir de dos matrices comerciales distintas y cinco fibras naturales vegetales.

\subsubsection{Matrices Poliméricas}

Como matrices poliméricas se han seleccionado dos termoplásticos biodegradables de base almidón distribuidos por Novamont SpA. (Italia) bajo el nombre comercial de Mater-Bi KE03B1® y Mater-Bi NF01U®.

\section{a) Mater-Bi K03 B1}

La composición exacta del Mater-Bi KE03B1 (Mater-Bi KE) no se conoce con exactitud porque se trata de un secreto comercial, pero gracias a partir de los ensayos de caracterización realizados se ha podido determinar que el componente mayoritario es un poliéster, probablemente la poli ( $\varepsilon$-caprolactona). Las características técnicas facilitadas por el fabricante para el Mater-Bi KE se resumen en la tabla siguiente.

Tabla 2.1. Especificaciones técnicas del Mater-Bi KE

\begin{tabular}{c|cc}
\hline & Unidades & Valores \\
\hline$T^{a}$ mínima de procesado & ${ }^{\circ} \mathrm{C}$ & 150,0 \\
$T^{a}$ máxima de procesado & ${ }^{\circ} \mathrm{C}$ & 220,0 \\
Temperatura de fusión & ${ }^{\circ} \mathrm{C}$ & $65,0-153,0$ \\
MFI & $\mathrm{g} / 10 \mathrm{~min}$ & 8,5 \\
Densidad & $\mathrm{g} / \mathrm{cc}$ & 1,2 \\
Viscosidad en fundido & $\mathrm{Pa} . \mathrm{s}$ & 770,0 \\
Tensión de rotura & $\mathrm{MPa}$ & 18,0 \\
Módulo de Young & $\mathrm{MPa}$ & 1400,0 \\
\hline
\end{tabular}

\section{b) Mater-Bi NF 01U}

El Mater-Bi NF01U (Mater-Bi NF), está compuesto por almidón y un poliéster biodegradable [1-2]. Las características técnicas del Mater-Bi NF se resumen en la tabla siguiente. 
Tabla 2.2. Especificaciones técnicas del Mater-Bi NF01U

\begin{tabular}{c|cc}
\hline & Unidades & Valores \\
\hline Temperatura de fusión & ${ }^{\circ} \mathrm{C}$ & 110,0 \\
MFI & $\mathrm{g} / 10 \mathrm{~min}$ & 3,0 \\
Densidad & $\mathrm{g} / \mathrm{cc}$ & 1,3 \\
Elongación hasta rotura & $\%$ & 560,0 \\
Tensión de rotura & $\mathrm{MPa}$ & 24,0 \\
Viscosidad en fundido & $\mathrm{Pa} . \mathrm{s}$ & 770,0 \\
Resistencia al desgarro & $\mathrm{N} / \mathrm{mm}$ & 78,0 \\
Módulo de Young & $\mathrm{MPa}$ & 95,0 \\
Permeabilidad al vapor de agua & $\mathrm{g} \cdot 30 \mu \mathrm{m} /(\mathrm{mq} \cdot 24 \mathrm{~h})$ & 950,0 \\
\hline
\end{tabular}

\subsubsection{Fibras naturales}

El algodón, el cáñamo, el yute, el kenaf y el lino son las fibras naturales vegetales escogidas como sistema de refuerzo para el diseño de los biocomposites. Estas fibras naturales han sido suministradas por la empresa Yute S.L (España). La Tabla 2.3. resume las propiedades física y mecánicas de las fibras naturales estudiadas. El valor del módulo elástico ha sido facilitado por el productor y las propiedades físicas de cada fibra se han determinado mediante la observación de más de 100 muestras, bajo microscopía óptica.

Tabla 2.3. Propiedades físicas y mecánicas de las fibras de algodón, cáñamo, yute, kenaf y lino

\begin{tabular}{rc|ccccc}
\hline & & Algodón & Cáñamo & Yute & Kenaf & Lino \\
\hline Longitud promedio & $\mathrm{mm}$ & $3,0 \pm 1,0$ & $1,0 \pm 0,5$ & $6,5 \pm 3,5$ & $10,0 \pm 5,0$ & $6,0 \pm 4,0$ \\
Diámetro promedio & $10^{2} \mathrm{~mm}$ & $1,8 \pm 1,2$ & $2,7 \pm 2,0$ & $2,0 \pm 0,5$ & $15,0 \pm 0,5$ & $1,0 \pm 0,5$ \\
Relación de forma & $\mathrm{mm}$ & $67,0-666,7$ & $150,7-214,0$ & $150,0-500,0$ & $25,2-150,2$ & $200,5-1000,4$ \\
Módulo de Young & $\mathrm{GPa}$ & $12,0 \pm 1,0$ & $50,0 \pm 2,0$ & $70,0 \pm 1,5$ & $40,0 \pm 1,0$ & $60,0 \pm 1,0$ \\
\hline
\end{tabular}

Previamente al conformado de los biocomposites, las fibras naturales han sido sometidas a un proceso de peletización bajo condiciones específicas de humedad y presión (Tabla 2.4). Con este proceso, se consiguió compactar las biofibras para facilitar su adición durante el procesado. 
Tabla 2.4. Condiciones de peletización de las fibras de algodón, cáñamo, yute, kenaf y lino

\begin{tabular}{c|cccc}
\hline & $\begin{array}{c}\text { Potencia } \\
(\mathrm{KW})\end{array}$ & $\begin{array}{c}\text { Diámetro } \\
\text { malla }(\mathrm{mm})\end{array}$ & $\begin{array}{c}\text { Humedad } \\
\text { dosificación }(\%)\end{array}$ & $\begin{array}{c}\text { Dificultad en } \\
\text { pelitizacíón }\end{array}$ \\
\hline Algodón & $0,5-1,0$ & 8,0 & 30 & Alta \\
Cáñamo & $0,2-0,8$ & 6,0 & Mínima & Alta \\
Yute & $0,8-1,0$ & 6,0 & 30 & Baja \\
Kenaf & $0,2-0,8$ & 6,0 & Minima & Media \\
Lino & $0,8-1,0$ & 8,0 & 30 & Ninguna \\
\hline
\end{tabular}

Las fibras pelitizadas se introdujeron junto a los pelets de la matriz comercial (proporción 10/90 en peso) en una extrusora de doble husillo co-rotativa (Werner \& Pfleiderer ZSK 25, Alemania) de $25 \mathrm{~mm}$ de diámetro (D) y de longitud 40D. La temperatura de procesado se fijó en $140{ }^{\circ} \mathrm{C}$ para el Mater-Bi NF y en $165^{\circ} \mathrm{C}$ para el Mater-Bi KE. A partir de los composites obtenidos se diseñaron placas de $2 \mathrm{~mm}$ de espesor. Para la obtención de estas placas se utilizó una prensa de platos calientes a $180{ }^{\circ} \mathrm{C}$ y un molde de $110 \times 110 \times 2 \mathrm{~mm}$. 


\subsection{METODOLOGÍA EXPERIMENTAL}

La caracterización de las matrices poliméricas, de las fibras naturales y de sus biocomposites respectivos, así como de la monitorización del proceso de degradación en tierra de las matrices poliméricas y de los biocomposites, se basa fundamentalmente en técnicas de Análisis Térmico. Según la I.C.T.A. (Confederación Internacional para el Análisis Térmico) se define éste como el conjunto de técnicas experimentales encargadas de medir una propiedad física o química de un material en función de la temperatura, bajo un programa controlado de temperatura. El resultado de la aplicación de estos métodos es una curva, que describe el comportamiento del material estudiado en términos de la propiedad física escogida. Evaluando los cambios que tienen lugar en esta propiedad, es posible obtener información acerca de los procesos macroscópicos que ocurren en la muestra sometida a análisis.

La caracterización de los materiales base y de los biocomposites se realizó mediante Termogravimetría (TGA), Calorimetría Diferencial de Barrido (DSC), Ensayos Mecánicos de Tensión, Análisis de Espectroscopía de Infrarrojos (FTIR) y de Microscopia Electrónica de Barrido (SEM). Además, la caracterización de la serie compuesta por la matriz Mater-Bi KE, se complementa con un Análisis Termo-Dinámo-Mecánico (DMTA).

La composición química de las fibras naturales se ha estudiado siguiendo:

o El protocolo de Theander y col. [3] para hidrolizar, reducir y acetilar las muestras, y conseguir así determinar el porcentaje de azúcares (relativo y absoluto) de cada fibra natural mediante cromatografía de gases (GC).

o El método Klason propuesto por Monties y col. [4] para cuantificar el porcentaje en lignina que presenta cada fibra natural

o La normativa Tappi 211om-85 [5] para determinar el porcentaje de cenizas de cada fibra natural 
La monitorización del proceso de degradación en tierra de las dos matrices poliméricas y de sus respectivos biocomposites se lleva a cabo mediante Análisis Termogravimétrico (TGA), Calorimetría Diferencial de Barrido (DSC), Análisis Infrarrojos (FTIR) y Microscopía Electrónica de Barrido (SEM). Además, se propone la evaluación del proceso de absorción de agua de ambas matrices poliméricas (Mater-Bi NF y Mater-Bi KE) y de sus respectivos biocomposites como estudio complementario a la degradación en tierra, por ser la hidrólisis la etapa previa a la biodegradación en tierra.

\subsubsection{Procesos Experimentales}

\section{a) Proceso de degradación acelerada en tierra}

Las matrices poliméricas (Mater-Bi KE y Mater-Bi NF), las diferentes fibras naturales (algodón, kenaf, cáñamo, yute y lino) y los biocomposites respectivos (Mater-Bi KE/algodón, Mater-Bi KE/kenaf, Mater-Bi KE/cáñamo, Mater-Bi KE/yute, Mater-Bi KE/lino, Mater-Bi NF/algodón, Mater-Bi NF/kenaf, Mater-Bi NF/cáñamo, Mater-Bi NF/yute y Mater-Bi $\mathrm{NF} /$ lino) se sometieron a un ensayo de degradación acelerada en tierra de acuerdo con la norma internacional DIN 53739 [6] equivalente a la ISO 846:1977 [7]. Las muestras se enterraron en una cámara de cultivo a escala laboratorio en tierra biológicamente activa y los parámetros de humedad relativa $(55 \%), \mathrm{pH}(\sim 7.5)$ y temperatura del medio $\left(28 \pm 2^{\circ} \mathrm{C}\right)$ se controlaron a lo largo de todo el proceso de degradación.

El deterioro macroscópico de las muestras enterradas determinó la duración del ensayo de degradación en tierra: 535 días para el Mater-Bi KE y sus biocomposites; y 200 días para el Mater-Bi NF y sus biocomposites. Las muestras se extrajeron a intervalos de tiempos determinados y posteriormente, se lavaron para detener el proceso de degradación y se guardaron para su posterior caracterización.

Con este proceso experimental se simulan las condiciones a las que se pueden ver sometidos los residuos poliméricos al ser depositados en un vertedero controlado. La caracterización térmica de las muestras degradadas durante distintos tiempos permite monitorizar el proceso de degradación en tierra de los materiales. Los cambios estructurales y morfológicos que se producen en los materiales debido al proceso de degradación se estudian por comparación entre los materiales puros y el degradado a tiempo máximo de 
enterramiento. Además, la influencia de las fibras naturales sobre el proceso de degradación en tierra se puede obtener de la comparación entre la matriz y los biocomposites respectivos.

\section{b) Proceso de absorción en agua}

Las matrices poliméricas y los biocomposites de algodón, cáñamo, kenaf, lino y yute, han sido sometidos a un proceso de absorción en agua siguiendo la metodología propuesta por la norma ASTM D570-98 [8]. Los materiales se sumergieron en baños isotermos (Ultronic 2000, Selecta) a diferentes temperaturas $\left(29^{\circ} \mathrm{C}, 35^{\circ} \mathrm{C}\right.$ y $42{ }^{\circ} \mathrm{C}\left( \pm 1^{\circ} \mathrm{C}\right)$ ) durante 480h. Previamente a su inmersión, las muestras se secaron en un horno Heraus B6 a $50{ }^{\circ} \mathrm{C}$ durante $24 \mathrm{~h}$ para eliminar su contenido de humedad superficial.

A intervalos determinados de tiempo, las probetas fueron extraídas del baño y secadas cuidadosamente con papel absorbente antes de ser pesadas. El aumento de masa se midió en una microbalanza Mettler Toledo (Columbus, $\mathrm{OH}$ ) con una precisión de 0,1 mg. La capacidad de absorción de las muestras se determinó mediante la ecuación 1.

$$
M t=\frac{w_{t}-w_{0}}{w_{0}}(\%)
$$

donde $M t$ es la capacidad de absorción de la muestra ensayada a un tiempo determinado, $\mathrm{w}_{\mathrm{t}}$ es la masa de la muestra a un tiempo determinado $\mathrm{y} \mathrm{w}_{0}$ es la masa inicial de la muestra.

Al estudiar el proceso de absorción de agua de un material, se determina su capacidad y tiempo de saturación, así como su mecanismo de absorción. La caracterización de los diferentes biocomposites permite estudiar la influencia de las diferentes fibras naturales sobre el proceso de absorción de la matriz polimérica.

\subsubsection{Técnicas Experimentales}

a) Análisis termogravimétrico (TGA)

Los ensayos termogravimétrico se han realizado en una termobalanza Mettler-Toledo 851 (TGA/SDTA) (Coulumbus, $\mathrm{OH}$ ), empleándose un método dinámico de 25 a $750{ }^{\circ} \mathrm{C}$, en un rango de velocidades de calentamiento de 3-30 ${ }^{\circ} \mathrm{C} / \mathrm{min}$ bajo atmósfera inerte de 
$\operatorname{Ar}(50 \mathrm{~mL})$ y un flujo de purga de $\mathrm{N}_{2}(200 \mathrm{~mL} / \mathrm{min})$. El peso inicial de las muestras varía entre 7-8 mg. Antes de análizar las muestras se realizó un blanco para restar el ruido del ambiente y del equipo a cada termograma. La pérdida de masa en \% ó $m g$ se obtuvo en función de la temperatura y el tiempo para cada muestra ensayada.

Con estos ensayos, se han identificado los porcentajes en masa de cada componente, la estabilidad térmica y la cinética de descomposición de cada material estudiado.

\section{b) Calorimetría diferencial de barrido (DSC)}

Los ensayos calorimétricos se han llevado a cabo en un DSC Mettler Toledo 822e (Columbus, OH) previamente calibrado con indio y zinc. A todos los ensayos se les ha restado la línea base. Los ensayos se han realizado en atmósfera inerte de $\mathrm{N}_{2}(50 \mathrm{~mL} / \mathrm{min})$ y como gas de purga $(200 \mathrm{~mL} / \mathrm{min})$ nitrógeno. Las muestras, con un peso entre $5-8 \mathrm{mg}$, se sellan en cápsulas de aluminio estándar previamente agujereadas. La velocidad de ensayo se fija en $10^{\circ} \mathrm{C} / \mathrm{min}$ para 3 rampas de temperatura:

i. Un primer barrido de -100 a $200{ }^{\circ} \mathrm{C}$ para eliminar la historia térmica del material

ii. Un barrido de enfriamiento hasta alcanzar $-100{ }^{\circ} \mathrm{C}$ para evaluar la cristalización del material

iii. Un segundo barrido de calentamiento para evaluar la fusión de la muestra analizada. El flujo de energía normalizado $(\mathrm{W} / \mathrm{gr})$ se obtiene en función de la temperatura y el tiempo.

A partir de las curvas calorimétricas se determinan las transiciones térmicas de primer y seudo-segundo orden; temperatura y entalpía de fusión ( $T f$ y $\Delta H f$ ), temperatura y entalpía de cristalización $(T c$ y $\Delta H c)$ y temperatura de transición vítrea $(T g)$.

\section{c) Ensayos de tensión}

Los ensayos de tensión se han realizado siguiendo la normativa ASTM 882D [10]. Las muestras ensayadas para ambas series de biocomposites y para las matrices puras son rectangulares, con unas dimensiones de 70x5x1 mm. 
El Mater-Bi NF y sus biocomposites han sido testados bajo condiciones atmosféricas a $23^{\circ} \mathrm{C}$ y $50 \%$ de humedad relativa en un equipo de ensayos electromecánicos Instron 5566 universal (Instron Corporation, MA, USA), empleando una carga de $100 \mathrm{~N}$ y una velocidad de $1 \mathrm{~mm} / \mathrm{min}$. La rotura por tensión se ha monitorizado durante los ensayos usando una cámara digital; las imagenes fueron analizadas mediante el programa Image J (Leica, Germany).

Los materiales compuestos de Mater-Bi KE se ensayaron en un equipo electromecánino Instron 4204 (Instron Corporation, MA, USA), empleando una carga de $1000 \mathrm{~N}$ y una velocidad de $0,5 \mathrm{~mm} / \mathrm{min}$.

El módulo de Young, la tensión a rotura y la tensión a carga máxima han sido evaluados para ambas matrices puras y sus respectivos composites.

\section{d) Análisis termo-mecánico-dinámico (DMTA)}

Las medidas viscoelásticas del Mater-Bi KE y los biocomposites Mater-Bi KE/algodón, Mater-Bi KE/kenaf, Mater-Bi KE/cáñamo, Mater-Bi KE/yute y Mater-Bi KE/lino se han realizado en un analizador termo-mecánico-dinámico MARK IV (Rheometric Scientifics, Alemania). Se han realizado medidas isotermas en barridos multifrecuencias de $0,1 \mathrm{~Hz}$ a $100 \mathrm{~Hz}$ tomando 4 frecuencias por década. En el intervalo de temperaturas de $-100 \mathrm{a}$ $25^{\circ} \mathrm{C}$ las medidas se han realizado cada $2{ }^{\circ} \mathrm{C}$, mientras que en el intervalo de 25 a $85^{\circ} \mathrm{C}$ las medidas han sido tomadas cada $4{ }^{\circ} \mathrm{C}$.

El comportamiento termo-mecánico-dinámico de las muestras se ha estudiado en términos de módulo de almacenamiento $\left(E^{\prime}\right)$, módulo de pérdidas $\left(E^{\prime}\right)$ y tangente de pérdidas $\left(\tan \delta=E^{\prime \prime} / E^{\prime}\right)$.

\section{e) Cromatografía de gases (CG)}

La cromatografía de gases se ha usado para analizar la fase orgánica de las fibras naturales y determinar la composición química de las fibras naturales. Para ello, se ha utilizado un cromatógrafo Hewlett-Packard HP-6890, equipado con una columna capilar BP X70 de dimensiones $12 \mathrm{mx} 0,32 \mathrm{~mm}$ ID (SGE Analytical Science) a $210{ }^{\circ} \mathrm{C}$, con helio como 
gas portador y con inositol como patrón interno (1250 mg inositol en $25 \mathrm{~mL}$ de agua destilada). La temperatura de inyección se fijó en $230{ }^{\circ} \mathrm{C}$ y la temperatura de detección en $250{ }^{\circ} \mathrm{C}$. Las curvas de calibración de cada monómero analizado (glucosa, manosa, xilosa, arabinosa y galactosa), se han determinado a partir de una disolución de mezcla de azucares patrones. Los picos obtenidos para cada muestra se han cuantificado mediante el cálculo de sus áreas y con la ayuda de las curvas de calibración definidas.

\section{f) Análisis infrarrojos (FTIR)}

Los espectros de infrarojos de la supeficie de las muestras poliméricas se han obtenido mediante un espectrometro FTIR, Spectrum 2000 de Perkin Elmer (Wellesley, MA) equipado con un accesorio Golden Gate de una sola refracción para el cálculo de las medidas de la refracción total atenuada (ATR).

Cada espectro se obtiene a partir de 24 barridos entre $4000 \mathrm{~cm}^{-1}$ y $600 \mathrm{~cm}^{-1}$ en intervalos de $1 \mathrm{~cm}^{-1}$. Mediante el programa Omnic 9 se realizó la corrección automática de la línea base y el suavizado de los espectros.

\section{g) Microscopia electrónica de barrido (SEM)}

Las micrografias de la superficie de la sección de fractura de cada muestra se han tomado con un microscopio eléctronico de barrido JEOL Ltd., Japan. Previamente, las muestras se rociaron con una aleación de oro/paladio y su fractura se ha realizado tras crionizar la muestra con nitrógeno líquido. 


\subsection{METODOLOGÍA DE ANÁLISIS}

\subsubsection{Composición química de las fibras naturales}

a) Descripción de la metodología propuesta para determinar el contenido de lignina, hemicelulosa y celulosa en las fibras naturales

Las fibras naturales (algodón, cáñamo, kenaf, lino y yute) se someten a un proceso de hidrólisis ácida, siguiendo el protocolo descrito por Theander y col. [3]. Para ello, en primer lugar se determina la humedad de cada una de las fibras mediante un analizador Mettler Toledo HB43 (Columbus, OH). A continuación, a $250 \mathrm{mg}$ de muestra seca se añaden $3 \mathrm{~mL}$ de ácido sulfúrico $\left(\mathrm{H}_{2} \mathrm{SO}_{4}\right)$ al $72 \%$ y se diluyen en $84 \mathrm{~mL}$ de agua destilada, la mezcla se deja reposar durante $45 \mathrm{~min}$ en un desecador a vacío. Finalmente, la hidrólisis se produce en un autoclave a $125^{\circ} \mathrm{C}$ durante $60 \mathrm{~min}$.

Tras la hidrólisis ácida, las muestras se filtran con agua caliente, originando dos tipos de productos: un líquido filtrado y un residuo sólido. El líquido filtrado se coloca en un vial de $100 \mathrm{~mL}$ junto a $1 \mathrm{~mL}$ de solución de standard interno (1250 mg inositol en $25 \mathrm{~mL}$ de agua destilada) y se enrasa con agua destilada. Estas muestras se guardan para el análisis de los azúcares libres. Por otra parte, el residuo filtrado se lava repetidamente con agua destilada fría y después se seca en una estufa Heraus B6 a $105{ }^{\circ} \mathrm{C}$ durante 24 h. De este residuo seco, se obtiene el porcentaje de lignina de cada fibra natural.

\section{Determinación del contenido de lignina en las fibras naturales}

El residuo sólido seco de la hidrólisis ácida esta constituido por el contenido en lignina y el contenido inorgánico de las fibras naturales,

$$
\text { Lignina Klason }+ \text { cenizas }=\frac{P}{M}(\%)
$$

donde $M$ es la masa inicial seca de la fibra natural y $P$ es la masa del residuo sólido filtrado y secado tras la hidrólisis ácida. 
Para obtener el contenido en lignina de cada muestra, se determina el porcentaje de cenizas mediante la norma Tappi 211 om-85 [5]. Para ello, se pesan $200 \mathrm{mg}$ de cada una de las fibras, que se depositan en crisoles limpios de porcelana y se mantienen en la mufla durante $6 \mathrm{~h}$ a $575^{\circ} \mathrm{C}$. Los crisoles se limpian con ácido clorhídrico durante $1 \mathrm{~h}$ a $575^{\circ} \mathrm{C}$.

De este modo, al residuo seco de cada fibra se le restan las cenizas resultantes y así se obtiene el contenido en lignina de cada fibra natural (ecuación 3).

$$
\text { Lignina Klason }=\frac{P-P^{\prime}}{M}(\%)
$$

donde $P^{\prime}$ es el porcentaje de las cenizas resultantes tras la pirólisis a $575^{\circ} \mathrm{C}$.

\section{Determinación de la composición de polisacáridos (hemicelulosa y celulosa) en las fibras naturales}

Siguiendo el protocolo modificado de Theander y col. [3], el líquido filtrado tras la hidrólisis ácida se reduce, y posteriormente se acetila para conseguir obtener alditoles detectables por cromatografía (Figura 2.1). Para ello:

i. Una alícuota de $1 \mathrm{~mL}$ de la muestra líquida hidrolizada de cada fibra natural se vierte en un tubo de ensayo de $10 \mathrm{~mL}$. A continuación se añaden $0,5 \mathrm{~mL}$ de solución de hidróxido amónico $\left[\mathrm{NH}_{4}(\mathrm{OH})\right] 12 \mathrm{M}$, consiguiendo un pH básico. La reducción se lleva a cabo con la adición de $0,2 \mathrm{~mL}$ de una solución de borohidruro de potasio $\left[\mathrm{K}\left(\mathrm{BH}_{4}\right)\right] 7,5 \mathrm{M}$ en agua caliente. Una hora después, las muestras se neutralizan con ácido acético concentrado $\left[\mathrm{CH}_{3} \mathrm{COOH}\right]$.

ii. La acetilación se realiza sobre $0,5 \mathrm{~mL}$ de la muestra neutralizada en un tubo de ensayo de $20 \mathrm{~mL}$ a $0{ }^{\circ} \mathrm{C}$, donde se adicionan $0,5 \mathrm{~mL}$ de 1 -metilimidazol $\left[\mathrm{C}_{4} \mathrm{H}_{5} \mathrm{~N}_{2}\right]$, $5 \mathrm{~mL}$ de anhídrido acético $\left[\left(\mathrm{CH}_{3} \mathrm{CO}_{2}\right) \mathrm{O}\right], 2 \mathrm{~mL}$ de etanol absoluto puro $\left[\mathrm{CH}_{3} \mathrm{CH}_{2} \mathrm{OH}\right], 4 \mathrm{~mL}$ de agua destilada fría, y $5 \mathrm{~mL}$ de hidróxido potásico $[\mathrm{KOH}]$ 7,5M. La solución resultante se deja reposar durante $5 \mathrm{nmin}$, apareciendo dos fases, una fase orgánica y otra inorgánica. 


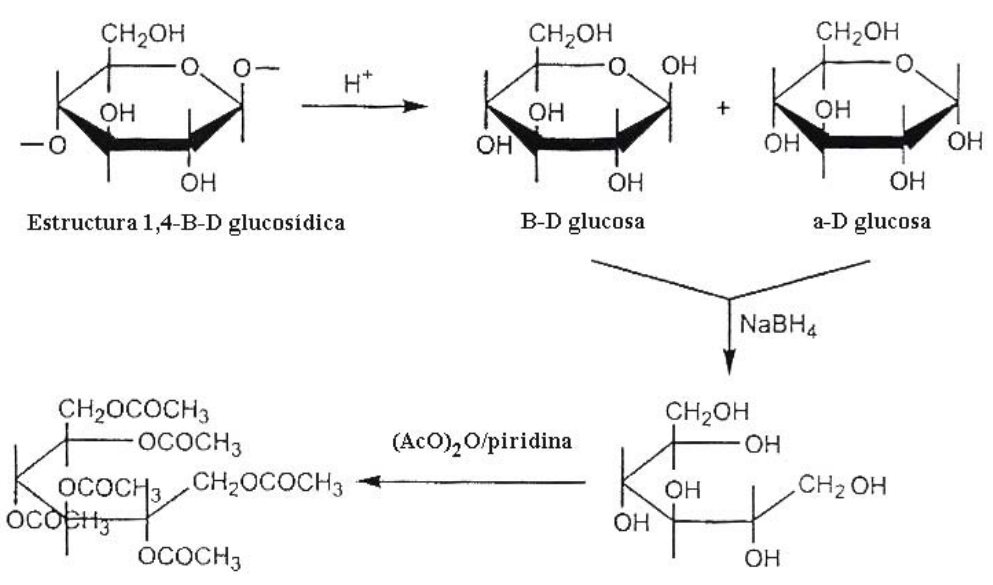

Figura 2.1. Secuencia de las reacciones de formación de alditoles a partir de la estructura de un polisacárido, mediante hidrólisis ácida, reducción con borohidruro potásico y acetilación [11].

A partir de la fase orgánica se determina la cantidad de cada monómero neutro (glucosa, manosa, xilosa, arabinosa y galactosa) presente en cada muestra de fibra natural mediante Análisis Cromatográfico. Los monómeros de glucosa determinarán el porcentaje de celulosa de cada fibra natural, mientras que la suma de los monómeros de manosa, xilosa, arabinosa y galactosa se asignará al porcentaje de hemicelulosa y pectina de cada fibra.

Para obtener las curvas de calibración de cada monómero, se prepara una disolución con diferentes concentraciones de azucares patrón: glucosa, manosa, xilosa, arabinosa y galactosa. Al igual que en las muestras de las fibras naturales, esta disolución de mezcla de patrones se hidroliza con ácido sulfúrico $\left[\mathrm{H}_{2} \mathrm{SO}_{4}\right]$ y se enrasa con agua destilada a $100 \mathrm{~mL}$. De esta disolución se extraen cinco volúmenes diferentes $(9 / 18 / 24 / 30 / 38 \mathrm{~mL})$ a los que se les añade $1 \mathrm{~mL}$ de patrón interno estándar en un tubo de ensayo de $100 \mathrm{~mL}$ que después, se enrasa con agua destilada. El proceso de reducción y acetilación para las distintas concentraciones de la disolución de mezcla de patrones es análogo al descrito anteriormente para las fibras naturales; la fase orgánica de estas muestras se analiza por cromatografía, y se construye una recta de calibrado a partir de las áreas de pico obtenidas para cada monómero en cada una de las concentraciones de mezcla, de forma que el valor de área del monómero detectado por cromatografía se corresponda con una concentración determinada. 


\section{b) Fundamentos teóricos}

Para el cálculo de las rectas de calibración, los valores promedios de los picos de los espectros de las disoluciones patrón $(A x)$, se normalizan con el valor del área del standard interno $(A i)$, y se representan en función de la concentración de monómero de cada disolución $(m x)$.

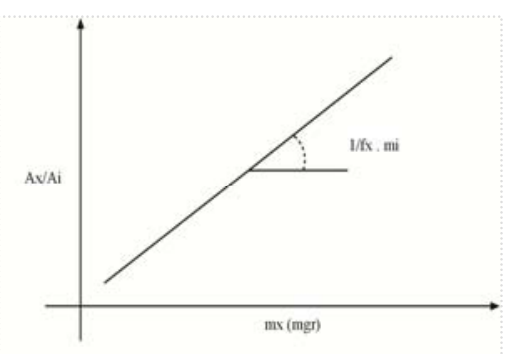

Figura 2.2. Construcción de la recta de calibrado de los monómeros

Conociendo las pendientes de las curvas de calibrado (1/fx.mi) se determinan tanto los valores relativos como absolutos de los monómeros que constituyen los distintos polisacáridos de las fibras naturales [3].

$$
X(\%)=100 \cdot \frac{f x \cdot A x \cdot m i}{\sum_{n} f x_{n} \cdot A x_{n}}
$$

donde, $X$ es el porcentaje del monómero estudiado, $m i$ la masa del patrón standard y $n$ el número de picos detectados por cromatografía.

Para el cálculo de los valores absolutos de los monómeros de las fibras naturales se propone la ecuación 5;

$$
m x=F \cdot f x \cdot m i \frac{A x}{A i}
$$

donde $F$ es un factor de corrección, que va a depender del monómero estudiado, así, para la arabinosa y la xilosa $F=0,88$ y para la galactosa, manosa y glucosa $F=0,9$. 


\section{c) Aplicación de la metodología}

La fase orgánica resultante de la reducción y acetilación del líquido residual de la hidrólisis ácida de las fibras naturales y de las muestras de la disolución de monómeros patrón, se analizan por cromatografía de gases.

Los espectros de todas las muestras analizadas contienen seis picos, a seis tiempos de detección diferentes correspondientes a los cinco monómeros y al standard interno. El área de cada pico $(A x)$ se calcula directamente del programa del equipo. En primer lugar se calculan las áreas de los picos de las muestras de mezcla de azucares patrón, para poder construir las curvas de calibración (Figura 2.3)
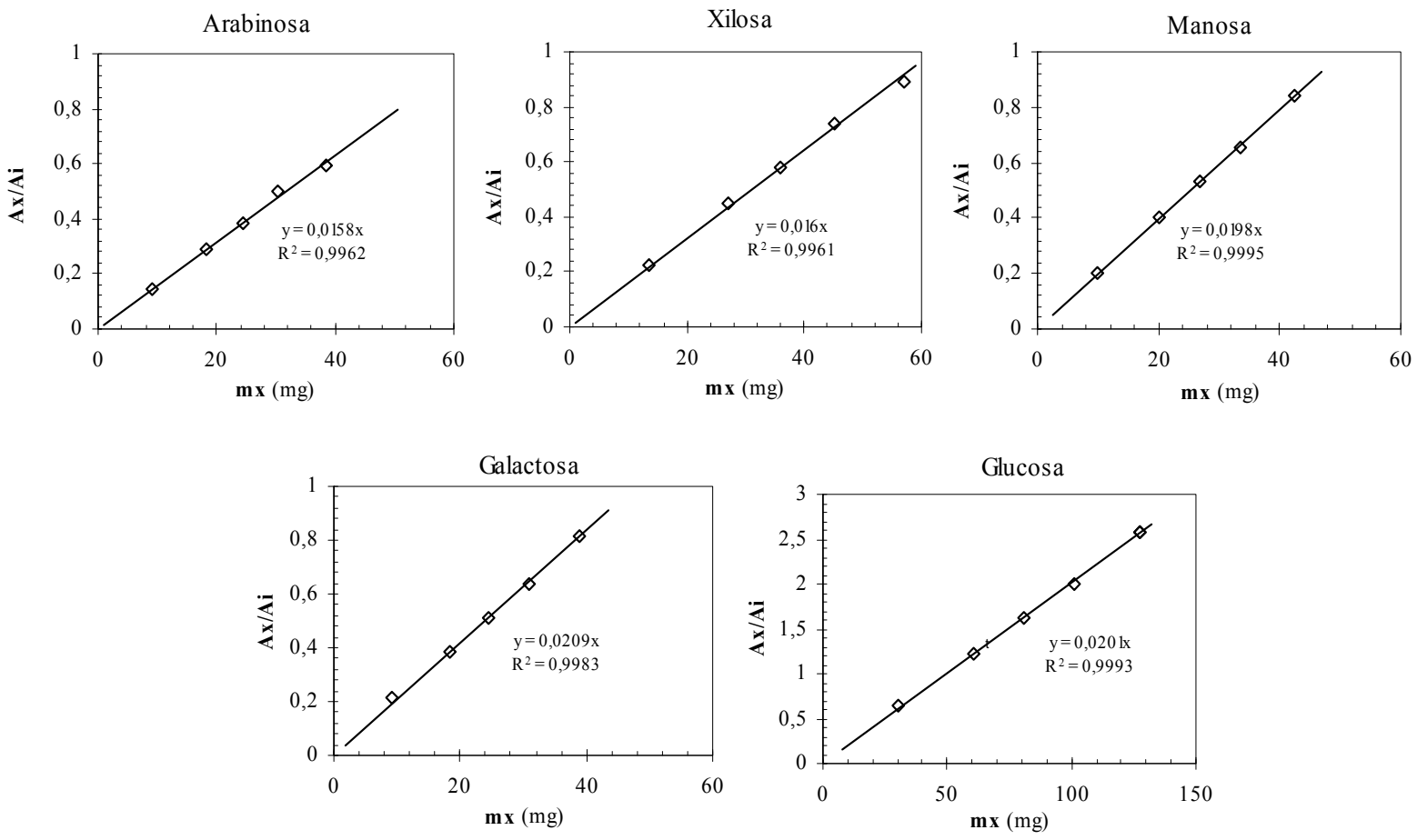

Figura 2.3. Curvas de calibración de los cinco monómeros constituyentes de los polisacáridos de las fibras naturales

De los espectrogramas de las muestras de fibras naturales, se han calculado los valores de las áreas de cada pico y se ha promediado su valor. Aplicando la metodología de análisis propuesta para el calculo absoluto y relativo del contenido de las fibras naturales, se obtienen los valores clasificados en las Tablas 2.5 y 2.6, respectivamente. La desviación de todos estos valores es de un $1 \%$.

Tabla 2.5. Porcentaje relativo de monómeros de las fibras naturales estudiadas 


\begin{tabular}{c|ccccc}
\hline & $\begin{array}{c}\text { Arabinosa } \\
(\%)\end{array}$ & $\begin{array}{c}\text { Xilosa } \\
(\%)\end{array}$ & $\begin{array}{c}\text { Manosa } \\
(\%)\end{array}$ & $\begin{array}{c}\text { Galactosa } \\
(\%)\end{array}$ & $\begin{array}{c}\text { Glucosa } \\
(\%)\end{array}$ \\
\hline Algodón & $<1,0$ & $<1,0$ & $<1,0$ & $<1,0$ & 97,4 \\
Lino & $<1,0$ & 7,6 & 1,5 & $<1,0$ & 90,0 \\
Cáñamo & 4,2 & 3,4 & 6,3 & 3,0 & 83,0 \\
Kenaf & 1,3 & 22,5 & 2,3 & 1,6 & 72,3 \\
Yute & $<1,0$ & 12,3 & $<1,0$ & 3,6 & 83,9 \\
\hline
\end{tabular}

Tabla 2.6. Porcentaje absoluto de monómeros de las fibras naturales estudiadas

\begin{tabular}{c|ccccc}
\hline & $\begin{array}{c}\text { Arabinosa } \\
(\%)\end{array}$ & $\begin{array}{c}\text { Xilosa } \\
(\%)\end{array}$ & $\begin{array}{c}\text { Manosa } \\
(\%)\end{array}$ & $\begin{array}{c}\text { Galactosa } \\
(\%)\end{array}$ & $\begin{array}{c}\text { Glucosa } \\
(\%)\end{array}$ \\
\hline Algodón & $<1,0$ & $<1,0$ & $<1,0$ & $<1,0$ & 95,0 \\
Lino & $<1,0$ & 6,9 & 1,3 & $<1,0$ & 81,0 \\
Cáñamo & 3,6 & 2,9 & 5,5 & 3,5 & 72,1 \\
Kenaf & 1,0 & 19,5 & 2,0 & 1,4 & 62,7 \\
Yute & $<1,0$ & 11,1 & $<1,0$ & 3,3 & 75,6 \\
\hline
\end{tabular}

La manosa, galactosa, xilosa y arabinosa son monómeros presentes en la hemicelulosa, del mismo modo, la manosa y la arabinosa pueden estar presentes en la composición de las pectinas, por tanto a partir de la suma de estos monómeros se obtiene el contenido en hemicellulosa y pectina de las fibras naturales. La celulosa es un polímero de glucosa, por tanto el contenido en glucosa se puede relacionar con el contenido en celulosa de las fibras naturales. Si a los porcentajes de lignina se le suman los valores de hemicelulosa y celulosa, se obtiene la composición química de las fibras naturales (Tabla 2.7).

Tabla 2.7. Composición química de las fibras naturales secas

\begin{tabular}{c|cccc}
\hline & $\begin{array}{c}\text { Hemicelulosa/ } \\
\text { pectina }(\%)\end{array}$ & $\begin{array}{c}\text { Celulosa } \\
(\%)\end{array}$ & $\begin{array}{c}\text { Lignina } \\
(\%)\end{array}$ & $\begin{array}{c}\text { Ceniza } \\
(\%)\end{array}$ \\
\hline Algodón & 2,5 & 95,4 & -- & 2,0 \\
Lino & 8,9 & 80,6 & 3,0 & 7,4 \\
Cañamo & 13,8 & 74,2 & 5,8 & 6,2 \\
Kenaf & 24,0 & 62,8 & 12,1 & 1,2 \\
Yute & 14,6 & 75,6 & 7,0 & 2,8 \\
\hline
\end{tabular}




\subsubsection{Análisis Termogravimétrico}

Según la I.C.T.A, el Análisis Termogravimétrico ó la Termogravimetría se define como la técnica de análisis térmico en la que la masa de una sustancia se mide en función de la temperatura, bajo un programa controlado de temperatura y tiempo.

La Termogravimetría es una técnica analítica óptima para estudiar la estabilidad térmica de los sistemas poliméricos [12,13]. El estudio de los parámetros termogravimétricos, permite el análisis de la composición de las mezclas, de la determinación de las cargas en formulaciones compleja y además, proporciona un indicativo de la temperatura máxima que puede usarse en el procesado del material. La caracterización de la descomposición térmica de estos sistemas ayuda a optimizar las condiciones de procesado de los biocomposites diseñados. Por otra parte, el análisis cinético de cada proceso de descomposición permite determinar parámetros como la Ea que monitorizan el proceso de degradación en tierra [14].

\section{a) Fundamentos teóricos del estudio cinético de la descomposición térmica}

La descomposición térmica de un material polimérico se puede representar genéricamente por la siguiente reacción:

$$
A_{\text {sólido }} \rightarrow B_{\text {sólido }}+C_{\text {gas }}
$$

El estudio cinético de una reacción química presenta diversos aspectos. Uno de ellos se refiere al estudio de las leyes cinéticas fenomenológicas que rigen la velocidad de las reacciones en función de las concentraciones de reactivos o productos, la temperatura, etc. Un segundo aspecto se concreta al definir la forma con la que las constantes de velocidad dependen de la temperatura.

La ecuación de velocidad que describe el grado de descomposición térmica, se expresa mediante una función matemática que depende de la temperatura absoluta $(T)$ y del grado de conversión $(\alpha)$.

$$
\frac{d \alpha}{d t}=f(\alpha) k(T)
$$


donde $\alpha$ se define, según la ecuación 8 , como la pérdida de masa en un tiempo $\mathrm{t}$ $\left(w_{0}-w\right)$, dividido por la pérdida de masa total $\left(w_{0}-w_{\infty}\right)$, siendo la masa inicial $\left(w_{0}\right)$, la masa final $\left(w_{\infty}\right)$ y la masa en un tiempo determinado, $(w)$. La función del grado de conversión es por tanto $(f(\alpha))$.

$$
\alpha=\frac{\omega_{o}-\omega}{\omega_{o}-\omega_{\infty}}
$$

Por otro lado, el modelo casi universal que se acepta para ajustar y modelizar la dependencia de la velocidad de la reacción con la temperatura en un proceso de degradación, es la ecuación de Arrhenius:

$$
K(T)=A \cdot \exp \left(\frac{-E a}{R T}\right)
$$

donde, $R$ es la constante universal de los gases, $T$ es la temperatura absoluta, Ea es la energía de activación y $A$ es el factor pre-exponencial.

Los análisis termogravimétricos se pueden realizar de forma isoterma, donde se define la velocidad como $\beta=\frac{d T}{d t}$. Considerando esta constante y combinando las ecuaciones 7,8 y 9 se llega a la siguiente ecuación,

$$
\frac{d \alpha}{d T}=\frac{A}{\beta} \cdot \exp \left(\frac{-E a}{R T}\right) f(\alpha)
$$

Integrando la ecuación, $\mathrm{y}$ tomando como condiciones iniciales $\mathrm{t}_{0}=\alpha_{0}$

$$
\int_{\alpha_{0}}^{\alpha_{p}} \frac{d \alpha}{f(\alpha)}=\frac{A}{\beta} \int_{T_{o}}^{T_{p}} \exp \left(\frac{-E a}{R T}\right) d T
$$

Si se toma $\alpha_{0}=0$, se obtiene la función de conversión integral $(g(\alpha))$

$$
g(\alpha)=\int_{0}^{\alpha_{p}} \frac{d \alpha}{f(\alpha)}=\frac{A}{\beta} \int_{0}^{T_{p}} \exp \left(\frac{-E a}{R T}\right) d T
$$


Las funciones algebraicas empleadas más frecuentemente para definir la función diferencial $f(\alpha)$ e integral $g(\alpha)$ se muestran en la Tabla 2.8.

Tabla 2.8. Expresiones algebraicas de la función diferencial f(a) y la función integral g(a) para los procesos en estado sólido más habituales.

\begin{tabular}{|c|c|c|c|}
\hline Modelos & $f(\alpha)$ & $g(\alpha)$ & Procesos en estado sólido \\
\hline $\mathbf{A}_{2}$ & $2(1-\alpha)[-\ln (1-\alpha)]^{-1}$ & {$[-\ln (1-\alpha)]^{1 / 2}$} & $\begin{array}{l}\text { Nucleación y crecimiento } \\
\text { (Avrami 1) }\end{array}$ \\
\hline $\mathbf{A}_{3}$ & $3(1-\alpha)[-\ln (1-\alpha)]^{-1 / 2}$ & {$[-\ln (1-\alpha)]^{1 / 3}$} & $\begin{array}{l}\text { Nucleación y crecimiento } \\
\text { (Avrami 2) }\end{array}$ \\
\hline $\mathbf{A}_{4}$ & $4(1-\alpha)[-\ln (1-\alpha)]^{-1 / 3}$ & {$[-\ln (1-\alpha)]^{1 / 4}$} & $\begin{array}{l}\text { Nucleación y crecimiento } \\
\text { (Avrami 3) }\end{array}$ \\
\hline $\mathbf{R}_{\mathbf{1}}$ & 1 & $\alpha$ & $\begin{array}{l}\text { Reacción controlada en la interfase } \\
\text { (movimiento unidimensional) }\end{array}$ \\
\hline $\mathbf{R}_{\mathbf{2}}$ & $2(1-\alpha)^{1 / 2}$ & {$\left[1-\ln (1-\alpha)^{1 / 2}\right]$} & $\begin{array}{l}\text { Reacción controlada en la interfase } \\
\text { (contracción de área) }\end{array}$ \\
\hline $\mathbf{R}_{\mathbf{3}}$ & $3(1-\alpha)^{2 / 3}$ & {$\left[1-\ln (1-\alpha)^{1 / 3}\right]$} & $\begin{array}{l}\text { Reacción controlada en la } \\
\text { interfase } \\
\text { (contracción de volumen) }\end{array}$ \\
\hline $\mathbf{D}_{1}$ & $1 /(2 \alpha)$ & $\alpha^{2}$ & Difusión unidimensional \\
\hline $\mathbf{D}_{2}$ & $-1 / \ln (1-\alpha)$ & $(1-\alpha) \ln (1-\alpha)+\alpha$ & Difusión bidimensional \\
\hline $\mathbf{D}_{3}$ & $3(1-\alpha)^{2 / 3} / 2\left[1-(1-\alpha)^{1 / 3}\right]$ & {$\left[1-\ln (1-\alpha)^{1 / 3}\right]^{2}$} & Difusión tridimensional \\
\hline $\mathbf{F}_{1}$ & $1-\alpha$ & $-\ln (1-\alpha)$ & $\begin{array}{l}\text { Nucleación aleatoria con un } \\
\text { núcleo en la partícula individual. }\end{array}$ \\
\hline $\mathbf{F}_{2}$ & $(1-\alpha)^{2}$ & $1 /(1-\alpha)$ & $\begin{array}{l}\text { Nucleación aleatoria con dos } \\
\text { núcleos en la partícula individual. }\end{array}$ \\
\hline $\mathbf{F}_{3}$ & $1 / 2(1-\alpha)^{3}$ & $1 /(1-\alpha)^{2}$ & $\begin{array}{l}\text { Nucleación aleatoria con tres } \\
\text { núcleos en la partícula individual. }\end{array}$ \\
\hline PT & $\alpha(1-\alpha)$ & $\ln (\alpha / 1-\alpha)$ & $\begin{array}{l}\text { Modelo de auto catálisis Prout- } \\
\text { Tompkins, el crecimiento ocurre } \\
\text { por un mecanismo de ruptura de } \\
\text { cadenas }\end{array}$ \\
\hline
\end{tabular}

\section{b) Descripción de la metodología propuesta para analizar los datos termogravimétricos}

\section{Determinación de los parámetros termogravimétricos}

A partir de los termogramas obtenidos se identifican las diferentes regiones de pérdidas de masa de cada material y se calculan los parámetros termogravimétricos que las definen: pérdida de masa (\%), onset ó temperatura inicial de descomposición $\left({ }^{\circ} \mathrm{C}\right)$, temperatura máxima de pico $\left({ }^{\circ} \mathrm{C}\right)$ y residuo $(\%)$. De este modo, se identifica el porcentaje de los diferentes componentes, la estabilidad térmica y el residuo del material estudiado. 


\section{Determinación de la cinética de cada proceso de descomposición}

A continuación, a partir de los datos termogravimétricos, se estudia la cinética de cada proceso de descomposición térmica mediante una metodología de análisis precisa y eficaz:

i. Se aplica un método de deconvolución sobre la curva termogravimétrica diferencial (DTG) para la separación de cada proceso de descomposición.

ii. A partir de los métodos isoconversionales de Friedman [15] y Flynn-WallOzawa [16] se obtienen los valores de energía de activación (Ea).

iii. A continuación, se usa el método de Kissinger [17] para cotejar los valores de Ea obtenidos. Este método se propone, por ser de los tres el más sencillo e igualmente eficaz.

iv. El método de Criado [18] permite seleccionar de entre una serie de modelos cinéticos $(f(\alpha))$, aquel ó aquellos que mejor ajusten a los datos experimentales de descomposición térmica de cada proceso.

v. Finalmente, el método de Coats-Redfern [19] se usa para calcular los valores de $E a$ a partir de los modelos cinéticos elegidos y seleccionar de todos ellos el que ofrezca la $E a$ más similar a la obtenida mediante los métodos isoconversionales y de Kissinger. Una vez determinada la función cinética $f(\alpha)$ se calcula el factor pre-exponencial (A) mediante el método de Flynn-Wall-Ozawa y CoatsRedfern, completando la tripleta cinética de cada proceso de descomposición.

a) Método de deconvolución para separar los procesos de descomposición

El método de deconvolución propuesto permite obtener el grado de conversión en función de la temperatura ó el tiempo, de cada proceso por separado y discernir con claridad la temperatura máxima de cada contribución aunque ésta se encuentre solapada a otro proceso. Para ello, cada contribución individual de la curva diferencial del termograma estudiado se representa de acuerdo con la siguiente ecuación asimétrica:

$$
y_{i}=A \cdot\left(\frac{1}{1+\exp \left(\frac{-\left(x-x_{c}+\frac{w_{1}}{2}\right)}{w_{2}}\right)}\right) \cdot\left(1-\frac{1}{1+\exp \left(\frac{-\left(x-x_{c}+\frac{w_{1}}{2}\right)}{w_{3}}\right)}\right.
$$


donde $x_{c}$ es un parámetro de posición relativo a la temperatura máxima de la curva, $A$ es un parámetro de amplificación y $w_{1}, w_{2}, w_{3}$ son parámetros asociados con la dispersión y la simetría de la curva. Este módelo de deconvolución propuesto, considera que los valores medidos de $(d w(\%) / d T)=y$, y a su vez que $y=y_{0}+\sum_{i=1}^{n} y_{i}$, donde $y_{0}$ es la línea base de cada curva DTG y $n$ es el número total de los picos a deconvolucionar.

b) Determinación de la Energía de Activación (Ea) y del factor pre-exponencial (A)

o Método de Friedman. Método isoconversional diferencial que se basa en la ecuación 10

$$
\ln \left(\frac{d \alpha}{d t}\right)=\ln A f(\alpha)-\frac{E a}{R T}
$$

La Ea se calcula a partir de la pendiente de los gráficos isoconversionales al representar $\ln \left(\frac{d \alpha}{d t}\right)$ vs 1/T para grados de conversión fijos.

o Método de Flynn-Wall-Ozawa. Método isoconversional integral que se define a partir de la Ecuación 12, tomando logaritmos y usando la aproximación de Doyle [20].

$$
\log \beta=\log \frac{A E a}{g(\alpha) R}-2.315-0.4567 \cdot\left(\frac{E a}{R T}\right)
$$

Los valores de $E a$ pueden calcularse a partir del gráfico que representa $\log \beta$ vs $1 /$ T para un grado de conversión determinado.

o Método de Kissinger. Método integral no isoconversional definido a partir de la reordenación de la Ecuación 12, asumiendo que $\left(\frac{2 R T}{E}\right) \rightarrow 0$ y que $T=\operatorname{Tmax}$, siempre que este pico máximo de descomposición se produzca bajo el mismo grado de conversión para todas las velocidades de calentamiento consideradas.

$$
\ln \frac{\beta}{{T_{\max }}^{2}}=\ln \frac{A R}{g(\alpha) E a}-\frac{E a}{R T_{\max }}
$$

La representación de $\ln \frac{\beta}{T^{2}}$ vs $1 / T$ permite determinar la $E a$ como un valor promedio del proceso de descomposición térmica. 
c) Determinación del modelo cinético que describe el mecanismo de reacción

o Método de Criado. Criado definió la ecuación $\mathrm{z}(\alpha)=f(\alpha) \mathrm{g}(\alpha)$ a partir de las ecuaciones 10 y 16.

$$
\frac{z(\alpha)}{z(0,5)} \rightarrow \frac{f(\alpha) g(\alpha)}{f(0,5) g(0,5)}=\left(\frac{T}{T_{0,5}}\right)^{2} \frac{(d \alpha / d t)}{(d \alpha / d t)_{0,5}}
$$

La parte izquierda de esta igualdad representa la curva teórica reducida que se obtiene a partir de los datos experimentales. La parte derecha de esta ecuación es la curva reducida teórica, definida a partir de los modelos propuestos en la Tabla 2.8. Los dígitos 0,5 se refieren a un valor de conversión de 0,5. Al representar en una misma gráfica las curvas reducidas teóricas (Figura 2.4) frente a la curva reducida experimental, se podría obtener una primera aproximación sobre que tipo de modelo cinético sigue el proceso de descomposición estudiado.

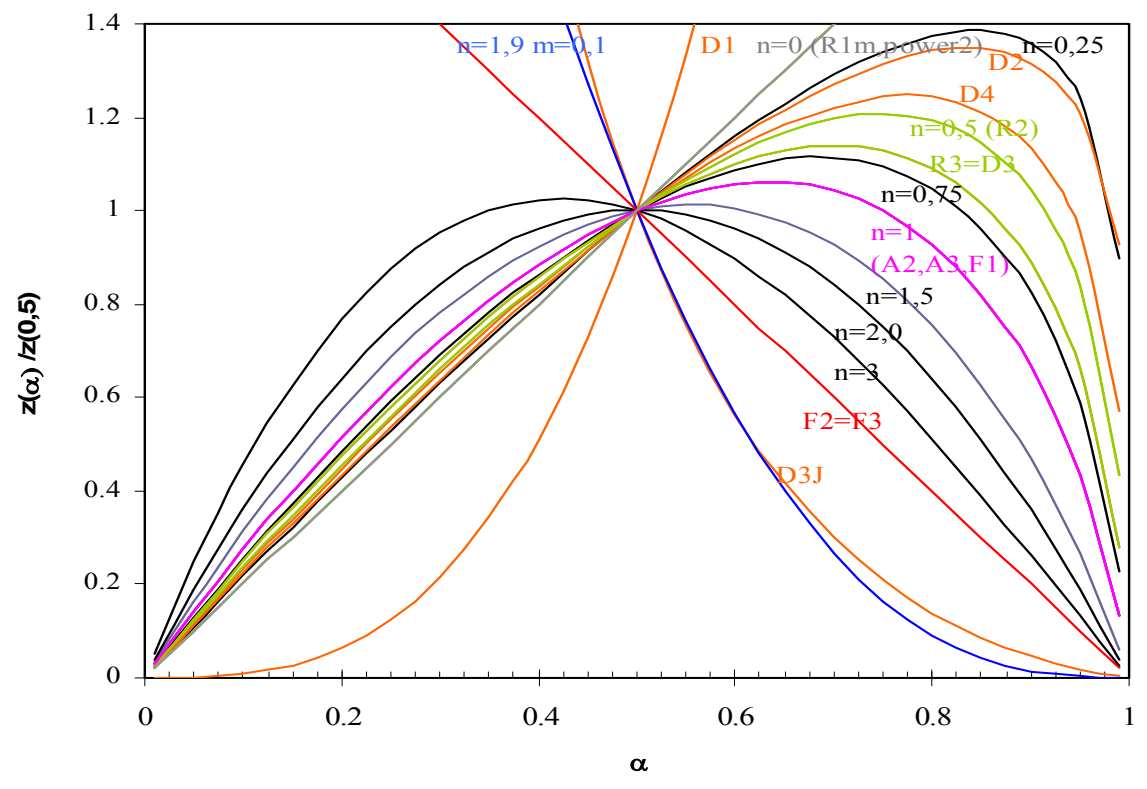

Figura 2.4. Curvas maestro reducidas de diferentes modelos cinéticos

o Método de Coats-Redfern. Método integral propuesto a partir de la ecuación 12 y asumiendo que $\left(\frac{2 R T}{E}\right) \rightarrow 0$

$$
\ln \frac{g(\alpha)}{T^{2}}=\ln \frac{A R}{\beta E a}-\frac{E a}{R T}
$$


A partir de un modelo cinético propuesto y por tanto de la función $g(\alpha)$ descrita para este modelo, la representación lineal del $\ln \frac{g(\alpha)}{T^{2}}$ vs $1 / T$ permite determinar la $E a$ y el factor $A$ a partir de la pendiente y la ordenada de origen, respectivamente.

\section{c) Aplicación de la metodología}

A continuación, se describe la metodología empleada para analizar los resultados termogravimétricos y cinéticos de todos los materiales ensayados. Como ejemplo se aplica sobre el Mater-Bi KE 03B1.

La Figura 2.5 muestra las curvas diferenciales del termograma (DTG) del Mater-Bi KE puro a diferentes velocidades de calentamiento; el Mater-Bi KE presenta una descomposición térmica compleja con dos regiones principales de pérdida de masa. La Tabla 2.9 resume los valores de los parámetros termogravimétricos de las principales regiones de pérdida de masa para las diferentes velocidades de calentamiento.

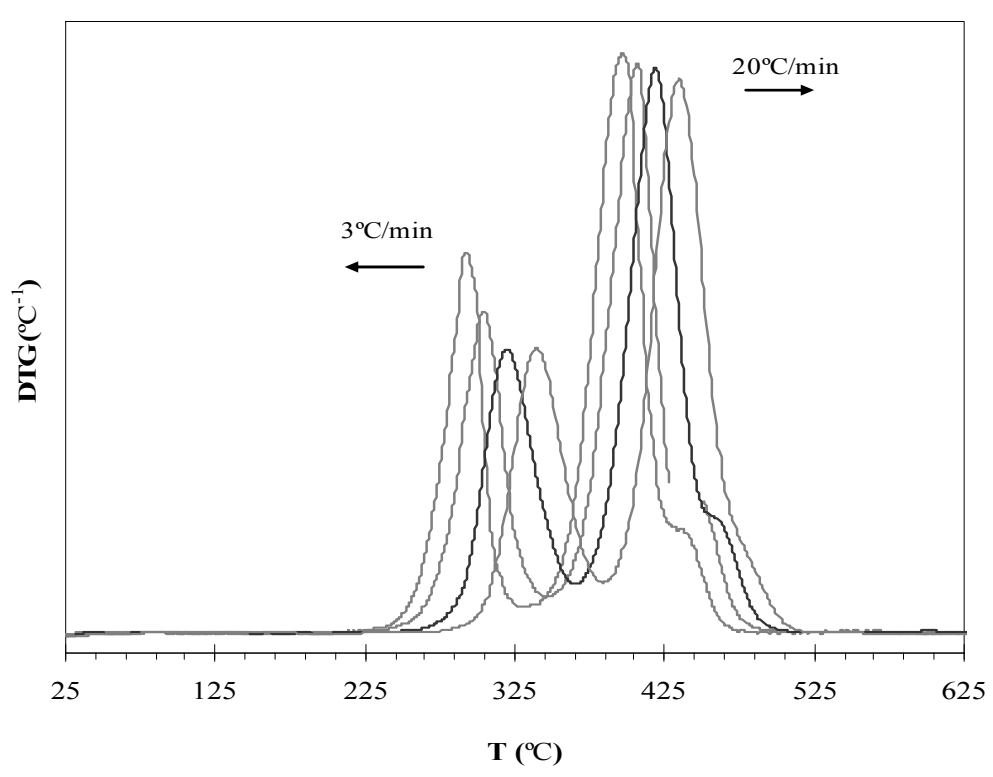

Figura 2.5. Curvas DTG del Mater Bi KE 03B1 a diferentes velocidades de calentamiento

La primera región con una pérdida de masa del 33\%, aparece centrada entre 290-350 ${ }^{\circ} \mathrm{C}$ y se atribuye a la descomposición térmica del almidón presente en el Mater-Bi KE [21-23]. La pérdida de masa que se observa en este rango de temperaturas se asocia con la descomposición de los enlaces de unión $\alpha-(1,6)$ de monómeros de glucosa o con la deshidratación del "levoglucosan $\left(\mathrm{C}_{6} \mathrm{H}_{10} \mathrm{O}_{5}\right)$ " y con la formación de otros productos volátiles, 
tales como el dióxido de carbono, monóxido de carbono, aldehídos, furanos, 2-metilfuranos y cetonas [24-26]. La segunda región de pérdida de masa, es la zona principal de descomposición con una pérdida de masa del $67 \%$, centrada alrededor de $395-440{ }^{\circ} \mathrm{C}$, y se asocia con la pirolisis del componente sintético del Mater-Bi [27].

Tabla 2.9. Parámetros termogravimétricos del Mater-Bi KE a diferentes velocidades de calentamiento

\begin{tabular}{|c|c|c|c|c|c|c|c|}
\hline \multirow{3}{*}{$\begin{array}{c}\boldsymbol{\beta} \\
\left({ }^{o} \mathrm{C} / \mathrm{min}\right)\end{array}$} & \multicolumn{3}{|c|}{$\begin{array}{c}\mathbf{1}^{\text {a }} \text { Región de pérdida masa } \\
\text { Pérdida }\end{array}$} & \multicolumn{3}{|c|}{$\begin{array}{c}2^{\mathbf{0}} \text { Región de pérdida de masa } \\
\text { Pérdida }\end{array}$} & \multirow{3}{*}{$\begin{array}{c}\text { Residuo } \\
\text { Masa } \\
(\%)\end{array}$} \\
\hline & Onset & de masa & $\operatorname{Tmax}$ & Onset & de masa & $T \max$ & \\
\hline & $\left({ }^{\circ} \mathrm{C}\right)$ & $(\%)$ & $\left({ }^{\circ} \mathrm{C}\right)$ & $\left({ }^{\circ} \mathrm{C}\right)$ & $(\%)$ & $\left({ }^{\circ} \mathrm{C}\right)$ & \\
\hline 3 & $274,5 \pm 0,7$ & $31,8 \pm 0,5$ & $292,8 \pm 1,0$ & $374,0 \pm 1,0$ & $67,8 \pm 1,0$ & $397,2 \pm 0,4$ & $1,3 \pm 0,7$ \\
\hline 5 & $285,2 \pm 1,0$ & $31,4 \pm 0,9$ & $304,5 \pm 0,7$ & $384,3 \pm 0,5$ & $66,5 \pm 0,5$ & $407,0 \pm 0,5$ & $1,5 \pm 0,6$ \\
\hline 10 & $298,9 \pm 0,5$ & $31,4 \pm 0,4$ & $319,4 \pm 0,5$ & $395,9 \pm 0,6$ & $67,0 \pm 0,5$ & $419,0 \pm 1,0$ & $1,5 \pm 0,5$ \\
\hline 20 & $319,9 \pm 0,8$ & $31,5 \pm 0,7$ & $335,5 \pm 0,6$ & $413,3 \pm 0,8$ & $66,6 \pm 0,9$ & $434,5 \pm 0,5$ & $1,2 \pm 0,5$ \\
\hline 30 & $326,0 \pm 0,6$ & $31,0 \pm 0,8$ & $351,0 \pm 0,7$ & $419,0 \pm 0,5$ & $66,6 \pm 1,0$ & $437,6 \pm 0,6$ & $1,0 \pm 1,0$ \\
\hline
\end{tabular}

La cinética de los principales procesos de descomposición térmica del Mater-Bi KE se ha estudiado siguiendo la metodología descrita. En primer lugar, los métodos que se han utilizado son: el método diferencial de Friedman y el método integral de Flynn-Wall-Ozawa. Estos métodos, permiten el cálculo de las Ea independientemente del mecanismo de degradación térmica seguido por cada proceso de descomposición [28].

Para poder aplicar el método de Friedman sobre cada proceso de descomposición, previamente se aplica el método de deconvolución descrito anteriormente.

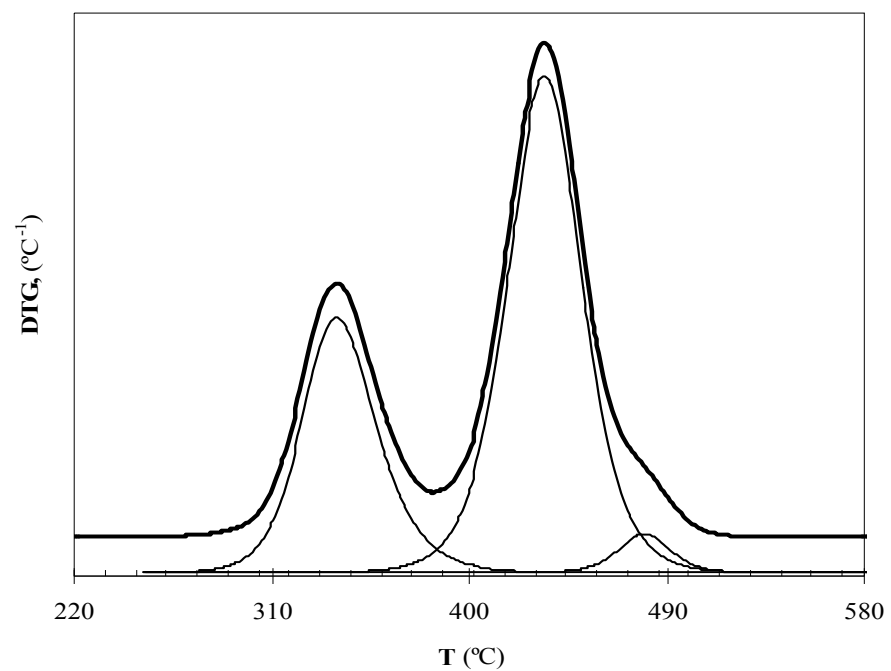

Figura 2.6. Deconvolución de la curva diferencial termogravimétrica del Mater-Bi KE. 
Una vez separados los procesos de descomposición térmica del Mater-Bi KE, se calcula el grado de conversión de cada uno de ellos (Figuras 2.7).
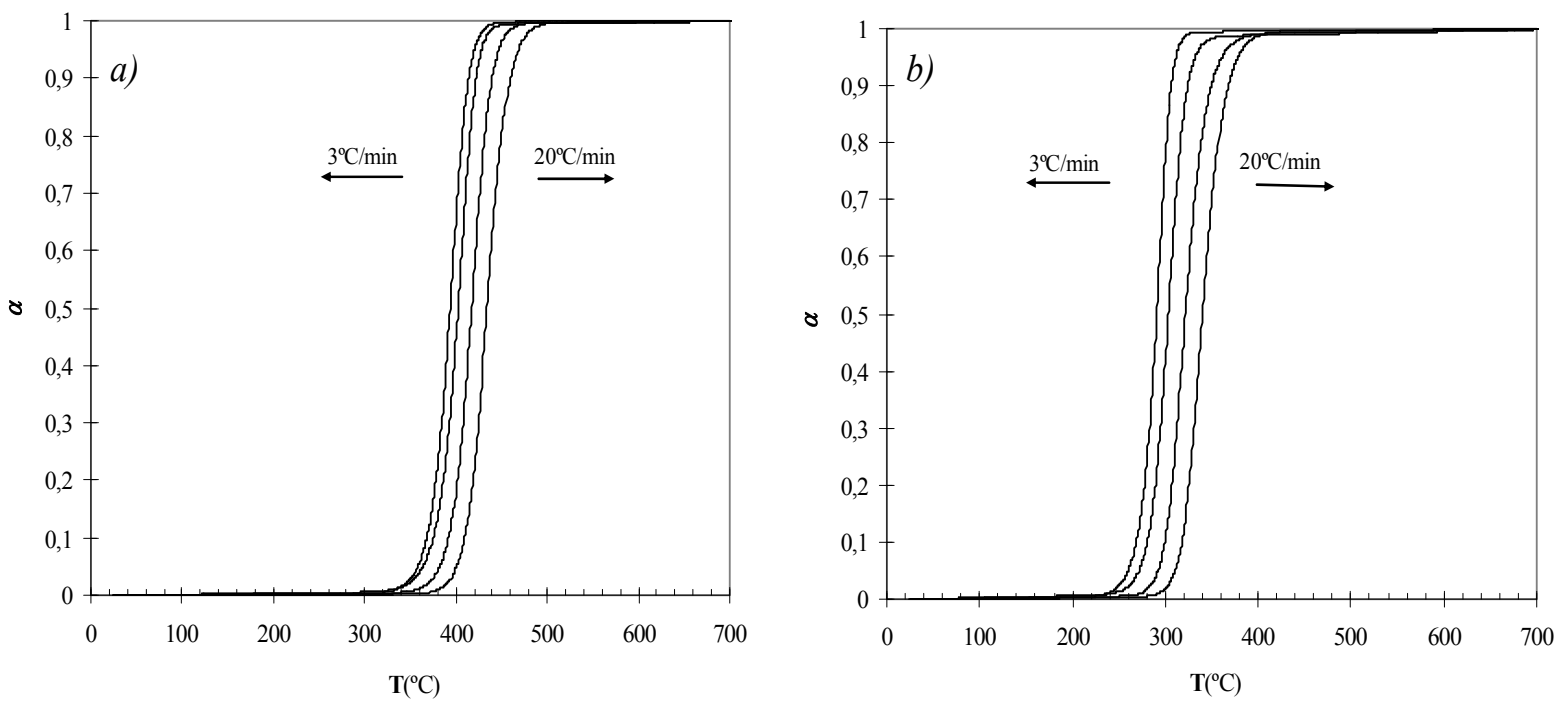

Figura 2.7. Grado de conversión del primer proceso de descomposición térmica en función de la temperatura a diferentes velocidades calentamiento a) del primer y b) del segundo proceso de descomposición térmica.

Representando la derivada de la conversión en función del tiempo frente a la inversa de la temperatura se obtienen una serie de líneas rectas que se definen para un grado de conversión constante, estas curvas son las curvas de Friedman (Figuras 2.8).
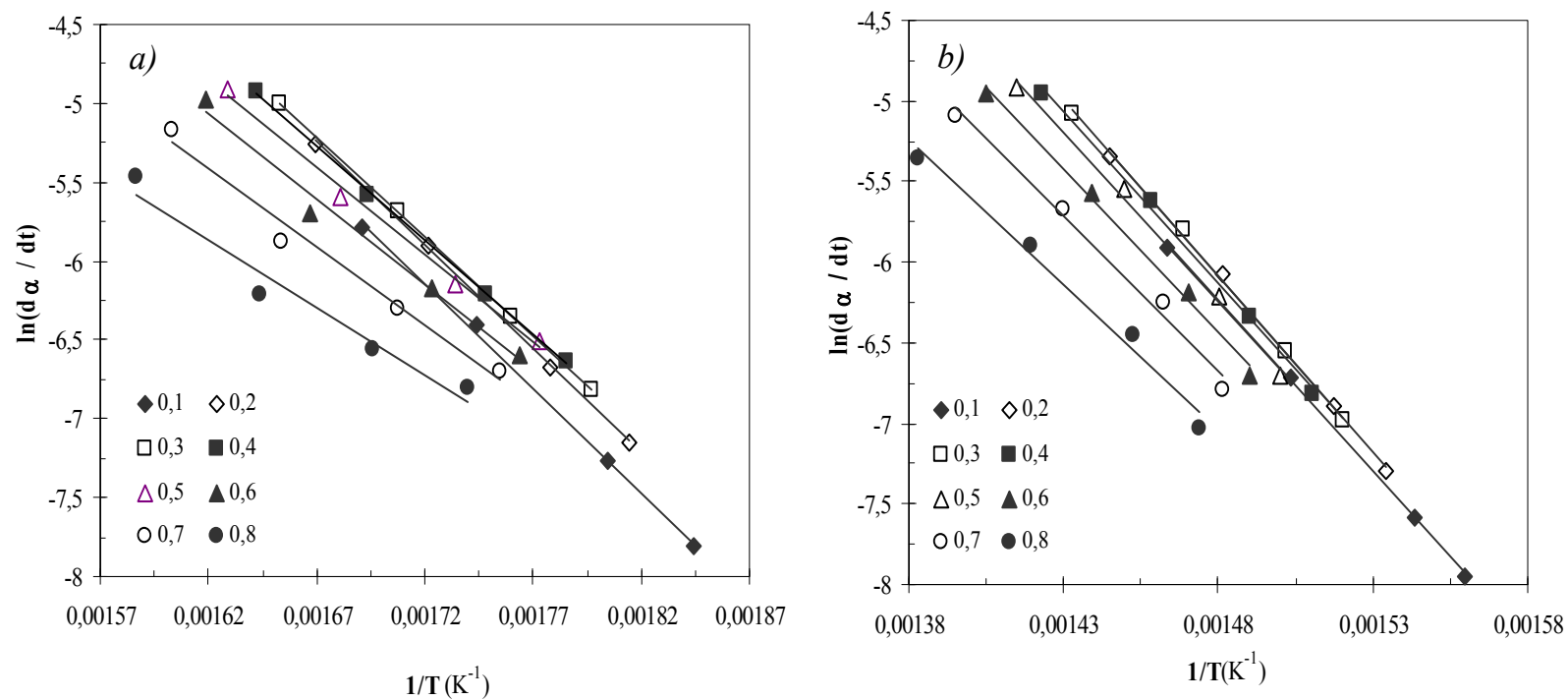

Figura 2.8. Representación del método de Friedman para el a) primer proceso y b) segundo proceso de descomposición. 
A partir de las pendientes de las rectas se calculan las Ea de cada proceso de descomposición (Tabla 2.9). El valor de Ea para el proceso asociado con la descomposición del almidón es de $98 \pm 8 \mathrm{~kJ} / \mathrm{mol}$ para un rango de $\alpha$ de 0,2 a 0,8 . El proceso de descomposición asociado con la descomposición térmica del material sintético muestra un valor medio de energía de activación de $175 \pm 5 \mathrm{~kJ} / \mathrm{mol}$ para un rango de $\alpha$ de 0,1 a 0,8 .

Tabla 2.10. Energías de activación calculadas mediante el método de Friedman.

\begin{tabular}{|c|c|c|c|c|}
\hline$\alpha$ & \multicolumn{2}{|c|}{$\begin{array}{l}1^{\mathrm{er}} \text { Proceso de Descomposición } \\
E q\end{array}$} & \multicolumn{2}{|c|}{$\begin{array}{l}2^{\mathbf{0}} \text { Proceso de Descomposiciór } \\
E q\end{array}$} \\
\hline 0,1 & 112 & 0,9983 & 176 & 0,9994 \\
\hline 0,2 & 106 & 0,9992 & 180 & 0,9989 \\
\hline 0,3 & 105 & 1,0000 & 180 & 0,9985 \\
\hline 0,4 & 100 & 0,9989 & 177 & 0,9977 \\
\hline 0,5 & 96 & 0,9946 & 175 & 0,9962 \\
\hline 0,6 & 94 & 0,9960 & 170 & 0,9935 \\
\hline 0,7 & 90 & 0,9909 & 170 & 0,9901 \\
\hline 0,8 & 90 & 0,9889 & 171 & 0,9910 \\
\hline
\end{tabular}

A continuación se aplica el método de Flynn-Wall-Ozawa. Este método permite determinar las $E a$ y la expresión $\log \frac{A E a}{g(\alpha) R}$ de donde una vez conocido el modelo cinético que describe al mecanismo de descomposición de cada proceso, se determina $\mathrm{g}(\alpha)$ y se calcula el factor cinético A. La Figuras 2.9 muestran las curvas isoconversionales de este método integral para el primer y el segundo proceso de descomposición.
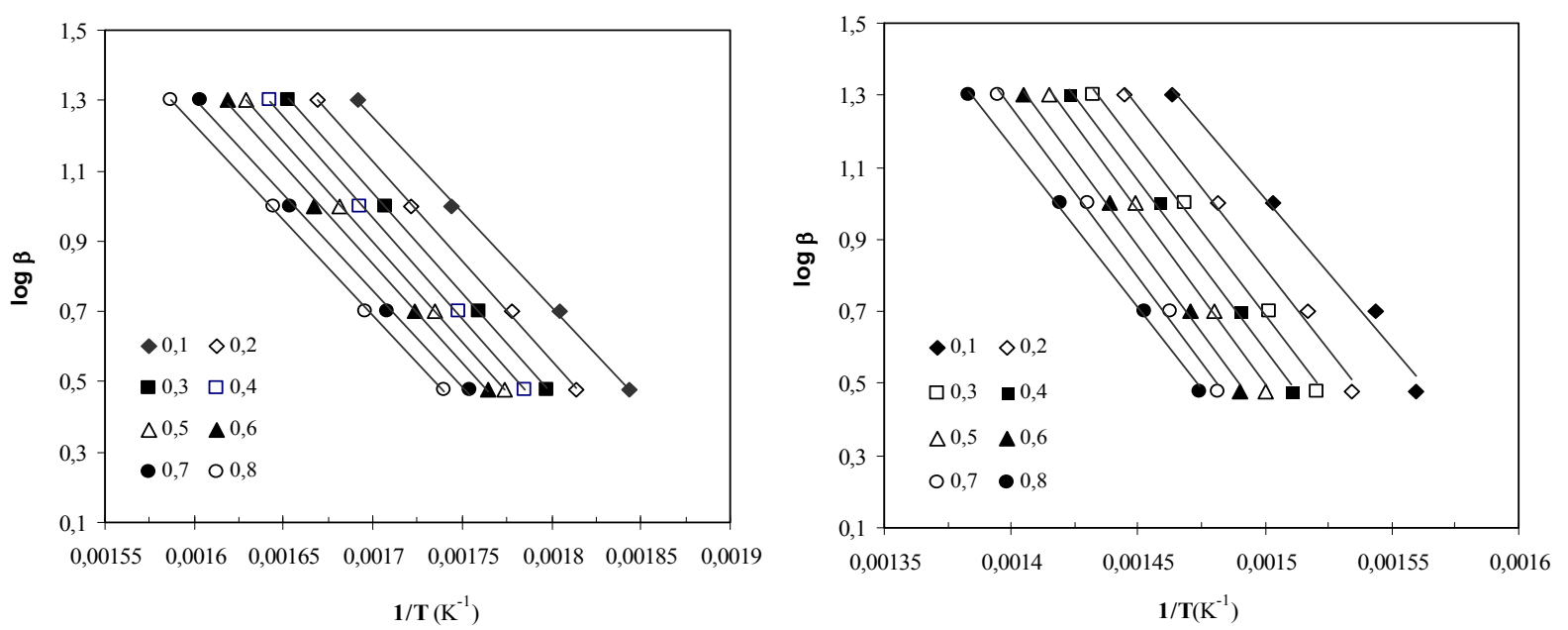

Figura 2.9. Representación del método de Flynn-Wall-Ozawa para el a) primer y b) el segundo proceso de descomposición 
La Tabla 2.11 resume los valores de las energías de activación obtenidas a partir de las pendientes de las rectas así como el valor para el parámetro $\log _{\frac{A(\alpha) R}{A E a}}$, obtenido de la intersección del eje de ordenada. Los valores promedios obtenidos mediante el método de Flynn-Wall-Ozawa coinciden con los valores obtenidos mediante el método de Friedman para cada proceso de descomposición. Siendo estos valores promedios de $100 \pm 3 \mathrm{~kJ} / \mathrm{mol}$ y $172 \pm 3$ $\mathrm{kJ} / \mathrm{mol}$ para el primer y el segundo proceso respectivamente

Tabla 2.11. Parámetros cinéticos calculados mediante el método de Flynn-Wall-Ozawa

\begin{tabular}{|c|c|c|c|c|c|c|c|c|}
\hline \multirow[b]{2}{*}{$\alpha$} & \multicolumn{4}{|c|}{$1^{\mathrm{er}}$ Proceso de Descomposición } & \multicolumn{4}{|c|}{$2^{\text {on }}$ Proceso de Descomposición } \\
\hline & $\begin{array}{c}E a \\
(\mathrm{~kJ} / \mathrm{mol})\end{array}$ & $\log [A E a / g(\alpha) R]$ & $\begin{array}{l}A \\
\min ^{-1} \\
\end{array}$ & $R^{2}$ & $\begin{array}{c}E a \\
(\mathrm{~kJ} / \mathrm{mol})\end{array}$ & $\log [A E a / g(\alpha) R]$ & $\begin{array}{c}A \\
\min ^{-1} \\
\end{array}$ & $R^{2}$ \\
\hline 0,1 & 97 & 10.3 & $10^{9.3}$ & 0,9992 & -- & -- & - & -- \\
\hline 0,2 & 103 & 10.7 & $10^{9.6}$ & 0,9995 & 174 & 14,2 & $10^{12.9}$ & 0,9933 \\
\hline 0,3 & 104 & 10.7 & $10^{9.7}$ & 0,9998 & 169 & 14,5 & $10^{13.3}$ & 0,9955 \\
\hline 0,4 & 104 & 10.7 & $10^{9.7}$ & 0,9997 & 171 & 14,6 & $10^{13.5}$ & 0,9973 \\
\hline 0,5 & 104 & 10.6 & $10^{9.5}$ & 1 & 176 & 14,9 & $10^{13.8}$ & 0,9974 \\
\hline 0,6 & 102 & 10.4 & $10^{9.3}$ & 0,9989 & 176 & 14,8 & $10^{13.8}$ & 0,9976 \\
\hline 0,7 & 99 & 10.0 & $10^{8.9}$ & 0,9976 & 172 & 14,4 & $10^{13.6}$ & 0,9967 \\
\hline 0,8 & 99 & 10.0 & $10^{8.8}$ & 0,9995 & -- & -- & -- & -- \\
\hline
\end{tabular}

El siguiente método descrito en la metodología, es el método de Kissinger. Representando el logaritmo neperiano de la velocidad de calentamiento con respecto a la inversa de la temperatura máxima de cada proceso de descomposición se obtienen las curvas de Kissinger. A partir de las pendientes de estas representaciones lineales se calcula la $E a$ de cada uno de los procesos (Figura 2.10).

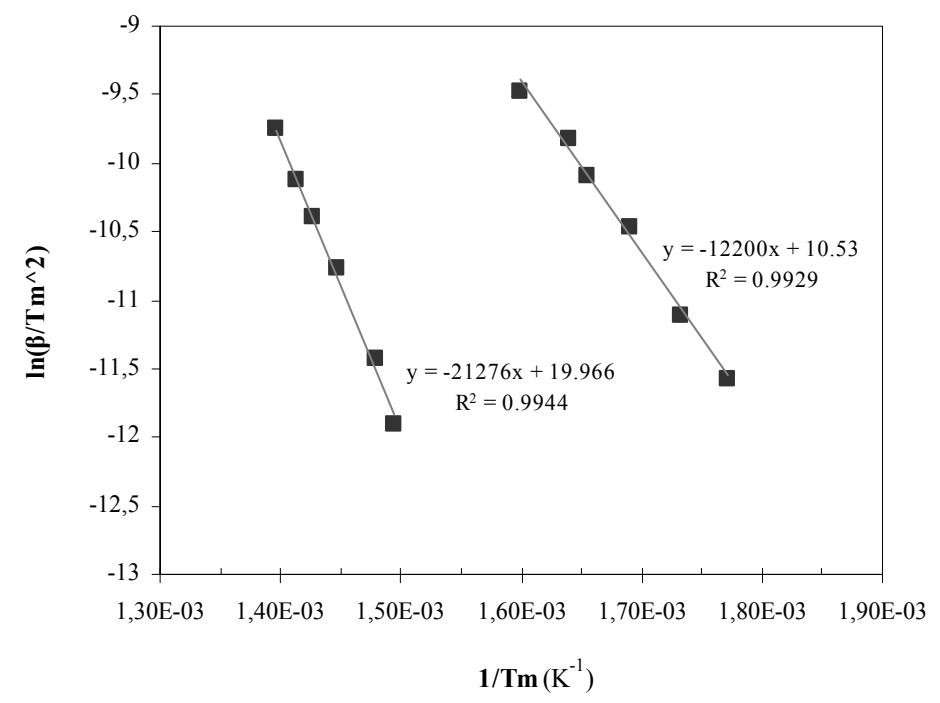

Figura 2.10. Representación del método de Kissinger para el primer y el segundo proceso de descomposición del Mater-Bi KE 
Los valores obtenidos mediante el método de Kissinger son $101 \mathrm{~kJ} / \mathrm{mol}$ para el primer proceso y $177 \mathrm{~kJ} / \mathrm{mol}$ para el segundo proceso. La $E a$ obtenida mediante el método de Kissinger coincide con los métodos empleados anteriormente, comprobándose de este modo su efectividad y fiabilidad. La selección de este método para la determinación de la Ea de los materiales sometidos al proceso de degradación en tierra agiliza la metodología de análisis.

Una vez determinado el primer parámetro de la tripleta cinética, la $E a$, mediante tres métodos cinéticos diferentes, se aplica el método de Criado para discernir cual de las funciones cinéticas propuestas (Tabla 2.8) se aproxima más al comportamiento de descomposición térmica de los procesos principales del Mater-Bi KE.

Las Figura 2.11, comparan las curvas reducidas teóricas (parte izquierda de la ecuación propuesta por Criado) con las curvas experimentales deconvolucionadas (parte derecha de la ecuación propuesta por Criado) obtenidas de los datos termogravimétricos.

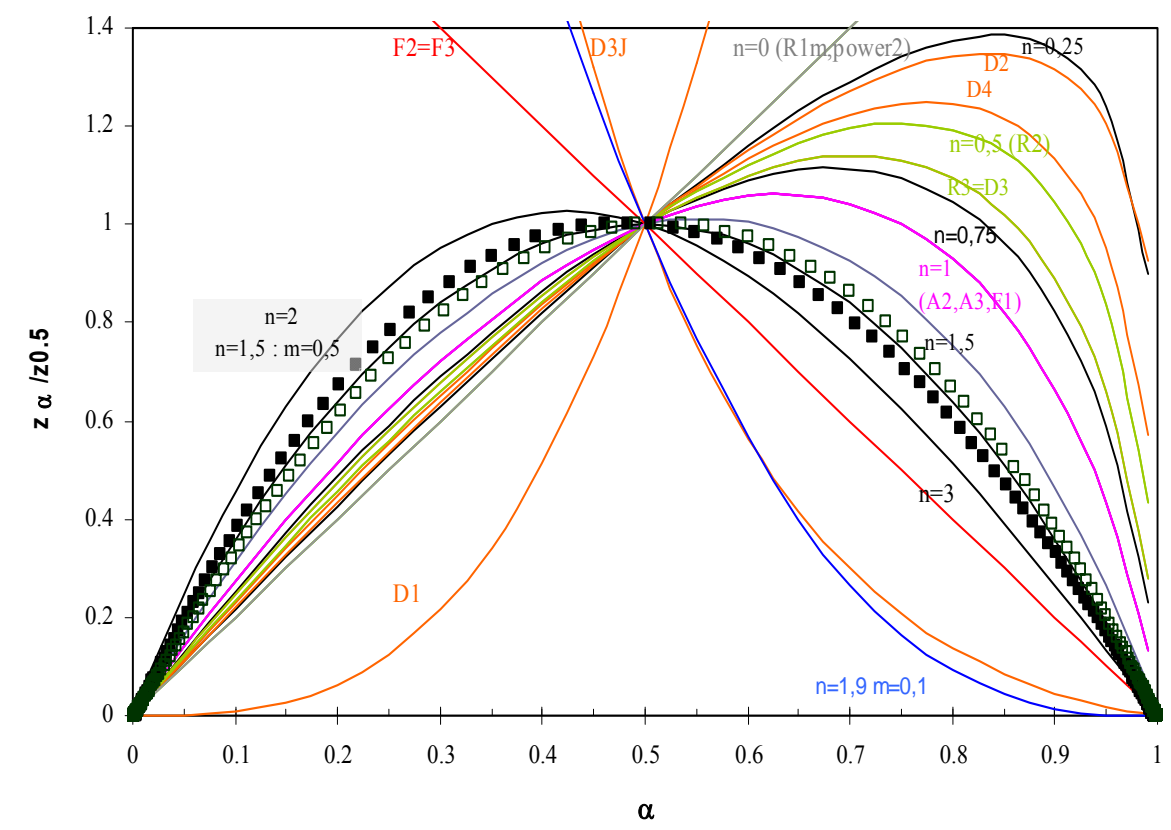

Figura 2.11. Aplicación del método de Criado para el $\mathbf{a})$ primer proceso y el $\square$ ) segundo proceso de descomposición del Mater-Bi KE.

Tanto para el primer como para el segundo proceso de descomposición térmica, la curva reducida experimental podría representarse tanto por el modelo cinético $f(\alpha)=(1-\alpha)^{2}$ como por el modelo $f(\alpha)=\alpha^{95}(1-\alpha)^{15}$. 
El método de Coats-Redfern permite averiguar cual de estos mecanismos es el más adecuado. A partir de la $g(\alpha)$ de cada uno de los modelos cinéticos propuestos se calculan las Ea de cada proceso (Tabla 2.12).

Tabla 2.12. Parámetros cinéticos calculados mediante el método de Coats-Redfern

\begin{tabular}{c|cc|cc}
\hline \multirow{2}{*}{ Model } & \multicolumn{2}{|c|}{ Primer Proceso } & \multicolumn{2}{c}{ Segundo Proceso } \\
& $\begin{array}{c}\text { Ea } \\
(\mathrm{kJ} / \mathrm{mol})\end{array}$ & $\begin{array}{c}A \\
\left(\mathrm{~min}^{-1}\right)\end{array}$ & $\begin{array}{c}\text { Ea } \\
(\mathrm{kJ} / \mathrm{mol})\end{array}$ & $\begin{array}{c}A \\
\left(\mathrm{~min}^{-1}\right)\end{array}$ \\
\hline$n 1,5 \mathrm{m0}, 5$ & $101 \pm 2,0$ & $10^{9,0}$ & $172 \pm 1,0$ & $10^{13,0}$ \\
$n=2$ & $230 \pm 2,0$ & $10^{19,0}$ & $341 \pm 3,0$ & $10^{25,4}$ \\
\hline
\end{tabular}

Partiendo de la suposición que da como válida la $E a$ calculada mediante los tres métodos anteriores, aquel modelo propuesto por Criado que proporcione la $E a$ más similar a las propuestas por Friedman, Flynn-Wall-Ozawa y Kissinger es el más adecuado. Como se puede observar en la tabla, tanto para el primer como para el segundo proceso de descomposición el modelo escogido es el $f(\alpha)=\alpha^{05}(1-\alpha)^{15}$.

Una vez determinado el modelo cinético y conocido su $g(\alpha)$, se puede despejar el factor $A$ de la Tabla 2.11, comprobando si su valor coincide con el propuesto por CoatsRedferdn, así la tripleta cinética de cada proceso de descomposición del Mater-Bi KE quedará definida.

\subsubsection{Análisis Calorimétrico}

Según la I.C.T.A, la Calorimetría Diferencial de Barrido (DSC) consiste en someter a la muestra problema a un programa controlado de temperatura donde se miden las diferencias de temperatura entre una muestra y una referencia, estas diferencias se traducen en energías absorbidas o desprendidas por dicha muestra con respecto a la de referencia.

Los materiales poliméricos son susceptibles de experimentar transiciones que involucran tanto a transformaciones físicas como químicas. Las primeras corresponden a transformaciones entre un estado vítreo y otro amorfo (la transición vítrea), o bien a transiciones en las que participa un orden cristalino (procesos de fusión, cristalización, transiciones cristal-cristal). Cuando se producen estas transiciones se absorbe o libera energía 
en forma de calor. Muchos de estos cambios físicos o químicos se ven favorecidos al aumentar la temperatura de dichos materiales.

\section{a) Descripción de la metodología}

\section{Identificación de las transiciones térmicas}

De los termogramas calorimétricos se obtienen los parámetros que definen las transiciones térmicas del material (temperaturas y entalpías): la primera curva (barrido de calentamiento) proporciona información relativa a la historia térmica del procesado del material, la segunda curva (barrido de enfriamiento) aporta información acerca del proceso de cristalización y la tercera curva (segundo barrido de calentamiento) proporciona información relativa al proceso de fusión.

Los valores de los parámetros calorimétricos, se obtienen directamente del STAR Evaluation Software. Para su correcta evaluación, se traza una línea base por debajo de cada transición. La temperatura de fusión $(T m)$ se determina como el máximo del pico principal endotérmico del segundo barrido de calentamiento, una vez eliminada la historia térmica. La temperatura de cristalización $(T c)$ se asigna al punto máximo del pico principal exotérmico del barrido de enfriamiento. Las entalpías de cristalización y fusión ( $\Delta H c$ y $\Delta H f$ respectivamente) se obtienen mediante la integración de los picos correspondientes. En los biocomposites estos valores se corrigen en función de la proporción volumétrica del material que conforma la matriz polimérica en el biocomposite [29], tal y como se muestra en las ecuaciones 19 y 20.

$$
\begin{aligned}
\Delta H_{C} & =\frac{\Delta H_{\text {Biocomposi te }_{C}}}{1-w w} \\
\Delta H_{f} & =\frac{\Delta H_{\text {Biocomposite }_{f}}}{1-w w}
\end{aligned}
$$

donde, el $\Delta H_{\text {Biocomposite }}$ se refiere a las entalpias del biocomposite enfibrado calculadas directamente de los termogramas y $w w$ es la fracción de la fibra natural añadida.

La temperatura de transición vítrea (Tg) se obtiene directamente del software del equipo y se calcula como el punto de inflexión de esta transición térmica. 


\section{b) Aplicación de la metodología}

En la Figura 2.12 se observa la respuesta del Mater-Bi KE ante las tres rampas de temperatura a las que ha sido sometido.

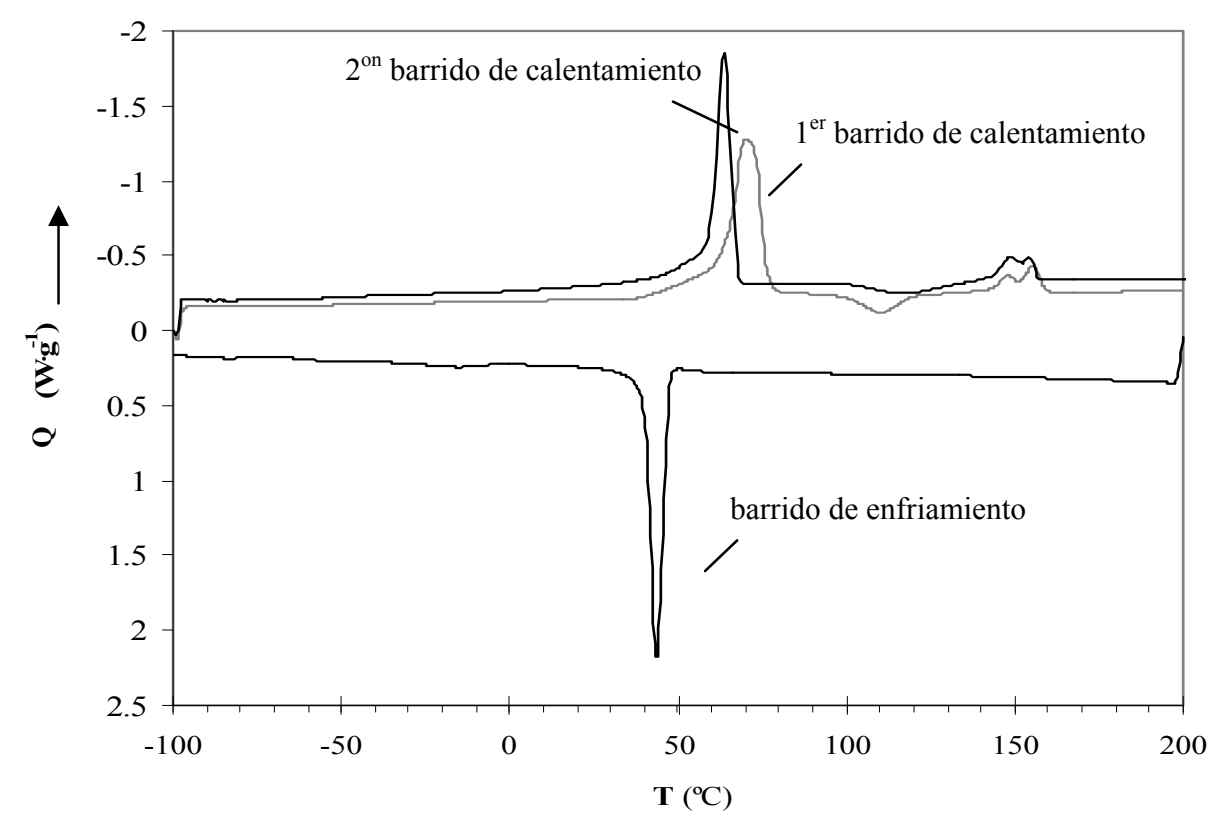

Figura 2.12. Curvas calorimétricas del Mater-Bi KE

En las dos curvas de calentamiento se identifican las mismas transiciones térmicas; un pico principal endotérmico entre $20^{\circ} \mathrm{C}$ y $80{ }^{\circ} \mathrm{C}$, un pequeño hombro exotérmico entre $95^{\circ} \mathrm{C} \mathrm{y}$ $127^{\circ} \mathrm{C}$ y dos picos endotérmicos solapados situados entre $127^{\circ} \mathrm{C}$ y $165^{\circ} \mathrm{C}$. En el barrido de enfriamiento sólo se observa un pico exotérmico alrededor de $43{ }^{\circ} \mathrm{C}$ y se intuye una transición vitrea alrededor de $-45^{\circ} \mathrm{C}$.

Los valores obtenidos en el primer barrido incluyen información relativa a la historia térmica del polímero. El pico endotérmico principal del segundo barrido de calentamiento, y el pico exotérmico del barrido de enfriamiento, se asocian con la fusión y la cristalización de la fase cristalinas del polímeros sintético biodegradable que junto al almidón conforman el Mater-Bi KE [30]. Por otra parte, el pequeño hombro exotérmico y los pequeño picos endotérmicos observados en el barrido de calentamiento podrían ser transiciones secundarias relacionadas con reorganizaciones de las cadenas de almidón [31]. 
En la Figura 2.13 se muestra como se calculan los parámetros característicos del barrido de enfriamiento y del segudo barrido de calentamiento mediante el programa STAR Evaluation Software.

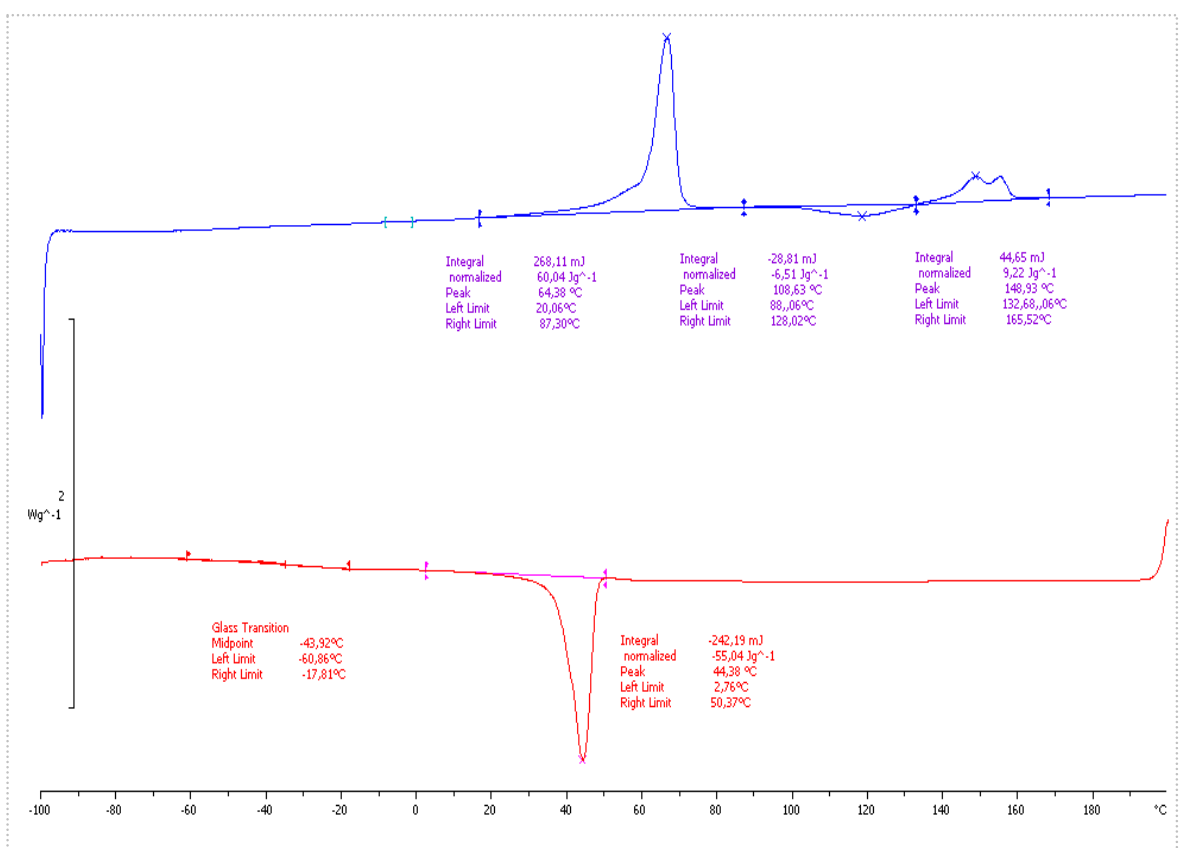

Figura 2.13. Cálculo de los parámetros característicos de cada barrido de termperatura

\subsubsection{Análisis Termo-Mecánico-Dinámico}

Los polímeros tienen la propiedad de no adaptarse instantáneamente a una nueva situación de equilibrio cuando se les somete a una acción externa mecánica, eléctrica o magnética. Estos procesos que se caracterizan por presentar un tiempo de adaptación o relajación, reciben el nombre de fenómenos de relajación.

La existencia de estos tiempos de relajación molecular determina que el comportamiento mecánico de los polímeros desde un punto de vista macroscópico, sea el de un material viscoelástico, donde todos los procesos de relajación se miden en función de la frecuencia y/o temperatura.

Las tensiones y las deformaciones en los experimentos dinámicos son variables con el tiempo y tienen un carácter sinusoidal, de manera que su relación debe ser descrita por una variable compleja. Para describir este comportamiento se definen dos módulos, E' (módulo de almacenamiento) que es la parte real de la variable compleja, E” (módulo de pérdidas) que 
representa la parte imaginaria y un ángulo de fase $\delta$, cuya tangente mide la relación entre E"/E' y explica el retraso de la reacción de un polímero al aplicar una tensión armónica simple de frecuencia angular determinada (w) (Figura 2.14).

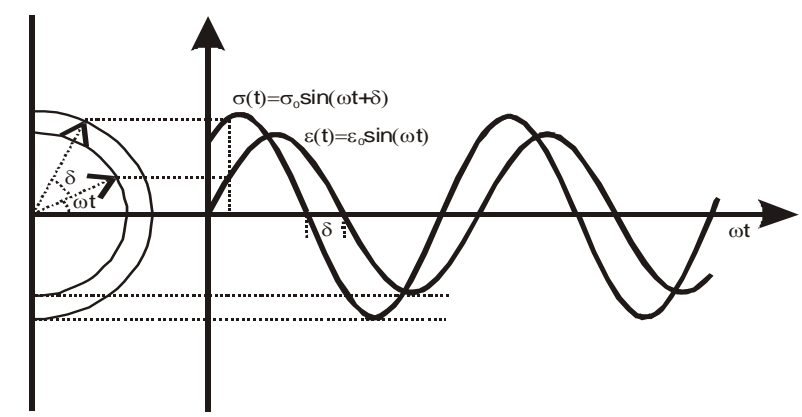

Figura 2.14. Representación del retraso de la tensión en un ángulo de fase $\delta$ [32].

\section{a) Fundamentos teóricos}

Cuando un material viscoelástico se somete a deformaciones periódicas de tipo sinusoidal, la respuesta en tensión está desfasada; en un sólido perfecto, el esfuerzo y la deformación están en fase mientras que en un fluido están desplazados en $90^{\circ}$. Este desfase se cuantifica mediante el ángulo de desfase $\delta$ y la tensión se expresa mediante la ecuación 22,

$$
\begin{gathered}
\varepsilon=\varepsilon_{0} \cos (w t) \\
\sigma=\sigma_{0} \cos (w t+\delta)
\end{gathered}
$$

donde, $\omega$ es la frecuencia angular, $\delta$ es el ángulo de desfase, $\sigma_{0}$ es la amplitud de la tensión y $\varepsilon_{0}$ la amplitud de la deformación.

A partir de las ecuaciones anteriores, y según las relaciones trigonométricas, la tensión puede expresarse del siguiente modo:

$$
\begin{gathered}
\sigma=\sigma_{0} \cos (w t) \cos \delta-\sigma_{0} \operatorname{sen}(w t) \operatorname{sen} \delta \\
\sigma=\sigma_{0} \cos (w t) \cos \delta-\sigma_{0} \operatorname{sen}\left(\mathrm{w} t+\frac{\pi}{2}\right) \operatorname{sen} \delta
\end{gathered}
$$

donde, la tensión muestra dos componentes, una en fase con la deformación $\left(\sigma_{0} \cos \delta\right)$, y otra $\left(\sigma_{0} \operatorname{sen} \delta\right)$ con un desfase de $90^{\circ}$ con la deformación. 
Si la ecuación 24 se multiplica y divide por la amplitud de la deformación, $\varepsilon_{0}$, el módulo se descompone en una componente en fase (parte real) y en otra componente desfasada (parte imaginaria),

$$
\sigma=\left[\left(\frac{\sigma_{0}}{\varepsilon_{0}} \cos \delta\right) \cos (w t)-\left(\frac{\sigma_{0}}{\varepsilon_{0}} \operatorname{sen} \delta\right) \cos \left(w t+\frac{\pi}{2}\right)\right] \cdot \varepsilon_{0}
$$

donde, $E^{\prime}=\frac{\sigma_{0}}{\varepsilon_{0}} \cos \delta$ es la parte real del módulo, y $E^{\prime \prime}=\frac{\sigma_{0}}{\varepsilon_{0}} \operatorname{sen} \delta$ es la parte imaginaria del módulo.

$$
\sigma=\varepsilon_{0} E^{\prime} \cos (w t)+\varepsilon_{0} E^{\prime \prime} \operatorname{sen}(w t)
$$

Reescribiendo las expresiones de la tensión y la deformación en su forma compleja se obtienen las siguientes expresiones,

$$
\begin{gathered}
\varepsilon^{*}=\sigma_{0} \exp (i w t) \\
\sigma^{*}=\sigma_{0} \exp (i(w t+\delta))
\end{gathered}
$$

El módulo complejo $\mathrm{E}^{*}$ se obtiene al dividir la tensión por deformación y viene dado por la siguiente expresión:

$$
E^{*}=\frac{\sigma}{\varepsilon}=\frac{\sigma_{0}}{\varepsilon_{0}} \exp (i \delta)=\frac{\sigma_{0}}{\varepsilon_{0}}(\cos \delta+i \operatorname{sen} \delta)=E^{\prime}+i E^{\prime \prime}
$$

donde la parte real del módulo, $E$ ', se conoce como el módulo de almacenamiento y la parte imaginaria del módulo, E', es el módulo de pérdidas.

El módulo de almacenamiento $\left(E^{\prime}\right)$, representa la parte elástica de la respuesta y está relacionado con el almacenamiento de energía en forma de energía potencial, y con su liberación durante la deformación periódica. El módulo de pérdidas ( $E$ '”), está asociado a la respuesta viscosa del material y se corresponde con la pérdida de energía debida a los movimientos internos. 
Por otra parte, la tangente del ángulo de pérdidas, tan $\delta$ se define como el cociente entre la energía disipada (en forma de calor) y la energía almacenada por ciclo y se expresa,

$$
\tan \delta=\frac{E^{\prime \prime}}{E^{\prime}}
$$

\section{Interpretación molecular}

Para una mayor comprensión de los ensayos dinámicos se describen una serie de consideraciones;

- Cuando la frecuencia de deformación es más rápida que el tiempo necesario para que las moléculas se desplacen, el material aparece como rígido, es como si los movimientos moleculares no existiesen.

- Si la frecuencia de deformación es similar al tiempo necesario para que ocurran los movimientos moleculares, los movimientos moleculares tienen lugar y esto se refleja en el comportamiento macroscópico; las moléculas al completar sus movimientos disipan una cierta energía en forma de calor que es característica de las relajaciones viscoelásticas y se conoce como pérdida mecánica. Estas pérdidas mecánicas son máximas cuando se produce un fenómeno, que se podría calificar de resonancia interna entre la vibración mecánica de algún elemento de las cadenas poliméricas, y la frecuencia de la tensión impuesta.

- Cuando la frecuencia de deformación es extremadamente lenta comparada con los movimientos moleculares, éstos pueden producirse de forma reversible y contribuyen a relajar automáticamente la tensión. Macroscópicamente aparece como un material blando, muy deformable.

Las relajaciones en los polímeros están por tanto relacionadas con la movilidad molecular. Estos movimientos pueden ser movimientos cooperativos (movimientos intermoleculares) de grandes partes del polímero en la cadena principal asociados a la transición vítrea, o bien a temperaturas más bajas movimientos cooperativos de grupos laterales con la cadena principal, movimientos de los grupos laterales o interacciones con pequeñas moléculas ocluidas en la matriz polimérica (movimientos intramoleculares). Así, los procesos de relajación dependen de la estructura molecular del polímero y de su morfología y 
los parámetros macroscópicos que los caracterizan pueden ser relacionados en principio con otros de carácter molecular.

En general, los parámetros que caracterizan una relajación son: el tiempo de relajación, la energía de activación aparente de la relajación y la función de relajación.

\section{b) Descripción de la metodología}

En primer lugar se identifican y caracterizan las diferentes regiones de relajación para así construir el mapa de Arrhenius y calcular la $E a$ y el parámetro relacionado con el volumen libre.

\section{Identificación de las diferentes regiones de relajación}

En primer lugar, los ensayos termo-dinámicos-mecánicos, se representan en términos de módulo de almacenamiento $\left(E^{\prime}\right)$, módulo de pérdidas $\left(E^{\prime \prime}\right)$ y tangente de pérdidas ( $E$ '/ $E$ ') en función de la temperatura para una frecuencia constante que varia en un rango de frecuencias de 0,1-100 Hz. De estas curvas experimentales se identifican las diferentes zonas de relajación y se observa si estas regiones poseen un pico ó más de uno.

\section{Caracterización de las diferentes regiones de relajación}

Para ajustar las funciones de relajación se propone el modelo de Fouss-Kirkwood [33].

$$
E^{\prime \prime}(w)=E_{\max }^{\prime} \operatorname{sech} \ln \left(w \tau_{0}\right)
$$

donde $\tau_{0}$ es el tiempo de relajación.

Este modelo combinado con el modelo de Charles-Worth [34] permite ajustar los datos experimentales obtenidos en función de la temperatura para deconvolucionar los picos solapados, considerando que el valor obtenido del módulo de pérdidas E” equivale a:

$$
E^{\prime \prime}=\sum_{i=1}^{n} E_{i}
$$

donde $i$ representa el número de picos solapados. 
De este modo, se determinan los valores de $\mathrm{E}^{\prime}{ }_{\max } \mathrm{y} \mathrm{T}_{\max }$ para cada pico solapado de cada región de relajación.

\section{Construcción del Mapa de Arrhenius: Cálculo de Ea y mv}

Una vez identificado el $\mathrm{T}_{\max }$ de cada transición de relajación en los espectros a distintas frecuencias. Se representa el logaritmo de cada frecuencia frente a la inversa de $\mathrm{T}_{\max }$ y así, se construye el mapa de Arrhenius. La tendencia lineal de las relajaciones secundarias del material permitirá calcular su Ea mediante la relación de Arrhenius, ecuación 33.

$$
\ln w=\ln w_{0}-\frac{E_{a}}{R} \cdot \frac{1}{T}
$$

donde $E_{a}$ es la energía de activación aparente y $R$ la constante universal de los gases.

Por otra parte, las transiciones de seudo-segundo orden, como la transición vítrea, se ajusta a la ecuación de Vogel-Fulcher (ecuación 34) [35] que permite correlacionar los tiempos de relajación con la temperatura máxima de cada relajación.

$$
\log w_{\text {max }}=A^{\prime}-\frac{m v}{\left(T-T_{\infty}\right)}
$$

donde $\mathrm{A}^{\prime}$ es un parámetro constante, $\mathrm{T}_{\infty}$ se conoce como temperatura de Vogel y representa la temperatura correspondiente a un volumen libre igual a cero, para el cual no puede tener lugar el proceso de relajación y el parámetro mv está relacionado con el volumen libre relativo, $\varphi g$, a la temperatura $\mathrm{Tg}$ por:

$$
m v=B \frac{T g-T \infty}{f g}=\frac{B}{\alpha}
$$

donde el volumen libre relativo se define como, $f g=(V-V f) / V f, B$ se considera cercano a la unidad, y $\alpha_{\mathrm{f}}$ es el coeficiente de dilatación térmica 


\section{c) Ejemplo de aplicación}

La Figura 2.15 muestra el módulo de almacenamiento $\left(E^{\prime}\right)$ y el modulo de pérdidas $\left(E^{\prime}\right)$ en función de la temperatura para un rango de frecuencias de 0,1-100 Hz. En la Figura 2.15, se observan dos zonas de relajación diferentes que se denominan $\alpha$ y $\beta$ en orden decreciente de temperatura. En la primera zona de relajación $\left(35-70{ }^{\circ} \mathrm{C}\right)$ aparecen dos contribuciones solapadas: un pico mayor alrededor de $60{ }^{\circ} \mathrm{C}$ y un pequeño hombro situado a temperaturas más bajas, que se asocian con el movimiento inicial de las cadenas moleculares antes del proceso de fusión del Mater-Bi KE. La zona de relajación $(\beta)$ se presenta en el rango de temperaturas entre -65 y $20^{\circ} \mathrm{C}$. Se trata de una zona de relajación compleja en la que probablemente aparezca solapada la transición vítrea del componente sintético, la transición vítrea y la relajación secundaria del almidón [36].

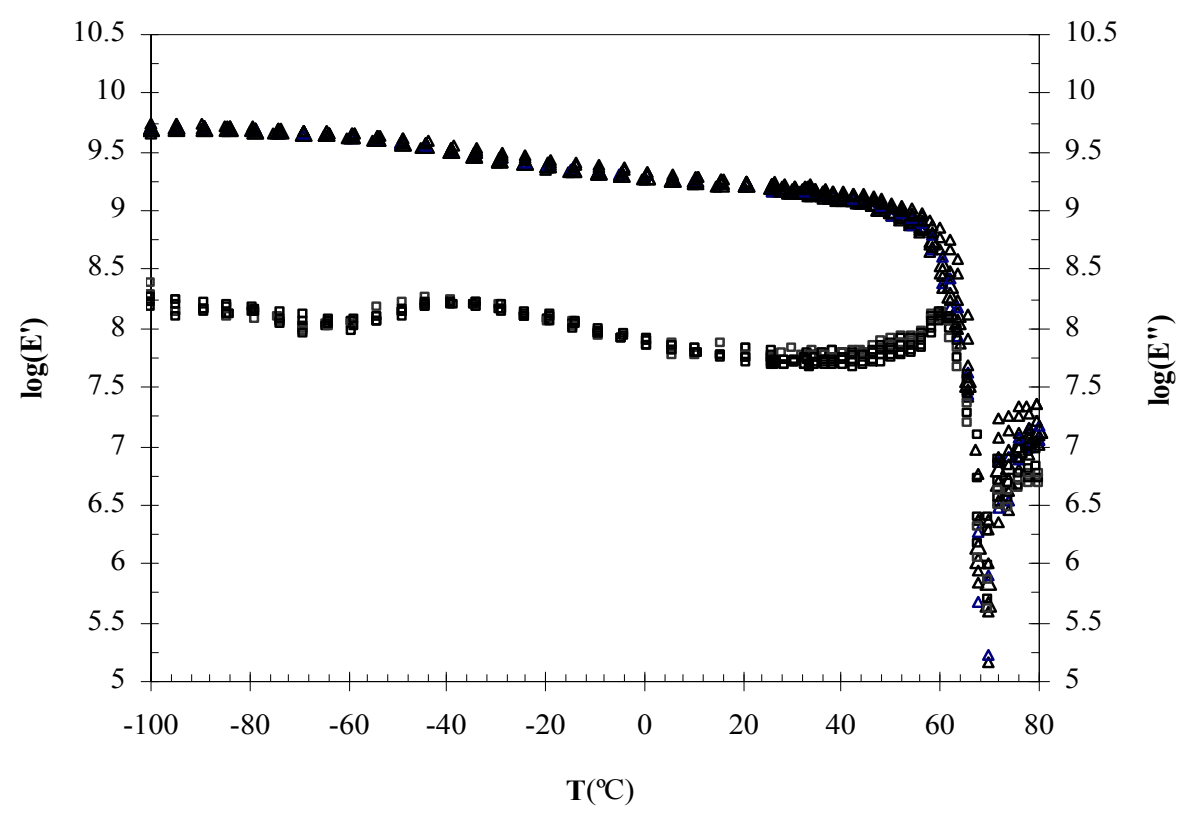

Figura 2.15. Representación del módulo de almacenamiento E'(curva superior) y del módulo de pérdidas E" (curva inferior).

A continuación se ajustan los valores experimentales del módulo de pérdidas ( $E$ ”) de ambas zonas de relajación al modelo empírico de Fouss-Kirkwood y Charlesworth para todas las frecuencias estudiadas. La Figura 2.16 muestra un ejemplo del ajuste de la curva E" en función de la temperatura, a una frecuencia de $1 \mathrm{~Hz}$. Para todas la frecuencias se realiza el mismo tipo de ajuste, identificándose en todas ellas, cinco relajaciones $\left(\alpha_{\mathrm{I}}, \alpha_{\mathrm{II}}, \beta_{\mathrm{I}}, \beta_{\mathrm{II}}, \beta_{\mathrm{III}}\right)$ que se caracterizan mediante la determinación del módulo máximo de almacenamiento $\left(E{ }^{\prime}{ }_{\max }\right)$ y su correspondiente temperatura $\left(T_{\max }\right)$. 


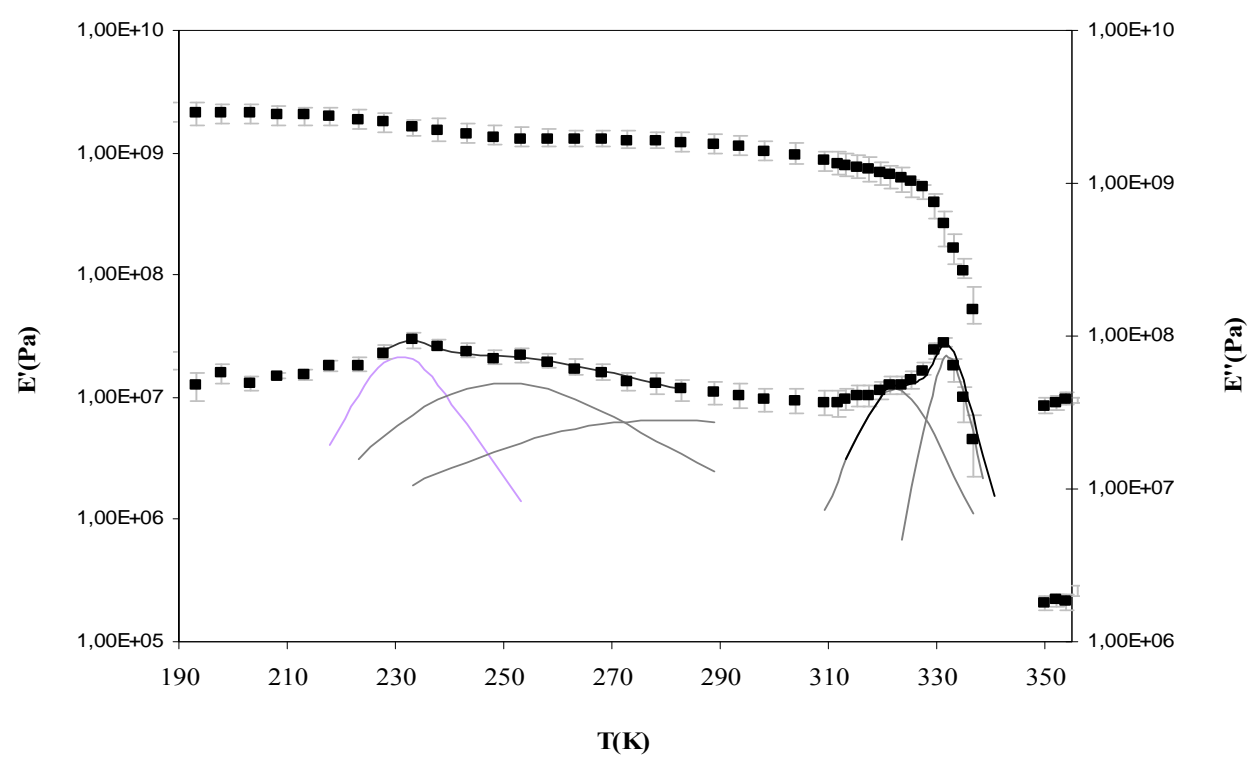

Figura 2.16. Variación del módulo de almacenamiento E'(curva superior) y del módulo de pérdidas E” (curva inferior) en función de la temperatura a una frecuencia de $1 \mathrm{~Hz}$. Aplicación del modelo de Fouss-Kirkwood.

La representación del $\ln (f)$ frente a la inversa de la $T_{\max }$ de cada una de las relajaciones identificadas da lugar al mapa de Arrhenius de este material (Figura 2.17).
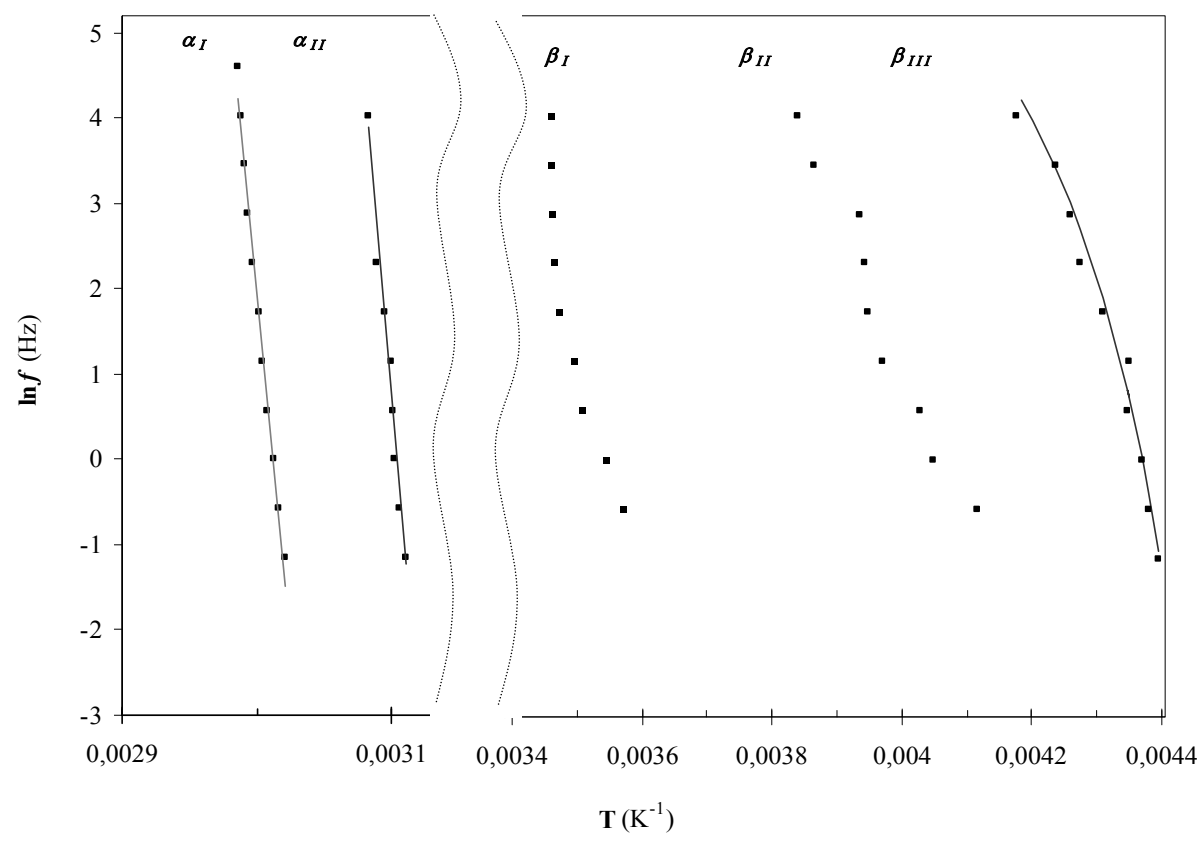

Figura 2.17. Mapa de Arrhenius de las relajaciones del Mater-Bi KE.

Las relajaciones $\alpha_{\text {I }}$ y $\alpha_{\text {II }}$ asociadas con los movimientos moleculares de las cadenas anteriores al proceso de fusión muestran una clara pendiente en línea recta que se ajusta a la 
ecuación de Arrhenius y de la que se obtiene los valores de Ea. En cambio, la relajación $\beta_{\mathrm{I}} \mathrm{y}$ $\beta_{\text {II }}$ no muestra una tendencia clara y la relajación $\beta_{\text {III }}$ muestra una curva característica de la transición vítrea. La curva obtenida para la relajación $\beta_{\text {III }}$ se ajusta a la ecuación de VogelFulcher para obtener el coeficiente relacionado con la expansión térmica del material. La Tabla 2.13 resume los parámetros termo-mecánicos-dinámicos de estas relajaciones.

Tabla 2.13. Parámetros viscoelásticos de las relajaciones térmicas del Mater-Bi KE.

\subsubsection{Análisis del Proceso de Absorción en Agua.}

\begin{tabular}{|c|c|c|c|c|c|c|}
\hline & \multicolumn{2}{|c|}{$\begin{array}{c}\alpha \text { relaxation zone } \\
{[310-345 K]}\end{array}$} & \multicolumn{4}{|c|}{$\begin{array}{c}\text { B relaxation zone } \\
{[225-290 K]}\end{array}$} \\
\hline & $\begin{array}{c}\mathrm{Ea}_{\alpha \mathrm{I}} \\
(\mathrm{kJ} / \mathrm{mol})\end{array}$ & $\begin{array}{c}\mathrm{Ea}_{\alpha \mathrm{II}} \\
(\mathrm{kJ} / \mathrm{mol})\end{array}$ & $A^{\prime}$ & $\begin{array}{l}\mathrm{m}_{\mathrm{v}} \\
(\mathrm{K})\end{array}$ & $\begin{array}{l}\mathrm{T}_{\infty} \\
(\mathrm{K})\end{array}$ & $\begin{array}{c}\alpha_{\mathrm{f}} \\
\left(\mathrm{K}^{-1}\right)\end{array}$ \\
\hline Mater-Bi KE & $1334 \pm 6$ & $1531 \pm 8$ & $8,9 \pm 1$ & $99,7 \pm 10$ & $218,3 \pm 6$ & $100,3 \cdot 10^{-4} \pm 10$ \\
\hline
\end{tabular}

La alta capacidad hidrofílica de las fibras naturales puede tener efectos indeseados en las propiedades mecánicas y en la estabilidad dimensional y térmica de los composites. Además, la hidrólisis del almidón es el primer paso hacia el proceso de biodegradación de las matrices compuestas de almidón termoplástico. Por tanto, la evaluación de los mecanismos de absorción y de los niveles de saturación máxima son factores fundamentales a tener en cuenta no sólo para el diseño de los composites y la evaluación de sus propiedades durante su ciclo de vida, sino para la determinación de su biodegradabilidad.

\section{a) Fundamentos teóricos}

La penetración de agua en el interior de los materiales compuestos se produce, simultáneamente, mediante tres mecanismos diferentes; el proceso principal consiste en la difusión de las moléculas de agua en el interior de los espacios microscópicos que existen entre las cadenas de los polímeros: el siguiente mecanismo es el transporte por capilaridad de las moléculas de agua dentro del espacio vacío que queda entre la interfase fibra/matriz polimérica; y finalmente, el transporte por microroturas en la matriz, formadas durante el proceso de fabricación del material compuesto. 
A pesar de que estos tres mecanismos se dan simultáneamente cuando los materiales compuestos se ven expuestos a un ambiente de humedad, el efecto global puede ser modelizado adecuadamente considerando únicamente el proceso de difusión [37].

En general, el comportamiento de difusión en los polímeros puede clasificarse en base a la movilidad relativa del líquido penetrante y de los segmentos del polímero en tres tipos de difusión disitintos:

Caso I: Difusión de Fick. En este caso, el coeficiente de difusión es mucho menor que la movilidad de los segmentos del polímero. El equilibrio se alcanza rápidamente y se mantiene con independencia del tiempo.

$>$ Caso II (y Super Caso II). En este caso, la movilidad del agente penetrante es mucho mayor que los otros procesos de relajación. Esta difusión se caracteriza por el desarrollo de una frontera entre la parte externa hinchada y el núcleo vítreo del polímero. Esta zona límite o interfacial, avanza a velocidad constante y el núcleo disminuye hasta llegar a alcanzar una concentración de equilibrio del penetrante en todo el polímero.

Difusión anómala (no Fickiana). Este caso de difusión ocurre cuando la movilidad del agente penetrante y la de los segmentos de polímero son comparables. Este caso representa un comportamiento intermedio entre el Caso I y el Caso II.

Estos tres casos de difusión se pueden discernir teóricamente por la forma de la curva de absorción representada por la ecuación 36:

$$
\frac{M_{t}}{M_{\infty}}=k t^{n}
$$

donde $M_{t}$ representa el contenido de agua para un tiempo t, $M_{\infty}$ es el contenido en agua en el equilibrio, $K$ es una constante y $n$ es el coeficiente constante que va a determinar el mecanismo de difusión que sigue el proceso de absorción estudiado. Para un comportamiento de difusión de Fick el valor de n será igual a 0,5, para el Caso II n será igual a 1 y para el caso de una difusión anómala, el coeficiente $n$ muestra un valor intermedio $(0,5<\mathrm{n}<1)$. 
El contenido en agua, $M t$, puede ser descrito como el aumento de masa del material tras la absorción del agua de acuerdo con la ecuación 1.

La absorción de humedad en polímeros reforzados con fibras naturales sigue generalmente el Caso I de Fick [38]. Cuando el coeficiente de difusión $D$ es constante, se aplica la segunda Ley de Fick:

$$
\frac{\partial C}{\partial t}=D \cdot \frac{\partial^{2} C}{\partial x^{2}}
$$

Para el caso especial en el que el polímero de espesor determinado, $(L)$ se encuentre en un baño a tiempo infinito, la concentración de la supercie, es una constante, $C_{\text {ext }}$ y la ecuación se transforma en;

$$
\frac{C_{\text {ext }}-C_{x, t}}{C_{\text {ext }}-C_{0}}=\frac{4}{\pi} \cdot \sum_{n=0}^{\infty} \frac{1}{2 n+1} \cdot \sin \left(\frac{(2 n+1) \pi x}{L}\right) \cdot \exp \left(-\frac{(2 n+1)^{2} \cdot \pi^{2}}{L^{2}} \cdot D \cdot t\right)
$$

El contenido total de humedad de la lámina plana en el tiempo $t(M t)$, en términos de contenido total de humedad en el equilibrio $\left(M_{\infty}\right)$, puede ser obtenida integrando la expresión anterior por el espesor del film:

$$
\frac{M t}{M_{\infty}}=1-\frac{8}{\pi^{2}} \cdot \sum_{n=0}^{\infty} \frac{1}{(2 n+1)^{2}} \cdot \exp \left(-\frac{(2 n+1)^{2} \cdot \pi^{2}}{L^{2}} \cdot D \cdot t\right)
$$

Para tiempos pequeños, $\left(M_{t} / M_{\infty} \leq 0.5\right)$, la solución de la ecuación se transforma en

$$
\frac{M_{t}}{M_{\infty}}=\frac{4}{L} \cdot\left(\frac{D}{\pi}\right)^{0.5} \cdot t^{0.5}
$$

Para tiempos largos de inmersión, la ecuación correspondiente es:

$$
\frac{M_{t}}{M_{\infty}}=1-\frac{8}{\pi^{2}} \cdot \exp \left(-\frac{D \cdot \pi^{2}}{L^{2}} \cdot t\right)
$$


Se pueden destacar algunas de las características más importantes de las curvas de difusión en polímeros:

o La curva de absorción como función de la raíz cuadrada del tiempo es lineal en la región inicial. El coeficiente de difusión se puede obtener de la pendiente de la curva en esta zona lineal.

o Por encima de esta zona lineal, la curva de absorción es cóncava a la abscisa.

o El proceso de difusión está fuertemente influenciado por la temperatura. La dependencia de la temperatura del coeficiente de difusión puede expresarse por la relación de Arrhenius:

$$
D=D_{0} \cdot \exp \left(-\frac{E a}{R T}\right)
$$

donde $D_{0}$ es el índice de permeabilidad, $E_{a}$ es la energía de activación del proceso de difusión y $R$ es la constante universal de los gases.

\section{b) Descripción de la metodología}

Por todo lo descrito, el estudio de absorción se define como una valiosa técnica para determinar, la capacidad máxima de absorción, el tiempo de saturación y el mecanismo de difusión del agua en los materiales bajo estudio.

\section{Cantidad de agua absorbida: Parámetros de saturación}

Como ya se ha dicho, las muestras se han sometido a un proceso de absorción en agua a tres temperaturas diferentes, siguiendo la normativa ASTM D 570-98 [8]. A determinados tiempos de inmersión el contenido en agua se calcula determinando la variación de la masa por pesada gavimétrica, siguiendo la ecuación 36.

En primer lugar, se evalúan las curvas de absorción del agua que representan la evolución del contenido en agua de las muestras con el tiempo de inmersión a temperatura constante. De estas curvas se puede extraer el contenido en agua que pueden llegar a absorber los materiales hasta llegar a su saturación, $\left(M_{S}\right)$, valor que corresponde con el 95\% del contenido en agua en equilibrio para largos periodos de inmersión $\left(M_{\infty}\right)$. Junto a este valor, se determinará el tiempo que tarda el material en alcanzar este equilibrio $\left(t_{s}\right)$. Este tiempo de saturación se corresponde con el tiempo transcurrido cuando el material ha alcanzado el contenido de saturación (Figura 2.18). 


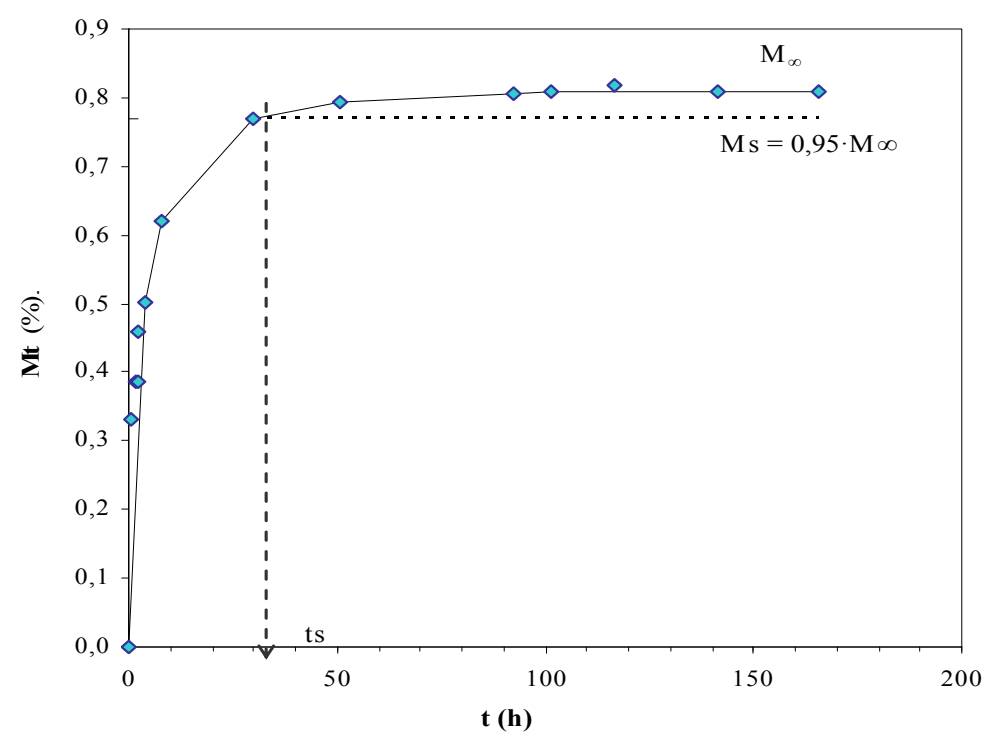

Figura 2.18. Estimación del tiempo de saturación ( $\left.t_{s}\right)$

\section{Determinación del mecanismo de difusión}

A continuación se realizará un estudio de difusión de los materiales. Para ello, se calcula el coeficiente $n$, el cual determina el modelo de difusión seguido por cada material. El modo de difusión que siguen los materiales estudiados se evalúa teóricamente mediante la forma de la curva de absorción representada por la ecuación 43. Tomando log sobre la ecuación 40, se obtiene la ecuación siguiente,

$$
\log \left(\frac{M_{t}}{M_{\infty}}\right)=\log (k)+n \cdot \log (t)
$$

\section{Determinación del coeficiente de difusión y la energía de activación}

Una vez confirmado que la absorción de las muestras sigue un modelo de difusión de Fick, Caso I, se evalúa el coeficientes de difusión de este modelo $(D)$. Para tiempos cortos de inmersión $\left(M_{t} / M_{\infty} \leq 0,5\right)$ los datos experimentales se ajustan a la ecuación 39. Representando la curva de absorción en función de la raíz cuadrada del tiempo, se comprueba que la región inicial es lineal, y así, se calcula dicho coeficiente.

Finalmente, la dependencia con la temperatura del coeficiente de difusión se estudia mediante la teoría de Arrhenius, ecuación 42. 


\section{c) Aplicación de la metodología}

Todos los materiales estudiados en la tesis han sido sometidos a este proceso de absorción. Como ejemplo, se muestra la aplicación de esta metodología descrita para el análisis del proceso de absorción del Mater-Bi KE. Dos muestras de este material se pesan y miden cuidadosamente, antes de ser sumergidas en tres baños a temperaturas distintas $\left(29^{\circ} \mathrm{C}, 35^{\circ} \mathrm{C}, 42^{\circ} \mathrm{C}\right)$. Las muestras se extraen a intervalos de tiempo determinados y se pesan para determinar la cantidad de agua absorbida. La Figura 2.19 muestra la curva de absorción del Mater-Bi KE a $29^{\circ} \mathrm{C}, 35^{\circ} \mathrm{C} \mathrm{y} 42^{\circ} \mathrm{C}$.

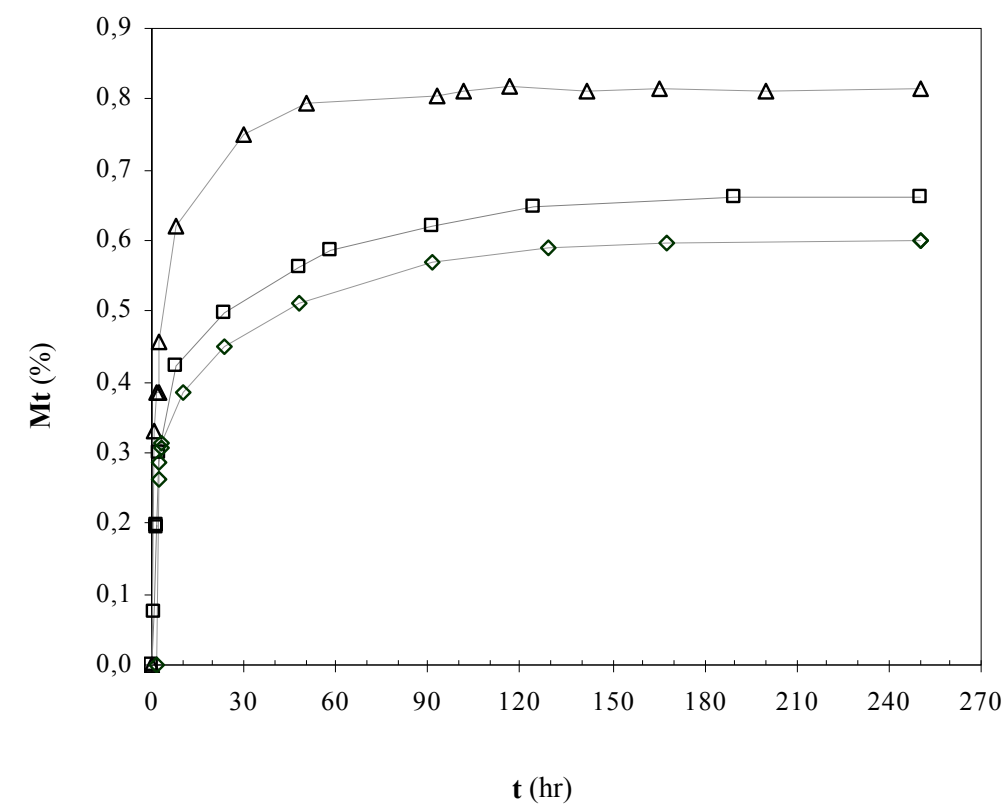

Figura

de absorción de agua para el Mater-Bi KE a $) 29^{\circ} \mathrm{C}$, 口) $35^{\circ} \mathrm{C}$ y 4$) 42^{\circ} \mathrm{C}$.

2.19. Curvas

En esta figura se observa como a medida que aumenta la temperatura de absorción aumenta el contenido de humedad. A continuación, se evalúa el contenido en agua que pueden llegar a absorber el material hasta alcanzar su saturación, y el tiempo que tarda el material en alcanzar el equilibrio. En la Tabla 2.14 se resumen los datos de saturación del Mater-Bi KE para cada temperatura. Además del aumento de la absorción con el aumento de la temperatura se observa una disminución del tiempo de saturación. Estos resultados indican un aumento de la velocidad de absorción del agua a medida que aumenta la temperatura de absorción

Tabla 2.14. Parámetros de saturación para el Mater-Bi KE.

\begin{tabular}{rrr|rrr}
\hline & $\mathbf{M}_{\text {s }}(\%)$ & \multicolumn{3}{c}{$\mathbf{t}_{\mathbf{S}}(\mathrm{h})$} \\
$\mathbf{2 9}^{\circ} \mathbf{C}$ & $\mathbf{3 5}^{\circ} \mathbf{C}$ & $\mathbf{4 2}^{\mathbf{}} \mathbf{C}$ & $\mathbf{2 9}^{\circ} \mathbf{C}$ & $\mathbf{3 5}^{\circ} \mathbf{C}$ & $\mathbf{4 2}^{\mathbf{}} \mathbf{C}$ \\
\hline 0,5 & 0,6 & 0,75 & 44,0 & 34,5 & 25,0 \\
\hline
\end{tabular}


A continuación, se estudia el mecanismo de difusión y la cinética del proceso de absorción. La determinación del mecanismo depende del valor del coeficiente $n$ que se calcula como el valor de la pendiente al representar $\log \left(M_{t} / M_{\infty}\right)$ frente a $\log (t)($ Figura 2.20).

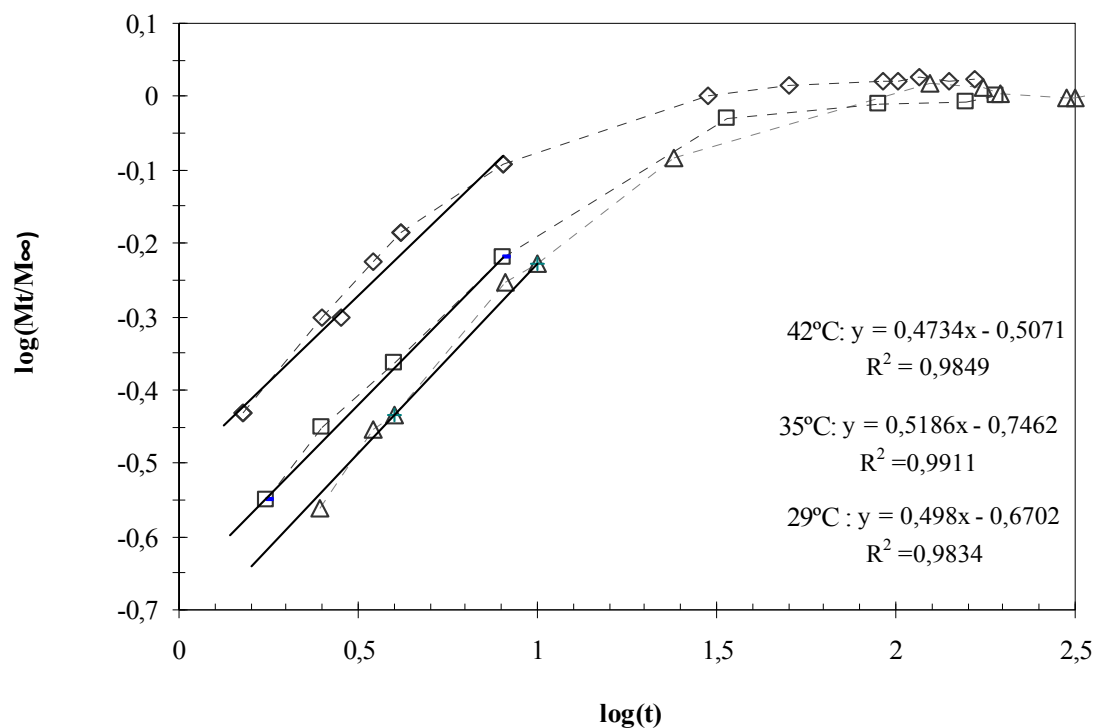

Figura 2.20. Determinación del modelo de difusión del Mater-Bi KE a 4$) 29^{\circ} \mathrm{C}$, 口) $35^{\circ} \mathrm{C}$ y $)_{4} 42^{\circ} \mathrm{C}$.

Una vez comprobado que la absorción de agua del Mater-Bi KE sigue el modelo de difusión de Fick $(\mathrm{n}=0,5)$ para todas las temperaturas experimentales, se calcula el valor del coeficiente de difusión de este material. La Figura 2.21 muestra la representación de $M_{t} / M_{\infty}$ frente $a 4 \cdot L^{-1} t^{1 / 2} \cdot \Pi^{-1 / 2}$ de donde se obtiene el coeficiente de difusión, $D$.

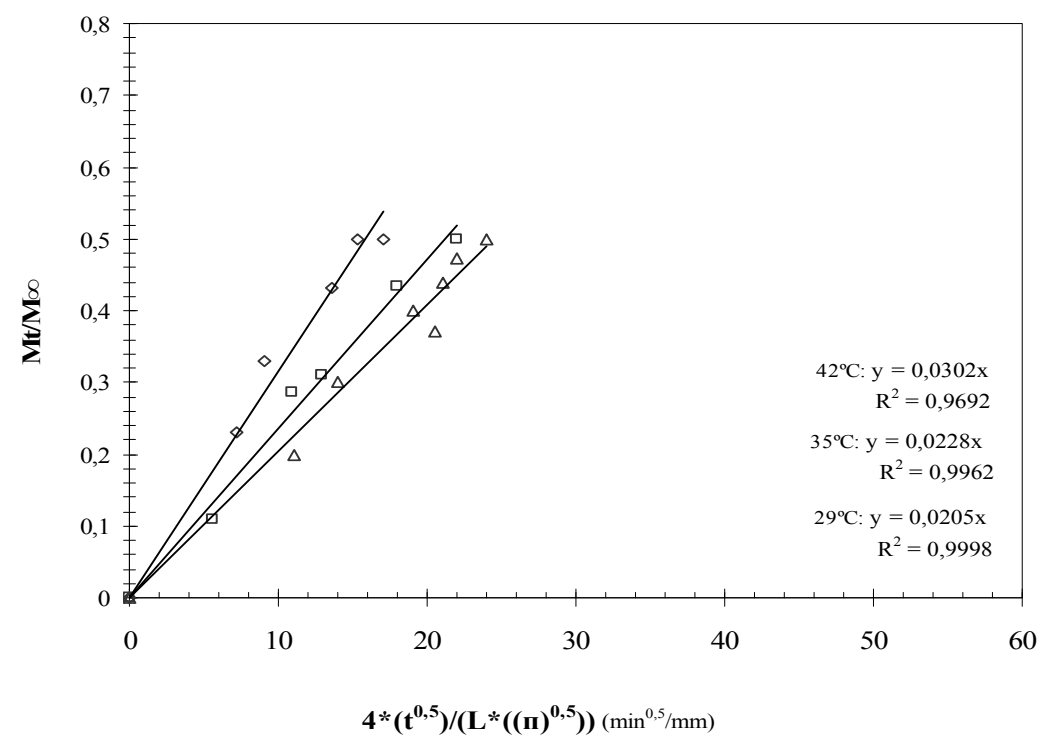


Figura 2.21. Cálculo del coeficiente de difusión del Mater-Bi KE a partir de la curva normalizada de Fick

Se observa como el coeficiente de difusión aumenta al aumentar la temperatura de absorción, confirmando la mayor facilidad de la penetración del agua al Mater-Bi KE a temperaturas mayores.

Finalmente, se representa la dependencia de Arrhenius del coeficiente de difusión con la temperatura experimental del proceso de absorción (Figura 2.22).

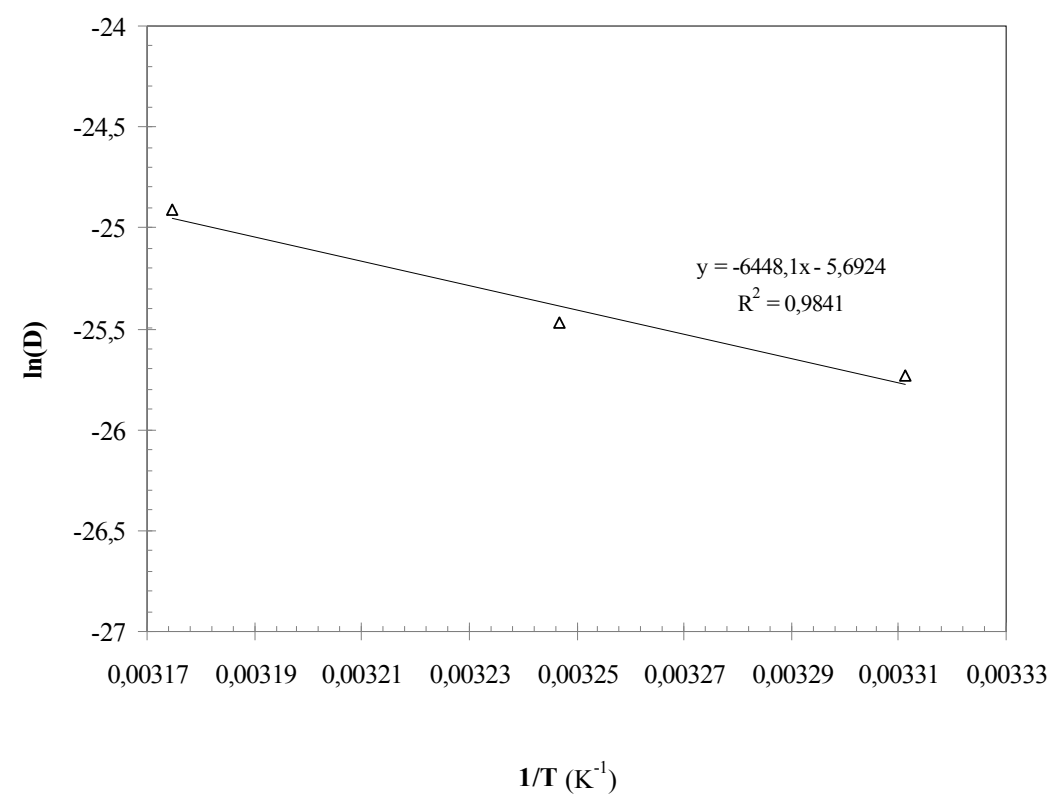

Figura 2.22. Cálculo de la Ea del proceso de absorción del Mater-Bi KE.

A partir de la pendiente de la curva se obtiene un valor de $E a$ de $54 \mathrm{~kJ} / \mathrm{mol}$ para el proceso de absorción del Mater-Bi KE.

\section{Referencias}

1. Mezzanotte V, Bertani R, Degli Innocenti F, Tosin M. Polym Degrad Stab 2005; 87: 51.

2. Marini L. Mater-Bi® NF type: Biodegradable Plastic Pellets for Films Environmental Product Declaration (EDP)

3. Theander O, Westerlund EA. J Agric Food Chem 1986; 34:330.

4. Monties B. Agronomie 1986; 4: 387.

5. TAPPI (Technical Association of the Pulp and Paper Industry), T 211 om-85. Ash in wood and pulp, 1993.

6. DIN 53739. Testing of plastics. Influence of Fungi and Bacteria. Visual Evaluation. Change in Mass and Physical Properties, Nov. 1984. 
7. ISO 846. Plastics. Evaluation of the action of microorganisms, May. 1998.

8. ASTM D570-98(2010)e1. Standard Test Method for Water Absorption of Plastics.

10. ASTM D882-09. Standard Test Method for Tensile Properties of Thin Plastic Sheeting.

11. Hoebler C, Barry JL, David A, Delort-Laval J. J. Agric. Food Chem 1989; 37 (2): 360.

12. Huadong Wang, Jie Yang, Shengru Long, Xiaojun Wang, Zheng Yang, Guangxian Lic. Polym Degrad Stab 2004; 83: 229.

13. Yang J, Miranda R, Roy C. Polym Degrad Stab 2001; 73: 455.

14. Moriana R, Contat L, Santonja-Blasco L, Ribes-Greus A. J Appli Polymer Sci 2008; 109: 1177.

15. Friedman HL. Journal Polym Sci 1964; 6: 183.

16. Ozawa T. Bull Chem Soc Jpn. 1965; 88: 6.

17. Kissinger HE. J Res Natl Bur Stand 1956; 57: 217.

18. Criado JM. Thermochimic Acta 1978; 24:86.

19. Coats AW, Redfern JP. Nature 1964; 201:68.

20. Doyle CD. J Appl Polym. Sci 1961; 5: 285.

21. Rath SK, Singh RP. J Appl Polym Sci 1998; 70: 1810.

22. Griffin GJL, editor. Chemistry and Technology of Biodegradable Polymers. Glasgow: Blackie Academic Professional, 1994.

23. Chandra R, Rustgi R. Polym Degrad Stab 1997; 56: 185.

24. Wenbo J, X Qiao, Kang S. Carbohydrate Polymers 2006; 65: 139.

25. Jin-Hui Y, Jiu-Gao Y, Xiao-Fei M. Carbohydrate Polymers 2006; 63: 218.

26. Aggarwal D, Dollimore D, Heon K. Journal of thermal analysis 1997; 50; 7.

27. Alvarez VA, Vázquez A. Polym Degrad Stab 2004; 84: 13.

28. Petrovic ZS, Zavargo ZZ. J Appl Polym Sci 1986; 32: 4353.

29. Avérous L, Boquillon N. Carbohydrate Polymers 2004; 56: 111.

30. Bastioli C, editor. Handbook of Biodegradable Polymers. Shrewsbury: Rapra Technology, 2005.

31. Ge XC, Xu Y, Meng YZ, Li RKY. Compos Sci Tech 2005; 65: 2219.

32. Saénz V. Contribución al estudio de la degradación ambiental de poliolefinas fotoestabilizadas 2002, Tesis doctoral.

33. Fuoss RM, Kirkwood JG. J Am Chem Soc 1941; 2: 385.

34. Charlesworth JM. J Mater Sci 1993; 28: 399.

35. Fulcher GS. J Am Ceram Soc 1925; 6: 339.

36. Avérous L, Moro L, Dole P, Fringant C. Polymer 2000; 41: 4157.

37. Pothan LA, Thomas S. J Appl Polym Sci 2004; 91: 38556.

38. Wang W, Sain M, Cooper PA . Compos Sci Tech 2006; 66: 379. 

Caracterización de las fibras naturales

3.1 Introducción

3.2 Resultados y discusión 



\subsection{INTRODUCCIÓN}

En este capítulo se han caracterizado las fibras naturales escogidas como sistema de refuerzo en el diseño de los biocomposites. Las propiedades de un composite dependen fundamentalmente de las propiedades intrínsecas de cada uno de los constituyentes químicos que lo conforman [1], así como de las propiedades en la interfase, relacionadas con las interacciones entre los distintos componentes. Las fibras naturales vegetales se caracterizan por poseer en su composición un porcentaje elevado de celulosa seguido de hemicelulosa y lignina. La composición exacta de cada fibra depende a su vez de un gran número de factores tales como la especie de la que provenga, el tiempo de cultivo, la zona y las condiciones climáticas [2]. La relación de forma de las fibras naturales junto a otros factores físicos, tales como la cristalinidad y la morfología, definen la arquitectura del sistema de refuerzo que es uno de las propiedades que hay que tener en cuenta para conseguir un biocomposite de calidad [3]. Además, para conseguir un refuerzo eficaz se debe considerar la tensión máxima de tracción, la deformación a ruptura y el modulo elástico deseados para el composite a diseñar [3]. Asimismo, también se requiere de información relativa a la estabilidad y comportamiento térmico de cada componente de la matriz polimérica y del biocomposite para determinar de las condiciones óptimas de procesado $[3,4]$.

De este modo, el propósito de este capitulo, es determinar la composición química y evaluar las propiedades mecánicas, morfológicas, estructurales y térmicas de las fibras naturales. os objetivos específicos de este capitulo son los siguientes:

1. Determinar la composición química de cada fibra natural.

2. Determinar la relación de forma de las fibras naturales.

3. Determinar las propiedades mecánicas de las fibras elegidas.

4. Determinar las transiciones térmicas de las fibras naturales.

5. Determinar la cristalinidad de las fibras naturales a partir de grupos funcionales específicos que definen su estructura química.

6. Determinar la estabilidad y el comportamiento térmico de las fibras naturales.

7. Relacionar estas propiedades físicas y térmicas con la composición de cada fibra natural. 
La metodología de análisis propuesta para alcanzar los objetivos descritos, se ha basado en las siguientes técnicas experimentales: determinación de la composición química de las fibras naturales mediante hidrólisis ácida y análisis de los monosacáridos resultantes por Cromatografía de Gases (GC); estudio de las propiedades mecánicas mediante un Análisis de Tensión; evaluación de la morfología de las fibras naturales mediante Microscopia Óptica y Microscopia Electrónica de Barrido (SEM); estudio de las transiciones térmicas de las fibras naturales mediante Análisis Calorimétrico (DSC); determinación de los grupos funcionales relacionados con el índice de cristalinidad de cada fibra natural por Análisis Infrarrojo de Transformada de Fourier (FTIR) y estudio de la estabilidad y la cinética de descomposición térmica mediante Análisis Termogravimétrico (TGA). Los resultados de estos análisis se recogen en una contribución denominada “Comparative Morphologic, Structural and Thermal Analisys Studies of Different Natural Fibres”.

La determinación de la composición química de cada fibra natural se ha llevado a cabo según el procedimiento de análisis descrito en el Capitulo 2. La fibra natural que posee un mayor contenido de celulosa en su composición es el algodón (91\%) seguido por el lino (77\%) el yute (72\%), el cáñamo (68\%) y finalmente, por el kenaf (58\%). Las fibras de kenaf presentan el contenido más alto en hemicellulosa (22\%) y lignina (12\%). Las fibras que más difieren entre ellas, desde el punto de vista de composición química, son el algodón y el kenaf.

El módulo de Young varía entre 12 y $70 \mathrm{GPa}$ para todas las fibras estudiadas de acuerdo con la información facilitada por el productor. Por lo general, las fibras que muestran un mayor contenido en celulosa presentan un mayor módulo de Young. Sin embargo, la fibra de algodón no cumple esta tendencia y pese a tener el mayor contenido en celulosa, tiene el módulo de Young más bajo. Las fibras que presentan un mayor módulo de Young son las fibras de lino y yute. En términos de propiedades mecánicas, estas fibras podrían considerarse como potencialmente competitivas frente a las fibras de vidrio, que presentan un módulo de $75 \mathrm{GPa}[3]$.

Se han calculado los parámetros físicos (longitud y diámetro) que definen la relación de forma de cada fibra natural. Para ello se han observado 100 muestras diferentes de cada fibra natural mediante microscopia óptica. Todas las fibras utilizadas presentan una gran 
heterogeneidad. Los valores de relación de forma mayores son los obtenidos para el algodón (67-667) y el yute (230-1428), mientras que el lino (136-500), el cañamo (10-214) y el kenaf (25-150) muestran valores menores.

Las micrografias muestran que las fibras naturales son largas, cilíndricas y poseen un final en forma de cuña. Además, las fibras de algodón son las únicas que presentan canales en su superficie.

El comportamiento calorimétrico de las fibras naturales se ha estudiado para identificar las transiciones térmicas del material. En el termograma calorimétrico del primer barrido de calentamiento de todas las fibras naturales aparece un pico endotérmico asociado a la evaporación del agua absorbida, que aumenta en función del contenido de hemicelulosa/pectina presente en su formulación. Los termogramas calorimétricos de los posteriores barridos no presentan ninguna transición de primer orden, esto es debido a que los materiales lignocelulósicos en estado natural presentan una estructura con un gran número de puentes de hidrógeno que se descompone térmicamente antes de alcanzar su punto de fusión.

Con el objetivo de determinar un parámetro que permita comparar la cristalinidad de unas fibras con otras se analiza el espectro de infrarrojos de cada una de ellas. Akerholm et al. [5] y Focher et al. [6] aplicaron esta técnica para determinar la cristalinidad de la celulosa natural. A partir de los espectros de la supeficie de las fibras poliméricas se han identificado las bandas caracteristicas de los principales componentes de la fibra natural y se ha calculado el índice de cristalinidad así como el contenido de humedad de cada una de ellas. Las fibras de algodón, lino y yute son más cristalinas que las fibras de kenaf y cañamo, debido a que estas últimas contienen menos celulosa en su composición.

Además, se ha analizado la segunda derivada del espectro para identificar los enlaces intermoleculares en la región de estiramiento de los $\mathrm{OH}$, relacionados con las distintas fases cristalinas de la celulosa natural $\left(\mathrm{I}_{\alpha} \mathrm{y} \mathrm{I}_{\beta}\right)$. Para todas las fibras naturales estudiadas, la fase cristalina $I_{\beta}$ es la mayoritaría. Asimismo, se ha determinado la fibra natural que posee más enlaces intermoleculares del tipo $\mathrm{I}_{\beta}$. El yute, el algodón y el lino son las fibras que muestra una mayor intensidad en la banda asociada con el alomorfo $I_{\beta}$. 
Finalmente se ha utilizado el análisis termogravimétrico para monitorizar los mecanismos de degradación térmica de las fibras naturales [7], identificar los procesos de descomposición de cada uno de sus componentes y definir los parámetros termogravimétricos que los caracterizan. Los procesos de descomposición térmica de los componentes de cada una de las fibras naturales aparecen solapados en la misma región de temperatura $\left(200-550^{\circ} \mathrm{C}\right)$. Por tanto se aplica un método de deconvolución para separar cada una de las contribuciones. De este modo se obtiene la estabilidad térmica y la pérdida de masa de cada componente químico individualmente. Las fibras con mayor contenido en celulosa (algodón, lino y yute) presentan una mayor estabilidad térmica que las muestras de menor contenido en celulosa (kenaf y cáñamo).

El alto porcentaje residual de la descomposición térmica de las fibras naturales indica la posibilidad de una repolimerización de los volátiles emitidos durante su pirolisis en atmósfera inerte. Mediante análisis calorimétrico se demuestra la competitividad entre los procesos de formación de residuo y la evaporación de levoglucosan durante dicha pirólisis. Las fibras de cáñamo, kenaf y algodón presentan un comportamiento exotérmico indicando el dominio de las reacciones responsables de la repolimerización y la formación de residuo, mientras que la fibra de lino y yute presenta un comportamiento endotérmico atribuido a la descomposición de las cadenas y a la evaporación de levoglucosan.

La metodología de análisis termogravimétrico empleada para la determinación del porcentaje de cada componente de las fibras naturales, permite predecir los valores obtenidos mediante el análisis químico de las fibras naturales. Concretamente estos resultados demuestran que el porcentaje de humedad contenido en las fibras podría obtenerse con prácticamente la misma precisión si se realiza un análisis químico convencional, si se calcula a partir del termograma termogravimétrico, ó incluso a partir del calorimétrico. Asimismo, se ha demostrado que el aumento de la hidrofilidad de la fibra natural esta relacionado con el contenido de hemicelulosa/pectina de las fibras.

La cinética de descomposición térmica de cada proceso se determina mediante la determinación de la tripleta cinética: parámetro exponencial $(A)$, energía de activación $(E a)$ y módelo cinético que describe el mecanismo de descomposición $f(\alpha)$. Para ello, se ha seguido una metodología en la que intervienen hasta cinco métodos de análisis cinético. A partir de 
esta metodología se ha evaluado la cinética de descomposición térmica de los componentes mayoritarios de los materiales lignocelulósicos (hemicelulosa/pectina y celulosa), obteniéndose que su comportamiento térmico se podría modelizar mediante dos reacciones de orden $n \approx 1$. La cinética de descomposición de la celulosa es similar en todas las fibras naturales $\left(\mathrm{f}(\alpha)=(1-\alpha)^{l}, E a=200 \mathrm{KJ} / \mathrm{mol}, A=10^{15} \mathrm{~min}^{-1}\right)$ y responde a los valores bibliográficos [8-10]. Sin embargo, en la región de descomposición de la hemicelulosa/pectina se observan variaciones en la $A\left(10^{8,4}-10^{11,4} \mathrm{~min}^{-1}\right)$, la $E a(168-194 \mathrm{KJ} / \mathrm{mol})$ y en el orden de reacción $(1-1,7)$. La dispersión obtenida en los resultados experimentales puede tener su origen en el método de deconvolución aplicado para separar las diferentes contribuciones del proceso de termodegradación de la hemicelulosa/pectina y la lignina. La celulosa es el componente con mayor proporción de celulosa, y por tanto su proceso de termodescomposición es muy fácil de discernir. No ocurre lo mismo con los procesos de descomposición de la hemicelulosa/pectina y de la lignina que se presentan como dos hombros solapados a derecha e izquierda del proceso de descomposición de la celulosa respectivamente, por tanto, la separación de ambos componentes representa una mayor dificultad y depende del mayor o menor contenido de ambos en cada fibra.

\section{Referencias}

1. Satyanarayana KG, Ravikumar KK, Sukumaran K, Mukherjee PS, Pillai SGK, Kulkarni AK. $J$ Mater Sci 1986; 21: 57.

2. Mohanty AK, Misra M, Drzal TD editors. Natural Fibers, Biopolymers and Biocomposites. Boca Raton: Taylor \& Francis, 2005.

3. Fowler PA, Hughes JM, Elias RM. Sci Food Agric 2006; 86:1781.

4. Yao F, Wu Q, Lei Y, Guo W, Xu Y. Polym Degrad Stab 2008; 93: 90.

5. Akerholm M, Hinterstoisser B, Salmén L. Carbohydr Res 2003; 339: 569

6. Focher B, Naggi A, Torri G, Cosani A, Terbojevich M. Carbohydr Res 1992; 17: 97.

7. Muller-Hagedorn M, Bockhorn H, Krebs L, Muller U. J Anal Appl Pyrol 2003; 68: 231.

8. Varhegyi G, Jakab E, Antal MJ. Energy Fuels 1994c; 8: 1345.

9. Alves SS, Figueiredo JL. J Anal Appl Pyrolysis 1988; 13: 123.

10.Koufopanos CA, Maschio G, Lucchesi A. Can J Chem Eng 1991; 69: 907. 



\subsection{RESULTADOS Y DISCUSIÓN}

“COMPARATIVE MORPHOLOGICAL, STRUCTURAL AND THERMAL ANALYSIS STUDIES OF DIFFERENT NATURAL FIBRES" 



\title{
“COMPARATIVE MORPHOLOGICAL, STRUCTURAL AND THERMAL ANALYSIS STUDIES OF DIFFERENT NATURAL FIBRES"
}

\begin{abstract}
Cotton, flax, hemp, kenaf and jute natural fibres have been selected to assess their suitability as reinforcement in composite materials. It is known that the use of natural fibres in the composite engineering can be a good alternative for replacing traditional fillers such as glass and carbon fibres [1]. The chemical composition of each natural fibre was analyzed, together with their physical aspect and the Young Modulus. Scanning Electron Microscopy (SEM) was performed to establish differences between the superficial appearance of each natural fibre; Fourier-Transform Infrared Spectroscopy (FTIR) was used to elucidate their crystalline structure and finally, the thermal behaviour was investigated by Differential Scanning Calorimetry (DSC) and Thermogravimetric Analysis (TGA). Significant differences were observed in the chemical composition of each natural fibre: Cotton fibres present the highest cellulose percentage (91\%) followed by flax $(77 \%)$, whereas kenaf fibres have the highest percentage in hemicellulose and lignin (22\% and $11 \%$ respectively). These differences in the chemical composition may influence the morphologic and thermal properties of each natural fibre. The crystallinity index and the moisture were evaluated from the FTIR spectra. Kenaf and hemp fibres have the lowest crystallinity index among the studied fibres, due to their low cellulose composition. In addition, the moisture of the natural fibres increases as a function of the hemicellulose percengage. Second derivative FTIR spectra confirm that the cellulose crystallinity of all the studied fibres consists mainly of $\mathrm{I}_{\beta}$ crystalline phase, with jute, flax and cotton being the fibre that displays the major $\mathrm{I}_{\beta}$ crystalline phase. Again, jute, cotton and flax exhibit higher thermal stability compared to kenaf and hemp. Thus, the crystallinity and the thermal stability depend principally on cellulose content, whereas the moisture is related to the hemicellulose present in each natural fibre. The kinetics of the thermal decomposition processes were analysed using different models including Friedman, Flynn-Wall-Ozawa, Criado and Coats-Redfern methods. The results suggest that decomposition of the cellulose and hemicellulose follow a one-step reaction mechanism of order $n$. The results suggest that cellulose pyrolysis can be model with the same kinetic parameters $\left(\mathrm{f}(\alpha)=(1-\alpha)^{l}, E a=200 \mathrm{~kJ} / \mathrm{mol}, A=10^{15} \mathrm{~min}^{-1}\right)$ for all studied fibres. However, the region where most of the hemicellulose is pyrolysed shows differences in the Ea (168-194 kJ/mol), $A\left(10^{8,4}-10^{11,4} \mathrm{~min}^{-1}\right)$ and $n(1-1,7)$ parameters, probably due to the difficulties to separate the hemicellulose/pectin contribution from the cellulose one.
\end{abstract}

Keywords: Natural Fibres, Cristallinity Index, Chemical Composition, Thermal properties 


\section{Experimental Procedure}

\section{Materials}

Cotton, flax, hemp, kenaf and jute natural fibres were provided by Yute S.L. (Spain). The average length and diameter of each natural fibre were determined by optical microscopy over 100 fibres. The average Young Modulus of each natural fibre was provided by the manufacturer. The average mechanical and physical properties of the natural fibres are summarised in Table 1.

Table 1. Physical and mechanical properties of natural fibres

\begin{tabular}{c|cccc}
\hline & $\begin{array}{c}\text { Average } \\
\text { lengh } \\
(\mathrm{mm})\end{array}$ & $\begin{array}{c}\text { Average } \\
\text { diameter } \\
\left(\cdot 10^{2} \mathrm{~mm}\right)\end{array}$ & $\begin{array}{c}\text { Young- } \\
\text { Modulus } \\
(\mathrm{GPa})\end{array}$ & $\begin{array}{c}\text { Aspect } \\
\text { form }\end{array}$ \\
\hline Cotton & $3,0 \pm 1,0$ & $1,8 \pm 1,2$ & $12,0 \pm 1,0$ & $67,0-666,7$ \\
Flax & $6,0 \pm 4,0$ & $2,0 \pm 0,3$ & $70,0 \pm 1,5$ & $136,6-500,0$ \\
Hemp & $1,0 \pm 0,5$ & $7,7 \pm 7,0$ & $50,0 \pm 2,0$ & $10,7-214,0$ \\
Kenaf & $10,0 \pm 5,0$ & $15,0 \pm 0,5$ & $40,0 \pm 1,0$ & $25,0-150,0$ \\
Jute & $6,5 \pm 3,5$ & $1,0 \pm 0,3$ & $60,0 \pm 1,0$ & $230,7-1428,5$ \\
\hline
\end{tabular}

\section{Chemical Composition Measurements}

The samples of natural fibres were hydrolised and two different products were obtained: a solid product conformed from lignin and inorganic residue and a liquid product of carbohydrates. The lignin content in natural fibres was measured using Klason method, according to the procedure reported by Monties et al. [2]. The samples were therefore pyrolysed in a furnace during 6 hours at a temperature of $500^{\circ} \mathrm{C}$ to obtain the ashes of each one. The carbohydrate composition was analysed following a modified protocol from Theander et al. [3], based on reduction with sodium borohydride, acetylation, and chromatographic determination. The samples were then examined by gas chromatography (GC) using a Hewlett-Packard HP-6890 chromatograph. Inositol was used as an internal standard. Separation was performed in a BP X70 capillary column with dimensions $12 \mathrm{mx} 0,32 \mathrm{~mm}$ ID (SGE Analytical Science) operated at $210^{\circ} \mathrm{C}$ with helium as the carrier gas. The injector temperature was kept at $230{ }^{\circ} \mathrm{C}$ and the detector temperature was $250{ }^{\circ} \mathrm{C}$. In addition, the humidity of the samples was assessed using a Mettler Toledo HB43 moisture analyzer (Columbus, $\mathrm{OH})$. 


\section{Scanning electron microscopy (SEM) Measurements}

SEM micrographs were obtained from cryogenic sectioned samples after sputtering with gold/palladium, using a JEOL JSM-5400 scanning electron microscope (JEOL Ltd., Japan).

\section{Differential Scanning Calorimetry (DSC) Measurements}

DSC measurements were performed on a Mettler Toledo DSC 822e (Columbus, OH) previously calibrated with indium and zinc standards. Samples were sealed in standard aluminium pans previously pierced. Natural fibres were submitted to the following thermal scans:

(i) First heating scan from $-100^{\circ} \mathrm{C}$ to $200{ }^{\circ} \mathrm{C}$, hold at $200{ }^{\circ} \mathrm{C}$ for 3 minutes

(ii) Cooling scan from $200^{\circ} \mathrm{C}$ to $-100{ }^{\circ} \mathrm{C}$, hold at $-100{ }^{\circ} \mathrm{C}$ for 3 minutes

(iii) Second heating scan from $-100^{\circ} \mathrm{C}$ to $450^{\circ} \mathrm{C}$.

The heating and cooling rates were set at $10{ }^{\circ} \mathrm{C} / \mathrm{min}$. The measurements were performed five times to assure a good reproducibility and the average was considered as representative values.

\section{Fourier Transform Infrared Spectrometry (FTIR) Measurements}

The FTIR spectra were recorded at room temperature in a FTIR spectrometer Spectrum 2000 from Perkin Elmer, equipped with a Golden single-reflection accessory for attenuated total reflection (ATR) measurements. Each spectra was obtained by the performance of 24 scans between 4000-600 $\mathrm{cm}^{-1}$ at intervals of $1 \mathrm{~cm}^{-1}$. The FTIR peaks were automatically baseline corrected using Omnic 7 Software. The measurements were performed seven times to assure the accuracy of the measurements.

\section{Thermogravimetric (TGA) Measurements}

The thermal decomposition of the natural fibres was evaluated by dynamic thermogravimetric analysis (TGA) using a Mettler-Toledo TGA/SDTA 851 (Columbus, OH). Approximately 4,5 mg of sample was heated between 25 and $750^{\circ} \mathrm{C}$ at different heating rates in the range of 3 , $5,10,20$, and $30{ }^{\circ} \mathrm{C} / \mathrm{min}$ under intert atmosphere with an argon flow of $50 \mathrm{~mL} / \mathrm{min}$. The measurements were performed three times to assure the reliability of the measure. 


\section{Results and Discussion}

\section{Chemical Composition Measurements}

The carbohydrate composition of the natural fibres was determined from the quantification of the area peaks from chromatographic curves and the calibration curves elaborate from a mixture of standards (glucose, mannose, xylose, arabinose and galactose). The amount of cellulose results from the percentage of glucose, whereas the amount of hemicellulose/pectin corresponds to the the percentage of the remaining sugars. The obtained percentages are summarised in Table 2. The solid product from the hydrolysis was dried and weight and the results are also shown in Table 2. All the measurements were duplicated and a deviation of less than $1 \%$ was found for all the samples.

Table 2. Carbohydrate composition and solid product from the hydrolysis of natural fibres

Once the ash values

\begin{tabular}{c|ccc}
\hline & $\begin{array}{c}\text { Hemicellulose/ } \\
\text { Pectin }(\%)\end{array}$ & $\begin{array}{c}\text { Cellulose } \\
(\%)\end{array}$ & $\begin{array}{c}\text { Lignin/Ash } \\
(\%)\end{array}$ \\
\hline Cotton & 2,5 & 95,5 & 2,0 \\
Flax & 8,9 & 80,6 & 10,4 \\
Hemp & 13,8 & 74,2 & 12,0 \\
Kenaf & 24,0 & 62,8 & 13,3 \\
Jute & 14,6 & 75,6 & 9,8 \\
\hline
\end{tabular}

were determined, the chemical composition based on the main components of each natural fibre (hemicellulose/pectin, cellulose and lignin) were calculated and their values are summaresed in Table 3.

Table 3. Percentage of the main components of natural fibres

\begin{tabular}{c|ccc}
\hline & $\begin{array}{c}\text { Hemicellulose/ } \\
\text { Pectin }(\%)\end{array}$ & $\begin{array}{c}\text { Cellulose } \\
(\%)\end{array}$ & $\begin{array}{c}\text { Lignin } \\
(\%)\end{array}$ \\
\hline Cotton & 2,5 & 97,5 & --- \\
Flax & 9,6 & 87,2 & 3,2 \\
Hemp & 14,2 & 79,0 & 6,6 \\
Kenaf & 24,3 & 63,4 & 12,2 \\
Jute & 15,3 & 78,0 & 6,8 \\
\hline
\end{tabular}


Finally, taking into account the ash and humidity percentages of the natural fibre the chemical composition of the natural fibres is showed in Table 4.

Table 4. Chemical composition of natural fibres

\begin{tabular}{c|ccccc}
\hline & $\begin{array}{c}\text { Hemicellulose/ } \\
\text { Pectin }(\%)\end{array}$ & $\begin{array}{c}\text { Cellulose } \\
(\%)\end{array}$ & $\begin{array}{c}\text { Lignin } \\
(\%)\end{array}$ & $\begin{array}{c}\text { Ash } \\
(\%)\end{array}$ & $\begin{array}{c}\text { Humidity } \\
(\%)\end{array}$ \\
\hline Cotton & 2,4 & 91,5 & -- & 2,0 & 4,0 \\
Flax & 8,5 & 77,0 & 2,8 & 7,0 & 4,5 \\
Hemp & 12,9 & 69,7 & 5,4 & 5,8 & 5,1 \\
Kenaf & 22,3 & 58,2 & 11,2 & 1,4 & 7,0 \\
Jute & 14,1 & 71,8 & 6,5 & 2,5 & 5,5 \\
\hline
\end{tabular}

From these values, a direct relation can be observed between the humidity and the hemicellulose/pectin percentages. Figure 1 displays the humidity percentage as a function of the hemicellulose/pectin composition and a linear increase is observed, evidencing the humidity content of each natural fibre depends of the most hydrophilic component present, this is, hemicellulose/pectin.

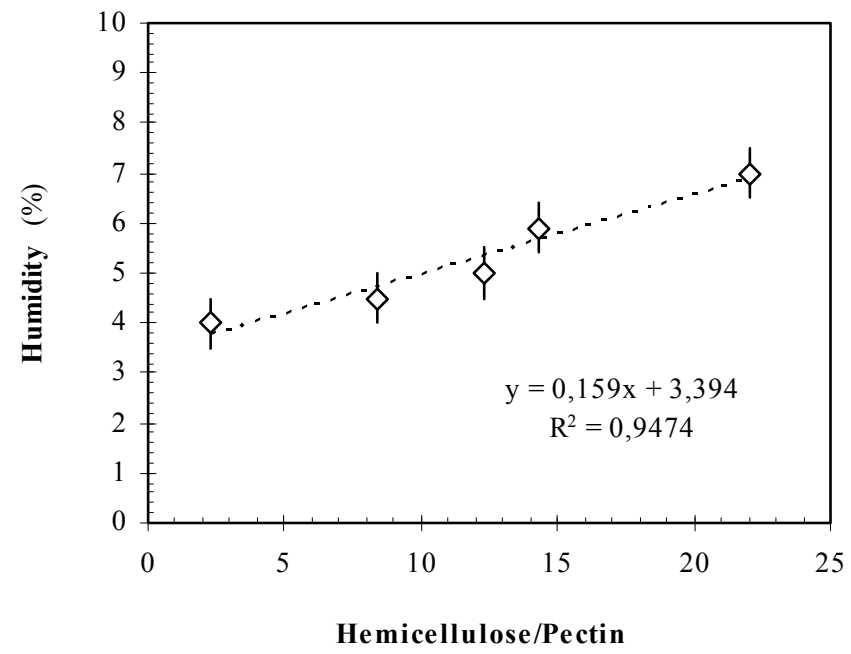

$(\%)$

Figure 1. Humidity percentage as a function of the hemicellulose and pectin content by chemical analysis

\section{Scanning Electron Microscopy Measurements}

Figure 2 shows that natural fibres are like microscopic tubes, i.e., cell walls surrounding the center lumen [4], with different hierarchical microstructures. It is known that the cell wall is build up of several layers: the primary layer first deposited during the cell growth and the latter-grown secondary layer. This secondary layer is formed from oriented reinforcing 
semicrystalline cellulose microfibrils embedded in a hemicelluloses/lignin matrix of varying composition. Thus, biofibres can be considered to be composites of hollow cellulose fibrils, held together by a lignin and hemicellulose matrix [5]. Such microfibrils typically have a diameter of about $10-30 \mathrm{~nm}$, are made up of 30 to 100 cellulose molecules in extended chain conformation.
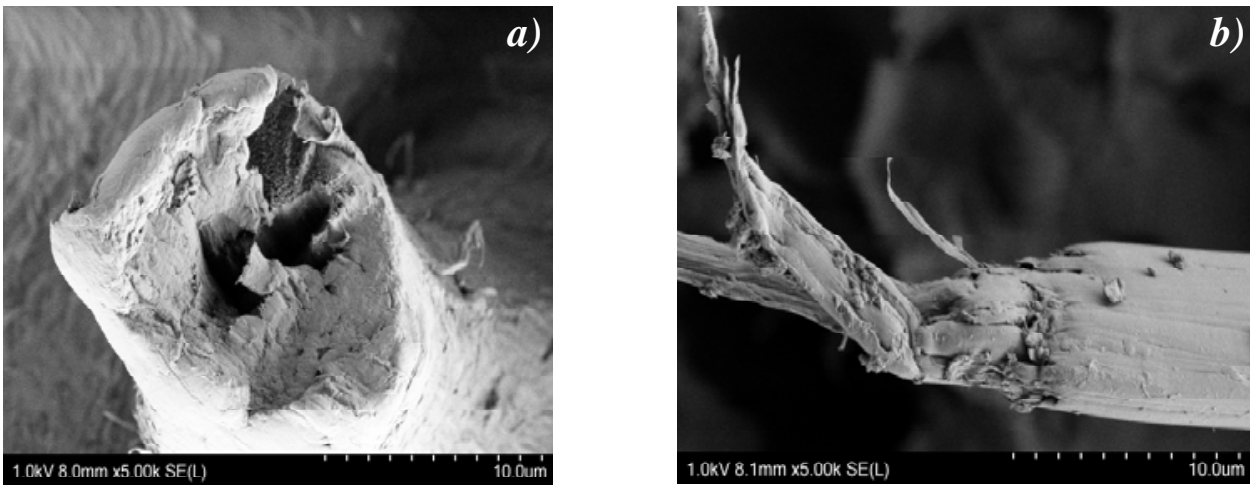

Figure 2. Scanning Electron Micrographs of a cross-section of a) flax and b) jute fibres.

Figure 3 shows the cross-section of cotton, flax, jute fibres observed by SEM. The studied fibres are long cylinders with tapered end. Moreover, cotton fibres show twist channels in the surface (Figure $3 d$ ) that the rest of fibres do not show.

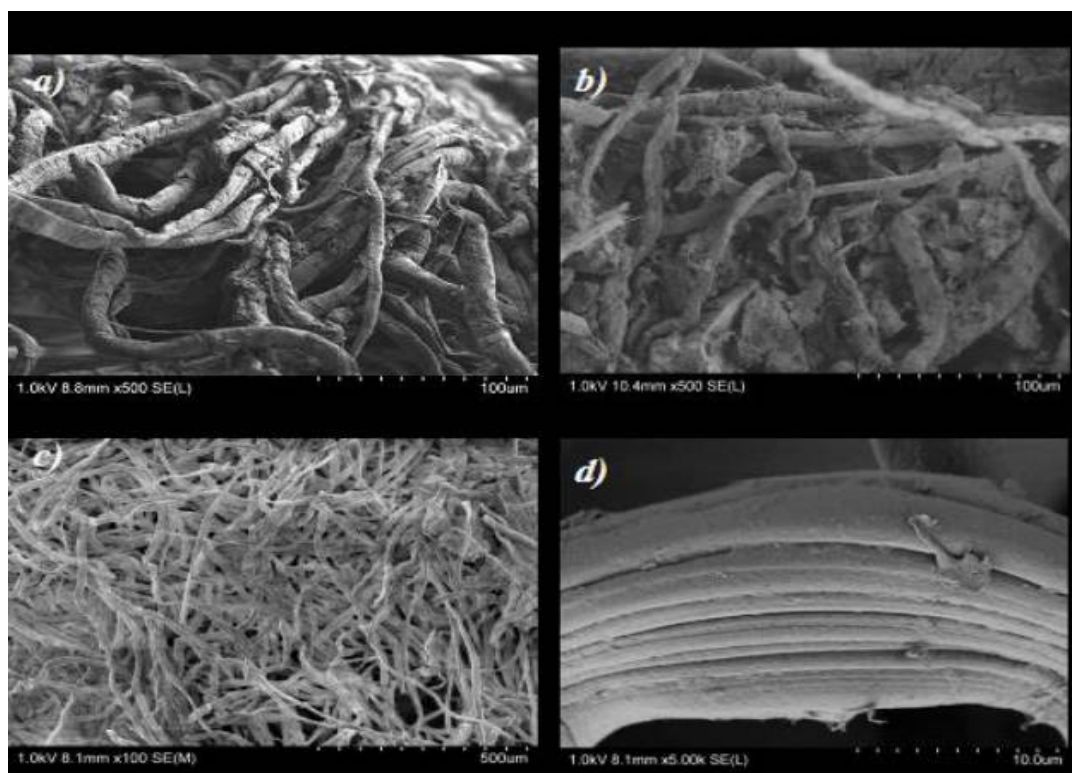

Figure 3. Scanning Electron Micrograph of a cross-section of a) flax fibre, b) jute fibre and c-d) cotton fibres. 


\section{Differential Scanning Calorimetry Measurements}

Figures $4 a$ and $4 b$ show the calorimetric thermograms from the first and second heating scan for the natural fibres. The first heating scan displays a big endothermic peak around $90^{\circ} \mathrm{C}$ with overlapping shoulders at higher temperatures for all natural fibres. In the second heating scan (from -100 to $200{ }^{\circ} \mathrm{C}$ ) this big endothermic peak disappears, and only a small peak centred at higher temperatures than $130^{\circ} \mathrm{C}$ remains for almost all the samples.
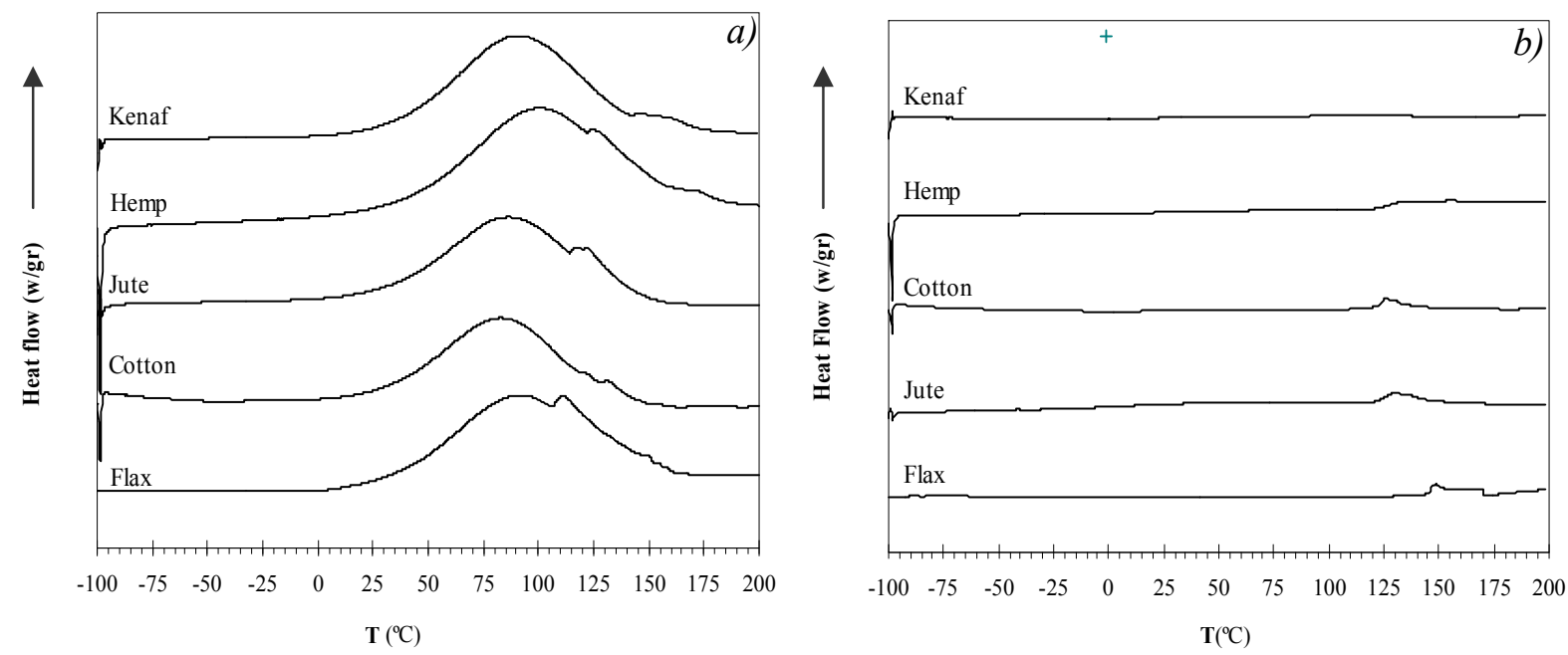

Figure 4. a) First heating and b) second heating scans for cotton, flax, hemp, kenaf and jute fibres

In the cooling scan (Figure 5) no thermal transition is displayed. For this reason, the great endothermic peak that appears in the first heating scan could be associated with the evaporation of the absorbed water. The small thermal transition at temperatures higher than $130{ }^{\circ} \mathrm{C}$ that appears in the second heating scan could be related to reorganizations of cellulose chains, once the cellulose is dried [6].

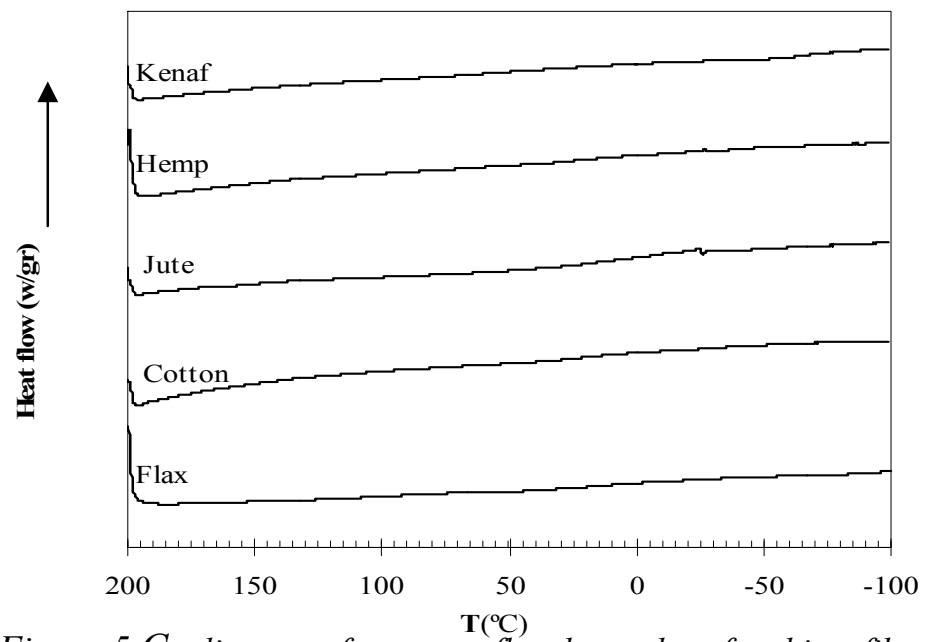

Figure 5.Cooling scan for cotton, flax, hemp, kenaf and jute fibres 
In order to determine the enthalpic values associated with the absorbed water the small thermal transition that appears in the second heating scan was subtracted to the big endothermic peak of the first heating scan. These values have been plotted as a function of the hemicellulose/pectin composition (Figure 6) and a linear increase is observed. These results agree with those displayed in the chemical composition (Figure 1).

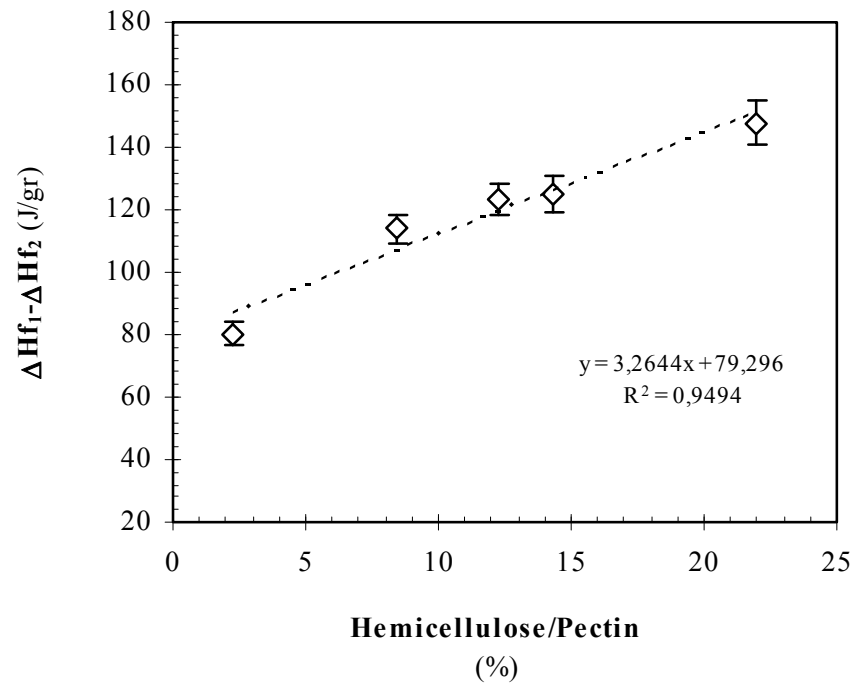

Figure 6. Enthalpic values related to the absorbed water as a function of the hemicellulose and pectin content by calorimetric analysis

\section{Fourier Transform Infrared Spectrometry Measurements}

The main differences between the natural fibres spectra of each fibre have been assessed. Figure 7 displays the FTIR spectra of all the studied fibres. Table 5 summarises the main bands of the spectra of the natural fibres.

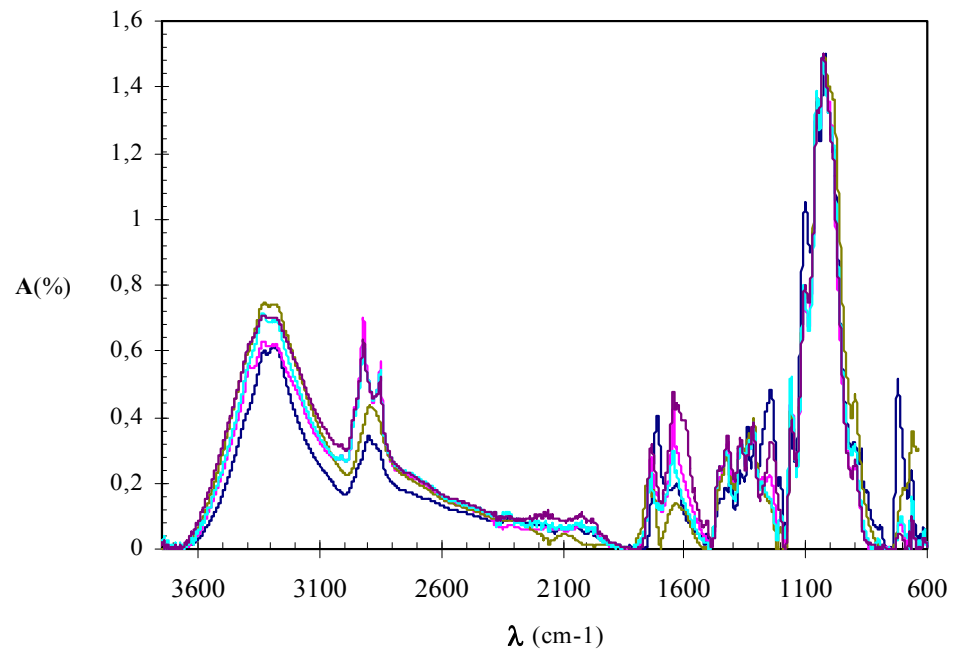

Figure 7. FTIR spectra for-) cotton, -) flax, -) hemp, -) kenaf and -) jute fibres 
Table 5. Characteristic absorption bands of natural fibres

\begin{tabular}{|c|c|c|}
\hline $\begin{array}{c}\text { Absorption bands } \\
\left(\mathrm{cm}^{-1}\right)\end{array}$ & Functional groups & References \\
\hline $4000-2995$ & OH stretching & [7] \\
\hline $3580 ; 3560$ & free $\mathrm{OH}$ & {$[8]$} \\
\hline $3455-3435$ & intramolecular hydrogen bonding of $2 \mathrm{OH} \ldots . . \mathrm{O} 6$ & [9],[10] \\
\hline $3337-3341$ & intramolecular hydrogen bonding of $3 \mathrm{OH} \ldots . . \mathrm{O} 5$ & {$[9],[10]$} \\
\hline $3230-3310$ & intermolecular hydrogen bonding of $6 \mathrm{OH} \ldots \mathrm{O} 3$ & {$[9],[10]$} \\
\hline 3240 & I $\alpha$ phase & {$[11],[12]$} \\
\hline 3270 & I $\beta$ phase & {$[11],[12],[13]$} \\
\hline 2915-2900 & $\mathrm{CH}$ stretching & [7] \\
\hline 1730 & $\begin{array}{l}\mathrm{C}=\mathrm{O} \text { stretching of methyl esters and carboxylic acid in pectin and to } \\
\text { the acetyl groups in hemicellulose }\end{array}$ & {$[7]$} \\
\hline $1630-1640$ & $\mathrm{OH}$ bending mode of water & [7] \\
\hline $1420-1430$ & $\mathrm{HCH}$ and $\mathrm{OCH}$ in-plane bending & [7] \\
\hline 1314-1318 & $\mathrm{COH}$ bending & [7] \\
\hline 1158-1160; 900 & Glucopyranose ring; $\mathrm{COC}, \mathrm{CCO}$ and $\mathrm{CCH}$ deformation and stretching & {$[7]$} \\
\hline $1130-1000$ & $\mathrm{OH}$ bending & [7] \\
\hline 896-898 & $\mathrm{CH}$ wang & [7] \\
\hline 750 & I $\alpha$ phase & [11], [14] \\
\hline 710 & I $\beta$ phase & {$[11],[14]$} \\
\hline 664 & $\mathrm{COH}$ out of plane bending & [7] \\
\hline
\end{tabular}

Three characteristic bands placed around $3435 \mathrm{~cm}^{-1}, 3339 \mathrm{~cm}^{-1}$ and $3292 \mathrm{~cm}^{-1}$ can be observed in the region related to hydrogen-bonded $\mathrm{OH}$ stretching for all the spectra of the studied natural fibres. Cotton fibres seem to have a predominant number of intermolecular hydrogen bonding of $6 \mathrm{OH} . . \mathrm{O} 3$ in their structure, whereas flax, hemp, kenaf and jute fibres seem to have a predominant intramolecular hydrogen bonding of $3 \mathrm{OH}$.....O5 .

In addition to this, these five fibres show differences in the region of the $\mathrm{C}-\mathrm{H}$ stretching vibrations. Cotton and jute fibres show a single peak at 2899 and $2890 \mathrm{~cm}^{-1}$ respectively, both related to the $\mathrm{C}-\mathrm{H}$ stretching vibrations of cellulose, whereas kenaf, flax and hemp fibres show a doublet at $2920 \mathrm{~cm}^{-1}$ and $2850 \mathrm{~cm}^{-1}$, attributed to the anti-symmetrical and symmetrical $\mathrm{CH}_{2}$ stretching vibrations of non-cellulose polysaccharides [15], respectively.

Different intensities in the bands placed around $1640 \mathrm{~cm}^{-1}$ can be observed, attributed to the $\mathrm{OH}$ bending mode of water. Jianxin He et al.[16] proposed the use of the peak ratio between 1640 and $2900 \mathrm{~cm}^{-1}$ to determine the moisture index of each natural fibre (MI). Figure 8 displays the moisture index of each natural fibre as a function of the hemicellulose/pectin composition; a linear increase of the moisture index with the hemicellulose/pectin percentage can be also observed. These results agree with those displayed in the chemical composition 
and calorimetric results confirming the kenaf and jute fibres have the highest moisture index due to the highest hemicellulose/pectin content.

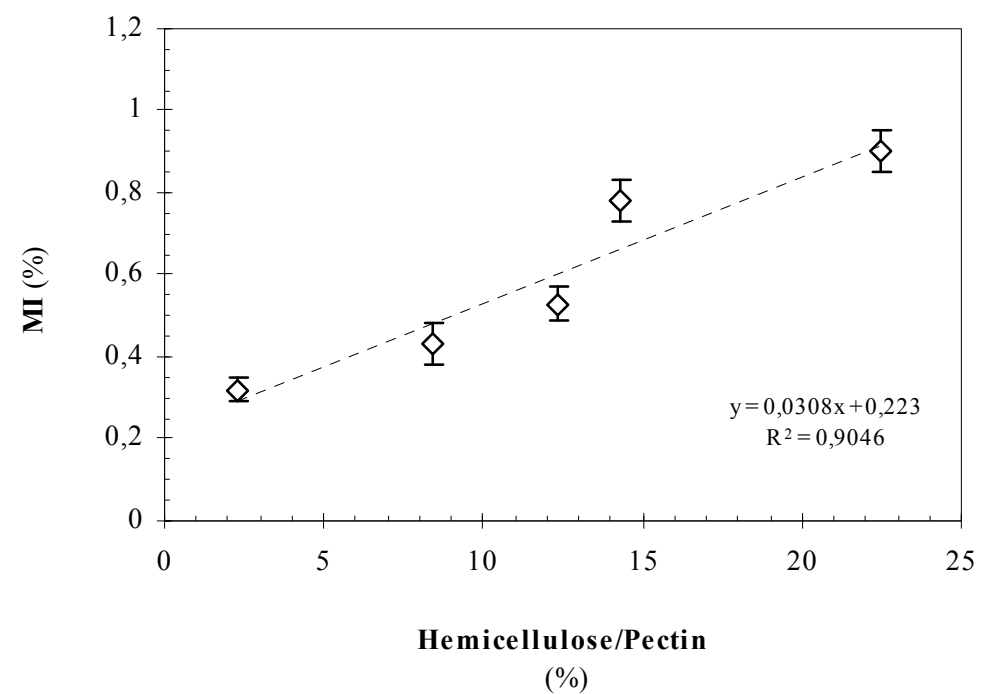

Figure 8. Index of moisture content as a function of the hemicellulose and pectin content by FTIR analysis

The degree of crystallinity can be estimated by infrared spectroscopy using some empirical parameters, such as the crystallinity index (CrI) and the hydrogen-bond intensity (HBI). These parameters are defined as a function of the relative intensity of certain bands (at 4000$2995 \mathrm{~cm}^{-1}, 2900 \mathrm{~cm}^{-1}, 1430 \mathrm{~cm}^{-1}, 1370 \mathrm{~cm}^{-1}$, and $900 \mathrm{~cm}^{-1}$ ) that are especially sensitive to the crystalline and amorphous regions in the cellulose. The empirical parameters used to asses the degree of crystallinity are:

o The ratio of the absorbance height of the maximum peak between $4000-2990 \mathrm{~cm}^{-1}$ and $1337 \mathrm{~cm}^{-1}\left(\mathrm{H}_{4000-2990} / \mathrm{H}_{1337}\right)$ as an empirical HBI parameter [17].

0 The absorbance ratio $H_{1371} / H_{2900}$ and the area ratio $A_{1371} / A_{665}$ as an empirical crystallinity index parameter (CrI) [18-19].

Table 6 summarises the values of crystalline index and hydrogen-bond intensity for all natural fibres. 
Table 6. Hydrogen-bond intensity (HBI) and crystalline index (CrI) of natural fibres.

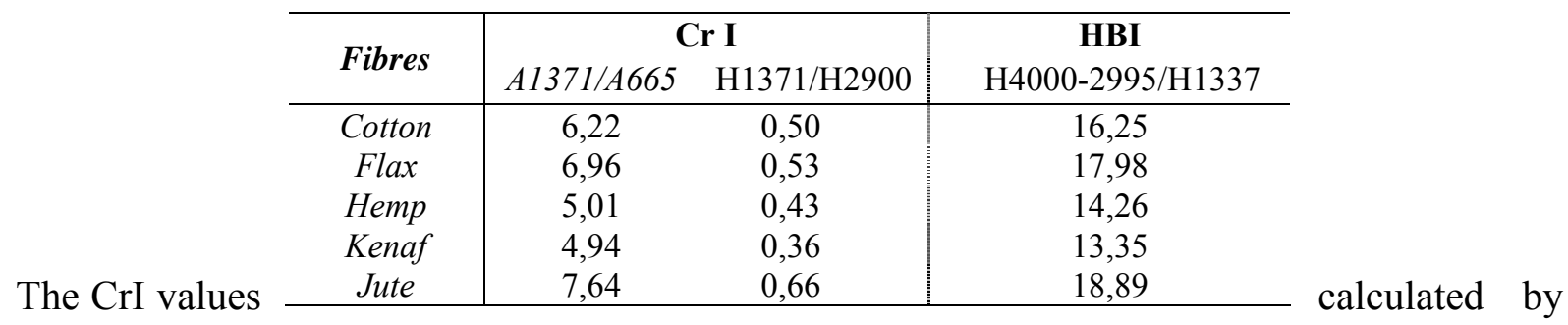

the two methods and the HBI follow the same trend for the five fibres. Kenaf and hemp fibres, with lower cellulose percentages of $57 \%$ and $69 \%$, respectively, exhibit lower crystalline features than jute, flax and cotton fibres with higher cellulose content.

The second derivatives of the FTIR spectra (Figure 9) allow to identify the relative contents of the crystalline allomorph in major content, by improving the resolution of the $\mathrm{OH}$ stretching group. The bands at 3268 and $710 \mathrm{~cm}^{-1}$ are characteristic of the $\mathrm{I}_{\beta}$ crystalline phase, whereas the bands at $3230 \mathrm{~cm}^{-1}$ and $750 \mathrm{~cm}^{-1}$ identify the $\mathrm{I}_{\alpha}$ crystalline phase. The higher relative intensity of the bands related to the $\mathrm{I}_{\beta}$ phase in all the natural fibres indicates that the cellulose in these natural fibres consists mainly of $I_{\beta}$ phase [20]. Jute, flax and cotton fibres have the highest intensity of the bands at 3270 and $710 \mathrm{~cm}^{-1}$ and therefore the highest $\mathrm{I}_{\beta}$ allomorph content.

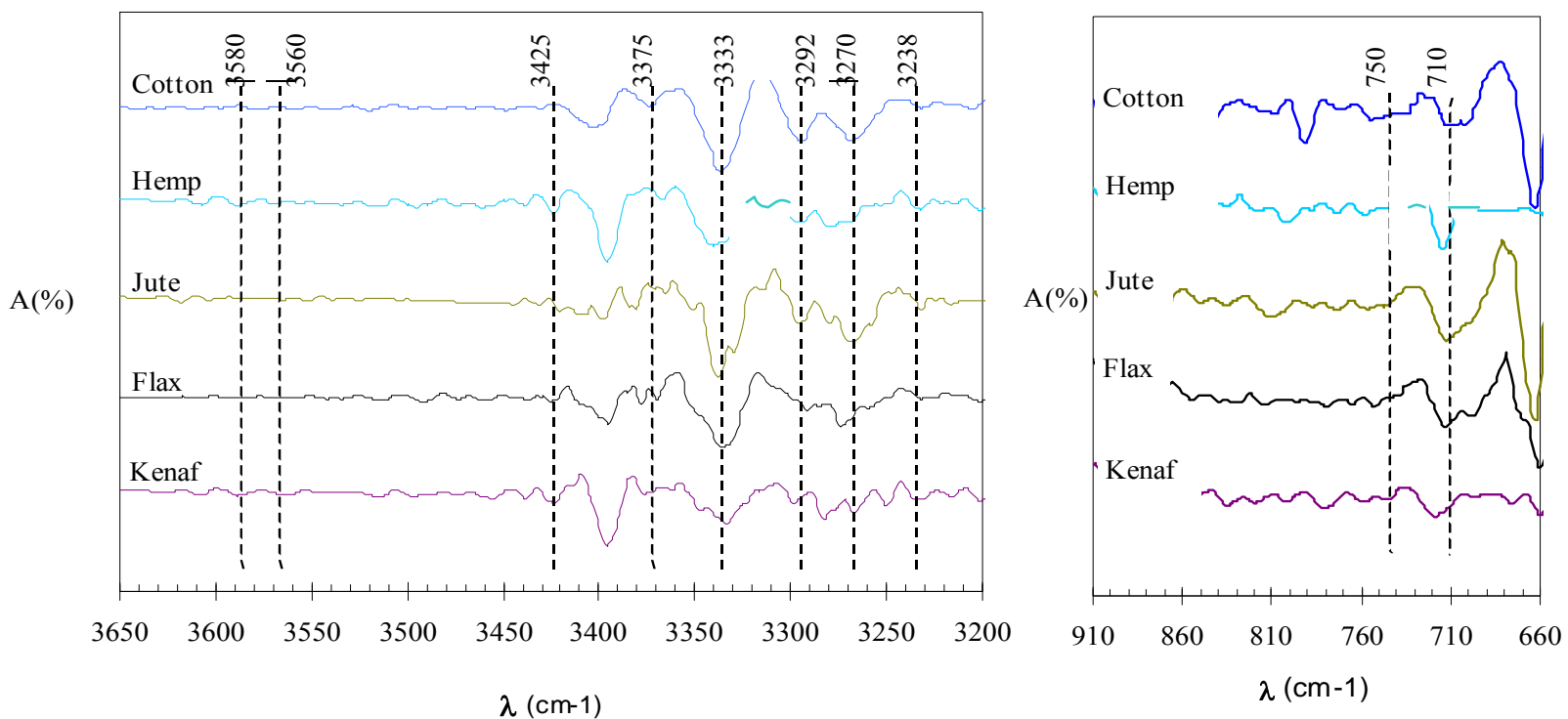

Figure 9. Second Derivative FTIR Spectra for-) cotton, -) flax, -) hemp, -) kenaf and -) jute fibres 
The thermal degradation of the natural fibres was analysed in detail by dynamical thermogravimetry at different heating rates. The thermogravimetric (TG) and derivative (DTG) curves of each natural fibre at a heating rate of $20^{\circ} \mathrm{C} / \mathrm{min}$ are displayed in Figure 10; similar patterns were obtained at different heating rates for each natural fibre but they are not shown here for the sake of clarity. However, as it was expected, the onset and the temperature peak increase as a function of the heating rate.

Several mass-loss regions can be observed for the pyrolysis of natural fibres [21]. The first mass-loss region between 40 and $130{ }^{\circ} \mathrm{C}$ can be attributed to the water absorption [22]. The second mass-loss region (from 207 to $560^{\circ} \mathrm{C}$ ) shows a complex thermal decomposition process with a main peak placed between 350 and $370{ }^{\circ} \mathrm{C}$, associated to the thermal decomposition of cellulose [23]. In addition, an overlapping shoulder related to the pyrolysis of both hemicellulose and pectins appears at lower temperatures (around 262 and $322{ }^{\circ} \mathrm{C}$ ) [24] and a tail is displayed above $467^{\circ} \mathrm{C}$, which is related to the degradation of lignin (for the fibres with certain lignin composition) [25] or to the final decomposition reactions of cellulose components to form tar or char [24]. Table 7 summarises the thermal degradation parameters of selected natural fibres at a heating rate of $20^{\circ} \mathrm{C} / \mathrm{min}$.

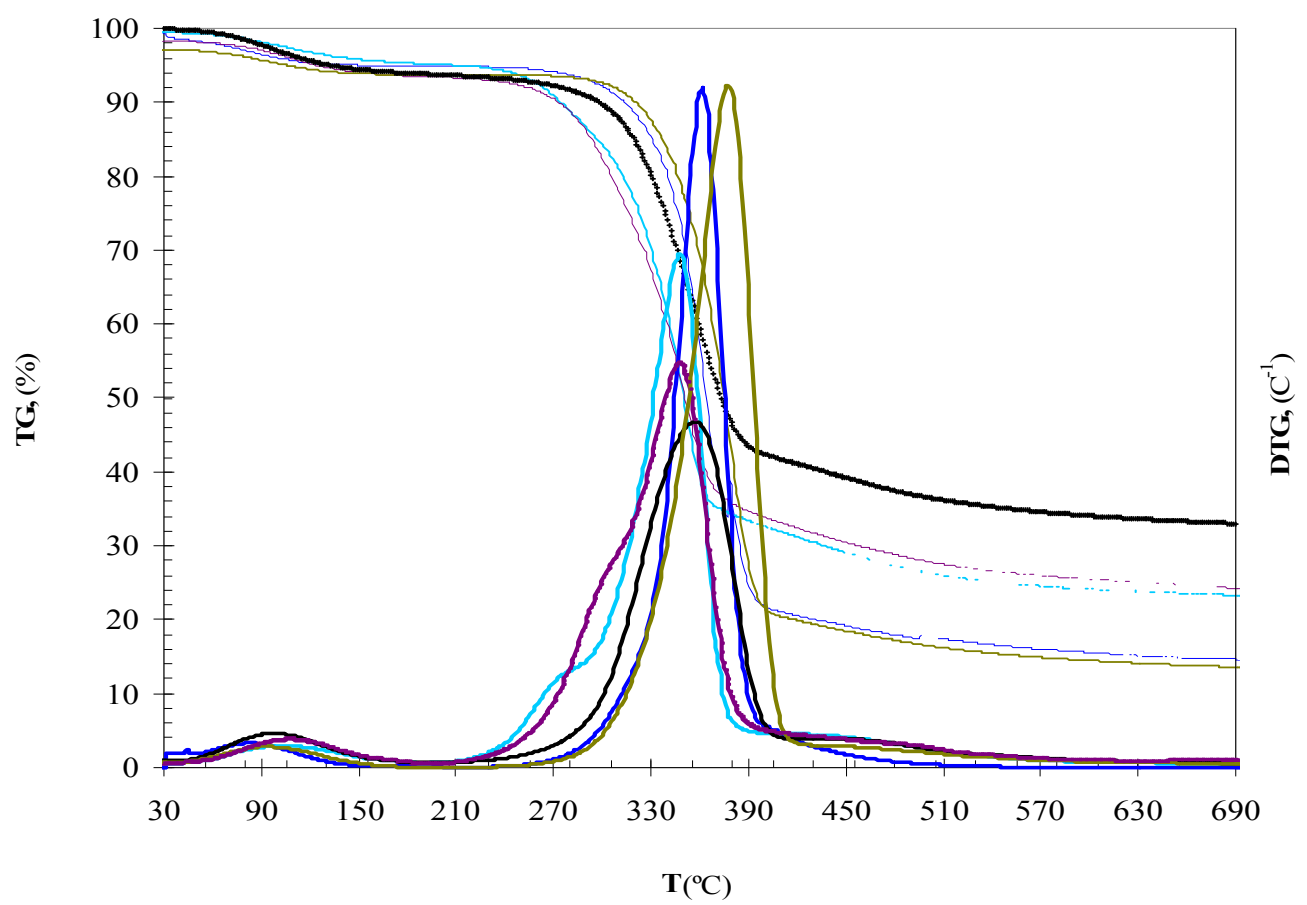

Figu

re 10. Thermogravimetric(TG) and derivative curves (DTG) for -) cotton, -) flax, -) hemp, -) kenaf and -) jute fibres 
Table 7. Thermogravimetric parameters of cotton, hemp, kenaf, flax and jute fibres from the DTG curves at a heating rate of $20^{\circ} \mathrm{C} / \mathrm{min}$

\begin{tabular}{|c|c|c|c|c|c|c|c|c|c|c|c|c|}
\hline \multirow[b]{2}{*}{ Fibres } & \multicolumn{2}{|c|}{ Humidity region } & \multicolumn{9}{|c|}{ Mass-loss main region } & \multirow{2}{*}{$\begin{array}{c}\text { Residue } \\
\begin{array}{c}\text { Mass } \\
(\%)\end{array} \\
\end{array}$} \\
\hline & $\begin{array}{l}\text { Mass } \\
\text { loss } \\
(\%) \\
\end{array}$ & $\begin{array}{c}\mathrm{T} \\
\text { peak } \\
\left({ }^{\circ} \mathrm{C}\right) \\
\end{array}$ & $\begin{array}{r}\text { Onset } \\
\left({ }^{\circ} \mathrm{C}\right)\end{array}$ & $\begin{array}{c}\text { Mass } \\
\text { Loss }_{0} \\
(\%)\end{array}$ & $\begin{array}{c}\mathrm{T} \\
\text { peak }_{0} \\
\left({ }^{\circ} \mathrm{C}\right)\end{array}$ & $\begin{array}{r}\mathrm{T}_{\mathrm{H}} \\
\left({ }^{\circ} \mathrm{C}\right)\end{array}$ & $\begin{array}{l}\mathrm{ML}_{\mathrm{H}} \\
(\%)\end{array}$ & $\begin{array}{c}\mathrm{T}_{\mathrm{C}} \\
\left({ }^{\circ} \mathrm{C}\right)\end{array}$ & $\begin{array}{c}\mathrm{ML}_{\mathrm{C}} \\
(\%)\end{array}$ & $\begin{array}{c}\mathrm{T}_{\mathrm{T}} \\
\left({ }^{\circ} \mathrm{C}\right)\end{array}$ & $\begin{array}{c}\mathrm{ML}_{\mathrm{T}} \\
(\%)\end{array}$ & \\
\hline Cotton & $3,4 \pm 0,5$ & $90,5 \pm 0,2$ & $308,9 \pm 0,4$ & $80,5 \pm 1,0$ & $360,8 \pm 0,4$ & $323,1 \pm 1,5$ & $2,2 \pm 0,5$ & $362,3 \pm 0,4$ & $77,0 \pm 1,0$ & $410,4 \pm 0,3$ & $<1$ & $14,0 \pm 0,7$ \\
\hline Flax & $4,3 \pm 1,0$ & $102,5 \pm 2,9$ & $301,0 \pm 2,0$ & $61,8 \pm 0,6$ & $358,5 \pm 1,6$ & $327,9 \pm 1,0$ & $5,5 \pm 2,0$ & $376,1 \pm 0,6$ & $53,5 \pm 1,0$ & $419,0 \pm 1,0$ & $2,5 \pm 1,5$ & $33,4 \pm 1,0$ \\
\hline Hemp & $5,1 \pm 0,8$ & $99,8 \pm 1,1$ & $258,5 \pm 2,6$ & $70,7 \pm 0,1$ & $348,2 \pm 1,0$ & $306,9 \pm 1,5$ & $9,0 \pm 0,5$ & $358,6 \pm 0,8$ & $56,8 \pm 0,5$ & $391,7 \pm 1,2$ & $3,0 \pm 0,8$ & $23,0 \pm 0,2$ \\
\hline Kenaf & $6,0 \pm 1,0$ & $106,3 \pm 0,8$ & $255,5 \pm 1,0$ & $68,8 \pm 0,3$ & $347,1 \pm 0,3$ & $308,6 \pm 0,5$ & $16,5 \pm 0,5$ & $356,7 \pm 0,3$ & $41,0 \pm 0,8$ & $391,7 \pm 1,0$ & $8,7 \pm 0,2$ & $25,0 \pm 0,1$ \\
\hline Jute & $5,5 \pm 0,8$ & $100,2 \pm 1,6$ & $314,4 \pm 1,0$ & $79,2 \pm 1,0$ & $372,4 \pm 0,7$ & $326,3 \pm 2,5$ & $10,8 \pm 1,0$ & $379,9 \pm 0,5$ & $54,0 \pm 2,0$ & $416,9 \pm 1,0$ & $6,6 \pm 0,7$ & $15,3 \pm 0,3$ \\
\hline
\end{tabular}


The first mass-loss region associated to the humidity percentage appears centred at $100{ }^{\circ} \mathrm{C}$ and represents more than $3 \%$ of mass loss in all the samples. According to the chemical analysis, Figure 11 shows that the humidity percentage of the natural fibres increases as a function of the hemicelullose/pectin content with a good regression and a similar slope as that showed in Figure 1.

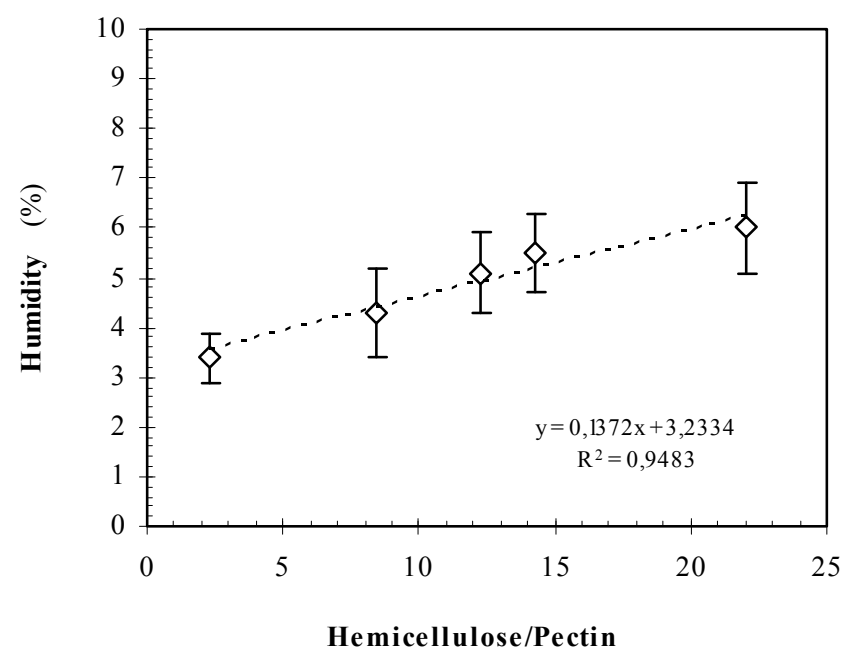

$(\%)$

Figure 11. Humidity percentage as a function of the hemicellulose and pectin content by thermogravimetric analysis

The onset temperature, the mass loss, the residue percentage and the temperature peak for the second mass-loss region $\left(206-600^{\circ} \mathrm{C}\right)$ were directly obtained from the thermograms. Jute, cotton and flax fibres display the highest values from the onset and the temperature peak. Hemp and kenaf fibres show an onset $45{ }^{\circ} \mathrm{C}$ lower than the ones shown by jute fibres. The natural fibres with higher cellulose content exhibit improved thermal stable material, similarly to the crystalline index.

The individual contributions of the three overlapped processes in the second mass-loss region, hemicellulose/pectin (peak H), cellulose (peak $C$ ), and high temperature tail (peak $T$ ) were determined using a deconvolution procedure based on an asymmetrical model (equation 1).

$$
y_{i}=A \cdot\left(\frac{1}{1+\exp \left(\frac{-\left(x-x_{c}+\frac{w_{1}}{2}\right)}{w_{2}}\right)}\right) \cdot\left(1-\frac{1}{1+\exp \left(\frac{-\left(x-x_{c}+\frac{w_{1}}{2}\right)}{w_{3}}\right)}\right)
$$

Here, $x_{c}$ is a position parameter related to the curve maximum; $A$ is an amplification parameter; and $w_{1}, w_{2}, w_{3}$ describe the dispersion and symmetry of the curve. The proposed 
deconvolution model considers that the measured value of $(d w(\%) d T)=y$ is equivalent to $\mathrm{y}=\mathrm{y}_{0}+\sum_{\mathrm{i}=1}^{\mathrm{n}} \mathrm{y}_{\mathrm{i}}$, where $\mathrm{y}_{0}$ is the baseline of each DTG curve and $n$ is the total number of deconvoluted peaks. The results of the fitting procedure for the deconvolution of the thermal decomposition processes for cotton, flax, hemp, kenaf and jute fibres are displayed in Figure 12.

The temperatures for each deconvoluted peak (named $T_{H}, T_{C}$, and $T_{T}$ respectively) were directly obtained by the mathematical fitting, corresponding to the value of $x_{c}$ parameter in each individual contribution. The mass-loss percentage equivalent to each individual process (named $M L_{H}, M L_{C}$ and $M L_{T}$ ) were calculated as the area of each deconvoluted peak; this percentage is related to the hemicellulose/pectin, cellulose, and lignin content from the results of carbohydrate analysis (without taking into account the ash values of each fibre). Table 8 compares the hemicellulose/pectin, cellulose and lignin percentages from the chemical analysis (Table 3) to the relative $M L_{H}, M L_{C}$ and $M L_{T}$ dates from the thermogravimetric analysis confirming the proposed thermogravimetric methodoly allows assessing the percentage of the chemicals of the natural fibres. The ash values are not taking into account in this comparation due to the high residues values obtained from the thermogravimetric results comparing with the chemical dates.

Table 8. Comparative results between the chemical analysis and the thermogravimetric results.

\begin{tabular}{c|cc|cc|cc}
\cline { 2 - 6 } \multicolumn{2}{c}{} & \multicolumn{2}{c|}{ Hemicellulose/Pectin (\%) } & \multicolumn{2}{c|}{ Cellulose ( \%) } & \multicolumn{2}{c}{ Lignin (\%) } \\
\hline \multirow{2}{*}{ Cotton } & 2,5 & 2,7 & 97,4 & 96,7 & --- & CA \\
Flax & 9,6 & 9,3 & 87,2 & 88,1 & 3,2 & 4,2 \\
Hemp & 14,2 & 14,1 & 79,0 & 80,3 & 6,6 & 6,0 \\
Kenaf & 24,3 & 23,9 & 63,4 & 63,4 & 12,2 & 12,6 \\
Jute & 15,2 & 15,1 & 78,0 & 77,3 & 6,8 & 7,3 \\
\hline
\end{tabular}

${ }^{*}$ CA $=$ Chemical Analysis

**TGA $=$ Thermogravimetric Analysis 

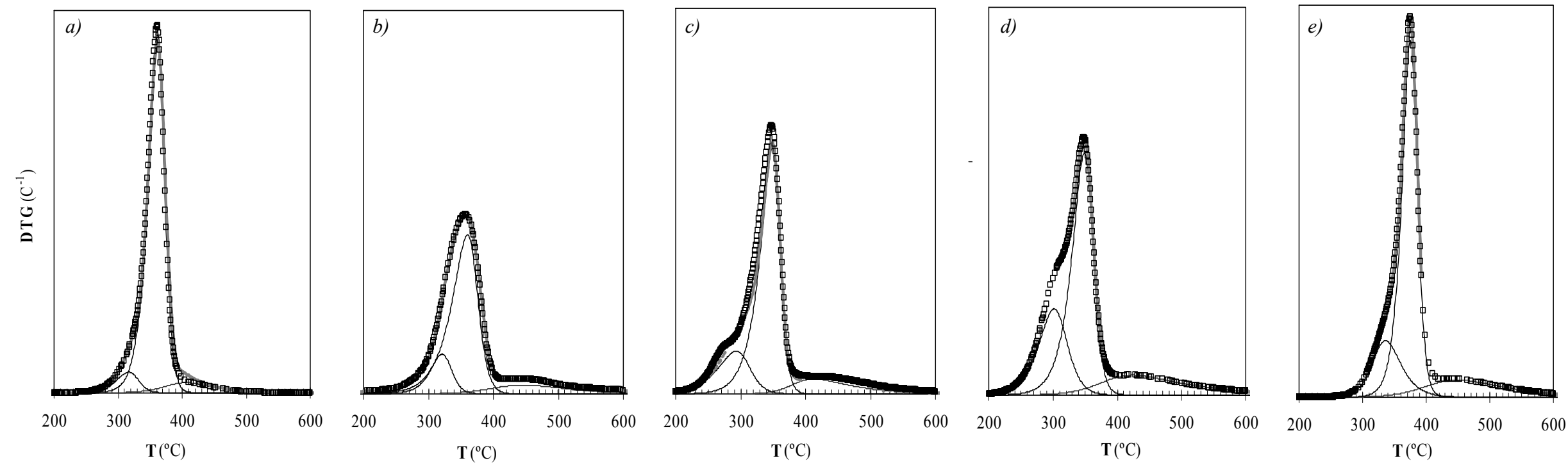

Figure 12. () DTG, fitting (-), (--) peak H, (--) peak C and (--) peak $T$ curves of a) cotton, b) flax, c) hemp d) kenaf and e) jute fibres 
The high values of the residue observed for the natural fibres, may be due to the repolymerisation of volatile products that increase the char content during the pyrolysis of cellulose fibres [26]. Mok and Antal [27] established that the volatilisation of glycolaldehyde with char formation is an exotherm process due to the formation of levoglucosan, whereas volatilisation without concurrent char formation is a endothermic process. Thus, tar and char formation [28,29] are two competitive pathways that may occur during the pyrolysis of the cellulose.

In this sense, Shafizadeh et al. [30] proposed a mechanism of different reactions (Figure 13), taking into account the reactivity of the cellulose, and the possibility of producing char by means of secondary reactions.

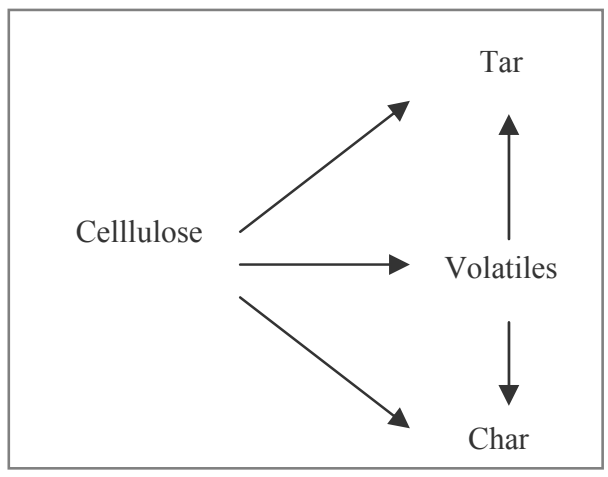

Figure 1.3 The Shafizadeh mechanisms

Figure 14 displays the second calorimetric heating scan for all the studied fibres from $200^{\circ} \mathrm{C}$ to $450^{\circ} \mathrm{C}$. An endothermic behaviour related to the thermal decomposition of the cellulose can be observed for the jute and flax fibres, whereas kenaf, hemp and cotton fibres display an exothermic behaviour. Thus, the production of char is dominant over the formation of tar in kenaf, hemp and cotton fibres.

Moreover, it is known that the formation of char is catalysed by the major duration of vaporsolid contact [31]. The calorimetric thermograms were thus carried out without the tops of the pans to control this variable. As it was expected, the minor vapor-solid contact duration produces a decrease in the exotherm transitions and an increase in the endothermic transitions, confirming the production of tar or char during cellulose pyrolysis. 


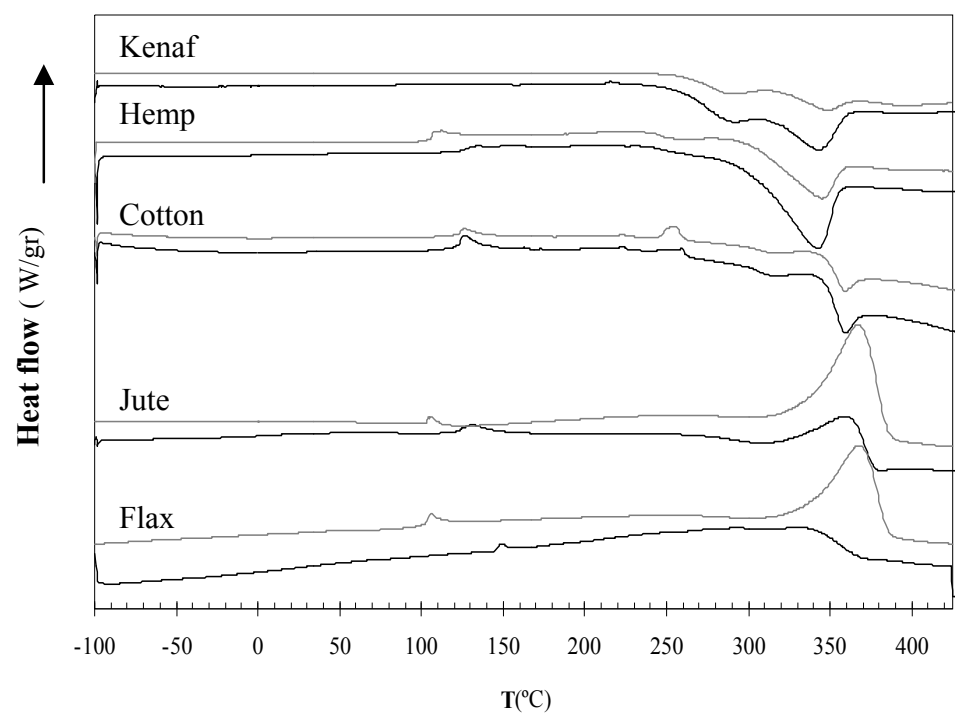

Figure 14 . Second heating scans for natural fibres from 200 to $425^{\circ} \mathrm{C}$-) with tops, -) without tops.

A thermogravimetric methodology was successfully applied on the first and second thermal decomposition region to determine the kinetic parameters, $E a, f(\alpha)$ and $A$ : Iso-conversional Friedman and Flynn-Wall-Ozawa methods [32,33] were employed to determine the $E a$ values; Criado method [34] was used to identify the $f(\alpha)$ of each thermal decomposition process (the proposed kinetic models are summarized in Table 9); and Coats-Redfern method [35] was finally employed to discuss the probable $f(\alpha)$ and to determine the A parameter value.

Table 9. Algebraic expressions for $f(\alpha)$ for the kinetic models used

\begin{tabular}{|c|c|c|c|}
\hline Kinetic Models & $f(\alpha)$ & Kinetic Models & $f(\alpha)$ \\
\hline D1 & $1 / 2(1-\alpha)-1$ & $n+m=1,8 ; n=1,7$ & $\alpha^{0,1}(1-\alpha)^{1,7}$ \\
\hline D2 & $-\ln (1-\alpha)$ & $n+m=2 ; n=1,5$ & $\alpha^{0,5}(1-\alpha)^{1,5}$ \\
\hline D3 & $3 / 2(1-\alpha)^{2 / 3}\left(1-(1-\alpha)^{1 / 3}\right)^{-1}$ & $n+m=2 ; n=1,9$ & $\alpha^{0,1}(1-\alpha)^{1,9}$ \\
\hline D4 & $3 / 2(1-\alpha)^{1 / 3}\left(1-(1-\alpha)^{1 / 3}\right)^{-1}$ & $n+m=2 ; n=1,2$ & $\alpha^{0,8}(1-\alpha)^{1,2}$ \\
\hline$R 1$ & 1 & $n=1 / F 1$ & $(1-\alpha)$ \\
\hline$R 2$ & $2(1-\alpha)^{1 / 2}$ & $n=1,5$ & $(1-\alpha)^{1.5}$ \\
\hline R3 & $3(1-\alpha)^{2 / 3}$ & $n=2$ & $(1-\alpha)^{2}$ \\
\hline
\end{tabular}

The Friedman and Flynn-Wall-Ozawa plots were performed for all the natural fibres; Figure 15 shows the Friedman and Flynn-Wall-Ozawa plots for the cotton fibres as an example. 

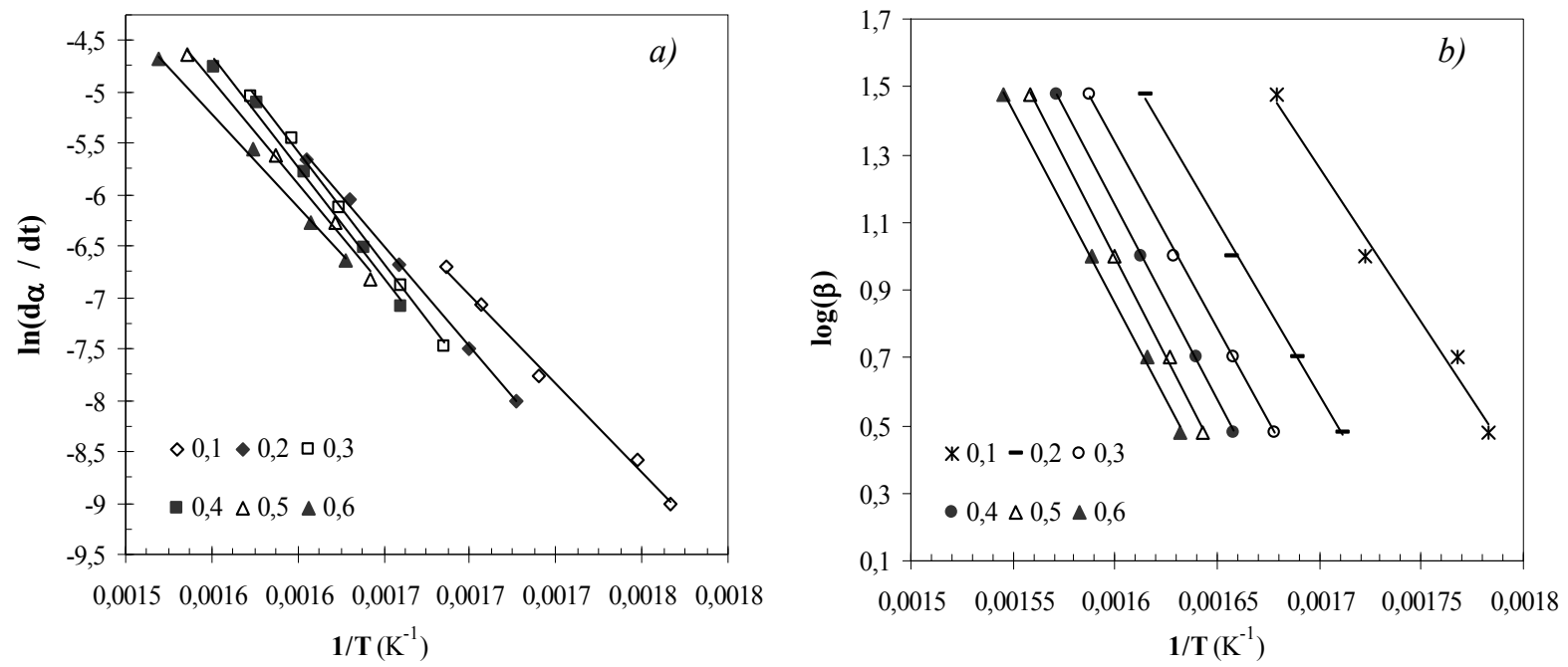

Figure 15.a) Friedman curves for the cotton fibre and b) Flynn-Wall-Ozawa curves for the kenaf fibres

The trend of Ea as a function of $\alpha$ for all the natural fibres by both isoconversional methods are displayed in Figure 16. The isoconversional Friedman and Flynn-Wall-Ozawa methods offer an $E a$ range of approximate $150-205 \mathrm{~kJ} / \mathrm{mol}$ for all the natural fibres in the studied conversion range. Activation energy changes drastically from $\alpha=0,1$ to $\alpha=0,3$ and remains then quite stable at higher conversion. This indicates that the degradation mechanism at low conversion is different from that at high conversion, possibly, indicating the cleavage of linkages with different bond energies. Two different $\alpha$ intervals can be thus distinguished where the decomposition of one or several constituents are predominant. The thermal decomposition process associated to the most of the hemicellulose/pectin presents a band range of $150-190 \mathrm{~kJ} / \mathrm{mol}$ whereas the thermal decomposition process related to the most of the cellulose remains almost constant around $190-205 \mathrm{~kJ} / \mathrm{mol}$ for all studied fibres.

The $E a$ found at higher conversion range $(0,3 \leq \alpha<0,7)$ are similar to those reported in literature [36-38]. However, the average $E a$ values for the lower conversion in the range $0,1 \leq$ $\alpha<0,3$ are higher than those expected for the hemicellulose component $(105-111 \mathrm{~kJ} / \mathrm{mol})$ [39]. This fact could be due to the overlapped initial decomposition process of cellulose, which is attributed to the formation of the ether bond with an Ea of $90-179 \mathrm{~kJ} / \mathrm{mol}$ [40]. Table 10 summarises the average $E a$ values of these two $\alpha$ regions obtained by iso-conversional methods. 

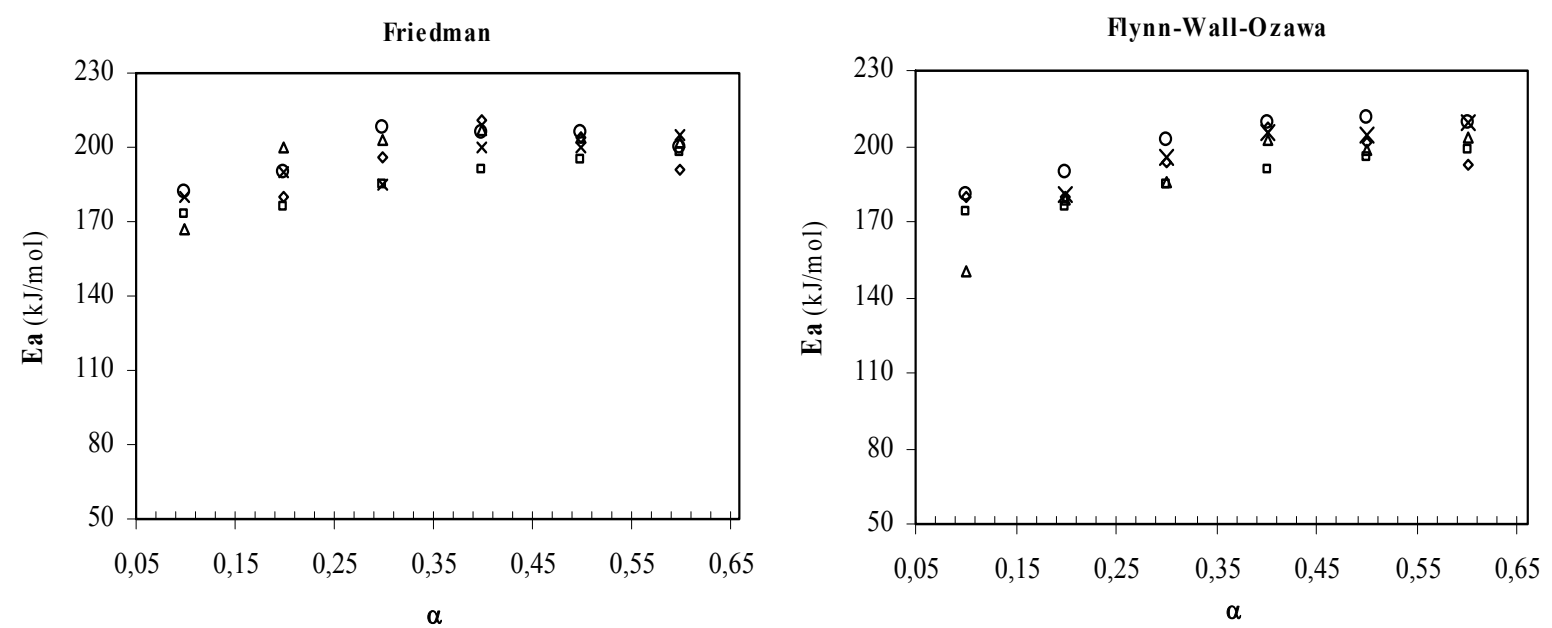

Figure 16. Ea of o) cotton, $\diamond)$ flax, $x$ ) hemp, $\square$ ) kenaf and $\Delta$ ) jute fibres as a function of the $\alpha$

Table 10. Kinetic parameters of cotton, hemp, kenaf, flax and jute fibres

\begin{tabular}{ll|c|cc|ccc}
\hline & & $\begin{array}{c}\text { Friedman } \\
\text { Ea } \\
\text { (kJ/mol) }\end{array}$ & \multicolumn{2}{|c|}{$\begin{array}{c}\text { Flynn-wall-Ozawa } \\
\text { A }\end{array}$} & \multicolumn{3}{|c}{ Coats-Redfern and Criado } \\
Cotton & $0,3 \leq \alpha<0,7$ & $204 \pm 3$ & $10^{15,0} \pm 3$ & $206 \pm 3$ & $10^{15,6} \pm 2$ & $205 \pm 2$ & $(1-\alpha)^{1}$ \\
& $0,1 \leq \alpha<0,3$ & $184 \pm 5$ & $10^{11,0} \pm 4$ & $181 \pm 8$ & $10^{11,0} \pm 4$ & $183 \pm 3$ & $(1-\alpha)^{1,7}$ \\
\hline \multirow{2}{*}{ Flax } & $0,3 \leq \alpha<0,7$ & $201 \pm 3$ & $10^{15,0} \pm 3$ & $200 \pm 2$ & $10^{15,0} \pm 4$ & $202 \pm 2$ & $(1-\alpha)^{1}$ \\
& $0,1 \leq \alpha<0,3$ & $177 \pm 4$ & $10^{9,5} \pm 2$ & $178 \pm 3$ & $10^{9,0} \pm 3$ & $177 \pm 2$ & $(1-\alpha)^{1,5}$ \\
\hline \multirow{2}{*}{ Kenaf } & $0,3 \leq \alpha<0,7$ & $194 \pm 3$ & $10^{14,8} \pm 4$ & $195 \pm 3$ & $10^{14,8} \pm 3$ & $193 \pm 2$ & $(1-\alpha)^{1}$ \\
& $0,1 \leq \alpha<0,3$ & $177 \pm 5$ & $10^{9,0} \pm 3$ & $178 \pm 6$ & $10^{8,9} \pm 4$ & $177 \pm 3$ & $(1-\alpha)^{1}$ \\
\hline \multirow{2}{*}{ Hemp } & $0,3 \leq \alpha<0,7$ & $202 \pm 3$ & $10^{14,9} \pm 2$ & $205 \pm 3$ & $10^{14,0} \pm 4$ & $205 \pm 3$ & $(1-\alpha)^{1}$ \\
& $0,1 \leq \alpha<0,3$ & $185 \pm 5$ & $10^{11,0} \pm 4$ & $183 \pm 6$ & $10^{11,4} \pm 3$ & $184 \pm 5$ & $(1-\alpha)^{1,5}$ \\
\hline \multirow{2}{*}{ Jute } & $0,3 \leq \alpha<0,7$ & $203 \pm 3$ & $10^{15,6} \pm 3$ & $202 \pm 2$ & $10^{15,6} \pm 2$ & $202 \pm 3$ & $(1-\alpha)^{1}$ \\
& $0,1 \leq \alpha<0,3$ & $168 \pm 5$ & $10^{8,5} \pm 2$ & $171 \pm 9$ & $10^{8,4} \pm 4$ & $169 \pm 2$ & $(1-\alpha)^{1,2}$ \\
\hline
\end{tabular}

Criado and Coats-Redfern methods allow the determination of the kinetic model that provides the closest values of $E a$ to those obtained from the iso-conversional methods, confirming the assumption of a first order mechanism $(\mathrm{n}=1)$ for the decomposition kinetics of natural fibres from a $0,3 \leq \alpha<0,7$ range conversion where the pyrolisis of the cellulose is occurring [37-38].

The great deviation between the average $E a$ values from the iso-conversional methods can influence the choice of kinetic mechanism at lower conversion regions. Thus, the proposed kinetic models in Table 9 constitute an approximation to predict the thermal behaviour of this 
region, where the thermal decomposition of hemicellulose is principally taking place. As it is observed for the cellulose decomposition, the hemicellulose decomposition follows a singlestep mechanism of order $n$ in all the studied fibres. However, this region shows differences in the $E a(168-194 \mathrm{KJ} / \mathrm{mol}), A\left(10^{8,4}-10^{11,4} \mathrm{~min}^{-1}\right)$ and $n(1-1,7)$ kinetic parameters for each natural fibre. The differences in the kinetic parameters can be attributed to the applied deconvolution method due to the difficulties separate the hemicellulose/pectin contribution from the cellulose one.

\section{Conclusions}

The chemical composition of cotton, flax, jute, kenaf and hemp natural fibres were calculated based on the content of cellulose, hemicelluloses and lignin. These natural fibres were characterised by SEM, TGA, DSC and FTIR. The differences found in the chemical composition of each natural fibre may influence their morphologic and thermal properties.

The studied fibres are long cylindrical with a tapered end. Moreover, cotton fibres show twist channels in the surface. The higher content of cellulose in cotton, flax and jute fibres seems to be responsible for a superior hydrogen bond intensity and crystalline index. The $I_{\beta}$ phase is the predominant cellulose allomorph in all the natural fibres, with jute, flax and cotton fibres having the highest $\mathrm{I}_{\beta}$ content.

The moisture content of natural fibre increases as a function of hemicellulose/pectin content, due to its strong hydrophilic character The same trend and the same percentages of moisture is stated in the samples by means of chemical and thermogravimetric analysis. Cotton, flax and jute fibres display improved thermal stability than hemp and kenaf fibres, again due to the most cellulose content in their formulation. The proposed thermogravimetric methodoly allows assessing the percentage of each chemicals of the natural fibres.

Jute and flax fibres display an endothermic behaviour related to the thermal decomposition of cellulose that can be attributed to the depolymerisation of cellulose to form tar, whereas the rest of the fibres show an exothermic behaviour due to the reaction to form char.

The kinetics of the thermal decomposition processes were analysed using different methods including Friedman, Flynn-Wall-Ozawa, Criado and Coats-Redfern. The results suggest that 
the thermal decomposition of the main components of the natural fibres (hemicellulose and cellulose) can be model by means of a simple mechanisms nth order. Cellulose pyrolysis can be model with the same kinetic parameters for all studied fibres. However, the region where most of the hemicellulose is pyrolysed shows differences in the $E a, A$ and $n$ parameters, probably due to the difficulties to separate the hemicellulose/pectin contribution from the cellulose one.

\section{References}

1. Mohanty AK, Misra M, Drzal TD editors. Natural Fibers, Biopolymers and Biocomposites. Boca Raton: Taylor \& Francis, 2005.

2. Monties B. Agronomie 1986; 4: 387

3. Theander O, Westerlund EA. J Agric Food Chem 1986; 34: 330.

4. Mohanty AK, Misra M, Drzal LT. J Polyms Environ 2002; 10: 1/2.

5. Maya JJ, Thomas S. Carbohydr Polym 2008; 71: 343.

6. Moriana R, Karlsson S, Ribes-Greus A. Polymer Composites 2010,

7. Proniewicz LM, Paluszkiewciz C, Weselucha-Birczysimnska A, Majcherczyk H, Bara Simniski A, Konieczna A. J Mol Struct 2001; 596: 163.

8. Kondo T. Cellulose 1997;4: 281.

9. Gardner KH, Blackwell J. Bioquim Biophys Acta 1974; 343: 232.

10. Scwanninger M, Rodrigues JC, Pereira H, Hinters-toisser B. Vib Spectrosc 2004; 36: 23.

11. Sugiyama J, Vuong R, Chanzy H. Macromolecules 1991; 24: 4168.

12. Kokot S, Czarnik B, Ozaki Y. Biopolymers 2002; 67: 456.

13. Marechal Y, Chanzy H. J Mol Struct 2000;

14. Sugiyama J, Persson J, Chanzy H. Macromolecules 1991; 24: 2461

15. Andreeva QA, Burkova LA, Grebenkin AN, Grebenkin AA. Russ J Appl Chem 2002; 75: 1513.

16. He J, Tang Y, Wang SY. Iranian Polymer Journal 2007; 16: 807

17. Nada AM, Kamel S, Sakhawy ME. Polym Degrad Stab 2000; 70: 347.

18. Nelson ML, Connor RT. J Appl Polym Sci 1964; 8: 1325.

19. Arkerholm M, Hinterstoisser B, Salmen L. Carbohyd Res 2004; 339: 569.

20. Larsson PT, Westermark U, Iversen T. Carbohydr Res 1995; 278: 24.

21. Varhegyi G, Antal MJ, Szekely T, Szabo P. Energy Fuels 1989;3:329.

22. Mamleev V, Bourbigot S, Yvon J. J Anal Appl Pyrolysis 2007; 80: 151

23. Aggarwal P, Dollimore D, Heon K. J Therm Anal Calorim 1997; 50: 7.

24. Fei Y, Qinglin W, Yong L, Weihong G, Yanjun X. Polym Degrad Stab 2008; 93: 90.

25. Evans RJ, Milne TA. Energy Fuels 1987; 1: 123.

26. Antal MJ Jr, Varhegyi G. Ind Eng Chem Res 1995; 34: 703. 
27. Mok WSL, Antal MJ. Thermochim Acta 1983b;68: 165.

28. Kilzer FJ, Broido A. Pyrodynamics 1965; 2: 151: 263.

29. Broido A, Nelson MA. Combust Flame 1975; 24.

30. Shafizadeh F, Chin PPS. ACS Symp Ser 1977; 43: 57.

31. Antal MJ. In; Miller B, editors. J. Wiley: New York, 1982a.

32. Friedman HL. Journal Polym Sci 1964; 6: 183

33. Ozawa T. Bull Chem Soc Jpn. 1965; 88: 6.

34. Criado JM. Thermochimic Acta 1978; 24:86

35. Coats AW, Redfern JP. Nature 1964; 201:68.

36. Varhegyi G, Antal MJ, Szekely T, Till F, Jakab E. Energy Fuels 1988a; 2: 267.

37. Bilbao R, Arauzo J, Millera A. Thermochim Acta 1987a; 120: 121.

38. Bilbao R, Arauzo J, Millera A. Thermochim Acta 1987b; 120: 133

39. Gronli MG, Várhegyi G, Di Blasi C. Ind Eng Chem Res 2002; 41: 4201.

40. Mamleev V, Bourbigot S, Yvon J. J Anal Appl Pyrolysis 2007; 80: 141 



\section{Caracterización de matrices poliméricas y biocomposites}

4.1 Introducción

4.2 Resultados y discusión

- Mater-Bi KE y Biocomposites de Mater-Bi KE/Fibras Naturales

"Assessing the mechanical enhancement and the thermostabilising effect of adding cotton fibres to a starch-based matrix using thermal analysis"

Rosana Moriana, L Santonja-Blasco, J.D.Badia, A. Ribes-Greus Journal of Applied Polymer Science,2010

"Improved thermo-mechanical properties by the addition of different natural fibres in starch-based sustainable biocomposites"

Rosana Moriana, Francisco Vilaplana, Sigbritt Karlsson, A. Ribes-Greus Composites Part A,2010

" Thermal, mechanical and morphological properties of reinforced jute and flax fibres biocomposites"

- Mater-Bi NF y Biocomposites de Mater-Bi NF/Fibras Naturales

"Comparative study of different biocomposites based on thermoplastic starch (Mater-Bi NF 01U) reinforced with natural fibres"

Resumen de resultados 



\subsection{INTRODUCCIÓN}

En los composites enfibrados la matriz polimérica es el sostén de las fibras naturales a la vez que éstas mejoran las propiedades finales de la propia matriz. Este resultado sólo se consigue si la matriz ofrece una estabilidad estructural así como una interfase fibra-matriz que asegure su adhesión y compatibilidad [1].

El carácter hidrófilo de las fibras naturales es uno de los principales escollos para su uso como refuerzo en el diseño de composites con matrices hidrófobas. Con el fin de mejorar la compatibilidad entre la matriz y las fibras naturales estas se someten a tratamientos químicos [2] como la alcalinación o la cianoetilación. Otro modo de abordar el problema es elegir matrices con carácter hidrófilo. Así, la elección de dos materiales termoplásticos de base almidón (Mater-Bi KE03B1 y Mater-Bi NF01U) presenta una doble ventaja: por una parte su origen vegetal y por otra el carácter hidrófilo de la matriz.

Para garantizar las propiedades principales del biocomposite diseñado a partir de las fibras naturales y los termoplásticos de base almidón es necesario caracterizar las matrices poliméricas y evaluar la influencia de cada una de las fibras naturales sobre la morfología, las propiedades térmicas y mecánicas de las matrices poliméricas.

De este modo los objetivos específicos de este capítulo son los siguientes:

1. Describir la metodología de análisis para la caracterización de las matrices poliméricas y de los biocomposites enfibrados diseñados a partir de estas matrices.

2. Caracterizar las matrices poliméricas y los biocomposites preparados.

3. Evaluar la influenza de cada una de las fibras naturales sobre las matrices poliméricas, teniendo en cuenta las diferencias en su composición química, parámetro de forma y módulo de Young.

La metodología de análisis propuesta, para la caracterización de las matrices poliméricas y de los biocomposites reforzados, se basa en las siguientes técnicas experimentales: Análisis de Tensión (INSTRON), Microscopía Electrónica de Barrido (SEM), Análisis Calorimétrico (DSC), Análisis Térmo-Mecánico-Dinámico (DMTA), y Análisis Termogravimétrico (TGA). 
La influencia de las fibras naturales en las propiedades mecánicas en tracción de las matrices poliméricas se evalúan mediante el ensayo de tensión en términos de módulo de elasticidad ó módulo de Young, resistencia a tracción y deformación a rotura. Los resultados experimentales obtenidos se resumen en la Tabla 4.1.

Tabla 4.1. Propiedades mecánicas de los materiales estudidados

\begin{tabular}{r|ccc}
\hline & $\begin{array}{c}\text { Módulo de } \\
\text { Young } \\
(\mathrm{MPa})\end{array}$ & $\begin{array}{c}\text { Resistencia } \\
\text { a tracción } \\
(\mathrm{MPa})\end{array}$ & $\begin{array}{c}\text { Deformación } \\
\text { a rotura } \\
(\%)\end{array}$ \\
\hline Mater-Bi KE & $457,0 \pm 45,0$ & $3,6 \pm 0,5$ & $3,9 \pm 0,2$ \\
\hline Mater-Bi KE/cotton & $809,0 \pm 25,0$ & $2,8 \pm 0,3$ & $1,4 \pm 0,2$ \\
Mater-Bi KE/flax & $656,0 \pm 42,0$ & $2,6 \pm 0,6$ & $1,9 \pm 0,3$ \\
Mater-Bi KE/hemp & $804,0 \pm 61,0$ & $3,2 \pm 0,5$ & $1,5 \pm 0,3$ \\
Mater-Bi KE/kenaf & $790,0 \pm 35,0$ & $4,0 \pm 0,3$ & $1,5 \pm 0,3$ \\
Mater-Bi KE/jute & $839,0 \pm 30,0$ & $4,8 \pm 0,3$ & $1,7 \pm 0,3$ \\
\hline Mater-Bi NF & $220,0 \pm 50,0$ & $6,6 \pm 0,6$ & $21,0 \pm 4,0$ \\
\hline Mater-Bi NF/cotton & $323,5 \pm 35,0$ & $5,8 \pm 0,8$ & $6,0 \pm 2,0$ \\
Mater-Bi NF/flax & $298,0 \pm 15,0$ & $5,0 \pm 1,0$ & $4,2 \pm 1,5$ \\
Mater-Bi NF/hemp & $357,0 \pm 55,0$ & $6,6 \pm 0,3$ & $5,9 \pm 1,4$ \\
Mater-Bi NF/kenaf & $320,0 \pm 10,0$, & $6,7 \pm 0,4$ & $6,7 \pm 1,0$ \\
Mater-Bi NF/jute & $433,3 \pm 80,0$ & $8,4 \pm 0,9$ & $4,7 \pm 1,0$ \\
\hline
\end{tabular}

Comparando las propiedades mecánicas de las matrices poliméricas con las de sus biocomposites resultantes se observa:

- $\quad$ Un aumento del módulo de Young en todos los biocomposites enfibrados. En las ambas series se observa la misma tendencia; el biocomposite de yute muestra el valor del módulo más alto seguido por el biocomposite de algodón y el de cáñamo, los valores más bajos son para los biocomposites de kenaf y lino.

- Variaciones en la resistencia a tracción dependiendo de la fibra natural adicionada. Los biocomposites de kenaf y cáñamo de ambas series muestran una resistencia a tracción similar a la de sus matrices poliméricas respectivas. En cambio, los biocomposites de lino y algodón presentan una resistencia menor, y los biocomposites de yute una resistencia mayor que la de las matrices poliméricas por si solas.

- $\quad$ Una disminución de la deformación a rotura de más de un 50\% en todos los composites. 
La microscopía electrónica de barrido analiza la interfase fibra-matriz polimérica y evalua la dispersión y adhesión de las fibras naturales en la matriz. Los termogramas calorimétricos tanto de las matrices como de sus respectivos biocomposites identifican y caracterizan las transiciones de fusión y cristalización de los materiales estudiados mediante la determinación la temperatura de fusión y cristalización $\left(T_{m} y T_{c}\right)$ así como sus entalpías respectivas $\left(\Delta H_{m} y \Delta H_{c}\right)$. Los ensayos térmo-mecánico-dinámicos evalúan el comportamiento viscoelástico del Mater-Bi KE y de sus biocomposites. A partir de los espectros mecánicos se identifica y caracteriza la relajación mecánica asociada a la transición vítrea y la relajación mecánica asociada a los movimientos percusores de la fusión. Finalmente, a partir de los análisis termogravimétrico se identifican los diferentes procesos de descomposición térmica, así como su estabilidad térmica (onset, Tpico) y su cinética de descomposición $(f(\alpha), E a, A)$.

Todos los resultados experimentales de la caracterización del Mater-Bi KE y del Mater-Bi NF y de sus biocomposites se han estructurado en las siguientes contribuciones científicas, dos de ellas aceptadas en revistas indexadas.

$\checkmark \quad$ "Assessing the Mechanical Enhancement and the Thermostabilising Effect of Adding Cotton Fibres to a Starch-Based Matrix using Thermal Analysis". En esta contribución, además de la influencia de la adición del algodón sobre la morfología y las propiedades térmicas y mecánicas del Mater-Bi KE, se evalúa la validez y efícacia de la metodología de análisis propuesta.

$\checkmark \quad$ "Improved Thermo-Mechanical Properties by the Addition of Different Natural Fibres on the Enhancement in Starch-Based Sustainable Biocomposites". En esta comunicación, se caracterizan los biocomposites de Mater-Bi KE/algodón, Mater-Bi $\mathrm{KE} /$ cañamo y Mater-Bi KE/kenaf mediante la metodología de análisis empleada en la publicación anterior. Las diferencias en los resultados experimentales obtenidos se correlacionan con la composición química de cada fibra natural. Las fibras más distintas desde el punto de vista de composición química son el algodón y el kenaf; el algodón presenta un $90 \%$ de celulosa y un $2 \%$ en hemicelulosa en su formulación, mientras que el kenaf presenta tan un $57 \%$ de celulosa, un $22 \%$ en hemicelulosa y un $12 \%$ en lignina. Se escoge además la fibra de cañamo porque su composición química es intermedia entre el algodón y el kenaf. 


\section{$\checkmark \quad$ "Mechanical, Thermal and Morphological Properties of the Reinforced Flax} and Jute Fibre Biocomposites". El estudio de los biocomposites de Mater-Bi KE se completa con esta contribución. En este caso las fibras seleccionadas como sistema de refuerzo han sido las fibras de lino y yute, por presentar el módulo elástico más grande y más parecido al de las fibras de vidrio.

$\checkmark \quad$ “Comparative study of different biocomposites based on thermoplastic starch (Mater-Bi NF01U) reinforced with natural fibres”. En esta contribución se caracterizan la matriz polimérica (Mater-Bi NF) y los biocomposites (Mater-Bi NF/algodón, Mater-Bi NF/lino, Mater-Bi NF/cañamo, Mater-Bi NF/kenaf y Mater-Bi NF/jute) mediante TGA, DSC, Ensayos de Tensión y SEM con el fin de establecer la influencia de cada fibra sobre las propiedades de la matriz.

\section{Referencias}

1. Mohanty AK, Misra M, Drzal TD editors. Natural Fibers, Biopolymers and Biocomposites. Boca Raton: Taylor \& Francis, 2005.

2. Ismail L, Mega HPS AK. Polymer International 2001; 50: 606. 


\subsection{RESULTADOS Y DISCUSIÓN}

"ASSESSING THE MECHANICAL ENHANCEMENT AND THE THERMOSTABILISING EFFECT OF ADDING COTTON FIBRES TO A STARCH-BASED MATRIX USING THERMAL ANALYSIS" 



\title{
“ASSESSING THE MECHANICAL ENHANCEMENT AND THE THERMOSTABILISING EFFECT OF ADDING COTTON FIBRES TO A STARCH-BASED MATRIX USING THERMAL ANALYSIS"
}

\author{
Rosana Moriana $^{1}$, J.D. Badia ${ }^{1}$, L. Santonja-Blasco ${ }^{1}$, A. Ribes-Greus ${ }^{1 *}$
}

${ }^{1}$ Instituto de Tecnología de Materiales (ITM), Universidad Politécnica de Valencia, Camino de Vera s/n, E-46022 Valencia, Spain

\begin{abstract}
A renewable biocomposite based on a commercial starch-based thermoplastic matrix reinforced with cotton fibres has been prepared and characterised. Several thermal analyses techniques such as Differential Scanning Calorimetric (DSC), Thermogravimetry (TGA) and Dynamic Mechanical Thermal Analyses (DMTA) have been used to compare the bulk properties of the pure starch thermoplastic matrix and the reinforced biocomposite. The addition of the cotton fibres to a starch-based matrix has been evaluated by different thermal parameters which can be used as indicators of changes in mechanical and thermal properties of pure matrix and reinforced biocomposites. Vogel-FulcherTamman-Hesse equation was applied to fit the mechanical glass-rubber relaxation of the polymeric matrix and the reinforced biocomposite. To characterise the thermal decomposition process of both materials, a methodology is proposed to obtain the apparent activation energy, pre-exponential factor and to identify the kinetic models of the thermal decomposition processes. The chosen thermal parameters indicated certain compatibility between the cotton fibres and the starch-based thermoplastic matrix. An improvement of the mechanical properties has been observed maintaining and assuring their thermal stability to allow optimising the processing parameters.
\end{abstract}

Keywords: Biofibres, Biopolymers, Thermal Properties 


\section{Introduction}

The design of new polymeric materials based on polysaccharides has driven special attention in the recent years as an alternative to the use of petroleum-derived plastics [1]. However, these materials have a limited use due to their poor physical properties, difficult processing and low water resistance [2]. Blending polysaccharide materials with synthetic biodegradable polymers, such as polyesters, could be a good solution to improve their properties. Different commercial blends based on thermoplastic starch can be found in the market, like Mater-Bi ${ }^{\circledR}$ (Novamont, Italy) [3], Bioplast (Biotech, Germany) [4] or Biopar (Biop Biopolymer Technologies AG, Germany) [4]. In specific applications it is necessary to prepare reinforced biocomposites with reliable structural and functional stability during their storage and service life, ensuring a complete material loop without any environmental hazard $[5,6]$. Natural fibres have proved to be efficient reinforcements in biodegradable materials [7,8]. Cellulosic materials provide advantages from the point of view of the fibre-matrix adhesion [9], especially with polar-matrix materials and open up further possibilities for using thermoplastic starch-based blends as polymeric matrices in reinforced biocomposites.

The aim of this work is to characterise a biocomposite based on a commercial thermoplastic starch matrix reinforced with cotton fibres and study the influence of the natural fibres on the thermal and viscoelastic properties of the polymeric matrix. Analytical procedures based on thermal analysis techniques have been carried out. Different thermal parameters of each analytical technique have been selected to monitor and control the bulk properties of the matrix and the reinforced biopolymer, to assess their suitability and to optimise the processing conditions $[10,11]$.

\section{Experimental Procedure}

\section{Materials and Sample Preparation}

The polymeric matrix consists of thermoplastic starch-based material commercialised under the Mater-Bi ${ }^{\circledR}$ trademark by Novamont SPA, Novara (Italy). The Mater-Bi ${ }^{\circledR}$ range of bioplastics is manufactured by using renewable resources including natural starch and biodegradable synthetic polymers (commonly polyesters) [12-14]. A wide range of Mater$\mathrm{Bi}{ }^{\circledR}$ grades are available in the market, depending on the manufacturing processes and the bioplastics composition [15]. Mater-Bi ${ }^{\circledR}$ KE03B1 (named as Mater-Bi KE) was chosen as 
biodegradable matrix to prepare the reinforced biocomposite. The elastic modulus of this material, measured by ASTM 68, is $1400 \mathrm{MPa}$, the tensile stress at break is $18 \mathrm{MPa}$, and the elongation at break is $150 \%$.

Cotton is the natural fibre employed as reinforcement, provided by Yute S.L. (Spain). Fibres were subjected to a pelletisation process under the following conditions: power $(0,5-1 \mathrm{~kW})$, filter diameter $8 \mathrm{~mm}$, and humidity of dosage $30 \%$. The average length and fibre diameter of the cotton fibre were determined by optical microscopy over 100 fibres. The length was $3 \pm 1$ $\mathrm{mm}$ and the average diameter was $0,0175 \pm 0,0125 \mathrm{~mm}$. The aspect ratio was $450 \pm 35$ and the tensile modulus measured by ASTM-D638 was $12 \mathrm{GPa}$. The Mater-Bi KE matrix and the pelletisated cotton fibres were incorporated in a co-rotative twin screw extruder (Werner \& Pfleiderer ZSK 25, Germany), with a screw length of 40D and a diameter of $25 \mathrm{~mm}$. Samples were then obtained by compression moulding with a Carver $\mathrm{M}$ press under a processing temperature of $438 \mathrm{~K}$ (Carver, USA).

This compounding process has been carried out to prepare samples with different percentages in weight of natural fibres. Rheological analysis defines the samples of $10 \%$ percentage of natural fibres as the best to be processed. The samples were shaped as rectangular bars with dimensions 110x110x2 mm.

\section{Differential Scanning Calorimetry Measurements}

The DSC measurements were performed on a Mettler Toledo DSC $822^{\mathrm{e}}$ Instrument (Columbus, $\mathrm{OH}$ ) previously calibrated with indium and aluminium standards. Samples of 7-8 mg were placed in standard aluminium pans previously sealed and pierced. Mater-Bi KE, cotton fibres and their reinforced Mater-Bi KE/cotton biocomposites samples were submitted to the same dynamic program: samples were initially heated at $10 \mathrm{~K} / \mathrm{min}$ from 173 to $473 \mathrm{~K}$ (first heating scan) in order to delete the thermal history of these materials. After holding the temperature at $473 \mathrm{~K}$ for $3 \mathrm{~min}$., they were cooled at $10 \mathrm{~K} / \mathrm{min}$ from 473 to $173 \mathrm{~K}$ (cooling scan), and their crystallization processes were analyzed. Finally and after holding the temperature at $173 \mathrm{~K}$ during $3 \mathrm{~min}$, samples were re-heated at $10 \mathrm{~K} / \mathrm{min}$ from $173 \mathrm{~K}$ to $473 \mathrm{~K}$ (second heating scan) to study the melting processes. The measurements were performed at least three times to assure a good reproducibility and the average values have been considered as representative results. 


\section{Dynamic Mechanical Thermal Measurements}

Viscoelastic measurements were carried out in a dynamic-mechanical-thermal analyser MARK IV DMTA (Rheometric Scientific, United Kingdom). A sinusoidal deformation was

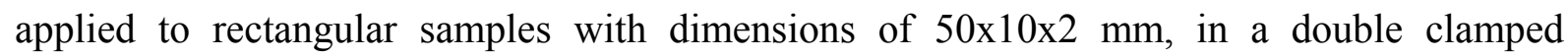
cantilever mode with a force of $0,01 \mathrm{~N}$. Iso-steps mesurements were performed in multifrequency scans between $0,1 \mathrm{~Hz}$ and $100 \mathrm{~Hz}$, using 4 frequencies per decade. The region from $173 \mathrm{~K}$ to ambient temperature $(298 \mathrm{~K})$ was studied for all samples by performing multifrequency scans with a step rate of $2 \mathrm{~K} / \mathrm{scan}$; on the other hand, between $298 \mathrm{~K}$ and $363 \mathrm{~K}$ the step rate was set to $4 \mathrm{~K} / \mathrm{scan}$. The values of loss tangent ( $\tan \delta$ ), storage modulus (E'), and loss modulus (E'') were determined. In order to assure a good reproducibility, the measurements were performed two times.

\section{Thermogravimetric Measurements}

Dynamic thermogravimetric analysis was performed using a Mettler-Toledo 851 (TGA) module (Columbus, $\mathrm{OH})$ under argon atmosphere $(50 \mathrm{ml} / \mathrm{min})$, at different heating rates (3-30 $\mathrm{K} / \mathrm{min}$ ) in a temperature range between 298 and $1023 \mathrm{~K}$. Temperature peak, onset, mass loss percentage, apparent activation energy, pre-exponential factor and kinetic models were the parameters selected to characterise the thermodegradation processes. All these thermal measurements have been assessed five times and the average values were considered as representative results.

\section{Results and Discussion}

\section{Differential Scanning Calorimetry mesurements}

Samples were initially characterised by calorimetric measurements to analyse the effect of the addition of natural fibres into the polymeric matrix. The calorimetric thermograms of MaterBi KE, cotton fibres and their Mater-Bi KE/cotton biocomposites are displayed in Figure 1. The melting and the crystallisation temperatures $(T m$ and $T c$,) were directly determined from the calorimetric thermograms as the values of the maxima of the endothermic and exothermic peaks, respectively. The melting and crystallisation enthalpies $(\Delta H m$ and $\Delta H c)$ were determined from each area of each thermal transition. 
The Mater-Bi KE thermogram corresponding to the cooling scan presents a unique main exothermic peak around $316 \mathrm{~K}$ with a crystallisation enthalpy around $55 \mathrm{~J} / \mathrm{g}$. The heating scan displays some thermal transitions: a main endothermic peak around $336 \mathrm{~K}$ with a melting enthalpy of $61 \mathrm{~J} / \mathrm{g}$, a small exothermic peak around $389 \mathrm{~K}$ and two overlapped endothermic peaks placed between $421 \mathrm{~K}$ and $427 \mathrm{~K}$ with very small enthalpic values, around $10 \mathrm{~J} / \mathrm{g}$.
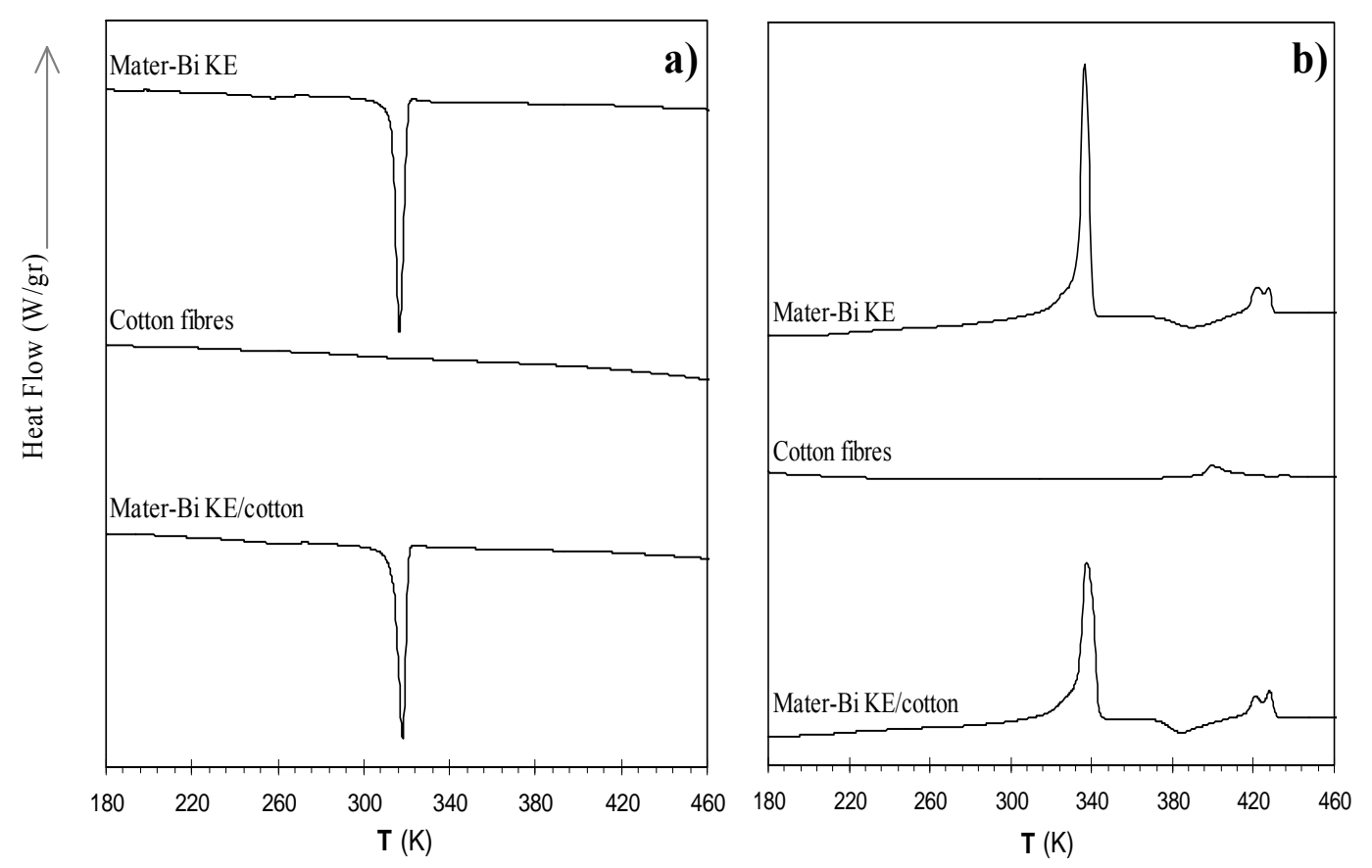

Figure 1. DSC thermograms of the a) second scan and b) third scan of the pure Mater-Bi KE, cotton fibre and reinforced Mater-Bi KE/cotton biocomposite.

Bastioli et. al [16] describes the Novamont's starch-based technology as a process that could destroy the crystallinity of amylose and amylopectin from starch. Thus the main endotermic and exothermic peaks should be related to the melting and the crystallisation transition of the crystalline phase of the synthetic biodegradable polymer present in the Mater-Bi KE, respectively. The small peaks may be secondary transitions related to reorganizations of molecular chains probably of starch [17]. These small peaks will not be considered in this study due to the low enthalpy interchanged. Calorimetric thermograms of cotton fibre corresponding to the heating scan show a small endothermic peak that does not appear in the cooling scan, as displayed at Figure 1. Thus, these small peaks may also be secondary transitions related to reorganizations of cotton molecular chains. 
The calorimetric thermograms of the reinforced Mater-Bi KE/cotton biocomposite show that the presence of cotton fibres does not produce sensitive changes in the shape of the thermograms of the matrix. However, the crystallisation temperature of the reinforced Mater$\mathrm{Bi} \mathrm{KE} /$ cotton is $319 \mathrm{~K}$, slightly higher than the one of the pure Mater-Bi KE The same slight increase of crystallisation temperature was observed by Digabel et al. [18] when cellulose fillers were incorporated on the biodegradable aromatic copolyester matrix and it was described as a nucleation effect linked to the filler surface.

The melting and crystallisation enthalpies of the reinforced Mater-Bi KE/cotton biocomposite ( $\triangle H m_{\text {composite }}$ and $\Delta H c_{\text {composite, }}$ respectively), were corrected considering that only the polymeric matrix contributed to the transitions. The crystallisation and melting enthalpies obtained for the reinforced Mater-Bi KE/cotton biocomposites are $65 \mathrm{~J} / \mathrm{g}$ and $70 \mathrm{~J} / \mathrm{g}$ respectively. These values are also higher than the ones obtained for the pure Mater-Bi KE. These results suggested that the cotton fibres will act as nucleation agents of the molecular chains of the synthetic component and enhance their crystallisation as well, as Digabel et al. [18] observed in other reinforced biocomposites.

\section{Dynamic Mechanical Thermal Measurements}

The changes caused by the addition of the fibre on the viscoelastic behaviour of both Mater$\mathrm{Bi} \mathrm{KE}$ and the reinforced Mater-Bi KE/cotton biocomposites have been analysed.

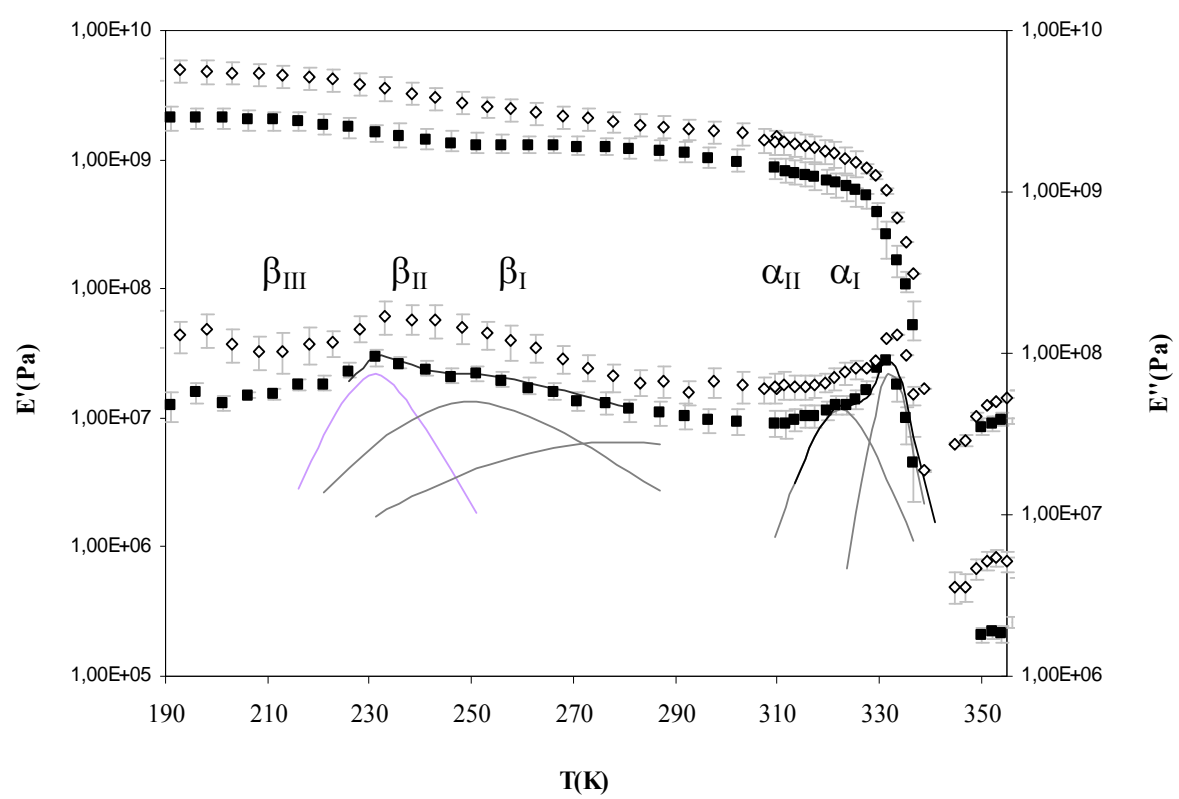

Figure 2. Isochronal representation of the storage modulus E' (upper plots) and loss modulus E" (lower plots) for (ロ) pure Mater-Bi KE and (O) reinforced Mater-Bi KE/cotton biocomosites at $1 \mathrm{~Hz}$. 
Figure 2 shows the isochronal mechanical spectrum of Mater-Bi KE at $1 \mathrm{~Hz}$ in terms of the storage (E') and loss modulus (E") at the temperature range of 175-335 K; similar curves are obtained for all the other frequencies but are not displayed for the sake of clarity. Two different relaxations zones called $\alpha$ and $\beta$ in decreasing temperature order are observed. The $\alpha$ relaxation peaks comprises two peaks; the first relaxation peak $\left(\alpha_{\mathrm{I}}\right)$ appears centred at around $333 \mathrm{~K}$ together with an overlapped small shoulder at $323 \mathrm{~K}\left(\alpha_{\mathrm{II}}\right)$. These $\alpha$ relaxation peaks can be assigned to long segment chain movements associated to the melting of the synthetic component of the Mater-Bi KE, in agreement with the previous results from DSC. Furthermore, a broad, complex and overlapped relaxation zone $(\beta)$, between $210-290 \mathrm{~K}$, is observed in the wide range subambient temperature region. Three overlapped subrelaxations can be distinguished at the loss modulus plot, which unfortunately cannot be clearly assigned at this stage; $\beta_{\mathrm{I}}$ relaxation centred at $282 \mathrm{~K}, \beta_{\mathrm{II}}$ relaxation centred at $248 \mathrm{~K}$ and $\beta_{\mathrm{III}}$ relaxation centred at $228 \mathrm{~K}$.

When the cotton fibres are added into the Mater-Bi KE, higher values for the storage and loss moduli are observed. Furthermore, the storage modulus is linearly dependent on the temperature (Figure 3), showing a higher reinforcing effect at lower temperatures.

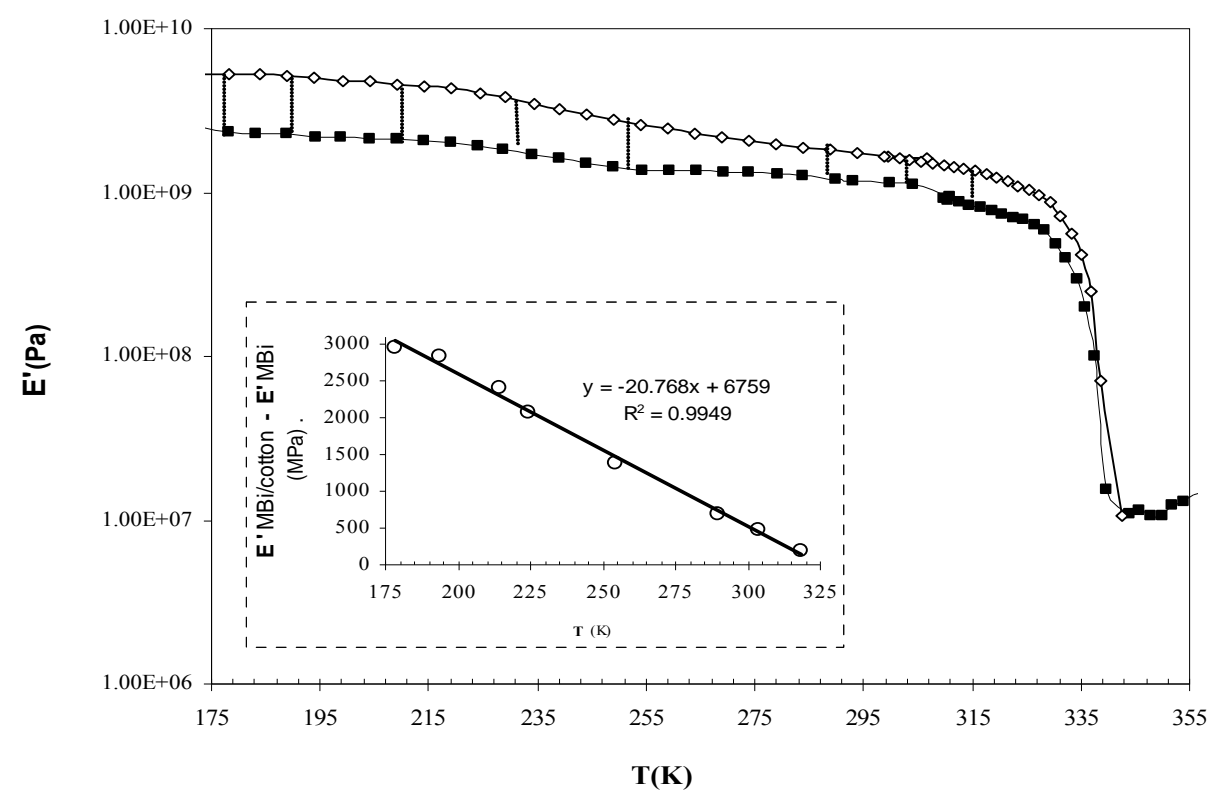

Figure 3. Representation of the difference between the storage modulus of the (ロ) pure Mater-Bi KE and (O) reinforced Mater-Bi KE/cotton biocomosites at $10 \mathrm{~Hz}$ as a function of the temperature. 
The different relaxations zones of Mater-Bi KE and reinforced Mater-Bi KE/cotton bicomposite can be characterised by their loss modulus maximum and their corresponding temperature ( $\left.{ }^{\prime \prime}{ }_{\max }, \operatorname{Tmax}\right)$; these values were obtained for both materials at all frequencies and were analysed by fitting the loss modulus data to the Fuoss-Kirkwood empirical model (1).

$$
E^{\prime \prime}{ }_{i}=E^{\prime \prime}{ }_{\max } \cdot \sec h\left(m_{F K} \cdot \ln \left(\frac{f}{f_{\text {max }}}\right)\right)
$$

where $E^{\prime \prime}{ }_{\max }$ corresponds to the maximum of the loss modulus, $f$ is the studied frequency, $f_{\max }$ is the frequency at which the $E^{\prime \prime}{ }_{\max }$ occurs, and $m_{F K}$ is an empirical parameter lying in the interval $0<m_{F K} \leq 1$.

Since the studied dynamic-mechanical relaxations appear to be overlapped in the temperature regions, Charlesworth deconvolution procedure should be applied (2).

$$
E^{\prime \prime}=\sum_{i} E_{i}^{\prime \prime}
$$

An example of the fitting results can be observed for Mater-Bi KE at a frequency of $1 \mathrm{~Hz}$ in Figure 2. The five relaxation peaks that have been labelled as $\alpha_{\mathrm{I}}, \alpha_{\mathrm{II}}, \beta_{\mathrm{I}}$ and $\beta_{\mathrm{II}}, \beta_{\mathrm{II}}$ are displayed at $334 \mathrm{~K}, 323 \mathrm{~K}, 288 \mathrm{~K}, 257 \mathrm{~K}$ and 234, respectively. The addition of fibres slightly increases the temperature of $\alpha$ relaxation peaks $\left(T_{\text {maxal }}=337 \mathrm{~K}\right.$ and $\left.T_{\text {maxaII }}=327 \mathrm{~K}\right)$ and $\beta_{\mathrm{I}}, \beta_{\mathrm{II}}$ and $\beta_{\text {III }}$ peaks $\left(T_{\max \beta \mathrm{I}}=292 \mathrm{~K}, T_{\max \beta I I}=260 \mathrm{~K}\right.$ and $\left.T_{\max \beta \mathrm{III}}=237 \mathrm{~K}\right)$ can be observed.

Figure 4 represents the Arrhenius maps for the $\alpha_{\mathrm{I}}, \alpha_{\mathrm{II}}$ and $\beta_{\mathrm{I}}, \beta_{\mathrm{II}}$, $\beta_{\mathrm{III}}$ relaxation peaks for the Mater-Bi KE, respectively. The $\alpha_{\mathrm{I}}$ and $\alpha_{\mathrm{II}}$ relaxation peaks of both Mater-Bi KE and Mater-Bi KE/cotton biocomposite display a straight line that can be fit to Arrhenius equation (3), indicating that $\alpha$ relaxations correspond with intramolecular relaxations. This fact support the interpretation given earlier for $\alpha$ relaxation peaks, which were associated to long segment movements chain prior to the melting of the synthetic component of the Mater-Bi KE.

$$
f_{\max }=f_{0} \cdot \exp \left(-E_{a} / R T_{\max }\right)
$$

The $\alpha_{\mathrm{I}}$ relaxation peak presents lower $E a$ values $(1334 \mathrm{~kJ} / \mathrm{mol})$ than the $\alpha_{\text {II }}$ relaxation peak $(1531 \mathrm{~kJ} / \mathrm{mol})$. When cotton fibres are added, not significant changes can be observed in the 
Ea of the $\alpha_{\text {I }}$ relaxation peak $(1326 \mathrm{~kJ} / \mathrm{mol})$. Unlikely, a significant increase of Ea in $\alpha_{\text {II }}$ relaxation peak $(1617 \mathrm{~kJ} / \mathrm{mol})$ is displayed.
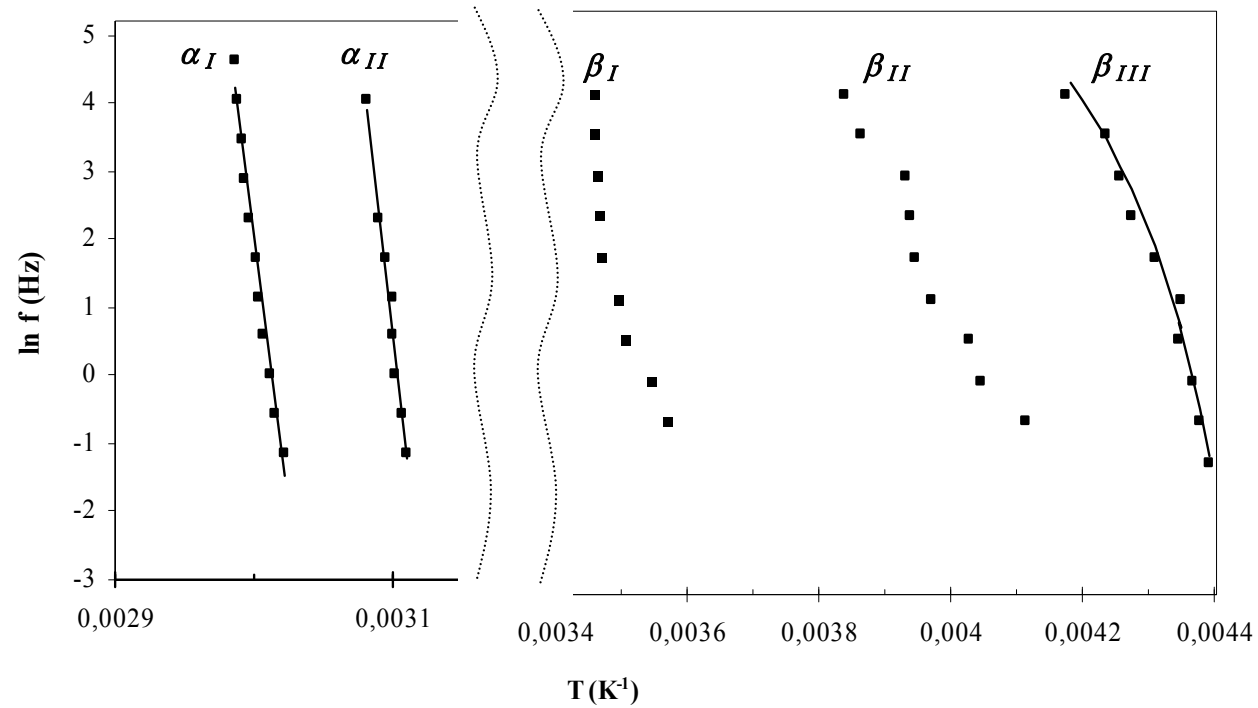

Figure 4. Arrhenius maps for the $\alpha$ and $\beta$ relaxations for Mater-Bi KE.

These viscoelastic parameters show that the addition of cotton fibres in the Mater-Bi KE increases the activation energies and the maximum temperature especially for the $\alpha_{\text {II }}$ relaxation peak. This fact could be related to the increase of the crystallinity index of the synthetic component of Mater-Bi KE, which could hinder the molecular movements of these chains.

In the Figure 4 it can also be seen that the $\beta_{\mathrm{I}}$ and $\beta_{\mathrm{II}}$ relaxation peak does not display a clear tendency whereas the $\beta_{\text {III }}$ relaxation peak shows a characteristic curve of a glass transition. Different studies on blends of plasticized starch and polyesters attributed this subambient region to the rich-polymer phase. Averous et al. [21] studied different compositions of wheat thermoplastic starch/polycaprolactone(PCL) with different amounts of glycerol and water as plasticizers and reported that several contributions in this temperature region $(210-280 \mathrm{~K})$ could be described: a secondary relaxation attributed to the thermoplastic starch, a glass transition of the PCL and a thermoplastic starch glass transition for the most plasticized starch formulations. Thus, the $\beta_{\mathrm{I}}$ and $\beta_{\mathrm{II}}$ relaxation peak does not show a clear behaviour with the frequency due to the complex combination of effects involved in it. The $\beta_{\text {III }}$ relaxation, could be associated to the glass transition of the synthetic polyester component of the pure Mater-Bi $\mathrm{KE}$, maybe influenced at the same time by the glass transition of the plasticized starch component if we consider that PCL and a plasticizer are constituents of the Mater-Bi KE. 
The Vogel-Fulcher-Tammann-Hesse equation [22] has been employed to study the mechanical relaxation associated with the glass transition of the Mater-Bi KE and Mater-Bi $\mathrm{KE} /$ cotton biocomposite.

$$
\ln \tau_{i}=A^{\prime}+\frac{m_{v}}{T m_{i}-T_{\infty}}
$$

Here, $\tau_{i}$ is the relaxation time; $A^{\prime}$ is an empirical parameter; $T m_{i}$ is the maximum temperature peak, and $T_{\infty}$ is the temperature at which the free volume would be zero. The parameter $m_{v}$ is related to the relative free volume at the glass transition temperature, according to the following expression:

$$
m_{v}=\frac{B}{\alpha_{f}}
$$

where $\alpha_{f}$ is the thermal expansion coefficient of the free volume and $B$ is an empirical parameter whose value is close to the unity. The thermal expansion coefficient $\left(\alpha_{f}\right)$ of both pure Mater-Bi KE and the reinforced Mater-Bi KE/cotton biocomposite are $103 \cdot 10^{-4} \mathrm{~K}^{-1}$ and $92 \cdot 10^{-4} \mathrm{~K}^{-1}$ respectively; the addition of cotton fibres slightly decreases the thermal expansion coefficient, indicating interactions between natural fibres and pure Mater-Bi KE. The interaction between cellulose and the polymeric matrix modifies the molecular mobility of the amorphous phase and the possibility of rearrangement of the polymeric matrix chains. These chains may progressively occupy the original free volume or fold themselves, increasing the crystalline phase. These results agree with the increase in the crystalline content by the fibres addition assessed by the calorimetric analysis.

\section{Thermogravimetric Measurements}

\section{Thermal Stability}

To design a suitable biocomposite, it is convenient to assure their thermal stability to optimise the processing parameters and understand the effect of the fibres on thermal degradation reaction mechanisms to control the environmental impact

Figure 5 shows the differential thermogravimetric curve of pure Mater-Bi KE at the heating rate of $20 \mathrm{~K} / \mathrm{min}$. Similar patterns were obtained at different heating rates and they are not shown here for the sake of clarity. These thermograms display a complex thermal decomposition with two main mass-loss regions. The first mass-loss region shows an onset and a peak temperature at $592 \mathrm{~K}$ and $608 \mathrm{~K}$ respectively, with a mass loss of around $32 \%$. 
This mass loss is assigned to the pyrolysis of starch [23,24]. The second mass-loss region displays an onset and a peak temperature at $687 \mathrm{~K}$ and $708 \mathrm{~K}$ respectively and a mass loss of around $67 \%$. This mass-loss region is assigned to the synthetic biodegradable component of Mater-Bi KE [25,26].

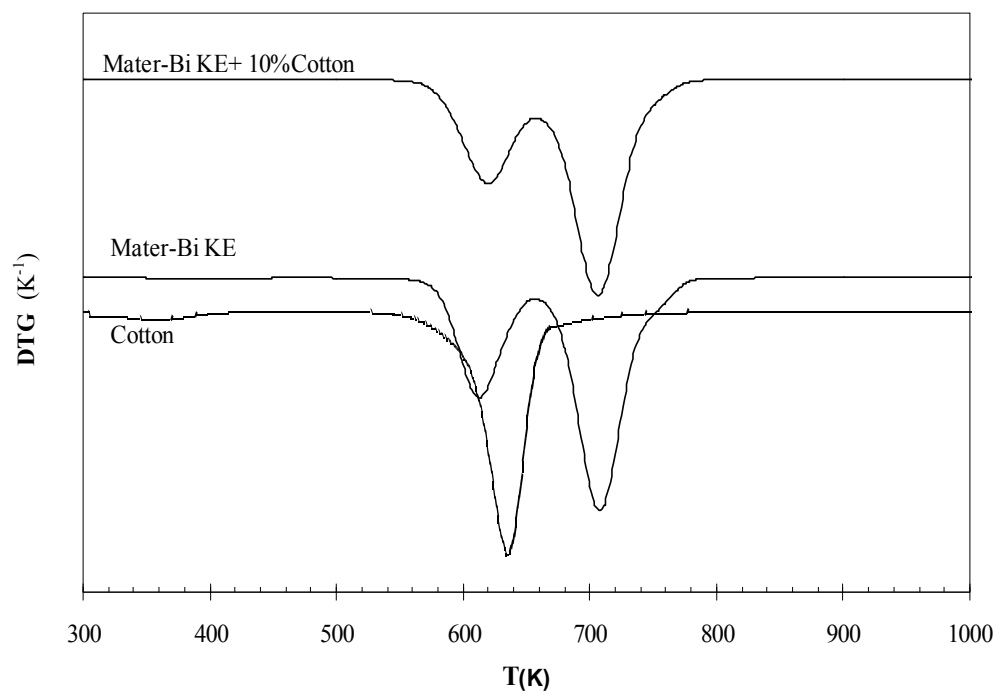

Figure 5. DTG curves of pure Mater-Bi KE, cotton fibres and Mater-Bi KE/cotton biocomposite at the heating rate of $20 \mathrm{~K} / \mathrm{min}$.

Figure 5 displays the differential thermogravimetric curve for cotton fibre at a heating rate of $20 \mathrm{~K} / \mathrm{min}$. In agreement with literature [27,28], several mass-loss regions can be observed for the pyrolysis of natural fibres. The first region, which onset and peak temperature are $340 \mathrm{~K}$ and $366 \mathrm{~K}$ respectively, represents an approximately $3 \%$ of mass-loss and is attributed to the loss of water absorbed by the biofibres. At higher temperatures, between 483-675 K, the second and main mass-loss region of cotton fibers [29,30] appears which represents an approximately $95 \%$ of mass loss. This complex process is associated to the thermal decomposition of hemicellulose, pectin, glucosidic links, and $\alpha$-cellulose $[24,25,29,30]$.

Figure 5 also plots the DTG curve of the reinforced Mater-Bi KE/cotton biocomposite that present two main mass-loss regions, similarly to the pure Mater-Bi KE. In the first mass-loss region both contributions are overlapped: the thermal decomposition of the starch present in the Mater-Bi KE and the hemicellulose/pectin, cellulose of the cotton fibre. These first massloss region shows an onset and peak temperature at $598 \mathrm{~K}$ and $617 \mathrm{~K}$ respectively that is slightly high than the corresponding to the pure Mater-Bi KE. The second complex mass-loss region displays an onset and a peak temperature at $689 \mathrm{~K}$ and $707 \mathrm{~K}$ respectively, which 
should be attributed to the biodegradable synthetic component present in the pure Mater-Bi KE. When the matrix is reinforced, an slightly increase in both the onset and the peak temperature related to the first mass-loss region can be observed, whereas the region associated to the synthetic component of Mater-Bi KE is not affected significantly by the addition of fibres. These thermogravimetric results indicate a weak improvement on the thermal stability of biocomposites probably due to a higher and longer thermal resistance of cellulose fibres than the starch polymer.

\section{Kinetic Analysis}

In order to deeply analyse the thermal degradation reaction it would be necessary to assess the kinetic triplet, including the apparent activation energy $(E a)$, the kinetic model $(f(\alpha))$ and the pre-exponential parameter $(A)$ of each individual thermal decomposition process. A deconvolution method based on an assimetrical model that has already been successfully applied in previous works for starch-based materials [26] is employed in this work to separate the thermal decomposition processes.

The methodology proposed to analyse the kinetic parameters was carefully checked: isoconversional of Friedman [30] and Flynn-Wall-Ozawa [31] were firstly used to determine the apparent activation energy; Kissinger method [32] was applied to confirm these values; Criado method [33] was fitted to identify the kinetic model that follows each thermal decomposition process; Coats-Redfern method [34] was finally employed to discuss the probable degradation kinetic model and to determine the pre-exponential factor.

\section{Friedman Method}

Table 1 summarises the $E a$ values of each thermal decomposition process of Mater-Bi KE, cotton fibres and their reinforced Mater-Bi KE/cotton biocomposite. The average Ea values obtained from Friedman method related to the thermal decomposition of starch and the synthetic component are $98 \mathrm{~kJ} / \mathrm{mol}$ and $175 \mathrm{~kJ} / \mathrm{mol}$, respectively. Furthermore, the average $E a$ value from the conversion range of 0,2-0,6 attributed to depolymerisation of the cellulose from the cotton fibres is $200 \mathrm{~kJ} / \mathrm{mol}$ [35-37]. When cotton fibres are incorporated into the Mater-Bi KE an increase in the $E a$ of both thermal decomposition regions of Mater-Bi KE can be observed; this effect is more significant on the synthetic component. 
Table 1. Apparent activation energies for Mater-Bi KE, Mater-Bi-KE/cotton and cotton fibre determined by Friedman method.

\begin{tabular}{|c|c|c|c|c|c|c|c|c|c|c|}
\hline \multirow[b]{2}{*}{$\alpha$} & \multicolumn{6}{|c|}{ [545-660K] } & \multicolumn{4}{|c|}{$[660-785 \mathrm{~K}]$} \\
\hline & $\begin{array}{c}\text { Mater-Bi } \\
\mathrm{Ea} \\
(\mathrm{kJ} / \mathrm{mol})\end{array}$ & $\mathrm{R}^{2}$ & $\begin{array}{c}\text { Mater-B } \\
/ \text { Cotton } \\
\text { Ea } \\
(\mathrm{kJ} / \mathrm{mol})\end{array}$ & $\mathrm{R}^{2}$ & $\begin{array}{c}\text { Cotton } \\
\mathrm{Ea} \\
(\mathrm{kJ} / \mathrm{mol})\end{array}$ & $\mathrm{R}^{2}$ & $\begin{array}{c}\text { Mater-Bi } \\
\mathrm{Ea} \\
(\mathrm{kJ} / \mathrm{mol})\end{array}$ & $\begin{array}{l}K E \\
\qquad \mathrm{R}^{2}\end{array}$ & $\begin{array}{l}\text { Mater- } B \\
/ \text { Cotton } \\
\text { Ea } \\
(\mathrm{kJ} / \mathrm{mol})\end{array}$ & $\mathrm{R}^{2}$ \\
\hline 0,1 & 112 & 0,9983 & 123 & 0,9946 & 179 & 0,9950 & 176 & 0,9994 & 292 & 0,9934 \\
\hline 0,2 & 106 & 0,9992 & 110 & 0,9950 & 205 & 0,9984 & 180 & 0,9989 & 301 & 0,9962 \\
\hline 0,3 & 105 & 1,0000 & 108 & 0,9945 & 209 & 0,9976 & 180 & 0,9985 & 299 & 0,9980 \\
\hline 0,4 & 100 & 0,9989 & 116 & 0,9994 & 216 & 0,9943 & 177 & 0,9977 & 292 & 0,9989 \\
\hline 0,5 & 96 & 0,9946 & 110 & 0,9976 & 214 & 0,9900 & 175 & 0,9962 & 289 & 0,9999 \\
\hline 0,6 & 94 & 0,9960 & 110 & 0,9923 & 201 & 0,9971 & 170 & 0,9935 & 284 & 0,9985 \\
\hline 0,7 & 90 & 0,9909 & 109 & 0,9903 & ------ & ------- & 170 & 0,9901 & 289 & 0,9882 \\
\hline 0,8 & 90 & 0,9889 & 109 & 0,9909 & ------- & -------- & 171 & 0,9910 & -- & -- \\
\hline
\end{tabular}

\section{Flynn-Wall-Ozawa method}

The Flynn-Wall-Ozawa method allows calculating the $E a$ and the $\ln [g(\alpha) / A]$ values (Table 2). The $E a$ obtained for each thermal decomposition process are in good agreement to those calculated by applying Friedman method, and confirm that the major changes occur in the decomposition process related to the synthetic biodegradable component. 
Table 2. Kinetic parameters associated with the thermal decomposition processes of MBi KE, MBi KE/cotton biocomposite and cotton fibres determined by Flynn-Wall-Ozawa method.

\begin{tabular}{|c|c|c|c|c|c|c|c|c|c|c|c|c|c|c|c|}
\hline \multirow[b]{3}{*}{$\alpha$} & \multicolumn{9}{|c|}{ [545-660K] } & \multicolumn{6}{|c|}{$[660-785 K]$} \\
\hline & \multicolumn{3}{|c|}{ Mater-Bi KE } & \multicolumn{3}{|c|}{ Mater-Bi KE/Cotton } & \multicolumn{3}{|c|}{ Cotton } & \multicolumn{3}{|c|}{ Mater-Bi KE } & \multicolumn{3}{|c|}{ Mater-Bi KE/Cotton } \\
\hline & $\begin{array}{c}\mathrm{Ea} \\
(\mathrm{kJ} / \mathrm{mol})\end{array}$ & $\ln \left[\frac{A R}{g(\alpha) E a}\right]$ & $\underset{\min ^{-1}}{A}$ & $\begin{array}{c}\mathrm{Ea} \\
(\mathrm{kJ} / \mathrm{m} \\
\mathrm{ol}) \\
\end{array}$ & $\ln \left[\frac{A R}{g(\alpha) E a}\right]$ & $\begin{array}{l}\text { A } \\
\min ^{-1}\end{array}$ & $\begin{array}{c}\mathrm{Ea} \\
(\mathrm{kJ} / \mathrm{m} \\
\mathrm{ol})\end{array}$ & $\ln \left[\frac{A R}{g(\alpha) E a}\right]$ & $\begin{array}{c}\mathrm{A} \\
\min ^{-1}\end{array}$ & $\begin{array}{c}\mathrm{Ea} \\
(\mathrm{kJ} / \mathrm{m} \\
\mathrm{ol})\end{array}$ & $\ln \left[\frac{A R}{g(\alpha) E a}\right]$ & $\begin{array}{l}\mathrm{A} \\
\min ^{-1}\end{array}$ & $\begin{array}{c}\mathrm{Ea} \\
(\mathrm{kJ} / \\
\mathrm{mol})\end{array}$ & {$\left[\frac{A R}{g(\alpha) E a}\right.$} & $\begin{array}{c}\mathrm{A} \\
\min ^{-1}\end{array}$ \\
\hline 0,1 & 97 & 10,3 & $10^{9.3}$ & 121 & 11,3 & $10^{11,7}$ & 175 & 16,8 & $10^{11,5}$ & --- & --- & --- & --- & --- & --- \\
\hline 0,2 & 103 & 10,7 & $10^{9.6}$ & 118 & 11,2 & $10^{11,0}$ & 200 & 18,3 & $10^{13,3}$ & 174 & 14,2 & $10^{12.9}$ & 295 & 14,2 & $10^{20,7}$ \\
\hline 0,3 & 104 & 10,7 & $10^{9.7}$ & 116 & 10,9 & $10^{10,6}$ & 204 & 19,3 & $10^{14,5}$ & 169 & 14,5 & $10^{13.3}$ & 302 & 14,5 & $10^{21,0}$ \\
\hline 0,4 & 104 & 10,7 & $10^{9.7}$ & 114 & 10,9 & $10^{10,2}$ & 213 & 19,9 & $10^{15,2}$ & 171 & 14,6 & $10^{13.5}$ & 302 & 14,6 & $10^{21,0}$ \\
\hline 0,5 & 104 & 10,6 & $10^{9.5}$ & 116 & 11,0 & $10^{10,4}$ & 214 & 20,0 & $10^{15,4}$ & 176 & 14,9 & $10^{13.8}$ & 301 & 14,9 & $10^{20,8}$ \\
\hline 0,6 & 102 & 10,4 & $10^{9.3}$ & 110 & 10,8 & $10^{9,5}$ & 202 & 18,6 & $10^{14,3}$ & 176 & 14,8 & $10^{13.8}$ & 291 & 14,8 & $10^{20,3}$ \\
\hline 0,7 & 99 & 10,0 & $10^{8.9}$ & 106 & 10,7 & $10^{9,0}$ & 204 & 18,7 & $10^{14,4}$ & 172 & 14,4 & $10^{13.6}$ & 281 & 14,5 & $10^{19,0}$ \\
\hline 0,8 & 99 & 9,9 & $10^{8.8}$ & 106 & 10,7 & $10^{8,8}$ & --- & --- & -- & --- & --- & --- & --- & --- & --- \\
\hline
\end{tabular}

Table 3. Algebraic expressions for $f(\alpha)$ for the kinetic models used.

\begin{tabular}{|c|c|c|c|}
\hline Kinetic Models & $\begin{array}{c}\text { Differential form } \\
f(\alpha)\end{array}$ & Kinetic Models & $\begin{array}{c}\text { Differential form } \\
f(\alpha)\end{array}$ \\
\hline D1 & $1 / 2(1-\alpha)-1$ & $\mathrm{n}+\mathrm{m}=1,8 ; \mathrm{n}=1,7$ & $\alpha^{0.1}(1-\alpha)^{1.7}$ \\
\hline D2 & $-\ln (1-\alpha)$ & $n+m=2 ; n=1,5$ & $\alpha^{0.5}(1-\alpha)^{1.5}$ \\
\hline D3 & $3 / 2(1-\alpha)^{2 / 3}\left(1-(1-\alpha)^{1 / 3}\right)^{-1}$ & $n+m=2 ; n=1,9$ & $\alpha^{0.1}(1-\alpha)^{1.9}$ \\
\hline D4 & $3 / 2(1-\alpha)^{1 / 3}\left(1-(1-\alpha)^{1 / 3}\right)^{-1}$ & $\mathrm{n}+\mathbf{m}=\mathbf{2} ; \mathrm{n}=1,2$ & $\alpha^{0.8}(1-\alpha)^{1.2}$ \\
\hline R1 & 1 & $n=1 / F 1$ & $(1-\alpha)$ \\
\hline $\mathbf{R 2}$ & $2(1-\alpha)^{1 / 2}$ & $\mathrm{n}=1.5$ & $(1-\alpha)^{1.5}$ \\
\hline $\mathbf{R 3}$ & $3(1-\alpha)^{2 / 3}$ & $\mathrm{n}=\mathbf{2}$ & $(1-\alpha)^{2}$ \\
\hline A2 & $2(1-\alpha)(-\ln (1-\alpha))^{1 / 2}$ & $\mathbf{n}=\mathbf{3}$ & $(1-\alpha)^{3}$ \\
\hline $\mathbf{A 3}$ & $3(1-\alpha)(-\ln (1-a))^{2 / 3}$ & Power 2 & $2 \alpha^{1 / 2}$ \\
\hline
\end{tabular}




\section{Kissinger method}

This method allows to asses $E a$ as an average, without considering the conversion degree. Figure 6 displays the results of the application of this method to both thermal degradation processes of Mater-Bi KE and its reinforced Mater-Bi KE/cotton biocomposite. These results agree with those obtained by applying Friedman and Flynn-Wall-Ozawa methods. Despite of being the most simplest method, Kissinger model show to be equally effective. This fact is of special interest to speed up the analytical methodology in latter degradation studies [38].

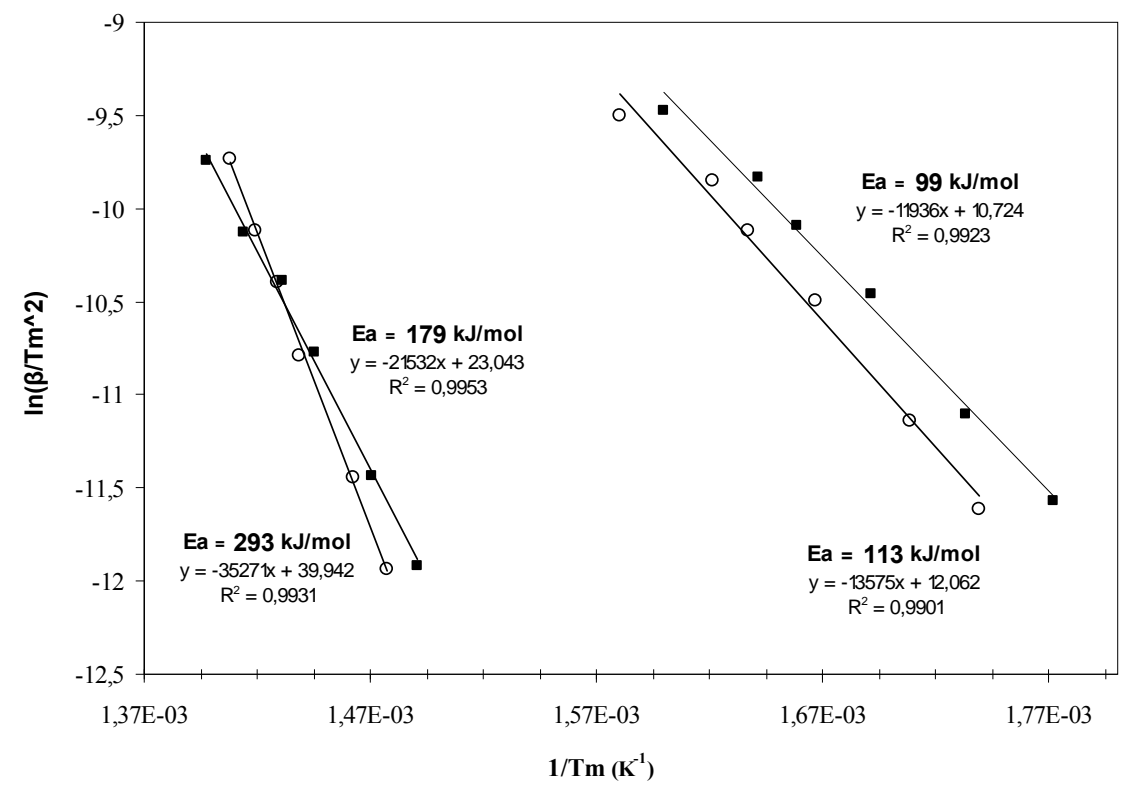

Figure 6. Kissinger plots for the (-) Mater-Bi KE and (०) Mater-Bi KE/cotton biocomposite.

\section{Criado Method and Coats-Redfern Method}

These methods have been used to determine the kinetic model followed by each thermal decomposition process and to calculate $E a$ values from the determined kinetic model. Table 3 summarises the kinetic models proposed to fit the master curves for applying Criado method. Figure 7 shows the comparison between the master curves and the experimental data from the thermal decomposition processes of Mater-Bi KE. Table 4 summarises the kinetic parameters for the kinetic models proposed by Criado. The $E a$ values obtained by Coats-Redferdn were checked with the calculated by means of Friedman, Flynn-Wall-Ozawa and Kissinger methods. The proposed model that displays the most similar values for the first and second thermal decomposition process is $(n+m=2 ; n=1.5)$. Thus, the decomposition kinetics for $\mathrm{MBi}$ KE occurs in a multistep process in which both decomposition processes follow a $(n+m ; n)$ type model, being the algebraic expression $f(\alpha)=\alpha^{0.5} \cdot(1-\alpha)^{1.5}$. Once the actual kinetic model was 
determined, the pre-exponential factor $A$ could be calculated from the $\ln [g(\alpha) / A]$ parameter obtained by Flynn-Wall-Ozawa method as displayed in Table 2.

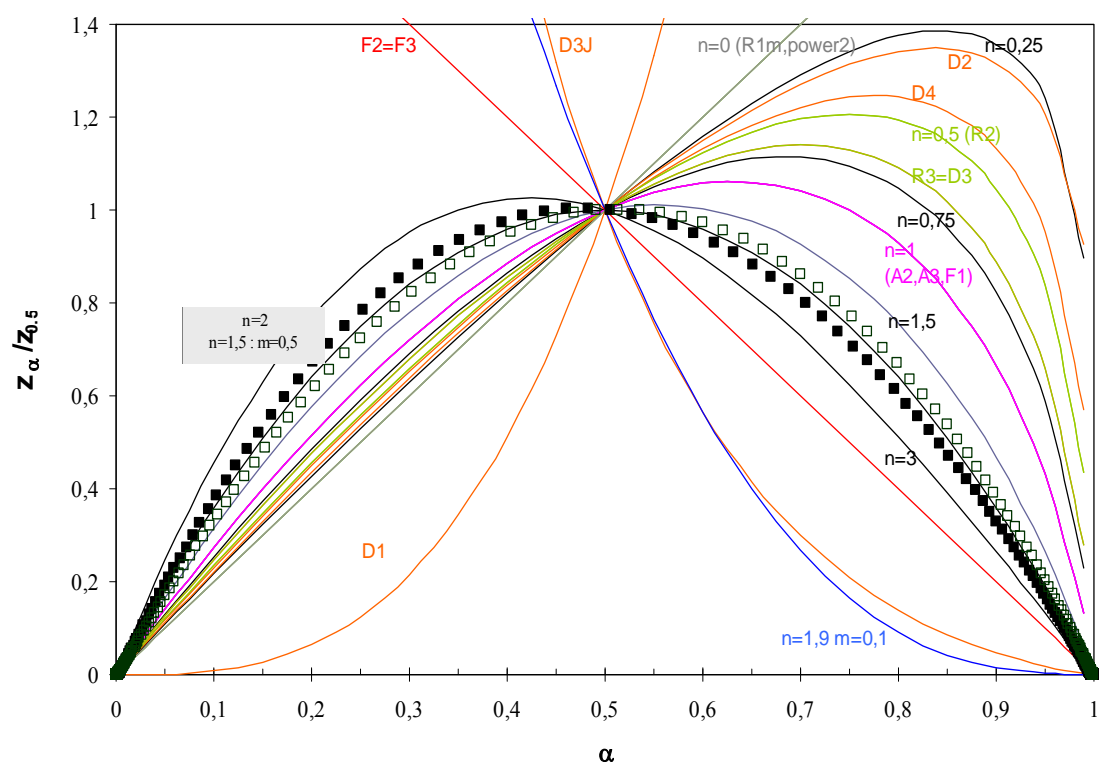

Figure 7. Criado plots for the ( $\square$ ) first and the ( $\square$ )second thermal decomposition process of Mater-Bi KE

The experimental curve that predicts the kinetic of the main thermal decomposition process of cotton fibres was calculated using the same procedure. The corresponding $E a$ calculated with the assumption of $n=1$ (being $204 \mathrm{~kJ} / \mathrm{mol}$ ) agrees with the values obtained from Friedman, Flynn-Wall-Ozawa and Kissinger methods. Thus, the assumption of a first order mechanism for cotton fibres is a good approach to understand the decomposition kinetics of cellulosic fibres.

Table 4. Kinetic parameters associated with the thermal decomposition processes of Mater-Bi KE and MaterBi KE/cotton determined by Coats-Redfern method.

\begin{tabular}{|c|c|c|c|c|c|c|c|c|}
\hline \multirow[b]{3}{*}{ Model } & \multicolumn{4}{|c|}{ Mater-Bi KE } & \multicolumn{4}{|c|}{ Mater-Bi KE/cotton } \\
\hline & \multicolumn{2}{|c|}{ First Process } & \multicolumn{2}{|c|}{ Second Process } & \multicolumn{2}{|c|}{ First Process } & \multicolumn{2}{|c|}{ Second Process } \\
\hline & $\begin{array}{c}\mathrm{Ea} \\
(\mathrm{kJ} / \mathrm{mol})\end{array}$ & $\begin{array}{c}\mathrm{A} \\
\left(\mathrm{min}^{-1}\right)\end{array}$ & $\begin{array}{c}\mathrm{Ea} \\
(\mathrm{kJ} / \mathrm{mol})\end{array}$ & $\begin{array}{c}\mathrm{A} \\
\left(\mathrm{min}^{-1}\right)\end{array}$ & $\begin{array}{c}\mathrm{Ea} \\
(\mathrm{kJ} / \mathrm{mol})\end{array}$ & $\begin{array}{c}\mathrm{A} \\
\left(\mathrm{min}^{-1}\right)\end{array}$ & $\begin{array}{c}\mathrm{Ea} \\
(\mathrm{kJ} / \mathrm{mol})\end{array}$ & $\begin{array}{c}\mathrm{A} \\
\left(\mathrm{min}^{-1}\right)\end{array}$ \\
\hline$n 1,5 \mathrm{m0,5}$ & 101 & $10^{9,0}$ & 172 & $10^{13,0}$ & 111 & $10^{10,1}$ & 156 & $10^{12,0}$ \\
\hline $\mathrm{n} 1,7 \mathrm{m0,1}$ & 194 & $10^{16,0}$ & 305 & $10^{22,5}$ & 205 & $10^{19,0}$ & 290 & $10^{20,5}$ \\
\hline$n=2$ & 230 & $10^{19,0}$ & 341 & $10^{25,4}$ & 275 & $10^{20,0}$ & 330 & $10^{24,6}$ \\
\hline$n=1,5$ & 206 & $10^{17,3}$ & 316 & $10^{23,5}$ & 254 & $10^{19,8}$ & 278 & $10^{20,0}$ \\
\hline
\end{tabular}


Finally, the kinetic mechanism of the reinforced biocomposites was studied and the results are summarized in Table 4. The actual reaction mechanisms related to the first decomposition region is $f(\alpha)=(1-\alpha)^{1,5} \alpha^{0.5}$; the reaction mechanism of the starch present in the Mater-Bi KE is therefore not affected by the addition of the fibres. However, the thermal decomposition process related to the synthetic component changed from $f(\alpha)=(1-\alpha)^{1,5} \alpha^{0,5}$ to $f(\alpha)=(1-\alpha)^{1,7} \alpha^{0.1}$. This result indicates that the addition of fibres significantly modifies the decomposition kinetics of the synthetic component of Mater-Bi KE and justifies the higher values of $E a$ for the synthetic component. The changes in these kinetic parameters point out the good interactions between the polymeric matrix and the natural fibre.

\section{Conclusions}

Thermal Analysis has been proved to be accurate and useful to assess the changes in the thermal and mechanical properties of pure Mater-Bi KE and its reinforced Mater-Bi $\mathrm{KE} /$ cotton biocomposite. The interactions between the polymeric matrix and the cotton fibres have a nucleant effect in the crystallisation of the molecular chains of the synthetic component of the matrix, enhancing the crystalline phase of the reinforced Mater-Bi $\mathrm{KE} /$ cotton biocomposite. According to these results, the addition of natural fibres provides an increase of the temperature and the activation energy associated to the movements prior to the melting of the synthetic component of pure Mater-Bi KE. An increase in the storage and loss modulus of the pure Mater-Bi KE is assessed when the cotton fibres are added. The thermal expansion coefficient of the pure Mater-Bi KE decreases with the addition of cotton fibres, indicating a rearrangement of the polymeric chains of the synthetic component of pure MaterBi KE. These thermo-mechanical results suggest an enhancement in the mechanical properties of the reinforced Mater-Bi KE/cotton biocomposite.

The kinetic methodology proposed to analyse the thermal decomposition behaviour also demonstrated that the most important changes in the kinetic model have been observed for the synthetic component of the pure Mater-Bi KE. Finally, the slight increase of the onset temperature and the activation energy of the first thermodecomposition process assure the thermal stability of the reinforced Mater-Bi KE/cotton biocomposite. 


\section{References}

[1] Mohanty AK, Misra M, Drzal TD editors. Natural Fibers, Biopolymers and Biocomposites. Boca Raton: Taylor \& Francis, 2005

[2] Davidson VJ, Paton D, Diosady LL, Laroque G. J Food Science 1984; 49: 453.

[3] Bastioli, C. Polym Degrad Stab 1998; 59: 263

[4] Mohanty AK, Misra M, Hinrichsen G. Macromol Mater Eng 2000; 276/277: 1

[5] Scott G, editor. Degradable Polymers. Netherlands: Kluwer Academic Publishers, 2002.

[6] Clarinval A, Halleux J. In: Smith R editor. Biodegradable polymers for industrial applications. London; Woodhead Publishing, 2005.

[7] Mohanty AK, Misra M, Drzal TD. J Polymer Environ 2002; 10; 1/2

[8] Bledzki AK, Gassan J. Prog Polym Sci 1999; 24: 221.

[9] Fowler PA, Hughes JM, Elias RM. Sci Food Agric 2006; 86:1781

[10] Puglia D, Tomassuci A, Kenny JM. Polym Adv Tech 2003; 14: 749.

[11] Mohanty AK, Misra M, Hinrichsen G. Macromol Mater Eng 2000; 276/277: 1

[12] Di Franco CR, Cyras VP, Busalmen JP, Ruseckaite RA, Vazquez A. Polym Degrad Stab 2004; 86: 95.

[13] Morreales M, Scaffaro S, Maio A, La Mantia FP. Compos Appl Sci Manuf 2008; 39: 503.

[14] Scaffaro R, Morreale M, Lo Re G, La Mantia FP. Polym Degrad Stab 2009; 8:1220.

[15] Bastioli C, Belloti V, Rallis A. Rheol Acta 1994; 33: 307

[16] Bastioli C editor. Handbook of Biodegradable Polymers. Shrewsbury: Rapra Technology, 2005. Taylor \& Francis, 2005.

[17] Ge XC, Xu Y, Meng YZ, Li RKY. Compos Sci Tech 2005; 65; 2219.

[18] Digabel FL, Avérous L. Carbohydr Polymer 2006; 66: 537.

[19] Fuoss RM, Kirkwood JG. J Am Chem Soc 1941; 2: 385.

[20] Charlesworth JM. J Mater Sci 1993; 28: 399.

[21] Avérous L, Moro L, Dole P, Fringant C. Polymer 2000; 41: 4157.

[22] Fulcher GS. J Am Ceram Soc 1925; 6: 339.

[23] Griffin GJL, editor. Chemistry and Technology of Biodegradable Polymers. Glasgow: Blackie Academic Professional, 1994.

[24] Turker N, Mark J. editors. Low Environmental Impact Polymers. Shrewsbury: Rapra Technology, 2004.

[25] Alvarez VA, Vázquez A. Polym Degrad Stab 2004; 84: 13

[26] Moriana-Torró R, Contat-Rodrigo L, Santonja-Blasco L, Ribes-Greus A. J Appl Polym Sci 2008; 109: 1177

[27] Fukatsu K. Polym Degrad Stab 2002; 75: 479

[28] Mamleev V, Bourbigot S, Yvon J. J Anal Appl Pyrolysis 2007; 80: 151 
[29] Aggarwal P, Dollimore D, Heon K. J Therm Anal 1997; $50: 7$.

[30] Friedman, J Appl Polym Sci 1964; 6: 183.

[31] Ozawa T, Bull Chem Soc Jpn 1965; 38: 1881.

[32] Kissinger HE. J Res Natl Bur Stand 1956; 57: 217.

[33] Criado JM. Thermochimic Acta 1978; 24:86.

[34] Coats AW, Redfern JP. Nature (Lond) 1964; 201: 68.

[35] Fei Y, Qinglin W, Yong L, Weihong G, Yanjun X. Polym Degrad Stab 2008; 93: 90.

[36] Quajai S, Shanks RA. Polym Degrad Stab 2005; 89: 327.

[37] Mamleev V, Bourbigot S, Le Bras M, Yvon J, Lefebvre J. Chem Eng Sci 2006; 61: 1276.

[38] Moriana R, Karlsson S, Ribes-Greus A. Polym Compos 2010 (pending of publication). 

"IMPROVED THERMO-MECHANICAL PROPERTIES BY THE ADDITION OF DIFFERENT NATURAL FIBRES IN STARCH-BASED SUSTAINABLE BIOCOMPOSITES “ 



\title{
Improved thermo-mechanical properties by the addition of natural fibres in starch-based sustainable biocomposites
}

\author{
Rosana Moriana a, Francisco Vilaplana ${ }^{\text {b }}$, Sigbritt Karlsson ${ }^{\text {b }}$, Amparo Ribes-Greus ${ }^{\mathrm{a}, *}$ \\ a Instituto de Tecnología de Materiales (ITM), Universidad Politécnica de Valencia, Camino de Vera s/n, E-46022 Valencia, Spain

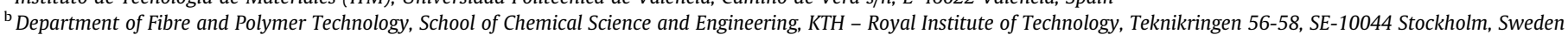

\section{A R T I C L E I N F O}

Article history:

Received 24 December 2009

Received in revised form 12 August 2010

Accepted 3 October 2010

Available online $\mathrm{xxxx}$

\section{Keywords:}

A. Polymer-matrix composites (PMCs)

D. Electron microscopy

B. Thermomechanical

D. Thermal analysis

\begin{abstract}
A B S T R A C T
Sustainable biocomposites based on thermoplastic starch copolymers (Mater-Bi KE03B1) and biofibres (cotton, hemp and kenaf) were prepared and characterised in terms of their thermo-mechanical and morphological properties. Biocomposites exhibit improved thermal stability and mechanical properties in comparison with the Mater-Bi KE. Biofibres act as suitable thermal stabilizers for the Mater-Bi KE, by increasing the maximum decomposition temperature and the Ea associated to the thermal decomposition process. Biofibre addition into the Mater-Bi KE results in higher storage modulus and in a reduction of the free-volume-parameter associated to the Mater-Bi KE glass transition. The influence of different biofibres on the thermo-mechanical properties of the biocomposites has been discussed. Hemp and kenaf enhance the thermal stability and reduce the free volume-parameter of Mater-Bi KE more significantly than cotton fibres, although the latter exhibits the highest mechanical performance. These differences may be explained by the improved interaction of lignocellulosic fibres with the Mater-Bi KE, due to the presence of hemicellulose and lignin in their formulation.
\end{abstract}

(c) 2010 Elsevier Ltd. All rights reserved.

\section{Introduction}

The substitution of traditional polymer-based composite materials based on a synthetic thermoplastic matrix reinforced with fillers such as glass, carbon or aramid fibres by environmentallyfriendly composites with a biodegradable matrix and natural fibres is considered of fundamental importance due to the increasing environmental consciousness [1]. Thermoplastic starch polymers have drawn attention among other biodegradable materials, due to their raw material availability and low price; unfortunately, these materials still have poor mechanical properties and remarkable sensitivity to moisture, which limit their applicability [2,3]. Different approaches can be used to design thermoplastic starch materials with enhanced structural and functional stability during use, which could broaden their application range. In addition to starch chemical modifications such as the addition of crosslinking agents and the development of multilayer and grafting products, different authors have proposed blending starch physically with other degradable polymers [4], to enhance its mechanical and thermal properties and to ensure its biodegradability. Some of these polymers include chitin/chitosan [5], pectin, cellulose and its derivatives [6,7], bacterially-derived polyesters like poly ( $\beta$-hydroxybutyrate-co- $\beta$-hydroxyvalerate) PHBV [8], poly(lactic

\footnotetext{
* Corresponding author. Tel.: +34 963879817.

E-mail address: aribes@ter.upv.es (A. Ribes-Greus).
}

acid) (PLA) [9] and poly(vinyl alcohol) (PVOH) [9,10] and synthetic-derived polyesters such as poly( $\varepsilon$-caprolactone) $[11,12]$. Some starch-based blends are nowadays marketed on a commercial scale, with trademarks as Mater-Bi ${ }^{\circledR}$ (Novamont, Italy), Bioplast $^{\circledR}$ (Biotech, Germany), Biopar ${ }^{\circledR}$ (Biop Biopolymer Technologies AG, Germany) and Novon ${ }^{\mathrm{TM}}$ (produced by Chisso in Japan and Warner Lambert in USA) [13].

Different natural fibres (flax, ramie, jute, palm and sisal among others) are described in the literature as reinforcement of starchbased thermoplastic polymers [14-17]. Most natural fibres are composed of cellulose, hemicelluloses and lignin with different relative amounts, except for cotton that has principally cellulose in its composition [18]. When natural fibres are mixed with polysaccharides (thermoplastic starch and its blends) their mechanical properties become notable improved. This fact has been attributed to the chemical similarity of starch and plant fibres, providing good compatibility between them [19]. A good adhesion between natural fibre and polymeric matrix is necessary to define a good fibre/ matrix interface that can transfer externally-applied loads to the reinforcement via shear stresses over the interface [20]. As well as the fibre/matrix interface, other factor that determines the quality of the resulting composite is the fibre architecture (fibre geometry, fibre orientation, packing arrangement). However, the macroscopic properties of a composite are dictated by the intrinsic properties of each component, largely governed by their chemical constituents. One of the severe technologic drawbacks of 
biocomposites from renewable resources is the reduced processing and practical "window-use", with both matrix and fibres being very sensitive to temperature. Thus, the study of the thermal degradation of composites with natural fibres is an important aspect for deciding processing parameters such as product extrusion and injection temperatures and for designing the utilization conditions of the final products [21].

In this study, three different natural fibres, cotton, kenaf, and hemp fibres have been used as reinforcement into a commercial starch-based thermoplastic material, Mater-Bi KE 03B1. The aim of this work is to study the improved thermal stability in starchbased biocomposites by the addition of different natural fibres and the compatibilization between natural fibres and matrix through the viscoelastic and morphological properties.

\section{Experimental}

\subsection{Materials and sample preparation}

Commercial grade Mater-Bi KE03B1 (Mater-Bi KE), supplied by Novamont Novara S.P.A (Italy) was used as biodegradable matrix to prepare the reinforced biocomposite. In a previous work [22], Mater-Bi KE was reported to be a blend of thermoplastic starch and a polyester synthetic component with approximately $60 \%$ in content, according to infrared and thermogravimetric analyses. The synthetic component in Mater-Bi KE can be assigned to poly( $\varepsilon$-caprolactone) by comparison to the results reported by Mano et al. [23] on the thermal behaviour of some blends supplied by Novamont composed of thermoplastic starch with different biodegradable synthetic polymers; this will be discussed in detail in the following sections. Cotton, Kenaf and Hemp were the natural fibres employed as reinforcement, provided by Yute S.L. (Spain). The average length, fibre diameter, and form relation shape (defined as the fibre diameter/length ratio) of each kind of natural fibres were determined by optical microscopy over 100 fibres. The average mechanical and physical properties of the polymeric matrix and natural fibres are summarized in Table 1.

Reinforced composites with $10 \%$ (w/w) natural fibre were prepared in a co-rotative twin screw extruder under a processing temperature of $438 \mathrm{~K}$ (Werner \& Pfleiderer ZSK 25, Germany) following the same procedure reported in a preceding paper [22]. Rectangular bars with dimensions $110 \times 110 \times 2 \mathrm{~mm}$ were obtained by means of compression moulding at $453 \mathrm{~K}$.

\subsection{Chemical composition of natural fibres}

The lignin content in natural fibres was measured using Klason method, according to the procedure reported by Monties et al. [24].

Table 1

Mechanical and physical properties of pure Mater-Bi KE and natural fibres.

\begin{tabular}{llll}
\hline Materials & Characteristics & Units & Values \\
\hline Mater-Bi KE & Tensile stress at break & $\mathrm{MPa}$ & $18.0 \pm 1.0$ \\
& Elongation at break & $\%$ & $150.0 \pm 8.0$ \\
& Elastic modulus & $\mathrm{MPa}$ & $1400.0 \pm 10.0$ \\
Cotton fibre & Average length & $\mathrm{mm}$ & $3.0 \pm 1.0$ \\
& Average diameter & $10^{2} \mathrm{~mm}$ & $1.8 \pm 1.2$ \\
& Form relationshape & & $66.7-666.7$ \\
& Elastic modulus & $\mathrm{GPa}$ & $12.0 \pm 4.0$ \\
& Average length & $\mathrm{mm}$ & $10.0 \pm 5.0$ \\
Kenaf fibre & Average diameter & $10^{2} \mathrm{~mm}$ & $15.0 \pm 0.5$ \\
& Form relationshape & & $25.2-150.2$ \\
& Elastic modulus & $\mathrm{GPa}$ & $40.0 \pm 5.0$ \\
Hemp fibre & Average length & $\mathrm{mm}$ & $1.0 \pm 0.5$ \\
& Average diameter & $10^{2} \mathrm{~mm}$ & $2.7 \pm 2.0$ \\
& Form relationshape & & $150.7-214.0$ \\
& Elastic modulus & $\mathrm{GPa}$ & $50.0 \pm 6.0$ \\
\hline
\end{tabular}

The initial dry mass $M$ was calculated by measuring the humidity of the sample using a Mettler Toledo HB43 moisture analyser (Columbus, $\mathrm{OH}$ ). Three milliliters of a $72 \%$ hydro $\mathrm{H}_{2} \mathrm{SO}_{4}$ were added to $250 \mathrm{mg}$ of dry sample and it was left during $45 \mathrm{~min}$ in a desiccator under vacuum before diluting the solution with $84 \mathrm{~mL}$ of distilled water. The acid hydrolysis was carried out in an autoclave for $60 \mathrm{~min}$ at $398 \mathrm{~K}$; the samples were filtered afterwards when still warm. The filtered liquid was placed in a $100 \mathrm{~mL}$ vial together with $1 \mathrm{~mL}$ of internal standard solution (1250 mg inositol in $25 \mathrm{~mL}$ distilled water) and then the vial was brought to volume with distilled water; these filtered samples were kept for posterior polysaccharide analysis. The filtered residue was repeatedly washed with hot distilled water and then dried at $378 \mathrm{~K}$ during $24 \mathrm{~h}$; the dry residue was finally weighed and recorded as $P$. The lignin and mineral content were calculated according to:

Klason Lignins + ash $=\frac{P}{M}$

where $M$ is the initial dry mass and $P$ is the weigh of the dry residue after acid hydrolysis. The results obtained by the Klason method must be however corrected with the ash content, thus avoiding the overestimation caused by the presence of mineral substances in the natural fibres. The dry samples were therefore pyrolysed in a furnace during $6 \mathrm{~h}$ at a temperature of $773 \mathrm{~K}$, and the remaining ashes were weighed $\left(P^{\prime}\right)$. Finally, the lignin content was calculated according this equation:

Klason Lignins $=\frac{P-P^{\prime}}{M}(\%)$

The carbohydrate composition of the liquid extract after acid hydrolysis was analysed following a modified protocol from Theander et al. [25], based on reduction with sodium borohydride, acetylation, and chromatographic determination. The measurements were performed by duplicate. A $1 \mathrm{~mL}$ aliquot of the filtered liquid samples was taken and placed in a $10 \mathrm{~mL}$ test tube; $0.5 \mathrm{~mL}$ of $\mathrm{NH}_{4} \mathrm{OH}$ solution $12 \mathrm{M}$ were added to achieve a basic $\mathrm{pH}$. The reduction was carried out by the addition of $0.2 \mathrm{~mL}$ of potassium-borehydride $7.5 \mathrm{M}$ and placing the tubes in hot water during $1 \mathrm{~h}$. The samples were finally neutralised with acetic acid. Acetylation was performed by the addition of 1-methylimidazol $(0.5 \mathrm{~mL})$, acetic acid anhydride $(5 \mathrm{~mL})$, absolute pure ethanol $(2 \mathrm{~mL})$, cold distilled water $(4 \mathrm{~mL})$, and $\mathrm{KOH}(5 \mathrm{~mL})$ to $0.5 \mathrm{~mL}$ of the previously neutralised samples. The samples were then examined by gas chromatography (GC) using a Hewlett-Packard HP-6890 chromatograph. Inositol was used as an internal standard. Separation was performed in a BP X70 capillary column with dimensions $12 \mathrm{~m} \times 0.32 \mathrm{~mm}$ ID (SGE Analytical Science) operated at $483 \mathrm{~K}$ with helium as the carrier gas. The injector temperature was kept at $503 \mathrm{~K}$ and the detector temperature was $523 \mathrm{~K}$. Peaks were quantified by area, and a mixture of standards (glucose, mannose, xylose, arabinose and galactose) was used to elaborate calibration curves. The results from the two replications were averaged; in all cases, the standard deviations from replicates were below $1 \%$ of the mean values.

\subsection{Differential scanning calorimetry (DSC)}

DSC measurements were performed on a Mettler Toledo DSC 822 e (Columbus, $\mathrm{OH}$ ) previously calibrated with indium standard. Samples (between 5 and $8 \mathrm{mg}$ ) were sealed in standard aluminium pans previously pierced. Natural fibres, pure Mater-Bi KE, and their reinforced biocomposite samples were submitted to the following process: (i) heating scan from $173 \mathrm{~K}$ to $473 \mathrm{~K}$, hold at $473 \mathrm{~K}$ for $3 \mathrm{~min}$; (ii) cooling scan from $473 \mathrm{~K}$ to $173 \mathrm{~K}$, hold at $173 \mathrm{~K}$ for $3 \mathrm{~min}$; (iii) second heating scan from $173 \mathrm{~K}$ to $473 \mathrm{~K}$. The heating and cooling rates were set at $10 \mathrm{~K} / \mathrm{min}$. The melting temperature $(\mathrm{Tm})$ was determined at the maximum of the main endothermic 
peak from the second heating scan. The crystallisation temperature (Tc) was obtained at the maximum of the exothermic peak from the cooling scan. The different crystallization and melting enthalpies ( $\Delta H c$ and $\Delta H m$, respectively) were determined by integration of the corresponding peaks and the obtained values were corrected considering only the matrix composition in the biocomposite [26].

\subsection{Thermogravimetric analysis (TGA)}

The thermal decomposition of the natural fibres, pure Mater-Bi $\mathrm{KE}$ and their reinforced biocomposites was evaluated by dynamic thermogravimetric analysis (TGA) using a Mettler-Toledo TGA/ SDTA 851 (Columbus, OH). Approximately $8.5 \mathrm{mg}$ of sample was heated between 298 and $1023 \mathrm{~K}$ at different heating rates in the range of $3,5,10,20$, and $30 \mathrm{~K} / \mathrm{min}$ under an argon atmosphere flow of $50 \mathrm{~mL} / \mathrm{min}$. The values of the onset, maximum decomposition peak and mass loss, as well as the kinetic triplet of each thermal decomposition process of the studied materials were obtained.

\subsection{Dynamic mechanical thermal analysis (DMTA)}

The viscoelastic measurements of pure Mater-Bi KE and its reinforced biocomposites were carried out in a Dynamic-mechanicalthermal analyser MARK IV DMTA (Rheometric Scientific, United Kingdom). The sinusoidal deformation was applied to rectangular samples with dimensions of $50 \times 10 \times 2 \mathrm{~mm}$ in the double clamped cantilever mode. Multifrequency scans were performed between $0.1 \mathrm{~Hz}$ and $100 \mathrm{~Hz}$ using four frequencies per decade at a temperature region between $173 \mathrm{~K}$ and $363 \mathrm{~K}$. The temperature region from $173 \mathrm{~K}$ to $298 \mathrm{~K}$ was scanned in isothermal steps of $2 \mathrm{~K}$, while between $298 \mathrm{~K}$ and $365 \mathrm{~K}$ the scan was performed each $4 \mathrm{~K}$. The values of loss tangent $(\tan \delta)$, storage modulus $\left(E^{\prime}\right)$, and loss modulus $\left(E^{\prime \prime}\right)$ versus temperature and frequency were thus obtained.

\subsection{Scanning electron microscopy (SEM)}

SEM micrographs were obtained from cryogenic sectioned samples after sputtering with gold/palladium, using a JEOL JSM-5400 scanning electron microscope (JEOL Ltd., Japan).

\section{Results and discussion}

\subsection{Chemical composition/carbohydrate analysis}

Carbohydrate analysis was performed to asses the composition of the monosaccharides present in the studied natural fibres. Table 2 displays the relative percentage of each monosaccharide for cotton, kenaf and hemp fibres. The studied natural fibres present important differences in their chemical composition, as expected. Glucose concentration indicates the cellulose content, while different monosaccharides (mannose, xylose, arabinose and galactose) are also quantified to obtain the hemicellulose/pectin content. Cotton fibres possess the highest cellulose content (90\%); kenaf fibres present on the other hand the highest content in hemicelluloses/ pectins (22\%) and lignins (12\%). These differences in natural fibre composition may influence the thermal and the viscoelastic properties of starch-based composites, as it will be discussed in the following sections.

\subsection{Calorimetric measurements}

Fig. 1 shows the calorimetric thermograms from the cooling and second heating scans for pure Mater-Bi KE and its reinforced biocomposites. Pure Mater-Bi KE displays a prominent peak around $336 \mathrm{~K}$ in the heating scan and at $316 \mathrm{~K}$ in the cooling scan, which are related to the melting and the crystallization of the crystalline phase of the synthetic biodegradable polymer component in Mater-Bi KE [27]. The enthalpic values of the melting and crystallization transitions are $61 \mathrm{~J} / \mathrm{g}$ and $55 \mathrm{~J} / \mathrm{g}$, respectively. These calorimetric results are consistent with those previously reported for thermoplastic starch/poly( $\varepsilon$-caprolactone) blends by Mano et al. [23] and also in similar works [28,29]. A glass transition can be slightly distinguished at $223 \mathrm{~K}$; however, this thermal transition is difficult to assign at this stage from the calorimetric results [30].

Natural fibres have also been characterised by calorimetric measurements; only the second heating scan of cotton and hemp fibres displays a small thermal transition at 373-420 K that could be related to reorganizations of the cellulose chains. The presence of natural fibres does not induce extensive changes on the shapes of calorimetric thermograms. The temperature of the melting prominent peak related to the crystalline phase of the synthetic biodegradable polymer component is slightly higher in the reinforced biocomposites than in the pure Mater-Bi KE (Table 3) evidencing interactions between the studied natural fibres and the pure Mater-Bi KE.

The corrected enthalpies obtained for the reinforced biocomposites, taking into account the matrix content, are slightly higher than the enthalpies of pure Mater-Bi KE (Table 3). These results may indicate that the addition of the natural fibres in the pure Mater-Bi KE slightly enhances the crystallization of the molecular chains of the synthetic biodegradable component [31].

\subsection{Thermal degradation analysis}

The thermal degradation of, the natural fibres (cotton, kenaf, and hemp fibres), the pure Mater-Bi KE and their reinforced biocomposites (Mater-Bi KE/cotton, Mater-Bi KE/hemp, and Mater-Bi $\mathrm{KE} /$ kenaf) were analysed in detail by performing dynamical thermogravimetric analyses at different heating rates.

Fig. 2a shows the thermogravimetric (TG) and the differential thermogravimetric (DTG) curves of each natural fibre at a heating rate of $20 \mathrm{~K} / \mathrm{min}$; similar patterns were obtained at different heating rates for each natural fibre but they are not shown here for the sake of clarity. Several mass-loss regions can be observed for the pyrolysis of natural fibres in agreement with other studies $[32,33]$. The first mass-loss region between 300 and $430 \mathrm{~K}$ can be attributed to the loss of water absorbed by the biofibres. The second mass-loss region (480-830 K) shows a complex thermal decomposition process where up to three different overlapped peaks can be observed: a sharper and well-defined main peak centred around $620-635 \mathrm{~K}$ that is associated with the thermal decomposition of cellulose (labelled as peak C); an overlapping shoulder

Table 2

Chemical composition of natural fibres.

\begin{tabular}{|c|c|c|c|c|c|c|c|c|}
\hline Materials & Arabinose (\%) & Xylose (\%) & Mannose (\%) & Galactose (\%) & Glucose (\%) & Lignin (\%) & Ash (\%) & Humidity (\%) \\
\hline Cotton fibre & $<1.0$ & $<1.0$ & $<1.0$ & $<1.0$ & 90.7 & - & 2.0 & 4.0 \\
\hline Hemp fibre & 2.9 & 1.0 & 5.0 & 3.5 & 69.7 & 5.8 & 7.0 & 5.1 \\
\hline Kenaf fibre & 1.0 & 18.4 & 2.0 & 1.2 & 57.3 & 12.1 & 1.0 & 7.0 \\
\hline
\end{tabular}



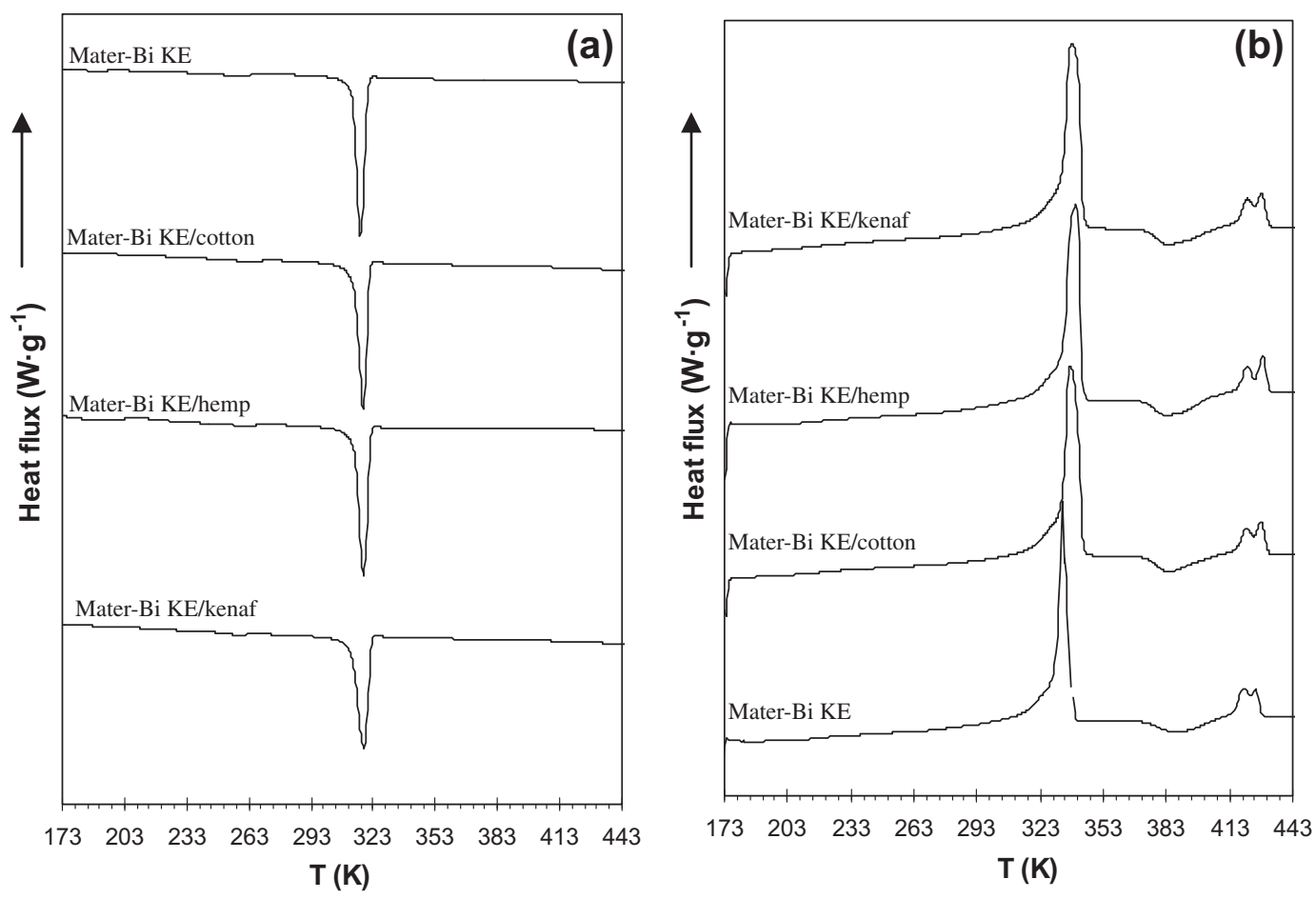

Fig. 1. DSC thermograms for Mater-Bi KE and reinforced biocomposites: (a) cooling scan and (b) re-heating scan.

Table 3

Calorimetric parameters of pure Mater-Bi KE and its reinforced biocomposites.

\begin{tabular}{lllll}
\hline Materials & $T m(\mathrm{~K})$ & $\Delta H m(\mathrm{~J} / \mathrm{g})$ & $T c(\mathrm{~K})$ & $\Delta H c(\mathrm{~J} / \mathrm{g})$ \\
\hline Mater-Bi KE & $336.0 \pm 0.5$ & $61.1 \pm 1.6$ & $315.0 \pm 0.5$ & $55.0 \pm 0.6$ \\
Mater-Bi KE/cotton & $338.7 \pm 1.0$ & $68.8 \pm 1.0$ & $319.2 \pm 0.6$ & $63.6 \pm 0.4$ \\
Mater-Bi KE/kenaf & $341.1 \pm 0.5$ & $65.7 \pm 0.2$ & $319.8 \pm 0.3$ & $61.9 \pm 1.0$ \\
Mater-Bi KE/hemp & $340.4 \pm 0.5$ & $64.6 \pm 1.5$ & $319.4 \pm 0.3$ & $58.6 \pm 1.5$ \\
\hline
\end{tabular}

that appears at lower temperatures and that is attributed to the pyrolysis of both hemicellulose and pectins (labelled as peak $\mathrm{H}$ ); and a tail displayed at higher temperatures (labelled as peak T), which is related to the degradation of lignin (for the fibres with certain lignin content) and to the final decomposition reactions of cellulose components to form tar or char. Kenaf and hemp fibres present a good defined hemicellulose shoulder overlapped to the thermal decomposition cellulose main peak, while in the cotton fibres the hemicellulose peak is overlapped to the cellulose main peak.

The individual contributions of the three overlapped processes in this second mass-loss region, hemicellulose/pectin (peak $\mathrm{H}$ ), cellulose (peak C), and high temperature tail (peak T) were determined using a deconvolution procedure based on an asymmetrical model (Eq. (3)); this mathematical procedure has already been successfully applied in previous works for starch-based materials and reinforced biopolymers [22].

$y_{i}=A \cdot\left(\frac{1}{1+\exp \left(\frac{-\left(x-x_{c}+\frac{w_{1}}{2}\right)}{w_{2}}\right)}\right) \cdot\left(1-\frac{1}{1+\exp \left(\frac{-\left(x-x_{c}+\frac{w_{1}}{2}\right)}{w_{3}}\right)}\right)$

where $x_{c}$ is a position parameter related to the curve maximum, $A$ is an amplification parameter and $w_{1}, w_{2}, w_{3}$ describe the dispersion and symmetry of the curve. The proposed deconvolution model considers that the measured value of $(d w(\%) / d T)=y$ is equivalent to $y=y_{0}+\sum_{i=1}^{n} y_{i}$, where $y_{0}$ is the baseline of each DTG curve and $n$ is the total number of deconvoluted peaks. The results of the fitting procedure for the deconvolution of the decomposition processes for cotton, kenaf and hemp fibres are displayed in Fig. 2bd, respectively.

The thermal degradation parameters of selected natural fibres are reported in Table 4 . The peak associated to the humidity content appears centred around $373 \mathrm{~K}$ and represents more than $3 \%$ of total mass loss in all the samples. The onset temperature, the mass loss, the residue content, and the temperature of maximum decomposition peak $\left(T_{0}\right)$ for the second mass-loss region (480$830 \mathrm{~K}$ ) were directly calculated from the thermograms. The peak temperatures for each region (named $T_{H}, T_{C}$, and $T_{T}$ respectively) were obtained by the mathematical fitting, corresponding to the value of $x_{c}$ parameter in each individual contribution. The massloss percentage equivalent to each individual process (named $M L_{H}, M L_{C}$ and $M L_{T}$ ) was calculated as the area of each deconvoluted peak; this percentage could be related to the hemicellulose/pectin, cellulose, and lignin content, as compared with the results of carbohydrate analysis.

Interesting information can be extracted from the thermogravimetric results about the thermal stability of the different fibres. Kenaf fibre displays the biggest mass-loss peak for the hemicellulose/ pectin region $\left(M L_{H}\right)$. Kenaf fibres also present the higher water content, which could be related to the fact that hemicellulose is the most hydrophilic component in natural fibres [34]. Cotton fibres present the lowest hemicellulose mass-loss percentage, the lowest residue content, and a higher onset decomposition temperature, $50 \mathrm{~K}$ higher than both hemp and kenaf fibres (around $532 \mathrm{~K}$ ); this fact indicates that pure cotton fibre is the most thermally-stable of all studied fibres.

Fig. 3 displays the TG and DTG curves of pure Mater-Bi KE and the reinforced biocomposites. Mater-Bi KE displays a complex thermal decomposition with two main mass-loss regions as reported in previous studies [22]: the first mass-loss region centred on $607 \mathrm{~K}$ is related to starch; and the second mass-loss region (around $708 \mathrm{~K}$ ) is associated to the synthetic component present in pure Mater-Bi KE. These results are consistent with the thermo- 
(a)
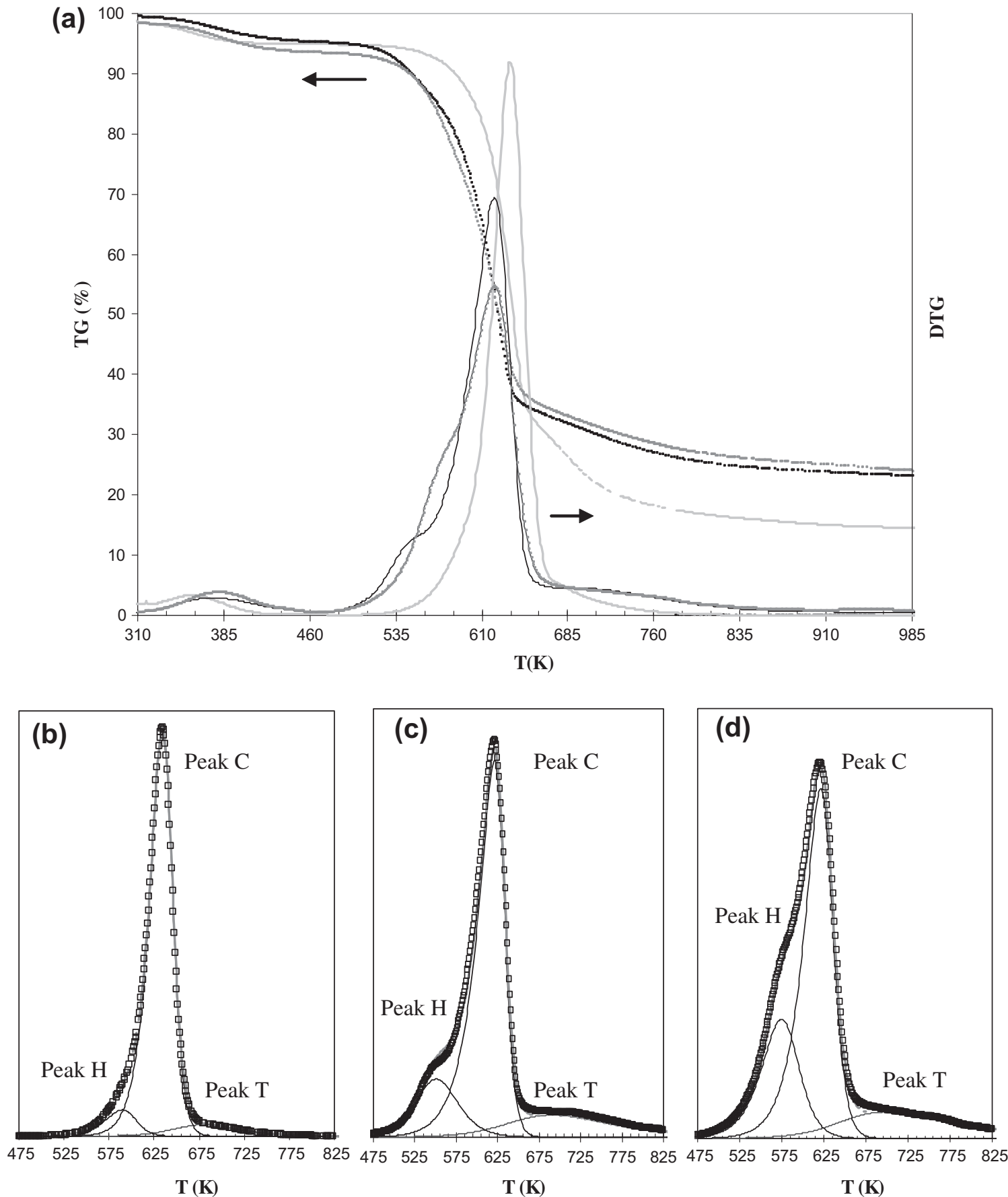

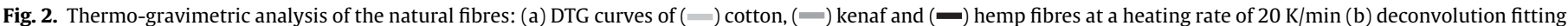
of cotton fibre, (c) deconvolution fitting of kenaf fibre and (d) deconvolution fitting of hemp fibre ( $\square$ experimental data, - - deconvoluted peaks, -- fitting curves).

gravimetric degradation behaviour of starch/poly( $\varepsilon$-caprolactone) blends in different studies [23,35].

The thermal decomposition of the three studied reinforced biocomposites presents two main mass-loss regions, similarly to the pure Mater-Bi KE. The thermogravimetric parameters from the performed thermograms of reinforced biocomposites are summarized in Table 5. When the pure Mater-Bi KE is reinforced, the region associated to the synthetic component of this polymeric matrix is not significantly affected by the addition of any of these fibres. In addition, the peak due to starch degradation in pure Mater-Bi KE is completely overlapped with hemicellulose/pectin and cellulose degradation of natural fibres and is displaced slightly to higher temperatures. This result provides a first indication about the improved thermal stability of the composites.

Although pure cotton fibre has previously shown the highest thermal stability, it is Mater-Bi KE/kenaf and Mater-Bi KE/hemp the reinforced biocomposites that exhibit the highest onset temperature. The reason for this enhanced thermal stability in the Mater-Bi KE/kenaf and Mater-Bi KE/hemp composites compared to Mater-Bi KE/cotton could be the better compatibility between fibres and matrix. The higher content of hemicellulose in kenaf fibres may enhance hydrogen bonding between the fibre and the starch-based matrix, contributing to improve interfacial adhesion and thermal stability. Moreover, the lignin component could also 


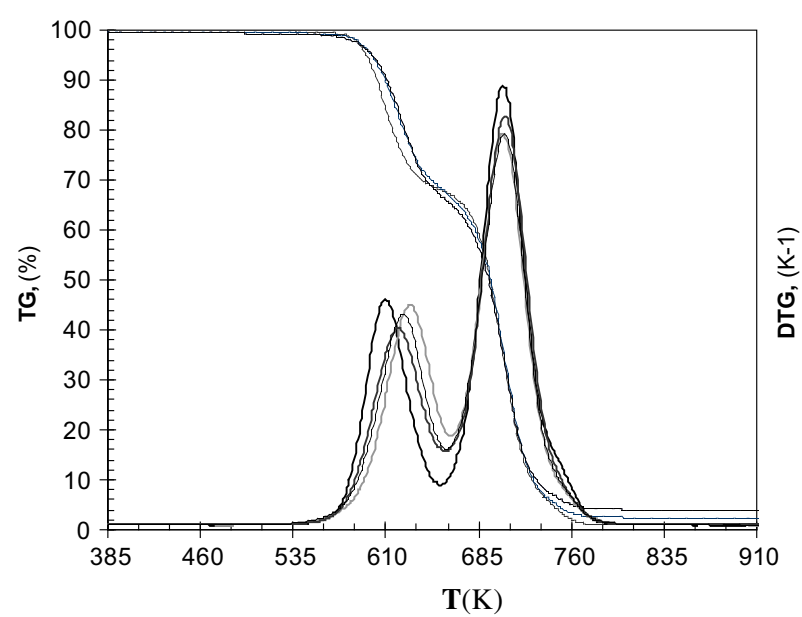

Fig. 3. Thermo-gravimetric analysis of the biocomposites: DTG curves of (-) Mater-Bi KE, (-) Mater-Bi KE/cotton, $(-)$ Mater-BI KE/kenaf and (-) Mater-Bi $\mathrm{KE} / \mathrm{hemp}$ at the heating rate of $20 \mathrm{~K} / \mathrm{min}$.

contribute to the increased thermal stability, due to its ability to interact with the hydrophobic parts of the Mater-Bi KE matrix [36].

Further kinetic analysis of the thermal decomposition kinetics was performed for the cellulose component of the natural fibres, the pure Mater-Bi KE, and their reinforced biocomposites. The apparent activation energies $(E a)$, the kinetic model that follows the reaction mechanism $(f(\alpha))$ and the pre-exponential factor $(A)$ were studied with a methodology reported in a previous work [22]. Iso-conversional Friedman and Flynn-Wall-Ozawa methods $[37,38]$ were employed to determine the apparent activation energy; Criado method [39] was used to identify the mechanism of each thermal decomposition process (the proposed kinetic models are summarized in Table 6; and Coats-Redfern method [40] was finally employed to discuss the probable degradation mechanism and to determine the pre-exponential factor.

Initially, the evolution of apparent activation energies $(E a)$ for the thermal decomposition of cellulose has been studied for each natural fibre using both iso-conversional methods (Friedman and Flynn-Wall-Ozawa), showing that the values of Ea do not drastically change with conversion between the conversion range from 0.3 to 0.6 . Table 7 summarizes the average values of $E a$ corresponding to the different natural fibres obtained by Friedman and FlynnWall-Ozawa method; both iso-conversional methods provide, as expected, similar values for the $E a$ for each biofibre [41]. Kenaf fibres show the lowest value of activation energy $(195 \mathrm{~kJ} / \mathrm{mol})$ among the studied fibres, assuring that pure kenaf is the fibre with lowest thermal stability. The reaction mechanisms involved in the main thermal decomposition of these natural fibres were assessed using Criado and Coats-Redfern methods. These methods allow the determination of the model that provides the closest Ea to the values obtained from the iso-conversionals, confirming the assumption of a first order mechanism $(n=1)$ [32] for the decomposition kinetics of natural fibres from a 0.3 to 0.6 range conversion. Once the $f(\alpha)$ have been identified, the pre-exponential factor has been calculated from Flynn-Wall-Ozawa method and confirmed using Coats-Redfern method (Table 7).

The kinetic parameters for each thermal decomposition process of the pure Mater-Bi KE have been studied in previous works [22]. The average $E a$ and the A related to the thermal decomposition of starch and the synthetic component were fixed as $98 \mathrm{~kJ} / \mathrm{mol}$ and $10^{9.5} \mathrm{~min}^{-1}$ and $175 \mathrm{~kJ} / \mathrm{mol}$ and $10^{13.5} \mathrm{~min}^{-1}$, respectively. This last result is similar to those obtained by Puglia et al. [21] from assessing the kinetics of the synthetic component of Mater-Bi ZF03U However, this result are smaller than those reported by Mano 
Table 5

Thermogravimetric parameters of pure Mater-Bi KE and its reinforced biocomposites.

\begin{tabular}{|c|c|c|c|c|c|c|c|}
\hline \multirow[t]{2}{*}{ Materials } & \multicolumn{3}{|c|}{ First mass-loss region } & \multicolumn{3}{|c|}{ Second mass-loss region } & \multirow{2}{*}{$\begin{array}{l}\text { Residue } \\
\text { (\%) }\end{array}$} \\
\hline & Onset (K) & Mass loss (\%) & $T$ peak $(\mathrm{K})$ & Onset (K) & Mass loss (\%) & $T$ peak $(\mathrm{K})$ & \\
\hline Mater-Bi KE & $592.0 \pm 1.0$ & $31.5+0.5$ & $608.6 \pm 1.0$ & $686.4 \pm 0.7$ & $66.6 \pm 0.7$ & $708.0 \pm 0.2$ & $1.2 \pm 0.1$ \\
\hline Mater-Bi KE/cotton & $596.5 \pm 1.0$ & $33.1 \pm 0.5$ & $617.4 \pm 0.6$ & $688.3 \pm 0.4$ & $65.0 \pm 0.6$ & $706.6 \pm 0.5$ & $2.5 \pm 0.5$ \\
\hline Mater-Bi KE/hemp & $600.1 \pm 0.5$ & $34.5 \pm 0.5$ & $623.5 \pm 0.3$ & $687.1 \pm 1.0$ & $61.0 \pm 1.0$ & $705.4 \pm 0.3$ & $4.0 \pm 0.5$ \\
\hline Mater-Bi KE/kenaf & $606.5 \pm 0.4$ & $35.1 \pm 1.0$ & $629.4 \pm 0.3$ & $688.9 \pm 1.2$ & $60.0 \pm 1.0$ & $705.5 \pm 0.6$ & $4.3 \pm 0.3$ \\
\hline
\end{tabular}

Table 6

\begin{tabular}{|c|c|c|c|}
\hline Kinetic models & Differential form $f(\alpha)$ & Kinetic models & Differential form $f(\alpha)$ \\
\hline D1 & $1 / 2(1-\alpha)-1$ & $n+m=1.8 ; n=1.7$ & $\alpha^{0.1}(1-\alpha)^{1.7}$ \\
\hline D3 & $3 / 2(1-\alpha)^{2 / 3}\left(1-(1-\alpha)^{1 / 3}\right)^{-1}$ & $n+m=2 ; n=1.9$ & $\alpha^{0.1}(1-\alpha)^{1.9}$ \\
\hline D4 & $3 / 2(1-\alpha)^{1 / 3}\left(1-(1-\alpha)^{1 / 3}\right)^{-1}$ & $n+m=2 ; n=1.2$ & $\alpha^{0.8}(1-\alpha)^{1.2}$ \\
\hline $\mathrm{R} 1$ & 1 & $n=1 / \mathrm{F} 1$ & $(1-\alpha)$ \\
\hline A2 & $2(1-\alpha)(-\ln (1-\alpha))^{1 / 2}$ & $n=3$ & $(1-\alpha)^{3}$ \\
\hline A3 & $3(1-\alpha)(-\ln (1-a))^{2 / 3}$ & Power 2 & $2 \alpha^{1 / 2}$ \\
\hline
\end{tabular}

Table 7

Kinetic parameters of pure Mater-Bi KE and its reinforced biocomposites.

\begin{tabular}{|c|c|c|c|c|c|c|c|}
\hline & & \multirow{2}{*}{$\begin{array}{l}\text { Friedman } \\
E a(\mathrm{~kJ} / \mathrm{mol})\end{array}$} & \multicolumn{2}{|c|}{ Flynn-wall-Ozawa } & \multicolumn{3}{|c|}{ Coats-Redfern and Criado } \\
\hline & & & $A\left(\min ^{-1}\right)$ & $E a(\mathrm{~kJ} / \mathrm{mol})$ & $A\left(\min ^{-1}\right)$ & $E a(\mathrm{~kJ} / \mathrm{mol})$ & $f(\alpha)$ \\
\hline \multirow[t]{2}{*}{ Mater-Bi KE } & First thermal decomposition process & $98 \pm 5$ & $10^{9.3} \pm 2$ & $102 \pm 2$ & $10^{9.0} \pm 2$ & $101 \pm 4$ & $\alpha^{0.5}(1-\alpha)^{1.5}$ \\
\hline & Second thermal decomposition process & $173 \pm 3$ & $10^{13.5} \pm 2$ & $175 \pm 5$ & $10^{13.5} \pm 2$ & $172 \pm 3$ & $\alpha^{0.5}(1-\alpha)^{1.5}$ \\
\hline \multirow[t]{2}{*}{ Mater-Bi KE/cotton } & First thermal decomposition process & $112 \pm 4$ & $10^{10.0} \pm 4$ & $113 \pm 3$ & $10^{10.0} \pm 3$ & $111 \pm 3$ & $\alpha^{0.5}(1-\alpha)^{1.5}$ \\
\hline & Second thermal decomposition process & $295 \pm 5$ & $10^{20.4} \pm 2$ & $297 \pm 5$ & $10^{20.5} \pm 2$ & $295 \pm 3$ & $\alpha^{0.1}(1-\alpha)^{1.7}$ \\
\hline Cotton fibres & Main thermal decomposition process & $204 \pm 4$ & $10^{15.0} \pm 4$ & $206 \pm 5$ & $10^{15.6} \pm 4$ & $205 \pm 2$ & $(1-\alpha)^{1}$ \\
\hline \multirow[t]{2}{*}{ Mater-Bi KE/kenaf } & First thermal decomposition process & $163 \pm 3$ & $10^{12.2} \pm 3$ & $159 \pm 5$ & $10^{12.0} \pm 4$ & $162 \pm 4$ & $\alpha^{0.2}(1-\alpha)^{1.4}$ \\
\hline & Second thermal decomposition process & $200 \pm 6$ & $10^{14.6} \pm 4$ & $199 \pm 5$ & $10^{14.9} \pm 2$ & $201 \pm 3$ & $\alpha^{0.4}(1-\alpha)^{1.6}$ \\
\hline Kenaf fibres & Main thermal decomposition process & $196 \pm 4$ & $10^{14.8} \pm 4$ & $195 \pm 5$ & $10^{14.8} \pm 4$ & $193 \pm 2$ & $(1-\alpha)^{1}$ \\
\hline \multirow[t]{2}{*}{ Mater-Bi KE/hemp } & First thermal decomposition process & $175 \pm 5$ & $10^{12.4} \pm 3$ & $175 \pm 5$ & $10^{13.0} \pm 2$ & $177 \pm 4$ & $\alpha^{0.2}(1-\alpha)^{1.6}$ \\
\hline & Second thermal decomposition process & $219 \pm 6$ & $10^{16.0} \pm 3$ & $222 \pm 6$ & $10^{16.8} \pm 2$ & $220 \pm 2$ & $\alpha^{0.2}(1-\alpha)^{1.3}$ \\
\hline Hemp fibres & Main thermal decomposition process & $201 \pm 3$ & $10^{14.9} \pm 4$ & $202 \pm 3$ & $10^{14.0} \pm 4$ & $202 \pm 3$ & $(1-\alpha)^{1}$ \\
\hline
\end{tabular}

et al. [23], around $300 \mathrm{~kJ} / \mathrm{mol}$ for the synthetic component. These differences could be due to the different kinetic model employed by Mano to asses the $E a$ (assuming a reaction order $n=1$ ) but us results fit better to a $(n+m ; \mathrm{n})$ type thermal decomposition kinetics model, being the algebraic expression $f(\alpha)=\alpha^{0.5}(1-\alpha)^{1.5}$.

Finally, the kinetic parameters of each thermal decomposition region for reinforced Mater-Bi KE/cotton, Mater-Bi KE/hemp and Mater-Bi KE/kenaf biocomposites have been studied. Each region has been separated using the aforementioned deconvolution method. When natural fibres are incorporated into the pure Mater-Bi KE, the $E a$ associated to both thermal decomposition regions increase for each one of the studied reinforced biocomposites (Table 7). Again, different effects on pure Mater-Bi KE activation energies are observed depending on the natural fibre added. Mater-Bi KE/ cotton biocomposites present the major increase of $E a$ in the decomposition process related to the synthetic biodegradable component. However the $E a$ of the thermal decomposition region associated to starch increases in the Mater-Bi KE/kenaf and Mater-Bi KE/hemp.

Regarding the kinetic mechanisms, the addition of all the studied natural fibres seems to affect the mechanistic thermal decomposition process of the synthetic component of the Mater-Bi KE. Cotton fibres do not affect the reaction mechanism related to the starch component; however, the thermal decomposition of lignucellulosic fibres such as kenaf and hemp may occur simultaneously to starch decomposition and therefore modify the apparent reaction mechanism.

\subsection{Dynamical mechanical thermal analysis (DMTA)}

The effects of the addition of natural fibres on the thermomechanical properties of the pure Mater-Bi KE and the viscoelastic behaviour of reinforced biocomposites were assessed using DMTA, by performing multifrequency scans on pure Mater-Bi KE and its reinforced biocomposites at a wide range of temperatures. Fig. 4 compares the evolution of the storage modulus $\left(E^{\prime}\right)$ with temperature for pure Mater-Bi KE and its reinforced composites for a frequency of $1 \mathrm{~Hz}$; similar curves were obtained for other frequencies. Higher values for the storage and loss modulus are observed over the whole range of temperatures for the composites in comparison with the pure Mater-Bi KE, with an increase that depends on the temperature. At the beginning of the test $(173 \mathrm{~K})$, the storage modulus for the composites is approximately twice as high as the one observed for the pure polymeric matrix, being the highest value for the Mater-Bi KE/cotton biocomposite. This increment in the storage modulus is similar to that reported by Belhassen et al. [42] when the dynamic mechanical response of adding $\alpha$ fibres to a starch-based biopolymer was analysed. In general, this improvement of the dynamical mechanical properties of Mater-Bi KE by adding natural fibres corresponds well with the reported enhancement of the tensile and impact properties in previous studies of similar starch-based biocomposites reinforced with lignocellulosic materials [43,44]; this favourable effect may be specially promoted in these materials by the existing interactions between fillers and polymeric matrix, due to the similar chemical 


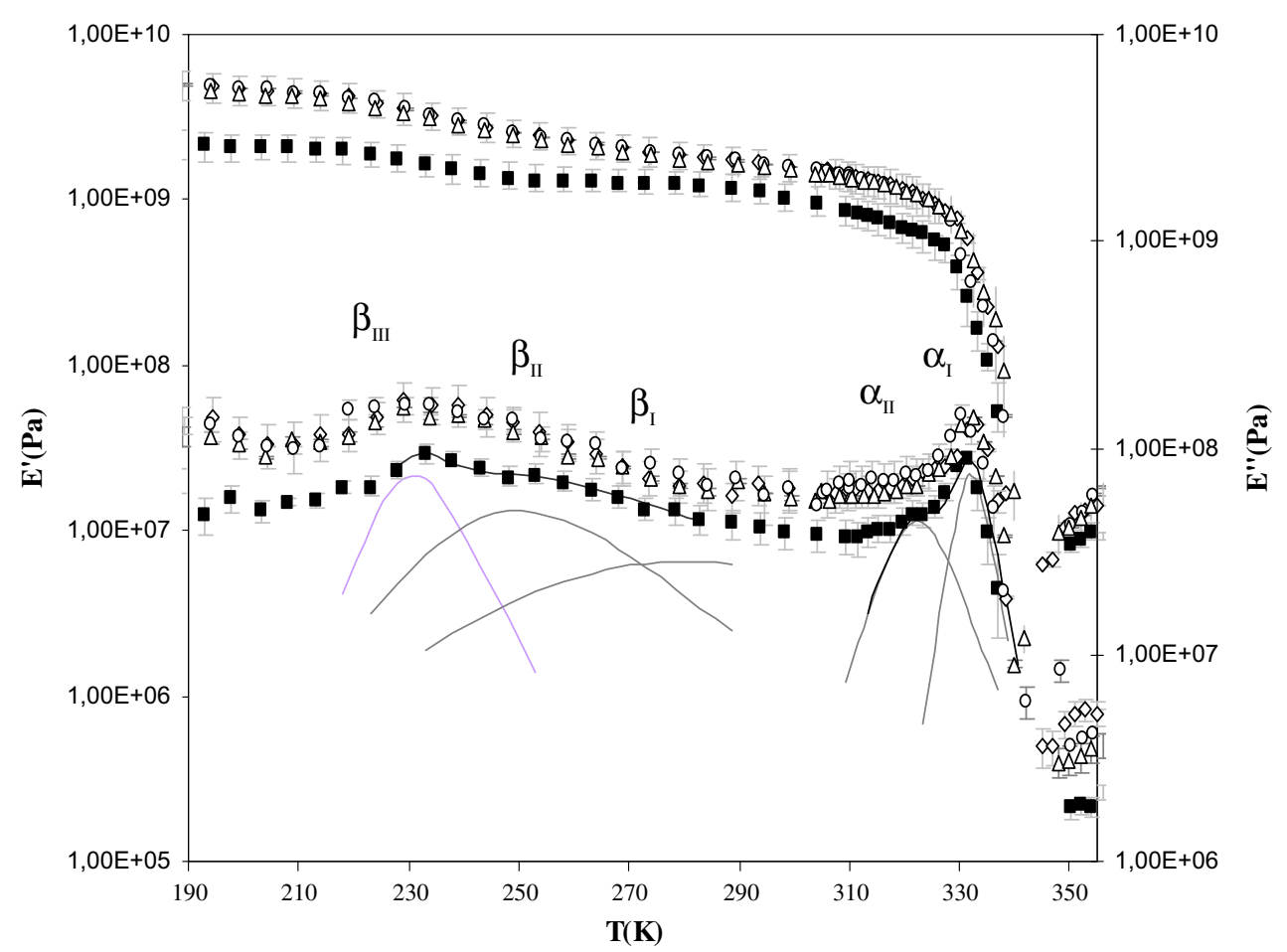

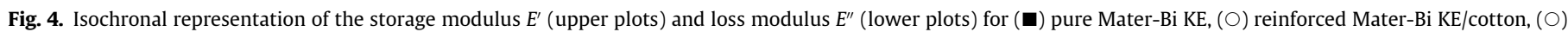
reinforced Mater-Bi KE/hemp and $(\diamond)$ reinforced Mater-Bi KE/kenaf at $1 \mathrm{~Hz}$ as a function of the temperature.

nature of the biocomposite components [45]. The cellulose content in the natural fibres was observed to have a prominent influence on the mechanical properties of the resulting biocomposites, with cotton fibres conferring the highest reinforcement effect among the natural fibres.

Two main viscoelastic relaxation zones can be observed in the loss modulus ( $\left.E^{\prime \prime}\right)$ curves for pure Mater-Bi KE and its reinforced composites, labelled as $\alpha$ and $\beta$ zones in decreasing temperature order, following a systematic approach (Fig. 4). The $\alpha$ relaxation zone appears between 310 and $345 \mathrm{~K}$ with a prominent peak centred at around $335 \mathrm{~K}$ (relaxation $\alpha_{\mathrm{I}}$ ) together with a small shoulder at $315 \mathrm{~K}$ (relaxation $\alpha_{\mathrm{II}}$ ), which is accompanied by a drastic collapse of the storage modulus. The $\alpha$ relaxations can be assigned to long-segment chain movements that may occur prior to the melting of the crystalline phase of the synthetic component of pure Mater-Bi KE. The $\beta$ relaxation can be observed in the subambient temperature range between 210 and $290 \mathrm{~K}$, as it was previously stated from the DSC results; in this range, different chain movements related to the pure Mater-Bi KE can occur and they contribute to this broad $\beta$ viscoelastic relaxation, including secondary and primary transitions of thermoplastic starch and the synthetic component of the Mater-Bi KE blend. Three overlapped subrelaxations $\left(\beta_{\mathrm{I}}, \beta_{\mathrm{II}}, \beta_{\mathrm{III}}\right)$ can be distinguished at the loss modulus plot: the $\beta_{\mathrm{I}}$ and $\beta_{\text {II }}$ relaxations are displayed between 230 and $290 \mathrm{~K}$ and unfortunately cannot be clearly assigned, while the $\beta_{\text {III }}$ relaxation (centred at $228-2324 \mathrm{~K}$ ) could be attributed to the glass transition of the amorphous phase of the synthetic polyester component, $\operatorname{poly}(\varepsilon-$ caprolactone), of Mater-Bi KE [30].

Following the same methodology assessed in previous works [46], modified Fuoss-Kirkwood empirical model (4) [47] and Charlesworth deconvolution procedure (5) [48] were applied to the experimental data of the pure Mater-Bi KE and its reinforced biocomposites, in order to fit the functions of relaxation and to obtain the values of the loss modulus maximum and the corresponding temperature $\left(E_{\max }^{\prime \prime}, T_{\max }\right)$ for each viscoelastic relaxation at the different frequencies. An example of these models is displayed in Fig. 4. Table 8 summarize the obtained fitting parameters $E_{\max }^{\prime \prime}, T_{\max }$ for each relaxation region at the frequency of $1 \mathrm{~Hz}$.

$$
\begin{aligned}
& E^{\prime \prime}=\frac{E_{\max }^{\prime \prime}}{\cosh \left[m_{F K} \cdot\left(\frac{1}{T}-\frac{1}{T_{\max }}\right)\right]} \\
& E^{\prime \prime}=\sum_{i} E_{i}^{\prime \prime}
\end{aligned}
$$

where $E_{\max }^{\prime \prime}$ corresponds to the maximum of the loss modulus relaxation, $m_{F K}$ is an empirical parameter lying in the interval $0<m_{F K} \leqslant 1$, and $T_{\max }$ is the temperature of the maximum of the loss modulus relaxation.

The Arrhenius maps represent the relationship between the distribution of the relaxation times and the temperature of the pure Mater-Bi KE and its reinforced biocomposites. Fig. 5 plots the temperature of the maximum of the loss modulus curves $\left(T_{\max }\right)$ from the Fuoss-Kirkwood fitting versus the frequency for all the studied relaxations. Both $\alpha$ relaxations, $\alpha_{\mathrm{I}}$ and $\alpha_{\mathrm{II}}$, of the pure Mater-Bi KE and its reinforced biocomposites show in all cases a lineal tendency in the Arrhenius maps (Fig. 5), indicating that $\alpha$ relaxations are intramolecular movements associated to long-segment chain movements precursors of the crystalline phase melting. Arrhenius Eq. (6) was therefore applied to obtain the activation energies $(E a)$ of $\alpha_{\mathrm{I}}$ and $\alpha_{\mathrm{II}}$ relaxations for pure Mater-Bi KE and its reinforced biocomposites (Table 8).

$\ln f=\ln f_{0}-\frac{E a}{R \cdot T_{\max }}$

When natural fibres are added to the pure Mater-Bi KE, differences in the trend of the activation energy related to $\alpha_{I}$ and $\alpha_{I I}$ relaxations can be observed. The Ea of the $\alpha_{I}$ relaxation decreases with the addition of natural fibres. Contrarily, a significant increase of $E a$ in the $\alpha_{\text {II }}$ relaxation zone can be observed for all the reinforced biocomposite; this fact could be related to the slight 


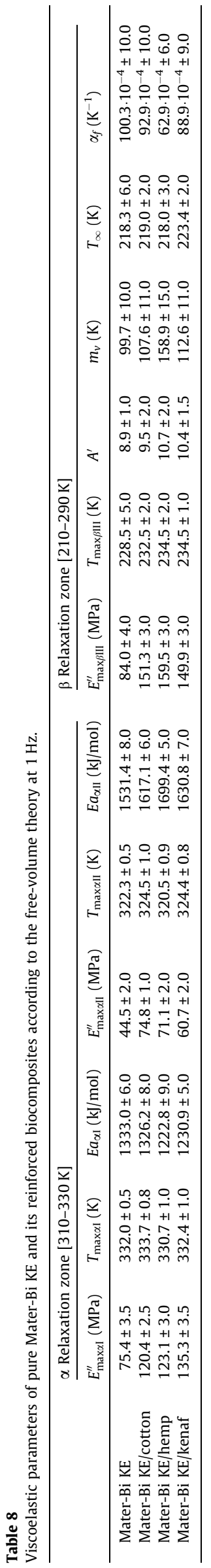

increase of the crystallinity of the synthetic component of Mater-Bi $\mathrm{KE}$, which could hinder the molecular movements of these chains. However, these increments in the activation energies of $\alpha_{\text {II }}$ relaxation are more significant for the Mater-Bi KE/hemp and Mater-Bi $\mathrm{KE} /$ kenaf biocomposites than for the Mater-Bi KE/cotton biocomposite. These results indicate that the affinity between the polymeric matrix and the natural fibres is other parameter to take into account in this increment.

The broad $\beta$ relaxation displays a complex behaviour for the different materials over the range of frequencies; deconvolution of the $\beta_{\mathrm{I}}, \beta_{\mathrm{II}}$ and $\beta_{\mathrm{III}}$ subrelaxations was difficult in many cases due to the weak signal of $\beta_{\text {I }}$ and $\beta_{\text {II }}$, so the Arrhenius maps could only be drawn for the $\beta_{\text {III }}$ subrelaxation. As it can be observed in Fig. 5, all the studied materials display a curved tendency in the Arrhenius maps, indicating that $\beta_{\mathrm{III}}$ relaxation are intermolecular movements typical of glass transition behaviours. The experimental data from the Arrhenius maps for the $\beta_{\text {III }}$ relaxation could be therefore fitted to the Vogel-Fulcher-Tammann-Hesse (VFTH) Eq. (7) [49-51] in order to obtain the parameter related to the free volume, Eq. (8):

$\ln \tau_{i}=A_{0}+\frac{m_{v}}{T-T_{\infty}}$

$m_{v}=\frac{B}{\alpha_{f}}=\frac{B}{f_{g}} \cdot\left(T_{g}-T_{\infty}\right)$

Here, $\tau_{i}$ is the relaxation time; $A_{0}$ is an empirical parameter; $T_{\infty}$ is the temperature at which the free-volume would be zero; $m_{v}$ is a parameter related to the relative free-volume at the glass transition temperature; $\alpha_{f}$ is the expansion coefficient of the free-volume; $T_{g}$ is the glass transition temperature; $B$ is an empirical parameter; and $f_{g}$ is the relative free-volume associated with the glass transition. The parameters obtained from the fitting of $\beta_{\text {III }}$ relaxation to VFTH equation are displayed in Table 8.

The addition of natural fibres induces a clear reduction in the free-volume-parameter associated to the pure Mater-Bi KE glass transition $\left(\alpha_{\mathrm{f}}\right)$; these changes may be related to the interfacial adhesion between the pure Mater-Bi KE and the natural fibres, which reduces the free volume fraction available for the pure Mater-Bi KE to perform the molecular movements associated to the glass transition. This reduction of the free volume parameter with natural fibre addition confirms the interaction between the lignocellulosic fillers and the polymeric matrix.

The decrease in the free volume parameter is markedly observed for Mater-Bi KE/kenaf and especially Mater-Bi KE/hemp composites, which could be related as well to the compatibility and interfacial adhesion between the pure Mater-Bi KE and kenaf and hemp fibres, rather than with cotton fibres. The reason for the adhesion could be again the higher content of hemicelluloses and lignin in hemp and kenaf than in cotton. In general, hemp and kenaf fibres present better interactions and interfacial adhesion with pure Mater-Bi KE; in contrast, the addition of cotton fibres results in the composite with highest storage modulus.

\subsection{Scanning electron microscopy (SEM)}

SEM was used to examine the microstructure and the interfacial adhesion of pure Mater-Bi KE and its reinforced biocomposites micrographs. Fig. 6a shows a particular structure for the pure Mater-Bi KE with granules clearly embedded and distributed within a continuous phase. Novamont starch-based technology proposes different supramolecular structures for the Mater- $\mathrm{Bi}^{\mathrm{TM}}$, from droplet-like to layered, that depend on the ratio between amylose and amylopectin, nature of possible additives, processing conditions and hydrophilicity of the macromolecular complexing agent (synthetic component of the blend) [27]. From the micrographs it is 


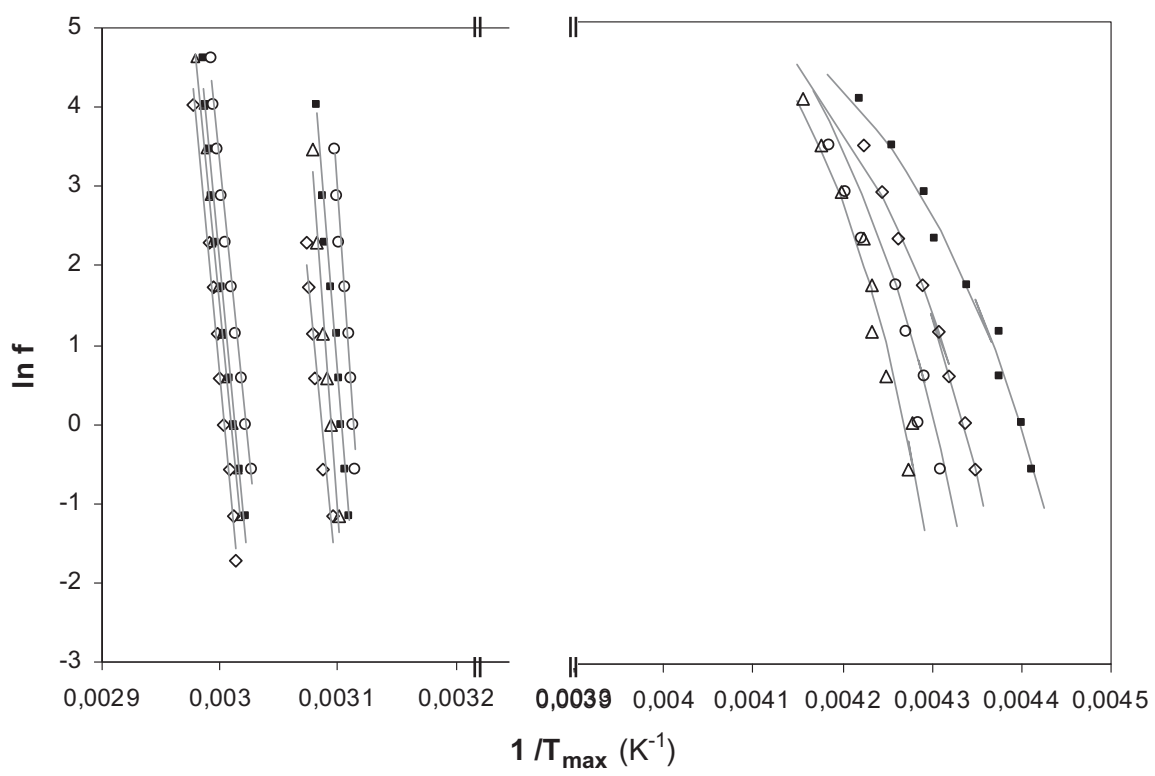

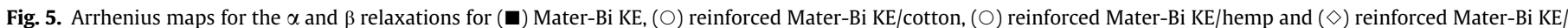
kenaf at $1 \mathrm{~Hz}$ as a function of the temperature.
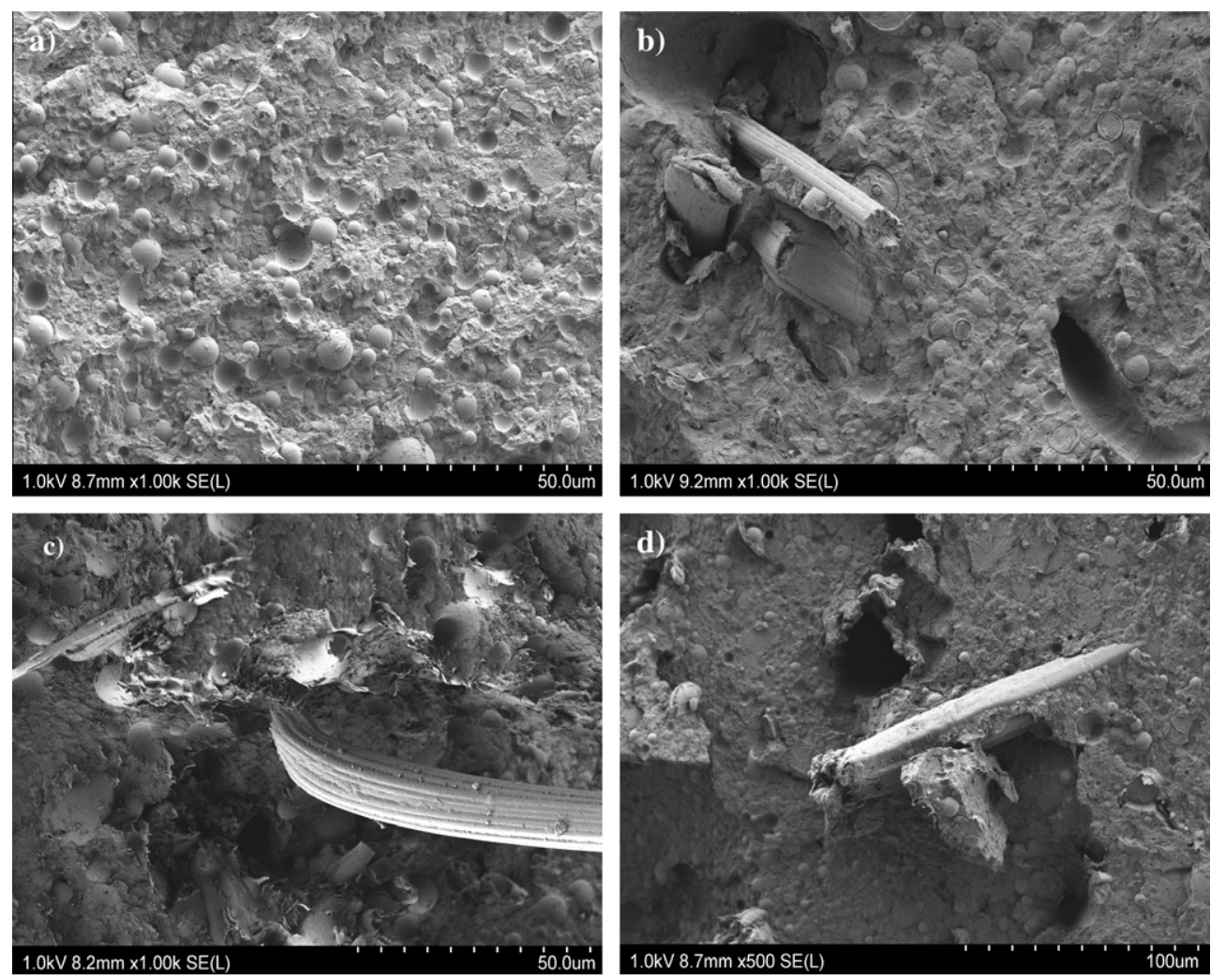

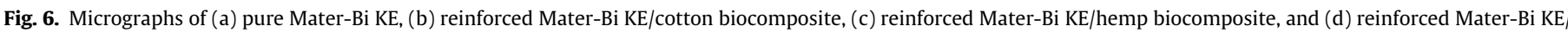
kenaf biocomposite.

clear that the dispersed phase consists of plasticized starch in the form of droplet-like particles.

The micrographs of the Mater-Bi KE/cotton, Mater-Bi KE/hemp, and Mater-Bi KE/kenaf (Fig. 6b-d, respectively) show good wettability between the pure Mater-Bi KE and the fibres, which indicates suitable interfacial adhesion. A "dirty" surface of the natural fibres, especially in Mater-Bi KE/kenaf (Fig. 6d) can be observed, with the pure Mater-Bi KE closely attached to the fibre; this agrees with the improved interfacial adhesion of fibres with certain hemicellulose and lignin content, in comparison with pure cellulosic fibres as cotton.

\section{Conclusions}

The improved thermal stability and thermo-mechanical properties of reinforced biocomposites has been demonstrated in 
comparison with pure Mater-Bi KE. In general, natural fibres can be successfully incorporated into pure Mater-Bi KE, enhancing the mechanical properties. At the same time, natural fibres act as suitable thermal stabilizers for pure Mater-Bi KE, by increasing the thermal stability and the activation energy associated to the thermal decomposition processes. These studies point out that hemp and kenaf fibres offer better interfacial interaction with the pure Mater-Bi KE, due to the compatibilizer effect of hemicellulose and partly lignin with both thermoplastic starch and the synthetic polyester contained in the polymeric matrix. Thus, hemp and kenaf fibres act as better thermal stabilisers for pure Mater-Bi KE that cotton fibres; this fact is particularly interesting, since cotton fibres exhibit the best thermal stability by themselves. On the other hand, cotton fibres provide the highest increase in the modulus but the lowest diminution in the thermal expansion coefficient associated to the glass transition. The choice of natural fibre reinforcement constitutes an interesting option to tailor the properties of the resulting composite materials, and allows broadening the application range of starch-based reinforced biocomposites.

\section{Acknowledgements}

The authors are grateful for the financial support received for this work from the Ministerio de Educación y Ciencia (Spanish Government) and the European Regional Development Found for the economical support through the Project ENE2007/67584/C0301. The Ministerio of Medio Ambiente (Spanish Government) is also acknowledged for its financial support through Project 555/ 2006/3-6.1.

\section{References}

[1] Mohanty AK, Misra M, Hinrichsen G. Biofibres, biodegradable polymers and biocomposites: an overview. Macromol Mater Eng 2000;276/277:1.

[2] Gomez MH, Aguilera JM. Changes in the starch fraction during extrusioncooking of corn. J Food Sci 1983;48:378.

[3] Davidson VJ, Paton D, Diosady LL, Laroque G. A model for mechanical degradation of wheat-starch in a single-screw extruder. J Food Sci 1984;49:453.

[4] Chiou BS, Glenn MG, Imam SH, Inglesby MK, Wood DF, Orts WJ. In: Mohanty AK, Misra M, Drzal LT, editors. Natural fibers biopolymers and biocomposites. Boca Raton: Taylor \& Francis; 2005.

[5] Mathew S, Brahmakumar M, Abraham TE. Microstructural imaging and characterization of the mechanical, chemical, thermal, and swelling properties of starch-chitosan blend films. Biopolymers 2006;82:176.

[6] Chiellini E, Cinelli P, Imam SH, Mao L. Composite films based on biorelated agro-industrial waste and poly(vinyl alcohol). Preparation and mechanical properties characterization. Biomacromolecules 2001;2:1029.

[7] Demirgöz D, Elvira C, Mano JF, Cunha AM, Piskin E, Reis RL. Starch-based biodegradable hydrogels with potential biomedical applications as drug delivery systems. Polym Degrad Stab 2000;70:161

[8] Shogren RL. Poly(ethylene oxide)-coated granular starch-poly(hydroxybutyrateco-hydroxyvalerate) composite materials. J Environ Polym Degrad 1995;3:75.

[9] Tianyi K, Xiuzhi SS. Starch, poly(lactic acid), and poly(vinyl alcohol) blends. J Polym Environ 2003;11:1566.

[10] Spiridon I, Popescu MC, Bodârlau R, Vasile C. Enzymatic degradation of some nanocomposites of poly(vinyl alcohol) with starch. Polym Degrad Stab 2008;93:1884.

[11] Odusanya OS, Manan DMA, Ishiaku US, Azemi BMN. Effect of starch predrying on the mechanical properties of starch/poly( $\varepsilon$-caprolactone) composite. J Appl Polym Sci 2003;87:877.

[12] Bastioli C. Properties and applications of Mater-Bi starch-based materials. Polym Degrad Stab 1998;59:263.

[13] Halley PJ. In: Smith R, editor. Biodegradable polymers for industrial applications. London: Woodhead Publishing; 2005

[14] Wollerdorfer $M$, Bader $H$. Influence of natural fibres on the mechanical properties of biodegradable polymers. Ind Crop Prod 1998;8:105.

[15] Curvelo AAS, Carvalho AJF, Agnelli JAM. Thermoplastic starch-cellolosic fibers composites: preliminary results. Carbohydr Polym 2001;45:183.

[16] Yongshang L, Lihui W, Xiaodong C. Melt rheological behavior of starch-based matrix composites reinforced with short sisal fibers. Carbohydr Polym 2006;63:198

[17] Alvarez VA, Vázquez A. Thermal degradation of cellulose derivatives/starch blends and sisal fibre biocomposites. Polym Degrad Stab 2004;85:13.
[18] Bismarck A, Mishra S, Lampke T. In: Mohanty AK, Misra M, Drzal LT, editors, Plant fibers as reinforcement for green composites. Natural fibers biopolymers and biocomposites. Boca Raton: Taylor \& Francis; 2005.

[19] Anon. Short sisal fibres as a reinforcement for biode-gradable polyester PBS. Addit Polym 2001; Part 12:9.

[20] Fowler PA, Hughes JM, Elias RM. Review biocomposites: technology, environmental credentials and market forces. J Sci Food Agric 2006;86: 1781.

[21] Puglia D, Tomassuci A, Kenny JM. Processing properties and stability of biodegradable composites based on Mater-Bi and cellulose fibres. Polym Adv Technol 2003;14:749.

[22] Moriana R, Sigbritt K, Ribes-Greus A. Assessing the influence of cotton fibres on the degradation in soil of a thermoplastic starch-based biopolymer. Polym Compos 2010. doi:10.1002/pc.21007 [published online]

[23] Mano JF, Konoirava D, Reis RL. Thermal properties of thermoplastic starch synthetic polymer blends with potential biomedical applicability 2003; $14: 127$

[24] Monties B. Chemical properties of milled wood lignin of grasses. Agronomie 1986;4:387.

[25] Theander O, Westerlund EA. Studies on dietary fiber. 3. Improved procedures for analysis of dietary fiber. Agric Food Chem 1986;34:330.

[26] Avella M, La Rota E, Martuscelli E, Raimo M, Sadocco P, Elegir G, et al. Poly(3hydroxybutyrate-co-3-hydroxyvalerate) and wheat straw fibre composites: thermal, mechanical properties and biodegradation behaviour. J Mater Sci 2000;35:829.

[27] Bastioli C. In: Bastioli C, editor. Handbook of Biodegradable polymers Shrewsbury: Rapra Technology/Taylor \& Francis; 2005.

[28] Matzinos P, Tserki V, Kontoyiannis A, Panayiotou C. Processing and characterization of starch/polycaprolactone products. Polym Degrad Stab 2002;77:17.

[29] Rosa DS, Lopes DR, Calil MR. Thermal properties and enaymatic degradation of poly (e-caprolactone) with starches. Polym Test 2005;24:756.

[30] Avérous L, Moro L, Dole P, Fringant C. Properties of thermoplastic blends: starch-polycaprolactone. Polymer 2000;41:4157.

[31] Digabel FL, Avérous L. Effects of lignin content on the properties of lignocellulose-based biocomposites. Carbohydr Polym 2006;66:537.

[32] Antal MJ, Varhegyi G. Cellulose pyrolysis kinetics: the current state of knowledge. Ind Eng Chem Res 1995;34:703.

[33] Ouajai S, Shanks RA. Composition, structure and thermal degradation of hemp cellulose after chemical treatments. Polym Degrad Stab 2005;89:327.

[34] Maya JJ, Sabu T. Review: biofibres and biocomposites. Carbohydr Polym $2008 ; 71: 343$

[35] Ruseckaitea RA, Jiménez A. Thermal degradation of mixtures of polycaprolactone with cellulose derivatives. Polym Degrad Stab 2003;81:353.

[36] Thielemans W, Wool RP. Butyrated kraft lignin as compatibilizing agent for natural fiber reinforced thermoset composites. Composites Part A 2004;35:327.

[37] Friedman HL. Kinetics and gaseous products of thermal decomposition of polymers. J Macromol Sci Pure Appl Chem 1967:57.

[38] Ozawa T. A new method of analyzing thermogravimetric data. Bull Chem Soc Jpn 1965;38:1881.

[39] Criado JM. Application of programmed temperature decomposition to study of solid decomposition reactions taking place through Prout and Tompkins mechanism. Thermochim Acta 1978;24:86.

[40] Coats AW, Redfern JP. Kinetics parameters from thermogravimetric data. Nature 1964;201:68.

[41] Fei Y, Qinglin W, Yong L, Weihong G, Yanjun X. Thermal decomposition kinetics of natural fibers. Polym Degrad Stab 2008;93:90.

[42] Belhassen R, Boufi S, Vilaseca F, López JP, Méndez JA, Franco E, et al. Biocomposites based on Alfa fibers and starch-based biopolymer. Polym Adv Technol 2008;114:313.

[43] Johnson Mark, Tucker Nick, Barnes Stuart, Kirwan Kerry. Improvement of the impact performance of a starch based biopolymer via the incorporation of Miscanthus giganteus fibres. Polym Test 2003;22:209.

[44] Curvelo AAS, de Carvalho AJF, Agnelli JAM. Thermoplastic starch-cellolosic fibers composites: preliminary results. Carbohydr Polym 2001;45:183.

[45] Yongshang Lu, Weng Lihui, Cao Xiaodong. Morphological, thermal, mechanical properties of ramie crystallites-reinforced plasticized starch biocomposites. Carbohydr Polym 2006;63:198.

[46] Moriana R, Santonja-Blasco L, Badia JD, Ribes-Greus A. Assessing the mechanical enhancement and the thermostabilising effect of adding cotton fibres to a starch-based matrix using thermal analysis. J Appl Polym Sci, in press.

[47] Fuoss RM, Kirkwood JG. Electrical properties of solids. VIII. Dipole moments in polyvinyl chloride-diphenyl systems. J Am Chem Soc 1941;63:385.

[48] Charlesworth JM. Deconvolution of overlapping relaxation in dynamic mechanical spectra. J Mater Sci 1993;28:399.

[49] Fulcher GS. Analysis of recent measurements of the viscosity of glasses. J Am Ceram Soc 1925:8:339.

[50] Tammann G, Hesse W, Abhängigkeit Die. Die Abhängigkeit der Viscosität von der Temperatur bie unterkühlten Flüssigkeiten. Zeitsch Anorg Allg Chem 1926;1:245.

[51] Vogel H. Temperature dependence of viscosity of melts. Phys Z 1921;22:645. 
"THERMAL, MECHANICAL AND MORPHOLOGICAL PROPERTIES OF REINFORCED JUTE AND FLAX FIBRES BIOCOMPOSITES" 



\title{
“THERMAL, MECHANICAL AND MORPHOLOGICAL PROPERTIES OF REINFORCED JUTE AND FLAX FIBRES BIOCOMPOSITES"
}

\begin{abstract}
Flax and jute fibres were selected as reinforcement for Mater-Bi KE03B with the purpose of improving its thermo-mechanical properties and preserving the biodegradability. Mater-Bi KE/flax and Mater-Bi KE/jute biocomposites were characterized systematically by TGA, DMTA, DSC and SEM to compare their thermal, mechanical and morphologic properties to the properties of pure Mater$\mathrm{Bi} \mathrm{KE}$. The presence of flax and jute natural fibres improves both the thermal and mechanical properties. The maximum decomposition temperature and the $E a$ associated to the first thermal decomposition process increase in the composite material due to the presence of the natural fibres, guaranteeing its thermal stability during the processing. Moreover, biofibres addition produces a higher storage modulus and a reduction in the free-volume-parameter of pure Mater-Bi KE. The higher thermal stability and storage modulus found in the Mater-Bi KE/jute biocomposite suggests enhanced interfacial adhesion between pure Mater-Bi KE and the jute fibres, due to the high presence of hemicellulose and lignin in the jute formulation compared to the flax fibres.
\end{abstract}

Keywords: Jute Fibres, Flax Fibres, Reinforced Biocomposites, Thermal Analysis, SEM 


\section{Results and Discussion}

\section{Differential Scanning Calorimetry Measurements}

Different thermal transitions for the pure Mater-Bi KE, natural fibres and its reinforced Mater-Bi KE/flax and Mater-Bi KE/jute biocomposites can be observed in the cooling and second heating scans from DSC (Figure 1). The endothermic peak around 336K in the heating scan and the main exothermic peak at $316 \mathrm{~K}$ present in the cooling scan are related to the melting and the crystallisation of the crystalline phase of the synthetic biodegradable polymer component in pure Mater-Bi KE [1]. Natural fibres display only a small thermal transition in the heating scan (between $373-420 \mathrm{~K}$ ) that could be related to reorganizations of cellulose chains. The addition of flax and jute fibres into Mater-Bi KE does not induce extensive changes on the shapes of the calorimetric thermograms. Table 1 summarises the calorimetric parameters from the cooling and second heating scans of pure Mater-Bi KE and its reinforced biocomposites.
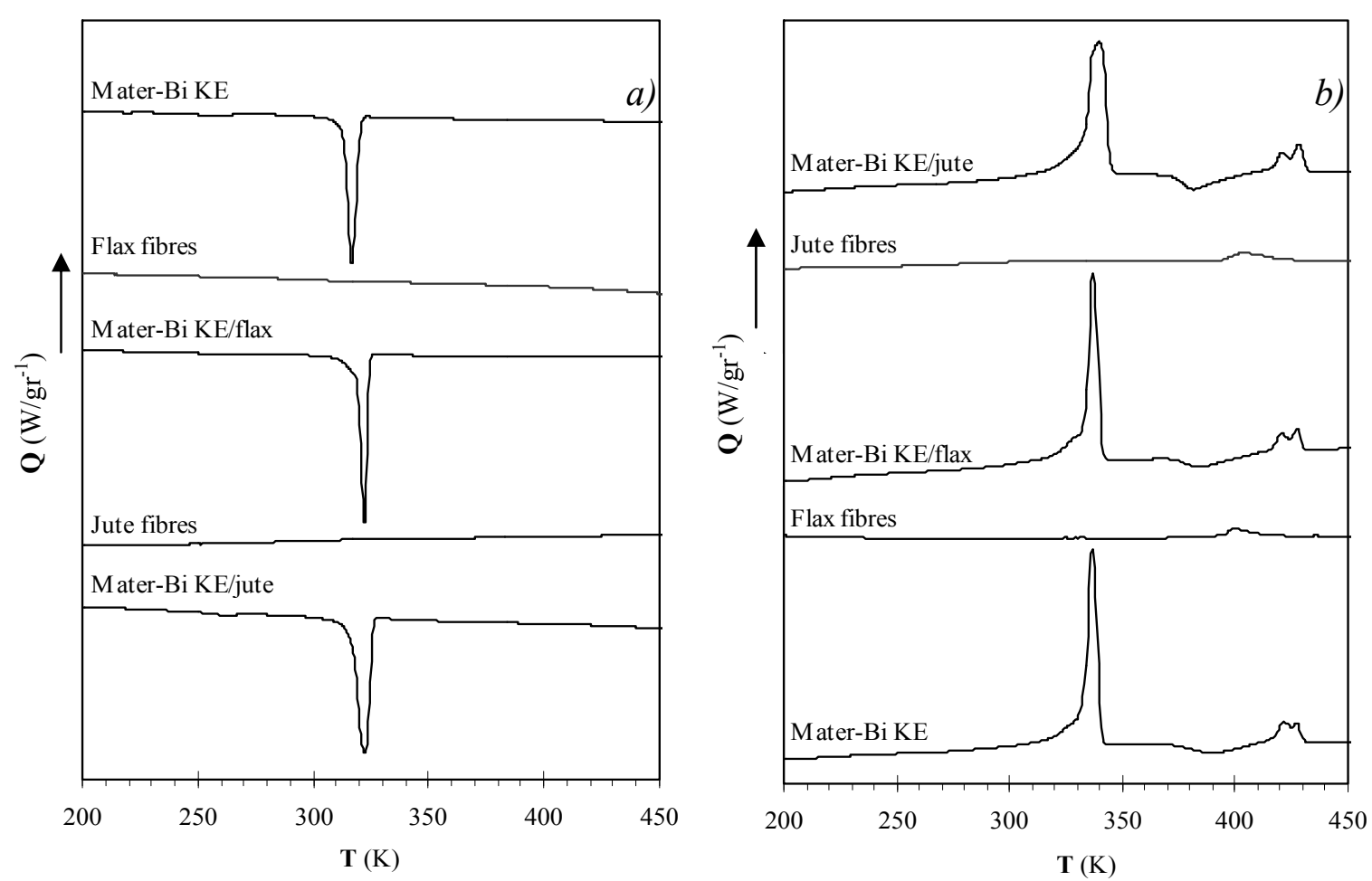

Figure 1. DSC thermograms of the a) second scan and b) third scan of the pure Mater-Bi KE, natural fibres and reinforced MBi KE/jute and Mater-Bi KE/flax biocomposite. 
The crystallisation temperatures and enthalpies of both reinforced biocomposites slightly increase with respect to those of the pure Mater-Bi KE, indicating interactions between the polymeric matrix and the natural fibres.

Table 1. Calorimetric parameters of the pure Mater-Bi KE and the reinforced Mater-Bi KE/flax and Mater-Bi KE/jute biocomposites

\begin{tabular}{r|cccc}
\hline & $\mathbf{T m}$ & $\Delta \mathbf{H m}$ & $\mathbf{T c}$ & $\Delta \mathbf{H c}$ \\
& $(\mathrm{K})$ & $(\mathrm{J} / \mathrm{g})$ & $(\mathrm{K})$ & $(\mathrm{J} / \mathrm{g})$ \\
\hline Mater-Bi KE & $336,0 \pm 0,5$ & $61,1 \pm 1,6$ & $316,0 \pm 0,5$ & $55,0 \pm 0,6$ \\
\hline Mater-Bi KE/flax & $337,8 \pm 1,0$ & $64,5 \pm 1,0$ & $319,4 \pm 0,9$ & $58,7 \pm 1,0$ \\
Mater-Bi KE/jute & $338,0 \pm 0,3$ & $64,8 \pm 0,7$ & $320,4 \pm 0,3$ & $59,3 \pm 0,3$ \\
\hline
\end{tabular}

\section{Thermal Decomposition Analysis}

The thermal decomposition of Mater-Bi KE/flax and Mater-Bi KE/jute were analysed in detail by performing dynamical thermogravimetric analyses at different heating rates. Figure 2 shows the differential thermogravimetric (DTG) curve of pure Mater-Bi KE and the natural fibres and Figure 3 displays the reinforced biocomposites at the heating rate of $20 \mathrm{~K} / \mathrm{min}$. Similar patterns were obtained at different heating rates and they are not shown here for the sake of clarity.
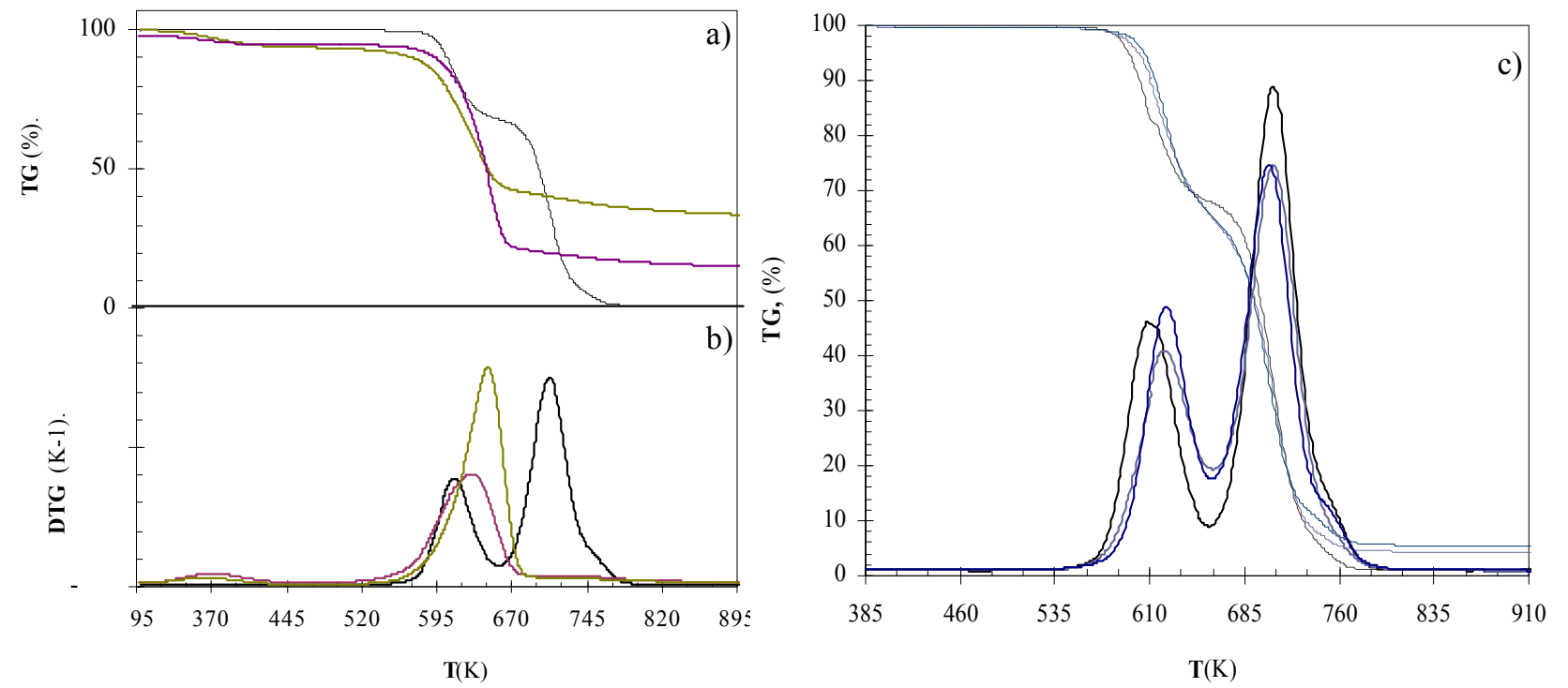

Figure 2. a) TG curves and b) DTG curves of -) pure Mater-Bi KE - ) flax -) and jute natural fibres, c)TG and DTG curves of -) pure Mater-Bi KE and the reinforced-) Mater-Bi KE/flax

-) and Mater-Bi KE/jute biocomposites. 
Similarly to the pure Mater-Bi KE, the thermal decomposition of both studied Mater-Bi $\mathrm{KE} /$ natural fibre biocomposites presents two main mass-loss regions at all the studied heating rates (Figure 3). The first mass-loss region $(520-660 \mathrm{~K})$ is related to both the starch present in pure Mater-Bi KE [2,3] and the hemicellulose and cellulose of the natural fibres (Figure 2). The second mass-loss region (around $660-800 \mathrm{~K}$ ) is associated to the synthetic component present in pure Mater-Bi KE [2,3]. The thermogravimetric parameters are summarised in Table 2.

When flax and jute fibres are added into the Mater-Bi KE, the onset temperature related to the first mass-loss region is displaced to higher temperatures (especially Mater-Bi KE/jute), whereas the thermogravimetric parameters associated to the synthetic component of this polymeric matrix are not significantly affected by the addition of any of these fibres.

The thermal decomposition kinetics were analysed and the kinetic parameters $(E a, A$ and $f(\alpha))$ of each thermal decomposition region for reinforced Mater-Bi KE/flax, and Mater-Bi KE/jute biocomposites were obtained: Friedman, Flynn-Wall-Ozawa and Kissinger methods[4-6] were employed to calculate Ea; Criado method [7] was performed to elucidate the possible kinetic model that follows the reaction mechanism of each thermal decomposition process; and Coats-Redfern [8] was finally used to identify the current kinetic model and to determine the pre-exponential factor.

The different regions were separated using an asymmetrical deconvolution method. When flax and jute fibres are incorporated into the pure Mater-Bi KE, the $E a$ values associated to both thermal decomposition regions increase. Table 3 summarised the kinetic values for pure Mater-Bi KE and the reinforced biocomposites. The first thermal decomposition region displays the most significant increase for both reinforced biocomposites. As a consequence, the thermal decomposition mechanism of starch changes more significantly than the thermal decomposition mechanism of the synthetic region (Table 3). 
Table 2. Thermogravimetric parameters of Mater-Bi KE, flax fibre, jute fibre and its reinforced Mater-Bi KE/flax and Mater-Bi KE/jute biocomposites.

\begin{tabular}{|c|c|c|c|c|c|c|c|}
\hline & \multicolumn{3}{|c|}{$[520-660 \mathrm{~K}]$} & \multicolumn{3}{|c|}{$[660-785 \mathrm{~K}]$} & \multirow{2}{*}{$\begin{array}{c}\text { Residue } \\
\text { Mass } \\
(\%) \\
\end{array}$} \\
\hline & $\begin{array}{r}\text { Onset } \\
(\mathrm{K})\end{array}$ & $\begin{array}{c}\text { Mass } \\
\text { loss } \\
(\%) \\
\end{array}$ & $\begin{array}{c}\mathrm{T} \\
\text { peak } \\
(\mathrm{K}) \\
\end{array}$ & $\begin{array}{r}\text { Onset } \\
(\mathrm{K})\end{array}$ & $\begin{array}{c}\text { Mass } \\
\text { loss } \\
(\%) \\
\end{array}$ & $\begin{array}{c}\mathrm{T} \\
\text { peak } \\
(\mathrm{K}) \\
\end{array}$ & \\
\hline Mater-Bi KE & $592,0 \pm 1,0$ & $31,5+0,5$ & $608,6 \pm 1,0$ & $686,4 \pm 0,7$ & $66,6 \pm 0,7$ & $708,0 \pm 0,2$ & $1,2 \pm 0,1$ \\
\hline Mater-Bi KE/flax & $599,0 \pm 1,0$ & $34,5 \pm 0,4$ & $622,1 \pm 0,5$ & $686,1 \pm 0,3$ & $59,0 \pm 1,5$ & $707,2 \pm 0,3$ & $5,3 \pm 0,5$ \\
\hline Mater-Bi KE/jute & $605,9 \pm 1,2$ & $34,6 \pm 1,0$ & $618,8 \pm 0,5$ & $688,1 \pm 0,3$ & $61,0 \pm 1,0$ & $706,6 \pm 0,3$ & $3,8 \pm 0,5$ \\
\hline
\end{tabular}

Table 3. Kinetic parameters of Mater-Bi KE and its reinforced Mater-Bi KE/flax and Mater-Bi KE/jute biocomposites.

\begin{tabular}{|c|c|c|c|c|c|c|c|c|}
\hline & & \multirow{2}{*}{$\begin{array}{c}\text { Kissinger } \\
\mathrm{Ea} \\
(\mathrm{kJ} / \mathrm{mol})\end{array}$} & \multirow{2}{*}{$\begin{array}{c}\text { Friedman } \\
\text { Ea } \\
(\mathrm{kJ} / \mathrm{mol})\end{array}$} & \multicolumn{2}{|c|}{ Flynn-Wall-Ozawa } & \multicolumn{3}{|c|}{ Coats-Redfern and Criado } \\
\hline & & & & $\begin{array}{c}\mathrm{A} \\
(\mathrm{min}-1)\end{array}$ & $\underset{(\mathrm{kJ} / \mathrm{mol})}{\mathrm{Ea}}$ & $\begin{array}{c}\mathrm{A} \\
\left(\mathrm{min}^{-1}\right)\end{array}$ & $\underset{(\mathrm{kJ} / \mathrm{mol})}{\mathrm{Ea}}$ & $f(\alpha)$ \\
\hline \multirow{2}{*}{ Mater-Bi KE } & First Thermal Decomposition Process & $98 \pm 6$ & $98 \pm 6$ & $10^{9,3} \pm 2$ & $102 \pm 2$ & $10^{9^{\prime} 0} \pm 2$ & $101 \pm 4$ & $\alpha^{0,5}(1-\alpha)^{1,5}$ \\
\hline & Second Thermal Decomposition Process & $173 \pm 3$ & $173 \pm 3$ & $10^{13^{\prime} 5} \pm 2$ & $175 \pm 5$ & $10^{13^{\prime} 5} \pm 2$ & $172 \pm 3$ & $\alpha^{0,5}(1-\alpha)^{1,5}$ \\
\hline \multirow{2}{*}{ Mater-Bi KE/flax } & First Thermal Decomposition Process & $155 \pm 4$ & $154 \pm 6$ & $10^{15^{\prime} 0} \pm 4$ & $153 \pm 4$ & $10^{15^{\prime} 4} \pm 3$ & $154 \pm 2$ & $\alpha^{0,3}(1-\alpha)^{1,6}$ \\
\hline & Second Thermal Decomposition Process & $219 \pm 5$ & $220 \pm 5$ & $10^{17^{\prime} 0} \pm 2$ & $219 \pm 6$ & $10^{17^{\prime} 4} \pm 2$ & $218 \pm 3$ & $\alpha^{0,3}(1-\alpha)^{1,5}$ \\
\hline \multirow{2}{*}{ Mater-Bi KE/jute } & First Thermal Decomposition Process & $170 \pm 5$ & $169 \pm 3$ & $10^{12,2} \pm 3$ & $170 \pm 5$ & $10^{10,4} \pm 2$ & $169 \pm 4$ & $\alpha^{0,4}(1-\alpha)^{1,7}$ \\
\hline & Second Thermal Decomposition Process & $211 \pm 5$ & $207 \pm 5$ & $10^{14,6} \pm 4$ & $209 \pm 6$ & $10^{15,4} \pm 2$ & $210 \pm 3$ & $\alpha^{0,3}(1-\alpha)^{1,5}$ \\
\hline
\end{tabular}




\section{Dynamical Mechanical Thermal Analysis}

The effects of the addition of flax and jute on the thermo-mechanical properties and the viscoelastic behaviour of reinforced biocomposites were assessed by performing multifrequency scans on the Mater-Bi KE/flax and Mater-Bi KE/jute biocomposites at a wide range of temperatures. Figure 3 compares the evolution of the storage modulus $\left(E^{\prime}\right)$ with temperature for pure Mater-Bi KE and the reinforced composites for a frequency of $1 \mathrm{~Hz}$; similar curves are obtained for other frequencies. Higher values of the storage and loss modulus are observed over the whole range of temperatures for the reinforced composites in comparison with pure Mater-Bi KE. The storage modulus of the reinforced biocomposites is highest for Mater-Bi KE/jute composite over the entire range of temperatures.

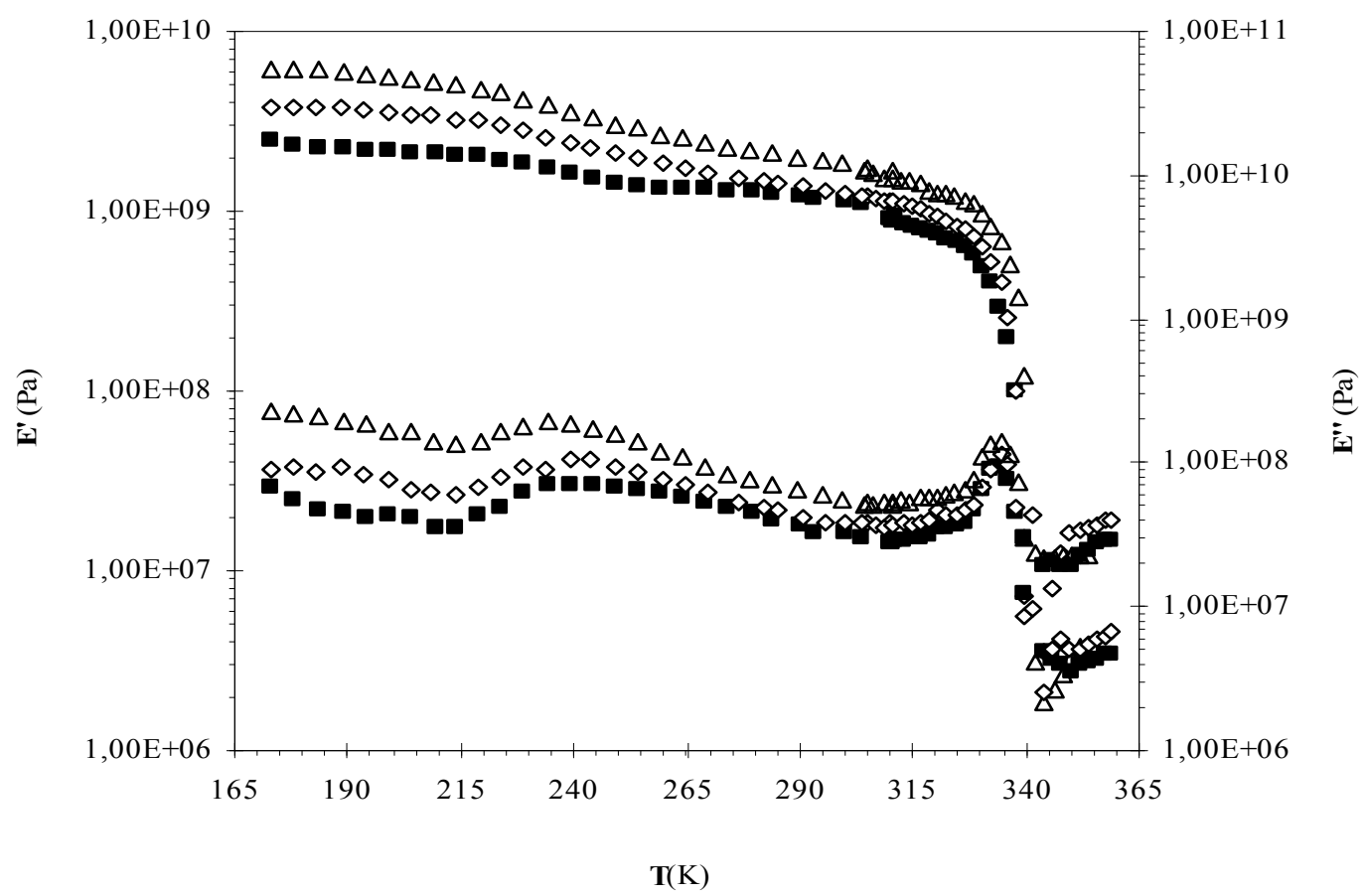

Figure 3. Isochronal representation of the storage modulus E' (upper plots) and loss modulus E" (lower plots) for (-) pure Mater-Bi KE, (०) reinforced Mater-Bi KE/flax biocomposite and $(\diamond)$ reinforced Mater-Bi $K E / j u t e$ biocomposite at $1 \mathrm{~Hz}$ as a function of the temperature

Two main viscoelastic relaxation zones (labelled as $\alpha$ and $\beta$ zones in decreasing temperature order) can be observed in the loss modulus (E') curves for pure Mater-Bi KE and its reinforced Mater-Bi KE/flax and Mater-Bi KE/jute composites (Figure 3). The $\alpha$ relaxation zone appears between $310 \mathrm{~K}-345 \mathrm{~K}$ with a prominent peak centred at around $332 \mathrm{~K}$ (relaxation $\alpha_{\mathrm{I}}$ ) together with a small shoulder at $322 \mathrm{~K}$ (relaxation $\alpha_{\text {III }}$ ). This zone is assigned to long segment chain movements associated to the melt of the crystalline phase of the synthetic component of pure Mater-Bi KE, according to DSC results. The $\beta$ relaxation zone between 
$210 \mathrm{~K}$ and $290 \mathrm{~K}$ could be associated to different chain movements related to pure Mater-Bi KE $[9,10]$. Three overlapped subrelaxations can be distinguished in this temperature range: the $\beta_{\mathrm{III}}$ relaxation $(250-290 \mathrm{~K})$ that could be associated to the glass transition of the synthetic polyester component of pure Mater-Bi KE, and the $\beta_{\mathrm{I}}$ and $\beta_{\mathrm{II}}$ relaxation $(210-250 \mathrm{~K})$ that may be related to different overlapping contributions, such as the secondary and primary relaxation of the starch and the glass transition of the synthetic component.

Fuoss-Kirkwood empirical model [11] and Charlesworth deconvolution procedure [12] were applied to the experimental data of pure Mater-Bi KE and its reinforced biocomposites, in order to fit the relaxation functions and obtain the values of the loss modulus maximum and the corresponding temperature $\left(E{ }^{\prime}{ }_{\max }, T_{\max }\right)$ for each mechanical relaxation at the different frequencies. The broad $\beta$ relaxation zone displayed a complex behaviour for the different materials over the range of frequencies; deconvolution of the $\beta_{\mathrm{I}}$ and $\beta_{\mathrm{II}}$ subrelaxations was difficult in many cases due to their weak signal, so the Arrhenius maps could only be drawn for the $\beta_{\text {III }}$ subrelaxation.

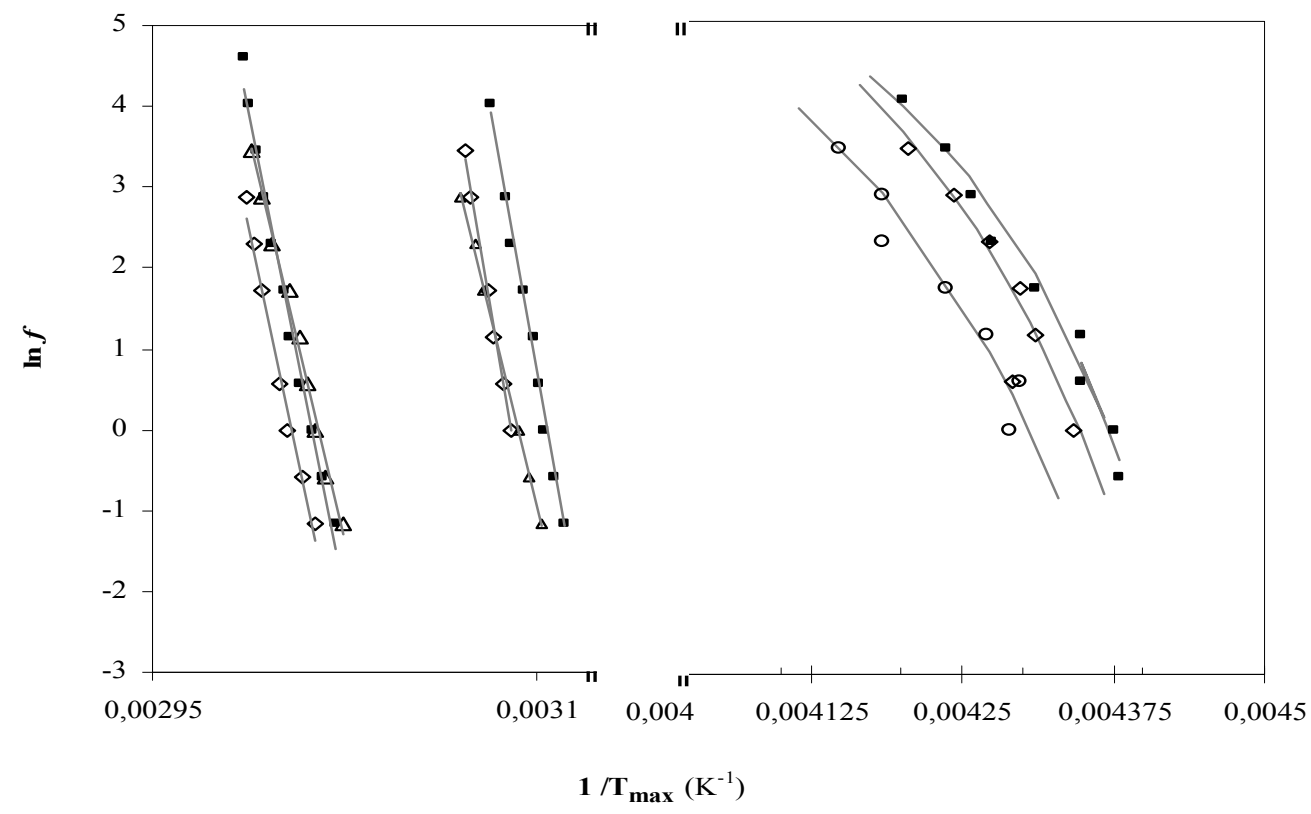

Figure 4. Arrhenius maps for the $\alpha$ and $\beta$ relaxations for (ロ) Mater-Bi KE, (०) reinforced Mater-Bi KE/flax biocomposite and $(\nabla)$ reinforced Mater-Bi KE/jute biocomposite as a function of the temperature

The Arrhenius maps for the pure Mater-Bi KE and its reinforced biocomposites were obtained by plotting the temperature of the maximum of the loss modulus curves $\left(\mathrm{T}_{\max }\right)$ from the Fuoss-Kirkwood fittings versus the frequency for all the studied relaxations (Figure 4). The 
$\beta_{\text {II }}$ peak of Mater-Bi KE/jute fibres is minor than the pure Mater-Bi KE during all the frequency range, however, the $\beta_{\text {II }}$ peak of Mater-Bi KE/flax is similar to that of the pure Mater-Bi KE at high frequencies.

Both $\alpha$ relaxations, $\alpha_{\mathrm{I}}$ and $\alpha_{\mathrm{II}}$, of the pure Mater-Bi KE and its reinforced biocomposites show in all cases a lineal tendency in the Arrhenius maps (Figure 4), indicating that $\alpha$ relaxations are intramolecular movements. Arrhenius equation was therefore applied to obtain the activation energies $(E a)$ of $\alpha_{\mathrm{I}}$ and $\alpha_{\mathrm{II}}$ relaxations for pure Mater-Bi KE and its reinforced biocomposites., The $E a$ of the $\alpha_{\mathrm{I}}$ relaxation is mainly affected When natural fibres are added to the pure Mater-Bi KE, which could be associated to the increase in the crystalline phase that hinders intramolecular movements.

In addition, all the studied materials display a curved tendency in the Arrhenius maps for the subrelaxation $\beta_{\mathrm{II}}$, which is associated to a typical glass transition behaviour. The experimental data from the Arrhenius maps for these relaxations could be therefore fitted to the VogelFulcher-Tammann-Hesse (VFTH) equation according to the free volume theory [13] in order to obtain the parameter related to the free volume. The addition of natural fibres induces a clear reduction in this parameter, which suggests a good interaction between the lignocellulosic fillers and the polymeric matrix. The decrease in the free volume parameter is markedly observed for Mater-Bi KE/jute.

Table 5. Viscoelastic parameters of the Mater-Bi KE and its reinforced Mater-Bi KE/flax and Mater-Bi KE/jute biocomposites according to the free-volume theory.

\begin{tabular}{|c|c|c|c|c|c|c|}
\hline & \multicolumn{2}{|c|}{$\begin{array}{c}\alpha \text { relaxation zone } \\
{[310-345 \mathrm{~K}]}\end{array}$} & \multicolumn{4}{|c|}{$\begin{array}{c}\boldsymbol{\beta} \text { relaxation zone } \\
{[210-290 \mathrm{~K}]}\end{array}$} \\
\hline & $\begin{array}{c}\mathrm{Ea}_{\alpha \mathrm{I}} \\
(\mathrm{kJ} / \mathrm{mol})\end{array}$ & $\begin{array}{c}\mathrm{Ea}_{\alpha \mathrm{II}} \\
(\mathrm{kJ} / \mathrm{mol})\end{array}$ & $A^{\prime}$ & $\begin{array}{l}\mathrm{m}_{\mathrm{v}} \\
(K)\end{array}$ & $\begin{array}{l}\mathrm{T}_{\infty} \\
(K)\end{array}$ & $\begin{array}{l}\alpha_{\mathrm{f}} \\
\left(K^{-1}\right)\end{array}$ \\
\hline Mater-Bi KE & $1333,0 \pm 6$ & $1531,4 \pm 8$ & $8,9 \pm 1$ & $99,7 \pm 10$ & $218,3 \pm 6$ & $100,3 \cdot 10^{-4}$ \\
\hline Mater-Bi KE/flax & $1292,0 \pm 9$ & $1625,0 \pm 8$ & $10,7 \pm 1$ & $164,8 \pm 12$ & $213,7 \pm 2$ & $83,4 \cdot 10^{-4}$ \\
\hline Mater-Bi KE/jute & $1285,7 \pm 9$ & $1628,3 \pm 8$ & $6,4 \pm 1$ & $119,8 \pm 10$ & $208,9 \pm 3$ & $60,9 \cdot 10^{-4}$ \\
\hline
\end{tabular}




\section{Scanning Electron Microscopy}

SEM was used to examine the microstructure and the interfacial adhesion of pure Mater-Bi $\mathrm{KE}$ and with flax and jute fibres. The micrographs of the Mater-Bi KE/jute and Mater-Bi KE/flax are displayed in Figure 5. Good wettability between the pure Mater-Bi KE and the fibres could be confirmed due to the absence of holes between the polymeric matrix and the fibres. Furthermore good dispersion between natural fibres and polymeric matrix can be observed.

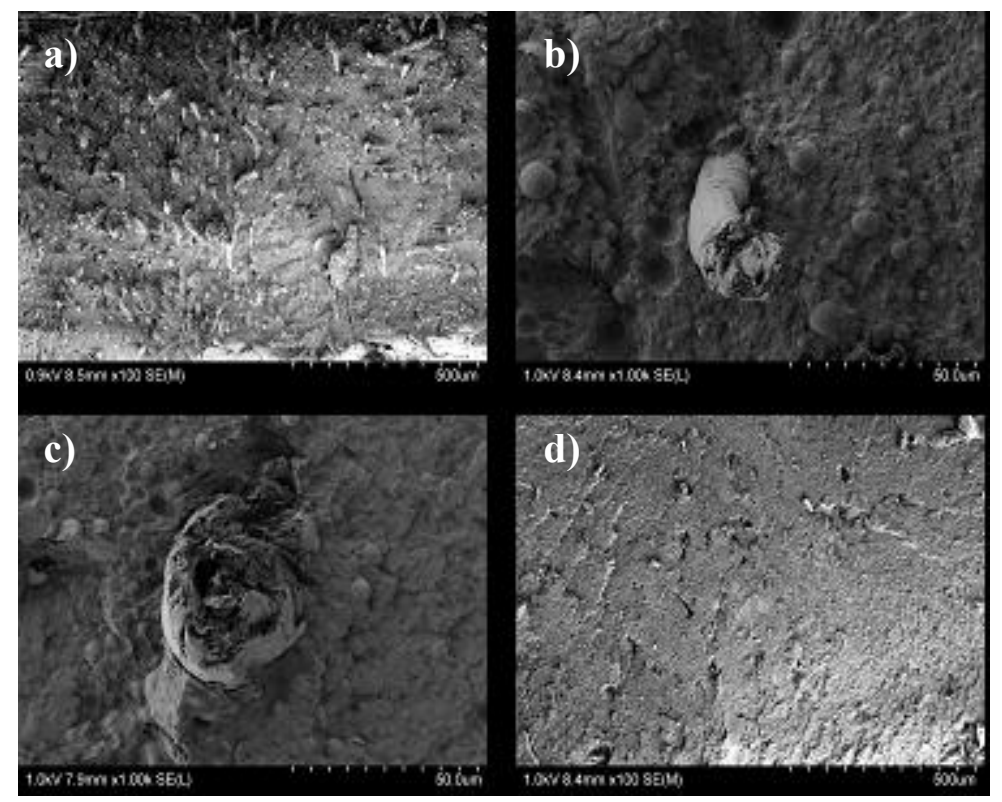

Figure 5. SEM micrographs of a)b)yute fibres and c) d) flax fibres.

\section{Conclusions}

Jute and flax fibres can be successfully incorporated into pure Mater-Bi KE. These natural fibres act as suitable thermal stabilisers for pure Mater-Bi KE, by increasing the thermal stability and the activation energy associated to both thermal decomposition processes. Furthermore, the addition of these fibres into the pure Mater-Bi KE increases the storage modulus and decreases the thermal expansion coefficient associated to the glass transition. Reinforced Mater-Bi KE/jute biocomposite displays the major increase in the thermal and mechanical properties: this could be attributed to the higher content of hemicellulose and lignin in jute fibre, which offers better interfacial interaction with pure Mater-Bi KE. 


\section{References}

1. Bastioli C, editor. Handbook of Biodegradable Polymers. Shrewsbury: Rapra Technology, 2005. Taylor \& Francis, 2005.

2. Moriana R, Badia J.D., Santonja-Blasco L, Ribes-Greus A. J Appli Polym Sci 2010; (pending of publication).

3. Moriana R, Vilaplana F, Karlsson S, Ribes-Greus A. Composites A: Science and Manufacturing 2010; (pending of publication).

4. Friedman KH. J Appl Polym Sci 1964; 6: 183.

5. Ozawa T. Bull Chem Soc Jpn 1965; 38: 1881.

6. Kissinger HE. J Res Natl Bur Stand 1956; 57: 217.

7. Criado JM. Thermochimic Acta 1978; 24:86.

8. Coats AW, Redfern JP. Nature (Lond) 1964; 201: 68.

9. Avérous L, Moro L, Dole P, Fringant C. Polymer 2000; 41: 4157.

10. Avella M, La Rota G, Martuscelli E, Raimo M, Sadocco P, Elegir G, Riva R. J Mater Sci 2000; 35: 829 .

11. Fuoss RM, Kirkwood JG. J Am Chem Soc 1941; 2: 385.

12. CH Charlesworth JM. J Mater Sci 1993; 28: 399.

13. Fulcher GS. J Am Ceram Soc 1925; 6: 339. 
"COMPARATIVE STUDY OF DIFFERENT BIOCOMPOSITES BASED ON A COMMERCIAL THERMOPLASTIC STARCH (MATER-BI NFO1U) REINFORCED WITH NATURAL FIBRES" 



\title{
“COMPARATIVE STUDY OF DIFFERENT BIOCOMPOSITES \\ BASED ON A COMMERCIAL THERMOPLASTIC STARCH (MATER-BI NFO1U) \\ REINFORCED WITH NATURAL FIBRES"
}

\begin{abstract}
The thermal and mechanical properties of a commercial starch-based material (Mater-Bi $\mathrm{NF}$ ) have been investigated to assess its suitability as matrix for the design of naturalfibre reinforced biocomposites. The influence of cotton, hemp, kenaf, jute and flax fibres on the thermal and mechanical properties of this polymeric matrix was evaluated. Thermogravimetric analysis (TGA) was used to analyse the thermal stability of the studied materials and to fully investigate their thermal decomposition processes. A kinetic analysis of the decomposition process has been performed, with the determination of the activation energies and the discussion of the reaction mechanism applying several isoconversional methods. Tensile analysis has been performed to guarantee the improvement in the mechanical properties after reinforcing with the biofibres by means of Young Modulus, strain at maximum load and strain at break. Furthermore, Scanning Electronic Microscopy (SEM) and Differential scanning calorimetry (DSC) were evaluated in order to obtain information about the morphology of the samples. The comparative study of the properties of each reinforced composite allows to asses the difference influence of each natural fibre on the polymeric matrix. Kenaf fibres provide better thermal stability, with opposite effects on the mechanical properties. While Mater$\mathrm{Bi} \mathrm{NF} /$ kenaf biocomposites display the smallest increase in the mechanical properties, Mater-Bi NF/jute shows the highest improvement in Young's Modulus and a similar thermal stability as the Mater-Bi NF/kenaf.
\end{abstract}

Keywords: Reinforced Mater-Bi NF/natural fibres biocomposites, Thermal analysis, Mechanical analysis, Natural Fibres 


\section{Results and discussion}

\section{Thermogravimetric analyses}

Figure 1 shows the differential thermogravimetric (DTG) curve of pure Mater-Bi NF and its reinforced biocomposites at the heating rate of $20 \mathrm{~K} / \mathrm{min}$; similar patterns were obtained at different heating rates for each natural fibre.

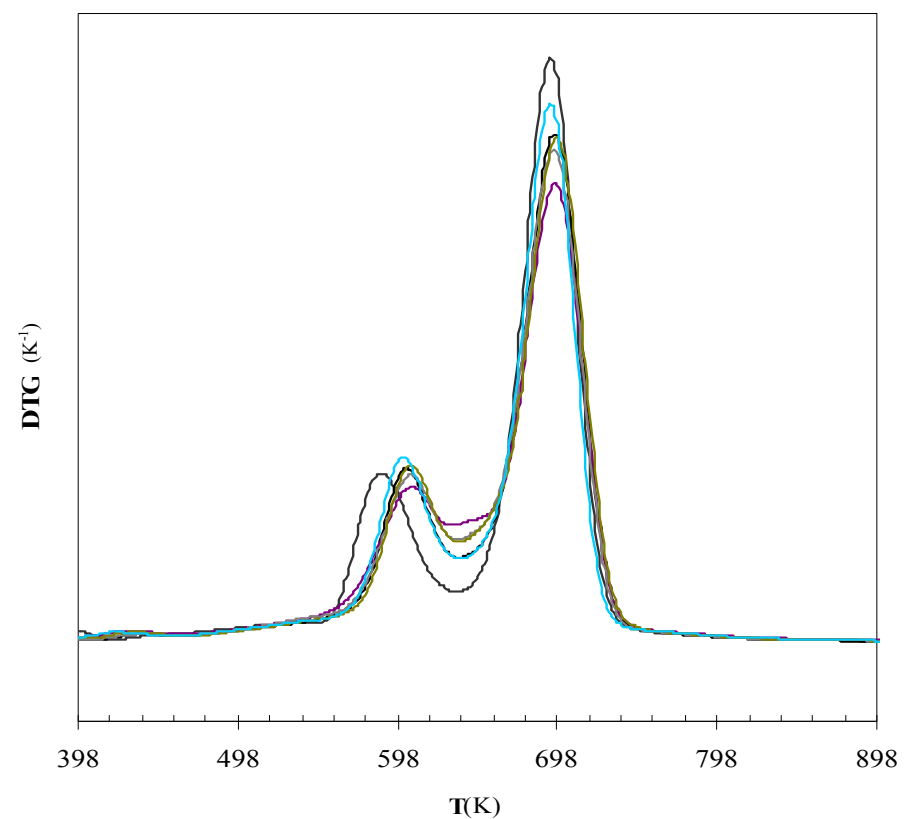

Figure 1. Differential thermogravimetric (DTG) curve (-) of the pure Mater-Bi NF, reinforced (-) Mater-Bi NF/cotton, (-) Mater-Bi NF/flax, (-) Mater-Bi NF/hemp, (-) Mater-Bi NF/jute and (-) Mater-Bi NF/kenaf biocomposites at the heating rate of $20 \mathrm{~K} / \mathrm{min}$

These DTG curves display a complex thermal decomposition with different mass-loss regions. The first one, with a mass loss of around $3 \%$ and centered at $373 \mathrm{~K}$ is related to the evaporation of low molecular weight compounds [1,2]. The second mass-loss region (573$635 \mathrm{~K}$ ) shows a maximum around $587 \mathrm{~K}$ and a $26 \%$ mass loss and is related to starch pyrolysis [2,3]. The third mass-loss region $(635-795 \mathrm{~K})$ is the main process with a mass loss of approximately $66 \%$ and should be attributed to the biodegradable synthetic polyester component of pure Mater-Bi NF [4]. Table 2 displays the characteristic thermogravimetric parameters for both Mater-Bi NF thermogravimetric processes at the heating rate of 20 $\mathrm{K} / \mathrm{min}$. 
Figure 2 compares the thermogravimetric profiles for each reinforced biocomposite with its respective natural fibre and the pure Mater-Bi NF, in order to assess the influence of each natural fibre on the Mater-Bi NF pyrolysis. It is well-known that thermogravimetric analysis of lignocellulosic materials displays a main peak resulting from the decomposition of cellulose, a lower temperature peak associated with hemicellulose pyrolysis and an attenuated peak at higher temperature related to lignin decomposition [5]. From Figure 2 a new overlapped contribution between the peak related to the starch and synthetic component appears as a result of the presence of each natural fibre.

Table 2 summarises the thermogravimetric parameters of the reinforced biocomposites at the heating rate of $20 \mathrm{~K} / \mathrm{min}$. When the matrix is reinforced, an increase in the peak temperature related to starch can be observed, whereas the region associated to the synthetic component of the pure Mater-Bi NF is not significantly affected by fibre addition. These thermogravimetric results indicate an improved thermal stability of the biocomposites, due to the higher thermal resistance of cellulose fibres compared to starch.

Although cotton and jute fibres have previously shown the most thermal stability, it is MaterBi NF/kenaf and Mater-Bi NF/jute which exhibit the highest onset temperature when the different reinforced composites are compared. The reason could be the better compatibility between kenaf and jute fibres and matrix due to high hemicellulose and lignin content, as already suggested in preceding papers [6]. 


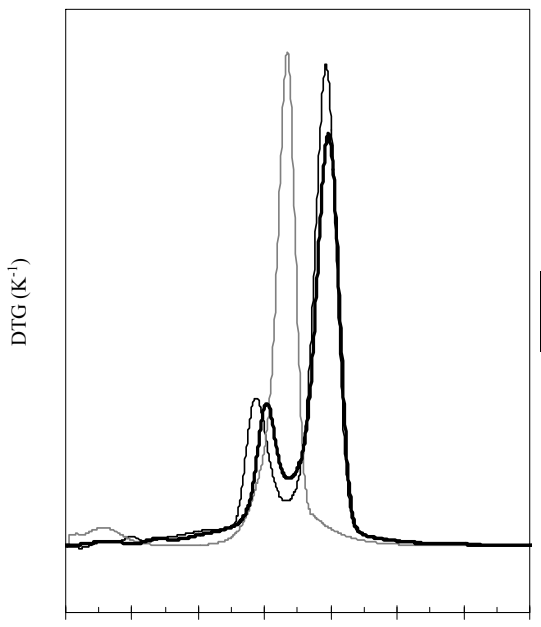

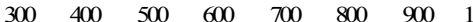
$\mathrm{T}(\mathrm{K})$

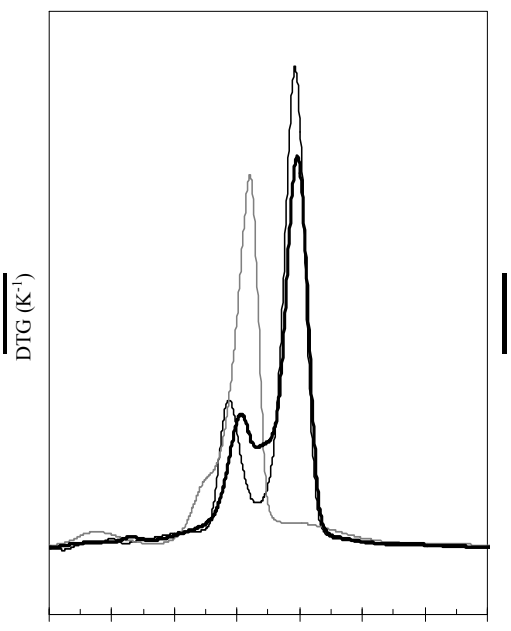

$\begin{array}{llllllll}300 & 400 & 500 & 600 & 700 & 800 & 900 & 100\end{array}$ $\mathrm{T}(\mathrm{K})$

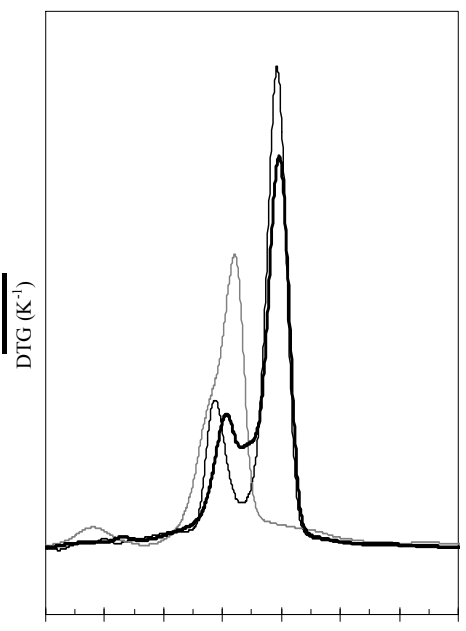

$300 \quad 400 \quad 500 \quad 600$

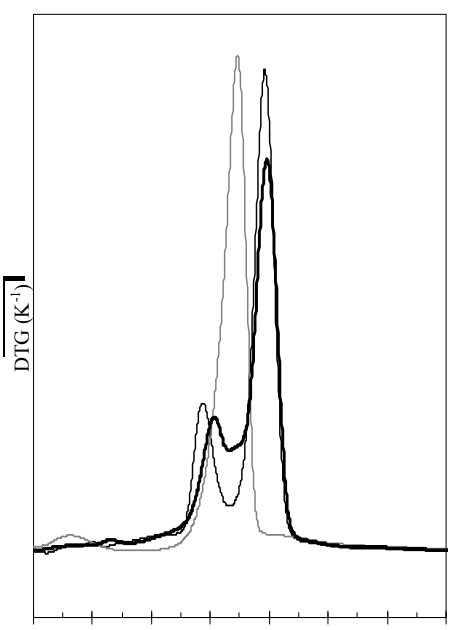

T(K)

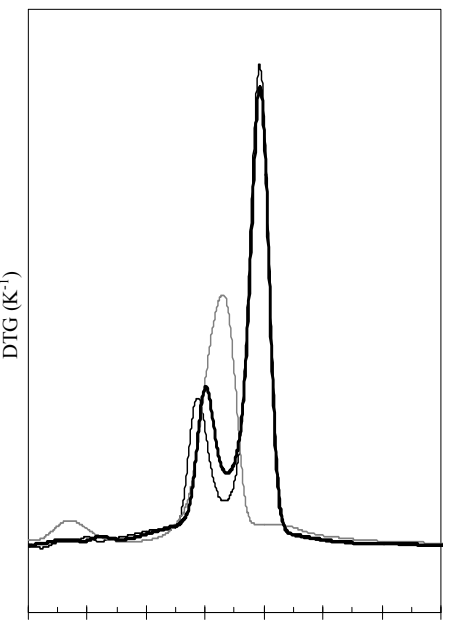

T(K)

Figure 2. DTG curves of (-)pure Mater-Bi KE, (-) reinforced biocomposites and (-) natural fibres for a)Mater-Bi NF/cotton, b)Mater-Bi NF/hemp, c) Mater-Bi NF/kenaf, d)Mater-Bi NF/jute and e) Mater-Bi NF/flax.

Table 2. Thermogravimetric parameters of reinforced biocomposites and pure Mater-Bi NF.

\begin{tabular}{|c|c|c|c|c|c|c|c|c|c|}
\hline & \multicolumn{2}{|c|}{$\begin{array}{c}\text { Moisture Process } \\
{[383 \mathrm{~K}-430 \mathrm{~K}]}\end{array}$} & \multicolumn{3}{|c|}{$\begin{array}{c}\mathbf{1}^{\text {st }} \text { Thermal Decomposition Process } \\
{[450 \mathrm{~K}-634 \mathrm{~K}]}\end{array}$} & \multicolumn{3}{|c|}{$\begin{array}{c}2^{\text {nd }} \text { Thermal Decomposition Process } \\
{[634 \mathrm{~K}-950 \mathrm{~K}]}\end{array}$} & \multirow{2}{*}{$\begin{array}{c}\text { Residue } \\
\text { Mass } \\
(\%)\end{array}$} \\
\hline & $\begin{array}{c}\text { Mass Loss } \\
(\%)\end{array}$ & $\begin{array}{c}\text { T peak } \\
(\mathrm{K})\end{array}$ & $\begin{array}{r}\text { Onset } \\
(\mathrm{K})\end{array}$ & $\begin{array}{c}\text { Mass Loss } \\
(\%)\end{array}$ & $\begin{array}{c}\text { T peak } \\
(\mathrm{K})\end{array}$ & $\begin{array}{r}\text { Onset } \\
(\mathrm{K})\end{array}$ & $\begin{array}{c}\text { Mass Loss } \\
(\%)\end{array}$ & $\begin{array}{c}\text { T peak } \\
(\mathrm{K})\end{array}$ & \\
\hline Mater-Bi NF & $1,2 \pm 0,3$ & $375,3 \pm 1,0$ & $561,1 \pm 0,3$ & $21,9 \pm 0,8$ & $585,5 \pm 2,0$ & $675,2 \pm 1,0$ & $68,5 \pm 0,5$ & $694,2 \pm 0,9$ & $7,6 \pm 0,5$ \\
\hline Mater-Bi NF/cotton & $1,0 \pm 0,2$ & $368,7 \pm 0,2$ & $577,6 \pm 1,0$ & $23,5 \pm 0,2$ & $603,6 \pm 0,4$ & $678,1 \pm 1,0$ & $63,9 \pm 1,0$ & $696,3 \pm 0,3$ & $9,9 \pm 0,5$ \\
\hline Mater-Bi NF/hemp & $1,4 \pm 0,2$ & $369,5 \pm 1,5$ & $578,8 \pm 0,2$ & $25,4 \pm 1,5$ & $604,9 \pm 2,0$ & $677,1 \pm 1,0$ & $60,9 \pm 3,0$ & $696,6 \pm 1,0$ & $9,1 \pm 1,0$ \\
\hline Mater-Bi NF/kenaf & $1,7 \pm 0,5$ & $373,0 \pm 0,5$ & $583,5 \pm 1,0$ & $22,5 \pm 1,0$ & $604,0 \pm 0,6$ & $675,5 \pm 0,4$ & $65,0 \pm 1,0$ & $693,4 \pm 0,2$ & $7,6 \pm 0,3$ \\
\hline Mater-Bi NF/flax & $1,9 \pm 0,5$ & $368,7 \pm 0,2$ & $578,3 \pm 0,3$ & $24,4 \pm 0,3$ & $601,0 \pm 0,3$ & $675,8 \pm 0,3$ & $62,6 \pm 0,3$ & $693,4 \pm 0,3$ & $9,4 \pm 0,3$ \\
\hline Mater-Bi NF/jute & $1,5 \pm 1,0$ & $376,1 \pm 0,5$ & $582,3 \pm 1,0$ & $28,5 \pm 0,5$ & $606,8 \pm 0,7$ & $678,4 \pm 0,3$ & $62,0 \pm 1,3$ & $696,6 \pm 0,5$ & $7,5 \pm 0,3$ \\
\hline
\end{tabular}


Further analysis of the thermal decomposition kinetics was performed for pure Mater-Bi NF and its reinforced biocomposites; the kinetic parameters including the activation energies $(E a)$, the kinetic model that follows the reaction mechanism $(f(\alpha))$ and the pre-exponential factor $(A)$, were studied with a similar methodology reported in previous work [6,7]. This methodology successfully determines the kinetic parameters using a deconvolution method based on asymmetrical model, the iso-conversional Friedman and Flynn-Wall-Ozawa methods[8,9], Kissinger [10], Criado [11] and Coats-Redfern [12] methods.

Table 3. Kinetic parameters of Mater-Bi NF and its reinforced biocomposites.

\begin{tabular}{|c|c|c|c|c|c|c|c|}
\hline & & \multirow{2}{*}{$\begin{array}{c}\text { Kissinger } \\
\mathrm{Ea} \\
(\mathrm{kJ} / \mathrm{mol})\end{array}$} & \multirow{2}{*}{$\begin{array}{c}\text { Friedman } \\
\mathrm{Ea} \\
(\mathrm{kJ} / \mathrm{mol}) \\
\end{array}$} & \multicolumn{2}{|c|}{ Flynn-Wall-Ozawa } & \multicolumn{2}{|c|}{ Coats-Redfern and Criado } \\
\hline & & & & $\begin{array}{c}\mathrm{A} \\
(\min -1)\end{array}$ & $\begin{array}{c}\mathrm{Ea} \\
(\mathrm{kJ} / \mathrm{mol})\end{array}$ & $\begin{array}{c}\mathrm{Ea} \\
(\mathrm{kJ} / \mathrm{mol})\end{array}$ & $f(\alpha)$ \\
\hline \multirow{2}{*}{ Mater-Bi NF } & $\begin{array}{c}1^{\mathrm{er}} \\
\text { Process }\end{array}$ & $149 \pm 5$ & $147 \pm 5$ & $10^{11,0} \pm 2$ & $148 \pm 2$ & $150 \pm 4$ & $\alpha^{0,6}(1-\alpha)^{2,0}$ \\
\hline & $\begin{array}{c}2^{\text {nd }} \\
\text { Process } \\
\end{array}$ & $222 \pm 3$ & $221 \pm 3$ & $10^{15,3} \pm 2$ & $219 \pm 4$ & $221 \pm 3$ & $\alpha^{0,3}(1-\alpha)^{1,1}$ \\
\hline \multirow{2}{*}{ Mater-Bi NF/cotton } & $\begin{array}{c}1^{\mathrm{er}} \\
\text { Process }\end{array}$ & $159 \pm 4$ & $158 \pm 6$ & $10^{12,9} \pm 3$ & $160 \pm 4$ & $171 \pm 2$ & $\alpha^{0,3}(1-\alpha)^{1,5}$ \\
\hline & $\begin{array}{c}2^{\text {nd }} \\
\text { Process }\end{array}$ & $208 \pm 4$ & $209 \pm 3$ & $10^{15,9} \pm 2$ & $207 \pm 4$ & $208 \pm 3$ & $\alpha^{0,2}(1-\alpha)^{1,2}$ \\
\hline \multirow{2}{*}{ Mater-Bi NF/flax } & $\begin{array}{c}1^{\mathrm{er}} \\
\text { Process }\end{array}$ & $170 \pm 3$ & $176 \pm 3$ & $10^{13,4} \pm 2$ & $177 \pm 4$ & $177 \pm 4$ & $\alpha^{0,2}(1-\alpha)^{1,5}$ \\
\hline & $\begin{array}{c}2^{\text {nd }} \\
\text { Process }\end{array}$ & $206 \pm 3$ & $205 \pm 3$ & $10^{15,6} \pm 2$ & $205 \pm 3$ & $206 \pm 3$ & $\alpha^{0,3}(1-\alpha)^{1,1}$ \\
\hline \multirow{2}{*}{ Mater-Bi NF/hemp } & $\begin{array}{c}1^{\mathrm{er}} \\
\text { Process }\end{array}$ & $177 \pm 4$ & $184 \pm 4$ & $10^{14,2} \pm 3$ & $181 \pm 4$ & $182 \pm 2$ & $\alpha^{0,1}(1-\alpha)^{1,4}$ \\
\hline & $\begin{array}{c}2^{\text {nd }} \\
\text { Process }\end{array}$ & $204 \pm 3$ & $203 \pm 4$ & $10^{15,0} \pm 2$ & $203 \pm 2$ & $204 \pm 3$ & $\alpha^{0,3}(1-\alpha)^{1,0}$ \\
\hline \multirow{2}{*}{ Mater-Bi NF/kenaf } & $\begin{array}{c}1^{\mathrm{er}} \\
\text { Process }\end{array}$ & $185 \pm 3$ & $183 \pm 4$ & $10^{14,8} \pm 3$ & $182 \pm 4$ & $182 \pm 4$ & $\alpha^{0,2}(1-\alpha)^{1,4}$ \\
\hline & $\begin{array}{c}2^{\text {nd }} \\
\text { Process }\end{array}$ & $190 \pm 3$ & $190 \pm 2$ & $10^{15,0} \pm 2$ & $191 \pm 3$ & $189 \pm 2$ & $\alpha^{0,2}(1-\alpha)^{1,1}$ \\
\hline \multirow{2}{*}{ Mater-Bi NF/jute } & $\begin{array}{c}1^{\text {er }} \\
\text { Process }\end{array}$ & $180 \pm 3$ & $179 \pm 3$ & $10^{14,1} \pm 3$ & $179 \pm 2$ & $180 \pm 4$ & $\alpha^{0,4}(1-\alpha)^{1,5}$ \\
\hline & $\begin{array}{c}2^{\text {nd }} \\
\text { Process } \\
\end{array}$ & $197 \pm 2$ & $197 \pm 4$ & $10^{15,6} \pm 2$ & $195 \pm 4$ & $196 \pm 3$ & $\alpha^{0,3}(1-\alpha)^{1,0}$ \\
\hline
\end{tabular}

Table 3 summarises the values of the kinetic parameters for Mater-Bi NF and its reinforced biocomposites. When natural fibres are incorporated into the pure Mater-Bi NF, the $E a$ associated to the starch decomposition region increases for all studied reinforced biocomposites, whereas the $E a$ related to the synthetic decomposition region decreases. This different effect on both components of the pure Mater-Bi NF may be due to the better interaction of natural fibres with the starch component. 
The changes in the Ea values related to the starch and synthetic region depends on the hemicellulose and lignin content, respectively (Figure 3); the differences increase as a function of increasing hemicellulose/pectin and lignin content in the natural fibres.

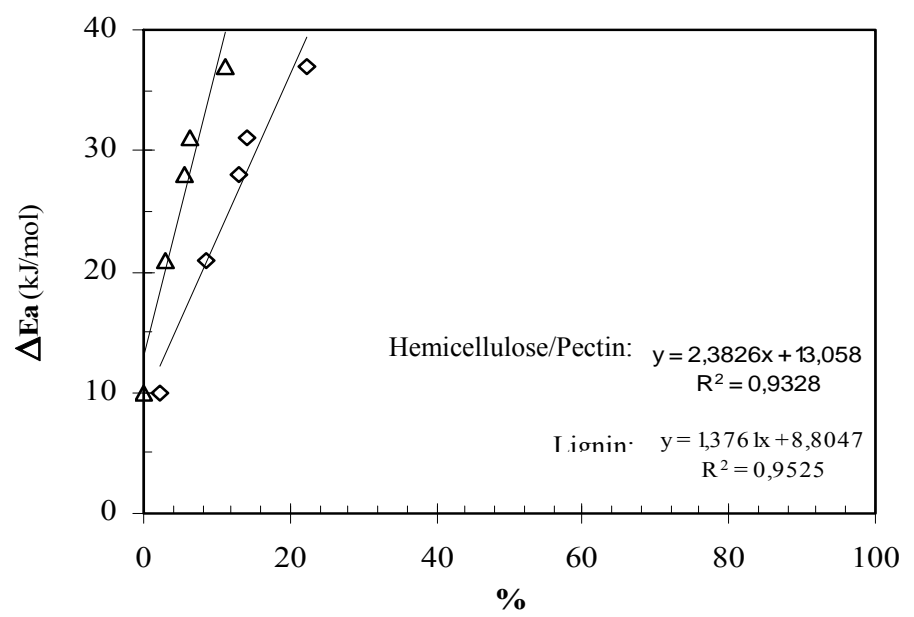

Figure 3. Changes in the Ea values as a function of the $(\diamond)$ hemicellulose/pectin and ( $\bullet)$ lignin content

\section{Mechanical measurements}

Figures 4 displays the Young Modulus values obtained for the reinforced biocomposites compared to the pure Mater-Bi NF.

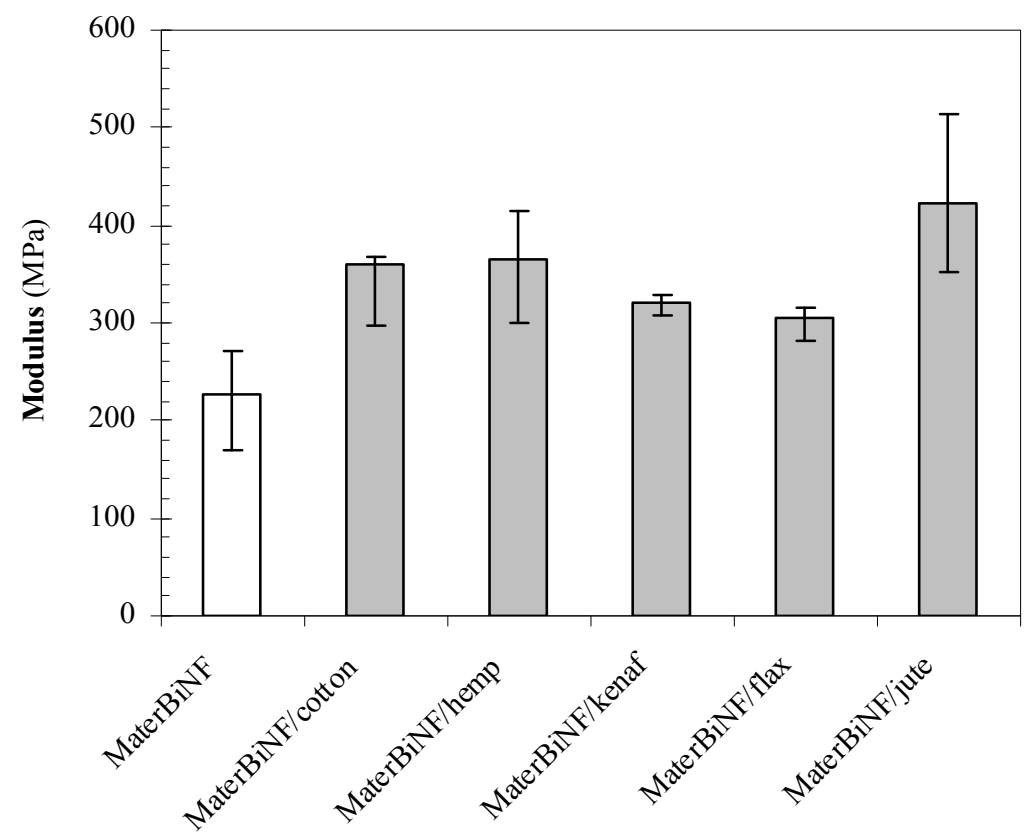

Figure 4. Young Modulus values for the pure Mater-Bi NF and its reinforced biocomposite 
In order to assess the interactions between the natural fibres and the polymeric matrix, the Young Modulus of the reinforced biocomposites is predicted by the rule of perfect mixtures.

$$
E_{\mathrm{RB}}=\mathrm{E}_{\mathrm{NF}} \cdot \mathrm{x}_{\mathrm{FN}}+\mathrm{E}_{\mathrm{PM}} \cdot\left(1-\mathrm{x}_{\mathrm{FN}}\right)
$$

Where $\mathrm{E}_{\mathrm{RB}}$ is the young Modulus of the reinforced biocomposites, $\mathrm{E}_{\mathrm{NF}}$ for the natural fibres, and $\mathrm{E}_{\mathrm{PM}}$ for the polymeric matrix, $\mathrm{x}_{\mathrm{FN}}$ is the volumetric percentage of natural fibres in the reinforced biocomposites.

Figure 5 compares the expected Young Modulus values for the reinforced biocomposites with the experimental values.

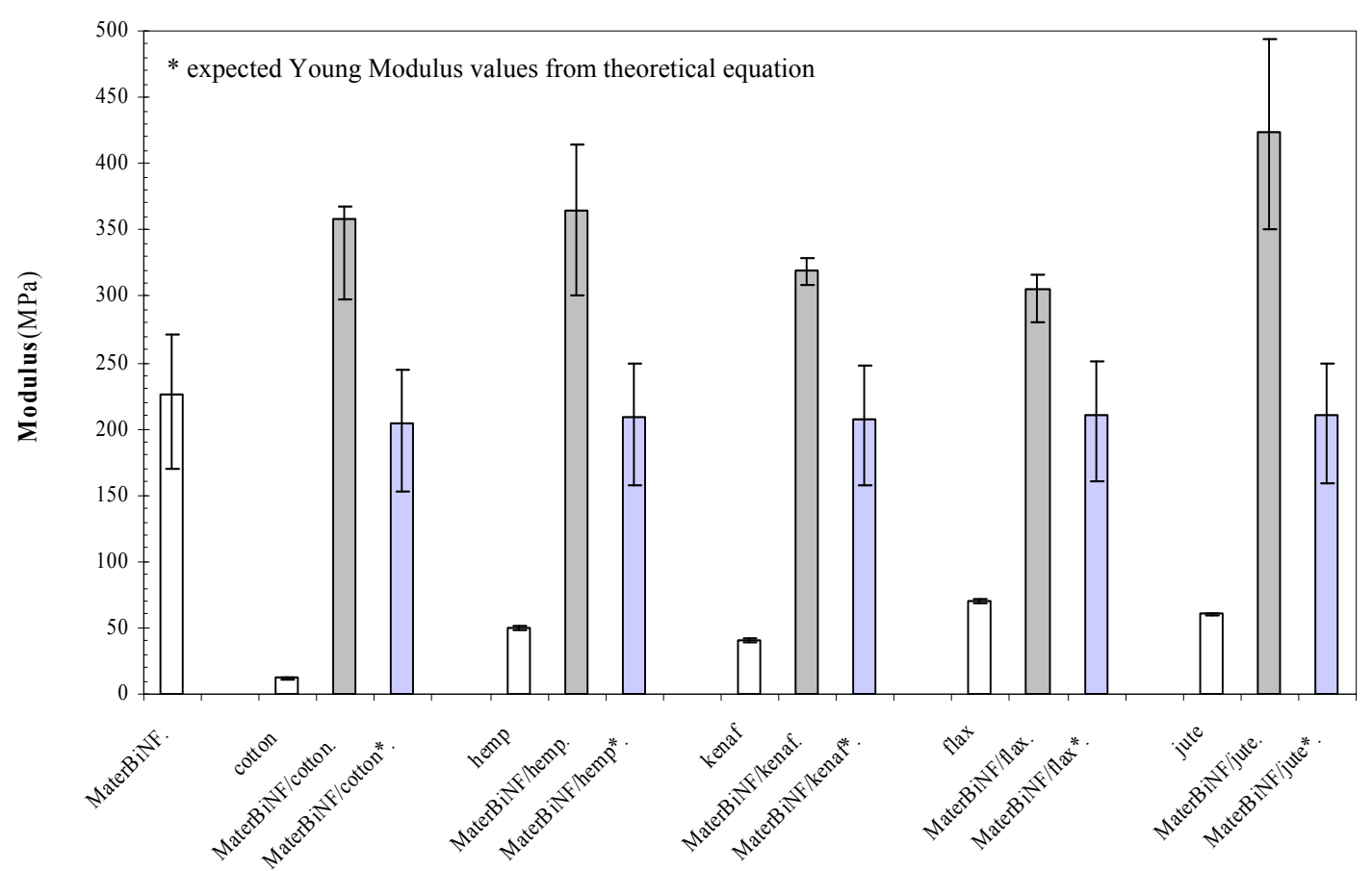

Figure 5. Young Modulus values for the pure Mater-Bi NF, natural fibres and reinforced biocomposites

The positive deviation between the theoretical and the experimental reinforced biocomposites values is defined as a positive effect of the reinforcing natural fibres on the Young modulus parameter may be due to the interactions between the components.

The Young's modulus of Mater-Bi NF increases with the addition of all natural fibres, Mater$\mathrm{Bi} \mathrm{NF} / \mathrm{jute}$ being the composite with the highest value and Mater-Bi NF/kenaf and Mater-Bi $\mathrm{NF} /$ flax biocomposites being the ones with the lowest modulus. 
Figure 5 displays the stress at maximum load for pure Mater-Bi NF and its reinforced biocomposites. The stress at maximum load of reinforced biocomposites decreases for Mater$\mathrm{Bi} \mathrm{NF} /$ cotton and Mater-Bi NF/flax whereas remains almost constant for Mater-Bi NF/kenaf and Mater-Bi NF/flax and increases for the Mater-Bi NF/jute if we compare with pure MaterBi NF.

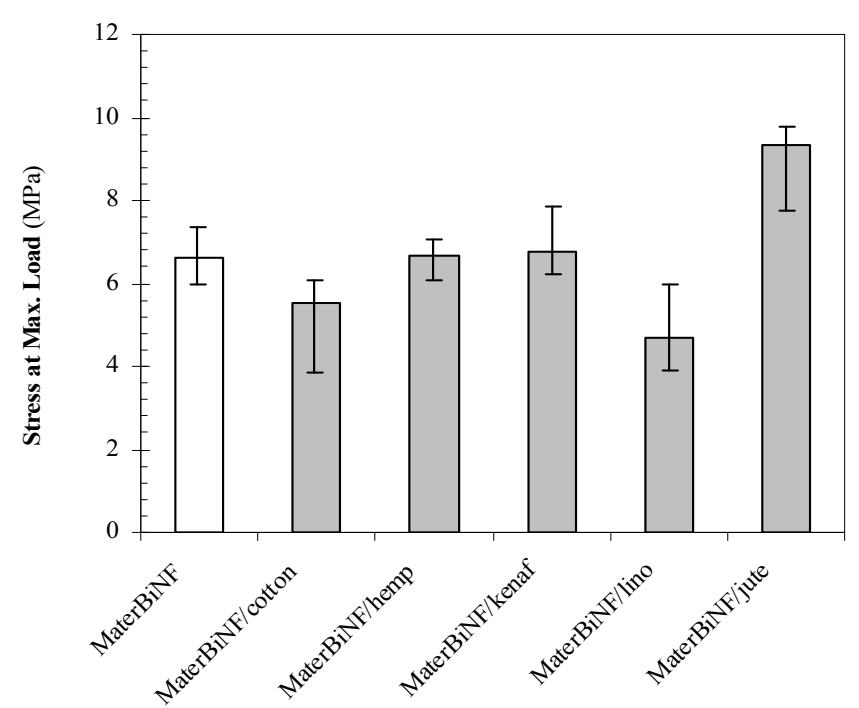

Figure 5. Stress at maximum load of pure Mater-Bi NF and its reinforced biocomposite

Figure 6 displays the strain at break of reinforced biocomposites and pure Mater-Bi NF.

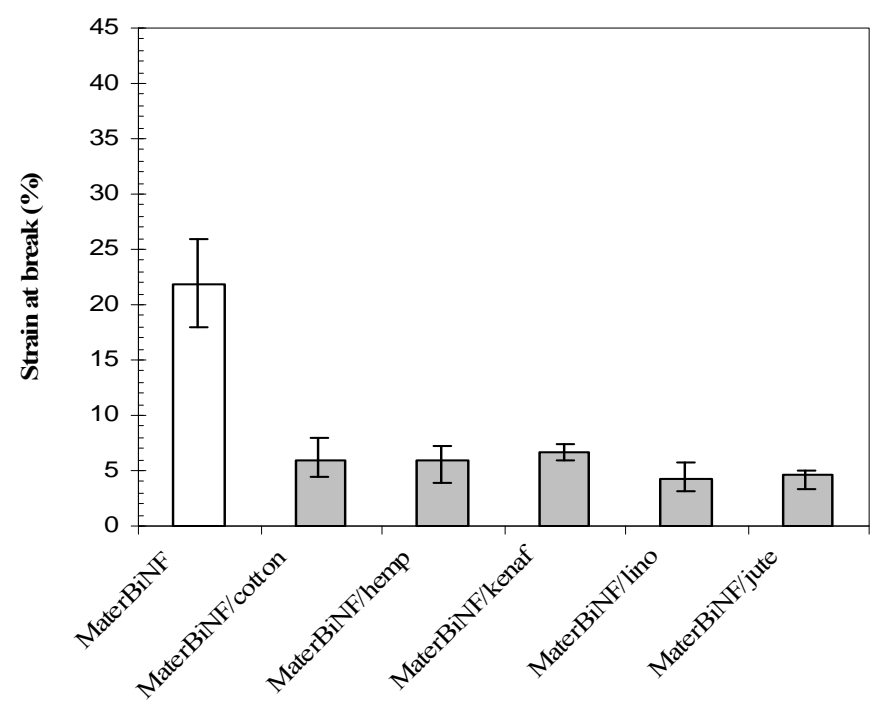

Figure 6. Strain at break of pure Mater-Bi NF and its reinforced biocomposite

The strain at break was reduced from $22 \%$ to about $5 \%$ for all the reinforced biocomposites. 
The higher modulus values of all the reinforced biocomposites confirm the reinforcing effect of the natural fibres, enhancing the stiffness of pure Mater-Bi NF. The lowest values of the stress at maximum load for the Mater-Bi NF/cotton and Mater-Bi NF/hemp suggests higher fragility of these materials that pure Mater-Bi NF. However, the mechanical results of MaterBi NF/jute, Mater-Bi NF/hemp and Mater-Bi NF/kenaf indicates a better mechanical behaviour (stiffness and resistivity) under stress conditions than pure Mater-Bi NF.

\section{Calorimetric measurements}

The calorimetric behaviour of pure Mater-Bi NF, reinforced Mater-Bi NF composites and natural fibres were assessed to determine the influence of each natural fibre on the calorimetric transition of pure Mater-Bi NF. Figure 8 shows the calorimetric thermograms from the cooling and second heating scans for pure Mater-Bi NF, and its reinforced biocomposites.
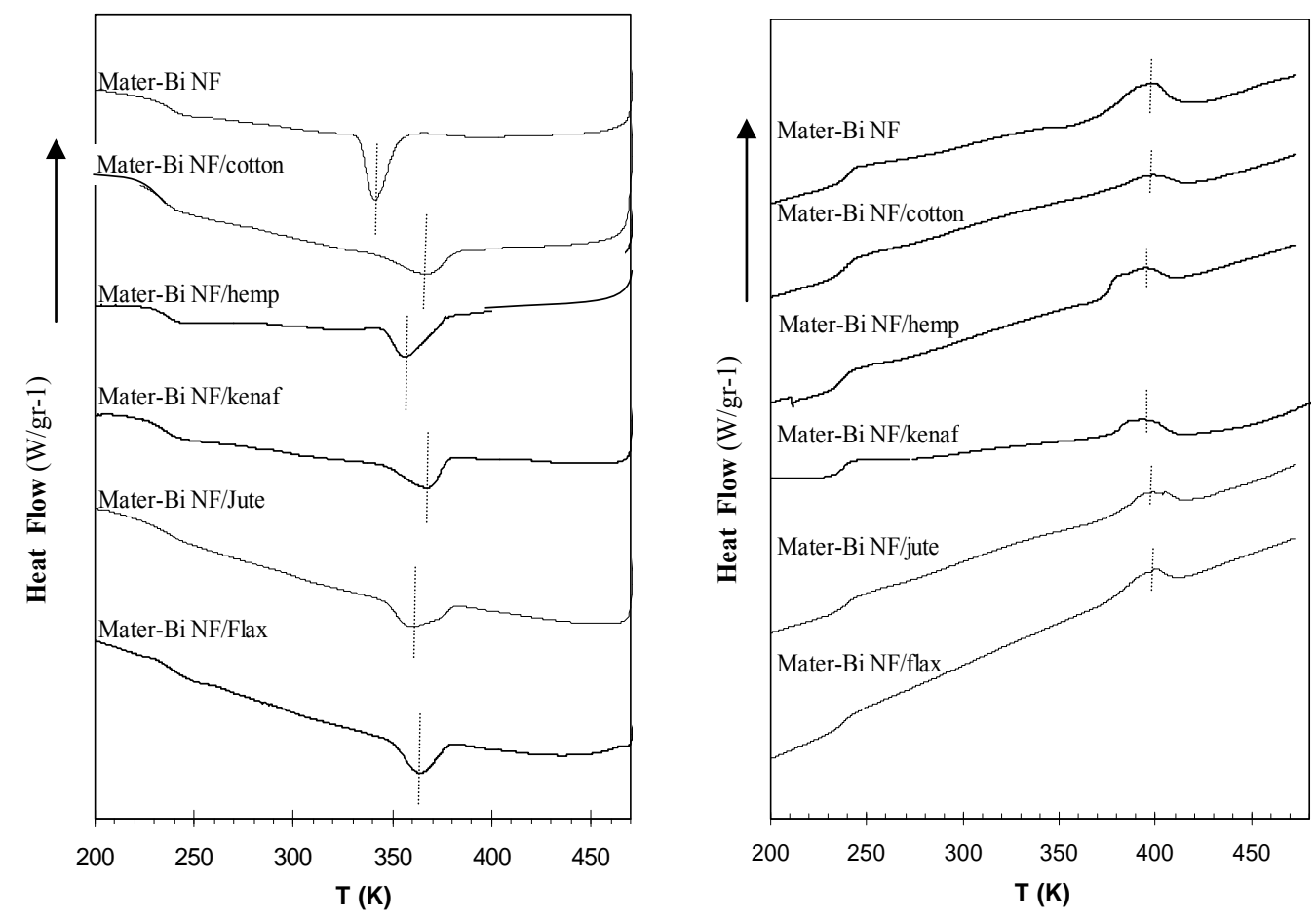

Figure 8. Calorimetric thermograms from the a) second and b) third temperature scan of the pure Mater-Bi $N F$, and its reinforced biocomposites

The pure Mater-Bi NF thermogram corresponding to the heating scan displays a main endothermic peak around $394 \mathrm{~K}$ and a clear glass transition around 240K. Moreover, the cooling scan presents a main exothermic peak at $341 \mathrm{~K}$ and again a clear glass transition 
around 237K. Bastioli et al.[13] indicated the almost disruption of the crystalline order of the starch chains during the Mater-Bi manufacture. Thus, the endothermic and exothermic peaks (at $394 \mathrm{~K}$ and $341 \mathrm{~K}$ respectively) are related to the crystallisation and the melting of the crystalline phase of the synthetic biodegradable polymer component of pure Mater-Bi NF.

The calorimetric behaviour of all natural fibres were also evaluated; displaying a main endothermic shoulder around $373 \mathrm{~K}$ related to the absorbed water in the first heating scan and a small thermal transition between $398 \mathrm{~K}$ y $473 \mathrm{~K}$ in the re-heating scan, that could be related to reorganizations of the cellulose chains.

Comparing the pure Mater-Bi NF with the reinforced biocomposites, the most significant changes can be observed on the cooling scan. The crystallisation temperature peak of the synthetic biodegradable component is higher and broader in the reinforced biocomposites than in the pure Mater-Bi NF (Table 4).

Table 4. Calorimetric parameters from pure Mater-Bi NF and its reinforced biocomposites

\begin{tabular}{|c|c|c|c|c|c|c|}
\hline & \multicolumn{3}{|c|}{ Second Heating Scan } & \multicolumn{3}{|c|}{ Cooling Scan } \\
\hline & $\begin{array}{l}\mathbf{T g} \\
(\mathrm{K}) \\
\end{array}$ & $\begin{array}{l}\mathbf{T m} \\
(\mathrm{K})\end{array}$ & $\begin{array}{c}\Delta \mathbf{H m} \\
(\mathrm{J} / \mathrm{g})\end{array}$ & $\begin{array}{l}\mathbf{T g} \\
(\mathrm{K}) \\
\end{array}$ & $\begin{array}{l}\text { Te } \\
(\mathrm{K}) \\
\end{array}$ & $\begin{array}{r}\Delta \mathbf{H c} \\
(\mathrm{J} / \mathrm{g})\end{array}$ \\
\hline Mater-Bi NF & $239,7 \pm 0,2$ & $394,5 \pm 2,0$ & $11,0 \pm 1,0$ & $236,7 \pm 1,2$ & $341,3 \pm 0,7$ & $13,5 \pm 0,7$ \\
\hline Mater-Bi NF/cotton & $238,4 \pm 0,2$ & $389,0 \pm 1,5$ & $14,6 \pm 0,5$ & $234,9 \pm 0,5$ & $365,1 \pm 0,5$ & $16,8 \pm 0,6$ \\
\hline Mater-Bi NF/flax & $238,0 \pm 0,1$ & $396,0 \pm 0,6$ & $14,9 \pm 0,5$ & $235,4 \pm 1,0$ & $363,5 \pm 0,2$ & $16,6 \pm 1,0$ \\
\hline Mater-Bi NF/hemp & $237,3 \pm 0,5$ & $392,0 \pm 2,0$ & $13,8 \pm 1,1$ & $235,3 \pm 1,0$ & $356,0 \pm 0,6$ & $16,8 \pm 0,3$ \\
\hline Mater-Bi NF/kenaf & $236,8 \pm 1,0$ & $393,1 \pm 1,5$ & $14,7 \pm 1,0$ & $235,6 \pm 1,0$ & $368,0 \pm 0,9$ & $15,7 \pm 1,2$ \\
\hline Mater-Bi NF/jute & $238,9 \pm 0,3$ & $394,6 \pm 0,5$ & $13,6 \pm 0,5$ & $235,3 \pm 0,9$ & $359,0 \pm 0,5$ & $16,6 \pm 0,6$ \\
\hline
\end{tabular}

The interactions between natural fibres and the pure Mater-Bi NF enhance the crystallisation process in more than $20 \mathrm{~K}$ and produce a more heterogeneous population of crystallites. Moreover, a slightly increase in the enthalpies values may indicate a major crystalline index in the reinforced biocomposites. 


\section{Scanning Electronic Microscopy}

SEM was used to examine the microstructure and the interfacial adhesion of pure Mater-Bi NF and its reinforced biocomposites. Figure 9 shows SEM micrograph of the fractured surface of reinforced biocomposites. The image shows very little fibre pull out and fibre cell wall splitting. It is also observed that some matrix material adheres to the surface of fibres indicating a good bond and interfacial adhesion between the matrix and the fibre.
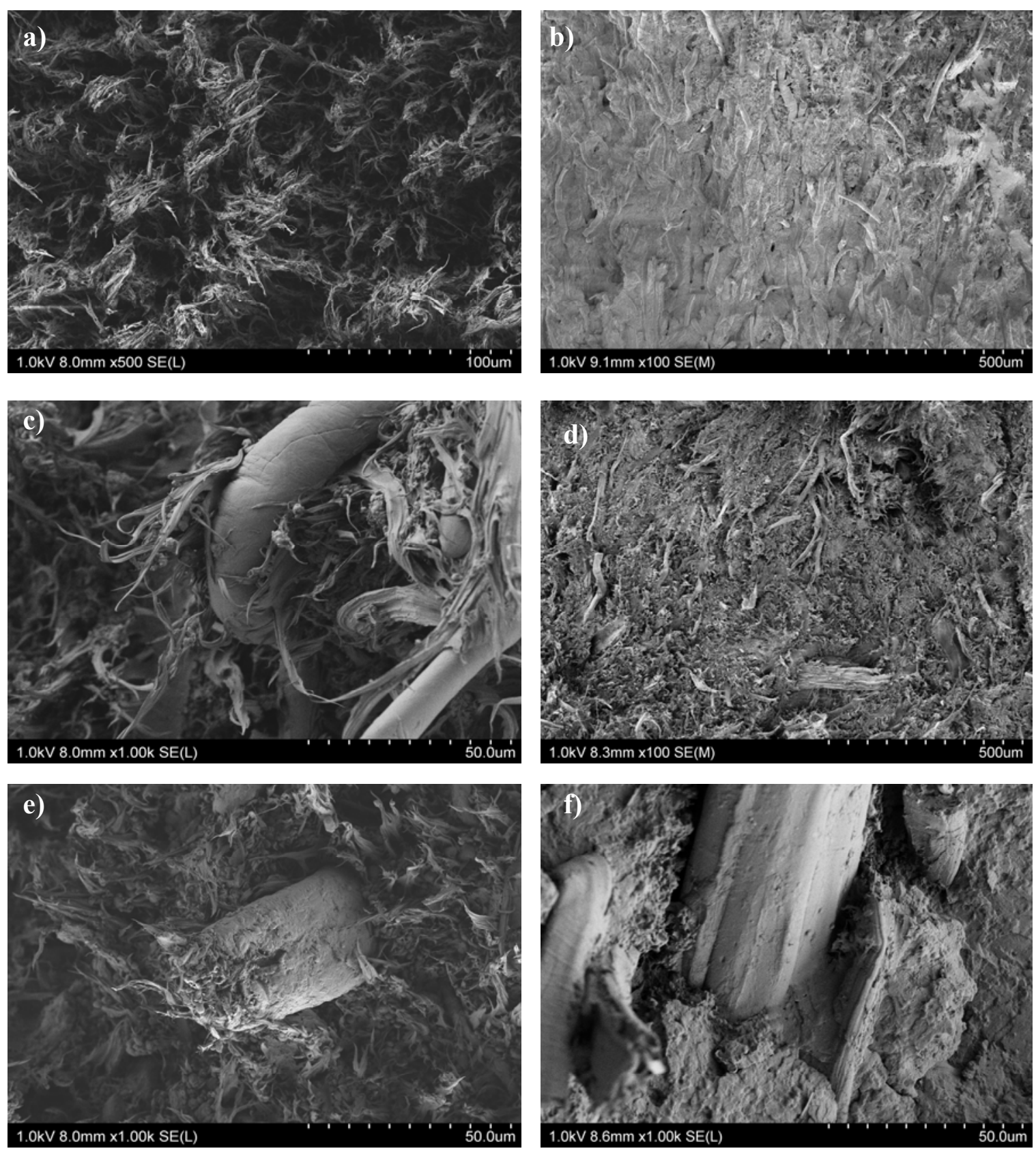

Figure 9. SEM micrographs of a)Mater-Bi NF, b)Mater-Bi NF/jute, c)Mater-Bi NF/flax, d)Mater-Bi NF/hemp e)Mater-Bi NF/kenaf and f)Mater-Bi NF/cotton 


\section{Conclusions}

According to the information above, depending on the composition of cellulose, each fibre could be useful to improve some wanted properties in composites such as mechanical and thermal properties. The most enhanced thermostabilising properties can be found with the addition of kenaf and jute fibres. At the same time, the reinforced Mater-Bi NF/jute shows the best mechanical properties in terms of young modulus and stress at load among all the reinforced biocomposites.

\section{References}

1. Griffin GJL, editor. Chemistry and Technology of Biodegradable Polymers. Glasgow: Blackie Academic Professional, 1994.

2. Mano JF, Koniarova D, Reis RL. J Mater Sci 2003; 14: 127.

3. Turker N, Mark J. editors. Low Environmental Impact Polymers. Shrewsbury: Rapra Technology, 2004.

4. Alvarez VA, Vázquez A. Polym Degrad Stab 2004; 84: 13

5. Evans RJ, Milne TA. Energy Fuels 1987; 1: 123.

6. Moriana R, Vilaplana F, Karlsson S, Ribes-Greus A. Composites A: Science and Manufacturing 2010; (pending of publication)

7. Moriana R, Badia J.D., Santonja-Blasco L, Ribes-Greus A. J Appli Polym Sci 2010; (pending of publication).

8. Friedman KH. J Appl Polym Sci 1964; 6: 183.

9. Ozawa T. Bull Chem Soc Jpn 1965; 38: 1881.

10. Kissinger HE. J Res Natl Bur Stand 1956; 57: 217.

11. Criado JM. Thermochimic Acta 1978; 24:86.

12. Coats AW, Redfern JP. Nature (Lond) 1964; 201: 68.

13. Bastioli C, editor. Handbook of Biodegradable Polymers. Shrewsbury: Rapra Technology, 2005. Taylor \& Francis, 2005 


\subsection{RESUMEN DE RESULTADOS}

A partir de la metodología de análisis propuesta se consigue caracterizar tanto a las matrices poliméricas como a sus biocomposites enfibrados, de este modo se evalúa la influencia de cada una de las fibras naturales sobres las propiedades mecánicas, térmicas y morfológicas de las matrices poliméricas.

En primer lugar, el Ensayo Mecánico de Tensión permite estudiar las propiedades de tracción de las matrices poliméricas (módulo de Young, resistencia y deformación a rotura):

- El Mater-Bi KE presenta un módulo de Young mayor y una deformación a rotura menor que el Mater-Bi NF.

- El Mater-Bi NF presenta una resistencia a tracción mayor que el Mater-Bi KE.

Comparando las propiedades mecánicas de las matrices poliméricas con las de sus biocomposites resultantes se observa:

- Un aumento del módulo de Young en todos los biocomposites enfibrados. Además se observa una desviación positiva del módulo de Young cuando se comparan los resultados obtenidos con los que se obtendría si se aplicara una ley de composición para mezclas ideales, lo cual es un indicio de las interacciones que se producen entre las fibras naturales y la matriz al preparar el biocomposite.

- Variaciones en la resistencia a tracción dependen de la fibra natural adicionada.

- Una disminución de la deformación a rotura de más de un $50 \%$ en todos los composites.

La evaluación de la influencia de cada una de las fibras naturales sobre las propiedades mecánicas de las matrices poliméricas se ha realizado teniendo en cuenta la composición química de cada una de ellas. Así se ha observado que, el valor del módulo de Young de cada una de las fibras naturales no muestra una relación directa con la composición química porque como se puede suponer depende de otros factores morfológicos y estructurales. Sin embargo, se establecen algunas generalidades: 
- El aumento que proporcionan las fibras naturales en el módulo de Young de las matrices poliméricas sigue la misma tendencia independientemente de la matriz considerada: el composite de yute muestra el valor del módulo más alto seguido por el composite de algodón, el de cáñamo, kenaf y lino.

- Las variaciones en la resistencia a tracción de los biocomposites también dependen únicamente de las fibras naturales adicionadas. En ambas series, los composites de kenaf y cáñamo muestran una resistencia a tracción similar a la de sus matrices poliméricas. En cambio, los composites de lino y algodón presentan una resistencia menor, y los composites de yute una resistencia a tracción mayor.

La caracterización mecánica de los biocomposites del Mater-Bi KE se ha ampliado mediante el estudio de su comportamiento viscoelástico y termo-mecánico. El espectro mecánico del Mater-Bi KE muestra dos zonas complejas de relajación ( $\alpha$ y $\beta$ ), la primera asociada con los movimientos precursores de la fusión del material sintético del Mater-Bi KE y las segunda relativa a los movimientos cooperativos de varios procesos: movimientos intermoleculares asociadas a la transición vítrea del material sintético del Mater-Bi KE y una relajación secundaria y primaria del almidón termoplastificado. Ambas zonas de relajación son complejas y se dividen a su vez en varías subrelajaciones. La relajación $\alpha$ se divide en dos subrelajaciones $\alpha_{\text {I }}$ y $\alpha_{\text {II }}$, de éstas se obtienen las energías de activación asociadas a los movimientos percusores de la fusión. La relajación $\beta$ se dividen en tres subrelajación, y de éstas la $\beta_{\text {III }}$ se asocia con los movimientos intermoleculares de la transición vítrea del material sintético, identificándose el parámetro relativo al volumen libre y el coeficiente de expansión térmica o dilatación.

Los cambios en las propiedades viscoelásticas que muestran los biocomposites enfibrados con respecto a la matriz polimérica, se enumeran a continuación:

- Aumenta el módulo de almacenamiento, indicando una mejora en las propiedades mecánicas. Siendo el Mater-Bi KE/yute el biocomposite que presenta un mayor incremento, seguido por el Mater-Bi KE/algodón, Mater-Bi KE/cañamo, Mater-Bi $\mathrm{KE} /$ kenaf y Mater-Bi KE/lino.

- Aumenta la $E a$ asociada con la relajación $\alpha_{\text {II }}$ en todos los biocomposites, indicando una mayor dificultad ante los movimientos intramoleculares de las cadenas del material. 
- Disminuye el coeficiente de expansión térmica, indicando una reducción del volumen libre del material debido a las interacciones entre las fibras y la matriz polimérica.

Al evaluar la influencia de la composición química de cada fibra natural sobre las propiedades viscoelásticas del Mater-Bi KE, se observa que:

- La $E a$ asociada con los movimientos percusores de la fusión del material aumenta a medida que disminuye el contenido en celulosa y aumenta el contenido de lignina y hemicelulosa/pectina (Figura 1). Estos resultados indican una mayor dificultad de los movimientos precursores de la fusión del componente sintético en función del aumento de la hemicelulosa/pectina y lignina, tal vez debido a mejores interacciones entre las fibras con mayor contenido de hemicelulosa/pectina y lignina en su composición.

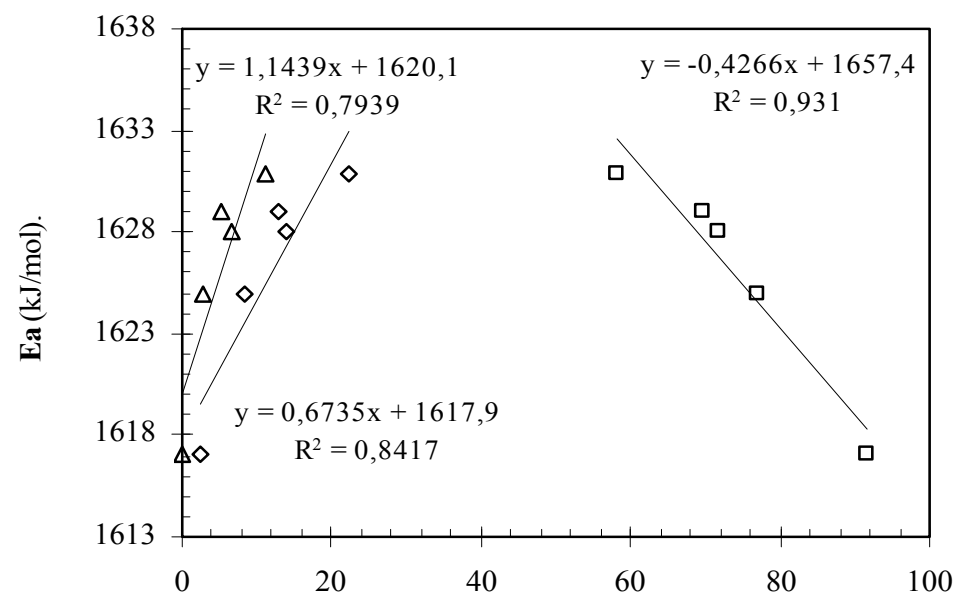

$(\%)$

Figura 1. Variación de la Ea asociada con los movimientos percusores de la fusión de los biocomposites de Mater-Bi KE en función del porcentaje de $\diamond)$ hemicelulosa/pectina,

4) lignina $y$ () celulosa de las fibras naturales

En segundo lugar, los Ensayos Calorimétricos permiten identificar y caracterizar las transiciones térmicas de las matrices poliméricas, así como obtener información relativa a su morfología. El Mater-Bi KE presenta una temperatura de fusión y de cristalización menor que el Mater-Bi NF. En cambio, las entalpías de fusión y cristalización del Mater-Bi KE son mayores que las del Mater-Bi NF. 
Al caracterizar los biocomposites enfibrados el efecto más significativo que se observa en las transiciones térmicas de las matrices poliméricas es un aumento en la temperatura de cristalización debido a las interacciones entre las fibras y la matriz.

Posteriormente, el Análisis Termogravimétrico describe la descomposición térmica del Mater-Bi KE y del Mater-Bi NF como un proceso complejo, con dos regiones principales de descomposición, la primera asociada a la descomposición térmica del almidón y la segunda a la descomposición del material sintético. Las principales diferencias térmicas obtenidas entre una matriz polimérica y otra, se resumen a continuación:

- El Mater-Bi KE presenta alrededor de un 10\% más de almidón en su composición que el Mater-Bi NF.

- El Mater-Bi KE presenta un valor de descomposición inicial del almidón, 30K mayor que el Mater-Bi NF, por tanto es la matriz polimérica más estable desde el punto de vista térmico.

- El modelo cinético que describe la descomposición de ambos procesos para ambos materiales, es del tipo $f(\alpha)=(1-\alpha)^{\mathrm{n}} \cdot \alpha^{\mathrm{m}}$.

La adición de las fibras naturales en las matrices poliméricas influye en las propiedades térmicas de las matrices poliméricas del siguiente modo:

- Aumenta la estabilidad térmica del Mater-Bi KE y del Mater-Bi NF.

- Aumenta la Ea del primer proceso de descomposición en ambas matrices poliméricas.

- Aumenta la Ea del segundo proceso de descomposición del Mater-Bi KE y disminuye la $E a$ del segundo proceso de descomposición del Mater-Bi NF.

- No modifica el modelo cinético que describe el mecanismo de descomposición, pero si que varían los coeficientes $n$ y $m$, más significativamente para el primer proceso de descomposición. 
La evaluación de la influencia de cada una de las fibras naturales sobre las propiedades térmicas de las matrices poliméricas se ha realizado teniendo en cuenta la composición química de cada una de ellas y se concluye que:

- La estabilidad térmica del primer proceso de descomposición aumenta en función del contenido de lignina y hemicelulosa/pectina y disminuye en función del contenido de celulosa para ambas matrices termoplásticas (Figura 2). De este modo, se confirma que los biocomposites con más hemicelulosa/pectina y lignina en su composición poseen mejores interacciones fibra /matriz.
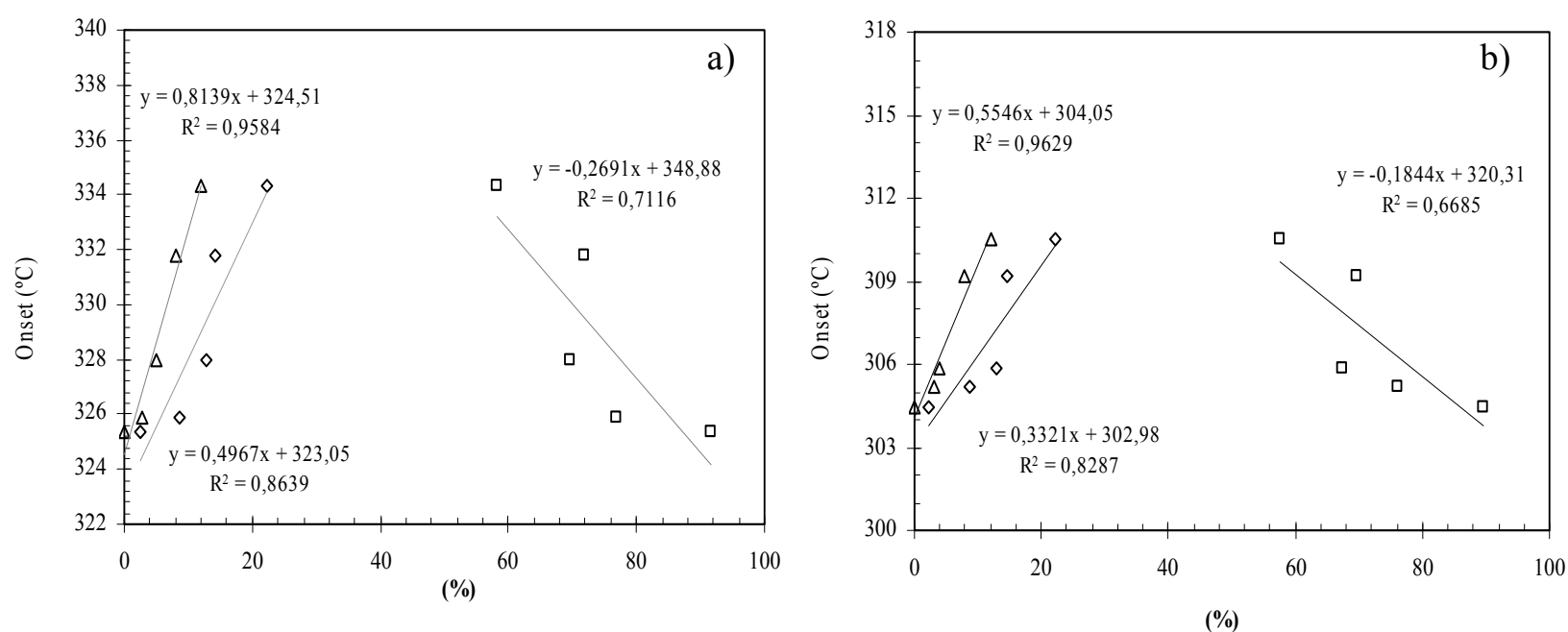

Figura 2. Representación de los valores de onset del primer proceso de descomposición del a) MaterBi KE y del b) Mater-Bi NF en función del porcentaje de ( $\square)$ celulosa, ( () hemicelulosa/pectina y ( $\triangle$ ) lignina de las fibras naturales

- Los biocomposites que poseen un mayor porcentaje de hemicelulosa/pectina en su composición (composites de kenaf, yute y cáñamo), son los que ofrecen un incremento más significativo de la $E a$ del primer proceso de descomposición en ambas matrices poliméricas.

- La Ea asociada con la descomposición del material sintético, aumenta proporcionalmente al contenido de celulosa, e inversamente proporcional al contenido de hemicelulosa/pectina y lignina para ambas series (Figure 3). Se demuestra así, que los materiales con mayor contenido de hemicelulosa/pectina y lignina presentan un valor menor en la energía de activación del proceso de descomposición del material sintético. 

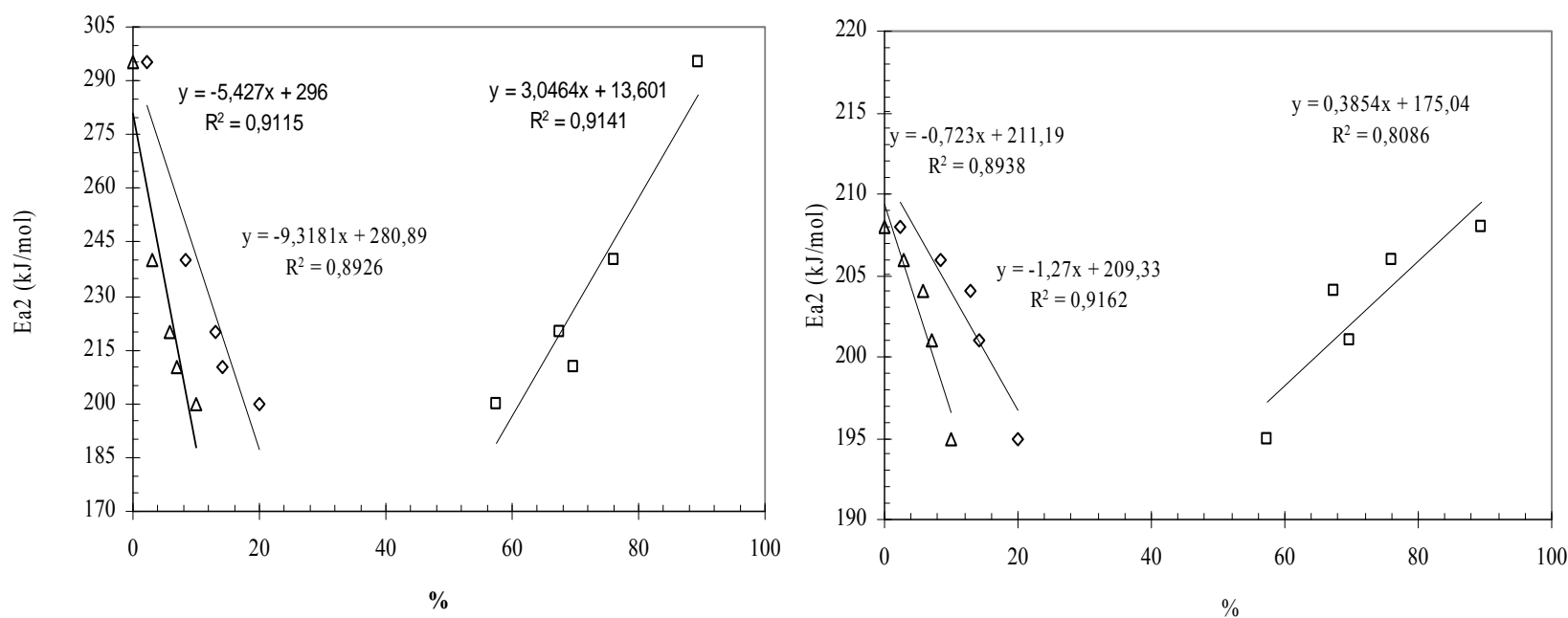

Figure 3. Representación de los valores de Ea del proceso de descomposición del componente sintético del a) Mater-Bi KE y del b) Mater-Bi NF en función del porcentaje de () celulosa, ( () hemicelulosa/pectina y ( $\bullet$ ) lignina de las fibras naturales

Finalmente, del Análisis Microscópico de la superficie de la sección de fractura de los biocomposites reforzados se observa una distribución homogénea de las fibras naturales y una buena adhesion entre las fibras y las matrices poliméricas. 
Estudio del proceso de absorción de agua

5.1 Introducción

5.2 Resultados y discusión 



\subsection{INTRODUCCIÓN}

Pese a las numerosas ventajas que poseen las fibras naturales como sistema de refuerzo en comparación con las fibras sintéticas, cabe destacar un inconveniente principal, las fibras naturales son altamente hidrófilas. La presencia de grupos hidroxilos y grupos con oxígeno presentes en su formulación atraen a las moléculas de agua estableciéndose puentes de hidrogeno [1]. El estudio de la absorción de agua en los composites reforzados con fibras naturales, la evaluación de los mecanismos de absorción y de los niveles de saturación máxima son factores fundamentales a tener en cuenta para el diseño de los composites y la determinación de su ciclo de vida. Los composites de fibras naturales sometidos a atmósferas de alta humedad a menudo absorben agua afectando negativamente a las propiedades mecánicas, térmicas, dieléctricas y de barrera. Por otra parte, la hidrólisis del almidón es el primer paso hacia el proceso de biodegradación de las matrices compuestas de almidón termoplástico.

Así, el objetivo principal de este capitulo es estudiar el mecanismo de absorción de agua sobre las dos series de biocomposites enfibrados con las distintas fibras naturales estudiadas en los capítulos anteriores.

Esquemáticamente, los objetivos específicos que se pretenden determinar son:

1. Optimizar la metodología de análisis para el estudio de la absorción del agua en biocomposites enfibrados con fibras naturales. Determinar el tiempo de saturación, el contenido máximo de humedad, el modelo de absorción que describe el mecanismo de absorción, el coeficiente de difusión y la energía de activación del proceso de absorción del material.

2. Determinar el mecanismo de absorción del agua en las matrices poliméricas puras, Mater Bi KE y Mater Bi NF.

3. Determinar el mecanismo de absorción del agua en los biocomposites reforzados con fibras naturales.

4. Establecer la influencia de cada fibra natural en los mecanismos de absorción de cada matriz polimérica. 
5. Evaluar la influencia de la absorción de agua sobre las propiedades térmicas de las matrices poliméricas y los biocomposites.

La metodología de análisis propuesta para el estudio de la absorción de agua se basa en la normativa ASTM D 570-98. Las muestras se someten a un proceso de absorción en agua a tres temperaturas diferentes. El contenido en agua se calcula por pesada gravimétrica a determinados tiempos de inmersión, obteniéndose tres curvas diferentes para cada temperatura de ensayo. De estas curvas se obtiene el contenido en agua máximo que absorben los materiales hasta llegar a su saturación $\left(M_{S}\right)$ y el tiempo que tarda el material en alcanzar este equilibrio $\left(t_{s}\right)$. A continuación se realizará un estudio del comportamiento de difusión de los materiales. Para ello, se calcularán los coeficientes $n$ y $K$, los cuales permiten identificar el modelo de difusión seguido por cada material. Finalmente, las matrices poliméricas y los biocomposites reforzados saturados se caracterizan por termogravimetria (TGA).

El análisis de los resultados experimentales obtenidos a partir de esta caracterización y la sistematización de las conclusiones han dado lugar a la siguiente contribución.

\section{$\checkmark$ Moisture Absorption Study of Reinforced Biocomposites}

Las dos matrices poliméricas que constituyen las dos series de biocomposites (MaterBi KE03B1 y Mater-Bi NF01U) y sus respectivos biocomposites (formados al reforzar con las fibras de algodón, cáñamo, kenaf, lino y yute) han sido sometidos a distintos procesos de absorción en agua a diferentes temperaturas $\left(29^{\circ} \mathrm{C}, 35^{\circ} \mathrm{C}\right.$ y $\left.42^{\circ} \mathrm{C}\right)$. El Mater-Bi NF presenta una mayor capacidad de absorción de agua y un tiempo de saturación menor que el Mater-Bi KE. Las fibras naturales influyen de manera análoga en ambas matrices poliméricas, aumentando la capacidad de absorción y reduciendo el tiempo de saturación. El tiempo de saturación disminuye en función del contenido en celulosa. Mientras que la capacidad de absorción hasta saturación aumenta en función del contenido de hemicelulosa, que es el componente más hidrofílico de las fibras naturales. 
El proceso de absorción de agua para ambas matrices poliméricas y para sus biocomposites sigue el modelo de Fick. A partir de este modelo se obtiene el coeficiente de difusión de cada material. Los biocomposites muestran valores de coeficientes de difusión menores que las matrices poliméricas puras correspondientes, indicando una mayor dificultad de difusión de las moléculas de agua en los biocomposites. Este resultado es coherente con la disminución del coeficiente de dilatación y consecuentemente del volumen libre de las moléculas a temperaturas cercanas a la $\mathrm{Tg}$, valores que se han calculado anteriormente a partir de las relajaciones mecánicas.

La dependencia del coeficiente de difusión con la temperatura se estudia mediante la teoría de Arrhenius y se obtienen las energías de activación del proceso de absorción de cada material. En general, las energías de activación de los biocomposites son más altas que las de las matrices poliméricas, indicando de este modo una mayor dificultad en la difusión debido a las interacciones matriz/fibra. Las diferencias entre los biocomposites de Mater-Bi KE son más significativas que las diferencias entre los biocomposites de Mater-Bi NF, tal vez debido a la alta hidrofilidad del Mater-Bi NF con respecto al Mater-Bi KE. Los biocomposites de Mater-Bi KE/kenaf y Mater-Bi KE/jute muestran los valores más elevados de energía de activación, tal vez debido a interacciones más fuertes entre estas fibras y la matriz polimérica, como se indicaba en el capitulo anterior .

Finalmente, mediante la caracterización térmica de las muestras hinchadas se ha medido la estabilidad térmica tanto de las matrices poliméricas como de los biocomposites reforzados durante el proceso de absorción de agua, estos resultados se podrán comparar con los obtenidos durante la degradación en tierra y servirán para interpretar la influencia del proceso de hidrólisis como percusor del proceso de biodegradación en tierra donde probablemente se combinen sinergéticamente.

\footnotetext{
1. Rowel RM, Banks WB, Gen Tech Rep FPL-GTR-50; USDA Forest Service, Forest Products Loratory, Madison, WI, 1985, p.24.
} 



\subsection{RESULTADOS Y DISCUSIÓN}

"MOISTURE ABSORPTION STUDY OF REINFORCED BIOCOMPOSITES" 

"MOISTURE ABSORPTION STUDY OF REINFORCED BIOCOMPOSITES"

\begin{abstract}
The poor resistance towards water absorption is one of the drawbacks of naturalfibre reinforced biocomposites. Cotton, flax, hemp, kenaf and jute fibres were employed as reinforcement of two different commercial biopolymers from renewable resources (Mater-Bi KE03B1 and Mater-Bi NF01U) to design two different sets of "green composites". The moisture absorption was studied by immersion in water at three different temperatures 29,35 , and $42^{\circ} \mathrm{C}$. Mater-Bi NF01U and its reinforced biocomposites display more water absorption capacity and shorter saturation times than Mater-Bi KE03B1 and its reinforced biocomposites. In general, presence of natural fibres in the reinforced biocomposites is responsible for higher saturation capacity and lower saturation time. The saturation capacity increases as a function of the hemicellulose content, whereas the saturation time increases as a function of the cellulose content. The water absorption process of both polymeric matrices and the corresponding reinforced biocomposites was found to follow the kinetics and mechanisms described by Fick's theory. In addition, the diffusivity coefficient values are greater for the polymeric matrices than for the reinforced, indicating a major difficulty to water uptake due to the interactions between the polymeric matrix and the natural fibres. The diffusivity coefficient showed Arrhenius dependence with the temperature for both sets of samples, and the activation energy of the absorption process was obtained for each material. The activation energy of all the reinforced biocomposites are higher than the corresponding pure polymeric matrix, indicating that water uptake is hindered by strong interfacial interactions between matrix and fibres. Mater-Bi KE/jute and Mater-Bi KE/kenaf biocomposites display the highest activation energy values, evidencing their strongest interactions between these fibres and the polymeric matrix. The thermal changes were monitored by thermogravimetic studies of the samples before and after exposure to water. The effect of water on the kinetics of thermodecomposition of all the studied reinforced biocomposites was assessed and the thermal stability of all the studied materials is assured in humidity ambient.
\end{abstract}

Keywords: Saturation Parameters, Fick's theory, diffusivity coefficient, Arrherius law, Green composites, TGA 


\section{Experimental Procedure}

\section{Materials and Sample preparation}

Commercial grade Mater-Bi NF01U® (Mater-Bi NF) and Mater-Bi KE03B1@ (Mater-Bi KE), supplied by Novamont Novara S.P.A (Italy) was used as biodegradable matrices to prepare the reinforced biocomposites. Cotton, flax, hemp, kenaf and jute fibres were employed as reinforcement, provided by Yute S.L. (Spain). The average length and fibre diameter were determined by optical microscopy over 100 fibres. The mechanical properties were provided by the manufacturer. The chemical composition (lignin, cellulose and hemicellulose content) were analysed by Klason method according to Theander et al.[1] and a deviation minor of $1 \%$ was obtained for all the values. The representative parameters for physical, mechanical and chemical properties are summarized in Table 1.

Table 1. Average length, fibre diameter and chemical composition of cotton, flax, hemp, kenaf and jute fibres.

\begin{tabular}{c|ccccc|ccc}
\hline Fibres & $\begin{array}{c}\text { Hemicellulose } \\
(\%)\end{array}$ & $\begin{array}{c}\text { Cellulose } \\
(\%)\end{array}$ & $\begin{array}{c}\text { Lignin } \\
(\%)\end{array}$ & $\begin{array}{c}\text { Ash } \\
(\%)\end{array}$ & $\begin{array}{c}\text { Humidity } \\
(\%)\end{array}$ & $\begin{array}{c}\text { Average } \\
\text { lengh } \\
(\mathrm{mm})\end{array}$ & $\begin{array}{c}\text { Average } \\
\text { diameter } \\
(\mathrm{mm})\end{array}$ & $\begin{array}{c}\text { E- } \\
\text { Modulus } \\
(\mathrm{GPa})\end{array}$ \\
\hline Cotton & 2,4 & 90,5 & -- & 2,0 & 4,0 & $3,0 \pm 1,0$ & $(1,8 \pm 1,2) \cdot 10^{-2}$ & $12,0 \pm 1,0$ \\
Flax & 8,5 & 77,0 & 2,8 & 7,0 & 4,5 & $6,0 \pm 3,0$ & $(1,0 \pm 0,5) \cdot 10^{-2}$ & $60,0 \pm 1,0$ \\
Hemp & 12,9 & 69,4 & 5,4 & 5,8 & 5,1 & $1,0 \pm 0,5$ & $(7,7 \pm 7,0) \cdot 10^{-2}$ & $50,0 \pm 2,0$ \\
Kenaf & 22,3 & 58,2 & 11,2 & 1,4 & 7,0 & $10,0 \pm 5,0$ & $(15,0 \pm 0,5) \cdot 10^{-2}$ & $40,0 \pm 1,0$ \\
Jute & 14,3 & 71,8 & 6,5 & 2,5 & 5,5 & $6,5 \pm 3,5$ & $(2,0 \pm 0,9) \cdot 10^{-2}$ & $70,0 \pm 1,5$ \\
\hline
\end{tabular}

Reinforced composites with $10 \%$ natural fibre were prepared in a co-rotative twin screw extruder (Werner \& Pfleiderer ZSK 25, Germany). The processing temperature was $165^{\circ} \mathrm{C}$ for the Mater-Bi KE and its reinforced biocomposites and $145^{\circ} \mathrm{C}$ for the Mater-Bi NF and its reinforced biocomposites. Rectangular bars with dimensions 110x110x2 mm were obtained by means of compression moulding at $180^{\circ} \mathrm{C}$.

\section{Water absorption test}

Water absorption studies were performed following the ASTM D 570-98 standard [2]. The specimens were first dried in an oven at $50^{\circ} \mathrm{C}$ and cooled to room temperature in desiccators. This process was repeated until the mass of the specimens remained constant. Then, two specimens of each sample were submerged in distilled water at different temperatures, $29^{\circ} \mathrm{C}$, $35^{\circ} \mathrm{C}$ and $42^{\circ} \mathrm{C}$. The specimens were removed from the water at certain periods of time and weighted in a high precision balance. When the content of water remained invariable in the specimens, they were removed and characterisated by thermogravimetric analysis. 
The content of water was calculated by the weight difference between the samples immersed in water and dry samples, through equation 1 :

$$
M t=\frac{w_{t}-w_{0}}{w_{0}}(\%)
$$

where $M t(\%)$ is moisture uptake, $w_{0}$ are the mass of the specimen dry and $w_{t}$ are the mass at time $t$ of experiment.

The obtained absorption results were fitted following equation 2:

$$
\frac{M_{t}}{M_{\infty}}=k t^{n}
$$

where $M_{\infty}$ is the moisture uptake at the equilibrium, and $k$ and $n$ are constants. The value of coefficient $n$ shows the diffusion behaviour of materials tested. In general, diffusion behaviour of polymeric composites can be classified in three different categories ( Fickian diffusion, Case I or Super Case II and Non-Fickian diffusion) according to the relative mobility of the penetrant towards the polymer segments. For Fickian diffusion, in which the rate of diffusion is much less than that of the polymer segment mobility, n equals 0,5 ,. For Case II where the penetrant mobility is much greater than other relaxation processes, $n=1$ (and for Super Case II $n>1$ ); and finally, for Non-Fickian diffusion, $n$ shows an intermediate value $(0,5<n<1)$ where the penetrant mobility and the polymer segment relaxation are comparable.

Once the diffusion model is evaluated, the parameters of the corresponding theoretical model can be calculated. The diffusion coefficient $D$ is the most important parameter of Fick's model, as this shows ability of solvent molecules to penetrate inside the composite structure. For initial uptake times $\left(\mathrm{M}_{\mathrm{t}} / \mathrm{M}_{\infty} \leq 0,5\right)$, the following equation can be used

$$
\frac{M_{t}}{M_{\infty}}=\frac{4}{L} \cdot\left(\frac{D}{\pi}\right)^{0.5} \cdot t^{0.5}
$$

where $\mathrm{L}$ is the thickness of the sample. By equation (3), the moisture diffusion coefficient is obtained from the slope of the linear part of the plot of $\mathrm{M}_{\mathrm{t}} / \mathrm{M}_{\infty}$ vs $(\text { time })^{0,5} \cdot b^{-1}$, where $b$ represents the thickness dimensions of the sample. 
The diffusion process is activated by an increase in temperature, as may be expected for a process that involves molecular mobility. In the case of Fickian diffusion, the diffusion coefficient is supposed to follow an exponential Arrhenius-type relation with temperature as expressed by equation 4 :

$$
D=D_{0} \cdot \exp \left(-\frac{E a}{R T}\right)
$$

where $D_{0}$ is the permeability index, $E a$ is the activation energy of the diffusion process and $R$ is the universal gas constant.

\section{Thermogravimetric measurements}

The thermal decomposition of saturated pure matrices and their reinforced biocomposites were evaluated by dynamic thermogravimetric analysis (TGA) using a Mettler-Toledo TGA/SDTA 851 (Columbus, OH). Approximately 8,5 mg of sample was heated between 25 ${ }^{\circ} \mathrm{C}$ and $750^{\circ} \mathrm{C}$ at $20^{\circ} \mathrm{C} / \mathrm{min}$ under an argon atmosphere flow of $50 \mathrm{ml} / \mathrm{min}$. The values of maximum decomposition temperature, onset and mass loss were obtained.

\section{Results and Discussion}

\section{Water absorption measurements}

Figure 1 shows the percentage of water absorbed as a function of the immersion time for both polymeric matrices at different experimental temperatures $\left(29,35\right.$ and $\left.42{ }^{\circ} \mathrm{C}\right)$. The absorption curves exhibit some differences in the swelling behaviour of the two polymeric matrices under study. The curve corresponding to Mater-Bi NF displays a first absorption step (from 0 to $900 \mathrm{~min}$ ) where the weight increases linearly before reaching a maximum and a posterior abrupt decrease. This fact can be attributed to the extraction of additives and/or the solubility of the material [3]. This behaviour is not observed in the Mater-Bi KE. On the other hand, Mater-Bi NF absorbs much more water $(\Delta \omega=6-8 \%)$ than the Mater-Bi $\operatorname{KE}(\Delta \omega=0,6-0,8 \%)$. Finally, the water uptake values increase as a function of the immersion temperature as expected, with approximately a $33 \%$ increase from $29^{\circ} \mathrm{C}$ to $42^{\circ} \mathrm{C}$ for both materials. 

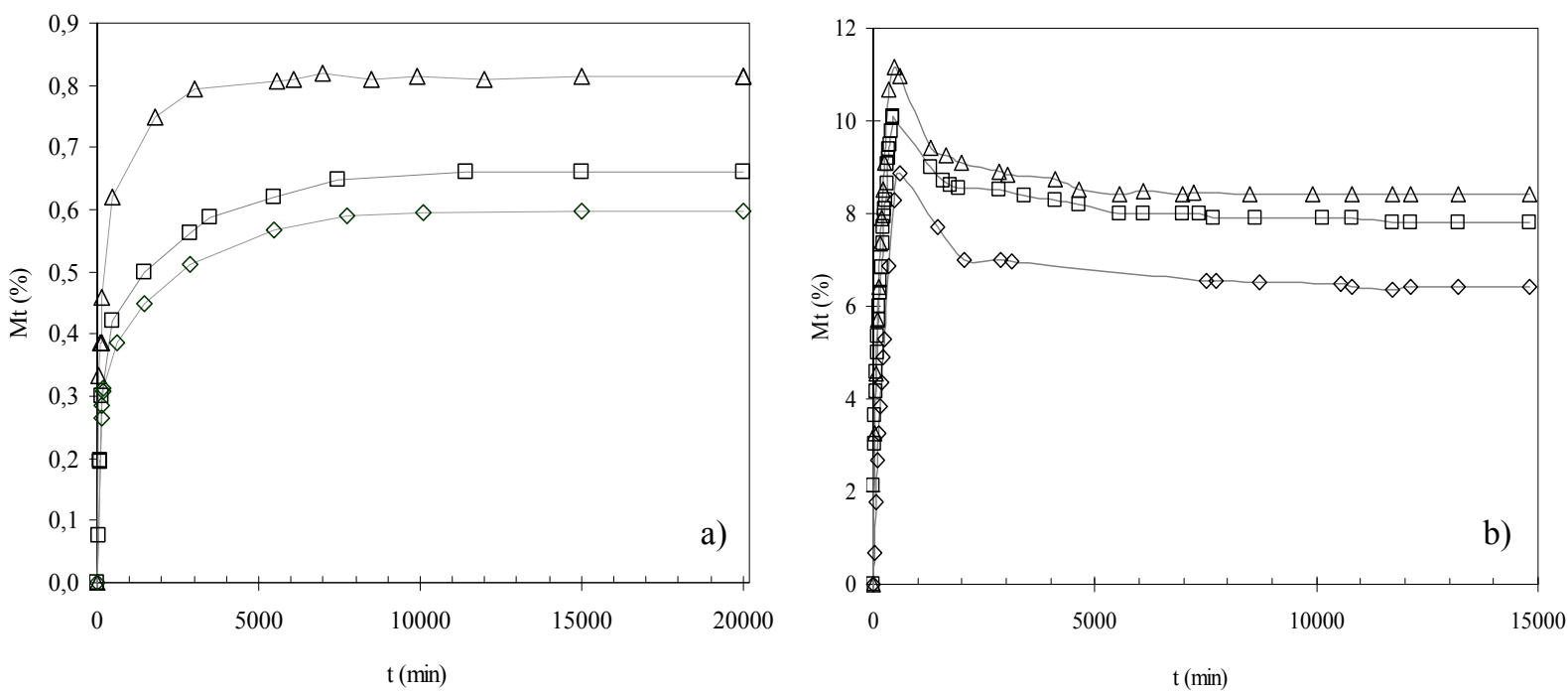

Figure 1. Absorption curves of a) Mater-Bi KE and b) Mater-Bi NF at (O) $29^{\circ} \mathrm{C}$, () $35^{\circ} \mathrm{C}$ and ( $(\Delta) 42^{\circ} \mathrm{C}$.

Figure $2 a$ ) and $2 b$ ) display the percentage of water absorbed plotted against time for all the samples at $35^{\circ} \mathrm{C}$. Similar patterns of the absorption curves are displayed for the other temperatures, but they are not showed for the sake of clarity.
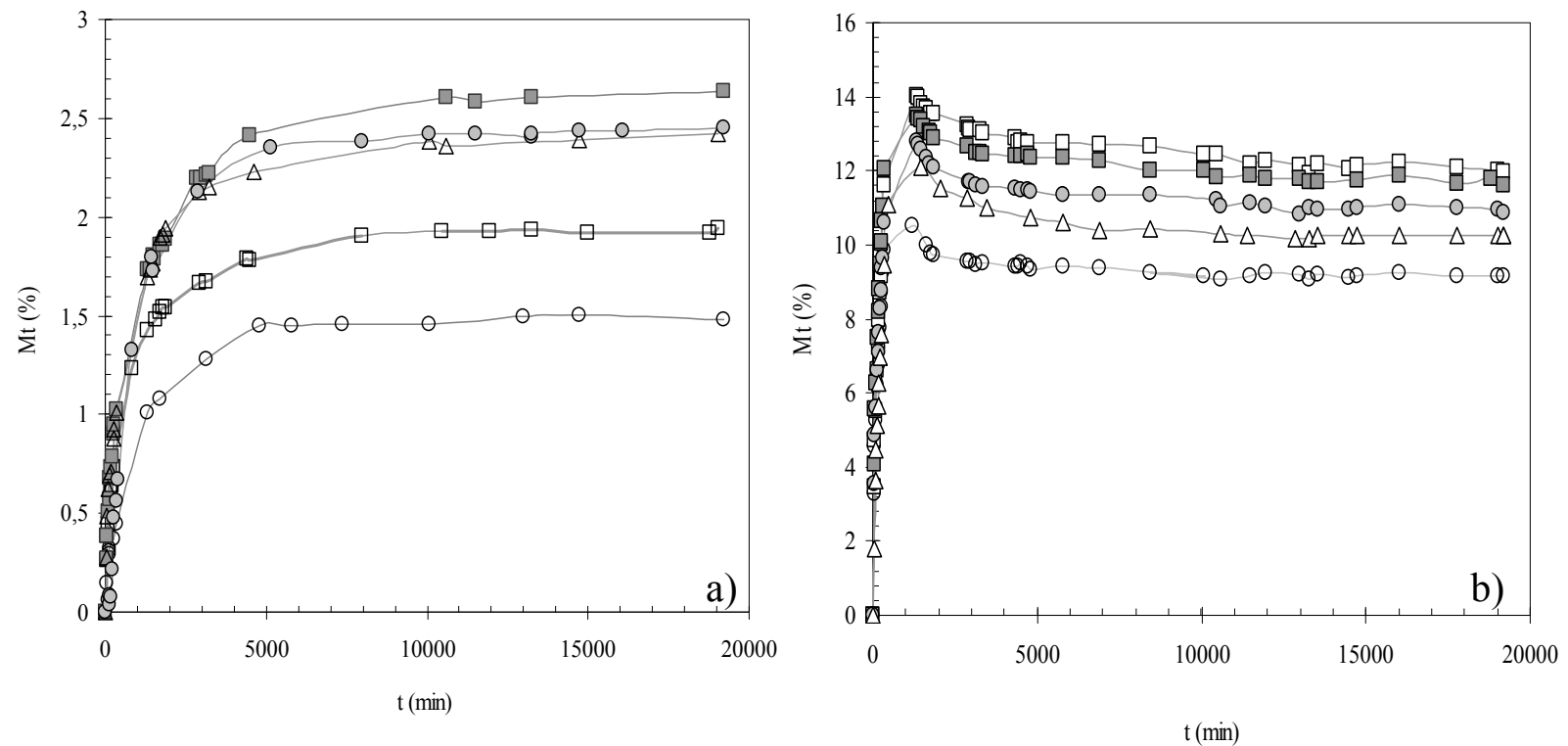

Figure 2. Absorption curves of a) Mater-Bi KE and b) Mater-Bi NF with (०) cotton, () flax, ( $($ ) hemp, (•) jute and (ロ) kenaffibres at $35^{\circ} \mathrm{C}$.

The moisture uptake at the equilibrium $(M s)$ and the saturation time $(t s)$ of each sample were evaluated from the absorption curves and the corresponding values for each material are summarised in Table 2. In general, reinforced biocomposites display higher absorption values and longer saturation times than their corresponding polymeric matrix. The Mater-Bi 
NF and its reinforced biocomposites need less than 9 hours to arrive to the moisture uptake at the equilibrium, whereas the Mater-Bi KE and its reinforced contents need more than 25 hours.

Table 2. Moisture uptake at equilibrium, saturation time and diffusion case selection parameters for pure matrices and their reinforced biocomposites.

\begin{tabular}{|c|c|c|c|c|c|c|c|c|c|c|c|c|}
\hline & \multicolumn{4}{|c|}{$29^{\circ} \mathrm{C}$} & \multicolumn{4}{|c|}{$35^{\circ} \mathrm{C}$} & \multicolumn{4}{|c|}{$42^{\circ} \mathrm{C}$} \\
\hline & $\begin{array}{l}M_{s} \\
(\%)\end{array}$ & $\begin{array}{c}\text { ts } \\
(\mathrm{min})\end{array}$ & $\mathrm{n}$ & $\begin{array}{c}\mathrm{k} \\
\left(\min ^{-2}\right)\end{array}$ & $\begin{array}{l}M_{s} \\
(\%) \\
\end{array}$ & $\begin{array}{c}\text { ts } \\
(\mathrm{min})\end{array}$ & $\mathrm{n}$ & $\begin{array}{c}\mathrm{k} \\
\left(\mathrm{min}^{-2}\right)\end{array}$ & $\begin{array}{l}M_{s} \\
(\%) \\
\end{array}$ & $\begin{array}{c}\text { ts } \\
(\mathrm{min})\end{array}$ & $\mathrm{n}$ & $\begin{array}{c}\mathrm{k} \\
\left(\min ^{-2}\right) \\
\end{array}$ \\
\hline Mater-Bi NF & 6,20 & 300,0 & 0,64 & 0,34 & 7,20 & 240,0 & 0,60 & 0,40 & 8,40 & 126,0 & 0,50 & 0,55 \\
\hline Mater-BiNF/cotton & 7,80 & 360,0 & 0,49 & 0,46 & 8,70 & 258,0 & 0,44 & 0,49 & 9,80 & 198,0 & 0,40 & 0,57 \\
\hline Mater-Bi NF/hemp & 9,30 & 444,0 & 0,48 & 0,45 & 10,40 & 331,0 & 0,45 & 0,50 & 11,30 & 240,0 & 0,45 & 0,59 \\
\hline Mater-Bi NF/kenaf & 10,60 & 474,0 & 0,51 & 0,33 & 11,20 & 337,0 & 0,44 & 0,47 & 12,50 & 252,0 & 0,41 & 0,52 \\
\hline Mater-Bi NF/jute & 9,70 & 462,0 & 0,52 & 0,34 & 10,70 & 324,0 & 0,44 & 0,44 & 12,00 & 234,0 & 0,45 & 0,59 \\
\hline Mater-Bi NF/flax & 10,40 & 456,0 & 0,56 & 0,30 & 11,30 & 318,0 & 0,49 & 0,39 & 12,30 & 222,0 & 0,40 & 0,68 \\
\hline Mater-Bi KE & 0,60 & 2640,0 & 0,46 & 0,21 & 0,70 & 2070,0 & 0,51 & 0,21 & 0,80 & 1500,0 & 0,48 & 0,29 \\
\hline Mater-BiKE/cotton & 1,10 & 4992,0 & 0,42 & 0,18 & 1,40 & 4170,0 & 0,48 & 0,14 & 1,80 & 2238,0 & 0,49 & 0,30 \\
\hline Mater-Bi KE/hemp & 2,10 & 7800,0 & 0,48 & 0,14 & 2,30 & 6360,0 & 0,50 & 0,14 & 2,90 & 4200,0 & 0,47 & 0,33 \\
\hline Mater-Bi KE/kenaf & 2,50 & 8040,0 & 0,44 & 0,13 & 2,70 & 6510,0 & 0,56 & 0,15 & 3,40 & 4818,0 & 0,43 & 0,27 \\
\hline Mater-Bi KE/jute & 1,90 & 7476,0 & 0,46 & 0,14 & 2,20 & 6240,0 & 0,46 & 0,17 & 2,70 & 3612,0 & 0,43 & 0,32 \\
\hline Mater-Bi KE/flax & 1,50 & 6906,0 & 0,46 & 0,13 & 1,80 & 5910,0 & 0,44 & 0,19 & 2,30 & 3024,0 & 0,43 & 0,21 \\
\hline
\end{tabular}

The hydrophilic character of the studied natural fibres is responsible of the higher values of the moisture uptake for the reinforced biocomposites compared to the polymeric matrices [4]. Hemicellulose is the most hydrophilic component from the natural fibre, so a positive correlation between the moisture uptake of the reinforced biocomposites and hemicellulose content of the corresponding natural fibre should be observed (Figure 3). In general, an increase in the water absorption capacity as a function of the hemicellulose content can be observed. However, the reinforced Mater-Bi NF/flax biocomposite presents an anomalous behaviour with similar absorption capacity as Mater-Bi NF/kenaf biocomposite for all the experimental temperatures (Figure 3b). This may be due to a higher porosity of to the existence of voids formed during processing. 

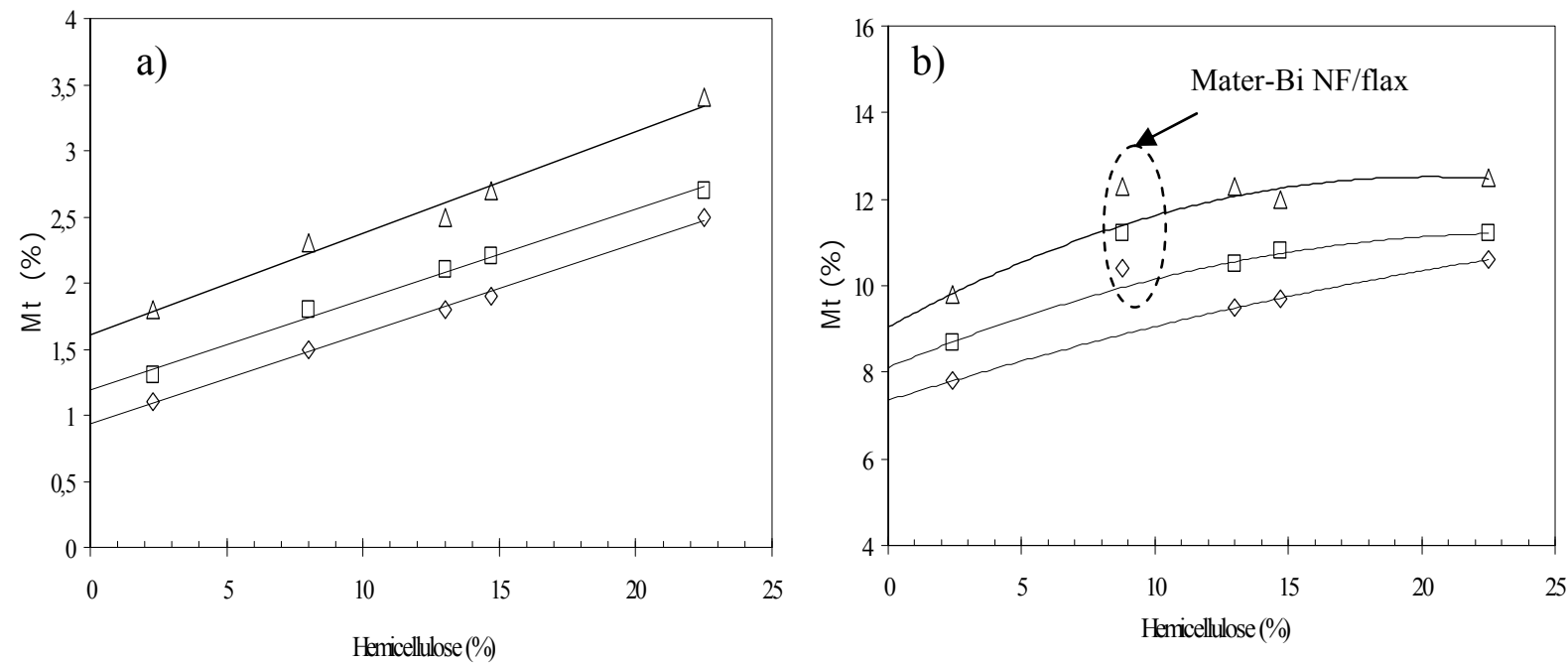

Figure 3. Moisture uptake of a) Mater-Bi KE and b) Mater-Bi NF as a function of the hemicellulose content at

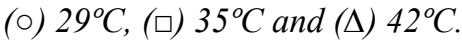

Furthermore, it can be noted that the materials with more amount of cellulose reach before the saturation time (Figure 4).
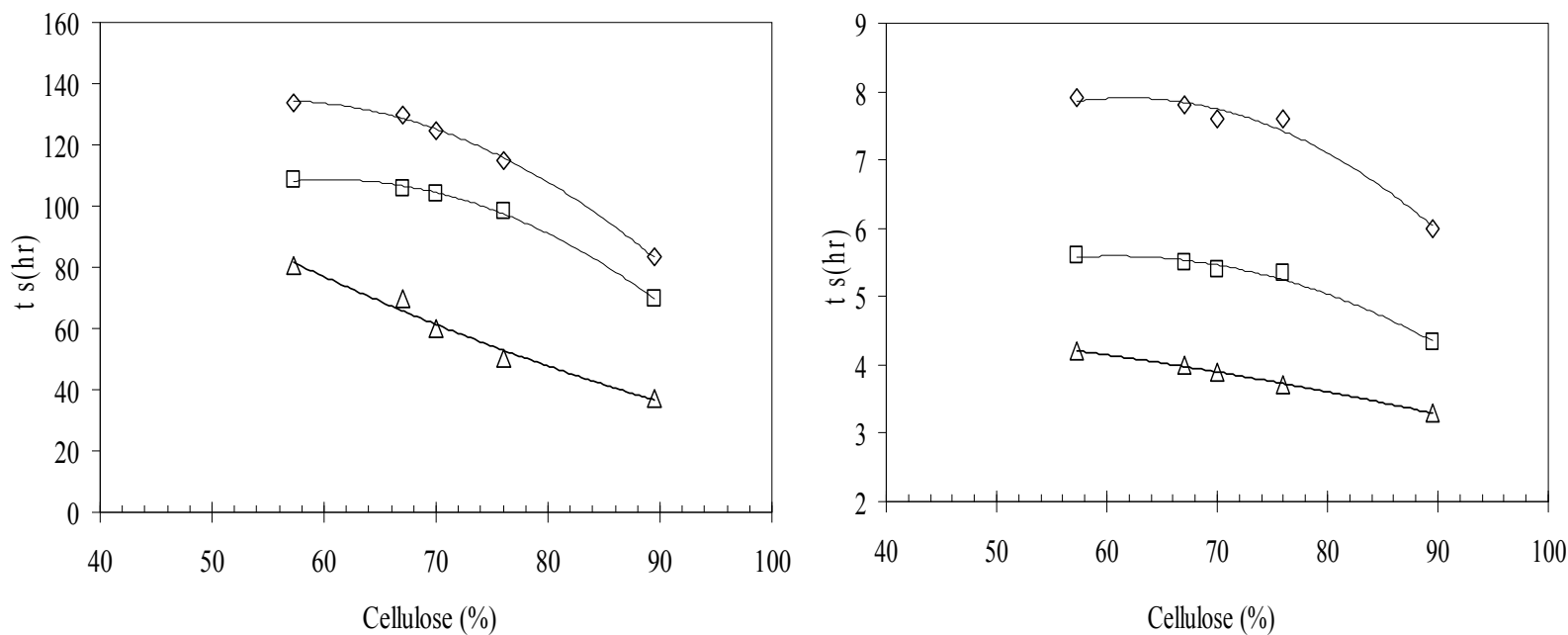

Figure 4. Saturation time of a) Mater-Bi KE and b) Mater-Bi NF as a function of the hemicellulose content at (०) $29^{\circ} \mathrm{C}$, () $35^{\circ} \mathrm{C}$ and ( $\triangle$ ) $42^{\circ} \mathrm{C}$.

Figure 5 displays the assessment of the diffusion mechanism and kinetics according to Fick's theory for Mater-Bi NF. Table 2 displays the values of the parameters $\mathrm{n}$ and $\mathrm{k}$. All the samples display $\mathrm{n}$ values close to 0,5 ; the diffusivity of the reinforced biocomposites at $29^{\circ} \mathrm{C}, 35^{\circ} \mathrm{C}$ and $42^{\circ} \mathrm{C}$ follow Fickian behaviour. 


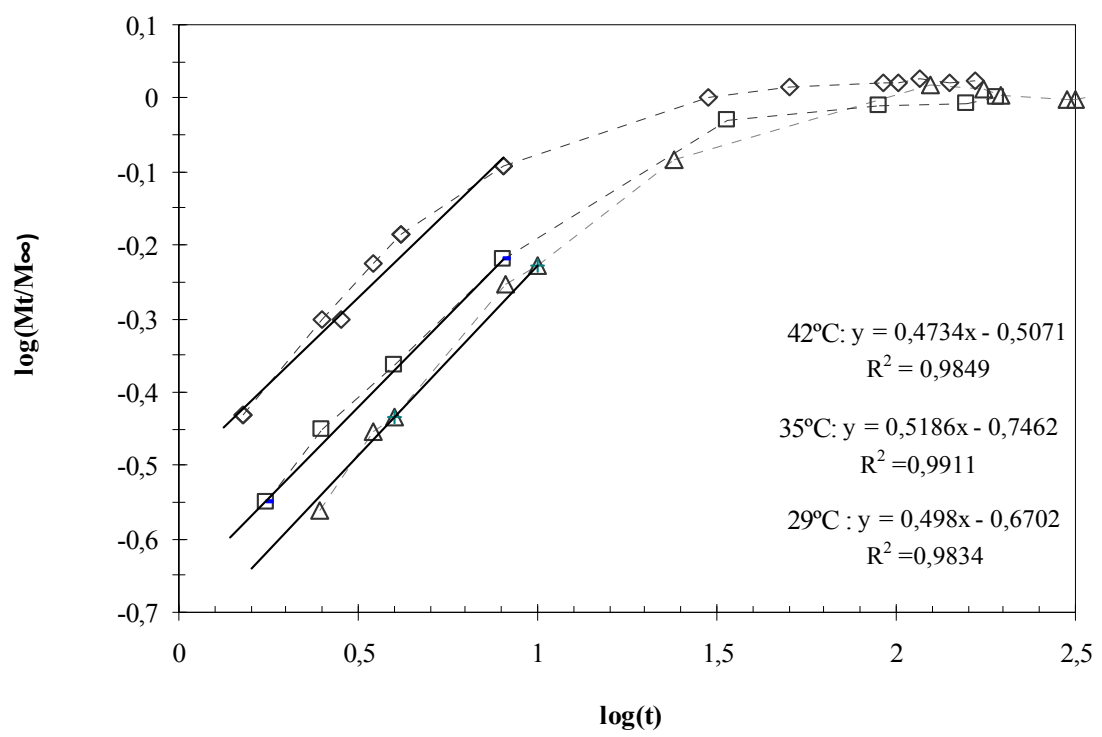

Figure 5. $\log \mathrm{Mt} / \mathrm{M}_{\infty}$ vs $\log (\mathrm{t})$ of Mater-Bi NF at $(\circ) 29^{\circ} \mathrm{C}$, ( ()$) 35^{\circ} \mathrm{C}$ and $(\Delta) 42^{\circ} \mathrm{C}$ to obtain $\mathrm{n}$ and $\mathrm{k}$ parameters.

Figure 6 describes the way to obtain the diffusivity parameters for the Mater-Bi KE. Table 3 summarizes the diffusion coefficients for all the materials.

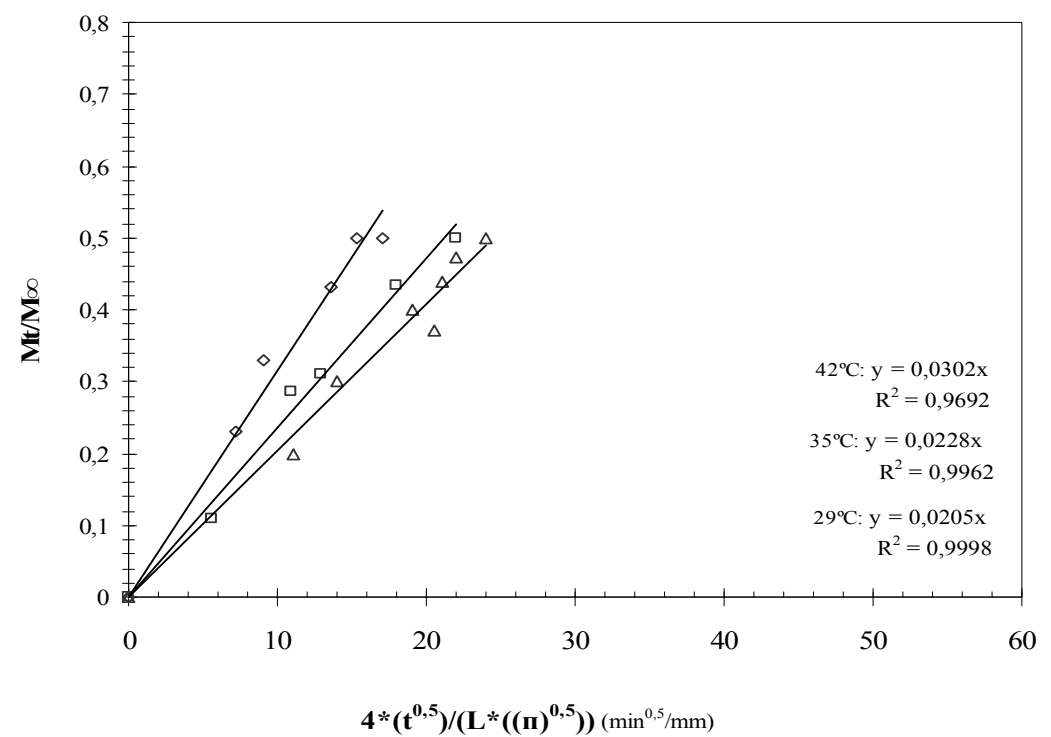

Figure 6. Mt $/ M_{\infty}$ vs $4 t^{0,5} \cdot L \cdot 3,14 \cdot 0,5$ of Mater-Bi KE at (O) $29^{\circ} \mathrm{C}$, () $35^{\circ} \mathrm{C}$ and $(\Delta) 42^{\circ} \mathrm{C}$ to obtain diffusivity parameters.

Table 3. Diffusion coefficient (D) and activation energy (Ea) for pure matrices and their reinforced biocomposites at different experimental temperature. 


\begin{tabular}{r|c|c|c|c}
\hline & \multicolumn{3}{|c|}{ Diffusion coefficient. 10 } & Ea \\
& $29^{\circ} \mathrm{C}$ & $\left.35^{\circ} \mathrm{C}\right)$ & $42^{\circ} \mathrm{C}$ & $(\mathrm{kJ} / \mathrm{mol})$ \\
\hline Mater-Bi NF & 34,93 & 59,65 & 95,51 & 71,8 \\
\hline Mater-BiNF/cotton & 33,31 & 58,62 & 94,2 & 72,3 \\
Mater-Bi NF/hemp & 31,00 & 56,00 & 85,0 & 72,2 \\
Mater-Bi NF/kenaf & 24,50 & 49,00 & 67,8 & 73,5 \\
Mater-Bi NF/jute & 29,50 & 54,34 & 80,1 & 73,2 \\
Mater-Bi NF/flax & 22,76 & 36,30 & 59,0 & 72,2 \\
\hline Mater-Bi KE & 7,04 & 8,12 & 15,20 & 53,7 \\
\hline Mater-BiKE/cotton & 4,76 & 6,48 & 10,16 & 54,0 \\
Mater-Bi KE/hemp & 2,90 & 4,50 & 7,18 & 64,5 \\
Mater-Bi KE/kenaf & 2,83 & 5,46 & 12,06 & 103,4 \\
Mater-Bi KE/jute & 3,85 & 7,27 & 14,60 & 96,7 \\
Mater-Bi KE/flax & 3,51 & 6,80 & 7,07 & 55,7 \\
\hline
\end{tabular}

The diffusion coefficient increases as a function of the experimental temperature for all the studied materials, as expected. The reinforced biocomposites absorb more water in its structure than the corresponding polymeric matrices; contrarily, the diffusion coefficient values of the pure matrices are higher than their respective composites. The presence of natural fibres contributes to slow down the diffusion mechanisms of the polymeric matrix, which could be due to the improved natural fibre/matrix interactions. Espert et al. [5] stated that with better adhesion between matrix and fibres, the velocity of the diffusional processes decreases since there are less gaps in the interfacial region and also more hydrophilic groups from the matrix are blocked by the natural fibre.

In general, reinforced Mater-Bi KE/natural fibres biocomposites present a better behaviour against water absorption than the reinforced Mater-Bi NF/natural fibres, since their diffusion coefficient values are the lowest. However, the presence of the natural fibres seems to influence in major extent on the diffusion coefficient of the Mater-Bi KE (45-59\%) than on the Mater-Bi NF (35-38\%).

In case of Fickian diffusion, the diffusion coefficient is supposed to follow an exponential Arrhenius-type relation with temperature as expressed by equation 5 . The diffusion processes are activated by an increase in temperature as it can be checked in Figure 7 and 8. 


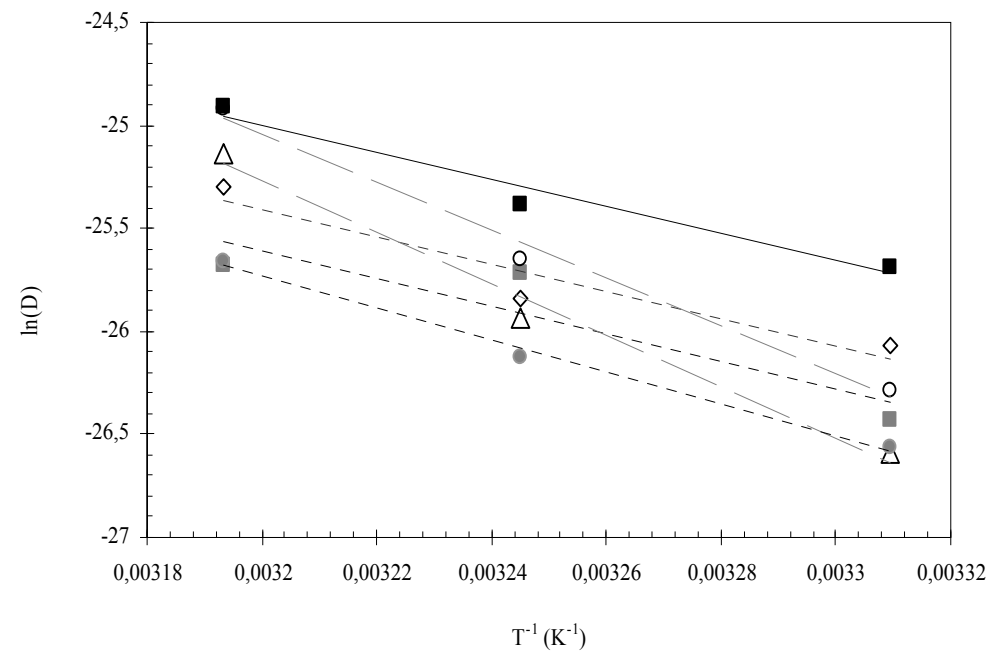

Figure 7. Arrhenius dependence of the diffusion coefficient with temperature for $\mathbf{n})$ pure Mater-Bi KE, $\diamond) M a t e r-B i$ KE/cotton, •) Mater-Bi KE/hemp, - Mater-Bi KE/flax o) Mater-Bi KE/jute and $\triangle$ )Mater-Bi KE/kenaf

Fibres incorporation in reinforced Mater-Bi KE biocomposites leads to an increase in the activation energy, indicating that water uptake is hindered by the strong interfacial interactions between fibres and matrix [6]. Mater-Bi KE/kenaf and Mater-Bi KE/jute exhibit higher activation energies, due to the higher presence of hemicellulose and lignin in its composition that enables strong interactions between these fibres with the polymeric matrix (Table 3).

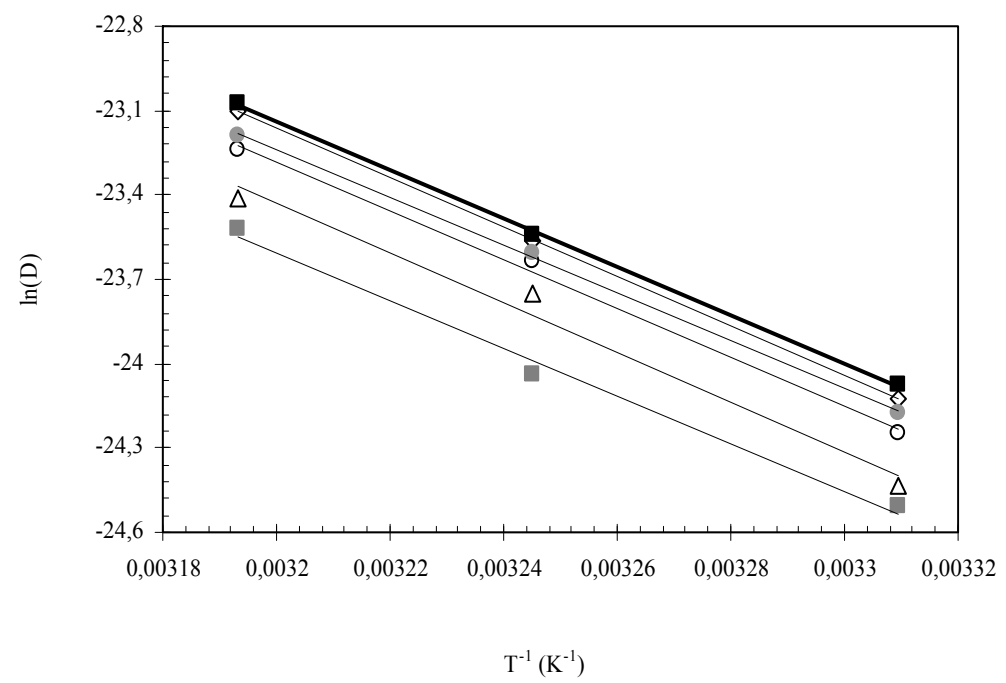

Figure 8. Arrhenius dependence of the diffusion coefficient with temperature for $\mathbf{\square}$ ) pure Mater-Bi $N F, \diamond)$ Mater-Bi NF/cotton, •) Mater-Bi NF/hemp, - Mater-Bi NF/flax ○) Mater-Bi KE/jute and A)Mater-Bi KE/kenaf The presence of the fibres in the reinforced Mater-Bi NF does not modify the activation energy values, which suggests that the matrix controls the mechanism of water penetration 
[7]. This different behaviour with respect to the set of Mater-Bi KE composites, maybe is due to the Mater-Bi NF is more hydrophilic than the Mater-Bi KE.

\section{Thermogravimetric results}

In order to study the influence of the moisture absorption on the thermal properties of both pure Mater-Bi NF and Mater-Bi KE, the saturated samples at $29^{\circ} \mathrm{C}$ were evaluated and compared with the respective non saturated. This temperature has been selected in order to establish the influence of the hydrolytic process on the posterior degradation of the materials in soil that is occurring at $28 \pm 1^{\circ} \mathrm{C}$. Figure 9 shows the thermogravimetric (TG) and differential thermogravimetric (DTG) curves of the non-saturated and saturated Mater-Bi KE at $29^{\circ} \mathrm{C}$, as an example.

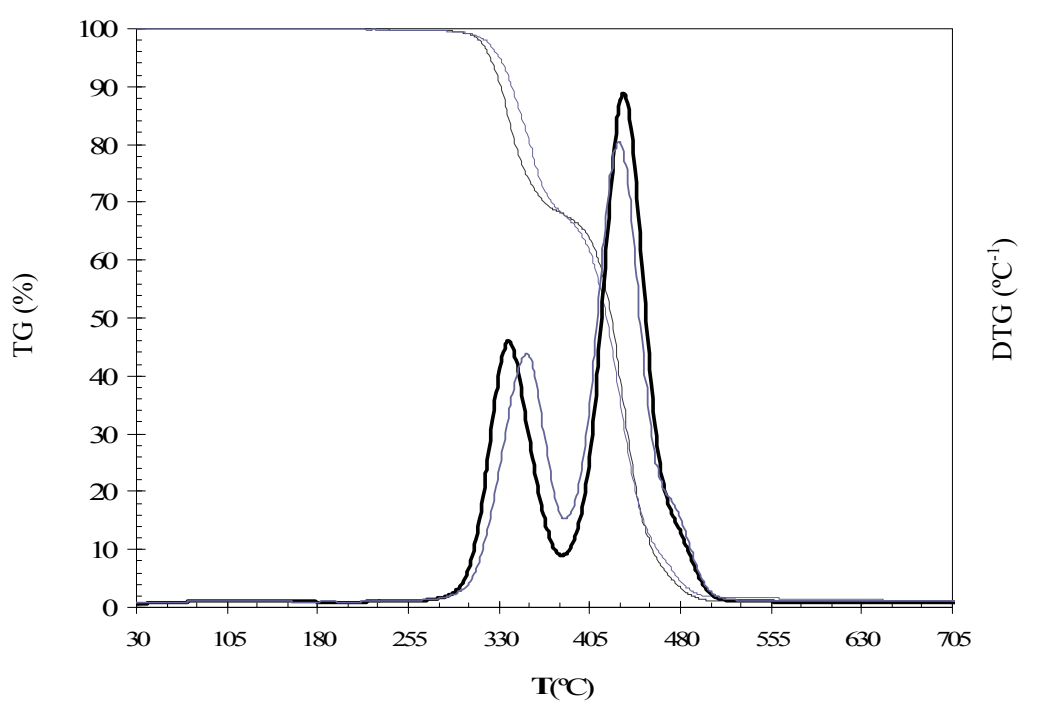

Figure 9. Thermogravimetric (TG) and differential thermogravimetric (DTG) curves of the -) pure Mater-Bi $\mathrm{KE}$ and the saturated Mater-Bi KE at -$) 29^{\circ} \mathrm{C}$.

Similarly to the non saturated polymeric matrix, the thermograms of both saturated polymeric matrices display a complex thermal decomposition process with two main mass-loss regions $[8,9]$. The first mass-loss region around $100^{\circ} \mathrm{C}$ is related to the water absorption process. The second mass-loss region $\left(250-360^{\circ} \mathrm{C}\right)$ is related to the pyrolisis of the starch and the massloss region placed at $360-520^{\circ} \mathrm{C}$ is attributed to the decomposition of the synthetic biodegradable component present in each polymeric matrix. Table 4 summarizes the characteristic thermogravimetric parameters: onset, mass loss and peak temperature of each thermal decomposition process of each polymeric matrix submitted to hydrolysis at $29^{\circ} \mathrm{C}$. 
Table 4. Thermogravimetric parameters for the saturated and non-saturated Mater-Bi KE and Mater-Bi NF.

\begin{tabular}{|c|c|c|c|c|c|c|c|c|c|}
\hline & \multicolumn{2}{|c|}{ Water loss region } & \multicolumn{3}{|c|}{$250-360^{\circ} \mathrm{C}$} & \multicolumn{3}{|c|}{$360-520^{\circ} \mathrm{C}$} & \multirow{2}{*}{$\begin{array}{c}\text { Residue } \\
\text { Mass } \\
(\%) \\
\end{array}$} \\
\hline & $\begin{array}{c}\text { Mass loss } \\
(\%)\end{array}$ & $\begin{array}{c}\text { T peak } \\
\left({ }^{\circ} \mathrm{C}\right)\end{array}$ & $\begin{array}{l}\text { Onset } \\
\left({ }^{\circ} \mathrm{C}\right)\end{array}$ & $\begin{array}{c}\text { Mass loss } \\
(\%)\end{array}$ & $\begin{array}{l}\text { T peak } \\
\left({ }^{\circ} \mathrm{C}\right)\end{array}$ & $\begin{array}{l}\text { Onset } \\
\left({ }^{\circ} \mathrm{C}\right)\end{array}$ & $\begin{array}{c}\text { Mass loss } \\
(\%)\end{array}$ & $\begin{array}{c}\text { T peak } \\
\left({ }^{\circ} \mathrm{C}\right)\end{array}$ & \\
\hline Mater-Bi KE & - & -- & $318,5 \pm 1,0$ & $31,5 \pm 0,5$ & $335,5 \pm 1,0$ & $412,9 \pm 0,7$ & $66,6 \pm 0,7$ & $434,5 \pm 0,2$ & $1,2 \pm 0,1$ \\
\hline Mater-Bi KE $29^{\circ} \mathrm{C}$ & --- & --- & $328,9 \pm 0,3$ & $32,5 \pm 0,4$ & $337,5 \pm 0,7$ & $411,0 \pm 0,3$ & $65,9 \pm 0,5$ & $418,8 \pm 0,8$ & $1,1 \pm 0,3$ \\
\hline Mater-Bi NF & $1,3 \pm 0,3$ & $103,0 \pm 0,3$ & $288,3 \pm 0,3$ & $21,9 \pm 0,8$ & $312,4 \pm 2,0$ & $402,1 \pm 1,0$ & $68,5 \pm 0,5$ & $421,1 \pm 0,9$ & $7,6 \pm 0,5$ \\
\hline Mater-Bi NF $29^{\circ} \mathrm{C}$ & $2,8 \pm 0,1$ & $100,0 \pm 0,3$ & $302,5 \pm 0,9$ & $18,1 \pm 0,3$ & $317,5 \pm 0,5$ & $400,1 \pm 1,0$ & $71,2 \pm 0,5$ & $416,9 \pm 0,3$ & $7,0 \pm 0,1$ \\
\hline
\end{tabular}


When both pure Mater-Bi KE and pure Mater-Bi NF are subjected to an absorption process, the main significant changes are occurring on the starchy component; since an increase in the thermal stability related to the decomposition of starch for both materials and a decrease in the mass loss of the pure Mater-Bi NF are observed. Thus, the most susceptible component to the absorption water is the starch. The decrease in the mass loss of the pure Mater-Bi NF may be assigned to the decrease in the absorption capacity (Figure 1) that was previously related to the extraction of additives and/or the solubility of the material; in this case, the solubility of the starch is confirmed.

By comparing the thermogravimetric values of the saturated reinforced biocomposites with the saturated values of the polymeric matrices, the major differences can be noticed again on the thermal decomposition process related to the starchy component. Figure 11 displays the values of the onset temperature related to the synthetic component for both pure polymeric matrices and their reinforced biocomposites.
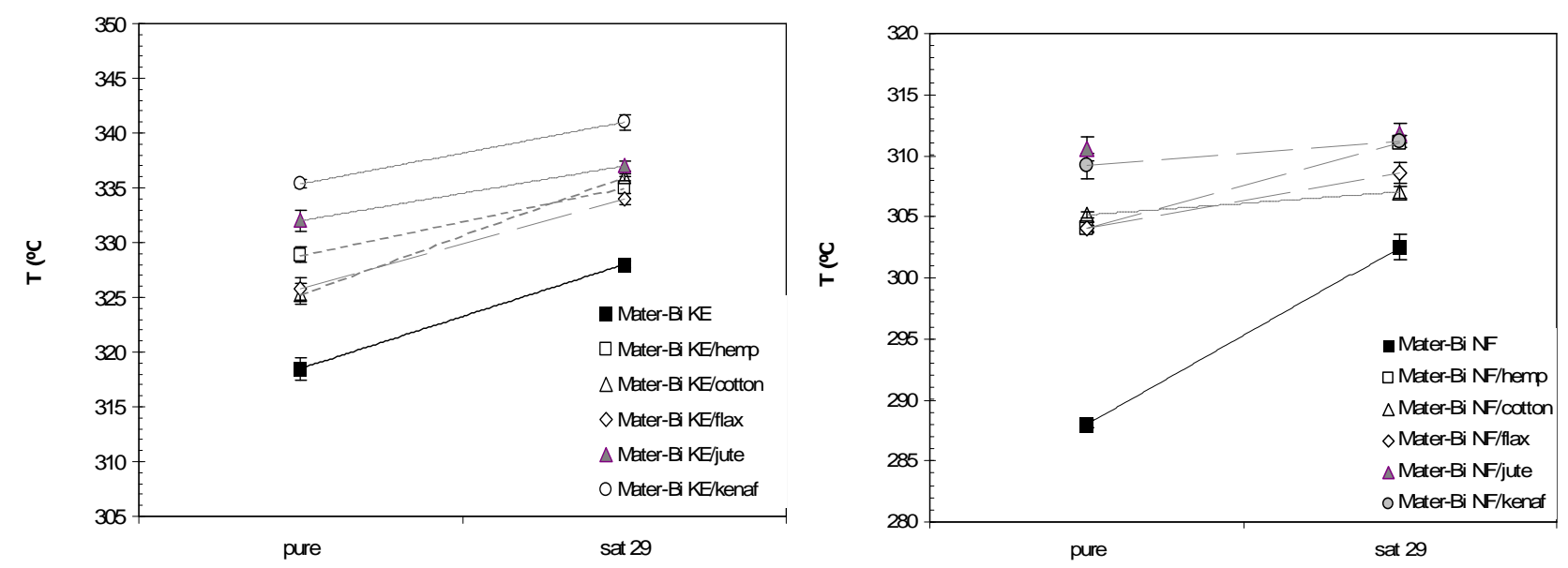

Figure 11. Changes in the onset temperature values related to the starch decomposition of a) pure Mater-Bi KE and its reinforced biocomposites and b) pure Mater-Bi NF and its reinforced biocomposites.

The reinforced Mater-Bi KE/cotton biocomposite present a similar increase in the thermal stability as that shown for the pure Mater-Bi KE due to the absorption process. The rest of the reinforced biocomposites display a smaller increase. It seems that this increase in the onset depends on the hemicellulose/pectin content (Figure 12); the materials with less percentage of hemicellulose/pectin has a major increase in the onset temperature due to the absorption process. 
In the Mater-Bi NF, the presence of natural fibres hinders the changes caused by the absorption process on the polymeric matrices in all the reinforced biocomposites. However, not significant changes can be observed between the different reinforced Mater-Bi NF biocomposites due to the absorption process.

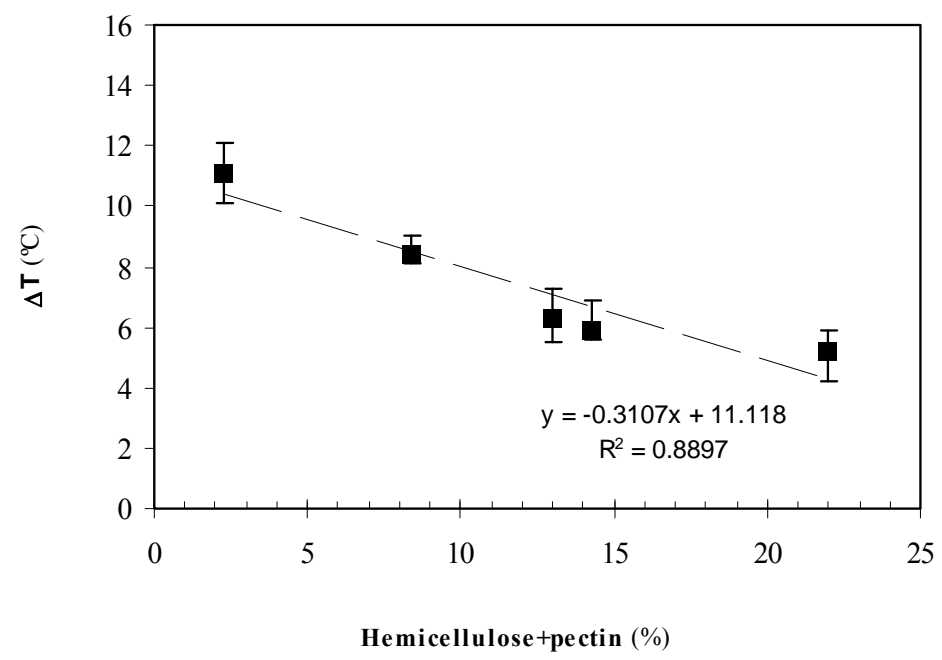

Figure 12. Onset temperature increment of the reinforced biocomposites as a function of hemicellulose+pectin percentage

The most interesting results of the thermogravimetric analysis are that not significant changes are obtained in the rest of the thermogravimetric parameters due to the presence of natural fibres. Thus it could be stated that the thermal stability of all the reinforced biocomposites are guaranteed in a water absorption process.

Kinetic analyses were performed to correlate the thermal decomposition behaviour of starchy component with its absorption process. Previous studies [3] have demonstrated that the apparent activation energy $(E a)$ is the most sensitive kinetic parameters to the degradation in soil process. Kissinger [8] and Coats Redfern [9] methods have been applied in order to assess the apparent activation energy and the kinetic model of the starch thermal decomposition process of each material hydrolyzed at $29^{\circ} \mathrm{C}$. Table 5 summarizes these kinetics results for all the studied materials. 
Table 5. Ea values for the saturated and non-saturated materials.

\begin{tabular}{r|cc|cc}
\hline & \multicolumn{3}{|c|}{ pure } & \multicolumn{2}{|c}{$\mathbf{2 9}^{\mathbf{0}} \mathbf{C}$} \\
\hline Mater-Bi KE & Ea $(\mathrm{kJ} / \mathrm{mol})$ & $\mathbf{f}(\boldsymbol{\alpha})$ & $\boldsymbol{E a}(\mathrm{kJ} / \mathrm{mol})$ & $\mathbf{f}(\boldsymbol{\alpha})$ \\
\hline Mater-Bi KE/cotton & $100 \pm 3$ & $\alpha^{0,5}(1-\alpha)^{1,5}$ & $116 \pm 3$ & $\alpha^{0,5}(1-\alpha)^{1,5}$ \\
\hline Mater-Bi KE/hemp & $112 \pm 1$ & $\alpha^{0,5}(1-\alpha)^{1,5}$ & $124 \pm 4$ & $\alpha^{0,5}(1-\alpha)^{1,5}$ \\
Mater-Bi KE/flax & $175 \pm 5$ & $\alpha^{0,2}(1-\alpha)^{1,6}$ & $163 \pm 3$ & $\alpha^{0,4}(1-\alpha)^{1,4}$ \\
Mater-Bi KE/kenaf & $155 \pm 4$ & $\alpha^{0,3}(1-\alpha)^{1,6}$ & $171 \pm 2$ & $\alpha^{0,3}(1-\alpha)^{1,6}$ \\
Mater-Bi KE/jute & $163 \pm 3$ & $\alpha^{0,2}(1-\alpha)^{1,4}$ & $153 \pm 3$ & $\alpha^{0,4}(1-\alpha)^{1,2}$ \\
\hline Mater-Bi NF & $170 \pm 5$ & $\alpha^{0,4}(1-\alpha)^{1,7}$ & $145 \pm 3$ & $\alpha^{0,5}(1-\alpha)^{1,5}$ \\
\hline Mater-Bi NF/cotton & $149 \pm 5$ & $\alpha^{0,6}(1-\alpha)^{2,0}$ & $171 \pm 2$ & $\alpha^{0,7}(1-\alpha)^{2,7}$ \\
Mater-Bi NF/hemp & $159 \pm 5$ & $\alpha^{0,3}(1-\alpha)^{1,5}$ & $193 \pm 3$ & $\alpha^{0,2}(1-\alpha)^{1,2}$ \\
Mater-Bi NF/ flax & $177 \pm 4$ & $\alpha^{0,2}(1-\alpha)^{1,5}$ & $190 \pm 1$ & $\alpha^{0,2}(1-\alpha)^{1,5}$ \\
Mater-Bi NF/kenaf & $170 \pm 3$ & $\alpha^{0,1}(1-\alpha)^{1,4}$ & $194 \pm 2$ & $\alpha^{0,3}(1-\alpha)^{1,2}$ \\
Mater-Bi NF/jute & $185 \pm 3$ & $\alpha^{0,2}(1-\alpha)^{1,4}$ & $199 \pm 2$ & $\alpha^{0,3}(1-\alpha)^{1,2}$ \\
\hline
\end{tabular}

When the pure polymeric matrices are subjected to an absorption process, an increase in the $E a$ related to the starchy component is observed. However, significant changes on the kinetic model can not observed.

In the Ea values of the reinforced Mater-Bi KE biocomposites, different behaviours are shown, depending on the natural fibre added. As it was stated in the mechanistic studies of the absorption process, the Mater-Bi KE/cotton and the Mater-Bi KE/flax follow the same trend that of the pure polymeric matrix. However, the Mater-Bi KE/hemp, Mater-Bi KE/jute and Mater-Bi KE/kenaf display a decreasing in the Ea during the absorption process. Thus the biocomposites with more amount of hemicellulose/pectin show a more different behaviour of the polymeric matrix.

On the other hand, the $E a$ values of the reinforced Mater-Bi NF biocomposites displays an increasing trend, where no difference is found between them, as it was observed in the mechanistic studies of the absorption process.

\section{Conclusions}


The presence of natural fibres in the reinforced biocomposites is responsible for a higher saturation capacity and lower saturation time for the reinforced biocomposites compared to the pure matrices. The saturation capacity increases as a function of the hemicellulose content, whereas the saturation time decreases as a function of the cellulose content.

The water absorption process of both polymeric matrices and the corresponding reinforced biocomposites follows Fick's kinetics and mechanisms. The diffusivity coefficients decrease for the reinforced biocomposites compared to the polymeric matrices, evidencing an increased difficulty for water uptake due to the interactions between the polymeric matrix and the natural fibres.

The diffusivity coefficient showed Arrhenius dependence with the temperature for both sets of samples. The apparent activation energies of the Mater-Bi KE reinforced biocomposites are higher than those presented by the corresponding polymeric matrix. The Mater-Bi KE/jute and Mater-Bi KE/kenaf display the highest Ea values, confirming the best matrix - fibre adhesion. Fibre presence in reinforced Mater-Bi NF does not modify the activation energy values, suggesting that in this case, the matrix controls the water penetration mechanism, due to its high hydrophilic character.

In order to establish the influence of the hydrolytic process on the posterior degradation in soil of the pure polymeric matrix and the reinforced biocomposites, the thermal properties of the saturated materials were assessed. When the pure polymeric matrices are subjected to an absorption process, an increase in the thermal stability and in the Ea related to the starch component are observed.

In the Mater-Bi NF, the presence of natural fibres hinders the changes caused by the absorption process on the polymeric matrices in all the reinforced biocomposites. However, not significant changes can be observed between the different reinforced Mater-Bi NF biocomposites due to the absorption process. 
In the reinforced Mater-Bi KE biocomposites the thermal stability decreases as a function of the hemicellulose/pectin content due to the absorption process. In addition, different behaviours can be observed in the Ea values depending on the natural fibre added; the Mater$\mathrm{Bi} \mathrm{KE} /$ hemp, Mater-Bi KE/jute and Mater-Bi KE/kenaf display a decreasing in the Ea during the absorption process. Thus, the presence of hemp, jute and kenaf fibres modifies the thermal properties of the pure Mater-Bi KE more significantly than cotton and flax fibres do during the absorption process.

\section{References}

1. Theander O, Westerlund EA. J Agric Food Chem 1986; 34:330.

2. ASTM D570-98(2010)e1. Standard Test Method for Water Absorption of Plastics

3. M Jacob, KT Varughese, S Thomas. J Appl Polym Sci 2006; 102: 416.

4. Mohanty AK, Misra M, Hinrichsen G. Macromol Mater Eng 2000; 276/277: 1.

5. Espert A, Vilaplana F, Karlsson S. Composites: Part A 2004; 35: 1267. 



\section{Caracterización de la degradación}

en tierra de las matrices poliméricas y sus biocomposites

6.1 Introducción

6.2 Resultados y discusión

- Mater-Bi KE y Biocomposites de Mater-Bi KE/Fibras Naturales

"Assessing the influence of cotton fibres on the degradation in soil of a thermoplastic starch-based biopolymer."

Rosana Moriana, Sigbritt Karlsson, A. Ribes-Greus Polymer Composites, 2010

"Charasterisation of the degradation of reinforced Mater-Bi KE/hemp, Mater-Bi KE/flax, Mater-Bi KE/kenaf biocomposites in soil."

- Mater-Bi NF y Biocomposites de Mater-Bi NF/Fibras Naturales

"Thermal analysis applied to the characterization of the degradation of reinforced Mater-Bi NF/natural fibres biocomposites in soil."

6.3 Resumen de resultados 



\subsection{INTRODUCCIÓN}

Una vez diseñados los biocomposites reforzados y demostradas sus propiedades, se va a monotorizar el proceso de degradación de cada material, así como el estudio de la influencia de las fibras naturales en el proceso de degradación en tierra de la matriz polimérica.

Esquemáticamente, los objetivos específicos de este capítulo son los siguientes;

1. Describir de la metodología de análisis para la monitorización de la degradación en tierra de las matrices poliméricas y de los biocomposites diseñados.

2. Caracterizar la degradación en tierra de las matrices poliméricas, Mater-Bi KE y Mater-Bi NF, y de los biocomposites preparados.

3. Evaluar la influencia de cada una de las fibras naturales sobre el proceso de degradación en tierra de cada matriz polimérica.

La metodología de análisis propuesta, se basa fundamentalmente en la monitorización en función del tiempo de degradación en tierra de distintos parámetros térmicos obtenidos a partir del análisis calorimétrico (DSC) y termogravimétrico (TGA). Estos parámetros son las entalpías de cristalización y fusión, las temperaturas de cristalización y fusión, la estabilidad térmica y la energía de activación de cada proceso de descomposición del material estudiado. Además, esta metodología se complementa con microscopía electrónica de barrido (SEM) y análisis espectroscópico por transformadas de Fourier (FTIR).

Todos los resultados experimentales de esta metodología de análisis se han estructurado en tres contribuciones científicas distintas, una de ellas aceptada en una revista indexada.

\section{$\checkmark \quad$ "Assessing the influence of cotton fibres on the degradation in soil of a} thermoplastic starch-based biopolymer". En esta comunicación, además de la influencia de la adición del algodón sobre la degradación en tierra del Mater-Bi KE, se evalúa la validez y eficacia de la metodología de análisis propuesta. Esta contribución ya ha sido publicada en la revista Polymer Composites. 
$\checkmark \quad$ “Characterization of the degradation of reinforced Mater-Bi KE/hemp, Mater-Bi KE/flax, Mater-Bi KE/jute and Mater-Bi KE/kenaf biocomposites in soil”. En esta contribución, se caracteriza la degradación en tierra del resto de los biocomposites preparados con Mater-Bi KE, es decir, el Mater-Bi KE/algodón, Mater-Bi KE/cañamo, Mater-Bi $\mathrm{KE} /$ kenaf, Mater-Bi KE/lino y Mater-Bi KE/yute mediante la metodología de análisis empleada en la publicación anterior, donde se estudia específicamente el Mater-Bi KE/algodón. A partir de los resultados obtenidos se evalua la influencia de cada fibra natural sobre el proceso de degradación en tierra del Mater-Bi KE.

$\checkmark \quad$ “Thermal analysis applied to the characterization of the degradation of reinforced Mater-Bi NF/natural fibres biocomposites in soil”. El estudio de la degradación en tierra de los biocomposites preparados con Mater-Bi NF se completa con esta contribución. 


\subsection{RESULTADOS Y DISCUSIÓN}

“ASSESSING THE INFLUENCE OF COTTON FIBRES ON THE DEGRADATION IN SOIL OF A THERMOPLASTIC STARCH-BASED BIOPOLYMER" 




\title{
Assessing the Influence of Cotton Fibers on the Degradation in Soil of a Thermoplastic Starch-Based Biopolymer
}

\author{
Rosana Moriana, ${ }^{1}$ Sigbritt Karlsson, ${ }^{2}$ Amparo Ribes-Greus ${ }^{1}$ \\ ${ }^{1}$ Instituto de Tecnología de Materiales (ITM), Universidad Politécnica de Valencia, Camino de Vera s/n, \\ E-46022 Valencia, Spain
}

\author{
${ }^{2}$ Department of Fibre and Polymer Technology, School of Chemical Science and Engineering, KTH-Royal \\ Institute of Technology, Teknikringen 56-58, SE-10044 Stockholm, Sweden
}

\begin{abstract}
Biocomposites consisting of cotton fibers and a commercial starch-based thermoplastic were subjected to accelerated soil burial test. Fourier transform infrared (FTIR) spectrometry analysis was carried out to provide chemical-structural information of the polymeric matrix and its reinforced biocomposites. The effects that take place as a consequence of the degradation in soil of both materials were studied by FTIR-ATR, differential scanning calorimetry (DSC), scanning electron microscopy (SEM), and thermogravimetric analysis (TGA). When the polymeric matrix and the reinforced biocomposite are submitted to soil burial test, the infrared studies display a decrease in the $\mathbf{C}=0$ band associated to the ester group of the synthetic component as a consequence of its degradation. The crystalline index of both materials decreased as a function of the degradation process, where the crystalline structure of the reinforced biocomposite was the most affected. In accordance, the degraded reinforced biocomposite micrographs displayed a more damaged morphology and fracture surface than the degraded polymeric matrix micrographs. On the other hand, the same thermal decomposition regions were assessed for both materials, regardless of the degradation time. Kissinger, Criado, and Coats-Redfern methods were applied to analyze the thermogravimetric results. The kinetic triplet of each thermal decomposition process was determined for monitoring the degradation test. The thermal study confirms that starch was the most biodegradable polymeric matrix component in soil. However, the pres-
\end{abstract}

Correspondence to: A. Ribes-Greus; e-mail: aribes@ter.upv.es

Contract grant sponsor: The Ministerio de Educación y Ciencia (Spanish Government) and the European Regional Development Found for the economical support; contract grant number: ENE2007/67584/C03-01; contract grant sponsor: the FPI pre-doctoral grant concession; contract grant sponsor: The Minesterio of Medio Ambiente (Spanish Government); contract grant number: 555/2006/3-6.1.

DOI 10.1002/pc.21007

Published online in Wiley InterScience (www.interscience.wiley.com). (C) 2010 Society of Plastics Engineers ence of cotton fiber modified the degradation rate of both matrix components; the degradability in soil of the synthetic component was slightly enhanced, whereas the biodegradation rate of the starch slowed down as a function of the soil exposure time. POLYM. COMPOS., 00:000-000, 2010. ( 2010 Society of Plastics Engineers

\section{INTRODUCTION}

The growing use of biodegradable plastics leads to an increasing research interest in improving thermomechanical properties and decreasing cost and, at the same time, preserving the biodegradability of these materials [1, 2]. More recently, the attention has been focused on the addition of natural fibers as reinforcing components for injection-moldable biopolymers because of their low density and ecological advantages [3]. In reinforced biocomposites, natural fibers provide biodegradability and desirable fiber-aspect ratio to the biodegradable polymeric matrix [4].

Scott et al. [5] suggested that traditional techniques, as the measurement of weight loss changes for studying polymer biodegradation, have some limitations because of the adhesion of soil and fungi to the polymer, which can mask real results and thus induce misleading information. In contrast to this weight loss conventional technique, earlier studies have shown that thermal analysis can be an alternative to assess the degradation in soil studies, providing useful information about the irreversible macroscopic effects on the polymers caused by the degradation process [6-9]. Composites prepared from a thermoplastic starchbased matrix (Mater-Bi KE03B $1^{\circledR}$ ) reinforced with cotton fibers were characterized in the present work to study the influence of natural fibers on its degradation process in soil. The biodegradability of thermoplastic starch-based material has been analyzed through a broad number of researches [10-13]; however, the biodegradability of rein- 
forced starch-based polymers composites is less studied. Schönweiz et al. [14] analyzed the degradation of Mater$\mathrm{Bi}^{\circledR}$, grade Y101U and grade $\mathrm{A} 105 \mathrm{H}$, with flax fibers during a controlled composting experiment. Results indicated that only the parts containing Mater-Bi $\mathrm{A} 105 \mathrm{H}$ were slowly degraded after 126 days of degradation. The degradation of composites of poly(vinyl alcohol), starch, and orange fibers in soil was assessed by Imam et al. [15], and it was concluded that the orange fibers did not greatly affect the degradation of this poly(vinyl alcohol)/starch blend. Di Franco et al. [16] studied the degradation of reinforced Mater-Bi $\mathrm{Z}^{\mathbb{R}}$ /sisal composites in biotic environments (soil and inoculated aqueous medium). Their results indicated that natural fiber indirectly promotes the biodegradation of these materials in both mediums. Recently, Alvarez et al. [17, 18] checked the behavior of Mater-Bi $\mathrm{Y}^{\circledR} /$ sisal composites buried in soil and water. These studies remarked that the presence of the natural fibers in the composites improves the water resistance and acts as a support for a microbial growth.

The purpose of this work was to analyze by thermal analysis the effects of the degradation in soil on both Mater-Bi KE03B $1^{\circledR}$ and reinforced biocomposite, to understand the influence of the natural fiber on the biodegradability of this thermoplastic starch-blend in soil. Differential scanning calorimetric (DSC) analysis was carried out to assess the thermal transition changes during the soil burial test. Furthermore, Fourier transform infrared (FTIR) spectrometry and scanning electron microscopy (SEM) were used as complementary techniques to obtain information about the structural and morphological changes that take place when the natural fiber is added into the polymeric matrix and its influence on the degradation of the Mater-Bi KE03B ${ }^{\circledR}$ in soil. Thermogravimetric analysis (TGA) of the polymeric matrix and the reinforced biocomposite at different degraded time was performed. An accurate and useful methodology that was successfully applied in previous works [7, 19] was employed to assess the degradation in soil of the polymeric matrix and the reinforced biocomposites in soil.

\section{EXPERIMENTAL}

\section{Materials and Sample Preparation}

A commercial thermoplastic starch-blend commercialized as Mater-Bi KE03B ${ }^{\circledR}{ }^{\circledR}$ (from now on named MaterBi KE) by Novamont, Novara SpA (Italy), was used as a biodegradable matrix to prepare the reinforced biocomposite. This biodegradable material usually consists of starch and polyester [16, 20, 21], as it has been observed in the FTIR measurements. The elastic modulus of this material, measured using ASTM-D638, is 1,400 MPa, the tensile stress at break is $18 \mathrm{MPa}$, and the elongation at break is $150 \%$, as reported in technical data sheet. Natural cotton fibers were employed as reinforcement. They were pro- vided by Yute S.L. (Spain). The average length and diameter of the cotton fiber were determined by optical microscopy over 100 fibers. The length was $3 \pm 1 \mathrm{~mm}$, and the average diameter was $0.0175 \pm 0.0125 \mathrm{~mm}$. The form relationship was $450 \pm 35$, and the $E_{\mathrm{f}}$ was $12 \mathrm{GPa}$. Composites with $10 \%$ of cotton fiber were prepared in a corotative twin screw extruder under a processing temperature of $165^{\circ} \mathrm{C}$ (Werner \& Pfleiderer ZSK 25, Germany). Rectangular bars with dimensions $110 \times 110 \times 2 \mathrm{~mm}^{3}$ were obtained by compression molding with a Carver $M$ press (Carver, USA).

\section{Soil Burial Test}

Samples of pure Mater-Bi KE, cotton fibers, and their reinforced composites were submitted to an accelerated degradation process according to the DIN 53739 international standard [22]. Samples were buried in active soil with a control of relative humidity $(55 \%), \mathrm{pH}(\sim 7.5)$, and temperature $\left(28^{\circ} \mathrm{C} \pm 2{ }^{\circ} \mathrm{C}\right)$. This soil burial test can be considered a realistic approach to the biodegradation process in a waste landfill.

The degradation process in soil was carried out during 535 days. After this time, samples could not be tested any more because of their macroscopic deterioration. At predetermined intervals of time test, the specimens were removed for characterization. Once removed, samples were washed with a soap solution to stop the degradation in soil process.

\section{FTIR Spectrometry}

The FTIR spectra were recorded, at room temperature, using a FTIR spectrometer Spectrum 2000 from Perkin Elmer (Wellesley, MA), equipped with a golden singlereflection accessory for attenuated total reflection measurements. Each spectrum was obtained by the performance of 32 scans between 4,000 and $600 \mathrm{~cm}^{-1}$ at intervals of $1 \mathrm{~cm}^{-1}$. The FTIR spectra were smoothed and fitted by an automatic base line correction by OMNIC 7.0 software.

\section{DSC Measurements}

DSC measurements have been performed on a Mettler Toledo DSC 822e Instrument (Columbus, OH) previously calibrated with indium standard. Samples of 7-8 mg were placed in standard aluminium pans that were sealed and pierced. Mater-Bi KE, cotton fibers, and their reinforced biocomposites samples were submitted to the same method. In the first scan, samples were heated from -100 to $200^{\circ} \mathrm{C}$ to delete the thermal history of the studied materials. After holding the temperature at $200^{\circ} \mathrm{C}$ for 3 min, the second scan from 200 to $-100^{\circ} \mathrm{C}$ was performed to analyze the crystallization processes. Finally and after holding the temperature at $-100^{\circ} \mathrm{C}$ during $3 \mathrm{~min}$, the third scan from -100 to $200^{\circ} \mathrm{C}$ takes place to study the 
melting processes. The heating and cooling rates were set at $10^{\circ} \mathrm{C} / \mathrm{min}$.

The crystallization temperature $\left(T_{\mathrm{c}}\right)$ is obtained at the maximum of the exothermic peak from the cooling second scan. The melting temperature $\left(T_{\mathrm{m}}\right)$ is determined at the maximum of the main endothermic peak from the third heating scan. By integration of the corresponding peaks, the heats of crystallization and melting $\left(\Delta H_{\mathrm{c}}\right.$ and $\left.\Delta H_{\mathrm{m}}\right)$ have been determined. In the reinforced biocomposites, these values should be corrected following Eqs. 1 and 2 , considering that only the polymeric matrix contributed to the transitions.

$$
\begin{aligned}
\Delta H_{\mathrm{c}} & =\frac{\Delta H_{\text {Biocomposite }_{\mathrm{c}}}}{1-w w} \\
\Delta H_{\mathrm{m}} & =\frac{\Delta H_{\text {Biocomposite }_{\mathrm{m}}}}{1-w w}
\end{aligned}
$$

Therefore, $\Delta H_{\text {Biocomposite }}$ are the enthalpies of the reinforced biocomposite directly calculated from the thermograms and $w w$ is the fraction of natural fiber added.

\section{SEM Measurements}

The fracture surface of the polymeric matrix and its reinforced biocomposites after and before degradation were studied. Scanning electron micrographs were obtained from cryogenic sectioned samples after sputtering with gold/palladium, using a JEOL JSM-5400 scanning electron microscope (JEOL Ltd., Japan).

\section{Thermogravimetric Measurements}

The thermal decomposition of the pure Mater-Bi KE, cotton fibers, and their reinforced biocomposites at different degradation times was evaluated by dynamic TGA. The measurements were performed using a Mettler-Toledo TGA/SDTA 851 (Columbus, OH). Approximately 8.5 $\mathrm{mg}$ of sample was heated between 25 and $750^{\circ} \mathrm{C}$ at different heating rates: $3,5,10,20$, and $30^{\circ} \mathrm{C} / \mathrm{min}$, under argon atmosphere (flow of $50 \mathrm{ml} / \mathrm{min}$ ). The degradation effects on the samples were evaluated through the changes on the thermal stability and the kinetics of the thermal decomposition processes.

All experimental measurements have been performed at least three times to assure good reproducibility, and the average values have been considered as representative results.

\section{RESULTS AND DISCUSSION}

\section{FTIR Spectrometry}

The FTIR spectrum of pure Mater-Bi KE is presented in Fig. 1, and the assignments of the main absorptions bands are $3,428 \mathrm{~cm}^{-1}(\mathrm{O}-\mathrm{H}$ stretching $)$ [23], 2,929

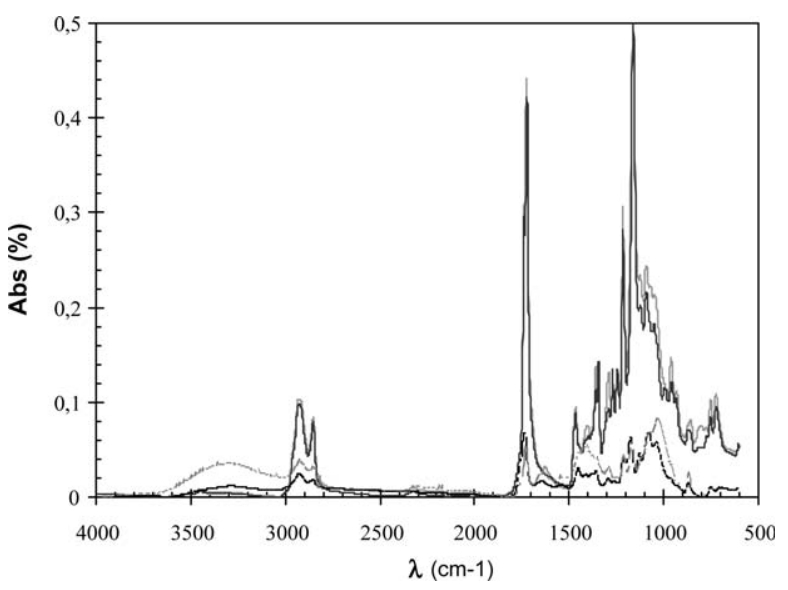

FIG. 1. FTIR spectra of the $(\square)$ pure Mater-Bi KE, $(\square)$ reinforced biocomposite, (-.) pure Mater-Bi KE at 535 days of degradation and (*$*)$ reinforced biocomposite at 535 days of degradation in soil.

$\mathrm{cm}^{-1}\left(\mathrm{CH}_{2}\right.$ asymmetric stretching) [23], 2,850 $\mathrm{cm}^{-1}$ $\left(\mathrm{CH}_{2}\right.$ symmetric stretching $)$ [23], $1,733 \mathrm{~cm}^{-1} \quad(\mathrm{C}=\mathrm{O}$ stretching) [24], 1,648 $\mathrm{cm}^{-1}(\mathrm{O}-\mathrm{H}$ bending of absorbed water) [25], $1,462 \mathrm{~cm}^{-1}$ ( $\mathrm{CH}_{2}$ deformation) [23], 1,445$1,325 \mathrm{~cm}^{-1}(\mathrm{C}-\mathrm{H}$ bending and wagging) [26], 1,243 $\mathrm{cm}^{-1}$ (O-H bending) [26], 1,250-900 $\mathrm{cm}^{-1}(\mathrm{C}-\mathrm{O}$ stretching) [23, 27], and 929-754 $\mathrm{cm}^{-1}$ (anhydroglucose ring stretching) [28]. The band placed at $1,733 \mathrm{~cm}^{-1}$ is characteristic of the carbonyl stretching vibration in the ester groups [24], indicating that the synthetic component of the Mater-Bi KE is a polyester.

Figure 1 displays the spectra of the degraded and nondegraded pure Mater-Bi KE and reinforced biocomposite. When cotton fibers are added into the Mater-Bi KE, a slight increase in the peak at $1,089 \mathrm{~cm}^{-1}$ attributed to the stretching of $\mathrm{C}-\mathrm{O}-\mathrm{C}$ group in the glycosidic bonds can be observed [29]. Moreover, the fingerprint peaks (1,500$600 \mathrm{~cm}^{-1}$ ) of both degraded materials with respect to the nondegraded ones decrease and become broader, indicating a chemical structure decay [30].

Figure $2 \mathrm{a}$ and $\mathrm{b}$ displays the spectra of the degraded materials scaled and shifted for an easier visualization. As the degradation time increases, the absorbance peak of $\mathrm{OH}$ stretching groups becomes wider, the intensity increases, and the maximum absorbance frequency is moved from original $3,428 \mathrm{~cm}^{-1}$ to $3,300 \mathrm{~cm}^{-1}$. These changes could be interpreted in terms of an increase in the concentration of $\mathrm{OH}$ groups as the ester groups are broken [31].

In addition, a decrease in the absorbance peak of the $\mathrm{C}=\mathrm{O}$ group $\left(1,733 \mathrm{~cm}^{-1}\right)$ can be distinguished as a function of the soil burial test, indicating a progressive deterioration of the synthetic component of pure Mater-Bi KE. This peak is the selected one to monitor the degradation of the synthetic component of pure Mater-Bi KE and reinforced biocomposite.

The bands placed at $1,089 \mathrm{~cm}^{-1}(\mathrm{C}-\mathrm{O}-\mathrm{C}$ stretch $)$ and $995 \mathrm{~cm}^{-1}(\mathrm{C}-\mathrm{O}-\mathrm{H}$ def $)$ are indicating reorganiza- 


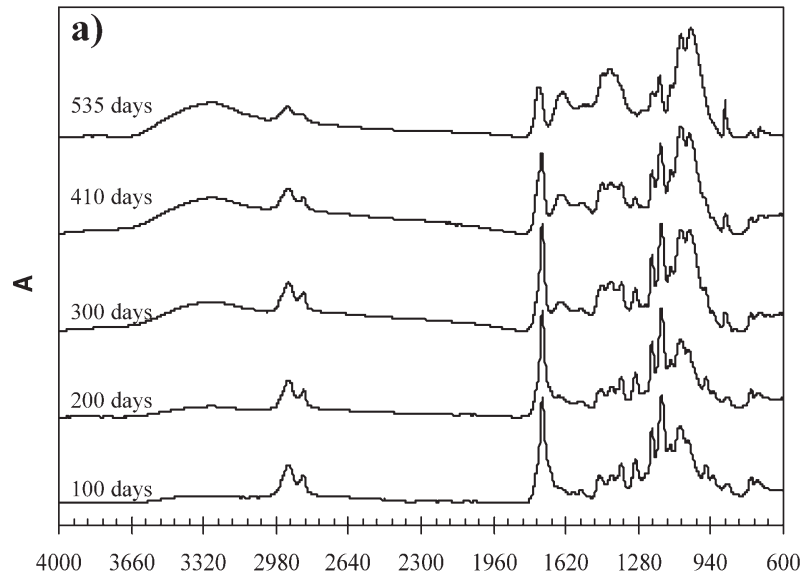

$\lambda(\mathrm{cm}-1)$

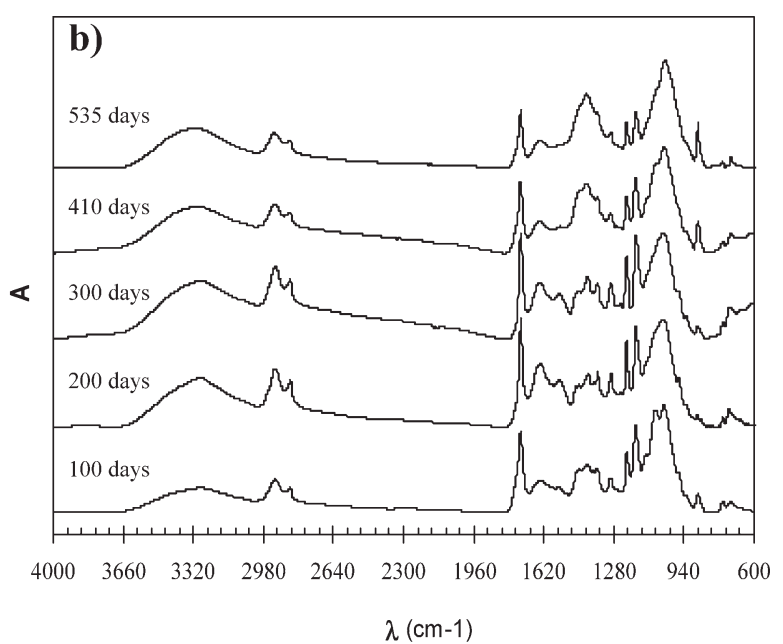

$\lambda(\mathrm{cm}-1)$

FIG. 2. FTIR spectra of the (a) pure Mater-Bi KE and (b) reinforced biocomposite at different exposure time.

tions in the starch component [32-34] due to the degradation in soil and influenced by the presence of natural fibers, in the case of the reinforced biocomposites. From these bands, the $\mathrm{C}-\mathrm{O}-\mathrm{C}$ functional group is chosen to monitor the starch degradation in the pure Mater-Bi KE and the starch together with the natural fiber degradation in the reinforced biocomposite.

To relate the degradation in soil changes of the synthetic component with the suffered from the starch component, the spectra are normalized with respect to the stretching vibration of the $\mathrm{C}-\mathrm{O}-\mathrm{C}$ group. Table 1 summarized the relative values of $\mathrm{I}_{\mathrm{C}=\mathrm{O}} / \mathrm{I}_{\mathrm{C}-\mathrm{O}-\mathrm{C}}$ for the degraded samples of the pure Mater-Bi KE and its reinforced biocomposite. In general, these results indicate a diminution of the characteristic band associated to the synthetic component with respect to the characteristic band related to the $\mathrm{C}-\mathrm{O}-\mathrm{C}$ functional groups due to the starch and the natural fiber. The diminution of $\mathrm{I}_{\mathrm{C}=\mathrm{O}} /$ $\mathrm{I}_{\mathrm{C}-\mathrm{O}-\mathrm{C}}$ in both materials suggests that the addition of the natural fiber does not obstruct the degradation of the synthetic component. Moreover, the lowest value of the band associated to the synthetic component for the reinforced biocomposite may indicate that the cotton fibers promote the degradation of the synthetic component of pure Mater-Bi KE.

TABLE 1. $\mathrm{I}_{\mathrm{C}=\mathrm{O}} / \mathrm{I}_{\mathrm{C}-\mathrm{O}-\mathrm{C}}$ of the pure Mater-Bi KE and the reinforced biocomposite as a function of the degradation in soil process.

\begin{tabular}{ccc}
\hline & \multicolumn{2}{c}{$\mathrm{I}_{\mathrm{C}=\mathrm{O}} / \mathrm{I}_{\mathrm{C}-\mathrm{O}-\mathrm{C}}$} \\
\cline { 2 - 3 } $\begin{array}{c}\text { Degradation } \\
\text { time (days) }\end{array}$ & Pure Mater-Bi KE & Reinforced biocomposite \\
\hline 0 & 1.76 & 1.73 \\
100 & 1.34 & 0.99 \\
200 & 1.34 & 0.98 \\
300 & 1.10 & 0.96 \\
410 & 0.91 & 0.88 \\
535 & 0.88 & 0.79 \\
\hline
\end{tabular}

\section{DSC Measurements}

Samples of pure Mater-Bi KE, cotton fibers, and the reinforced biocomposites were initially characterized by calorimetric measurements to analyze the possible thermal transition changes as a consequence of the soil burial test.

In previous work [19], cotton fiber was considered as a nucleant agent that can increase the crystallinity index as a result of a good interaction between the cotton fibers and the pure Mater-Bi KE. Figure 3 shows the cooling and heating scans of the cotton fibers as a function of the degradation time in soil. These cotton samples were subjected to a soil burial test only during 123 days, and after this time, the cotton samples could not be tested any more to their macroscopic deterioration. Only an increase in the endothermic shoulder in the heating scan attributed to reorganizations of cellulose chains can be observed as a result of the degradation in soil.

Figures 4 and 5 display the cooling and heating scan of pure Mater-Bi KE and the reinforced biocomposite, respectively, and nonsignificant changes on their shape can be observed as a function of the degradation in soil process. However, a decrease in the areas associated to the crystallization and melting of the crystalline chains of the synthetic polymer can be observed in both materials pure Mater-Bi KE and the reinforced biocomposite, as the degradation test progresses. Figure $6 \mathrm{a}$ and b plot the $\Delta H_{\mathrm{c}}$ and $\Delta H_{\mathrm{m}}$ of the crystalline chains of the synthetic component of the pure Mater-Bi KE and its reinforced biocomposite at different degradation times. During the first 300 days of exposure in soil, the crystalline content of both materials seems not to be affected by the degradation in soil. However, for a longer time, these values decrease for both materials, being the $\Delta H_{\mathrm{m}}$ and $\Delta H_{\mathrm{c}}$ of the reinforced biocomposite lower than the related to pure MaterBi KE. Thus, cotton fiber seems to enhance the decrease of the crystallinity index of the synthetic polymer when degradation in soil advances. 

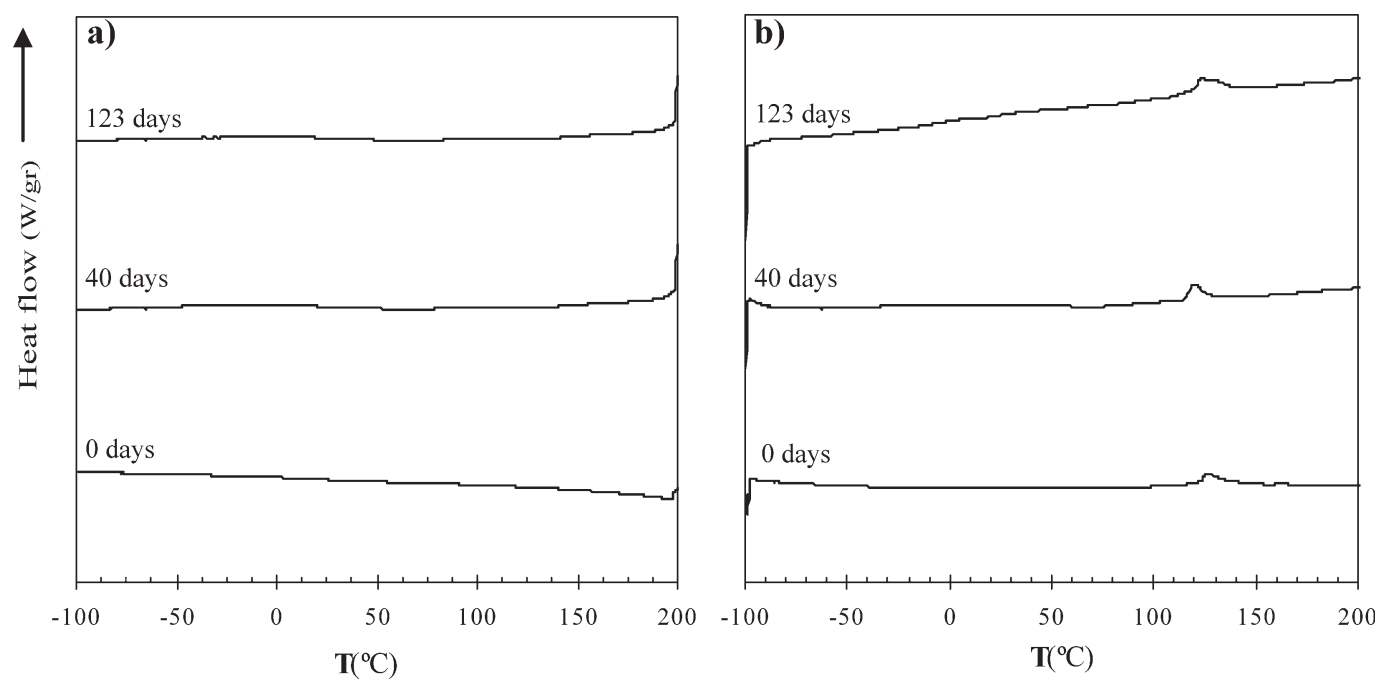

FIG. 3. DSC thermograms of the (a) second scan and (b) third scan of the cotton fibers as a function of the degradation in soil process.

SEM

Figure $7 \mathrm{a}$ and $\mathrm{b}$ displays the micrographs from the sectioned surface of pure Mater-Bi KE and reinforced biocomposite, respectively. A good dispersion and interaction of the natural fibers with the polymeric matrix can be observed.

In Fig. 7c and d, it was observed that the granular part of the Mater-Bi KE, which is associated to the starch [35, 36], disappears as a function of the degradation in soil. In contrast, these granular shapes remains unchanged in the reinforced biocomposite during the degradation, suggesting that the cotton fibers slow down the biodegradability of the starch.

Figure $7 \mathrm{~d}$ also shows that the natural fiber is damaged because of the degradation process in soil. According Bastioli et al. [37], the biodegradation of the synthetic component is caused by surface erosion due to the hydro-

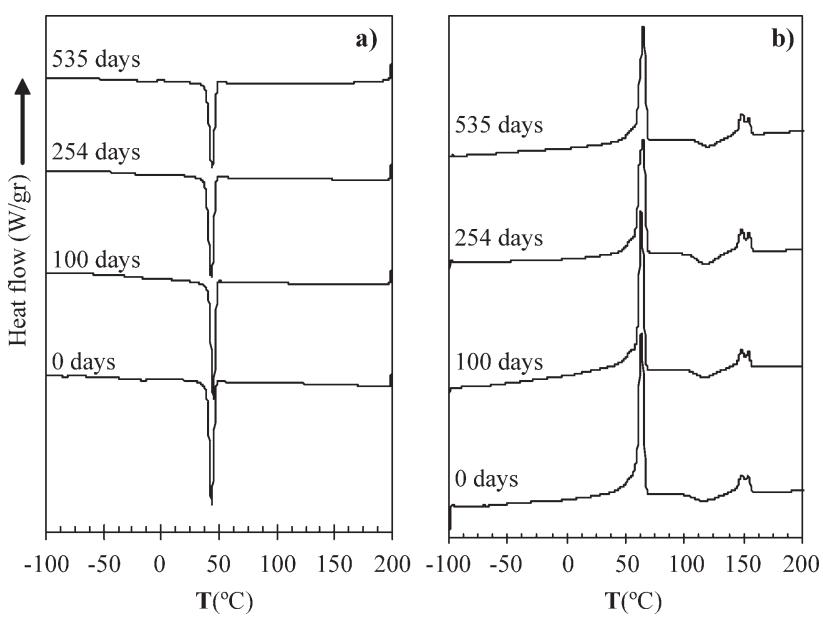

FIG. 4. DSC thermograms of the (a) second scan and (b) third scan of the pure Mater-Bi KE as a function of the degradation in soil process. lytic degradation of starch. Thus, the degradation of the cotton fibers could increase the available surface, enhancing the attack of the microorganisms to the synthetic component. As a result, the surface of the degraded reinforced biocomposite is rougher than the one of the pure Mater$\mathrm{Bi} \mathrm{KE}$, confirming that the presence of the cotton fiber enhances the degradation of the synthetic component by weakening its crystalline structure, according to the calorimetric results.

\section{Thermogravimetric Measurements}

TGA of pure Mater-Bi KE and the reinforced biocomposite was performed to ensure that the observed loss in morphological properties was not only due to morphological reorganizations during the soil burial test, but also due to its degradation process.

Figure 8 displays the evolution of the differential thermogravimetric (DTG) curve of cotton fiber at $20^{\circ} \mathrm{C} / \mathrm{min}$ as a function of degradation time. Similar patterns were

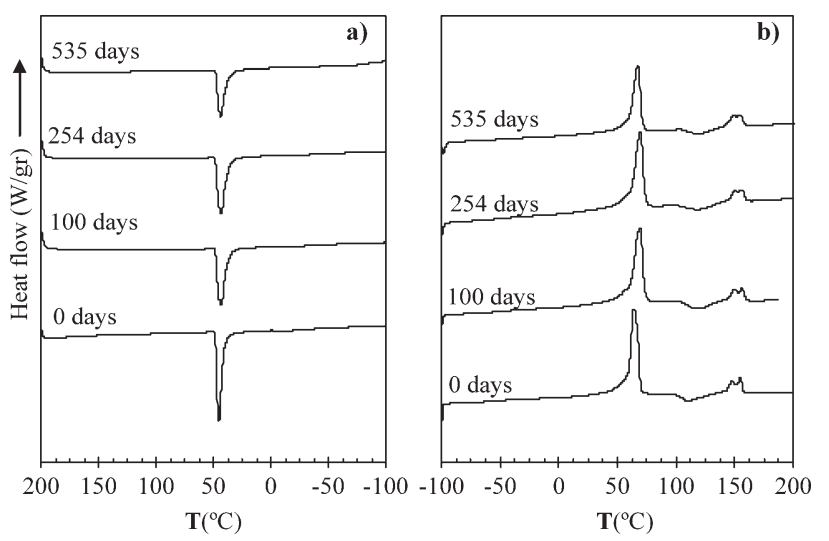

FIG. 5. DSC thermograms of the (a) second scan and (b) third scan of the reinforced biocomposites as a function of the soil burial test. 

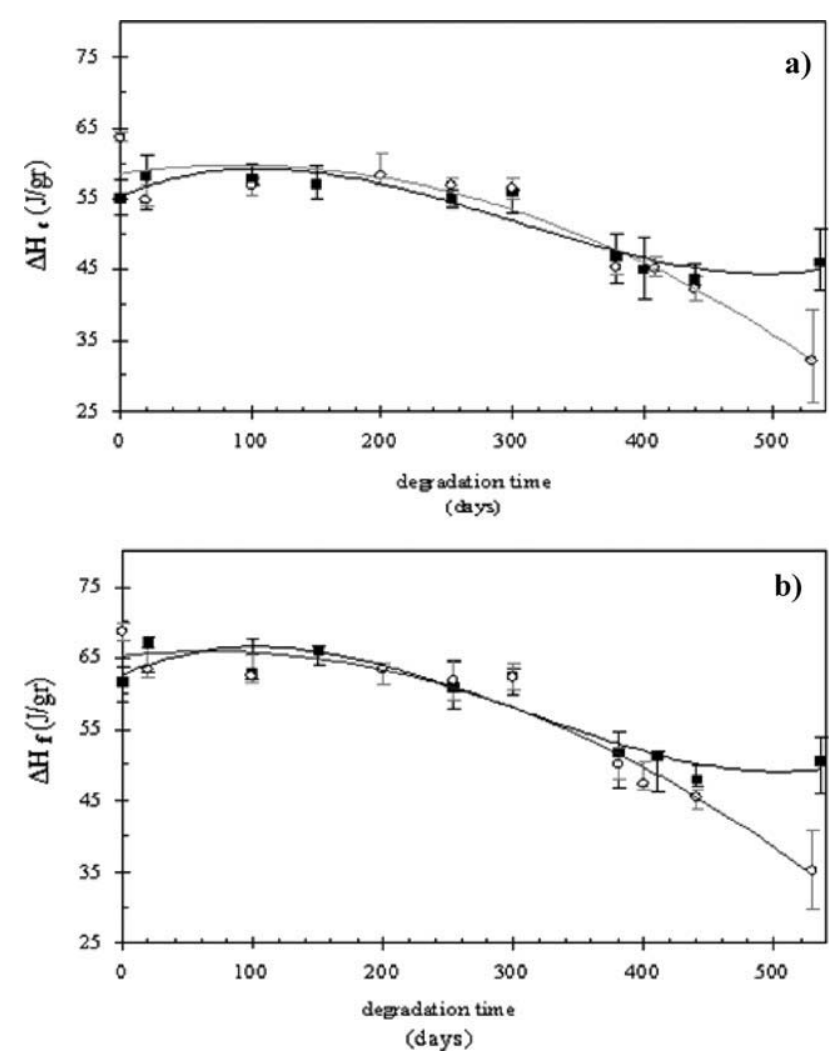

FIG. 6. Representation of the crystallization $\left(\Delta H_{\mathrm{c}}\right)$ and melting $\left(\Delta H_{\mathrm{m}}\right)$ enthalpies related to crystalline phase of the synthetic component of the (ם) pure Mater-Bi KE and $(\bigcirc)$ reinforced biocomposite as a function of the degradation in soil process.

obtained at different heating rates $\left(3,5,10\right.$, and $30^{\circ} \mathrm{C} /$ $\mathrm{min}$ ), and they are not shown here for the sake of clarity. Cotton fibers displays a complex thermal decomposition with two mass-loss regions. The first region $\left(30-160^{\circ} \mathrm{C}\right)$, which is attributed to the loss of absorbed water [38], increased from 3 to $5 \%$ of mass as a function of the degradation time. The second and main mass-loss region $\left(200-400^{\circ} \mathrm{C}\right)$ was associated to the thermal decomposition of hemicellulose, pectin, and cellulose [39, 40]. Once the degradation process in soil starts, the main mass-loss region of cotton fibers becomes narrower and significantly decreases, suggesting that the hemicellulose and cellulose are being removed during the degradation process in soil [41].

Figure 9 displays the pure Mater-Bi KE DTG curves as a function of degradation times at the heating rate of $20^{\circ} \mathrm{C} / \mathrm{min}$. TG curves obtained at the other heating rates are not showed for the sake of clarity. These thermograms display a complex thermal decomposition with two main mass-loss regions for all tested samples. According to our previous studies [19], the first mass-loss region centered on $335^{\circ} \mathrm{C}$ is related to the thermal decomposition of the starch component, and the second one that appears around $434^{\circ} \mathrm{C}$ is associated to the thermal decomposition of the synthetic component present in the pure Mater-Bi KE. Although the shape of pure Mater-Bi KE DTG curves do not change as a result of the soil burial test, changes in the thermal stability and in the mass loss can be observed. Table 2 summarizes the characteristic thermogravimetric parameters of each component present in the Mater-Bi $\mathrm{KE}$ at different degradation times.

The temperature peak of the first mass-loss region related to starch displayed different stages when the exposure in soil progresses. In a first stage from 0 to 24 days, the temperature peak shifted toward higher temperatures, reaching $354^{\circ} \mathrm{C}$. In a second stage from 24 to 200 days, the temperature peak remained constant. Finally, in the last stage from 200 to 535 days, a decrease in the temperature peak as a function of the exposure time was observed to reach $330^{\circ} \mathrm{C}$, probably due to chain scission reactions. On the other hand, the thermogravimetric parameters associated to the synthetic component of the pure Mater-Bi KE slightly and progressively decreased from 200 days to the end of the exposure time in soil.

The thermal decomposition of the reinforced biocomposite shows the same mass-loss regions as that of pure Mater-Bi KE. However, an increase in the temperature peak of the first mass-loss region is observed because the thermal decomposition of the most of the cotton fiber occurs in the same temperature region than the pyrolysis of the starch of pure Mater-Bi KE (Table 2). The thermogravimetric parameters of the reinforced biocomposite at each selected degradation time are also shown in Table 2. It is noticeable that the last stage of degradation in soil of starch began after of 300 days in the reinforced biocomposite instead of beginning at 200 days as in the pure Mater-Bi KE. Thus, cotton fibers seem to slow down the changes caused by the soil burial test on the starch present in the pure Mater-Bi KE; these results are in accordance with those found in the SEM micrographics.

On the other hand, nonsignificant changes are observed on the temperature peak associated to the synthetic component as a function of the soil burial test because of the presence of the cotton fibers. However, the mass-loss rate related to the synthetic component is major in the reinforced biocomposite than in the pure Mater-Bi KE, indicating a major degradation of the synthetic component in the reinforced biocomposites.

\section{Kinetic Analysis}

The kinetic parameters of rate law (the apparent activation energies $\left(E_{\mathrm{a}}\right)$, the kinetic model that describe the reaction mechanism $(f(\alpha))$ and the pre-exponential factor (A)) were studied to more deeply analyze the changes of reinforced biocomposites during the degradation in soil.

The methodology proposed to analyze the kinetic parameters of these materials was proved to be accurate and useful in previous works $[8,19]$. Figure 10 presents the results of applying the Kissinger method [42] to determine the $E_{\mathrm{a}}$ values of each thermal decomposition process at the selected degradation times, knowing that this "freemodel" method could asses as good results as isoconver- 

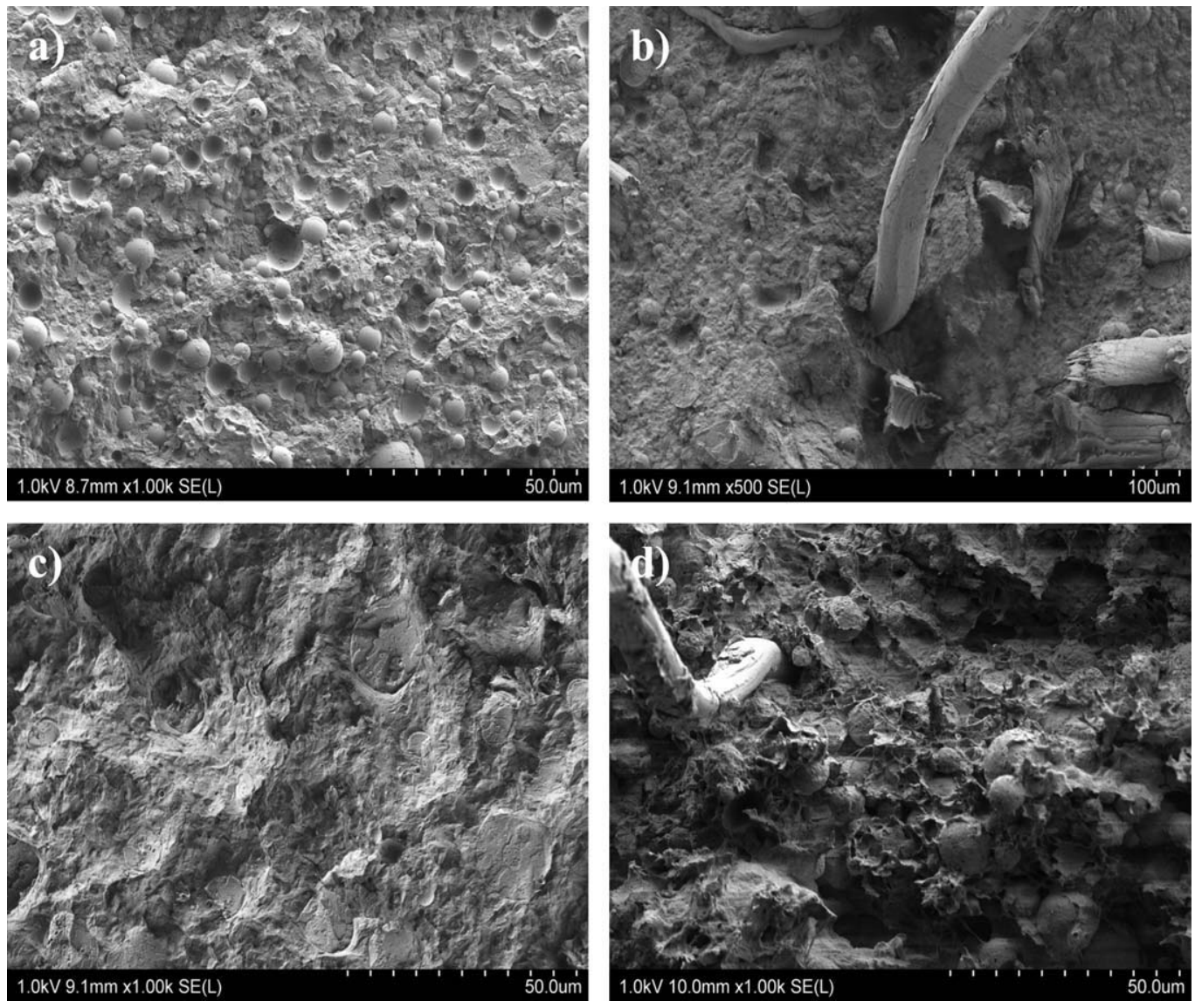

FIG. 7. Scanning electron micrographs of the sectioned surfaces of the (a) pure Mater-Bi KE, (b) reinforced biocomposite, (c) pure Mater-Bi KE at 535 days of degradation, and (d) reinforced biocomposite at 535 days of degradation.

sional Friedman and Flyn-Wall-Ozawa methods [43, 44]. Criado method [45] was also used to identify the probable $f(\alpha)$ of each thermal decomposition process, and CoatsRedfern method [46] was finally employed to determine the actual $f(\alpha)$ and the $A$.

Table 3 summarizes the kinetic parameters for the pure Mater-Bi KE and the reinforced biocomposite. The $E_{\mathrm{a}}$

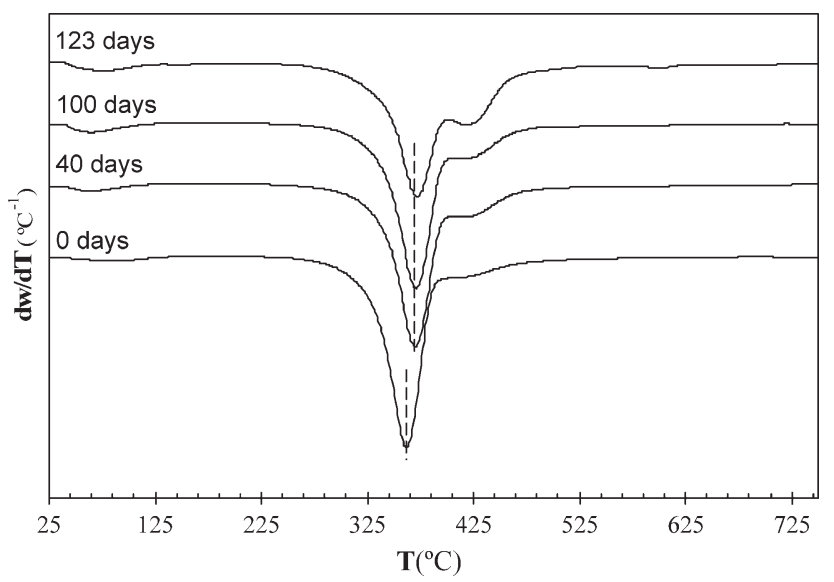

FIG. 8. DTG curves of cotton fibers as a function of the degradation in soil at the heating rate of $20^{\circ} \mathrm{C} / \mathrm{min}$. values of the first mass-loss region of both materials indicate different stages as the degradation in soil advances. These stages are determined by: (i) The $E_{\mathrm{a}}$ values increase $19 \mathrm{~kJ} / \mathrm{mol}$ during the first 24 days of degradation in soil for both materials. Bastioli et al. [37] proposed the

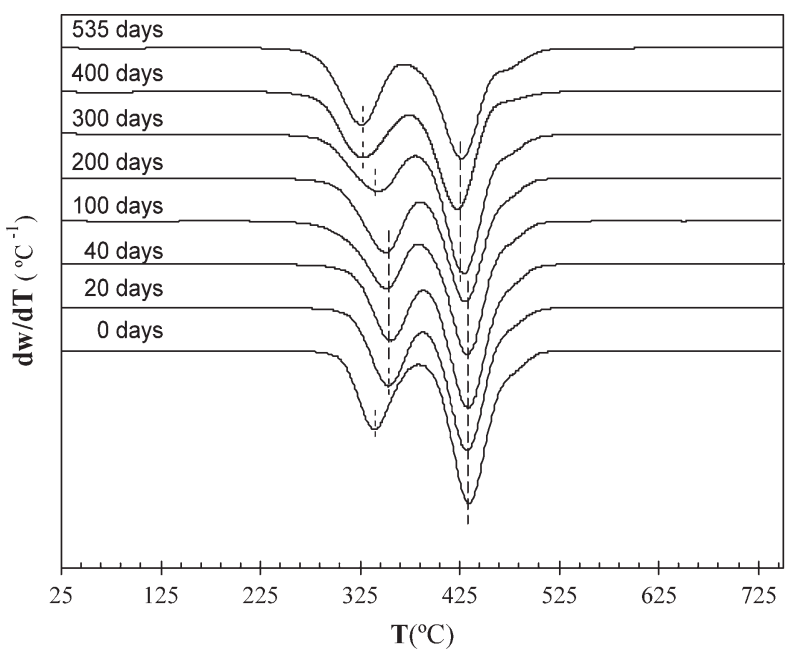

FIG. 9. DTG curves of the pure Mater-Bi KE as a function of the degradation in soil at the heating rate of $20^{\circ} \mathrm{C} / \mathrm{min}$. 


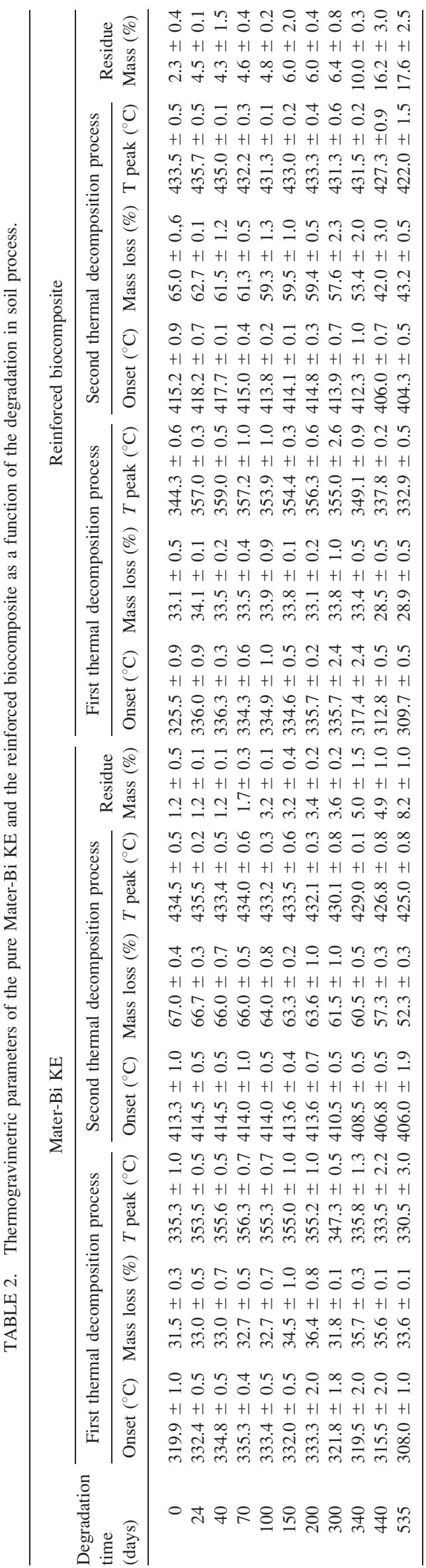

hydrolysis of the starch by extracellular enzymes as the first step to define the biodegradation mechanisms of the Mater-Bi. It is now possible to prove that fiber addition does not change the hydrolysis of the starch because of the increment in the activation energy is the same in both pure Mater-Bi KE and reinforced biocomposite. (ii) In a second stage, the $E_{\mathrm{a}}$ remained constant around $130 \mathrm{~kJ} / \mathrm{mol}$ in reinforced biocomposites and $118 \mathrm{~kJ} / \mathrm{mol}$ in pure Mater-Bi KE. Furthermore, this stage was longer in reinforced biocomposite (300 days of exposure in soil) than in pure Mater-Bi KE (200 days of degradation in soil). (iii) During the third stage, the $E_{\mathrm{a}}$ values started to decrease until similar values were reached in the pure Mater-Bi KE and the reinforced biocomposite.

The kinetic model of this first thermal decomposition process was assessed by Criado and Coats-Redfern (Table 3) methods. This thermal decomposition process occurs follow a $\mathrm{n}$ - and $\mathrm{m}$ - type mechanism, being the algebraic function $f(\alpha)=\alpha^{m}(1-\alpha)^{n}$. Initially, the $n$ and $m$ exponents were the same $m=0.5$ and $n=1.5$ for both nondegraded Mater-Bi KE and reinforced biocomposite. After 535 days of degradation in soil, the exponents change slightly; these were $m=0.3$ and $n=1.3$, and following a similar trend for pure Mater-Bi KE and the reinforced biocomposite.

The higher $E_{\mathrm{a}}$ value during a longer time (300 days of the exposure in soil) in the second stage of the first massloss region in reinforced biocomposite suggest that the presence of the cellulose and hemicelluse in the cotton fiber slow down the degradation in soil of starch. However, the stable interactions occurring between the cotton fibers and the starch do not alter the kinetic model that this first decomposition region follows, maybe due to the similar chemical composition of cotton fiber and starch [47].

By the addition of the fibers, the $E_{\mathrm{a}}$ values of the second mass-loss region associated to the thermal decompo-

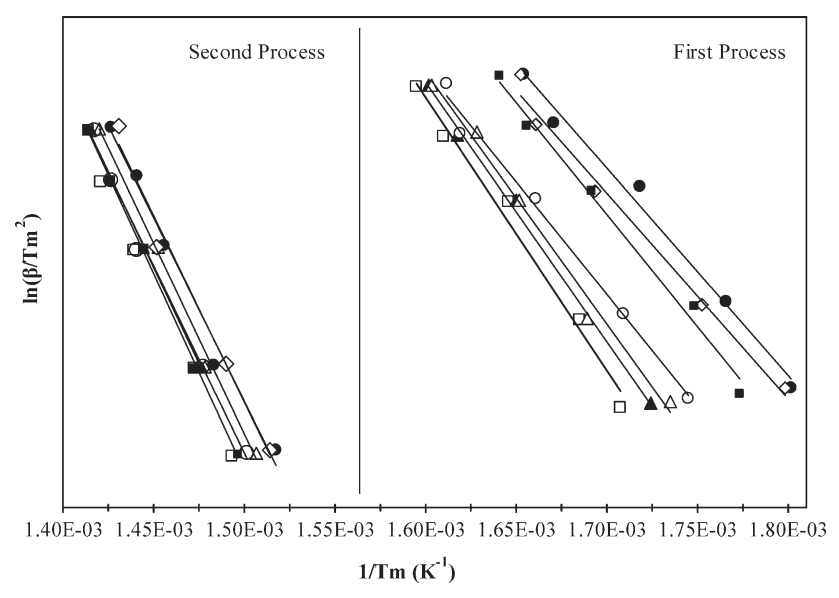

FIG. 10. Kissinger plots for the Mater-Bi KE and its reinforced biocomposite as a function of the selected degradation times; ( 0 ) 0 days, $(\square) 20$ days, $(\triangle) 100$ days, $(\boldsymbol{\Delta}) 200$ days, $(\bigcirc) 300$ days, $(\bullet) 410$ days and $(\diamond) 535$ days. 


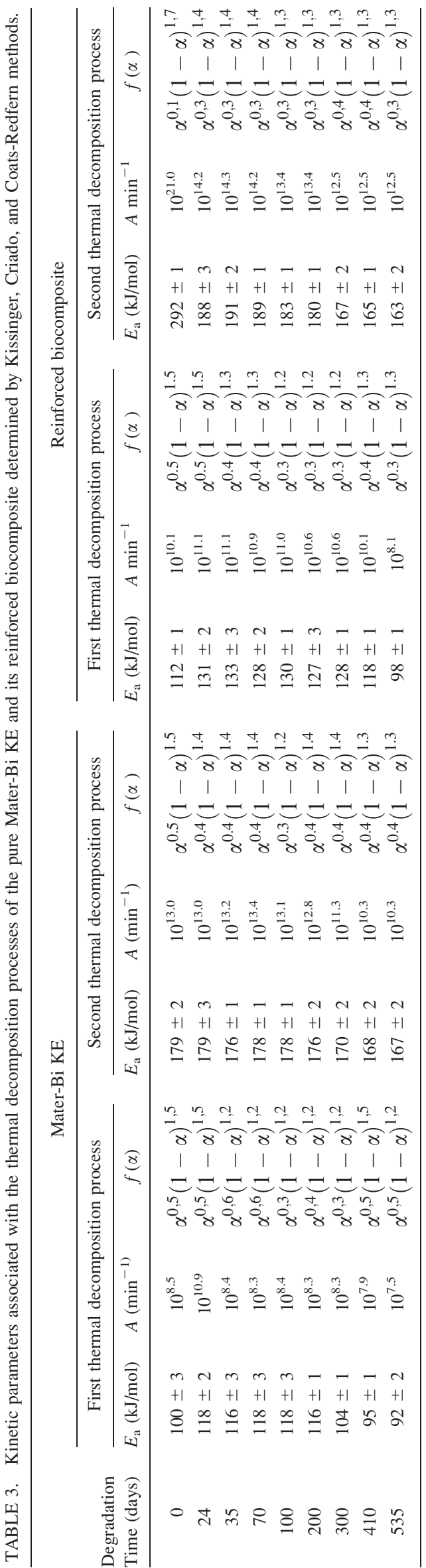

sition process of the synthetic component shows an important increase (from 179 to $292 \mathrm{~kJ} / \mathrm{mol}$ ). This result highlights that the addition of cotton fibers changes the initial thermal decomposition process of synthetic component. Furthermore, differences in the trend of the $E_{\mathrm{a}}$ values related to the thermal decomposition process of the synthetic component in the pure Mater-Bi $\mathrm{KE}$ and in the reinforced biocomposite are observed when the exposure in soil progresses. The $E_{\mathrm{a}}$ values of the synthetic component in the pure Mater-Bi KE exhibited two different stages: constant $E_{\mathrm{a}}$ values during the first 200 days of exposure and a decrease of $E_{\mathrm{a}}$ values from 200 to 535 days of exposure. This behavior agrees with the aforementioned theory by Bastioli et al. [37] who described the degradation of the synthetic component in the pure Mater-Bi as a consequence of the degradation of the starch. However, the $E_{\mathrm{a}}$ values related to the synthetic component of the reinforced biocomposite displays a uniform decrease as a function of the soil burial test, suggesting the degradation in the reinforced biocomposite depends not only on the starch but also on the cotton fiber presence. Thus, the degradation of cotton fibers enhances the available surface to the microorganism attack the synthetic component in the reinforced biocomposites.

The kinetic mechanism of the thermal decomposition process associated to the synthetic polymer was also assessed (Table 3). This thermal decomposition process also occurs following a $\mathrm{n}$ - and m-type mechanism, being the algebraic function $f(\alpha)=\alpha^{m}(1-\alpha)^{n}$. Initially, the $n$ and $m$ exponents are $m=0.5$ and $n=1.5$ and $m=0.1$ and $n=1.7$ for nondegraded pure Mater-Bi KE and reinforced biocomposite, respectively. After 535 days of degradation in soil, the $n$ and $m$ exponents reach similar values in both pure Mater-Bi KE and reinforced biocomposites. These results prove that the addition of cotton fibers modifies the initial decomposition kinetics of the synthetic component of the pure Mater-Bi KE and justifies the higher values of its initial $E_{\mathrm{a}}$. The similar kinetic parameters obtained for the pure Mater-Bi KE and its reinforced biocomposite point out that when the cotton fibers are degraded the synthetic component has a similar kinetic behavior in both materials.

\section{CONCLUSIONS}

Cotton fibers can be successfully incorporated into the pure Mater-Bi KE. The loss of physical properties of the pure Mater-Bi KE and the reinforced biocomposite has been assessed by thermal analysis. The accelerated soil burial test modifies the molecular structure of pure Mater$\mathrm{Bi} \mathrm{KE}$, decreasing the activation energies related to the starch and synthetic component from 200 days of degradation in soil. When cotton fibers are added into the pure Mater-Bi KE, the degradation of starch component is slowed down because of both the presence of cellulose and hemicellulose components and the interactions between the natural fiber and the pure Mater-Bi KE. The 
degradation of cotton enhances the available surface area and thus promotes the attack of the microorganisms to the synthetic component. As a consequence, the $\mathrm{C}=\mathrm{O}$ functional groups associated to the synthetic component, the crystalline structure and the superficial morphology are more damaged by the soil burial test in the reinforced biocomposites than in the pure Mater-Bi KE.

\section{ACKNOWLEDGMENTS}

The authors are grateful for the financial support received for this work from the Ministerio de Educación y Ciencia (Spanish Government) and the European Regional Development Found for the economical support and the FPI predoctoral grant concession. The Minesterio of Medio Ambiente (Spanish Government) is also acknowledged for its financial support.

\section{REFERENCES}

1. A.K. Mohanty, M. Misra, and T.D. Drzal, J. Polym. Envir., 10, 1 (2002).

2. P.A. Fowler, J.M. Hughes, and R.M. Elias, Sci. Food. Agric., 86, 1781 (2006).

3. A.K. Mohanty, M. Misra, and T.D. Drzal, Eds., Natural Fibers, Biopolymers and Biocomposites, Boca Raton, Taylor \& Francis, 2005.

4. A.K. Mohanty, M. Misra, and G. Hinrichsen, Macromol. Mater. Eng., 1, 276 (2000).

5. S.H. Imam, R.V. Greene, H.L. Griffin, Appl. Environ. Microbiol., 56, 1317 (1990).

6. R. Moriana-Torró, L. Contat-Rodrigo, L. Santonja-Blasco, and A. Ribes-Greus, J. Appl. Polym. Sci., 109, 1177 (2008).

7. L. Santonja-Blasco, L. Contat-Rodrigo, R. Moriana-Torró, and A. Ribes-Greus, J. Appl. Polym. Sci., 106, 2218 (2007).

8. J.D. Badia, R. Moriana, L. Santonja-Blasco, and A. RibesGreus, Macromol. Symp., 272, 93 (2008).

9. L. Contat-Rodrigo, A. Ribes-Greus, and C.T. Imrie, J. Appl. Polym. Sci., 86, 174 (2002).

10. C. Bastioli, A. Cerutti, I. Guanella, G.C. Romano, and G. Tosin, J. Envir. Poly. Degrad., 3, 2 (1995).

11. D. Dermirgöz, C. Elvira, J.F. Mano, A.M. Cunha, E. Piskin, and R.L. Reis, Polym. Degrad. Stab., 70, 161 (2000).

12. D.S. Rosa, J.E. Volponi, and C.G.F. Guedes, J. Appl. Polym. Sci., 102, 825 (2006).

13. D.S. Rosa, D.R. Lopes, and M.R. Calis, Polym. Test., 24, 756 (2005).

14. C. Schönweitz, Consolidated progress report for EU FAIR CT98-3919, European Commission, Directorate General XII-E. 2 2001; SDME 8/26.

15. S.H. Iman, P. Cinelli, S.H. Gordon, and E. Chielline, $J$. Polym. Environ., 13, 47 (2005).

16. C.R. Di Franco, V.P. Cyras, J.P. Busalmen, R.A. Ruseckaite, and A. Vazquez, Polym. Degrad. Stab., 86, 95 (2004).

17. V.A. Alvarez and A. Vázquez, Polym. Degrad. Stab., 91, 3156 (2006).
18. V.A. Alvarez, R.A. Ruseckaite, and A. Vázquez, J. Thermoplast. Compos. Mater., 20, 291 (2007).

19. R. Moriana, J.D. Badia, L. Santonja-Blasco, and A. RibesGreus, J. Appl. Polym. Sci., submitted for publication.

20. M. Morreales, S. Scaffaro, A. Maio, and F.P. La Mantia, Compos. A, 39, 503 (2008).

21. R. Scaffaro, M. Morreale, G. Lo Re, and F.P. La Mantia, Polym. Degrad. Stab., 8, 1220 (2009).

22. DIN 53739 Testing of plastics. Influence of Fungi and Bacteria. Visual Evaluation. Change in Mass and Physical Properties, Nov. 1984.

23. S.H. Imam, S.H. Gordon, A. Mohamed, R. Harry-O'kuru, B.S. Chiou, G.M. Glenn, and W.J. Orts, Polym. Degrad. Stab., 91, 2894 (2006).

24. G. Socrates, Infrared and Raman Characteristic Groups Frequencies, England, Wiley,2001.

25. W.F. Wolkers, E.A. Oliver, F. Tablin, and J.H. Crowe, Carbohydr. Res., 339, 1077 (2004).

26. J.W. Park, S.S. Im, S.H. Kim, and Y.H. Kim, Polym. Eng. Sci., 40, 2539 (2000).

27. S.M. Goheen and R.P. Wool, Appl. Polym. Sci., 42, 2691 (1991).

28. H. Chi, K. Xu, X. Wua, Q. Chen, D. Xue, C. Song, W. Zhang, and P. Wang, Food Chem., 106, 923 (2008).

29. X.F. Ma, J.G.J. Yu, K. He, and N. Wang, Macromol. Mater. Eng., 292, 503 (2007).

30. A. Pawlak and M. Mucha, Thermochim. Acta., 396, 153 (2003).

31. J. Kapusniak and P. Siemion, J. Food Eng., 78, 323 (2007).

32. P.D. Vasco, J. Blackwell, and J.L. Koenig, Carbohydr. Res., 9, 297 (1971).

33. P.D. Vasco, J. Blackwell, and J.L. Koenig, Carbohydr. Res., 23, 407 (1972).

34. J.J. Cael, J.L. Koenig, and J. Blackwell, Carbohydr. Res., 29, 123 (1973).

35. S.H. Imam, L. Chen, S.H. Gorden, R.L. Shorgen, D. Weisleder, and R.V. Greener, J. Polym. Environ., 6, 91 (1998).

36. C. Bastioli, Polym. Degrad. Stab., 59, 263 (1998).

37. C. Bastioli, Handbook of Biodegradable Polymers, Shrewsbury, Rapra Technology,2005.

38. V. Mamleev, S. Bourbigot, and J. Yvon, J. Anal. Appl. Pyrol., 80, 151 (2007).

39. P. Aggarwal, D. Dollimore, and K. Heon, J. Therm. Anal. Calorim., 50, 7 (1997).

40. Y. Fei, W. Qinglin, L. Yong, G. Weihong, and X. Yanjun, Polym. Degrad. Stab., 93, 90 (2008).

41. A.K. Mohanty, M. Misra, and G. Hinrichsen, Biofibres. Macromol. Mater. Eng., 1, 276 (2000).

42. H.E. Kissinger, J. Res. Natl. Bur. Stand., 57, 217 (1956).

43. H.L. Friedman, J. Appl. Polym. Sci., 6, 183 (1964).

44. T. Ozawa, Bull. Chem. Soc. Jpn., 38, 1881 (1965).

45. J.M. Criado, Thermochimic. Acta., 24, 86 (1978).

46. A.W. Coats and J.P. Redfern, Nature, 201, 68 (1964).

47. D. Puglia, A. Tomassuci, and J.M. Kenny, Polym. Adv. Tech., 14, 749 (2003). 
“CHARACTERISATION OF THE DEGRADATION OF REINFORCED MATER-BI KE/HEMP, MATER-BI KE/FLAX, MATER-BI KE/JUTE AND MATER-BI KE/KENAF BIOCOMPOSITES IN SOIL" 



\title{
"CHARACTERISATION OF THE DEGRADATION OF REINFORCED MATER-BI KE/HEMP, MATER-BI KE/FLAX, MATER-BI KE/JUTE AND MATER-BI KE/KENAF BIOCOMPOSITES IN SOIL"
}

\begin{abstract}
An accelerated soil burial tests have been performed on a pure commercial starchbased thermoplastic (Mater-Bi KE 03B1) and its different reinforced biocomposites (Mater-Bi KE/flax, Mater-Bi KE/kenaf, Mater-Bi KE/hemp and Mater-Bi KE/jute) for simulating non-controlled disposal. Degradation in soil promotes physical and chemical changes in the properties of all studied materials, as characterized by Differential Scanning Calorimetry (DSC), Thermogravimetric Analysis (TGA), Scanning Electron Microscopy (SEM) and Infrared Spectroscopy of Fourier (FTIR). A comparative study between the reinforced biocomposites allows the determination of the influence of flax, kenaf, hemp and jute fibres on the degradation of pure Mater-Bi KE. Thermogravimetric and kinetic results reveal that degradation in soil of pure Mater-Bi KE occurs in stages, where the degradation of the synthetic component results as a consequence of starch degradation. During the degradation in soil of the Mater-Bi KE, a decrease of the crystalline index and a decrease of the $\mathrm{C}=\mathrm{O}$ band associated to the ester group of the synthetic component can be observed. The degradation of the flax, hemp, kenaf and jute fibres enhances the available surface area and thus promotes the attack of the microorganisms to the synthetic component. Kenaf fibres acts as the main promoter of the degradation process in soil for the synthetic component of pure Mater-Bi KE, which could be due to the major percentage of hemicellulose in kenaf fibre.
\end{abstract}

Keywords: Natural fibres, Biopolymer, Thermal properties, Degradation in soil, Chemical Structure 


\section{Results and Discussion}

\section{Differential Scanning Calorimetry Measurements}

Samples of pure Mater-Bi KE and the reinforced biocomposites were initially characterised by calorimetric measurements to analyse the possible thermal transition changes as a consequence of the soil burial test. As it was reported in previous works [1,2], pure Mater-Bi $\mathrm{KE}$ displays a prominent peak around $63^{\circ} \mathrm{C}$ in the heating scan and at $43^{\circ} \mathrm{C}$ in the cooling scan, which are related to the melting and the crystallisation of the crystalline phase of the synthetic biodegradable component. The presence of natural fibres does not induce extensive changes on the shapes of calorimetric thermograms of reinforced biocomposites but only a slight increase in crystallisation temperatures.

All the studied samples were subjected to a soil burial test during 535 days. Figure 1 display the cooling scan curves for the pure Mater-Bi KE/hemp at selected soil burial times as an example. During the degradation in soil process, a decrease in the enthalpy areas $(\Delta \mathrm{Hm}$ and $\Delta H c)$ of the main peaks of pure Mater-Bi KE and the reinforced composites can be observed.

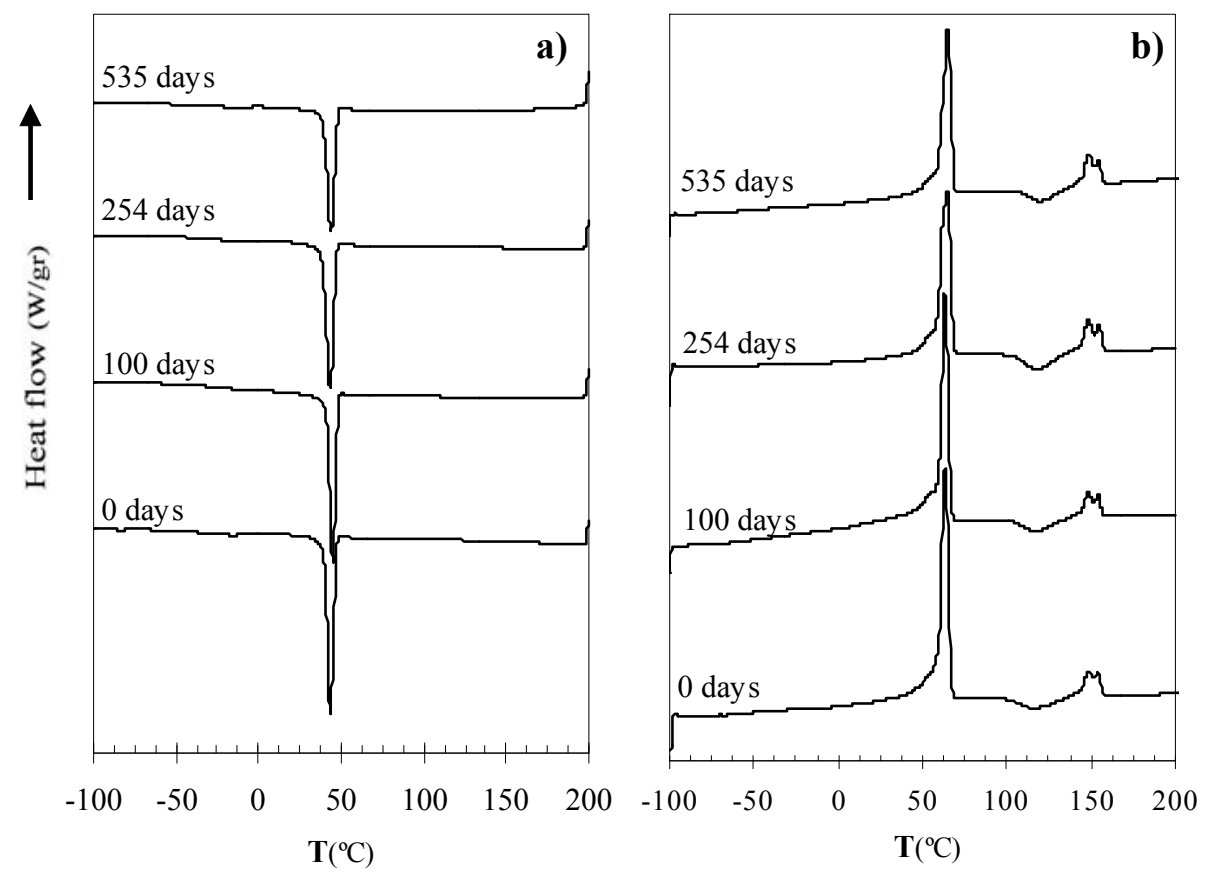

Figure 1. DSC thermograms of the a) second scan and $\mathbf{b}$ ) third scan of the pure Mater-Bi KE/hemp as a function of the degradation in soil process. 
In order to asses the influence of each natural fibre, Figure 2 plots the $\Delta H m$ of the crystalline phase of the synthetic component of the pure Mater-Bi KE and its reinforced biocomposite at different buried times. During the first 200 days the crystalline content of all materials seems unaffected by the degradation in soil. For longer times, the melting enthalpies, $\Delta \mathrm{Hm}$ of the crystalline phase of the synthetic component decrease for all materials, especially for the Mater-Bi KE/kenaf. The reinforced Mater-Bi KE/jute and Mater-Bi KE/hemp biocomposites have similar $\triangle H m$ values to pure Mater-Bi $\mathrm{KE}$, whereas the values for Mater-Bi KE/flax are higher. Thus, different fibres seem to affect the decrease in crystallinity of the composites with respect of the matrix in different ways as the degradation in soil advances.

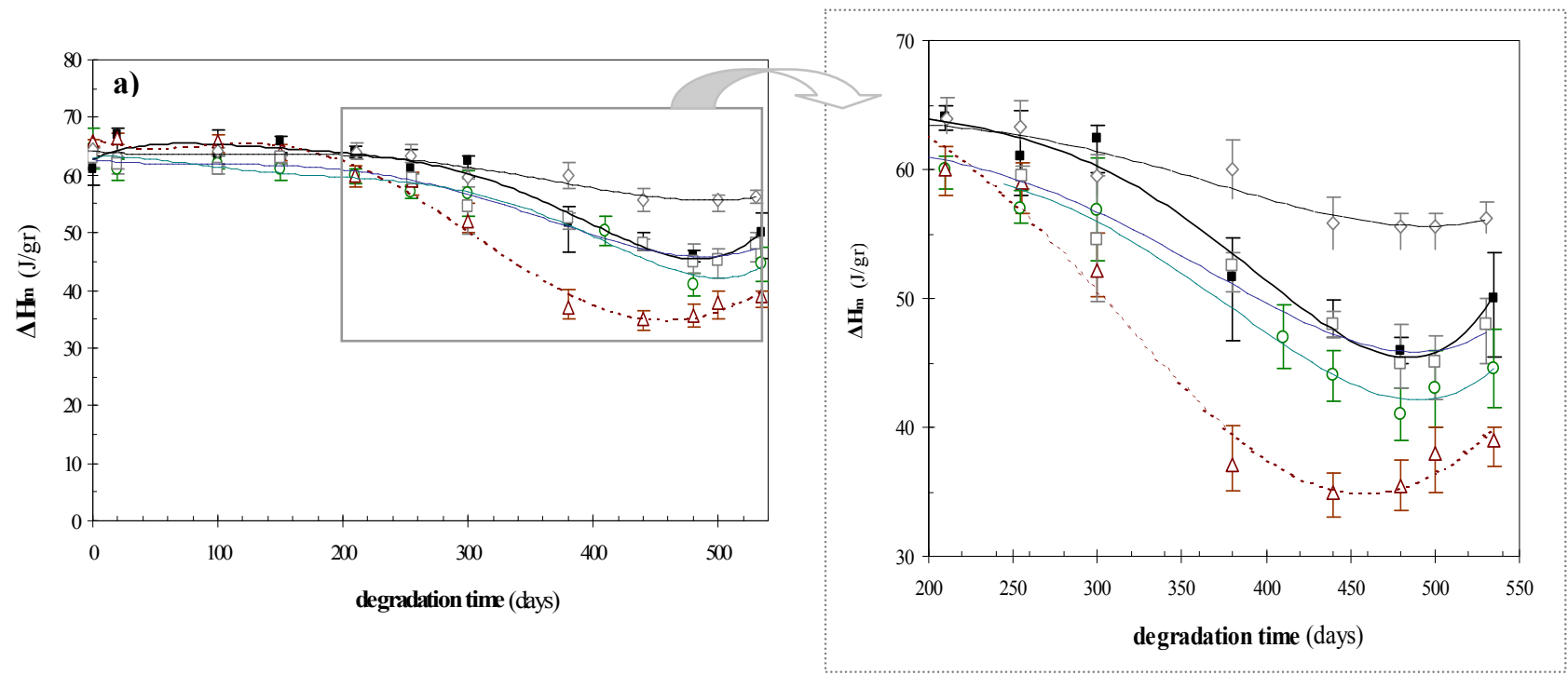

Figure 2. Evolution of the melting enthalpies related to crystalline phase of the synthetic component as a function of the degradation in soil process: (ロ) pure Mater-Bi KE, ( $\diamond)$ Mater-Bi KE/flax, (०) Mater-Bi KE/jute, ( $\square$ ) Mater-Bi KE/hemp and ( $\triangle$ ) Mater-Bi KE/kenaf

The evolution of the melting enthalpies as a function of the degradation time has a different minimum depending on the type of the natural fibre present in the biocomposite. These differences between the reinforced biocomposites can be clearly observed in Figure 2. The reinforced Mater-Bi KE/kenaf biocomposites reach this minimum at 450 days, whereas the rest of the fibres present this minimum at 480 days as the pure Mater-Bi KE. Thus, kenaf fibres seem to promote the degradation of the synthetic part of the pure Mater-Bi KE during the degradation in soil process. 


\section{Scanning Electron Microscopy}

Figures $3 a$ and $3 b$ display the micrographs from the sectioned surface of pure Mater-Bi KE and degraded pure Mater-Bi KE.
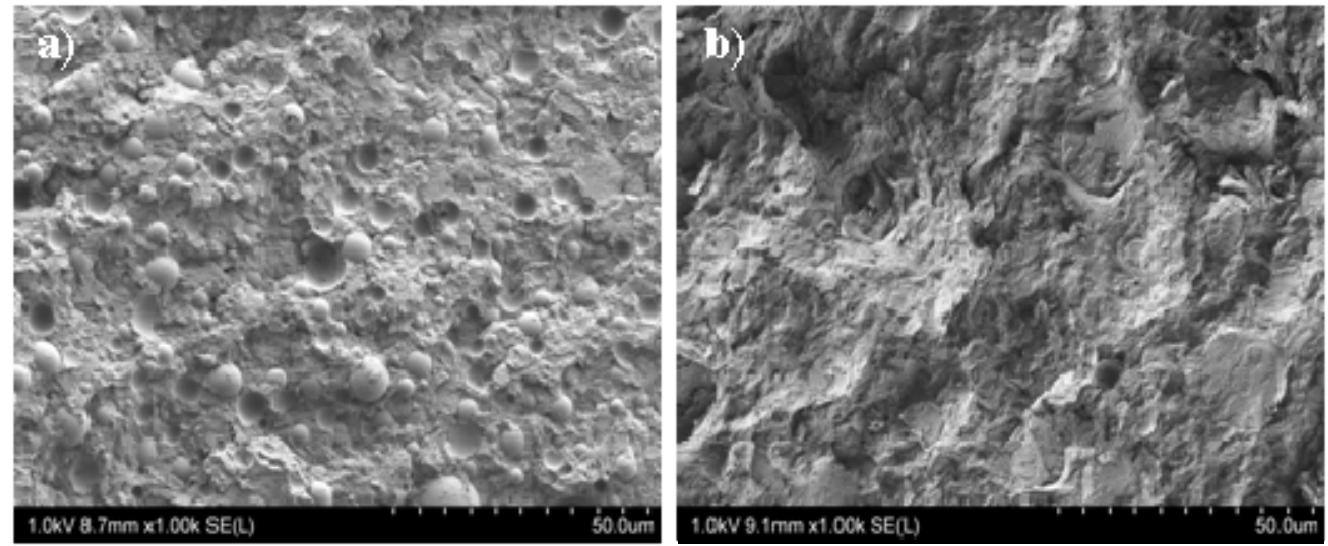

Figure 3. SEM micrographs of the sectioned surfaces of a) pure Mater-Bi KE, b) pure Mater-Bi KE at 535 days of degradation.

Figure $3 a$ shows a particular structure for pure Mater-Bi KE with granules clearly embedded and distributed within a continuous phase. The granular part of the Mater-Bi KE, associated to starch [3.4], disappears at the end of the soil burial test, as it can be observed in Figure $3 b$.

Figure 4 displays the micrographs of the surface of non degraded and degraded reinforced biocomposites. In the reinforced biocomposite, the granular shapes remained unchanged during the degradation (Figure $4 b, 4 d, 4 f$ and $4 h$ ) suggesting that the presence of natural fibres contributes to slow down the changes on the starch component caused by degradation in soil. The degraded reinforced Mater-Bi KE/hemp, Mater-Bi KE/kenaf and Mater-Bi $\mathrm{KE} / \mathrm{jute}$ biocomposites present rougher surfaces compared to pure Mater-Bi KE. However, the reinforced Mater-Bi KE/flax displays a less rough surface when is degraded (Figure 4d). These results confirm that the presence of kenaf, hemp and jute fibres affect in a major extent the degradation in soil of the synthetic component than the flax fibre, in agreement with the calorimetric results. 

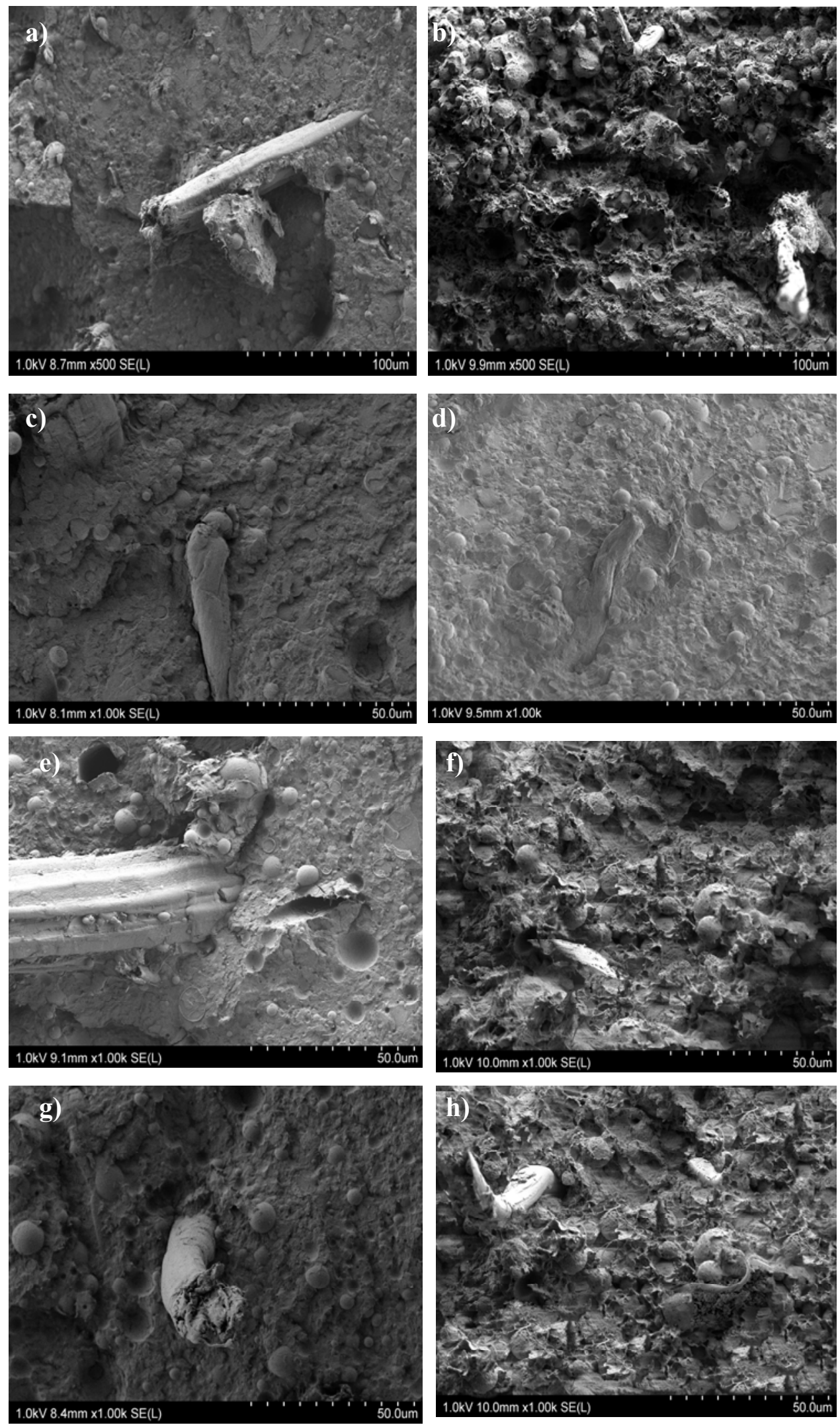

Figure 4.SEM micrographs of the sectioned surfaces of a) Mater-Bi KE/hemp, b) degraded Mater-Bi KE/hemp,c) Mater-Bi KE/flax, d) degraded Mater-Bi KE/flax, e) Mater-Bi KE/kenaf, f) degraded Mater-Bi KE/kenaf, g) Mater-Bi KE/jute and h) degraded Mater-Bi KE//jute. 


\section{Thermogravimetric Measurements}

Thermogravimetric analysis of pure Mater-Bi KE and its reinforced biocomposites was performed in order to determine the thermogravimetric and kinetic parameters of each thermal decomposition process through their degradation in soil. The profile of the derivative thermogravimentric curve of pure Mater-Bi KE does not change as a function of soil burial test, in agreement with in previous works [7]. Mater-Bi KE displays a complex thermal decomposition with two main mass-loss regions; the first mass-loss region centred at $335^{\circ} \mathrm{C}$ is related to the starch component and the second mass-loss region (around $434^{\circ} \mathrm{C}$ ) is associated to the synthetic component of the pure Mater-Bi KE. Changes in the thermogravimetric parameters can be observed for the pure Mater-Bi KE in both thermal decomposition regions as a function of the degradation in soil process (Table 1).

Table 1. Thermogravimetric parameters of degraded pure Mater-Bi KE.

\begin{tabular}{c|ccc|ccc}
\hline & \multicolumn{3}{|c|}{$\begin{array}{l}1^{\text {st }} \text { Thermal Decomposition } \\
\text { Region }\end{array}$} & \multicolumn{2}{|l}{$\begin{array}{l}2^{\text {nd }} \text { Thermal Decomposition } \\
\text { Region }\end{array}$} \\
\hline $\begin{array}{c}\text { Degradation } \\
\text { Time } \\
\text { (days) }\end{array}$ & $\begin{array}{c}\text { Onset1 } \\
\left({ }^{\circ} \mathrm{C}\right)\end{array}$ & $\begin{array}{c}\text { Mass } \\
\text { Loss1 } \\
(\%)\end{array}$ & $\begin{array}{c}\text { T peak1 } \\
\left({ }^{\circ} \mathrm{C}\right)\end{array}$ & $\begin{array}{c}\text { Onset2 } \\
\left({ }^{\circ} \mathrm{C}\right)\end{array}$ & $\begin{array}{c}\text { Mass } \\
\text { Loss2 } \\
(\%)\end{array}$ & $\begin{array}{c}\text { T peak 2 } \\
\left({ }^{\circ} \mathrm{C}\right)\end{array}$ \\
\hline 0 & $319,9 \pm 1,0$ & $31,5 \pm 0,3$ & $335,3 \pm 1,0$ & $413,3 \pm 1,0$ & $67,0 \pm 0,4$ & $434,5 \pm 0,5$ \\
24 & $332,4 \pm 0,5$ & $33,0 \pm 0,5$ & $353,5 \pm 0,5$ & $414,5 \pm 0,5$ & $66,7 \pm 0,3$ & $435,5 \pm 0,2$ \\
40 & $334,8 \pm 0,5$ & $33,0 \pm 0,7$ & $355,6 \pm 0,5$ & $414,5 \pm 0,5$ & $66,0 \pm 0,7$ & $433,4 \pm 0,5$ \\
70 & $335,3 \pm 0,4$ & $32,7 \pm 0,5$ & $356,3 \pm 0,7$ & $414,0 \pm 1,0$ & $66,0 \pm 0,5$ & $434,0 \pm 0,6$ \\
100 & $333,4 \pm 0,5$ & $32,7 \pm 0,7$ & $355,3 \pm 0,7$ & $414,0 \pm 0,5$ & $64,0 \pm 0,8$ & $433,2 \pm 0,3$ \\
200 & $333,3 \pm 2,0$ & $36,4 \pm 0,8$ & $355,2 \pm 1,0$ & $413,6 \pm 0,7$ & $63,6 \pm 1,0$ & $432,1 \pm 0,3$ \\
300 & $321,8 \pm 1,8$ & $31,8 \pm 0,1$ & $347,3 \pm 0,5$ & $410,5 \pm 0,5$ & $64,5 \pm 1,0$ & $430,1 \pm 0,8$ \\
440 & $315,5 \pm 2,0$ & $36,6 \pm 0,1$ & $333,5 \pm 2,2$ & $406,8 \pm 0,5$ & $57,3 \pm 0,3$ & $426,8 \pm 0,8$ \\
535 & $308,0 \pm 1,0$ & $33,6 \pm 0,1$ & $330,5 \pm 3,0$ & $406,0 \pm 1,9$ & $52,3 \pm 0,3$ & $425,0 \pm 0,8$ \\
\hline
\end{tabular}

When the reinforced biocomposites are submitted to soil burial test, the thermogravimetric parameters of both thermal decomposition regions (Table 1-3) display similar behaviour as the components in the pure Mater-Bi KE: three different stages for the starch decomposition (from 0 to 20 days, from 20 to 200 days and from 200 to 535 days) region and a decreasing trend from 200 days for the synthetic component. The first stage for the starch decomposition (0-24 days) where the onset is shifted towards higher temperatures was related to the hydrolysis of the starch in previous degradation studies [5]. In addition, in the analysis of the moisture process in Chapter 5 [6] it was stated that the increase in the onset of the starch during the swelling process depends on the hemicellulose/pectin content of the fibres. Thus, plotting the increments of onset as a function of the hemicellulose/pectin percentage of the 
natural fibre of the reinforced biocomposites, the same trend as in the swelling analysis is checked. This result confirms the assignation of the first stage degradation of the starch to its hydrolysis degradation.

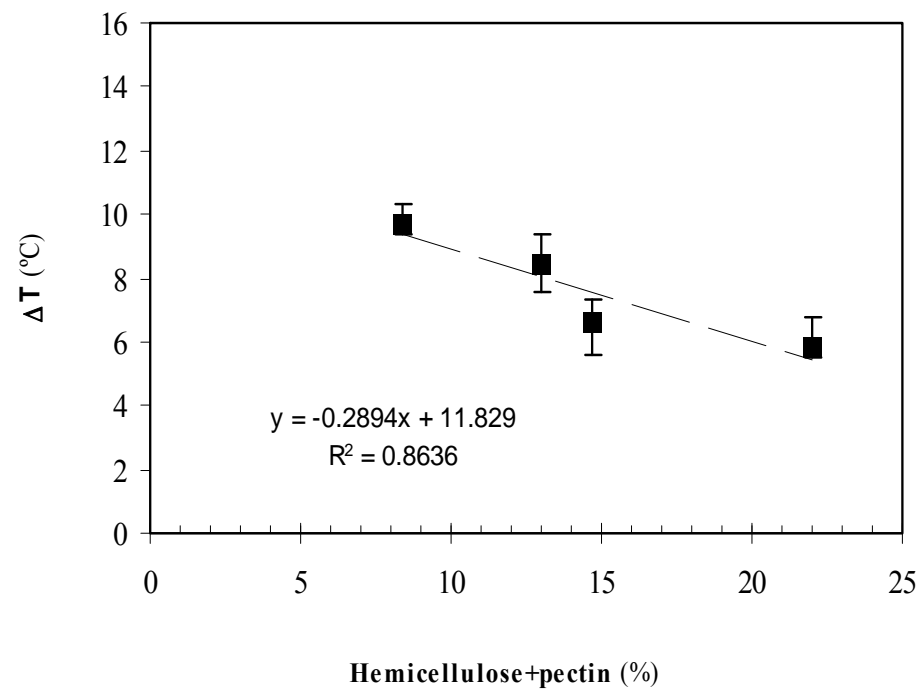

Figure 5. Onset temperature increment of the reinforced biocomposites as a function of hemicellulose +pectin percentage

Moreover, the obtained values of onset 1 and Tpeakl at the end of the soil burial test for the reinforced biocomposites are higher than that obtained for the pure Mater-Bi KE, being the Mater-Bi KE/flax the biocomposite that show a major onset1 value. Thus, the addition of fibres seems to slow down the changes caused by the soil burial test on the starch present in the pure Mater-Bi KE, being the Mater-Bi KE/flax the less degraded among all reinforced biocomposites. These results are in agreement with the morphologic changes observed in SEM micrographs. 
Table 2. Thermogravimetric parameters reinforced Mater-Bi KE/flax and Mater-Bi KE/hemp biocomposite as a function of the degradation in soil process.

\begin{tabular}{|c|c|c|c|c|c|c|c|c|c|c|c|c|c|c|}
\hline \multirow[b]{3}{*}{$\begin{array}{c}\text { Degradation } \\
\text { Time } \\
\text { (days) }\end{array}$} & \multicolumn{7}{|c|}{ Reinforced Mater-Bi KE/flax biocomposite } & \multicolumn{7}{|c|}{ Reinforced Mater-Bi KE/hemp biocomposite } \\
\hline & \multicolumn{3}{|c|}{$\begin{array}{l}\text { First Thermal Decomposition } \\
\text { Process }\end{array}$} & \multicolumn{3}{|c|}{$\begin{array}{l}\text { Second Thermal Decomposition } \\
\text { Process }\end{array}$} & \multirow{2}{*}{$\begin{array}{c}\text { Residue } \\
\begin{array}{l}\text { Mass } \\
(\%)\end{array}\end{array}$} & \multicolumn{3}{|c|}{$\begin{array}{l}\text { First Thermal Decomposition } \\
\text { Process }\end{array}$} & \multicolumn{3}{|c|}{$\begin{array}{l}\text { Second Thermal Decomposition } \\
\text { Process }\end{array}$} & \multirow{2}{*}{$\begin{array}{c}\text { Residue } \\
\text { Mass } \\
(\%)\end{array}$} \\
\hline & $\begin{array}{c}\text { Onset1 } \\
\left({ }^{\circ} \mathrm{C}\right)\end{array}$ & $\begin{array}{c}\text { Mass } \\
\text { Loss1 } \\
(\%)\end{array}$ & $\begin{array}{c}\text { T peak1 } \\
\left({ }^{\circ} \mathrm{C}\right)\end{array}$ & $\begin{array}{c}\text { Onset2 } \\
\left({ }^{\circ} \mathrm{C}\right)\end{array}$ & $\begin{array}{c}\text { Mass } \\
\text { Loss2 } \\
(\%)\end{array}$ & $\begin{array}{l}\text { T peak } 2 \\
\left({ }^{\circ} \mathrm{C}\right)\end{array}$ & & $\begin{array}{l}\text { Onset1 } \\
\left({ }^{\circ} \mathrm{C}\right)\end{array}$ & $\begin{array}{l}\text { Mass } \\
\text { Loss1 } \\
(\%)\end{array}$ & $\begin{array}{l}\mathrm{T} \text { peak1 } \\
\left({ }^{\circ} \mathrm{C}\right)\end{array}$ & $\begin{array}{l}\text { Onset2 } \\
\left({ }^{\circ} \mathrm{C}\right)\end{array}$ & $\begin{array}{c}\text { Mass } \\
\text { Loss2 } \\
(\%)\end{array}$ & $\begin{array}{l}\text { T peak } 2 \\
\left({ }^{\circ} \mathrm{C}\right)\end{array}$ & \\
\hline 0 & $324,6 \pm 1,0$ & $34,7 \pm 0,5$ & $345,8 \pm 0,5$ & $414,4 \pm 0,9$ & $60,7 \pm 1,0$ & $431,8 \pm 0,5$ & $5,5 \pm 0,2$ & $326,0 \pm 0,5$ & $34,5 \pm 0,5$ & $350,4 \pm 0,3$ & $414,0 \pm 1,0$ & $61,0 \pm 1,0$ & $432,3 \pm 0,3$ & $4,0 \pm 0,5$ \\
\hline 24 & $334,0 \pm 0,7$ & $35,5 \pm 0,2$ & $355,9 \pm 0,5$ & $416,5 \pm 0,2$ & $57,3 \pm 0,2$ & $433,7 \pm 0,4$ & $6,7 \pm 0,2$ & $334,4 \pm 0,5$ & $36,2 \pm 0,3$ & $359,2 \pm 1,3$ & $415,6 \pm 1,3$ & $58,6 \pm 0,4$ & $433,5 \pm 1,0$ & $5,1 \pm 0,3$ \\
\hline 40 & $335,0 \pm 0,3$ & $35,7 \pm 0,8$ & $355,4 \pm 1,0$ & $416,2 \pm 0,5$ & $57,6 \pm 1,5$ & $433,2 \pm 1,0$ & $5,3 \pm 3,5$ & $334,6 \pm 2,0$ & $37,4 \pm 0,2$ & $358,9_{ \pm 0,5}$ & $414,2 \pm 0,1$ & $58,2 \pm 0,4$ & $431,7 \pm 0,4$ & $5,8 \pm 0,5$ \\
\hline 70 & $333,9 \pm 0,5$ & $33,9 \pm 0,4$ & $353,2 \pm 0,5$ & $414,0 \pm 0,4$ & $61,3 \pm 0,5$ & $433,8 \pm 0,3$ & $5,6 \pm 0,4$ & $334,6 \pm 2,0$ & $37,3 \pm 0,5$ & $358,2 \pm 1,0$ & $413,7 \pm 0,3$ & $55,9 \pm 0,2$ & $431,2 \pm 0,3$ & $4,6 \pm 0,4$ \\
\hline 100 & $331,8 \pm 1,8$ & $34,7 \pm 0,9$ & $353,0 \pm 1,0$ & $414,3 \pm 0,2$ & $59,2 \pm 0,4$ & $430,9 \pm 0,2$ & $5,2 \pm 0,2$ & $334,2 \pm 1,0$ & $38,7 \pm 0,6$ & $356,9 \pm 0,3$ & $412,3 \pm 0,4$ & $52,8 \pm 0,5$ & $429,3 \pm 2,1$ & $8,3 \pm 0,2$ \\
\hline 210 & $331,6 \pm 1,5$ & $34,0 \pm 0,3$ & $352,7 \pm 1,0$ & $414,6 \pm 0,3$ & $56,5 \pm 0,7$ & $430,0 \pm 0,6$ & $8,0 \pm 1,0$ & $334,3 \pm 2,0$ & $38,1 \pm 1,2$ & $357,0 \pm 1,1$ & $413,1 \pm 0,3$ & $54,1 \pm 1,5$ & $430,3 \pm 0,4$ & $7,0 \pm 0,4$ \\
\hline 300 & $329,7 \pm 1,4$ & $31,2 \pm 0,9$ & $350,3 \pm 1,0$ & $413,0 \pm 0,7$ & $55,6 \pm 2,3$ & $428,7_{ \pm 1,2}$ & $10,2 \pm 0,8$ & $325,3 \pm 2,4$ & $35,8 \pm 0,6$ & $348,3 \pm 0,6$ & $410,8 \pm 0,9$ & $47,6 \pm 0,5$ & $428,3 \pm 0,6$ & $8,1 \pm 0,5$ \\
\hline 410 & $327,2 \pm 0,5$ & $31,6 \pm 0,5$ & $349,3 \pm 0,2$ & $408,0 \pm 1,0$ & $49,5 \pm 4,0$ & $425,7 \pm 1,0$ & $12,6 \pm 4,0$ & $323,3 \pm 2,4$ & $35,4 \pm 0,5$ & $346,6 \pm 2,0$ & $408,0 \pm 1,0$ & $49,7 \pm 2,0$ & $426,5 \pm 1,2$ & $8,3 \pm 2,0$ \\
\hline 440 & $323,8 \pm 2,7$ & $32,5 \pm 0,5$ & $346,0 \pm 3,2$ & $408,3 \pm 0,5$ & $50,5 \pm 1,0$ & $424,0 \pm 0,5$ & $12,2 \pm 3,0$ & $320,5 \pm 0,5$ & $35,5 \pm 0,9$ & $341,8 \pm 0,5$ & $407,3 \pm 0,5$ & $50,0 \pm 1,5$ & $426,3 \pm 0,9$ & $9,2 \pm 0,5$ \\
\hline 535 & $320,7 \pm 0,4$ & $33,5 \pm 1,0$ & $342,3 \pm 1,0$ & $409,3 \pm 0,5$ & $50,2 \pm 0,5$ & $425,0 \pm 0,5$ & $11,6 \pm 2,5$ & $315,0 \pm 0,5$ & $36,2 \pm 0,5$ & $338,2 \pm 2,0$ & $404,3 \pm 0,5$ & $48,2 \pm 1,5$ & $425,0 \pm 1,5$ & $9,6 \pm 1,0$ \\
\hline
\end{tabular}


Table 3. Thermogravimetric parameters reinforced Mater-Bi KE/kenaf and Mater-Bi KE/jute biocomposite as a function of the degradation in soil process.

\begin{tabular}{|c|c|c|c|c|c|c|c|c|c|c|c|c|c|c|}
\hline \multirow[b]{3}{*}{$\begin{array}{c}\text { Degradation } \\
\text { Time } \\
(\text { days }) \\
\end{array}$} & \multicolumn{7}{|c|}{ Reinforced Mater-Bi KE/kenaf biocomposite } & \multicolumn{7}{|c|}{ Reinforced Mater-Bi KE/jute biocomposite } \\
\hline & \multicolumn{3}{|c|}{$\begin{array}{l}\text { First Thermal Decomposition } \\
\text { Process }\end{array}$} & \multicolumn{3}{|c|}{$\begin{array}{l}\text { Second Thermal Decomposition } \\
\text { Process }\end{array}$} & \multirow{2}{*}{$\begin{array}{c}\text { Residue } \\
\begin{array}{l}\text { Mass } \\
(\%)\end{array} \\
\end{array}$} & \multicolumn{3}{|c|}{$\begin{array}{l}\text { First Thermal Decomposition } \\
\text { Process }\end{array}$} & \multicolumn{3}{|c|}{$\begin{array}{l}\text { Second Thermal Decomposition } \\
\text { Process }\end{array}$} & \multirow{2}{*}{$\begin{array}{l}\text { Residue } \\
\begin{array}{l}\text { Mass } \\
(\%)\end{array} \\
\end{array}$} \\
\hline & $\begin{array}{l}\text { Onset1 } \\
\left({ }^{\circ} \mathrm{C}\right)\end{array}$ & $\begin{array}{c}\text { Mass } \\
\text { Loss } 1 \\
(\%)\end{array}$ & $\begin{array}{l}\text { T peak1 } \\
\left({ }^{\circ} \mathrm{C}\right)\end{array}$ & $\begin{array}{l}\text { Onset2 } \\
\left({ }^{\circ} \mathrm{C}\right)\end{array}$ & $\begin{array}{c}\text { Mass } \\
\text { Loss2 } \\
(\%) \\
\end{array}$ & $\begin{array}{l}\text { T peak } 2 \\
\left({ }^{\circ} \mathrm{C}\right)\end{array}$ & & $\begin{array}{l}\text { Onset1 } \\
\left({ }^{\circ} \mathrm{C}\right)\end{array}$ & $\begin{array}{c}\text { Mass } \\
\text { Loss1 } \\
(\%) \\
\end{array}$ & $\begin{array}{l}\text { T peak1 } \\
\left({ }^{\circ} \mathrm{C}\right)\end{array}$ & $\begin{array}{l}\text { Onset2 } \\
\left({ }^{\circ} \mathrm{C}\right)\end{array}$ & $\begin{array}{c}\text { Mass } \\
\text { Loss2 } \\
(\%) \\
\end{array}$ & $\begin{array}{l}\text { T peak } 2 \\
\left({ }^{\circ} \mathrm{C}\right)\end{array}$ & \\
\hline 0 & $333,5 \pm 0,4$ & $35,1 \pm 1,0$ & $356,3 \pm 0,3$ & $415,7 \pm 1,2$ & $60,0 \pm 1,0$ & $432,3 \pm 0,6$ & $4,3 \pm 0,3$ & $333,4 \pm 2,0$ & $34,4 \pm 1,0$ & $356,3 \pm 1,0$ & $415,2 \pm 0,3$ & $61,0 \pm 1,0$ & $433,5 \pm 0,5$ & $3,5 \pm 0,4$ \\
\hline 24 & $339,3 \pm 1,0$ & $35,9 \pm 0,3$ & $360,8 \pm 2,0$ & $417,6 \pm 1,3$ & $58,9 \pm 1,2$ & $434,6 \pm 1,5$ & $4,8 \pm 0,5$ & $339,3 \pm 0,3$ & $35,1 \pm 0,1$ & $366,4 \pm 1,0$ & $419,5 \pm 0,3$ & $60,9 \pm 0,5$ & $434,6 \pm 0,8$ & $3,7 \pm 3,1$ \\
\hline 40 & $340,3 \pm 0,5$ & $36,5 \pm 0,2$ & $361,3 \pm 0,7$ & $417,9 \pm 0,1$ & $57,8 \pm 0,5$ & $434,9 \pm 0,4$ & $5,8 \pm 0,7$ & $339,9 \pm 0,3$ & $36,4 \pm 0,2$ & $360,4 \pm 0,4$ & $418,0 \pm 0,1$ & $55,9_{ \pm 0,1}$ & $434,9_{ \pm 0,1}$ & $5,3 \pm 1,5$ \\
\hline 70 & $338,3 \pm 0,7$ & $37,8 \pm 1,0$ & $359,6 \pm 0,6$ & $415,9 \pm 0,9$ & $54,4 \pm 0,5$ & $434,5 \pm 0,3$ & $6,8 \pm 0,4$ & $338,6 \pm 1,6$ & $36,6 \pm 0,3$ & $359,0 \pm 0,3$ & $413,5 \pm 0,8$ & $57,7 \pm 0,8$ & $430,8 \pm 0,6$ & $5,1 \pm 0,4$ \\
\hline 100 & $339,9 \pm 0,7$ & $37,8 \pm 1,0$ & $357,6 \pm 0,6$ & $414,8 \pm 0,5$ & $53,0 \pm 3,3$ & $433,0 \pm 0,3$ & $7,2 \pm 0,3$ & $337,9 \pm 0,5$ & $37,8 \pm 1,0$ & $356,6 \pm 0,6$ & $411,8 \pm 0,4$ & $53,1 \pm 3,0$ & $430,0 \pm 0,3$ & $6,9 \pm 2,0$ \\
\hline 200 & $338,2 \pm 1,5$ & $38,6 \pm 0,8$ & $357,8 \pm 0,8$ & $414,8 \pm 0,6$ & $52,9 \pm 1,4$ & $431,8 \pm 0,6$ & $7,3 \pm 0,6$ & $336,2 \pm 1,5$ & $38,6 \pm 0,8$ & $357,8 \pm 0,8$ & $414,0 \pm 0,6$ & $53,0 \pm 1,3$ & $431,8 \pm 0,6$ & $7,3 \pm 0,6$ \\
\hline 300 & $318,7 \pm 2,0$ & $39,5 \pm 0,6$ & $351,3 \pm 3,8$ & $412,5 \pm 0,9$ & $49,7 \pm 1,0$ & $428,5 \pm 0,4$ & $8,3 \pm 1,0$ & $321,4 \pm 1,4$ & $33,3 \pm 0,6$ & $350,8 \pm 1,6$ & $414,6 \pm 0,4$ & $55,3 \pm 1,6$ & $432,0 \pm 1,0$ & $10,0 \pm 1,0$ \\
\hline 380 & $313,4 \pm 2,0$ & $35,5 \pm 0,6$ & $346,6 \pm 2,0$ & $411,0 \pm 0,9$ & $53,3 \pm 3,3$ & $427,4 \pm 1,0$ & $8,5 \pm 1,0$ & $320,0 \pm 2,4$ & $32,4 \pm 0,9$ & $347,8 \pm 1,8$ & $412,0 \pm 1,0$ & $49,0 \pm 2,0$ & $427,1 \pm 1,5$ & $15,0 \pm 1,3$ \\
\hline 440 & $310,0 \pm 2,0$ & $34,0 \pm 1$ & $340,8 \pm 1,0$ & $406,5 \pm 0,9$ & $48,6 \pm 1,0$ & $426,1 \pm 1,0$ & $10,4 \pm 1$ & $319,0 \pm 1,1$ & $34,0 \pm 0,2$ & $348,6 \pm 0,5$ & $411,2 \pm 0,5$ & $53,0 \pm 2,0$ & $429,7 \pm 0,3$ & $15,2 \pm 2,0$ \\
\hline 535 & $310,5 \pm 0,8$ & $32,0 \pm 0,5$ & $336,8 \pm 1,0$ & $404,1 \pm 1,0$ & $48,6 \pm 1,0$ & $425,1 \pm 1,0$ & $10,4 \pm 1$ & $311,7_{ \pm 4,0}$ & $35,0 \pm 1,0$ & $336,7 \pm 2,0$ & $408,6 \pm 0,7$ & $51,2 \pm 1,0$ & $426,7 \pm 0,5$ & $15,0 \pm 1,5$ \\
\hline
\end{tabular}




\section{Kinetic analysis}

The kinetic parameters (the apparent activation energies $(E a)$, the kinetic model that describe the reaction mechanism $(f(a))$ and the pre-exponential factor $(A))$ were studied in order to analyse the changes in thermal decomposition behaviour of the four reinforced biocomposites during the degradation in soil, following the methodology proposed in previous works [6]. Kissinger method [7] allows the determination of the $E a$ values of each thermal decomposition process at the selected degradation times.

The behaviour of the $E a$ values of the first mass-loss region of pure Mater-Bi KE (Eal) confirms that the degradation of starch component occurs in three different stages, as it was suggested earlier (Figure 6).

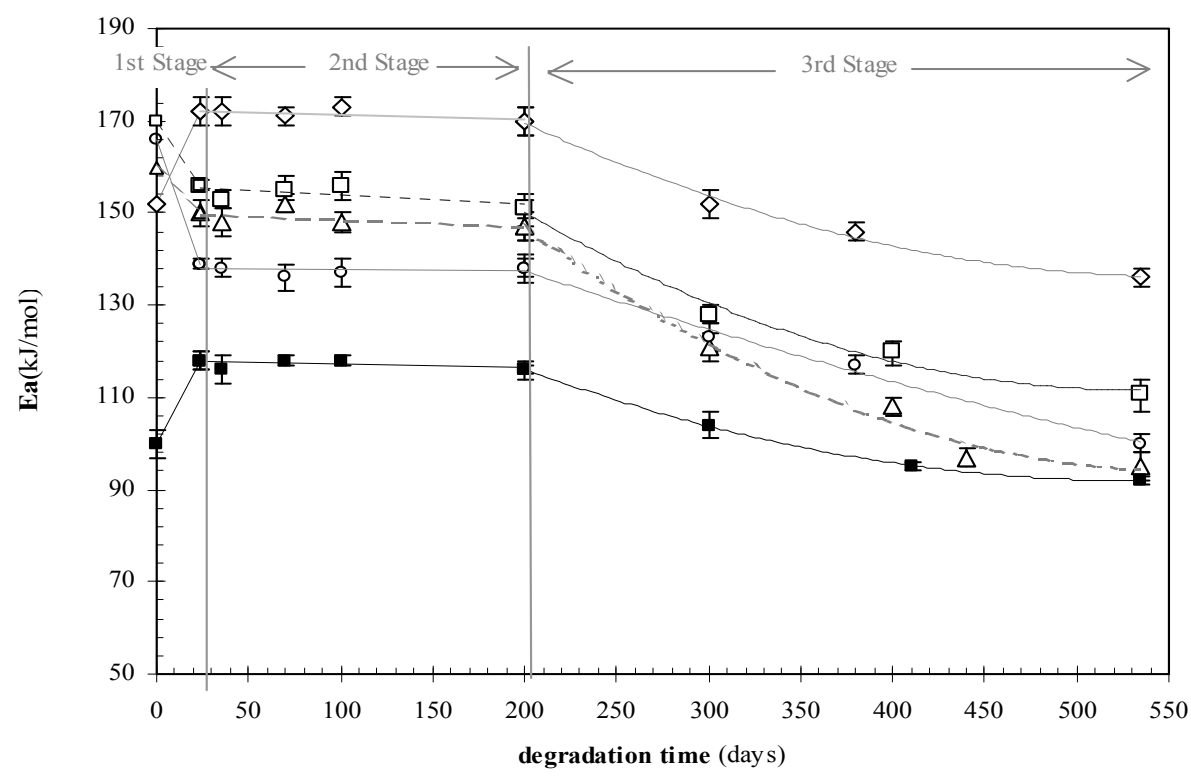

Figure 6. Representation of the Ea related to the starch component of the (一) pure Mater-Bi KE, ( ()$)$ Mater-Bi KE/flax, (O) Mater-Bi KE/jute, ( $\square$ ) Mater-Bi KE/hemp and ( $\Delta$ ) Mater-Bi KE/kenaf as a function of the degradation time in soil.

As it was observed in the absorption process [6], the presence of hemp, kenaf and jute fibres seem to modify the first stage of the starch degradation process in soil, since a decrease in the Eal values during the first 20 days can be observed. However, the addition of flax fibres does not alter the behaviour of the Eal as a function of the soil burial test. This first stage was related to hydrolysis. Thus, it is possible to prove that the flax fibre addition does not change the hydrolysis of the starch because of the increment in the $E a$ is the same in both pure Mater$\mathrm{Bi} \mathrm{KE}$ and Mater-Bi KE/flax composite. However, kenaf, jute and hemp modify this stage maybe due to the high hydrophilic character of these fibres. 
In the second stage (from 20 to 200 days) all the studied reinforced materials show a similar behaviour and the Eal remains unchanged. The reinforced biocomposites present higher $E a$ values than pure Mater-Bi KE in this stage, suggesting that the presence of cellulose and hemicellulose in natural fibres hinders starch degradation in soil. Finally, a decrease of the $E a$ is observed in the third stage, being most noticeable for Mater-Bi KE/kenaf.

Figure 7 displays the trend of the Ea values related to the synthetic component (Ea2) as a function of the soil burial test. Previous studies suggest that the degradation of the synthetic component in pure Mater-Bi KE is a consequence of starch degradation [4,8]. Thus, the $E a$ related to the synthetic component in pure Mater-Bi KE decrease when starch degradation starts (200 days). In the reinforced biocomposites, the decreasing rate is higher than in the pure Mater-Bi KE and starts from the beginning of the test. Thus, the degradation of the natural fibres could increase the available surface, enhancing the microorganisms attack to the synthetic component, resulting in a $E a 2$ decrease from the beginning of the degradation in soil test.

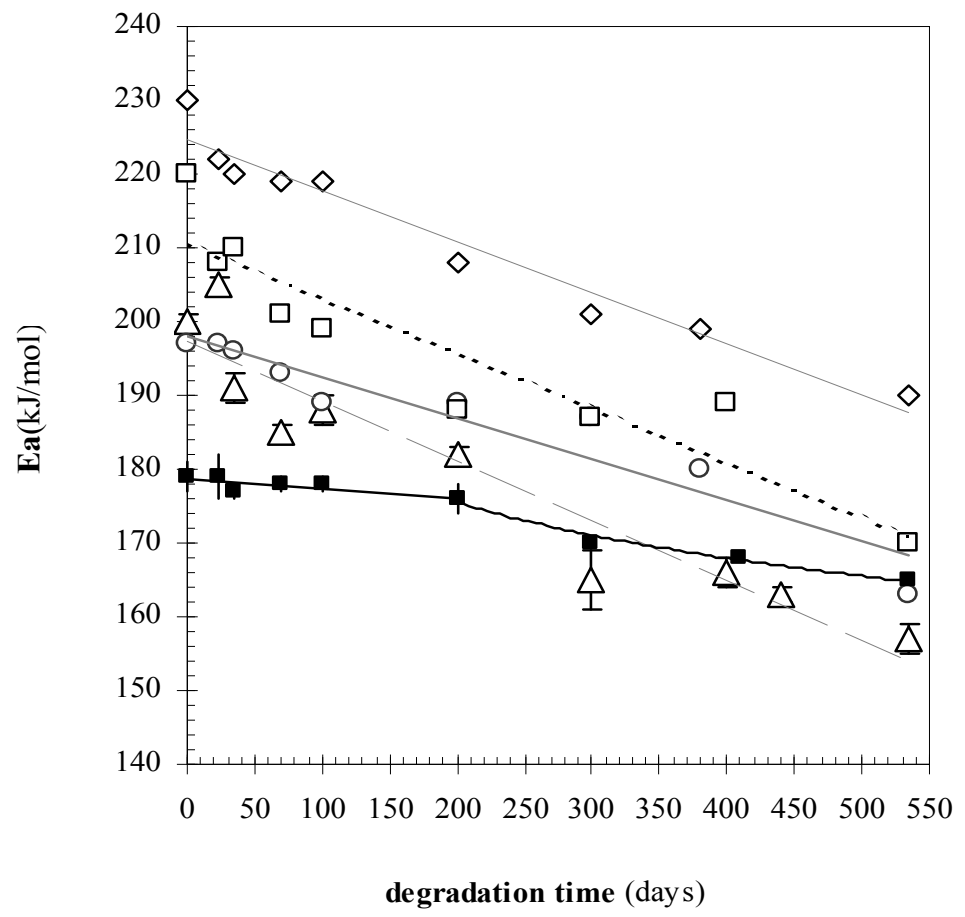

Figure 7. Representation of the Ea related to the synthetic component of the $(\mathbf{\square})$ pure Mater-Bi KE, $(\diamond)$ MaterBi KE/flax, ( () Mater-Bi KE/jute, ( $\square$ ) Mater-Bi KE/hemp and ( $\Delta$ ) Mater-Bi KE/kenaf as a function of the degradation time in soil. 
The reinforced Mater-Bi KE/kenaf biocomposite present the lower values of the Ea2 at the end of the soil burial test. This fact may be due to the higher hydrophilic nature of kenaf fibre due to its higher hemicellulose content (Figure 8), which alters the first stage of starch degradation and the subsequent degradation in soil of the synthetic component.

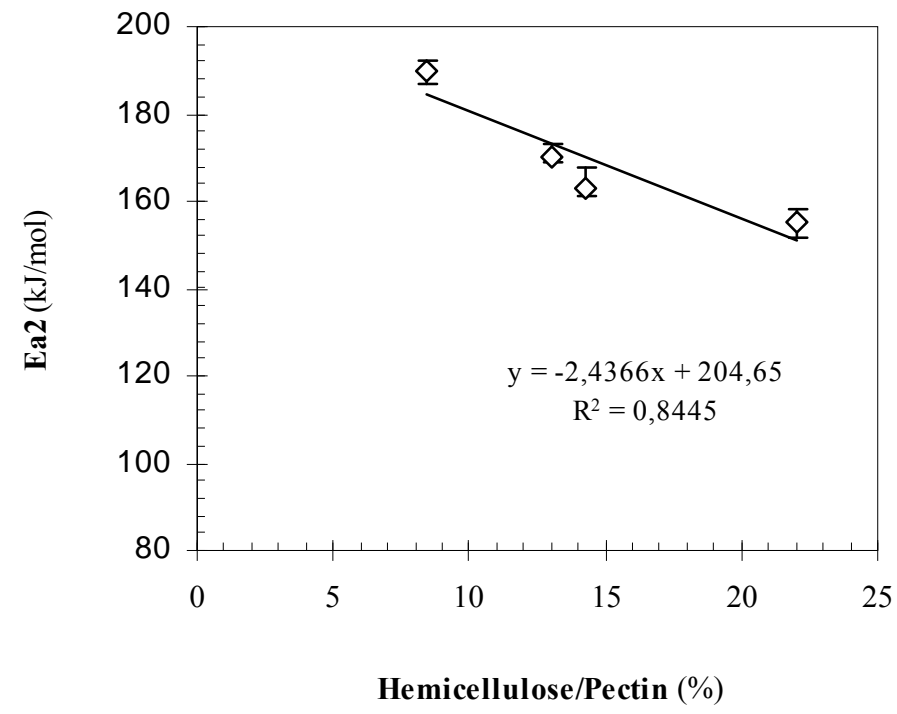

Figure 8. Representation of the Ea2 values of the degraded reinforced Mater-Bi KE/kenaf, Mater-Bi KE/jute, Mater-Bi KE/flax and Mater-Bi KE/hemp as a function of the hemicellulose/pectin content of natural fibres.

The kinetic model and the A values of both thermal decomposition processes were assessed by Criado [9] and Coats-Redfern [10] methods to complete the kinetic triplet. Table 4-5 display the kinetic model and the pre-exponential factor of each material at the different degradation times. The results confirm a autocatalytic mechanism for all the studied materials and also reveal that the degradation in soil process does not change this decomposition mechanism in any material regardless of the presence of natural fibres. 
Table 4. Kinetic parameters for reinforced Mater-Bi KE/flax, Mater-Bi KE/hemp, biocomposite as a function of the degradation in soil process

\begin{tabular}{|c|c|c|c|c|c|c|c|c|}
\hline \multirow[b]{3}{*}{$\begin{array}{c}\text { Degradation } \\
\text { Time } \\
\text { (days) }\end{array}$} & \multicolumn{4}{|c|}{ Reinforced Mater-Bi KE/flax biocomposite } & \multicolumn{4}{|c|}{ Reinforced Mater-Bi KE/hemp biocomposite } \\
\hline & \multicolumn{2}{|c|}{$\begin{array}{l}1^{\text {st }} \text { Thermal } \\
\text { Decomposition Process }\end{array}$} & \multicolumn{2}{|c|}{$\begin{array}{l}2^{\text {nd }} \text { Thermal } \\
\text { Decomposition Process }\end{array}$} & \multicolumn{2}{|c|}{$\begin{array}{l}1^{\text {st }} \text { Thermal Decomposition } \\
\text { Process }\end{array}$} & \multicolumn{2}{|c|}{$\begin{array}{l}2^{\text {nd }} \text { Thermal Decomposition } \\
\text { Process }\end{array}$} \\
\hline & $\begin{array}{c}\mathrm{A} \\
\left(\mathrm{min}^{-1}\right)\end{array}$ & $f(\alpha)$ & $\begin{array}{c}\mathrm{A} \\
\left(\min ^{-1}\right)\end{array}$ & $f(\alpha)$ & $\begin{array}{c}\mathrm{A} \\
\left(\mathrm{min}^{-1}\right)\end{array}$ & $f(\alpha)$ & $\begin{array}{c}\mathrm{A} \\
\left(\min ^{-1}\right)\end{array}$ & $f(\alpha)$ \\
\hline 0 & $10^{12,6}$ & $\alpha^{0,3}(1-\alpha)^{1,6}$ & $10^{16,1}$ & $\alpha^{0,3}(1-\alpha)^{1,5}$ & $10^{13,0}$ & $\alpha^{0,2}(1-\alpha)^{1,6}$ & $10^{16,8}$ & $\alpha^{0,2}(1-\alpha)^{1,3}$ \\
\hline 20 & $10^{14,0}$ & $\alpha^{0,4}(1-\alpha)^{1,6}$ & $10^{15,5}$ & $\alpha^{0,2}(1-\alpha)^{1,4}$ & $10^{12,1}$ & $\alpha^{0,4}(1-\alpha)^{1,4}$ & $10^{15,2}$ & $\alpha^{0,2}(1-\alpha)^{1,3}$ \\
\hline 100 & $10^{13,9}$ & $\alpha^{0,4}(1-\alpha)^{1,6}$ & $10^{15,4}$ & $\alpha^{0,2}(1-\alpha)^{1,4}$ & $10^{12,2}$ & $\alpha^{0,4}(1-\alpha)^{1,4}$ & $10^{14,9}$ & $\alpha^{0,2}(1-\alpha)^{1,3}$ \\
\hline 210 & $10^{13,8}$ & $\alpha^{0,4}(1-\alpha)^{1,4}$ & $10^{15,2}$ & $\alpha^{0,2}(1-\alpha)^{1,4}$ & $10^{10,8}$ & $\alpha^{0,4}(1-\alpha)^{1,4}$ & $10^{13,9}$ & $\alpha^{0,2}(1-\alpha)^{1,3}$ \\
\hline 300 & $10^{12,0}$ & $\alpha^{0,4}(1-\alpha)^{1,3}$ & $10^{14,9}$ & $\alpha^{0,2}(1-\alpha)^{1,3}$ & $10^{10,6}$ & $\alpha^{0,2}(1-\alpha)^{1,4}$ & $10^{12,5}$ & $\alpha^{0,4}(1-\alpha)^{1,3}$ \\
\hline 440 & $10^{11,4}$ & $\alpha^{0,4}(1-\alpha)^{1,2}$ & $10^{14,5}$ & $\alpha^{0,2}(1-\alpha)^{1,3}$ & $10^{10,0}$ & $\alpha^{0,2}(1-\alpha)^{1,4}$ & $10^{12,5}$ & $\alpha^{0,3}(1-\alpha)^{1,3}$ \\
\hline 535 & $10^{11,5}$ & $\alpha^{0,4}(1-\alpha)^{1,2}$ & $10^{14,0}$ & $\alpha^{0,2}(1-\alpha)^{1,3}$ & $10^{9,0}$ & $\alpha^{0,3}(1-\alpha)^{1,4}$ & $10^{12,5}$ & $\alpha^{0,2}(1-\alpha)^{1,2}$ \\
\hline
\end{tabular}


Table 5. Kinetic parameters for reinforced Mater-Bi KE/kenaf and Mater-Bi KE/jute biocomposite as a function of the degradation in soil process

\begin{tabular}{|c|c|c|c|c|c|c|c|c|}
\hline \multirow[b]{3}{*}{$\begin{array}{c}\text { Degradation } \\
\text { Time } \\
\text { (days) }\end{array}$} & \multicolumn{4}{|c|}{ Reinforced Mater-Bi KE/kenaf biocomposite } & \multicolumn{4}{|c|}{ Reinforced Mater-Bi KE/jute biocomposite } \\
\hline & \multicolumn{2}{|c|}{$\begin{array}{l}1^{\text {st }} \text { Thermal } \\
\text { Decomposition Process }\end{array}$} & \multicolumn{2}{|c|}{$\begin{array}{l}2^{\text {nd }} \text { Thermal } \\
\text { Decomposition Process }\end{array}$} & \multicolumn{2}{|c|}{$\begin{array}{l}1^{\text {st }} \text { Thermal Decomposition } \\
\text { Process }\end{array}$} & \multicolumn{2}{|c|}{$\begin{array}{l}2^{\text {nd }} \text { Thermal Decomposition } \\
\text { Process }\end{array}$} \\
\hline & $\underset{\left(\min ^{-1}\right)}{\mathrm{A}}$ & $f(\alpha)$ & $\underset{\left(\min ^{-1}\right)}{\mathrm{A}}$ & $f(\alpha)$ & $\underset{\left(\min ^{-1}\right)}{\mathrm{A}}$ & $f(\alpha)$ & $\underset{\left(\min ^{-1}\right)}{\mathrm{A}}$ & $f(\alpha)$ \\
\hline 0 & $10^{12,6}$ & $\alpha^{0,2}(1-\alpha)^{1,4}$ & $10^{14,9}$ & $\alpha^{0,4}(1-\alpha)^{1,6}$ & $10^{13,1}$ & $\alpha^{0,4}(1-\alpha)^{1,7}$ & $10^{15,5}$ & $\alpha^{0,3}(1-\alpha)^{1,5}$ \\
\hline 20 & $10^{11,9}$ & $\alpha^{0,4}(1-\alpha)^{1,1}$ & $10^{14,5}$ & $\alpha^{0,3}(1-\alpha)^{1,6}$ & $10^{11,5}$ & $\alpha^{0,5}(1-\alpha)^{1,4}$ & $10^{15,6}$ & $\alpha^{0,2}(1-\alpha)^{1,3}$ \\
\hline 100 & $10^{12,0}$ & $\alpha^{0,4}(1-\alpha)^{1,1}$ & $10^{14,0}$ & $\alpha^{0,3}(1-\alpha)^{1,6}$ & $10^{11,4}$ & $\alpha^{0,3}(1-\alpha)^{1,2}$ & $10^{14,1}$ & $\alpha^{0,2}(1-\alpha)^{1,3}$ \\
\hline 210 & $10^{11,0}$ & $\alpha^{0,4}(1-\alpha)^{1,1}$ & $10^{13,5}$ & $\alpha^{0,2}(1-\alpha)^{1,3}$ & $10^{11,1}$ & $\alpha^{0,4}(1-\alpha)^{1,3}$ & $10^{14,3}$ & $\alpha^{0,2}(1-\alpha)^{1,3}$ \\
\hline 300 & $10^{10,0}$ & $\alpha^{0,3}(1-\alpha)^{1,2}$ & $10^{12,1}$ & $\alpha^{0,3}(1-\alpha)^{1,1}$ & $10^{11,0}$ & $\alpha^{0,3}(1-\alpha)^{1,3}$ & $10^{14,5}$ & $\alpha^{0,3}(1-\alpha)^{1,3}$ \\
\hline 440 & $10^{7,8}$ & $\alpha^{0,4}(1-\alpha)^{1,0}$ & $10^{11,1}$ & $\alpha^{0,3}(1-\alpha)^{1,1}$ & $10^{10,1}$ & $\alpha^{0,3}(1-\alpha)^{1,3}$ & $10^{13,5}$ & $\alpha^{0,3}(1-\alpha)^{1,3}$ \\
\hline 535 & $10^{7,9}$ & $\alpha^{0,3}(1-\alpha)^{1,0}$ & $10^{10,1}$ & $\alpha^{0,3}(1-\alpha)^{1,0}$ & $10^{10}$ & $\alpha^{0,2}(1-\alpha)^{1,3}$ & $10^{14,0}$ & $\alpha^{0,1}(1-\alpha)^{1,2}$ \\
\hline
\end{tabular}




\section{Fourier Transform Infrared Spectrometry}

The FTIR spectra of pure Mater-Bi KE and the reinforced biocomposites are presented in Figure 9. The assignments of the main absorptions bands these materials are identified and summarised in Table 6.

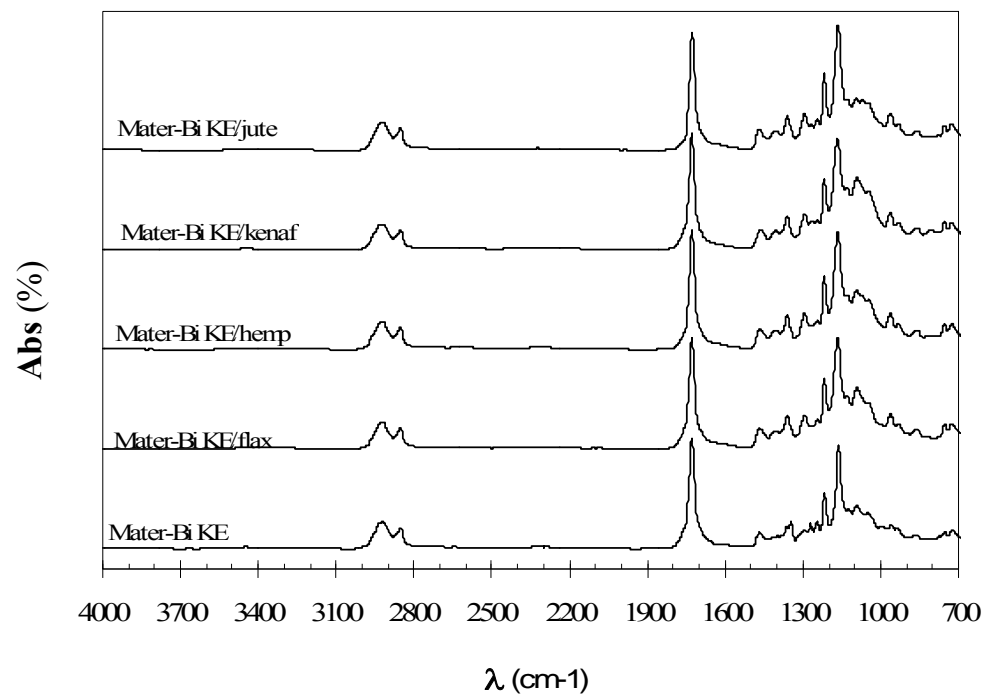

Figure 9. Spectra of the pure Mater-Bi KE and reinforced biocomposites.

Table 6. Characteristic absorption bands of pure Mater-Bi KE.

\begin{tabular}{c|l|l}
\hline $\begin{array}{c}\text { Absorption bands } \\
(\mathrm{cm}-1)\end{array}$ & \multicolumn{1}{|c}{ Functional groups } & References \\
\hline 3450 & OH stretching & {$[11]$} \\
2929 & $\mathrm{CH}_{2}$ asymmetric stretching & {$[11]$} \\
2850 & $\mathrm{CH}_{2}$ symmetric stretching & {$[11]$} \\
1733 & CO stretching & {$[12]$} \\
1648 & OH bending of absorbed water & {$[13]$} \\
1462 & $\mathrm{CH}_{2}$ deformation & {$[11]$} \\
1445 & CH bending & {$[14]$} \\
1325 & $\mathrm{CH}$ wagging & {$[14]$} \\
$1500-900$ & CO stretching region & {$[11]$} \\
1168 & CO stretching of the COH groups & {$[15]$} \\
1089 & CO stretching of the COC glycosidic groups & {$[16]$} \\
$929-754$ & Anhydroglucose ring stretching & {$[17]$} \\
\hline
\end{tabular}

When natural fibres are added into Mater-Bi KE a slight increase in the peak at $1089 \mathrm{~cm}^{-1}$ attributed to the stretching of C-O-C group in the glycosidic bonds [16] can be observed for all the reinforced biocomposites. 
Figure10 compares the spectrum of pure Mater-Bi KE with the degraded one. The peaks placed in the fingerprint region (1300-600 $\mathrm{cm}^{-1}$ ) decrease and become broader, indicating a decay in the chemical structure. Moreover, the absorbance peak of the $\mathrm{OH}$ stretching group becomes wider, the intensity increases and the maximum absorbance frequency is moved from original $3428 \mathrm{~cm}^{-1}$ to $3330 \mathrm{~cm}^{-1}$. These changes could be interpreted in terms of an increase in the concentration of $\mathrm{OH}$ groups as the ester groups are hydrolysed [18].

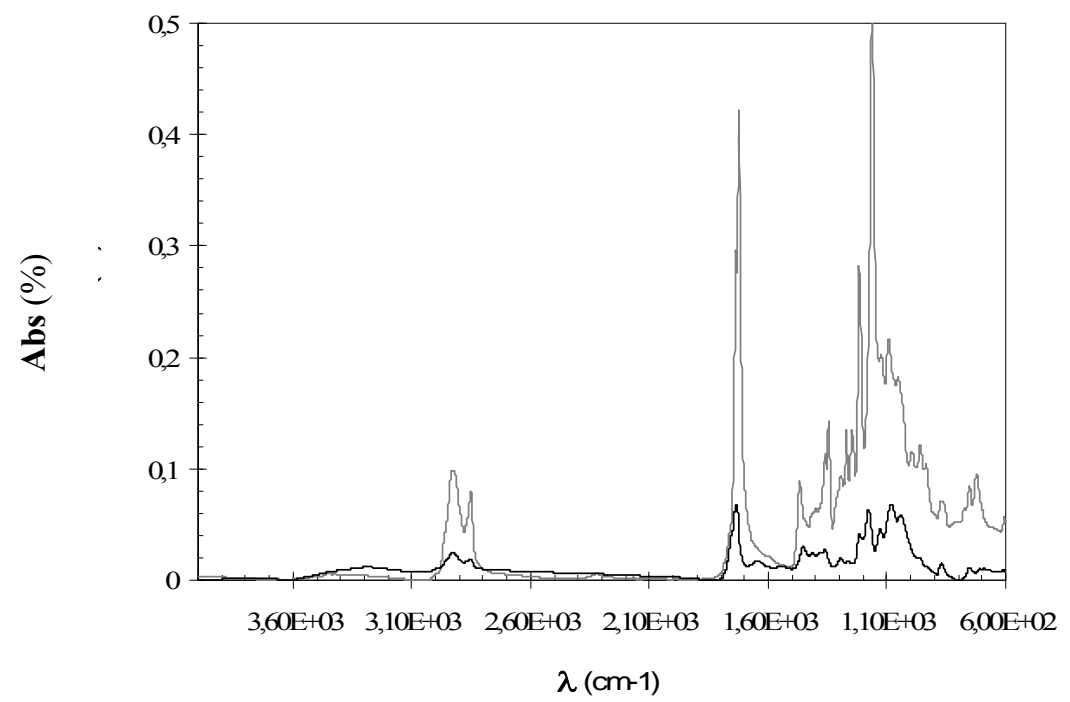

Figure 10. FTIR spectra of the -) pure Mater-Bi KE and -) pure Mater-Bi KE at 535 days of degradation in soil.

When the reinforced biocomposites are subjected to the degradation process, similar FTIR spectra are observed compared to degraded Mater-Bi KE (Figure 10). The $\mathrm{C}=\mathrm{O}$ group (1733 $\mathrm{cm}^{-1}$ ) peak is selected to monitor the degradation of the synthetic component of pure Mater-Bi $\mathrm{KE}$ and its reinforced biocomposites [6]. The band at $1089 \mathrm{~cm}^{-1}$ (C-O-C stretch) is chosen to monitor starch degradation in pure Mater-Bi KE and degradation of starch and natural fibres in the reinforced biocomposites. 


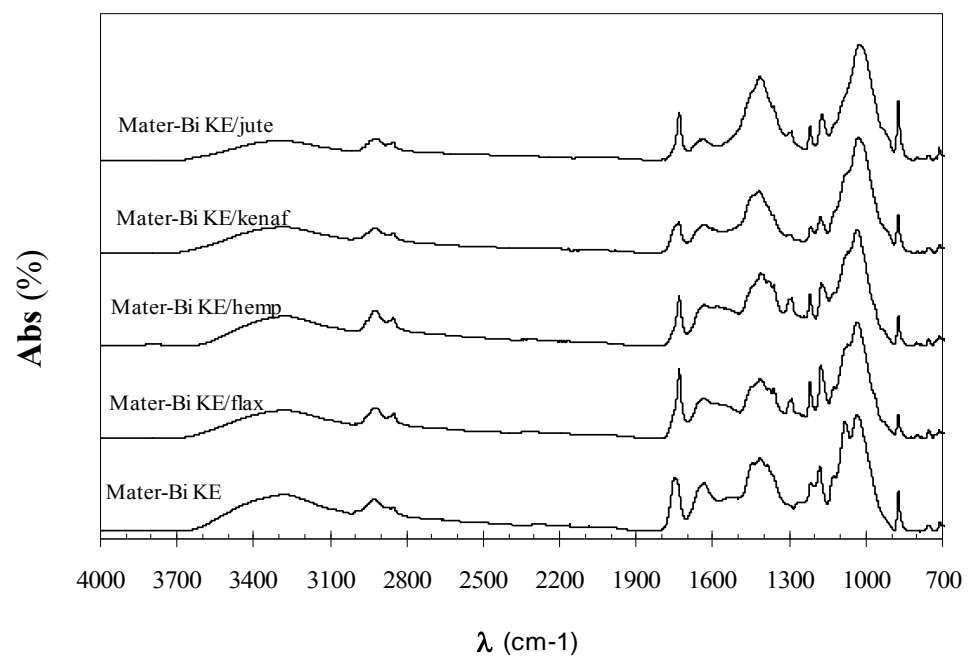

Figure 11. FTIR spectra of the degraded pure Mater-Bi KE and its reinforced biocomposites.

All spectra are normalised with respect to the stretching vibration of the C-O-C group, in order to relate the changes in the synthetic component with the ones in the starch component caused by degradation in soil. Table 7 summarises the relative values of $\mathrm{I}_{\mathrm{C}=\mathrm{O}} / \mathrm{I}_{\mathrm{C}-\mathrm{O}-\mathrm{C}}$ for the degraded samples of pure Mater-Bi KE and its reinforced biocomposites.

Table 7. $I_{C=O} / I_{C-O-C}$ of the pure Mater-Bi KE and the reinforced biocomposite as a function of the degradation in soil process.

\begin{tabular}{c|ccccc}
\hline $\begin{array}{c}\text { Degradation } \\
\text { Time } \\
\text { (days) }\end{array}$ & Mater-Bi KE & Mater-Bi KE/flax & Mater-Bi KE/hemp & Mater-Bi KE/kenaf & Mater-Bi KE/jute \\
\hline 0 & 1,76 & 1,70 & 1,55 & 1,52 & \\
100 & 1,34 & 1,49 & 0,90 & 0,70 & 0,65 \\
200 & 1,34 & 1,40 & 0,84 & 0,65 & 0,75 \\
300 & 1,10 & 1,30 & 0,70 & 0,50 & 0,65 \\
410 & 0,91 & 0,90 & 0,60 & 0,40 & 0,58 \\
535 & 0,88 & 0,84 & 0,46 & 0,32 & 0,44 \\
\hline
\end{tabular}

In general, a diminution of the $\mathrm{I}_{\mathrm{C}=\mathrm{O}} / \mathrm{I}_{\mathrm{C}-\mathrm{O}-\mathrm{C}}$ ratio is observed throughout the soil burial test, which suggests a progressive deterioration of the synthetic component especially for Mater-Bi $\mathrm{KE} /$ kenaf. These results are in agreement with the reported kinetic and calorimetric analyses, and may be related to the higher hemicellulose percentage in kenaf fibres, which is more susceptible to both hydrolytic and biodegradation processes. 


\section{Conclusions}

Thermogravimetric and kinetic results confirm that the degradation in soil of pure Mater-Bi KE occurs in stages, where the degradation of the synthetic component is triggered by starch degradation. The degradation of the synthetic component is assigned to a decrease of the crystalline index and a weaker $\mathrm{C}=\mathrm{O}$ band at the end of the accelerated degradation test.

The degradation of the starch component is slowed down when flax, hemp, kenaf and jute are added into pure Mater-Bi KE, due to the interactions between natural fibres and the polymeric matrix. The degradation of the natural fibres enhances the available surface area and thus promotes the attack of the microorganisms to the synthetic component from the beginning of the test, enhancing its degradation rate. However, only the synthetic component of the Mater$\mathrm{Bi} \mathrm{KE} /$ kenaf displays lower values in the thermogravimetric and kinetic parameters, in the crystalline index, and in the $\mathrm{C}=\mathrm{O}$ band at the end of the degradation in soil test than the pure Mater-Bi KE, indicating its major susceptibility towards degradation among all the studies materials. Contrarily, Mater-Bi KE/flax seems to be less affected by the degradation in soil process than Mater-Bi KE.

\section{References}

1. Moriana R, Badia J.D., Santonja-Blasco L, Ribes-Greus A. J Appli Polym Sci 2010; (pending of publication).

2. Moriana R, Vilaplana F, Karlsson S, Ribes-Greus A. Composites A: Science and Manufacturing 2010; (pending of publication).

3. Imam SH, Chen L, Gorden SH, Shorgen RL, Weisleder D, Greener RV. J Polym Environ 1998; 6: 91.

4. Bastioli C. Polym Degrad Stab 1998; 59: 263.

5. Moriana R, Karlsson S, Ribes-Greus A. Polymer Composites 2010; (pending of publication).

6. Moriana R, Ribes-Greus A. Chapter 5. Moisture Absorption study of reinforced biocomposites, 2010.

7. Kissinger HE. J Res Natl Bur Stand 1956; 57: 217.

8. Bastioli C editor. Handbook of Biodegradable Polymers. Shrewsbury: Rapra Technology, 2005.

9. Criado JM. Thermochimic Acta 1978; 24:86.

10. Coats AW, Redfern JP. Nature 1964; 201:68.

11. Imam SH, Gordon SH, Mohamed A, Harry-O'kuru R, Chiou BS, Glenn GM, Orts WJ. Polym Degrad Stab 2006; 91: 2894 
12. Socrates G, editor. Infrared and Raman Characteristic Groups Frequencies. England: J Wiley, 2001.

13. Wolkers WF, Oliver EA, Tablin F, Crowe JH. Carbohydr Res 2004; 339: 1077

14. Park JW, Im SS, Kim SH, Kim YH. Polym Eng Sci 2000; 40: 2539.

15. Goheen SM, Wool RP. Appl Polym Sci 1991; 42: 2691.

16. Ma XF, Yu JG J, He K, Wang N. Macromol Mater Eng 2007; 292: 503

17. Cael JJ, Koenig JL, Blackwell J. Carbohydr Res 1973; 29:123.

18. Kapusniak J, Siemion P. J Food Eng 2007; 78: 323. 

“THERMAL ANALYSIS APPLIED TO THE CHARACTERISATION OF THE DEGRADATION OF REINFORCED MATER-BI NF/NATURAL FIBRES BIOCOMPOSITES IN SOIL" 



\title{
"THERMAL ANALYSIS APPLIED TO THE CHARACTERISATION OF THE DEGRADATION OF REINFORCED MATER-BI NF/NATURAL FIBRES BIOCOMPOSITES IN SOIL"
}

\begin{abstract}
Biocomposites consisting of a commercial starch-based thermoplastic (Mater-Bi NF01U) reinforced with several natural fibres (cotton, hemp, kenaf, jute and flax) were subjected to an accelerated soil burial test. The changes in thermal stability and the decomposition kinetics studies by thermogravimetric analysis were correlated with structural and morphological information obtained by Differential Scanning Calorimetry (DSC), Scanning Electron Microscopy (SEM) and Infrared Spectroscopy of Fourier (FTIR). Pure Mater-Bi NF has a complex thermal decomposition with two main mass-loss regions, associated to the thermal decomposition of the starch and the synthetic components, respectively. Degradation in soil of pure Mater-Bi NF causes the disappearance of the starch mass-loss region and a diminution in the onset temperature of both regions, being these effects most noticeable during the first 40 days of degradation. In the reinforced biocomposites, the degradation of the starch component is slowed down may be due to the interaction between the polymeric matrix and the natural fibres. Degradation in soil also affects the morphology of pure Mater-Bi NF and the composites, causing an increase in crystalline content with more heterogeneous distribution. These results together with the decrease in the $\mathrm{C}=\mathrm{O}$ band of the ester group at the end of the accelerated degradation test confirms the degradation of the synthetic component in all the studied materials. This effect is more remarkable in the reinforced Mater-Bi NF/kenaf biocomposites.
\end{abstract}

Keywords: Natural fibres, Biopolymer, Thermal properties, Degradation in soil, Chemical Structure 


\section{Results and discussion}

\section{Thermogravimetric analysis}

The thermogravimetric curves for samples exposed to $0,20,40,100,150$ and 215 days of soil burial test have been analysed at different heating rates, in order to assess the changes in the thermal stability of pure Mater-Bi NF and its reinforced biocomposites. Longer exposure times were not able to be studied due to physical deterioration of the samples. Figure 1 shows the influence of the degradation process on the DTG curves of pure Mater-Bi NF at $20^{\circ} \mathrm{C} / \mathrm{min}$; the DTG curves for different heating rates $\left(3,5,10,30^{\circ} \mathrm{C} / \mathrm{min}\right)$ were also obtained but they are nor shown for the sake of clarity. Pure Mater-Bi NF displayed a complex thermal decomposition with two main mass-loss regions, as it was assessed in a previous chapter: a mass-loss region of $26 \%$ placed around $300-362^{\circ} \mathrm{C}$ related to the pyrolysis of starch, [1] and a mass-loss region of approximately $66 \%$ that take place at $362-600^{\circ} \mathrm{C}$ attributed to the biodegradable synthetic polyester component of pure Mater-Bi NF [2].

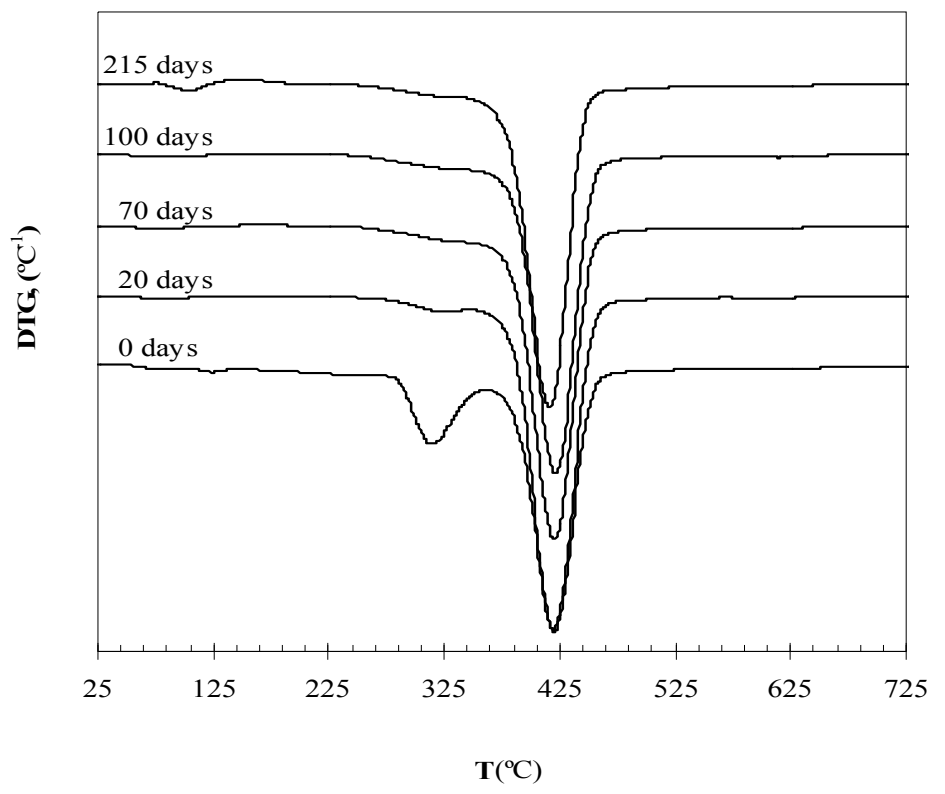

Figure 1. DTG curves of pure Mater-Bi NF at the heating rate of $20^{\circ} \mathrm{C} / \mathrm{min}$

Important changes in the shape of the DTG curves (Figure 1) and in the thermogravimetric parameters (Table 2) can be observed for pure Mater-Bi NF as the degradation process advances. Degradation in soil causes a dramatical reduction of the starch component content of pure Mater-Bi NF, with a total mass decrease of $75 \%$ in only 20 days of degradation in soil. As a consequence, the mass-loss percentage related to the synthetic component increases 
during the 20 first days, remains constant to 180 days of degradation, and decreases afterwards when its degradation is initiated. The onset values of the mass-loss region related to the synthetic component are reduced during the degradation process, suggesting a weaker thermal stability for this component as the degradation progresses.

Table 2. Thermogravimetric parameters of pure Mater-Bi NF as a function of the soil burial test.

\begin{tabular}{|c|c|c|c|c|c|c|c|c|c|}
\hline \multirow[b]{2}{*}{ days } & \multicolumn{2}{|c|}{ Moisture Process } & \multicolumn{3}{|c|}{$[225-360]^{\circ} \mathrm{C}$} & \multicolumn{3}{|c|}{$[360-600]^{\circ} \mathrm{C}$} & \multirow{2}{*}{\begin{tabular}{|c|} 
Residue \\
Mass \\
$(\%)$
\end{tabular}} \\
\hline & $\begin{array}{c}\text { Mass } \\
\text { loss } \\
(\%)\end{array}$ & $\begin{array}{c}\text { Tpeak } \\
\left({ }^{\circ} \mathrm{C}\right)\end{array}$ & $\begin{array}{l}\text { Onset } \\
\left({ }^{\circ} \mathrm{C}\right)\end{array}$ & $\begin{array}{c}\text { Mass } \\
\text { loss } \\
(\%)\end{array}$ & $\begin{array}{r}\text { T peak } \\
\left({ }^{\circ} \mathrm{C}\right)\end{array}$ & $\begin{array}{c}\text { Onset } \\
\left({ }^{\circ} \mathrm{C}\right)\end{array}$ & $\begin{array}{c}\text { Mass } \\
\text { loss } \\
(\%)\end{array}$ & $\begin{array}{c}\text { T peak } \\
\left({ }^{\circ} \mathrm{C}\right)\end{array}$ & \\
\hline 0 & $1,2 \pm 0,3$ & $96,2 \pm 1,0$ & $288,0 \pm 0,3$ & $21,9 \pm 0,8$ & $312,4 \pm 2,0$ & $402,1 \pm 1,0$ & $68,5 \pm 0,5$ & $421,1 \pm 0,9$ & $7,6 \pm 0,5$ \\
\hline 20 & $1,0 \pm 0,2$ & $94,0 \pm 0,2$ & $288,0 \pm 1,0$ & $5,2 \pm 0,3$ & $326,0 \pm 1,0$ & $401,4 \pm 1,0$ & $84,8 \pm 0,3$ & $419,8 \pm 0,5$ & $7,9 \pm 0,5$ \\
\hline 42 & $0,8 \pm 0,3$ & $96,4 \pm 0,4$ & $288,8 \pm 1,5$ & $5,1 \pm 0,3$ & $333,3 \pm 1,0$ & $401,0 \pm 0,4$ & $86,4 \pm 0,4$ & $420,5 \pm 1,0$ & $7,0 \pm 0,3$ \\
\hline 70 & $1,4 \pm 0,3$ & $99,0 \pm 0,5$ & --- & --- & . & $400,8 \pm 0,3$ & $81,0 \pm 0,6$ & $421,5 \pm 0,3$ & $10,2 \pm 0,3$ \\
\hline 100 & $1,6 \pm 0,3$ & $10,4 \pm 0,4$ & --- & --- & ---- & $398,0 \pm 0,3$ & $80,2 \pm 0,3$ & $421,5 \pm 0,3$ & $11,0 \pm 0,3$ \\
\hline 180 & $1,7 \pm 0,3$ & $10,5 \pm 0,5$ & --- & --- & --- & $396,2=$ & $82,2 \pm 0,8$ & 416 , & $10,2 \pm 0,5$ \\
\hline 215 & $2,0 \pm 0,3$ & $104,5 \pm 0,4$ & --- & --- & --- & $395,5 \pm 1,0$ & $76,0 \pm 1,0$ & $417,4 \pm 1,0$ & $13,0 \pm 1,0$ \\
\hline
\end{tabular}

The DTG curves of the reinforced biocomposites as a function of the degradation process show the same trend as that of pure Mater-Bi NF. As an example, Figure 2 shows the DTG curves of the reinforced Mater-Bi NF/kenaf biocomposite for each degradation time. When the reinforced biocomposites are submitted to an accelerated degradation test, the most affected mass-loss region is the starch region that now in the biocomposites is overlapped with the thermodegradation of hemicellulose and most of the cellulose from the natural fibres.

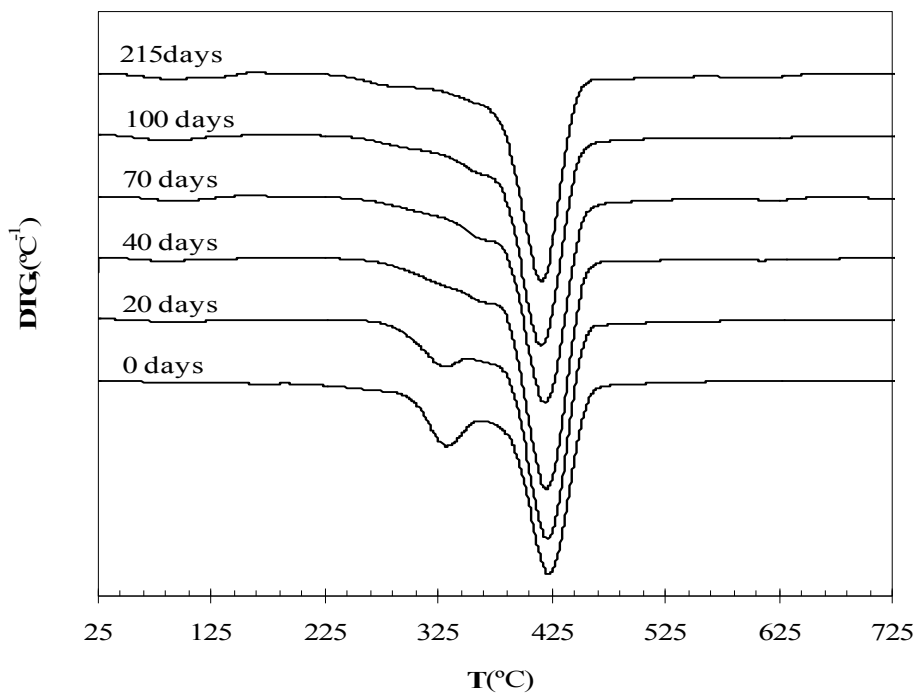

Figure 2. DTG curves of reinforced Mater-Bi NF/kenaf biocomposite as a function of the soil burial test. 
The thermogravimetric parameters of both main mass-loss regions for each reinforced biocomposite at each selected degradation time are shown in Table 3. It is noticeable that in the reinforced biocomposites the disappearance of the first thermal decomposition process is slowed down; this fact could be due to the interactions between the natural fibres and the starch in pure Mater-Bi NF. It seems that the disappearance of the starch in the reinforced biocomposites depends on the sum of the content of hemicellulose, pectin and cellulose percentages in its formulation; the reinforced biocomposites with less content of hemicellulose, cellulose and pectin in its formulation need more time to degrade the starch (Figure 2).

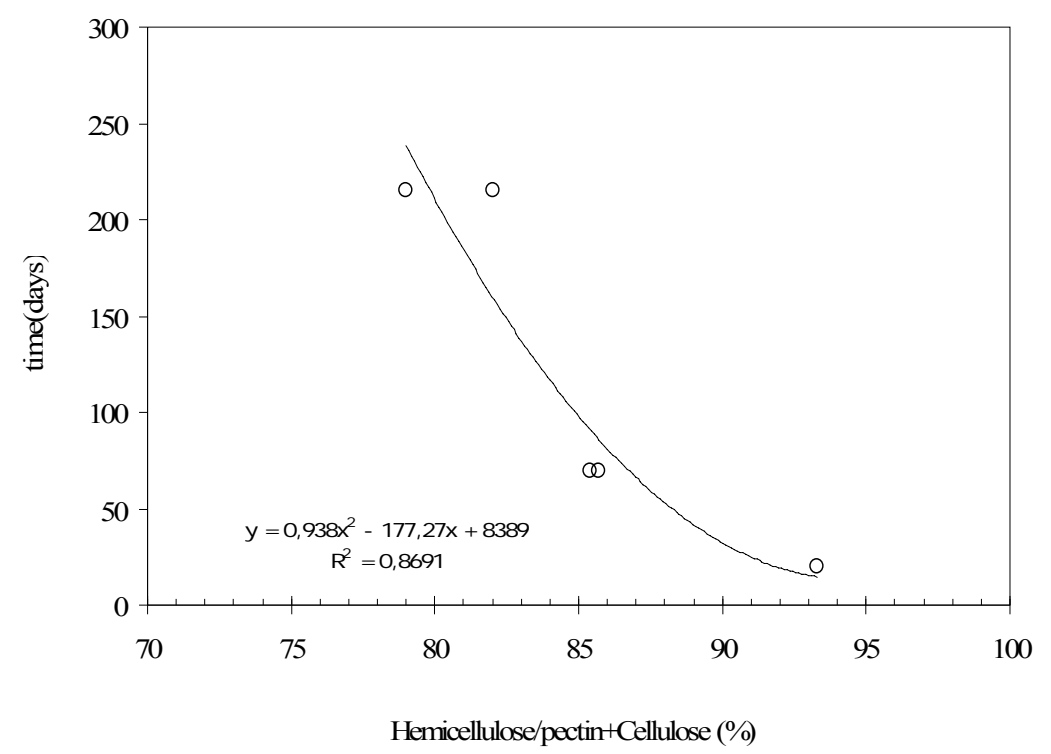

Figure 2. Time necessary to degradate the starch in the reinforced biocomposites as a function of the sum of cellulose, hemicellulose and pectin components.

On the other hand, no significant changes were observed in the thermal stability associated to the synthetic component as a function of the soil burial test due to the presence of the natural fibres. The mass loss rate related to the synthetic component at the end of the test is, however, lower in the reinforced biocomposites than in pure Mater-Bi NF, indicating a major degradation rate of the synthetic component in the reinforced biocomposites . 
Table 3. Thermogravimetric parameters of reinforced biocomposites as a function of the soil burial test

\begin{tabular}{|c|c|c|c|c|c|c|c|c|c|}
\hline \multicolumn{10}{|c|}{ Mater-Bi NF/cotton } \\
\hline \multirow[b]{2}{*}{$\begin{array}{c}\text { Tim } \\
\text { e } \\
\text { days }\end{array}$} & \multicolumn{2}{|c|}{ Moisture Process } & \multicolumn{3}{|c|}{$[225-360]{ }^{\circ} \mathrm{C}$} & \multicolumn{3}{|c|}{$[360-600]{ }^{\circ} \mathrm{C}$} & \multirow{2}{*}{$\begin{array}{c}\text { Residue } \\
\text { Mass } \\
(\%)\end{array}$} \\
\hline & $\begin{array}{c}\text { Mass } \\
\text { Loss } \\
(\%)\end{array}$ & $\begin{array}{c}\text { T peak } \\
\left({ }^{\circ} \mathrm{C}\right)\end{array}$ & $\begin{array}{r}\text { Onset } \\
\left({ }^{\circ} \mathrm{C}\right)\end{array}$ & $\begin{array}{c}\text { Mass } \\
\text { Loss } \\
(\%) \\
\end{array}$ & $\begin{array}{c}\text { T peak } \\
\left({ }^{\circ} \mathrm{C}\right)\end{array}$ & $\begin{array}{r}\text { Onset } \\
\left({ }^{\circ} \mathrm{C}\right)\end{array}$ & $\begin{array}{c}\text { Mass } \\
\text { Loss } \\
(\%)\end{array}$ & $\begin{array}{c}\text { T peak } \\
\left({ }^{\circ} \mathrm{C}\right)\end{array}$ & \\
\hline $\mathbf{0}$ & $1,0 \pm 0,2$ & $95,5 \pm 0,2$ & $304,5 \pm 1,0$ & $23,5 \pm 0,2$ & $330,5 \pm 0,4$ & $405,0 \pm 1,0$ & $63,9 \pm 1,0$ & $423,2 \pm 0,3$ & $9,9 \pm 0,5$ \\
\hline 20 & $1,5 \pm 0,2$ & $85,5 \pm 0,2$ & $302,0 \pm 1,0$ & $10,0 \pm 3,0$ & $335,0 \pm 0,6$ & $404,0 \pm 1,0$ & $75,0 \pm 3,0$ & $420,0 \pm 0,4$ & $9,0 \pm 0,5$ \\
\hline 42 & $1,5 \pm 0,2$ & $80,0 \pm 4,0$ & ---- & ---- & ---- & $400,6 \pm 1,0$ & $76,6 \pm 0,4$ & $418,7 \pm 0,4$ & $11,4 \pm 0,3$ \\
\hline 70 & $2,0 \pm 0,5$ & $84,0 \pm 4,0$ & ---- & ---- & ---- & $399,0 \pm 0,5$ & $69,5 \pm 2,0$ & $418,2 \pm 0,6$ & $15,2 \pm 2,5$ \\
\hline 100 & $2,5 \pm 0,2$ & $84,0 \pm 1,5$ & ---- & ---- & ---- & $396,6 \pm 0,3$ & $65,0 \pm 0,6$ & $417,1 \pm 0,3$ & $15,3 \pm 1,5$ \\
\hline 180 & $2,3 \pm 0,2$ & $87,7 \pm 0,2$ & ---- & ---- & ---- & $399,5 \pm 0,5$ & $64,4 \pm 0,2$ & $418,1 \pm 0,6$ & $15,5 \pm 1,0$ \\
\hline 215 & $3,5 \pm 0,2$ & $89,8 \pm 0,3$ & ---- & ---- & ---- & $398,0 \pm 0,3$ & $61,6 \pm 0,2$ & $417,9 \pm 0,3$ & $18,0 \pm 0,3$ \\
\hline \multicolumn{10}{|c|}{ Mater-Bi NF/flax } \\
\hline $\mathbf{0}$ & $2,0 \pm 0,5$ & $95,5 \pm 2,0$ & $305,0 \pm 0,3$ & $24,4 \pm 0,3$ & $328,0 \pm 0,3$ & $402,7 \pm 0,3$ & $62,6 \pm 0,3$ & $420,3 \pm 0,3$ & $9,4 \pm 0,3$ \\
\hline 20 & $1,7 \pm 1,0$ & $85,0 \pm 2,0$ & $296,5 \pm 1,0$ & $14,8 \pm 0,8$ & $324,6 \pm 1,0$ & $401,0 \pm 1,0$ & $68,4 \pm 1,2$ & $417,0 \pm 1,0$ & $12,2 \pm 0,2$ \\
\hline 42 & $2,4 \pm 0,2$ & $90,0 \pm 3,0$ & $279,0 \pm 1,0$ & $15,0 \pm 1,2$ & $348,5 \pm 0,5$ & $399,7 \pm 0,5$ & $67,0 \pm 3,0$ & $417,2 \pm 0,5$ & $14,0 \pm 0,5$ \\
\hline 70 & $1,7 \pm 0,7$ & $89,0 \pm 3,0$ & $276,0 \pm 1,0$ & $12,0 \pm 0,8$ & $349,6 \pm 0,5$ & $399,0 \pm 0,7$ & $69,6 \pm 3,0$ & $417,9 \pm 0,4$ & $14,0 \pm 1,7$ \\
\hline 100 & $2,0 \pm 0,3$ & $81,8 \pm 0,2$ & ---- & ---- & ---- & $398,0 \pm 0,5$ & $62,1 \pm 0,2$ & $418,0 \pm 0,7$ & $16,4 \pm 0,3$ \\
\hline 180 & $2,5 \pm 1,0$ & $120,0 \pm 1,0$ & ---- & ---- & ---- & $394,4 \pm 0,8$ & $66,2 \pm 3,5$ & $415,6 \pm 0,3$ & $16,0 \pm 0,3$ \\
\hline 215 & $3,7 \pm 0,2$ & $110,0 \pm 3,0$ & ---- & ---- & ---- & $395,5 \pm 1,2$ & $53,5 \pm 1,5$ & $417,4 \pm 0,2$ & $22,4 \pm 0,5$ \\
\hline \multicolumn{10}{|c|}{ Mater-Bi NF/hemp } \\
\hline $\mathbf{0}$ & $1,4 \pm 0,2$ & $86,4 \pm 1,5$ & $306,6 \pm 0,2$ & $25,4 \pm 1,5$ & $331,7 \pm 2,0$ & $404,0 \pm 1,0$ & $59,9 \pm 3,0$ & $423,5 \pm 1,0$ & $9,1 \pm 1,0$ \\
\hline 20 & $1,6 \pm 0,2$ & $86,4 \pm 1,5$ & $310,0 \pm 1,5$ & $17,0 \pm 0,4$ & $356,3 \pm 3,0$ & $401,0 \pm 1,0$ & $68,8 \pm 1,0$ & $420,5 \pm 0,3$ & $10,2 \pm 0,3$ \\
\hline 42 & $1,1 \pm 0,2$ & $86,5 \pm 1,5$ & $283,0 \pm 1,0$ & $14,5 \pm 0,5$ & $361,8 \pm 2,0$ & $400,4 \pm 0,2$ & $71,0 \pm 1,0$ & $419,0 \pm 0,5$ & $12,3 \pm 0,3$ \\
\hline 70 & $2,2 \pm 0,2$ & $88,5 \pm 0,2$ & $276,2 \pm 2,2$ & $17,0 \pm 1,2$ & $355,5 \pm 2,0$ & $398,5 \pm 0,2$ & $60,5 \pm 0,5$ & $417,6 \pm 1,0$ & $12,9 \pm 0,3$ \\
\hline 100 & $3,4 \pm 0,2$ & $93,0 \pm 0,2$ & $275,4 \pm 1,0$ & $20,7 \pm 0,5$ & $361,5 \pm 1,0$ & $397,3 \pm 0,2$ & $51,0 \pm 2,0$ & $414,5 \pm 1,0$ & $18,5 \pm 1,0$ \\
\hline 180 & $3,7 \pm 0,2$ & $97,6 \pm 0,3$ & $267,7 \pm 0,2$ & $11,0 \pm 0,4$ & $356,9 \pm 0,8$ & $394,5 \pm 0,2$ & $52,0 \pm 0,2$ & $414,0 \pm 0,5$ & $19,5 \pm 1,0$ \\
\hline 215 & $3,8 \pm 0,2$ & $101,7 \pm 0,2$ & $271,0 \pm 0,7$ & $11,0 \pm 0,4$ & $354,3 \pm 1,0$ & $393,7 \pm 0,5$ & $50,5 \pm 1,5$ & $415,8 \pm 0,5$ & $21,0 \pm 0,5$ \\
\hline \multicolumn{10}{|c|}{ Mater-Bi NF/jute } \\
\hline $\mathbf{0}$ & $1,5 \pm 1,0$ & $130,0 \pm 0,5$ & $309,0 \pm 1,0$ & $28,5 \pm 0,5$ & $333,7 \pm 0,7$ & $406,3 \pm 0,3$ & $62,0 \pm 1,3$ & $423,5 \pm 0,5$ & $7,5 \pm 0,3$ \\
\hline 20 & $1,9 \pm 0,5$ & $88,0 \pm 0,5$ & $301,2 \pm 0,5$ & $29,3 \pm 0,5$ & $326,0 \pm 0,5$ & $400,8 \pm 0,2$ & $55,2 \pm 0,5$ & $417,7 \pm 0,5$ & $9,8 \pm 0,3$ \\
\hline 42 & $1,5 \pm 0,5$ & $89,0 \pm 0,5$ & $306,6 \pm 0,2$ & $25,0 \pm 1,0$ & $334,8 \pm 1,2$ & $405,3 \pm 0,2$ & $63,0 \pm 2,1$ & $422,0 \pm 0,5$ & $9,4 \pm 0,3$ \\
\hline 70 & $1,3 \pm 0,2$ & $88,0 \pm 0,5$ & $291,5 \pm 0,5$ & $14,5 \pm 0,7$ & $368,3 \pm 0,5$ & $401,9 \pm 0,4$ & $72,2 \pm 0,3$ & $421,0 \pm 0,2$ & $9,6 \pm 0,3$ \\
\hline 100 & $1,3 \pm 0,2$ & $85,0 \pm 0,5$ & ----- & ----- & ----- & $399,2 \pm 0,5$ & $76,8 \pm 2,1$ & $419,2 \pm 1,1$ & $11,0 \pm 1,1$ \\
\hline 180 & $2,2 \pm 0,2$ & $92,0 \pm 1,5$ & ----- & ----- & ----- & $395,1 \pm 0,3$ & $68,4 \pm 1,8$ & $415,1 \pm 0,4$ & $13,6 \pm 0,5$ \\
\hline 215 & $2,2 \pm 0,2$ & $83,0 \pm 1,5$ & ---- & ---- & ---- & $396,8 \pm 0,6$ & $59,7 \pm 2,9$ & $415,3 \pm 0,5$ & $15,2 \pm 0,5$ \\
\hline \multicolumn{10}{|c|}{ Mater-Bi NF/kenaf } \\
\hline $\mathbf{0}$ & $1,7 \pm 0,5$ & $373,0 \pm 0,5$ & $311,3 \pm 1,0$ & $22,5 \pm 1,0$ & $331,0 \pm 0,6$ & $406,4 \pm 0,4$ & $65,0 \pm 1,0$ & $420,3 \pm 0,2$ & $7,6 \pm 0,3$ \\
\hline 20 & $1,5 \pm 0,2$ & $95,0 \pm 0,2$ & $301,7 \pm 0,5$ & $20,3 \pm 0,4$ & $332,3 \pm 0,3$ & $403,3 \pm 0,2$ & $67,1 \pm 1,5$ & $421,3 \pm 0,2$ & $10,9 \pm 0,2$ \\
\hline 42 & $1,4 \pm 0,4$ & $93,0 \pm 0,5$ & $293,6 \pm 2,0$ & $18,2 \pm 0,4$ & $366,0 \pm 0,6$ & $403,0 \pm 0,8$ & $70,0 \pm 0,8$ & $421,0 \pm 0,7$ & $10,4 \pm 0,6$ \\
\hline 70 & $1,7 \pm 0,2$ & $98,4 \pm 0,2$ & $282,9 \pm 2,0$ & $16,8 \pm 0,2$ & $367,0 \pm 0,4$ & $401,2 \pm 0,2$ & $67,1 \pm 0,7$ & $418,9 \pm 0,3$ & $12,9 \pm 0,3$ \\
\hline 100 & $2,2 \pm 0,2$ & $87,9 \pm 0,2$ & $271,0 \pm 2,2$ & $16,1 \pm 1,2$ & $368,8 \pm 1,0$ & $397,4 \pm 0,5$ & $66,0 \pm 0,6$ & $415,7 \pm 0,2$ & $14,5 \pm 0,2$ \\
\hline 180 & $2,7 \pm 0,5$ & $88,2 \pm 2,0$ & $268,3 \pm 0,2$ & $15,9 \pm 0,2$ & $367,5 \pm 0,2$ & $398,2 \pm 0,2$ & $65,3 \pm 0,4$ & $416,0 \pm 0,5$ & $15,1 \pm 1,2$ \\
\hline 215 & $3,0 \pm 0,2$ & $92,0 \pm 0,2$ & $259,0 \pm 1,0$ & $15,0 \pm 0,2$ & $367,0 \pm 0,3$ & $395,6 \pm 0,3$ & $62,6 \pm 0,4$ & $415,8 \pm 0,3$ & $17,0 \pm 0,8$ \\
\hline
\end{tabular}


Kinetic analyses were performed to correlate the thermal decomposition behaviour of synthetic component with its degradation in soil. Previous studies [3] have demonstrated that the activation energy $(E a)$ is the most sensitive kinetic parameters to the degradation in soil process. Kissinger [4] and Coats Redfern [5] methods have been applied in order to assess the activation energy of the main thermal decomposition process of each material at different exposure times. Figure 3 shows the plot of activation energy as a function of degradation in soil time for all studied materials.

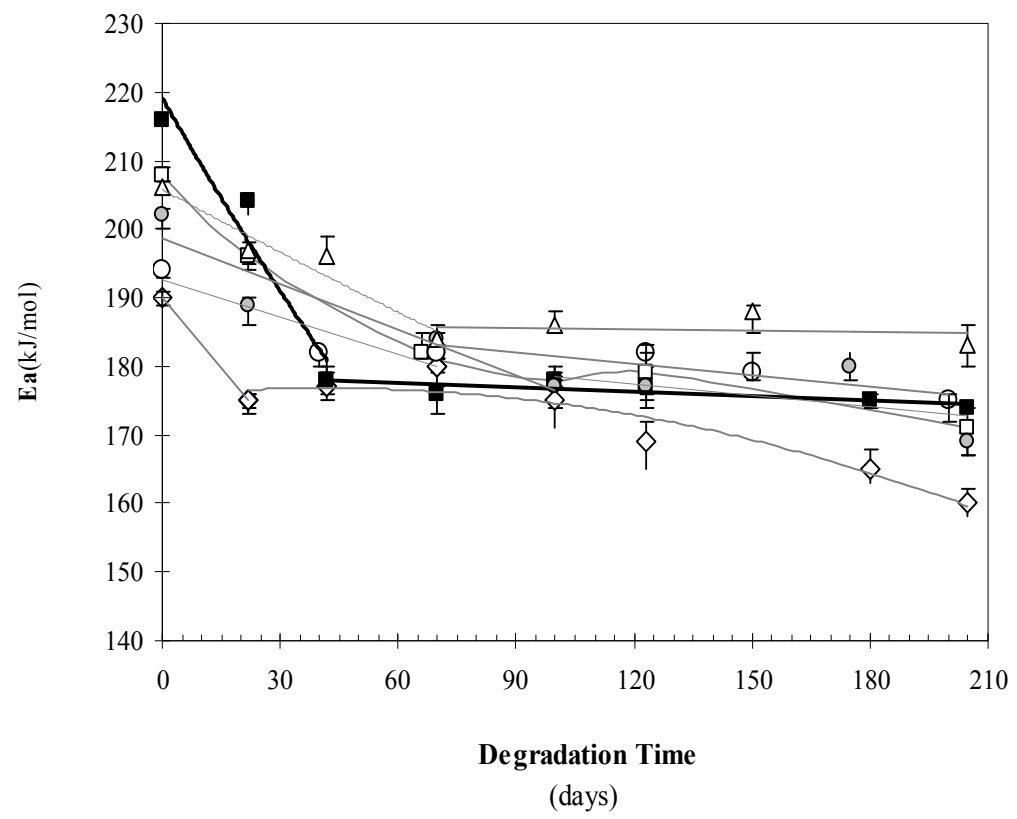

Figure 3. Activation energy values as a function of degradation time for the ( $\square$ ) pure Mater-Bi NF, $(\Delta)$ MaterBi NF/flax, (०) Mater-Bi NF/hemp, ( $\square$ ) Mater-Bi NF/cotton, (•) Mater-Bi NF/jute and ( () Mater-Bi NF/kenaf as a function of the degradation in soil process.

During the first 42 days of degradation in soil, the activation energy of pure Mater-Bi NF decreases in $38 \mathrm{~kJ} / \mathrm{mol}$, remaining constant for higher degradation times. The decrease of the $E a$ during the first degradation stage (up to 42 days) could be related to the loss of the majority of the starch component. When the reinforced biocomposites are submitted to soil burial tests, the most significant changes with respect to the pure Mater-Bi NF occurs in the first stage. The addition of kenaf fibres into the pure Mater-Bi NF reduces the duration of this first stage, maybe due to the high percentage of hemicellulose; the rest of the fibres, on the other hand, extend the duration of this stage. Moreover, at the end of the test the major changes are observed on the Mater-Bi NF/kenaf and Mater-Bi NF/flax biocomposites, 
providing lower and higher values of the activation energy than the pure Mater-BI NF, respectively.

Comparing the influence of each natural fibre, and taking into account the assessed relation between the activation energy associated to the synthetic component of the reinforced biocomposites (Ea2) with the lignin component of the natural fibres, the relation between the Ea2 with the lignin content at different degradation time has been studied (Figure 4). During the first 42 days of degradation it can be observed the same trend with the lignin content as that showed for the non-degraded reinforced biocomposites. From this moment, an anomalous behaviour of the Mater-Bi NF/flax (higher values than that expected) change the trend. From the Figure 4 it can be also appreciate the slowest degradation rate for the Mater-Bi NF/flax due to the minimum decrease in the Ea2 from the beginning to the end of the test. This fact could be due to the anomalous behaviour observed in the absorption process in Chapter 5.

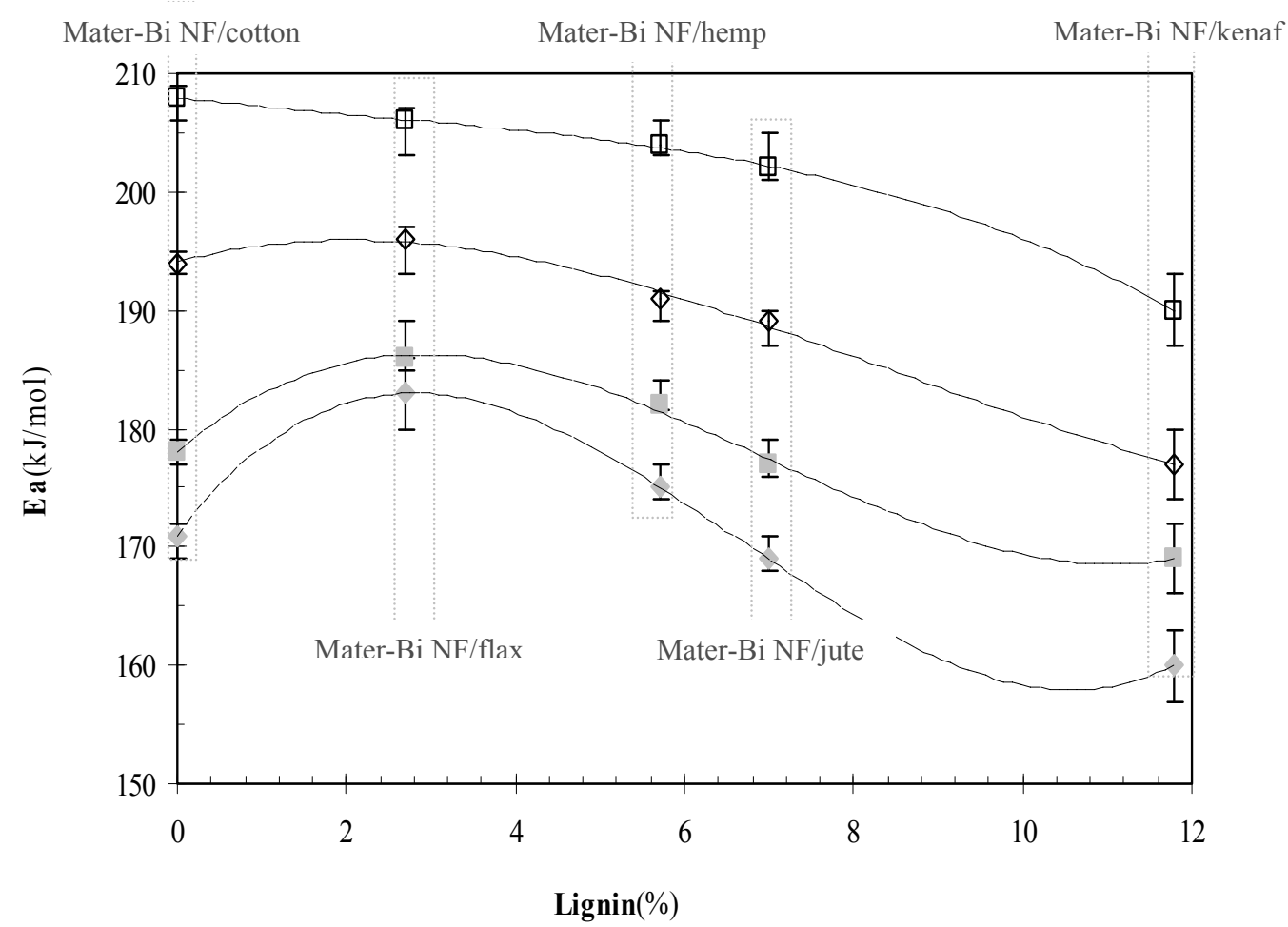

Figure 4. Activation energy values as a function of lignin percentage at $(\square 0$ days, (०) 42 days, ( $\square) 100$ days and , (०) 215 days of the degradation in soil process. 


\section{Calorimetric analysis}

Samples of pure Mater-Bi NF and the reinforced biocomposites were characterised by calorimetric measurements to analyse the possible thermal transition changes as a consequence of the soil burial test.

As it was reported in previous works, pure Mater-Bi NF displayed a prominent endothermic peak around $120^{\circ} \mathrm{C}$ and a main exothermic peak at $68^{\circ} \mathrm{C}$ in the cooling scan, which are related to the melting and the crystallisation processes of the crystalline phase of the synthetic biodegradable component, respectively [6]. Moreover, a clear glass transition around $-33^{\circ} \mathrm{C}$ in the heating scan and at $-36^{\circ} \mathrm{C}$ in the cooling scan can be observed. When pure Mater-Bi NF is subjected to soil burial test during 200 days, important changes in the cooling scan can be observed (Figure 5). The displacement of the main exothermic peak temperature and its great broadening indicate a new and more heterogenous crystalline distribution that is more liable to crystallize through out to the degradation in soil process. Thus, the degradation of the major part of starch ( the most amorphous component) increases the crystalline phase of the remaining material, that now are conformed from smaller crystallites due to the chain scissions during the degradation process.

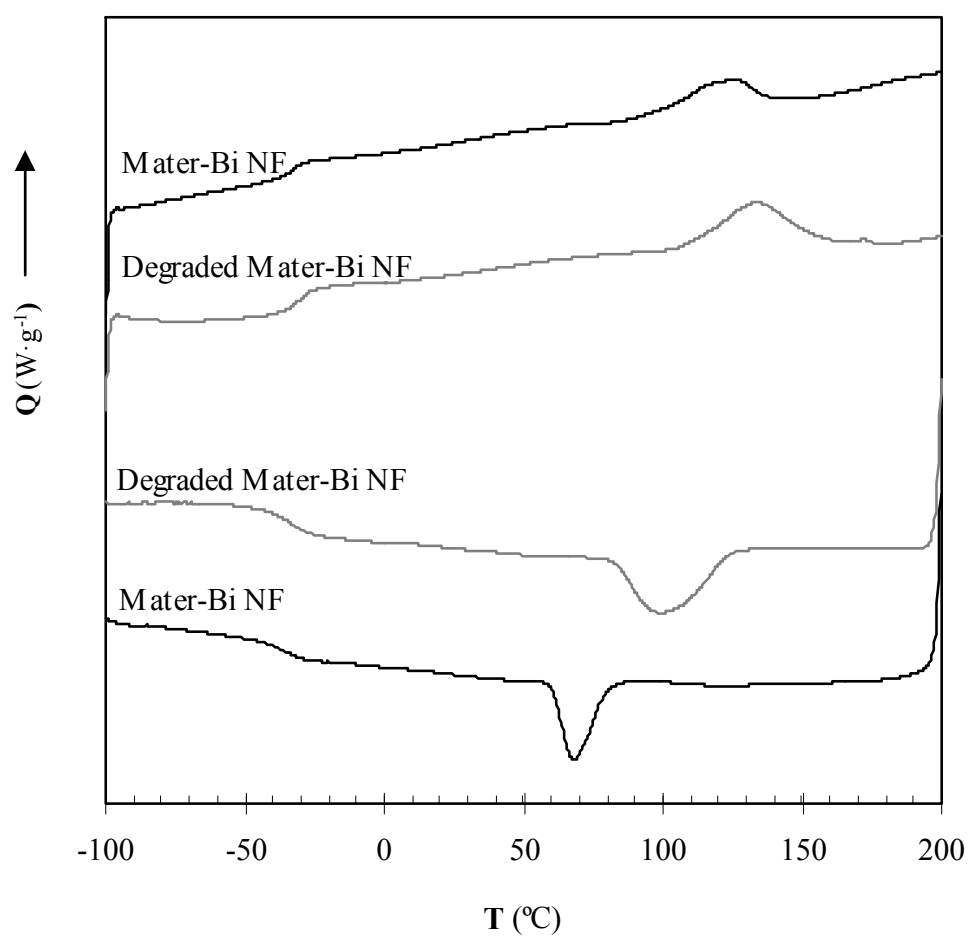

Figure 5. Calorimetric thermograms from the a) cooling and b) second heating temperature scan of the pure and degraded Mater-Bi NF. 
The presence of natural fibres does not induce extensive changes on the thermal transitions in the calorimetric thermograms. However, important differences in the cooling scan of each biocomposite can be observed when the reinforced biocomposites are subjected to soil burial test during 200 days. Figure 6 displays the cooling scan of the reinforced biocomposites at 200 days in soil. When the reinforced biocomposites are subjected to the soil burial test, a segregation of crystallites in two main populations is displayed. In addition, major differences in the calorimetric parameters can be observed.

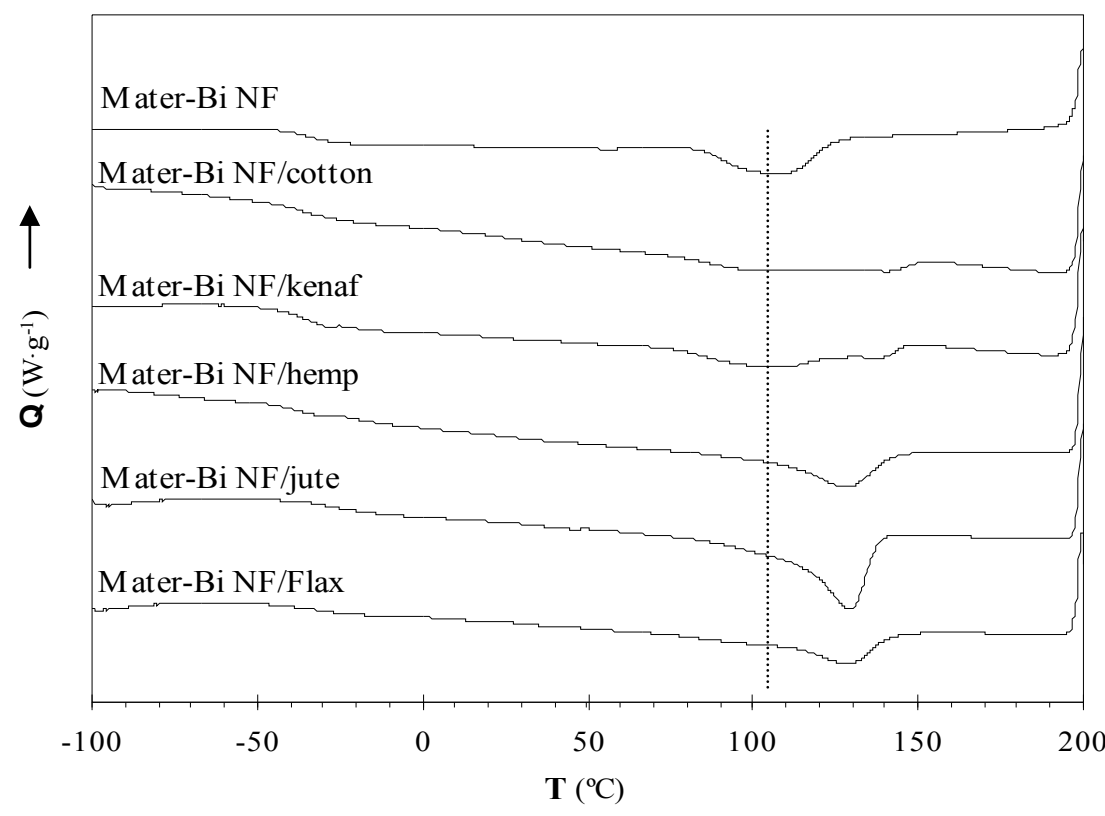

Figure 6. Calorimetric thermograms from the cooling temperature scan of the pure Mater-Bi NF and its reinforced biocomposites at 215 days of degradation

Table 4 summarises the onset, endset, Tc and $\Delta \mathrm{Hc}$ values of the main exothermic peak from the cooling scan for all the studied materials. Moreover, the degraded reinforced biocomposites present broader peaks and their crystallisation process begins earlier compared to the pure Mater-Bi NF. These results suggest that natural fibres decrease the crystalline phase of the polymeric matrix, produce a major variation of crystallites that are more easily crystallised than the ones for the degraded Mater-Bi NF. 
Table 4. Calorimetric parameters of degraded and non degradede pure Mater-Bi NF and its reinforced biocomposites.

\begin{tabular}{r|cccc|cccc}
\hline & \multicolumn{4}{|c|}{ Non degraded Materials } & \multicolumn{5}{c}{ After 200 days of degradation } \\
& $\begin{array}{c}\text { Onset } \\
\left({ }^{\circ} \mathrm{C}\right)\end{array}$ & $\begin{array}{c}\text { Tc } \\
\left({ }^{\circ} \mathrm{C}\right)\end{array}$ & $\begin{array}{c}\text { Endset } \\
\left({ }^{\circ} \mathrm{C}\right)\end{array}$ & $\begin{array}{c}\Delta H c \\
(\mathrm{~J} / \mathrm{gr})\end{array}$ & $\begin{array}{c}\text { Onset } \\
\left({ }^{\circ} \mathrm{C}\right)\end{array}$ & $\begin{array}{c}T c \\
\left({ }^{\circ} \mathrm{C}\right)\end{array}$ & $\begin{array}{c}\text { Endset } \\
\left({ }^{\circ} \mathrm{C}\right)\end{array}$ & $\begin{array}{c}\Delta H c \\
(\mathrm{~J} / \mathrm{gr})\end{array}$ \\
\hline Mater-Bi NF & $88,7 \pm 1,0$ & $68,1 \pm 0,7$ & $20,0 \pm 1,0$ & $12,7 \pm 1,2$ & $132,1 \pm 1,0$ & $102,6 \pm 1,6$ & $39,4 \pm 0,5$ & $27,0 \pm 0,5$ \\
\hline Mater-Bi/cotton & $105,5 \pm 0,5$ & $93,3 \pm 0,7$ & $25,7 \pm 1,0$ & $16,3 \pm 0,5$ & $153,3 \pm 1,0$ & $102,5 \pm 0,9$ & $25,5 \pm 0,5$ & $18,8 \pm 0,5$ \\
\hline Mater-Bi/flax & $104,1 \pm 1,1$ & $90,1 \pm 0,5$ & $23,5 \pm 1,0$ & $16,3 \pm 0,5$ & $144,7 \pm 0,5$ & $103,5 \pm 0,9$ & $24,00,6$ & $19,7 \pm 0,5$ \\
\hline Mater-Bi /hemp & $103,3 \pm 0,9$ & $82,2 \pm 0,6$ & $27,8 \pm 1,0$ & $16,3 \pm 0,9$ & $139,0 \pm 0,6$ & $104,2 \pm 0,6$ & $34,5 \pm 0,9$ & $22,2 \pm 0,5$ \\
\hline Mater-Bi/kenaf & $106,6 \pm 0,7$ & $101,8 \pm 0,9$ & $27,8 \pm 1,0$ & $17,0 \pm 1,2$ & $153,6 \pm 0,9$ & $\begin{array}{c}103,9 \pm 1,0 \\
133,0 \pm 0,6\end{array}$ & $27,7 \pm 0,5$ & $22,7 \pm 0,5$ \\
\hline Mater-Bi/jute & $105,7 \pm 1,1$ & $85,6 \pm 0,5$ & $20,3 \pm 1,0$ & $16,6 \pm 0,6$ & $136,3 \pm 0,9$ & $103,5 \pm 0,5$ & $37,2 \pm 0,9$ & $24,0 \pm 0,5$ \\
\hline
\end{tabular}

\section{Scanning electron microscopy (SEM)}

The SEM micrographs of the surfaces of the pure Mater-Bi NF and the reinforced biocomposites are shown in Figure 7. Comparing the degraded and non degraded Mater-Bi NF micrographs (Figure 7a-7b), a more damage morphology for the degraded samples can be dsitinguesed. Similar conclusions can be drawn for the reinforced biocomposites and the comparative it is not showed here for sake of shortness. Figure $7 c$ shows a detail of the natural fibre present in the reinforced Mater-Bi NF/hemp confirming the degradation of the natural fibre at the end of the soil burial test. Figures $7 c, 7 d, 7 e, 7 f$ display that degradation in soil produced a damage morphology, with smaller furrows and cavities.
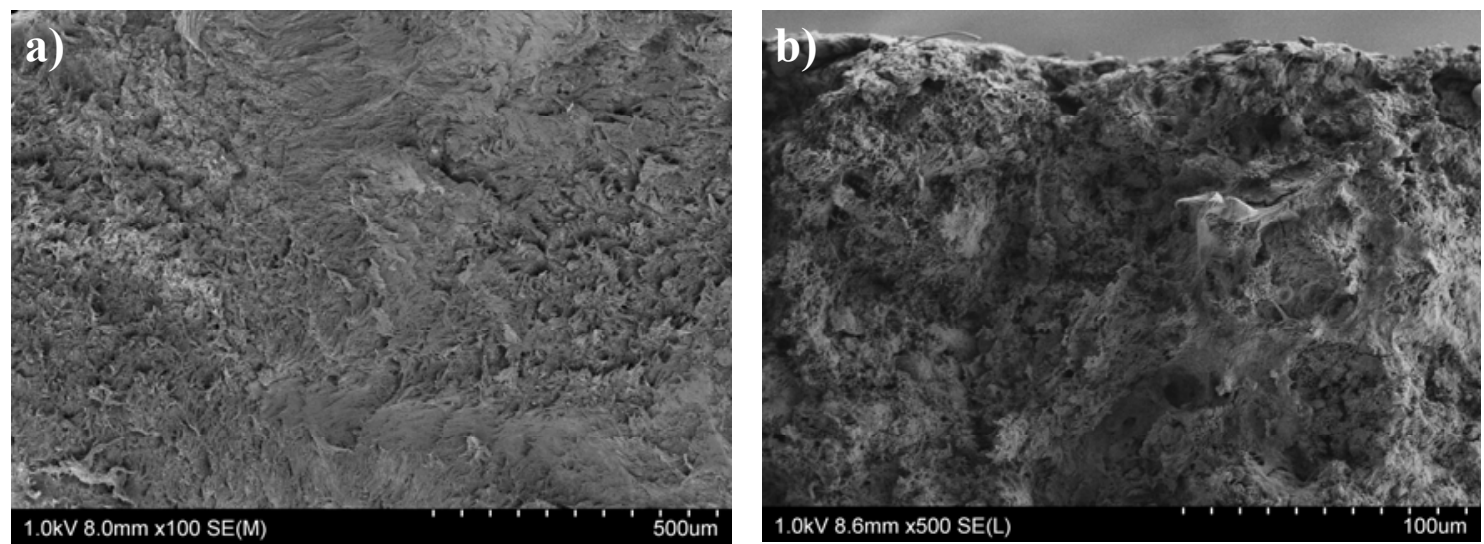

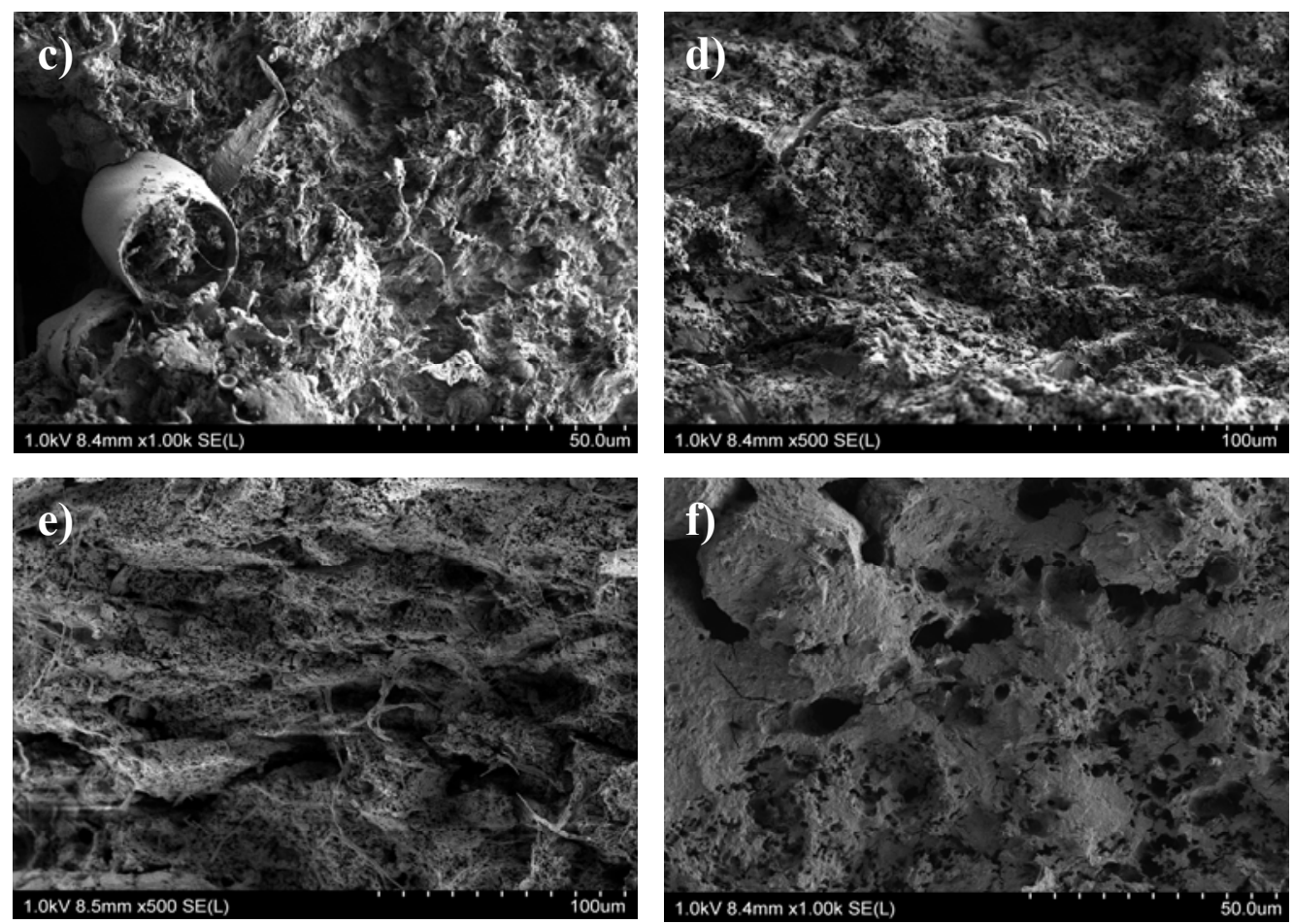

Figure 7. Micrographs of a) pure Mater-Bi NF, b) degraded Mater-Bi NF, c) degraded Mater-Bi NF/hemp biocomposite, c) degraded Mater-Bi NF/cotton biocomposite, d) degraded Mater-Bi NF/flax biocomposite and e) degraded Mater-Bi NF/kenaf biocomposites..

\section{Fourier Transform Infrared Spectroscopy}

The FTIR spectrum of pure Mater-Bi NF is displayed in Figure 8, and the assignments of the main functional groups are summarised in Table 5. Figure 8 displays also the spectra of the degraded pure Mater-Bi NF. The intensities of the fingerprint peaks $(1500-600 \mathrm{~cm}-1)$ in the degraded Mater-Bi NF spectra show a significant decrease and their width become broader, indicating a deterioration in the chemical structure due to the degradation process.

$\underbrace{e}_{0}$ 


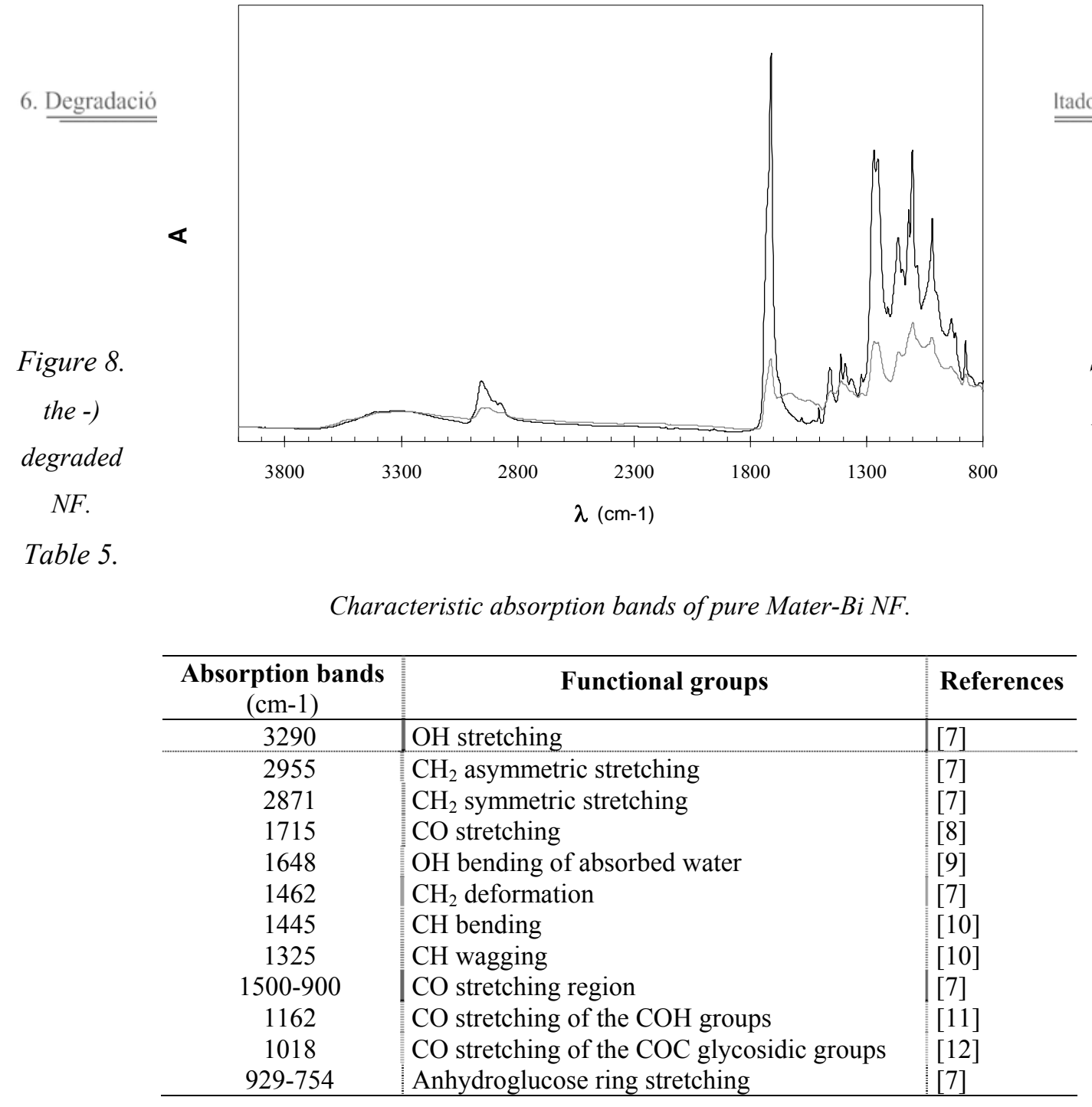

When natural fibres are added into the Mater-Bi NF, an increase in the $\mathrm{OH}$ bending peak at $1648 \mathrm{~cm}^{-1}$ is observed for all the reinforced biocomposites (Figure 9); these changes can be related with changes in the crystalline structure of the pure Mater-Bi NF [7].

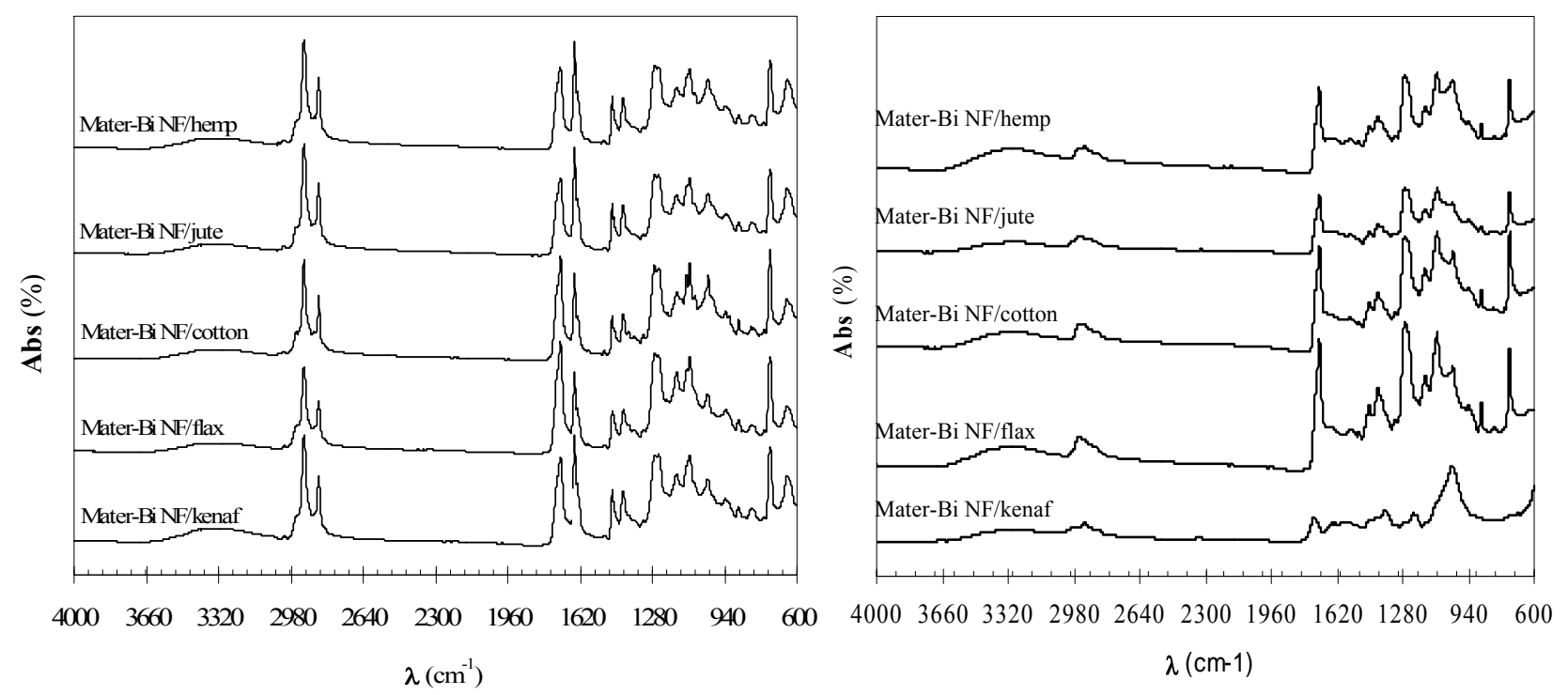


Figure 9. Spectrum of the reinforced biocomposites non-degraded and degraded during 200 days.

The $\mathrm{C}=\mathrm{O}$ group peak $\left(1715 \mathrm{~cm}^{-1}\right)$ is selected to monitor the degradation of the synthetic component of pure Mater-Bi NF and its reinforced biocomposite. The band placed at 1018 $\mathrm{cm}^{-1}$ (C-O-C stretch) is chosen to monitor starch degradation in pure Mater-Bi NF and the starch together with the natural fibre degradation in the reinforced biocomposites.

All spectra are normalised with respect to the stretching vibration of the C-O-C group, in order to relate changes of the synthetic component with respect of the starch component during degradation in soil. Figure 9 displays the normalised spectra of the degraded pure and reinforced biocomposites. Table 6 summarises the relative values of the ratio $\mathrm{I}_{\mathrm{C}=\mathrm{O}} / \mathrm{I}_{\mathrm{C}-\mathrm{O}-\mathrm{C}}$ for the degraded samples of the pure Mater-Bi NF and its reinforced biocomposites. The decrease in the $\mathrm{C}=\mathrm{O}$ band confirms the degradation of the synthetic component in all the studied materials. Among all these materials, only Mater-Bi NF/kenaf biocomposite has a lower value of $\mathrm{I}_{\mathrm{C}=\mathrm{O}} / \mathrm{I}_{\mathrm{C}-\mathrm{O}-\mathrm{C}}$ than the Mater-Bi NF; this indicates that, once degraded, this biocomposite presents a lower proportion of the synthetic component than the pure Mater-Bi NF.

Table 6. $I_{C=O} / I_{C-O-C}$ of the pure Mater-Bi KE and the reinforced biocomposite as a function of the degradation in soil process.

\begin{tabular}{c|cccccc}
\hline $\begin{array}{c}\text { Degradation } \\
\text { Time } \\
\text { (days) }\end{array}$ & Mater-Bi NF & Mater-Bi fflax & Mater-Bi /hemp & Mater-Bi/kenaf & Mater-Bi/cotton & Mater-Bi /jute \\
\hline 0 & 1,751 & 1,502 & 1,601 & 1,659 & 1,741 & 1,731 \\
200 & 0,791 & 0,952 & 0,897 & 0,591 & 0,878 & 0,861 \\
\hline
\end{tabular}

\section{Conclusions}

Thermogravimetric, DSC, SEM and FTIR analyses were performed in order to monitor the degradation of pure Mater-Bi NF and the reinforced Mater-Bi NF/cotton, Mater-Bi NF/hemp, Mater-Bi NF/flax, Mater-Bi NF/jute and Mater-Bi NF/kenaf biocomposites.

Pure Mater-Bi NF exhibits a complex thermal decomposition with two main mass-loss regions, the first one related to the thermal decomposition of the starch and the second one associated to the thermal decomposition of the synthetic component present in Mater-Bi NF. The most important changes occur during the first 40 days of degradation: the starch disappears and, as a consequence, the activation energies of the synthetic component decrease. The crystalline index of pure Mater-Bi NF increases once degraded, due to the 
degradation of the starch component. Moreover, the decrease in the mass loss related to the synthetic component and the $\mathrm{C}=\mathrm{O}$ band at the end of the accelerated degradation test confirms the degradation of the synthetic component during the degradation process.

When the reinforced biocomposites are submitted to soil burial test, the degradation of the starch component is slowed down in all the reinforced biocomposites due to the interaction between the starch component and the natural fibres. This diminution in the degradation rate of the starch component hinders the increase in the crystalline index of the reinforced biocomposites during the soil burial test. However, the presence of the natural fibres induces the appearance of a more heterogenous population of crystallites that can be easier crystallized. The decrease in the $\mathrm{C}=\mathrm{O}$ band confirms the degradation of the synthetic component in all the studied materials during the degradation in soil process. Among all the studied reinforced biocomposites, only the synthetic component of the Mater-Bi KE/kenaf present lower values of thermal stability, activation energy and $I_{C=O} / I_{C-O-C}$. compared pure Mater-Bi NF, indicating that only kenaf fibres promote the degradation of the synthetic component of pure Mater-Bi NF.

\section{References}

1. Griffin GJL, editor. Chemistry and Technology of Biodegradable Polymers. Glasgow: Blackie Academic Professional, 1994.

2. Mano F, Koniarova D, Reis RL. Journal of Material Science: Materials in Medicine 2003; 14: 127.

3. Moriana R, Karlsson S, Ribes-Greus A. Polym Comp 2010 (Pending of publication)

4. Kissinger HE. J Res Natl Bur Stand 1956; 57: 217.

5. Coats AW, Redfern JP. Nature 1964; 201:68.

6. Bastioli C. Polym Degrad Stab 1998; 59: 263.

7. Imam SH, Gordon SH, Mohamed A, Harry-O'kuru R, Chiou BS, Glenn GM, Orts WJ. Polym Degrad Stab 2006; 91: 2894

8. Socrates G, edito. Infrared and Raman Characteristic Groups Frequencies. England: J Wiley, 2001

9. Wolkers WF, Oliver EA, Tablin F, Crowe JH. Carbohydr Res 2004; 339: 1077

10. Park JW, Im SS, Kim SH, Kim YH. Polym Eng Sci 2000; 40: 2539.

11. Goheen SM, Wool RP. Appl Polym Sci 1991; 42: 2691

12. Ma XF, Yu JG J, He K, Wang N. Macromol Mater Eng 2007; 292: 503

13. Cael JJ, Koenig JL, Blackwell J. Carbohydr Res 1973; 29:123. 


\subsection{RESUMEN DE RESULTADOS}

La degradación en tierra de las matrices poliméricas y de los biocomposites enfibrados se ha estudiado, mediante análisis térmico, TGA y DSC. Esta metodología se complementa con SEM y FTIR. El deterioro macroscópico de los materiales estudiados durante el proceso de degradación en tierra, ha marcado la duración de los ensayos de cada material: 535 días para la serie de Mater-Bi KE y 215 días para la serie de Mater-Bi NF.

Los cambios de los parámetros termogravimétricos y cinéticos de cada proceso de descomposición en función del tiempo de degradación permite monitorizar el proceso de degradación de cada uno de los componentes de las matrices poliméricas.

Primeramente, se han caracterizado diferentes muestras de Mater-Bi KE sometidas a diferentes tiempos de degradación.

o Los cambios en la temperatura de pico, en el onset y en la Ea del proceso de termodescomposición del almidón en función del tiempo de degradación definen tres etapas diferentes para su degradación en tierra:

- Primera etapa (0-24 días de degradación). La estabilidad térmica y la Ea aumentan.

La estabilidad térmica aumenta en más de $10^{\circ} \mathrm{C}$ y la $E a$ en más de $16 \mathrm{~kJ} / \mathrm{mol}$. Estos resultados coinciden con los resultados obtenidos de caracterizar térmicamente al Mater-Bi KE saturado, es decir, tras ser sometido a un proceso de absorción de agua a una temperatura de $29^{\circ} \mathrm{C}$. Por tanto, esta primera etapa se asocia con la hidrólisis del almidón.

- Segunda etapa (40-200 días de degradación). La estabilidad térmica y la Ea se mantienen constantes.

- Tercera etapa (200-550 días de degradación). La estabilidad térmica y la Ea disminuyen.

La estabilidad térmica disminuye en $16^{\circ} \mathrm{C}$ y la $E a$ en $24 \mathrm{~kJ} / \mathrm{mol}$ indicando la ruptura de las cadenas de almidón. 
- La estabilidad térmica y la $E a$ del componente sintético biodegradable de la matriz polimérica, se mantiene constante durante los primeros 200 días de degradación, a partir de este momento se produce una disminución de $8^{\circ} \mathrm{C}$ y de $10 \mathrm{~kJ} / \mathrm{mol}$ de ambos parámetros termogravimétricos respectivamente. Estos resultados indicarían una posible degradación del componente sintético como consecuencia de la hidrólisis del almidón.

Del mismo modo, los cambios más importantes durante la degradación en tierra del Mater-Bi NF son:

o Una pérdida de masa de más del $75 \%$ del primer proceso de descomposición durante los primeros 40 días de degradación en tierra, indicando la degradación del almidón durante los primeros días de ensayos. En esta matriz polimérica no se distingue la etapa hidrolítica del almidón, tal vez debido a que esta matriz polimérica es más hidrofílica que la anterior, y la hidrólisis tiene lugar mucho más rápidamente que en el Mater-Bi KE.

o La tendencia decreciente de la estabilidad térmica del material sintético durante todo el proceso de degradación y la disminución de la $E a$ durante los primeros 40 días de degradación. Indicando una disminución de la estabilidad térmica del material en función del tiempo de degradación con cambios en el entorno molecular más acentuados durante los primeros 40 días, coincidiendo con la desaparición del almidón.

La caracterización calorimétrica de las muestras degradadas del Mater-Bi KE, muestra una disminución de las entalpías de fusión y cristalización a partir de los 200 días de degradación en tierra que pasa por un mínimo a los 480 días. Por tanto, la degradación en tierra produce una disminución de la fase cristalina asociada con el componente sintético del material a partir del momento en que el componente sintético y el almidón se biodegradan.

En cambio, el análisis calorimétrico del Mater-Bi NF revela que este material, una vez degrado, presenta mayor contenido cristalino y una distribución cristalina más heterogénea. El aumento del contenido cristalino se debe a la desaparición del almidón, que es el 
componente amorfo de la muestra y a la población más heterogénea de cristalitos a la degradación del componente sintético.

El análisis espectroscópico de ambas matrices poliméricas revela la disminución de la intensidad de banda del carbonilo del grupo éster del componente sintético, indicando su degradación debido al proceso de degradación en tierra.

Finalmente, de la comparación de las micrografías de las matrices poliméricas degradadas con las no degradadas se observa el deterioro de la morfología superficial de las muestras degradadas y la aparición de canales, huecos y poros, que confirmación la degradación del material.

De la caracterización termogravimétrica de los biocomposites reforzados degradados a diferentes tiempos y de su comparación con los resultados de la degradación de la matriz polimérica, se obtiene la influencia de las fibras naturales en el proceso de degradación.

A partir de las tendencias de la estabilidad térmica y de la $E a$ de los procesos de termodescomposición de los biocomposites de Mater-Bi KE en función del tiempo de degradación, se observa que:

o Durante la degradación, el primer proceso de descomposición mantiene las tres etapas de degradación identificadas para el almidón. Sin embargo,

- Se evalúan cambios en la primera etapa de degradación que dependen del tipo de fibra añadida. Concretamente:

El aumento que se produce en el onset durante los primeros 24 días de degradación varía en función del contenido de hemicelulosa/pectina de los biocomposites; a mayor porcentaje menor aumento de temperatura.

El aumento de la $E a$ observada en la matriz polimérica, se mantiene para el biocomposite Mater-Bi KE/algodón y Mater-Bi KE/lino. En cambio, los biocomposites con mayor contenido de hemicelulosa/pectina cambian las tendencias, observándose una disminución de las $E a$ en esta primera etapa. 
Estos cambios en las tendencias de los parámetros termogravimétricos durante los primerso 24 días de degradación en tierra coinciden con los obtenidos en el Capitulo 5 al caracterizar térmicamente a los biocomposites saturados en agua. Por tanto, esta primera etapa de los biocomposites enfibrados de Mater-Bi KE sigue asociándose a un proceso hidrolítico influenciado por la fibra natural presente en la formulación del biocomposite.

- Los valores de estabilidad térmica y Ea durante todo el proceso de degradación son mayores en los biocomposites que en la matriz polimérica, indicando una ralentización de la degradación del almidón debido a la presencia de la celulosa, de la hemicelulosa/pectina y de las interacciones entre las fibras naturales y la matriz polimérica.

o La presencia de las fibras naturales modifica la tendencia de la Ea del componente sintético durante el proceso de degradación en tierra. La tendencia decreciente de este parámetro en función del tiempo de degradación indica que en el biocomposite el componente sintético se degrada desde el inicio del proceso de degradación en tierra. Este hecho se debe a que la degradación de las fibras naturales aumenta el área superficial de ataque de los microorganismos al material sintético, facilitando su accesibilidad desde el inicio del proceso de degradación en tierra.

Cuando los biocomposites de Mater-Bi NF se someten al proceso de degradación en tierra, se observa:

o Una ralentización de la disminución de la pérdida de masa del primer proceso de descomposición que aumenta en función de la disminución de la suma de los porcentajes de hemicelulsa/pectina y celulosa en su composición.

o Cambios en la duración de la primera etapa de degradación del material sintético, sólo el Mater-Bi NF/kenaf consigue acelerar esta etapa mientras que el resto la ralentiza.

o Los valores de la $E a$ del material sintético en los biocomposites disminuyen en función del contenido de lignina durante todo el proceso de degradación. Sin embargo el Mater-Bi NF/lino presenta un comportamiento anómalo con esta tendencia en la segunda etapa de degradación. 
La caracterización calorimétrica de los biocomposites de Mater-Bi KE degradados, muestra al igual que para el Mater-Bi KE puro, una disminución de las entalpías de fusión y cristalización a partir de los 200 días de degradación en tierra, sin embargo, el Mater-Bi $\mathrm{KE} /$ kenaf alcanza su valor mínimo antes que la matriz polimérica y el Mater-Bi KE/lino un poco después.

A partir de los estudios calorimétricos de los biocomposites de Mater-Bi NF, se observa que la degradación en tierra produce un aumento del índice de cristalinidad y una distribución de cristalitos aún más heterogénea que la mostrada por la matriz degradada. Sin embargo, todos los biocomposites degradados presentan un índice cristalino menor que la matriz degradada, esto se atribuye a la ralentización de la desaparición del almidón en los biocomposites.

Los análisis morfológicos y espectroscópicos de ambas series de biocomposites, confirman la degradación de todos los materiales durante el proceso de degradación en tierra. 



\section{Conclusiones y trabajo futuro}

\subsection{Conclusions}

7.2 Conclusiones

7.3 Líneas de trabajo futuro 


\subsection{CONCLUSIONS}

The polymeric matrices (Mater-Bi KE and Mater-Bi NF), the natural fibres (cotton, hemp, kenaf, flax and jute) and the corresponding reinforced biocomposites were characterised by different experimental techniques, including: Tensile Test, Thermogravimetric Analysis (TGA), Differential Scanning Calorimetric (DSC), Dynamic Mechanical Thermal Analyses (DMTA), Infrared Spectroscopy (FTIR-ATR) and Scaning Electron Microscopy (SEM). The combination of the previous techniques defines a methodology for the characterisation of new biocomposites based on the study of their thermal, mechanical and structural properties.

Prior to study the properties of the biocomposites, the individual components (natural fibres and polymeric matrices) were characterised separately.

\section{Natural Fibres Properties}

The chemical composition of the natural fibres was obtained on the basis of their contents on cellulose, hemicellulose/pectin and lignin.

o The cellulose contents followed the sequence: cotton $(90 \%)>$ flax $(76 \%)>$ jute $(71 \%)>\operatorname{hemp}(69 \%)>\operatorname{kenaf}(57 \%)$.

o The kenaf, jute and hemp fibres presented the highest content in hemicelluloses/pectins (22\%, 15\% and $13 \%$ respectively).

o Kenaf and jute fibres possessed the highest content in lignins $(12 \%, 8 \%$ respectively)

The morphology and the thermal properties of the fibres varied with their chemical composition. The natural fibres with major content of cellulose showed the highest crystalline indexes and thermal stability, while the presence of hemicellulose/pectin promoted higher moisture contents in the fibres. 
The pyrolysis of the natural fibres proceeded through several decomposition processes; the thermal decomposition of the hemicellulose/pectin, cellulose and lignin occur overlapped from 210 to $510^{\circ} \mathrm{C}$. During the pyrolysis of the natural fibres, two competitive reactions take place: the formation of char and the evaporation of levoglucosan. These processes can be influenced by the re-polymerisation of the volatiles. According to the kinetic analysis performed on the thermogravimetric results, the degradation of the cellulose component in all the natural fibres procees following a kinetic model $n=1$.

\section{Polymeric Matrices Properties}

The two Mater-Bi matrices (Mater-Bi KE and Mater-Bi NF) were compared from the point of view of their thermo-mechanical, structural and morphological properties.

o Both polymeric matrices are semi-crystalline, with Mater-Bi KE having a higher crystalline index. On the other hand, Mater-Bi NF underwent higher melting and crystallisation temperatures than Mater-Bi KE. This indicates that less crystalline domains but more stable are formed in Mater-Bi NF.

o The thermal degradation of both polymeric matrices occurs through two main processes which similar decomposition mechanisms. The decomposition process at lower temperatures (around $300^{\circ} \mathrm{C}$ ) was related to the starch decomposition and the second (around $405^{\circ} \mathrm{C}$ ) to the biodegradable synthetic component. It was found that the Mater-Bi KE is more thermally stable than the Mater-Bi NF.

o The Mater-Bi NF was found to be more resistant, but showed less stiffness than Mater-Bi KE. 


\section{Reinforced Biocomposites Properties}

The reinforcement of the polymeric matrices with the natural fibres had several effects on the properties shown by the new biocomposites:

o The influence of the natural fibres on the mechanical properties is similar for both polymeric matrices.

o The increase in the Young Modulus and the diminution in the elongation confirm an increase in the stiffness of the biocomposites with respecto to the polymeric matrices, attributed to interactions between the natural fibres and the polymeric matrices.

- The reinforced biocomposites containing kenaf and hemp do not exhibit a variation of the resistant with the increase in the stiffness.

- On the other hand, the increase in the Young Modulus is accompanied with a major fragility in the biocomposites of cotton and flax.

- $\quad$ The presence of the jute fibres permits to obtain a more resistant and stiffer material than the polymeric matrix.

o The crystallisation temperature increased in the biocomposites, probably as a consequence of the interactions between the polymeric matrix and the natural fibres, which may be also responsible of the changes in the mechanical properties. The reinforced biocomposites display a positive deviation respect to the perfect blends'law.

0 The onset and Ea of the thermal decomposition related to the starch component increase, displaying an enhancement in the thermal stability of the reinforced biocomposites. It is possible to establish a clear correlation between the thermal stability of the biocomposites and the chemical composition of the natural fibres.

- The increase in the thermal stability of the reinforced biocomposites is greater as the hemicellulose/pectin and lignin contents increases, and diminishes as a function of the cellulose percentage.

- The reinforced biocomposites of kenaf, jute and hemp are the materials with a major thermal stability, exhibiting the most significant increments in the activation energy $\left(E_{a}\right)$ for both polymeric matrices. 
- Thus, the reinforced biocomposites with higher hemicellulose/pectin and lignin contents in their formulation more convenient interactions between the polymeric matrix and the natural fibres.

The absorption water tests on the polymeric matrices and the reinforced biocomposites were proposed as a previus stage of the biodegradation. The thermogravimetric properties of the polymeric matrices and the reinforced biocomposites were studied respect to water absorption.

o The Mater-Bi NF is the most hydrophilic polymeric matrix, exhibiting higher diffusion coefficients and shorter saturation times than Mater-Bi KE.

o In general terms, the presence of the natural fibres promotes higher saturation capacities and lower saturation times in the biocomposites. In particular, it was also observed that the saturation capacity increases with the hemicelulos/pectin contents in the fibres.

o The water absorption process in the polymeric matrices and the corresponding reinforced biocomposites followed the kinetics and mechanisms described by the Fick's theory. The reinforced biocomposites display lower coefficient diffusion than the corresponding polymeric matrices, suggesting the transport of water is somehow inhibited by the presence of the natural fibre.

o The thermal properties of the biocomposites submitted to the absorption tests at $29^{\circ} \mathrm{C}$ were also studied in order to determine possible hydrolytic effects in the materials. The results revealed that starch is the most affected component of the MarterBi matrices by the water absorption process, experiencing an increase on its thermal stability in the saturated matrices and biocomposites.

The degradation in soil of the polymeric matrices and the reinforced biocomposites has been carried out by means of Termogravimetric analysis (TGA), Differential Scanning calorimetric (DSC), Infrared Analysis (FTIR-ATR) and Scanning Electron Microscopy (SEM). 


\section{Degradation in soil of the polymeric matrices}

o In Mater-Bi KE, the degradation in soil of the starch component occurs through three stages. The first one occurs during the first 20 days and is related to the hydrolisis of the starch. During the second one not significant changes are observed. However, from the third stage of the starch degradation (around 200 days of degradation in soil) the degradation in soil of the synthetic component takes place.

o In Mater-Bi NF, the degradation of starch takes place at a greater rate than MaterBi KE, especially during the first 40 days, probably due to the higher hydrophilic character of this polymeric matrix. Due to the fast degradation of the starch the hydrolytic stage of the starch could not be monitorised.

\section{Degradation in soil of the reinforced biocomposites}

The reinforcement of the polymeric matrices with the natural fibres had several effects on the degradation in soil processs of the polymeric matrices.

o In general, the degradation of starch is slowed down due to the cellulose, hemicellulose/pectin and the interactions of natual fibres and the starch component.

- In the Mater-Bi KE, the presence of the natural fibres promotes changes in the first stage of hydrolysis of the degradation in soil, especially in the biocomposites containing higher hemicellulose/pectin content, possibly due to the higher hydrophilic character of these biocomposites.

- In the Mater-Bi NF, the reinforced bicomposites with higher content of hemicelullose/pectin and cellulose in its composition show a slower disappearance of the starch may be due to the stronger interactions in the reinforced biocomposites with more hemicellulose content.

o The degradation rate of the synthetic material depends on the polymeric matrix.

- The degradation rate of the synthetic material is higher in all the reinforced Mater-Bi KE biocomposites respect to the pure polymeric matrices This fact can be attributed to an increase in the available degradation surface of the synthetic component caused by the degradation of natural fibres.

- The degradation rate of the synthetic material in the Mater-Bi NF is modified due to the presence of the natural fibres. 
o The reinforced biocomposites containing flax display the lowest degradation rates, and are also the least affected by the degradation in soil process.

o On the other hand, kenaf is the only fibre capable to increase the degradation rate of the Mater-Bi synthetic material and to promote higher degradation states in the biocomposites than in the polymeric matrix.

The selection of a natural fibre as a reinforcement material depends on the required properties of design. In general, the addition of natural fibres increases the stiffness, decreases the elongation at break and enhances the thermal stability. The degradation of the components of the polymeric matrix is maintained in all the reinforced biocomposites. In particular, the biocomposites with higher hemicellulose/pectin contents in their formulation presents higher susceptibility towards degradation. 


\subsection{CONCLUSIONES}

La caracterización de las matrices poliméricas (Mater-Bi KE y Mater-Bi NF), de las fibras naturales (algodón, cáñamo, lino, yute y kenaf) y de sus respectivos biocomposites se ha llevado a cabo mediante las siguientes técnicas experimentales: Ensayos Mecánicos de Tensión, Termogravimetría (TGA), Calorimetría Diferencial de Barrido (DSC), Análisis de Espectroscopía de Infrarrojos (FTIR) y de Microscopia Electrónica de Barrido (SEM). El uso de las técnicas seleccionadas ha permitido definir una metodología precisa y eficaz para la correcta caracterización térmica, mecánica y estructural de los nuevos biocomposites diseñados.

Previamente a la determinación de las propiedades de los biocomposites, los materiales base (fibras naturales y matrices poliméricas) han sido caracterizados.

\section{Propiedades de las Fibras Naturales}

La composición química de cada fibra natural se ha determinado en base a su contenido en celulosa, hemicelulosa/pectina y lignina.

- La fibra natural que posee un mayor contenido de celulosa en su composición es el algodón (90\%) seguido por el lino (76\%), el yute (71\%), el cáñamo (69\%) y finalmente, por el kenaf (57\%).

- Las fibras de kenaf, yute y cáñamo presentan el contenido más alto en hemicelulosa/pectina $(22 \%, 15 \%$ y $13 \%$ respectivamente $)$.

- Las fibras de kenaf y yute tienen el mayor contenido en lignina (12\% y $8 \%$ respectivamente).

Estas diferencias en la composición química de las fibras naturales determinan su morfología y sus propiedades térmicas. Las fibras naturales con mayor contenido en celulosa presentan un índice cristalino y una estabilidad térmica más alta. Mientras que, las fibras con mayor contenido en hemicelulosa/pectina tienen un porcentaje mayor de humedad en su composición. 
La descomposición térmica de las fibras naturales muestra un proceso complejo, donde se distinguen la pérdida de la humedad (alrededor de $100^{\circ} \mathrm{C}$ ) y la descomposición solapada de la hemicelulosa/pectina, celulosa y lignina $\left(210\right.$ a $\left.510^{\circ} \mathrm{C}\right)$. Durante la pirólisis de los componentes de las fibras naturales tienen lugar dos reacciones competitivas: la formación de residuo carbonoso y la evaporación de levoglucosan, influenciadas a su vez por posibles reacciones secundarias de pirolisis provenientes de la repolimerización de los volátiles. En cuanto a la cinética de descomposición de las fibras naturales, la metodología empleada ha permitido modelizar el comportamiento térmico de la celulosa de todas la fibras naturales estudiadas mediante un mecanismo cinético de orden $n=1$.

\section{Propiedades de las Matrices Poliméricas}

De la caracterización termo-mecánica, estructural y morfológica del Mater-Bi KE y del Mater-Bi NF, se establecen una serie de similitudes y diferencias entre las matrices poliméricas.

o Ambas matrices poliméricas son semicristalinas; el Mater-Bi KE, es la matriz polimérica que presenta un mayor contenido cristalino en su composición. Sin embargo, el Mater-Bi NF presenta una temperatura de fusión y de cristalización mayor que el Mater-Bi KE. El Mater-Bi NF presenta por tanto, un dominio cristalino menor pero más estable que el Mater-Bi KE.

o La degradación térmica de ambas matrices poliméricas presenta una descomposición térmica compleja con dos procesos principales que siguen un mecanismo de descomposición similar. El proceso de descomposición que aparece a bajas temperaturas ( a partir de $300^{\circ} \mathrm{C}$ ) se asocia a la pirólisis del almidón y el segundo (a partir de $400^{\circ} \mathrm{C}$ ) al material sintético biodegradable. El Mater-Bi KE es más estable térmicamente que el Mater-Bi NF.

o El Mater-Bi NF es la matriz polimérica más resistente a tracción, sin embargo es menos rígida que el Mater-Bi KE. 


\section{Propiedades de los Biocomposites Enfibrados}

Al reforzar las matrices poliméricas con las fibras naturales se observan diferentes cambios en las propiedades de los biocomposites resultantes.

o El aumento del módulo y la disminución de la deformación en los biocomposites, confirman un aumento de la rigidez de las matrices poliméricas debido a las interacciones de las fibras naturales con las matrices poliméricas.

- Los biocomposites de kenaf y cáñamo no muestran una variación de su resistencia a tracción con el aumento de la rigidez.

- $\quad$ En cambio, en los biocomposites de algón y lino, el aumento del módulo de Young se traduce en una mayor fragilidad del material.

- $\quad$ La presencia de las fibras de yute en la formulación de los biocomposites consigue obtener un material menos frágil y más rígido que el de la matriz polimérica.

o El efecto más significativo que se observa en las transiciones térmicas es un aumento en la temperatura de cristalización, tal vez como consecuencia de las interacciones entre la matriz y las fibras naturales. Estas interacciones también se han estudiado en el análisis mecánico, donde todos los biocomposites reforzados presentan una desviación positiva respecto las leyes de composición ideales.

o El aumento del onset y de la Ea del proceso de descomposición del almidón demuestran un aumento de la estabilidad térmica de los biocomposites reforzados. Se establece una correlación clara entre la estabilidad térmica de los biocomposites y la composición química de las fibras naturales en su formulación.

- El aumento de la estabilidad térmica de los biocomposites aumenta en función del contenido de hemicelulosa/pectina y lignina, y disminuye en función del porcentaje de celulosa.

- Los biocomposites enfibrados con kenaf, yute y cáñamo son los materiales que ofrecen una mayor resistencia térmica. Además, los biocomposites enfibrados con kenaf, yute y cáñamo los que poseen los incrementos más significativos de energía de acitvación $(E a)$ en ambas matrices poliméricas.

- $\quad$ Por tanto, los biocomposites con más hemicelulosa/pectina y lignina en su formulación poseen mejores interacciones fibra/matriz. 
El proceso de absorción de agua de la matriz polimérica y de los biocomposites reforzados ha sido propuesto como etapa previa a la biodegradación en tierra. Las propiedades termogravimétricas de ambos materiales han sido estudiados en función del proceso de absorción en agua.

o El Mater-Bi NF es la matriz polimérica más hidrófila, y presenta un coeficiente de difusión mayor, así como un tiempo de saturación mucho menor que el Mater-Bi KE.

o En términos generales, la presencia de las fibras naturales en los biocomposites aumente la capacidad y disminuye el tiempo de saturación. En particular, se observa un aumento de la capacidad de absorción de los biocomposites en función del aumento del porcentaje de hemicelulosa/pectina en su formulación.

o El proceso de absorción en agua de las matrices poliméricas y de los biocomposites reforzados sigue la cinética y el mecánismo descrito por la teoría de Fick. Los biocomposites muestran valores de coeficientes de difusión menores que las matrices poliméricas correspondientes, indicando una mayor dificultad de difusión de las moléculas de agua en los biocomposites.

o Los materiales saturados a una temperatura de $29^{\circ} \mathrm{C}$ se han caracterizado mediante análisis termogravimétrico. El almidón es el componente más susceptible al proceso de absorción en agua de ambas matrices poliméricas; se observa un aumento de estabilidad térmica y de $E a$ del proceso de termodescomposición de este componente. La presencia de las fibras naturales no modifica estas tendencias, pero en el caso del Mater-Bi KE, se observa que el incremento de temperatura de los biocomposites depende del contenido de hemicelulosa/pectina, aumentando a medida que disminuye este porcentaje. Para el Mater-Bi NF se observan incrementos similares de $E a$ y estabilidad térmica en todos los biocomposites.

El estudio del proceso de degradación en tierra de las dos matrices poliméricas y de sus respectivos biocomposites se ha llevado a cabo mediante análisis Termogravimétrico (TGA), Calorimetría Diferencial de Barrido (DSC), Análisis Infrarrojos (FTIR) y Microscopía Electrónica de Barrido (SEM). 


\section{Degradación en tierra de las matrices poliméricas}

o En el Mater-Bi KE, la degradación en tierra del almidón se produce en tres etapas diferentes. La primera de ellas con una duración de 20 días se atribuye a la hidrólisis del almidón, durante la segunda etapa no se observan cambios significativos. En cambio, a partir de la tercera etapa de degradación del almidón (200 días) se producen reacciones de ruptura de cadenas y la degradación en tierra del componente sintético se ve favorecida.

o En el Mater-Bi NF, el almidón se degrada a gran velocidad, durante los primeros 40 días. Debido a que esta matriz polimérica es más hidrófila que la anterior y alcanza su saturación mucho más rápido la etapa hidrolítica del almidón en el Mater-Bi NF no se detecta. Los principales cambios en el material sintético se producen durante el tiempo en que se degrada la mayor parte del almidón.

\section{Degradación en tierra de los biocomposites reforzados}

o En general, la presencia de celulosa, hemicelulosa y las interacciones de ambos componentes con la matriz polimérica producen una ralentización de la desaparición del almidón.

- En el Mater-Bi KE, la presencia de celulosa, hemicelulosa y las interacciones de ambos componentes con la matriz polimérica producen una ralentización de la desaparición del almidón.

- En el Mater-Bi NF, los biocomposites con mayores porcentajes de hemicelulosa/pectina y celulosa en su composición muestran una desaparición más lenta del almidón, tal vez debido a las interacciones más fuertes entre los biocomposites con mayor contenido en hemicelulosa.

o La velocidad de degradación del material sintético depende de la matriz polimérica empleada.

- La velocidad de degradación del componente sintético es mayor que la de la matriz polimérica en todos los biocomposites de Mater-Bi KE. La degradación de las fibras naturales durante el proceso de degradación en tierra, consigue aumentar la superficie de ataque del material sintético y iniciar su biodegradación desde los primeros días de degradación en tierra. 
- La etapa inicial de degradación del material sintético en los biocomposites de Mater-Bi NF se modifica con la presencia de las fibras naturales

o De entre todos los biocomposites estudiados, el biocomposite de lino es el que parece menos afectado por la degradación en tierra y el que menor velocidad de degradación muestra.

o La fibra de kenaf es la única que consigue además de aumentar la velocidad de degradación del material sintético que el biocomposite presente mayor estado de degradación que la matriz polimérica pura una vez que ha finalizado el tiempo de exposición.

La selección de una u otra fibra natural como material de refuerzo va a depender de las propiedades finales de diseño escogidas. En general, la adición de fibras naturales aumenta la rigidez del material, disminuye su deformación a rotura y mejora su estabilidad térmica. Del mismo modo, la degradación de los componentes de la matriz polimérica se garantiza en todos los biocomposites. Los biocomposites con mayor contenido en hemicelulosa, por su carácter hidrófilo muestran una mayor capacidad para degradarse en tierra. 


\subsection{LÍNEAS DE TRABAJO FUTURO}

Los poliméricos biodegradables cuando se exponen a determinados ambientes se ven sometidos a distintos tipos de degradación (mecánica, térmica, química, et.) que modifican su estructura y en muchas ocasiones su biodegradabilidad. En la mayoría de los casos, los factores abióticos contribuyen a debilitar la estructura polimérica del material, comportándose como factores sinergéticos, ó incluso como factores iniciadores del proceso de biodegradación. Uno de los factores abióticos más importantes es la radiación UV del espectro solar

Por todo eso, la primera línea de continuación de esta Tesis Doctoral es el desarrollo de una metodología que permita estudiar la influencia de la degradación ambiental en las propiedades de los biocomposites diseñados y en su biodegradabilidad en tierra. Para ello, se proponen dos estudios complementarios:

a) Análisis de la influencia de la fotooxidación en las propiedades térmicas, estructurales y morfológicas de los biocomposites de Mater-Bi KE y Mater-Bi NF diseñados.

b) Análisis de la influencia de la fotooxidación en el proceso de degradación en tierra los biocomposites diseñados.

Durante el desarrollo de esta tesis se han encontrado una serie de puntos en los que se debería profundizar e incluso proponer una serie de estudios complementarios a la metodología empleada. Entre ellos, destaca el estudio cinético de la termodegradación de las hemicelulosa y de la lignina de fibras naturales. En primer lugar, para una correcta determinación de la cinética de descomposición de estos dos componentes se debería mejorar el método de deconvolución empleado para separar ambas contribuciones del pico principal de la celulosa. Además, el estudio de la descomposición térmica de los polímeros que constituyen la hemicelulosa y la lignina, podría ayudar a esclarecer el comportamiento térmico de ambos componentes durante la pirolisis de la fibra natural. 
Finalmente, se propone la evaluación del ciclo de vida de los materiales diseñados, con el objetivo de evaluar el impacto potencial sobre el medioambiente durante toda su vida en servicio y su deposición en tierra, teniendo en cuenta entradas como la energía, la materia prima, el agua y emisiones medioambientales como las producidas durante su transporte. Con todo esto se conseguiría establecer la diferencia entre el posible impacto de los composites sintéticos y los composites diseñados en este trabajo. 